JOINT TRANSPORTATION RESEARCH PROGRAM

FHWA/IN/JTRP-2009/33

Final Report

DEVELOPMENT OF A FRAMEWORK FOR EX POST FACTO EVALUATION OF HIGHWAY PROJECT COSTS IN INDIANA

Abhishek Bhargava

Samuel Labi

Kumares C. Sinha

March 2010 


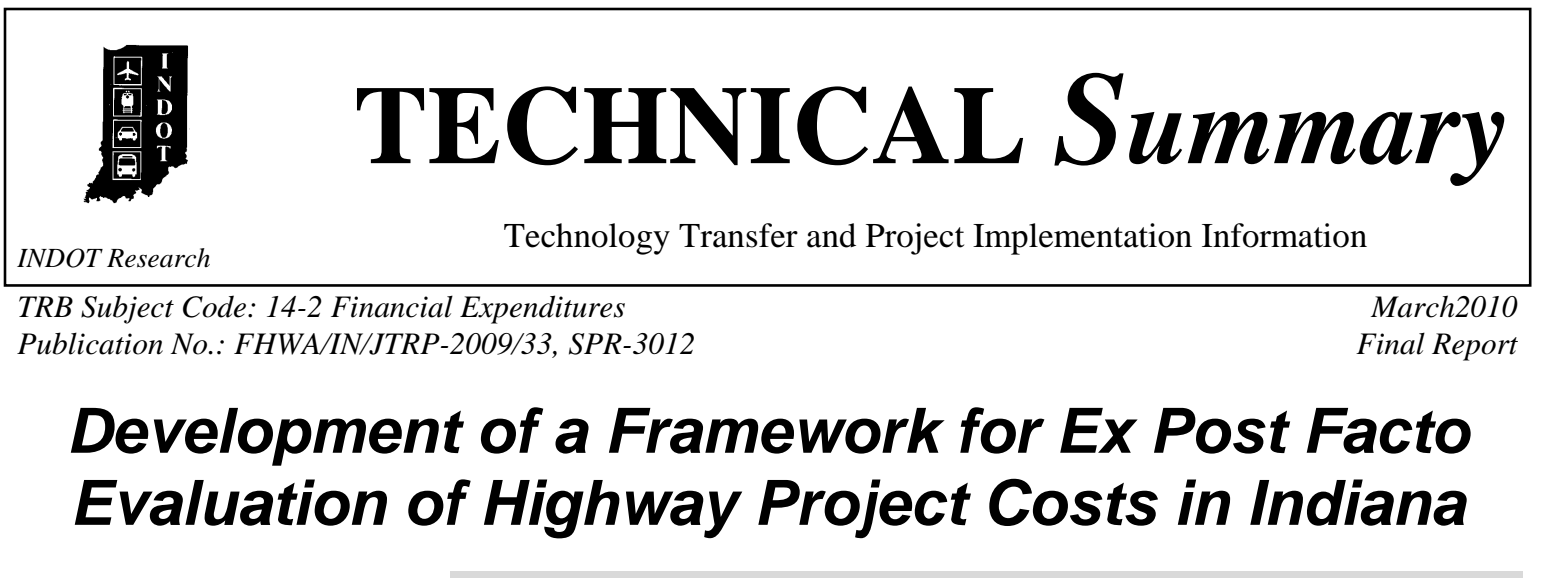

\section{Introduction}

To assess policy effectiveness and to determine the accuracy of ex-ante predictions, public agencies increasingly have begun to perform ex-poste evaluations. In the current environment that is characterized by funding limitations, stringent accountability requirements, and higher user expectations, such evaluations are considered critical because the results are useful to refine decisionmaking processes. The motivation for ex-poste evaluation is rooted in the fact that public agencies seek to maximize service to facility users and the community, and to provide facility level-of-service in a cost-effective manner. In the context of highway transportation, the extent to which these overall goals are achieved are assessed on scales of performance measures such as: project cost, reduction of travel time, increase in travel time reliability, improvement of air quality, reduced number of crashes, increased economic development, etc. Agency officials require knowledge of the true cost and benefits of agency actions in terms of these performance measures. That way, appropriate lessons could be learned and the decision-making processes could be enhanced.

A specific case in point is that involving project costs. INDOT is increasingly concerned about the reliability of cost estimates of its projects. Cost overruns associated with large scale and high visibility transportation projects can generate public relations problems for the agency. With increased media coverage of cost overrun, questions have arisen about the ability of highway agencies to forecast costs accurately.

What is needed, therefore, is a methodology to help the planners and decision-makers at INDOT to predict cost overruns, monitor and evaluate the cost estimates prepared during the project development process (PDP), so as to quantify the efficiency of the cost estimation processes. Also, there is a need to develop a methodological framework that can be used by highway agencies to identify projects that are susceptible to high cost overrun and underrun, so that appropriate proactive decisions (such as adjusting the contingency amounts) can be made to ameliorate the cost overrun problem.

\section{Findings}

The study product is a methodology for identifying contracts that are likely to experience cost overrun at different stages of the project development process. The methodology analyzes escalation patterns of cost estimates across the stages of project development. To facilitate implementation of the methodology, models were developed to identify contracts that are likely to experience cost overrun in Indiana.
The factors that were found to affect the probability and magnitude of cost overrun in Indiana included: contract work category, size, geographic location, highway functional class, route type, NHS status, contract classification, time duration between final design completion and project proposal, time duration between letting and project proposal, percentage difference between design estimate and proposed cost, percentage difference between letting and proposed cost, the probability of a contract type 
to exhibit a particular escalation pattern, and the variability in the probability to exhibit a particular escalation pattern.

For expansion (capacity addition) and bridge contracts, the probability of cost overrun increased with increase in contract size. For pavement projects, large contracts (exceeding \$5 million) were found to be more likely to experience a cost underrun compared to small contracts. Pavement contracts in urban areas were found to be more likely to experience cost overrun compared to their rural counterparts. For expansion and bridge contract cost overrun, no significant difference in cost overrun likelihood was found between urban and rural areas. Specifically, expansion and pavement contracts on Non-NHS highways were found to be more likely to experience cost overrun, compared to such contracts on NHS highways. Bridge contracts on Interstates were more likely to experience cost overrun compared to NonInterstates.

It was found that as the time duration between project proposal and design completion increased, the tendency of a contract to experience cost overrun increased. Longer time spans between project proposal and letting were also found to increase the probability of cost overrun. In addition, the risk of occurrence of a particular escalation pattern was found to influence the probability of cost overrun.

\section{Implementation}

A software tool was developed on the basis of the analytical relationships. This tool can be used to compare contracts in Indiana and to determine which are likely to follow a given escalation patterns or incur high cost overruns at the planning, design, and letting stages. Specifically, this tool can be used by INDOT to estimate the probability and magnitude of a cost overrun for a contract on the basis of its characteristics. The estimated probability and magnitude of cost overrun can be compared across a set of contracts, and the ones that are more likely to experience cost overrun can be identified. Implementing the study product is expected to enhance monitoring of project costs at INDOT. This is important at the current time as the agency strives to make its operations more transparent. By providing planners and decisionmakers with an estimate of the expected cost overrun, such personnel will be in a better position to give advice on adjustments to project contingency amounts.

A core group of persons at INDOT under advisement of FHWA is recommended for the project implementation. This group, to be represented by INDOT's Central Office and District planning divisions and research and development office, will have as its principal mission, the advancement and institutionalization of the most practicable methods outlined in the research report.

\section{Contacts}

For more information:

\section{Prof. Kumares C. Sinha}

Principal Investigator

School of Civil Engineering

Purdue University

West Lafayette IN 47907

Phone: (765) 494-2201

Fax: (765) 496-7996

Prof. Samuel Labi

Co-Principal Investigator

School of Civil Engineering

Purdue University

West Lafayette IN 47907

Phone: (765) 494-5926

Fax: (765) 496-7996
Indiana Department of Transportation

Office of Research \& Development

1205 Montgomery Street, P.O. Box 2279, West

Lafayette, IN 47906

Phone: (765) 463-1521

Fax: (765) 497-1665

Purdue University

Joint Transportation Research Program

School of Civil Engineering

West Lafayette, IN 47907-1284

Phone: (765) 494-9310

Fax: (765) 496-1105 
FINAL REPORT

FHWA/IN/JTRP-2009/33

\title{
DEVELOPMENT OF A FRAMEWORK FOR EX POST FACTO EVALUATION OF HIGHWAY PROJECT COSTS IN INDIANA
}

\author{
By \\ Abhishek Bhargava \\ Graduate Research Assistant \\ Samuel Labi \\ Assistant Professor of Civil Engineering \\ Kumares C. Sinha \\ Olson Distinguished Professor of Civil Engineering \\ Joint Transportation Research Program \\ Project No. C-36-64P \\ File No. 3-5-16 \\ SPR-3012 \\ In Cooperation with the \\ Indiana Department of Transportation \\ and the U.S. Department of Transportation \\ Federal Highway Administration
}

The contents of this report reflect the views of the authors, who are responsible for the facts and the accuracy of the data presented herein. The contents do not necessarily reflect the official views or policies of the Indiana Department of Transportation or the Federal Highway Administration. This report does not constitute a standard, specification or regulation

Purdue University

West Lafayette, IN, 47907

March 2010 


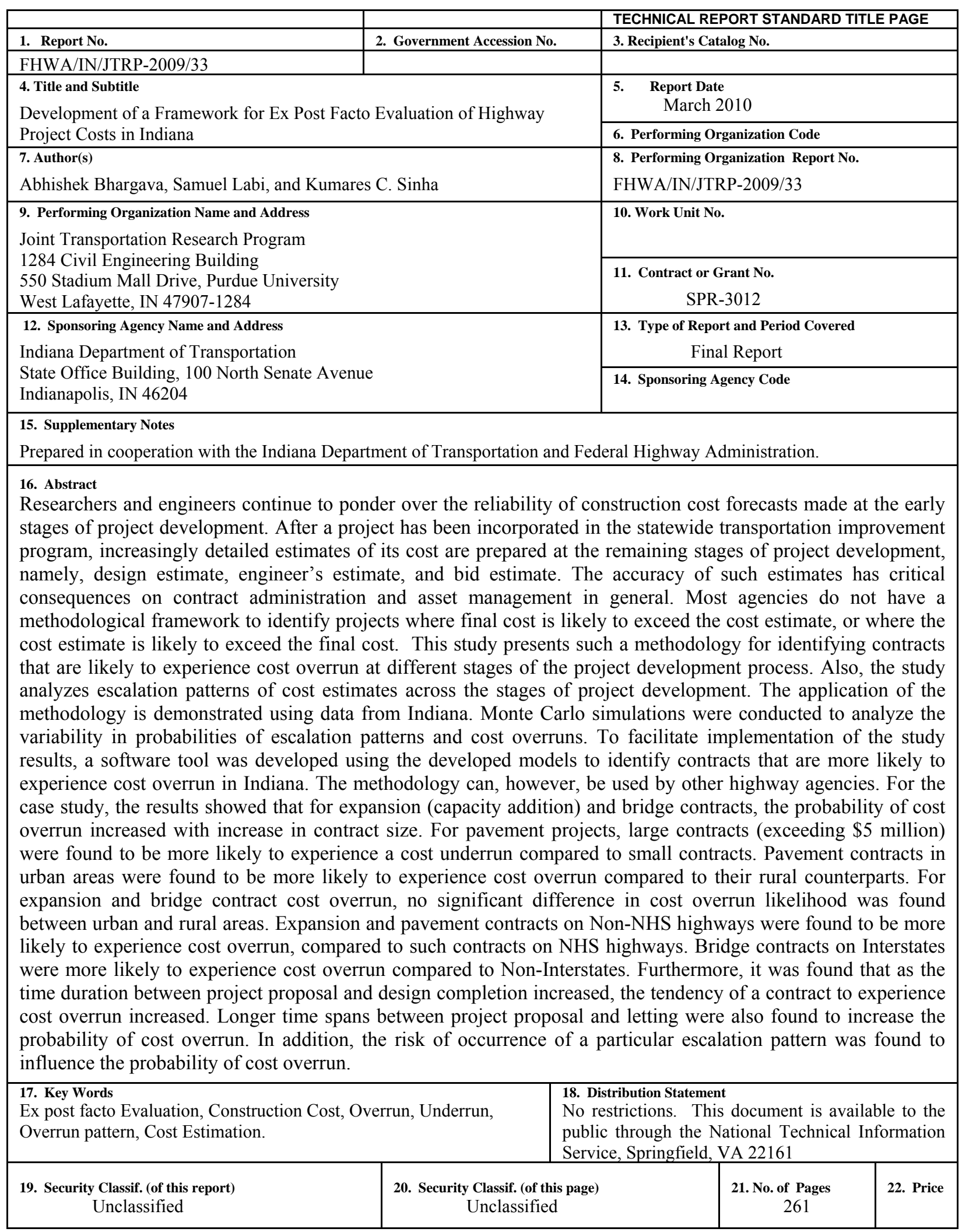




\section{ACKNOWLEDGMENTS}

The authors hereby acknowledge the constant support provided by members of the Study Advisory Committee: Samy Noureldin of INDOT Research Division; Brad Steckler, William Flora, Steve Smith, Dave Andrewski, Michelle Allen, Andrew Fitzgerald, Bob Williams, David Holtz of INDOT; Larry Heil of FHWA, and Mike Byers of American Concrete Pavement Association. The vital contributions of John Weaver of INDOT, and Professor Fred Mannering and graduate student Kevin Ford of Purdue are also acknowledged. 
TABLE OF CONTENTS

LIST OF TABLES

CHAPTER 2. LITERATURE REVIEW OF EX-POSTE EVALUATION STUDIES ..............................5

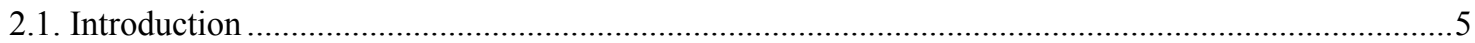

2.2. Sectors, Performance Measures, and Techniques.......................................................................5

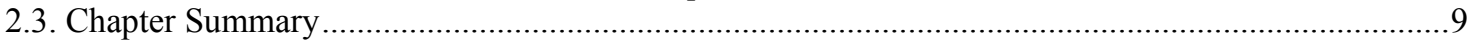

CHAPTER 3. HIGHWAY CONSTRUCTION COST ESTIMATION ................................................. 10

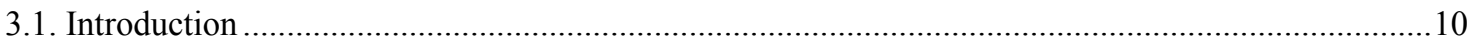

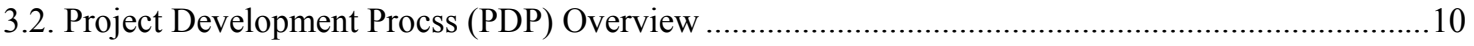

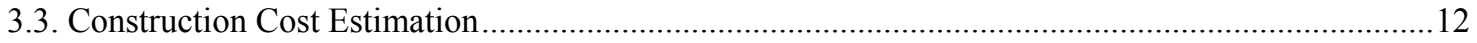

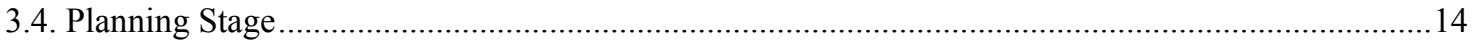

3.4.1. Estimation of Proposed Costs - State of Practice ...............................................................14

3.4.2. Research Studies on Estimating Proposed Cost ............................................................. 15

3.4.3. Accuracy of Proposed Cost Estimates ................................................................................ 16

3.5. Programming and Preliminary Design Stages .................................................................. 17

3.5.1. Programming and Preliminary Design Stage Cost Estimation ..............................................19

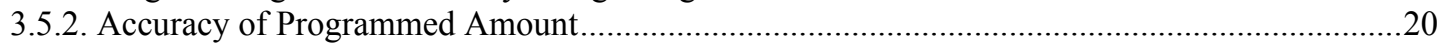

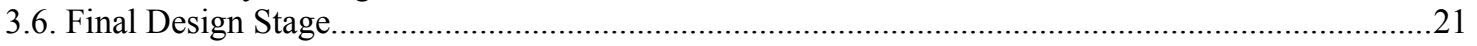

3.6.1. Estimation of Design Cost at Highway Agencies...............................................................21

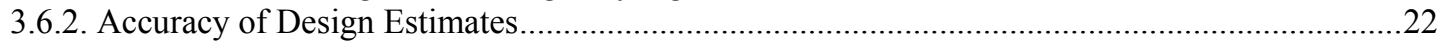

3.7. Contract Preparation and Advertisement Stage ...................................................................24

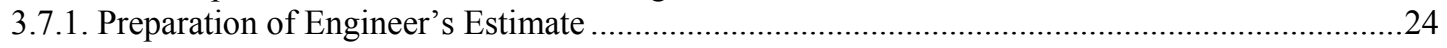

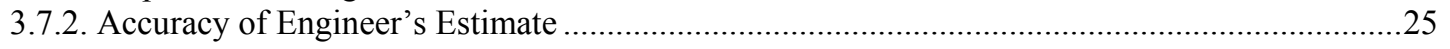

3.7.3. Determining Cost Overrun at Advertisement Stage ........................................................27

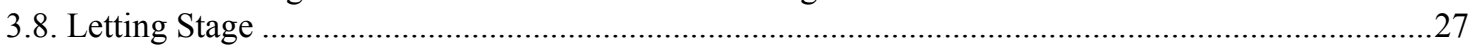

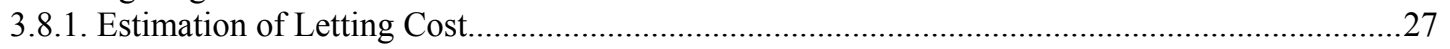

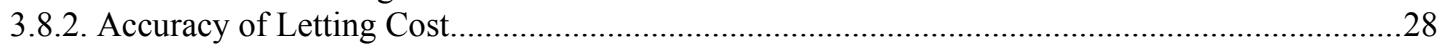

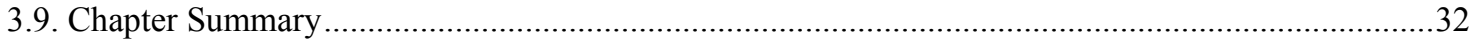




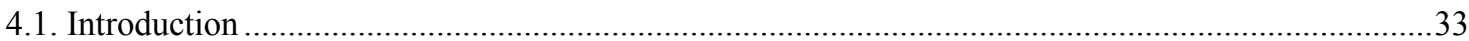

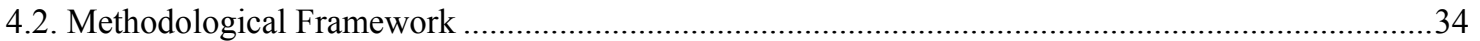

4.2.1. Step 1: Study Design, Data Acquisition, and Pre-Processing........................................................34

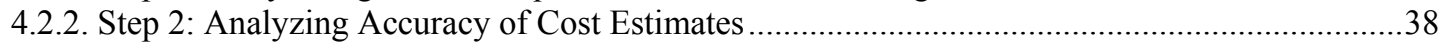

4.2.3. Step 3: Analysis of Escalation Pattern of Cost Estimates............................................................... 45

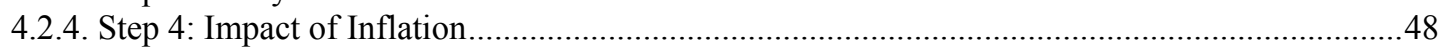

4.2.5. Step 5: Development of Risk-Based Econometric Analysis Framework ……….........................51

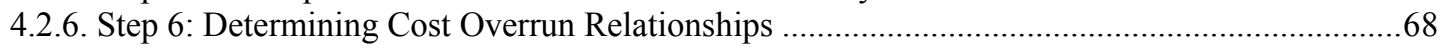

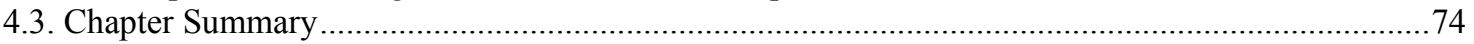

CHAPTER 5. DESCRIPTIVE ANALYSIS OF COST OVERRUN IN INDIANA …....................................75

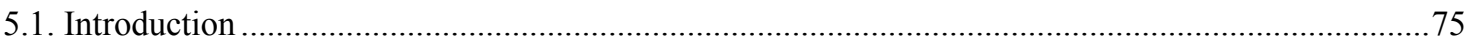

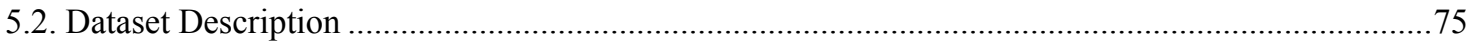

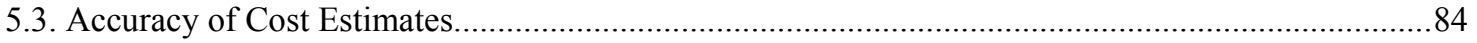

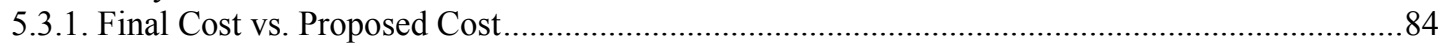

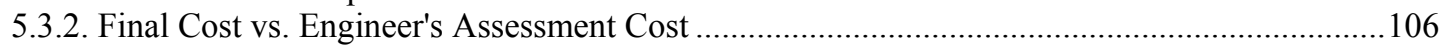

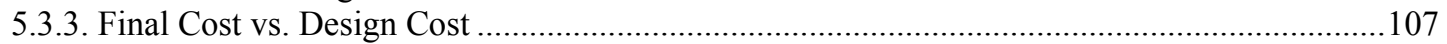

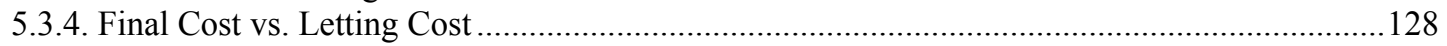

5.3.5. Letting Cost vs. Proposed Cost ………………............................................................. 144

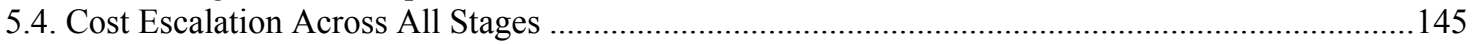

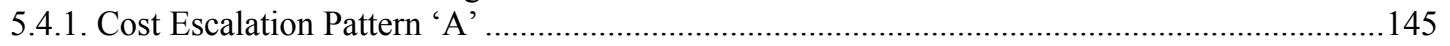

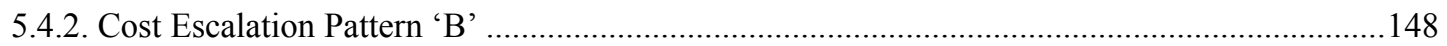

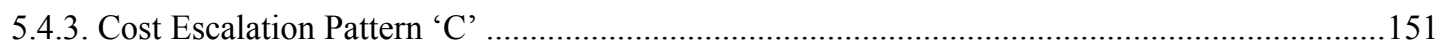

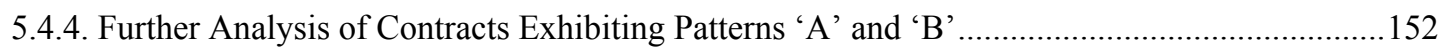

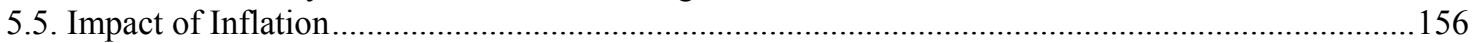

5.5.1. Proposed Cost Estimate vs. Final Construction Cost ………......................................................157

5.5.2. Final Cost vs. Design Cost .................................................................................................. 159

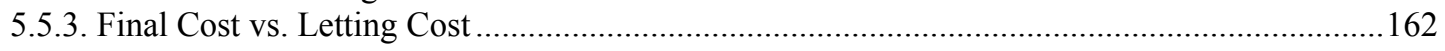

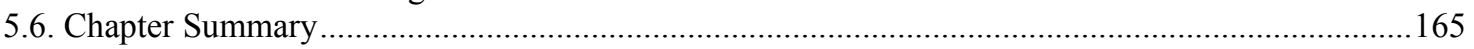

CHAPTER 6. ECONOMETRIC RISK-BASED ANALYSIS OF COST OVERRUN IN INDIANA ........166

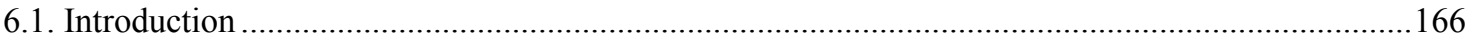

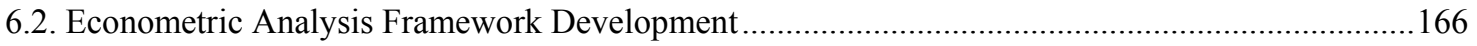

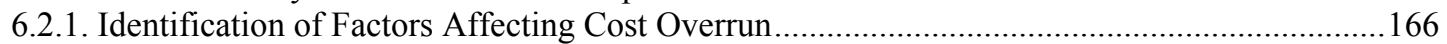

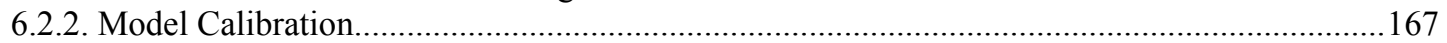

6.2.3. Methodology for Analyzing Impact of Contract Specific Factors Using Developed Models ... 167

6.3. Econometric Models for Expansion Contracts ..........................................................................168

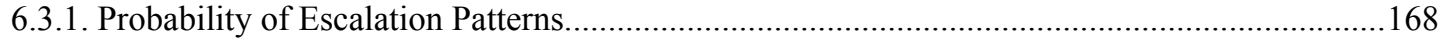

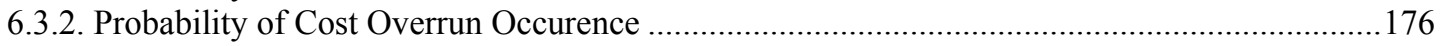

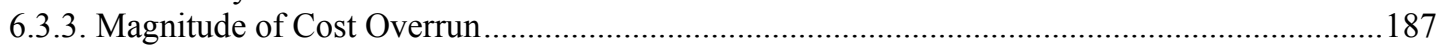

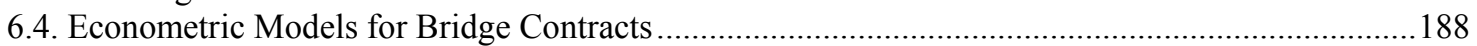

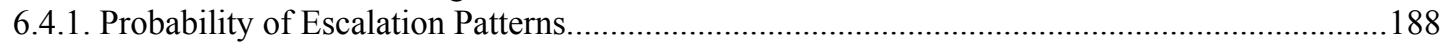

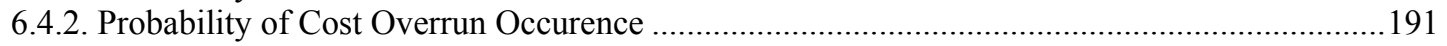

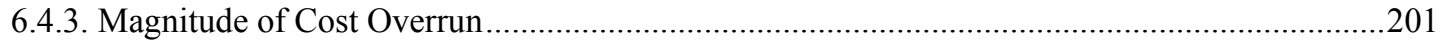

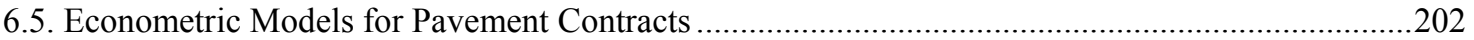

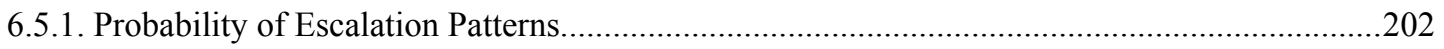

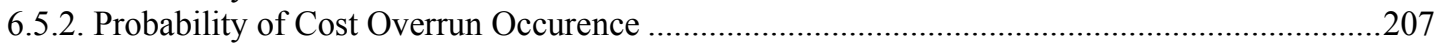

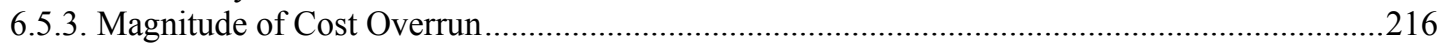


6.6. Econometric Models for Comparing Letting and Proposed Cost.............................................217

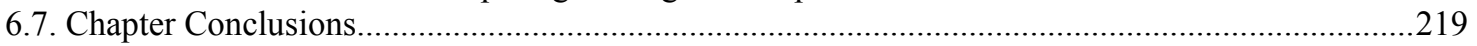

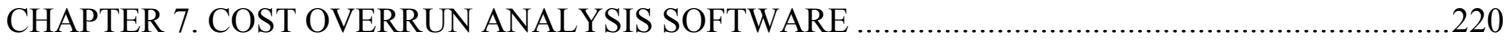

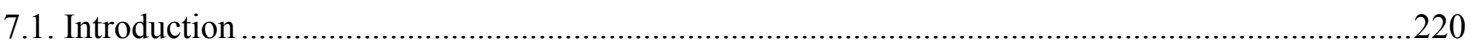

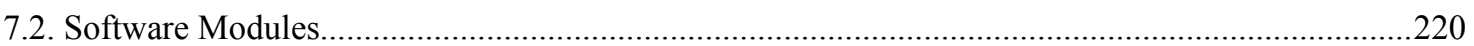

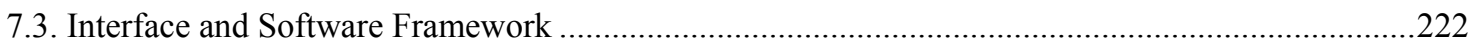

7.4. Example - Identifying Contracts Susceptible to Cost Overrun ...................................................226

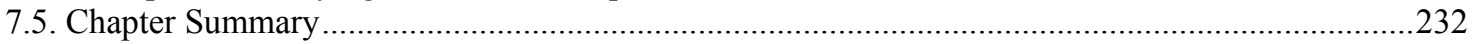

CHAPTER 8. SUMMARY, CONCLUSIONS AND RECOMMENDATIONS ...................................223

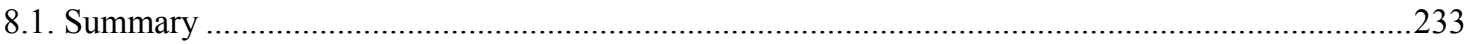

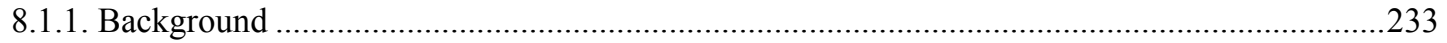

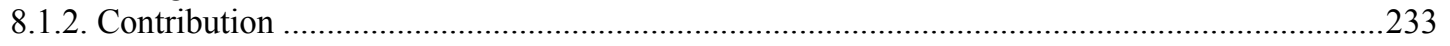

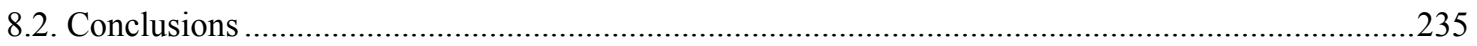

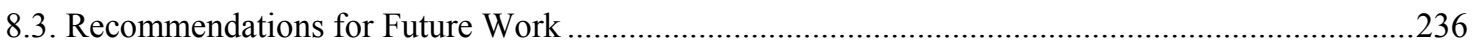

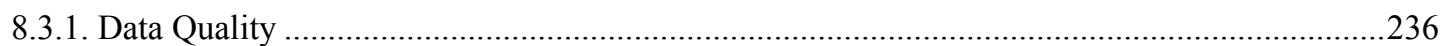

8.3.2. Development of Risk-based Econometric Framework ......................................................2237

8.3.3. Development of Cost Overrun Analysis Software ........................................................237

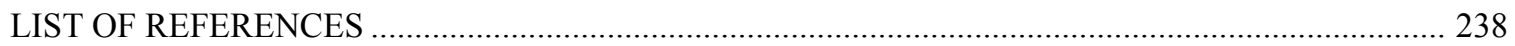

APPENDIX: CONTRACT TYPES EXPERIENCING COST OVERRUN IN INDIANA.......................247 


\section{LIST OF TABLES}

Table

3.1 Steps Involved in the Programming Phase of Project Development ....................................................18

3.2 Factors Responsible for Change Orders in Highway Construction .......................................................24

3.3 Annual Report of Accuracy of Engineer's Estimate at Washington DOT ………...............................25

3.4 Rate of Cost Overrun and Annual Cost Overrun Expenditure of Selected States .................................28

4.1 Factor Levels Corresponding to Discrete Contract-Specific Factors ..................................................36

4.2 Framework for the Two-Way Distribution Analysis of the Contracts ....................................................

4.3 Illustrating the Distribution of Contracts by Contract Size and Work Category ….................................38

4.4 Illustrating the Framework for Analysis of Cost Overrun by Cost Overrun Category ...........................42

4.5 Illustrating the Categorical Cost Overrun Analysis by Work and Cost Overrun Categories.................43

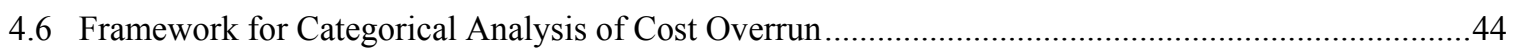

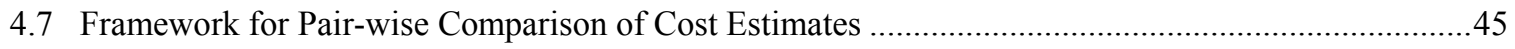

4.8 Contract-Specific Factors for Econometric Analysis Framework .......................................................56

4.9 Planning Stage Cost Overrun by Cost Overrun Category ………......................................................67

4.10 Risk-Based Econometric Analysis Framework for Analysis of Cost Overrun.......................................73

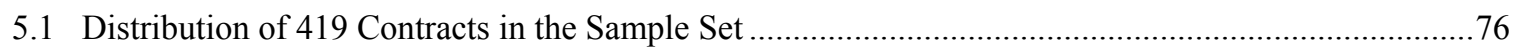

5.2 Classification and Distribution of 419 Contracts by Work Category …………...................................77

5.3 Distribution of Contracts in each Work Category by Size, Area, Route, and Contract Type................79

5.4 Distribution of Contracts of all Sizes by Area Type, Route Type, and Contract Type ......................... 80

5.5 Distribution of Contracts by Size, Work Category, and Area and Route Type in Each District............83

5.6 Analysis of Average Planning Stage Cost Overrun by Cost Overrun Category...................................85

5.7 Analysis of Planning Stage Cost Overrun by Work Category and Cost Overrun Category ..................86

5.8 Analysis of Planning Stage Cost Overrun by Contract Size and Cost Overrun Category .....................89

5.9 Analysis of Planning Stage Cost Overrun by Contract Type and Cost Overrun Category.....................92

5.10 Analysis of Planning Stage Cost Overrun by Route Type and Cost Overrun Category ........................94

5.11 Planning Stage Cost Overrun by NHS Status and Cost Overrun Category .........................................97

5.12 Analysis of Planning Stage Cost Overrun by District and Cost Overrun Category .............................100

5.13 Analysis of Planning Stage Cost Overrun by Area Type and Cost Overrun Category.........................103 
Table Page

5.14 Analyzing Difference between Proposed Cost and Engineer's Assessment Cost................................106

5.15 Analysis of Average Design Stage Cost Overrun by Cost Overrun Category.....................................107

5.16 Analysis of Average Cost Overrun of Final Cost over Design Cost by Work Category ......................109

5.17 Analysis of Average Design Stage Cost Overrun by Contract Size and Cost Overrun

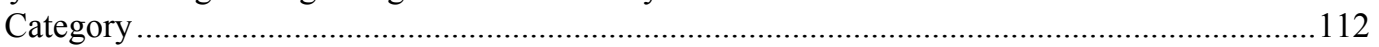

5.18 Analysis of Average Cost Overrun of Final Cost over Design by Contract Type...............................115

5.19 Analysis of Average Cost Overrun of Final Cost over Design Cost by Route Type............................118

5.20 Analysis of Average Design Stage Cost Overrun by Cost Overrun Category

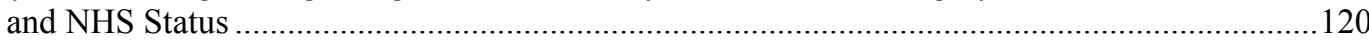

5.21 Analysis of Average Cost Overrun of Final Cost over Design Cost by District ....................................123

5.22 Average Design Stage Cost Overrun by Cost Overrun Category and Area Type ..............................125

5.23 Analysis of Average Letting Stage Cost Overrun by Cost Overrun Category ......................................128

5.24 Analysis of Average Letting Stage Cost Overrun by Cost Overrun and Work Category.....................130

5.25 Average Letting Stage Cost Overrun by Contract Size and Cost Overrun Category ..........................132

5.26 Analysis of Average Cost Overrun of Final Cost over Letting Cost by Contract Type ......................134

5.27 Analysis of Average Cost Overrun of Final Cost over Letting Cost by Route Type............................136

5.28 Analysis of Average Cost Overrun of Final Cost over Letting Cost by NHS Status .........................138

5.29 Analysis of Average Cost Overrun of Final Cost over Letting Cost by District ..................................140

5.30 Analysis of Average Cost Overrun of Final Cost over Letting Cost by Area Type .............................142

5.31 Analysis of Average Letting Stage Cost Overrun by Cost Overrun Category ...................................144

6.1 Model to Estimate Probability of Occurrence of Escalation Patterns for Expansion

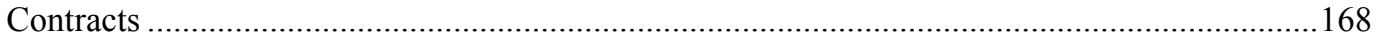

6.2 Multinomial Logit Model for Determining Occurrence Probability of Planning

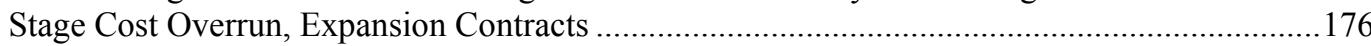

6.3 Multinomial Logit Model for Determining Occurrence Probability of Design

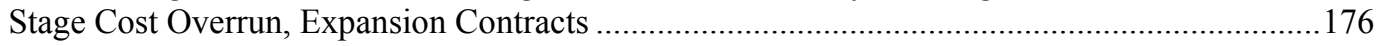

6.4 Multinomial Logit Model for Determining Occurrence Probability of Letting

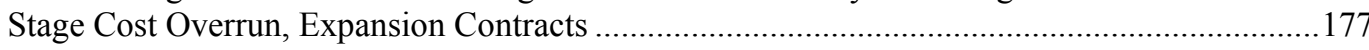

6.5 Comparison of Coefficients of the Factors Affecting Occurrence Probability of Planning, Design and Letting Stage Cost Overrun, Expansion Contracts.........................................178

6.6 Expected Value of Cost Overrun for Expansion Contracts by Cost Overrun Category .......................186

6.7 Multinomial Logit Model for Determining Probability of Escalation Pattern for Bridge Contracts

6.8 Multinomial Logit Model for Determining Probability of Planning Stage Cost Overrun for Bridge Contracts.

6.9 Multinomial Logit Model for Determining Probability of Design Stage Cost Overrun for Bridge Contracts. 
6.10 Multinomial Logit Model for Determining the Probability of Letting Stage Cost Overrun for Bridge Contracts.

6.11 Comparison of Coefficients of the Factors Affecting Probability of Planning, Design and Letting Stage Cost Overrun (Bridge Contracts)....

6.12 Expected Value of Cost Overrun for Bridge Contracts by Cost Overrun Category ........

6.13 Multinomial Logit Model to Determine Probability of Escalation Pattern (Pavement Contracts)

6.14 Multinomial Logit Model to Determine Probability of Planning Stage Cost Overrun for Pavement Contracts

6.15 Multinomial Logit Model to Determine Probability of Design Stage Cost Overrun for Pavement Contracts.....

6.16 Multinomial Logit Model to Determine Probability of Letting Stage Cost Overrun for Pavement Contracts .

6.17 Comparison of Coefficients of the Factors Affecting Probability of Planning, Design and Letting Stage Cost Overrun (Pavement Contracts) ............................................2209

6.18 Expected Value of Cost Overrun for Pavement Contracts by Cost Overrun Category ..... 216

6.19 Model to Determine Overrun of Letting Cost Compared to Proposed Cost, Expansion Contracts

6.20 Model to Determine Overrun of Letting Cost Compared to Proposed Cost for Bridge Contracts.

6.21 Model to Determine Overrun of Letting Cost Compared to Proposed Cost, Pavement Contracts.

7.1 A Hypothetical List of 15 Expansion Contracts 


\section{LIST OF FIGURES}

Figure $\quad$ Page

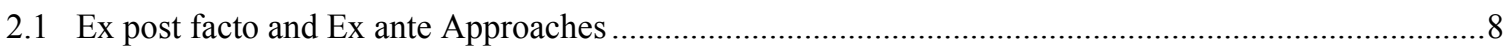

3.1 Stages of the Project Development Process ................................................................................ 11

3.2 Typical Progression of Cost Uncertainty Across the Stages of Project Development ........................13

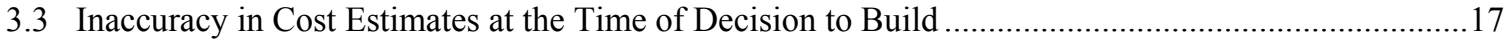

3.4 Comparison of Contract Award Amount to Programmed Amount for Contracts in

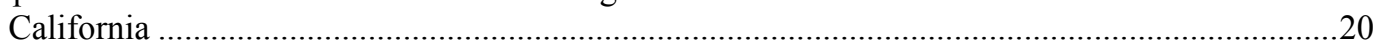

3.5 Percent of Projects Delivered Within the Programmed Amount in Missouri....................................21

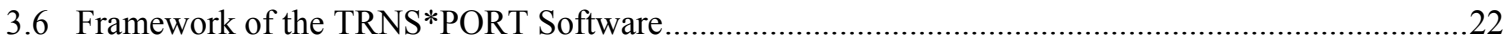

3.7 Percentage of Contracts for which Final Cost Exceeded the Engineer's Estimate

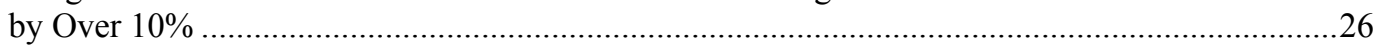

3.8 Comparison of Final Cost with Engineer's Estimate by Contract Size ...........................................26

3.9 Percentage of Contracts (Exceeding \$1 Million) for which Final Cost Exceeded

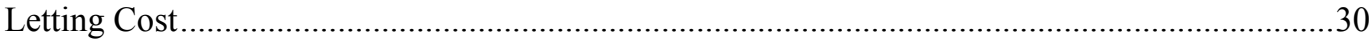

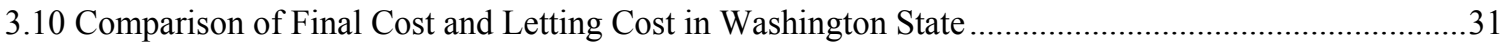

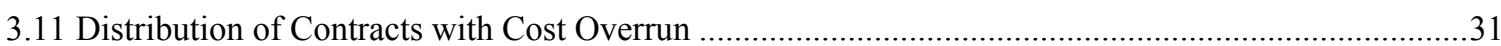

4.1 Information about Cost Estimates and Final Cost Sought for a Cost Overrun Study ..........................34

4.2 Schematic Representation of the ' $+/-10 \%$ Cost Overrun Bracket' ...................................................41

4.3 Graphical Representation of Cost Escalation Pattern ' $A$ ' . .........................................................46

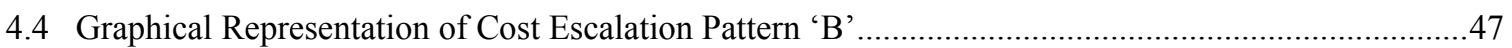

4.5 Graphical Representation of Cost Escalation Pattern ' $\mathrm{C}$ ' .............................................................48

4.6 Analysis Framework for Calculating Cost Overrun With / Without Inflation.................................50

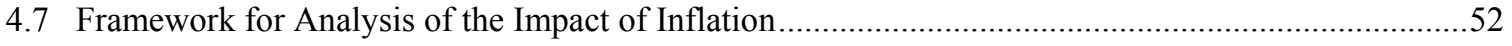

4.8 Proposed Risk-Based Econometric Analysis Framework ..........................................................5

4.9 Steps Involved in Preparing for the Development of Econometric Analysis Framework ...................55

4.10 A Hypothetical Nested Structure of Four Cost Escalation Patterns ..............................................58

4.11 3-Dimensional Illustration of a Multivariate Normal Distribution of the U-functions.......................63

4.12 A Hypothetical Nested Structure of Cost Overrun Categories ......................................................66

5.1 Histogram Distribution of Planning Stage Cost Overrun ...............................................................8

5.2 Analysis of Average Planning Stage Cost Overrun by Cost Overrun Category...............................85 
Figure Page

5.3 Percentage of Contracts Outside the ' $+/-10 \%$ Cost Overrun Bracket' at the Planning Stage by Work Category .....

5.4 Average Planning Stage Cost Overrun for Contracts Outside the ' $+/-10 \%$ Cost Overrun

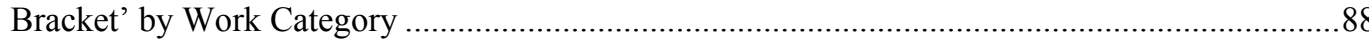

5.5 Percentage of Contracts Outside the ' $+/-10 \%$ Cost Overrun Bracket' at the Planning Stage by Contract

5.6 Average Planning Stage Cost Overrun for Contracts Outside the $+/-10 \%$ Cost Overrun Bracket' by Contract Size

5.7 Percentage of Contracts Outside the ' $+/-10 \%$ Cost Overrun Bracket' at the Planning Stage by Route Type

5.8 Average Planning Stage Cost Overrun for Contracts Outside the ' $+/-10 \%$ Cost Overrun Bracket' by Route Type

5.9 Percentage of Contracts Outside the ' $+/-10 \%$ Cost Overrun Bracket' at the Planning Stage by NHS Status

5.10 Average Planning Stage Cost Overrun for Contracts Outside the $+/-10 \%$ Cost Overrun Bracket' by NHS Status

5.11 Percentage of Contracts Outside the ' $+/-10 \%$ Cost Overrun Bracket' at the Planning Stage by Administrative District

5.12 Average Planning Stage Cost Overrun for Contracts Outside the $+/-10 \%$ Cost Overrun Bracket' by District

5.13 Percentage of Contracts Outside the ' $+/-10 \%$ ' Cost Overrun Bracket at the Planning Stage by Area Type

5.14 Average Planning Stage Cost Overrun for Contracts Outside the $+/-10 \%$ Cost Overrun Bracket' by Area Type

5.15 Histogram Distribution of Design Stage Cost Overrun

5.16 Analysis of Average Design Stage Cost Overrun by Cost Overrun Category 108

5.17 Percentage of Contracts Outside the ‘ $+/-10 \%$ ' Design Stage Cost Overrun Bracket by Work Category.

5.18 Average Design Stage Cost Overrun for Contracts Outside the ' $+/-10 \%$ Cost Overrun Bracket' by Work Category

5.19 Percent Contracts Outside the ‘ $+/-10 \%$ ’ Design Stage Cost Overrun Bracket by Contract Size

5.20 Average Design Stage Cost Overrun for Contracts Outside the ' $+/-10 \%$ Cost Overrun Bracket' by Contract Size

5.21 Percentage of Contracts Outside the ' $+/-10 \%$ ' Design Stage Cost Overrun Bracket by Contract Size

5.22 Average Design Stage Cost Overrun for Contracts Outside the ‘ $+/-10 \%$ Cost Overrun Bracket' by Contract Type

5.23 Percentage of Contracts Outside ‘ $+/-10 \%$ ’ Design Stage Cost Overrun Bracket by Route Type 
Figure Page

5.24 Average Design Stage Cost Overrun for Contracts Outside the ' $+/-10 \%$ Cost Overrun Bracket' by Route Type

5.25 Percentage of Contracts Outside the ‘ $+/-10 \%$ ' Design Stage Cost Overrun Bracket by NHS Status

5.26 Average Design Stage Cost Overrun for Contracts Outside the ' $+/-10 \%$ Cost Overrun Bracket' by NHS Status

5.27 Percentage of Contracts Outside the ‘ $+/-10 \%$ ’ Design Stage Cost Overrun Bracket by District.

5.28 Average Design Stage Cost Overrun for Contracts Outside the $+/-10 \%$ Cost Overrun Bracket' by District ................................................................................................. 125

5.29 Percent Contracts Outside the ‘+/-10\%’ Design Stage Cost Overrun Bracket by Area Type ..... 126

5.30 Average Design Stage Cost Overrun for Contracts Outside the ' $+/-10 \%$ Cost Overrun Bracket' by Area Type

5.31 Histogram Distribution of Letting Stage Cost Overrun. 128

5.32 A 95\% Confidence Interval Analysis of Average Letting Stage Cost Overrun by Cost Overrun Category

5.33 Percent Contracts with Letting Stage Cost Overrun $>10 \%$ by Work Category

5.34 Average Letting Stage Cost Overrun for Contracts with Overrun $>10 \%$ by Work Category....

5.35 Percent Contracts with Letting Stage Cost Overrun $>10 \%$ by Contract Size

5.36 Average Letting Stage Cost Overrun for Contracts with Cost Overrun $>10 \%$ by Contract Size

5.37 Percent Contracts with Letting Stage Cost Overrun $>10 \%$ by Contract Type.

5.38 Average Letting Stage Cost Overrun for Contracts with Cost Overrun $>10 \%$ by Contract Type

5.39 Percent Contracts with Letting Stage Cost Overrun $>10 \%$ by Route Type..... 136

5.40 Average Letting Stage Cost Overrun for Contracts with Overrun $>10 \%$ by Route Type

5.41 Percent Contracts with Letting Stage Cost Overrun $>10 \%$ by NHS Status..................................138

5.42 Average Letting Stage Cost Overrun for Contracts with Overrun $>10 \%$ by NHS Status ................139

5.43 Percent Contracts with Letting Stage Cost Overrun $>10 \%$ by District ....................................... 140

5.44 Average Letting Stage Cost Overrun for Contracts with Overrun $>10 \%$ by District ......................141

5.45 Percent Contracts with Letting Stage Cost Overrun $>10 \%$ by Area Type ...................................142

5.46 Average Letting Stage Cost Overrun for Contracts with Cost Overrun $>10 \%$ by Area Type.

5.47 Graphical Representation of Cost Escalation Pattern 'A' .145

5.48 Stage-to-Stage Cost Deviations for Pattern 'A' Contracts 146

5.49 Average Cost Deviation of Each Stage Relative to Proposed Cost for Pattern 'A' Contracts

5.50 Graphical Representation of Cost Escalation Pattern 'B'. 148 
Figure Page

5.51 Stage-to-Stage Cost Deviations for Pattern 'B' Contracts .........................................................149

5.52 Average Cost Deviation of Each Stage Relative to Proposed Cost for Pattern 'B' Contracts............150

5.53 Graphical Representation of Cost Escalation Pattern 'C' .........................................................151

5.54 Distribution of Contracts that Exhibit Cost Escalation Patterns 'A' and ' $\mathrm{B}$ ' by

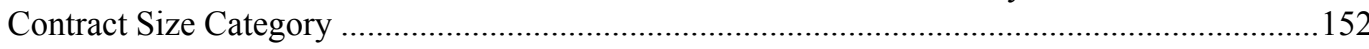

5.55 Distribution of Contracts that Exhibit Cost Escalation Patterns ' $A$ ' and ' $\mathrm{B}$ ' by Work Category.

5.56 Distribution of Contracts that Exhibit Cost Escalation Patterns 'A' and 'B' by Area Type

5.57 Percent Contracts Showing Cost Escalation Patterns 'A' and 'B' by Route Type

5.58 Distribution of Contracts that Exhibit Cost Escalation Patterns 'A' and 'B' by Route Type 155

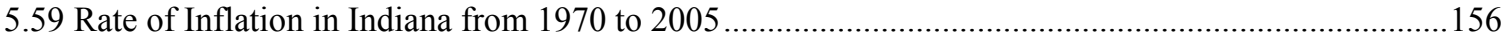

5.60 Growth of Construction Price Index (U.S.) and Inflation (Indiana) from 1970 to 2005 ....................156

5.61 Analysis of Impact of Inflation on Proposed Cost: Case 1 ........................................................ 157

5.62 Analysis of Impact of Inflation on Proposed Cost: Case 2 .....................................................157

5.63 Analysis of Impact of Inflation on Proposed Cost: Case 3 ......................................................158

5.64 Number of Years between the Final Construction Cost and Proposed Cost .................................158

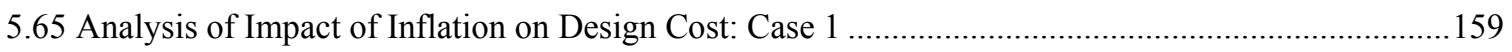

5.66 Analysis of Impact of Inflation on Design Cost: Case 2 ........................................................ 160

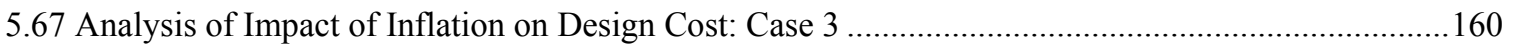

5.68 Number of Years between the Final Construction Cost and Design Cost....................................161

5.69 Analysis of Impact of Inflation on Letting Cost: Case 1 ........................................................... 161

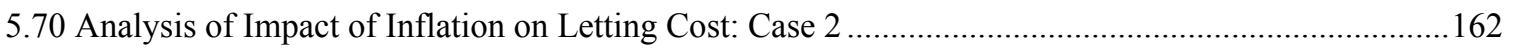

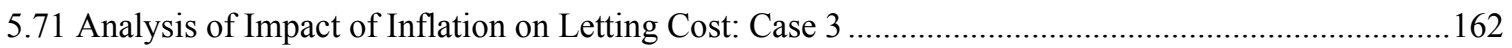

5.72 Number of Years between the Final Construction Cost and Letting Cost.....................................163

6.1 Comparison of Mean Probability of Escalation Patterns across Expansion Contracts of Different Sizes

6.2 Distribution of Probability of Occurrence of Escalation Pattern 'A' for Expansion Contracts in Seymour, Greenfield, and Laporte Districts

6.3 Distribution of Probability of Escalation Pattern ' $\mathrm{B}$ ' for Expansion Contracts by District...

6.4 Distribution of Probability of Escalation Pattern ' $C$ ' for Expansion Contracts by District.

6.5 Distribution of Probability of Escalation Pattern ' $\mathrm{C}$ ' for Expansion Contracts in Vincennes, Crawfordsville, and Fort Wayne Districts

6.6 Distribution of Probability of Escalation Pattern 'A' for Expansion Contracts by NHS Status / Route Type 
Figure $\quad$ Page

6.7 Distribution of Probability of Escalation Pattern ' $C$ ' for Expansion Contracts by NHS Status

6.8 Distribution of Probability of Escalation Pattern ' $\mathrm{B}$ ' for Expansion Contracts by NHS Status

6.9 Impact of Escalation Pattern 'B' on the Probability of Planning Stage Cost Overrun $>10 \%$ (Expansion Contracts)

6.10 Impact of Escalation Pattern 'B' on the Probability of Planning Stage Cost Overrun $>10 \%$ (Expansion Contracts)

6.11 Comparison of Probability of Planning Stage Cost Overrun by Contract Size for Expansion Contracts

6.12 Comparison of Mean Probability of Planning Stage Cost Overrun Greater than $10 \%$ by Contract Size and Geographic Location (District).

6.13 Mean Probability of Planning Stage Cost Underrun by NHS Status and Contract Size

6.14 Mean Probability of Planning Stage Cost Overrun by NHS Status and Contract Size

6.15 Mean Planning Stage Cost Overrun Across Expansion Contracts by Size and District. 186

6.16 Comparison of Probability of Escalation Patterns by Contract Size for Bridge Contracts.

6.17 Comparison of Probability of Escalation Pattern 'A' Across Districts (Bridge Contracts)

6.18 Comparison of Tendency to Exhibit Pattern 'B' Across NHS Status by Contract Size (Bridge Contracts)

6.19 Impact of Variability in Probability of Escalation Pattern 'B' on the Probability of Cost Overrun .

6.20 Probability of Planning Stage Cost Overrun by Contract Size for Bridge Contracts

6.21 Probability of Planning Stage Cost Overrun Between $0 \%$ and $10 \%$ by Contract Size and District for Bridge Contracts

6.22 Comparison of Probability of Planning Stage Cost Overrun Greater than $10 \%$ by NHS Status and Contract Size (Bridge Contracts)

6.23 Mean Planning Stage Cost Overrun (\%) for Bridge Contracts by Size and Functional Class

6.24 Mean Probability of Escalation Patterns by Contract Size for Pavement Contracts

6.25 Mean Probability of Escalation Pattern 'A' by Contract Size and District for Pavement Contracts.

6.26 Mean Probability of Escalation Pattern 'B' by Contract Size and District for Pavement Contracts

6.27 Mean Probability of Escalation Pattern 'A' by Contract Size and Route Type for Pavement Contracts.

6.28 Mean Probability of Planning Stage Cost Overrun Corresponding to Various Levels of Pavement Contract Size (Based on Proposed Cost).

6.29 Comparison of Mean Probability of Planning stage cost overrun Across Urban and Rural Area Contracts by Contract Size. 
Figure $\quad$ Page

6.30 Comparison of Mean Probability of Planning Stage Cost Overrun Across Urban and Rural Area Contracts in each District.........................................................................2 212

6.31 Comparison of Mean Probability of Letting Stage Cost Overrun Across Standalone

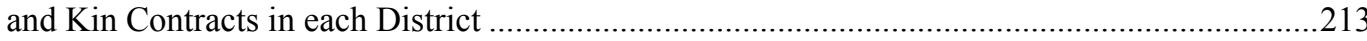

6.32 Comparison of Mean Probability of Planning Stage Cost Overrun Across Highway Functional Classes by Contract Size ...............................................................................214

7.1 Flowchart Depicting the Working of Cost Overrun Analysis Software .........................................221

7.2 Front Page Interface Showing the Features of the Cost Overrun Analysis Software ........................222

7.3 Select Criteria to Define Contract Types for Comparison Based on Planning

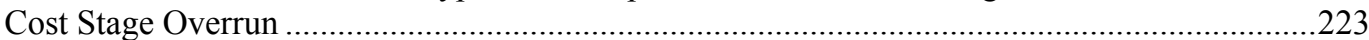

7.4 Reading Contract Types from a File for Comparison Based on Planning Cost

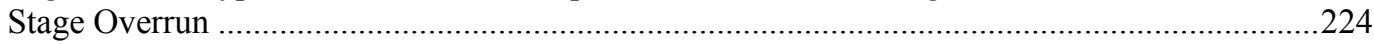

7.5 Entering Contract Specific Factors to Determine Planning Stage Cost Overrun ...........................225

7.6 Entering Contract Specific Factors to Determine Design Stage Cost Overrun ..............................226

7.7 Entering Contract Specific Factors to Determine Letting Stage Cost Overrun ..............................226

7.8 Probability of Occurrence of Escalation Pattern for the Hypothetical Contracts .............................2228

7.9 Probability of Occurrence of Escalation Pattern 'B' and its Variability ........................................228

7.10 Probability of Planning Stage Cost Overrun Categories for Hypothetical Contracts .......................229

7.11 Expected Cost Overrun for Hypothetical Contracts ....................................................................229

7.12 Interface Showing the Inputs and Results from Module 1........................................................230

7.13 Interface Showing the Inputs and Results from Module 2 .....................................................231

7.14 Interface Showing the Inputs and Results from Module 3.......................................................232 


\section{LIST OF ABBREVIATIONS}

$\begin{array}{ll}\text { CAS } & : \text { Construction Administration System } \\ \text { CES } & : \text { Cost Estimation System } \\ \text { DOT } & : \text { Department of Transportation } \\ \text { FHWA } & : \text { Federal Highway Administration } \\ \text { FTA } & : \text { Federal Transit Administration } \\ \text { INDOT } & : \text { Indiana Department of Transportation } \\ \text { INSTIP } & : \text { Indiana Statewide Transportation Improvement Program } \\ \text { JLARC } & : \text { Joint Legislative Audit and Review Commission } \\ \text { LAS } & : \text { Letting and Awards System } \\ \text { MPO } & : \text { Metropolitan Planning Organization } \\ \text { NHS } & : \text { National Highway System } \\ \text { NJDOT } & : \text { New Jersey Department of Transportation } \\ \text { PDP } & : \text { Project Development Process } \\ \text { PES } & : \text { Proposal and Estimates System } \\ \text { PMG } & : \text { Program Management Group } \\ \text { RTP } & : \text { Regional Transportation Plan } \\ \text { STP } & : \text { Statewide Transportation Plan } \\ \text { SPMS } & : \text { Statewide Project Management System } \\ \text { TIP } & : \text { Transportation Improvement Program } \\ \text { TRACER } & : \text { Transportation Cost Estimator } \\ \text { VDOT } & : \text { Virginia Department of Transportation } \\ \text { WSDOT } & : \text { Washington State Department of Transportation }\end{array}$




\section{CHAPTER 1. INTRODUCTION}

\subsection{Overall Background}

Highway agencies around the world are increasingly concerned about the reliability of cost estimates of projects within their jurisdiction. Cost overruns associated with large scale and high visibility transportation projects have received global attention and criticism. With increased media coverage of cost overrun, questions have arisen about the ability of highway agencies to forecast costs accurately. The cost overrun associated with the Bay Bridge replacement in San Francisco, California (ENR, 2001), the cost and time overrun associated with the Central Artery/Tunnel project in Boston (ENR, 2002(a); Murphy, 2002), and the $180 \%$ cost overrun associated with the Springfield Interchange project in Northern Virginia (ENR, 2002(b)) constitute just a few of the numerous articles that have received widespread attention from the public and from governments. According to an article in the Engineering News Record (ENR, 2002(c)), the final cost of most mega-projects can be significantly higher than the cost projections during the planning and development phases of the projects.

The issue of cost overrun has attracted attention of several federal agencies such as the Federal Highway Administration (FHWA) and the United States General Accounting Office (GAO, 2003). FHWA's National Highway Institute developed a new course to promote the importance of accuracy in construction cost estimation by measuring the risk and uncertainty in cost estimation using the principles of deterministic and probabilistic cost estimation (FHWA, 2008).

A hearing of the Transportation Subcommittee of the House Appropriations Committee of the United States Congress focused on the issue of infrastructure project costs. It identified the need to improve the quality of the initial cost estimates and to monitor the overall cost estimation process of major highway and bridge projects. The hearing also pointed out that information on the amount and reasons for cost overrun is generally unavailable, as this information is neither tracked by the FHWA or by state highway agencies (Schexnayder et al., 2003).

\subsection{Consequences of Inaccurate Cost Estimation}

As billions of dollars continue to be invested in the development of highway infrastructure, the issue of the accuracy of construction cost estimates remains a serious concern among highway agencies. Construction cost estimates prepared during the project development process play an important role in the delivery of 
efficient highway programs (Sinha and Labi, 2007). The selection of a transportation alternative over others is often influenced by decision-making criteria such as the cost-effectiveness factor, net present value, and benefit-to-cost ratio, which in turn are heavily hinged on the reliability of project cost estimates. An inaccurate cost estimate may result in the selection of a less cost-effective alternative, thereby having an adverse impact on the value of the investment. Given the volume of investment made on transportation infrastructure, a less than optimal return from projects can have a large cumulative adverse impact on the efficiency of the overall transportation system.

Furthermore, inaccurate estimation of construction cost of a project can jeopardize the entire transportation improvement program of a highway agency. For example, if the final construction cost of a project exceeds the forecast construction cost (even with contingencies), funds are diverted from other programmed projects in the transportation improvement program, resulting in a delay in the implementation of these projects. When programmed projects fail to get implemented at the scheduled optimal time for this reason, the programming schedule of the agency is disrupted and the consequences of a less-than-desired transportation system is borne both by the highway agencies and the users.

\subsection{Terminology}

In this study, cost overrun is calculated as the percentage difference between the final construction cost and the estimate of the construction cost that is prepared at any given stage of project development. A positive percentage difference indicates that final construction cost is more than the cost estimate, representing cost overrun; a negative percentage difference indicates that final construction cost is less than the cost estimate, which is termed a cost underrun. Different estimates of construction cost are prepared at the different stages of project development. Thus, cost overrun can be estimated with respect to the estimate at any given stage (defined later in Chapter 3).

\subsection{Goals and Objectives}

On the basis of the study background, the goals of this study are as follows:

a) To help the planners and decision-makers at highway agencies to evaluate the cost estimates prepared during the project development process (PDP), so as to quantify the efficiency of the process within their respective jurisdictions;

b) To develop a methodological framework that can be used by highway agencies to identify projects that are susceptible to high cost overrun and underrun, so that relevant decisions (such as setting an appropriate contingency amount) can be made when planning such projects. 
The specific objectives associated with these goals are as follows:

a) To assess the adequacy of methodologies and techniques that are used for the estimation of construction costs at various stages of project development by analyzing data on differences between the final cost and the cost estimated at each stage, using data on past projects;

b) To analyze the trends in cost overrun or underrun so that factors that are likely to influence the probability and magnitude of cost difference can be identified;

c) To develop risk-based econometric models that describe the relationship between probability of cost overrun / underrun and contract-specific factors such as: work type, area type (urban vs. rural), geographic location, NHS Status, highway functional class, and project size;

d) Using the developed models to propose a framework on the basis of that can be used to identify contracts likely to experience high cost overrun and underrun;

e) To develop a software tool that implements the framework, for forecasting cost overrun likelihood of projects in the Indiana Statewide Transportation Improvement Program (INSTIP).

\subsection{Organization of The Report}

The report is organized into seven chapters. In Chapter 1, the background, terminology, motivation, goals and objectives of the study are outlined. Chapter 2 presents a review of literature on the general subject of ex post facto evaluation, while Chapter 3 provides an overview of the state of practice and preliminary issues in ex post facto evaluation with specific focus on highway construction cost estimates. Cost estimates prepared at each stage of the project development process are discussed. Studies that have been conducted to determine the accuracy of these estimates and the factors affecting their inaccuracy are also discussed.

Chapter 4 presents the proposed methodology to (a) determine cost overrun / underrun associated with historical contracts and (b) to study the associated trends by contract specific factors. A methodology is also proposed to develop risk-based econometric models to identify the factors that significantly influence the accuracy of cost estimates.

Chapter 5 analyzes the cost differences associated with historical highway contracts in Indiana. In this chapter, the methodology presented in Chapter 4 is used to analyze the trends during project development. Risk-based econometric models are presented in Chapter 6, while Chapter 7 provides the software tool and demonstrates its application to INDOT projects. Chapter 8 summarizes the findings and conclusions of the study and presents recommendations for future work. 


\section{CHAPTER 2. LITERATURE REVIEW OF EX-POSTE EVALUATION STUDIES}

\subsection{Introduction}

To assess policy effectiveness and to determine the accuracy of ex ante predictions, public agencies increasingly have begun to perform ex post facto (or post-audit) evaluations. In the current environment that is characterized by funding limitations, stringent accountability requirements, and higher user expectations, such evaluations at public agencies, foreign governments, donor agencies, and global development banks are considered critical because the results are useful to refine decision-making processes. The motivation for ex post facto evaluation is rooted in the fact that public agencies seek to maximize service to facility users and the community, and to provide facility level-of-service in a costeffective manner. In the context of highway transportation, the extent to which these overall goals are achieved are assessed on scales of performance measures such as: reduction of travel time, increase in travel time reliability, improvement of air quality, reduced number of crashes, increased economic development, etc. Agency officials require knowledge of the true cost and benefits (effectiveness) of agency actions in terms of these performance measures. That way, appropriate lessons could be learned and the decision-making processes could be enhanced. This chapter discusses past experiences of ex post facto evaluations in different sectors, modes of transportation, and countries. Also the chapter identifies performance measures, approaches, and techniques for ex post facto evaluation.

\subsection{Sectors, Performance Measures, and Techniques}

Ex post facto evaluations are vital in both public and private sectors, and are used in all sectors of the economy (industrial, commercial, transportation agricultural, health, etc.). In the transportation sector, recent ex post facto analyses have primarily focused on rail and highway investments. In the case of rail investments, the relatively long service lives and high capital costs of rail asset construction and preservation, coupled with the predominantly private sector participation and profit motivation in the rail mode, necessitates the formulation of prudent policy decisions. Ex post facto studies of investments in the rail mode have stressed the need for appropriate design and maintenance decisions that yield cost-effective management of such assets over their entire service lives (Zoeterman, 2004).

The literature review conducted as part of the present study suggested that project economic analyses at the planning phase of project development generally tend to be overly optimistic. This could be due a variety of reasons such as inherent inaccuracies in the input variables for economic analysis, incorrect 
long-term forecasts of travel demand, or probably a desire to inflate benefit expectations so as to receive funding for a project. In any case, it is critical that cost estimates are constantly verified. In the rail industry, for example, forecasts of freight growth rates and overall size have been found to be frequently overestimated leading to lower-than-expected revenues even though rail's freight market share, compared to other modes, is generally stable (Anguera, 2005). Similarly, ex post facto evaluations show that the rate of return are not always the same as that expected during forecasting (Israel, 1972).

In the water resources sector, ex post facto analyses are commonplace and a number of such studies in that field have focused on social impacts (Andrews et al., 1974), environmental impacts (Bokhari, 1975; Ciliberti, 1980; Jingxun et al., 1991), and economic impacts (Haveman, 1972; Duckstein, 1975; Edwards and Salt, 1993; Feeney, 1995), or a combination of these and other performance measures (Grillenzoni et al., 1994). The cost and effectiveness of flood control projects and other natural/technological disaster responses are also commonly assessed through ex post facto studies (Galloway, 1980; Fischl, 1993; Cohen, 1995; Gruntfest, 1997). Wescoat and Halvorson (2000) compiled several ex post facto evaluations relating specifically to dams and other water-related projects (Wescoat, 2000).

In the context of highway transportation in particular, the phenomenon where an investment yields lower revenue and incurs higher construction costs than originally estimated, appears to be longstanding and prevalent. In recent years, however, there is encouraging statistical evidence that the growth of cost overruns has slowed (Pickrell, 1990; Flyvberg et al., 2002; Flyvberg et al., 2003; Dantata et al., 2006). This may be partially attributable to the adoption of policies of transparency/accountability, or the application of project cost prediction models.

As discussed in greater detail in Section 3.4.1, state transportation agencies have recently begun to develop cost prediction models relying on historical construction costs (i.e., similar project costs or specific line item unit costs). This arose out of explicit or implicit ex post facto evaluations at transportation agencies that identified the need for enhanced assessment of project costs at the planning stage. Virginia DOT developed an Excel spreadsheet entitled Project Cost Estimation System (PCES) to predict roadway and bridge construction costs. Specializing in Interstate/highway right-of-way and utility cost estimation, PCES requires basic inputs such as roadway dimensions, features, traffic patterns, and perceived project complexity, and has been found to be accurate within 22\% (Kyte et al., 2004). The Maryland State Highway Administration similarly uses a spreadsheet to predict early- and late-stage construction costs based on historical unit costs; the Florida DOT also predicts costs using historical data, but on a more aggregate scale; the Delaware DOT developed a detailed form to list all project costs while allowing for expert opinion of engineers regarding reasons for cost escalation; and Wisconsin DOT advertises project benefits, risk factors, and a range of cost probabilities (Kyte et al., 2004). To address highway agencies' need for a versatile cost estimation software, Earth Tech, Inc. developed TRACER, which predicts costs with minimal information and also allows for "what-if" scenarios to be simulated. 
Besides construction delivery costs, ex post facto evaluation has been carried out for other performance measures to assess highway operational policies, planning, and economic impacts/benefits. Such studies include those that recently explored the economic effectiveness of safety improvements (Andreassen, 1992; Commonwealth of Australia, 2007; Yannis et al., 2008), impacts of congestion management (Van der Loop, 2000; Evan, 2007), air quality enhancements (Farrell et al., 1998), and transit investments (Nakamura et al., 1989). Also for the highway mode, a number of studies have examined the differences in predicted investment outcomes using before and after analyses, in terms of benefit-cost and net-present value that utilized data on estimated and actual: travel time savings, construction costs, traffic growth, traffic composition, accident rates, average accident costs, length of evaluation period, discount rate, and amount of diverted traffic (Commonwealth of Australia, 2007). In 2001, the United Kingdom Highways Agency introduced Post Opening Project Evaluation (POPE) to evaluate post-implementation impacts of major road projects; the POPE program has focused on before and after estimates of costs and benefits in terms of traffic volumes, travel times, and number of accidents (Oxera Consulting Ltd., 2005). In the future, the Highways Agency's goal is to expand ex post facto studies to address environmental impacts (Oxera Consulting Ltd., 2005). Also, with explicit recognition of the fact that volatile assumptions made at the planning stage can significantly impact the effectiveness of planning decisions, Khisty (1981), Niemeier and Beard (1993), Guers and van Wee (2006), and McNeil and Mizusawa (2008) conducted ex post facto analyses to ascertain whether their planning methods yielded accurate assessments of actual outcomes of projects, and used a variety of tools including GIS, planning software, land use allocation methods, urban development philosophy, and asset management concepts.

Furthermore, another common performance measure used in ex post facto evaluation of highway investments is economic development (Weisbrod et al., 2001; Leong et al., 2003; Rychnowski et al., 2003; Weiss and Figura, 2004). The Federal Highway Administration (FHWA) encourages ex post facto analysis, primarily for this purpose (FHWA, 2009). In 2000, the U.S. Congress directed the FHWA to conduct the Economic Development Highways Initiative; this initiative combined the knowledge and experience of over 200 local, state, and regional officials in order to determine realistic expectations for economic development based on local economic conditions (Weiss and Figura, 2004).

European and Asian governments have expanded the use of ex post facto analysis beyond public works. Several studies have evaluated a variety of topics including policies relating to carbon dioxide and air pollution emissions (APREC, undated; Millock and Nauges, 2006), financial market effects from trade and mergers (Heckman et al., 1999; Fletcher, 2005; Isik-Dikmelik, 2006; Boumemellassa and Valin, 2008), urban development (Burgess and Arup, 2003; Gleave, 2008), social investments (European Social Fund, 2009) and even research policies in general (Aho et al., 2008). A list of other similar European studies is provided by the Center for Strategy and Evaluation Services (CSES, 2009). Most notably, researchers in France and Japan have developed refined procedures for conducting ex post facto evaluations. In Japan, these evaluations are recommended to be updated annually; in France, such evaluations are recommended 
to be conducted between three and five years after completion of a project (Ministry of Foreign Affairs of Japan, 2000; Jeannesson et al., 2007).

Other than public agencies, the main contributors to the literature on ex post facto studies are the development banks. The goal of global development organizations, such as the World Bank, Asian Development Bank, KfW Entwicklungsbank, and the Overseas Development Administration, is to essentially provide the most "good" for their limited resources. Such organizations have performed ex post facto evaluations to assess the effectiveness of investments with regards to economic development, antipoverty programs, fighting HIV/Aids, improving water resources/sanitation, and disaster relief (Asian Development Bank, 1990; Cairncross, 2002; Eriksen and Bhatti, 1993; Dayton, 1998; Chen and Ravllion, 2003). Lists of ex post facto reports for Kfw Entwicklungsbank and Overseas Development projects are provided by at Entwicklungsbank (2009) and Overseas Development Administration (1984). World Bank ex post facto studies are typically conducted every five to eight years (Gunnerson, 1989).

To conduct an ex post facto evaluation, data collection, data analysis, social studies, model calculations, simulation, and literature searches are typically required (Institut National de Recherche sur le Transports et Leur Securite, 1997).

While ex post facto studies are usually conducted at the end of a project, recently McNeil and Mizusawa (2008) suggested an adaptive approach combining ex post facto and ex ante analyses (Figure 2.1).

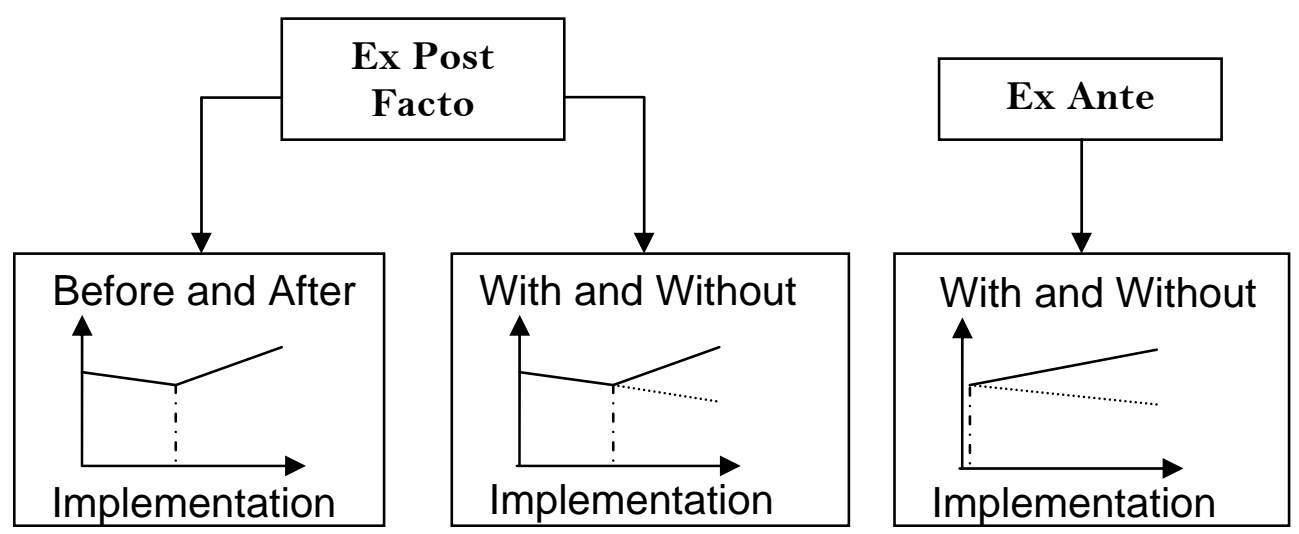

Figure 2.1. Ex post facto and Ex ante Approaches (McNeil and Mizusawa, 2008)

The 'with and without' ex post facto approach relies on a combination of collecting time-series data and on simulation analysis, allowing the agency to immediately switch investment strategies once a shift in effectiveness becomes apparent. The responsive nature of this analysis helps reduce heterogeneity; ex post facto analyses are susceptible to external influences that make the underlying cause behind a project's success or failure difficult to determine (McNeil and Mizusawa, 2008). Also, statistical or econometric 
models require a significant amount of data that may not be available. However, if sufficiently validated, these models can improve decision-making.

\subsection{Chapter Summary}

Overall, ex post facto analysis has proven worthwhile because it allows for the full assessment of the cost and effectiveness of a variety of policies and decisions in a wide range of sectors including transportation. Ex post facto studies have helped agencies set more realistic expectations in terms of their performance measures regarding investment costs and benefits. In the current era of limited funding and increased scrutiny of taxpayer-funded investments, ex post facto analyses are particularly important in helping to reduce the frequency and size of cost overruns. Thus, the conduction of regular ex post facto studies has been highly recommended at public agencies. The immediate recognition of trend reversal using an intermediate ex post facto analysis approach (i.e., continuously updated regression models) allows for the reduction of the influence of external effects. In the field of transportation, ex post facto analysis is in a nascent stage of development and is not yet fully applied to all projects in this sector. A reason for the limited use of ex post facto studies is the high cost of conducting such studies and the limitation of data availability. At the Indiana Department of Transportation, severe data limitations have precluded the conduction of ex post facto evaluations. However, as recent research has shown, lessons to be learned from such studies can lead to enhanced levels of service for all performance measures and reduction in agency costs in the long-term. On the basis of lessons learned from the literature review and discussed in this chapter, the subsequent chapters present and demonstrate a framework for ex post facto evaluation of Indiana highway project costs. 


\section{CHAPTER 3. HIGHWAY CONSTRUCTION COST ESTIMATION}

\subsection{Introduction}

A highway project can be described as a construction, maintenance or repair activity undertaken at a specific geographic location to address a highway transportation infrastructure need or requirement. In the United States, state departments of transportation are responsible for initiating and supervising the planning and development of their highway infrastructure projects. The planning, design and development of a project can span between two to ten years or more depending upon the project size and complexity. During this period, several estimates of the initial capital cost of the project are prepared. This chapter presents a detailed account of the various activities that are undertaken during the planning and development phase with particular focus on the estimation of construction costs and the methods and techniques used for their preparation.

\subsection{Project Development Process (PDP) Overview}

At most highway agencies, the development of a project starts with the conceptualization of the project need and scope and ends with the letting of the project for construction. As shown in Figure 3.1, this period can be divided into six stages: (a) Planning, (b) Programming and Preliminary Design, (c) Final Design, (d) Advertisement and Contract Preparation, (e) Letting, and (f) Construction. At the conceptual planning stage, a feasibility study is undertaken to justify the project and to define the project scope, scale, complexity, alternatives, and environmental and community impacts. The opinions of the public and other stakeholders are taken into consideration at this stage. A preliminary estimate of the cost is prepared. Then based upon all the above factors, the project is forwarded in the form of a formal proposal to the next stage, rejected, or postponed for submission at a later date. Conceptual planning of a project is followed by its inclusion in the network programming, and then preliminary design of the project (design stage). In programming, all proposed projects in the network (i.e., the entire state) are reviewed, evaluated and selected for inclusion in the state's transportation improvement program. The proposed projects are ranked in the order of their importance, relevance, need, cost-effectiveness, and their ability to meet the highway agency's goals and objectives within the specified budget constraints. 


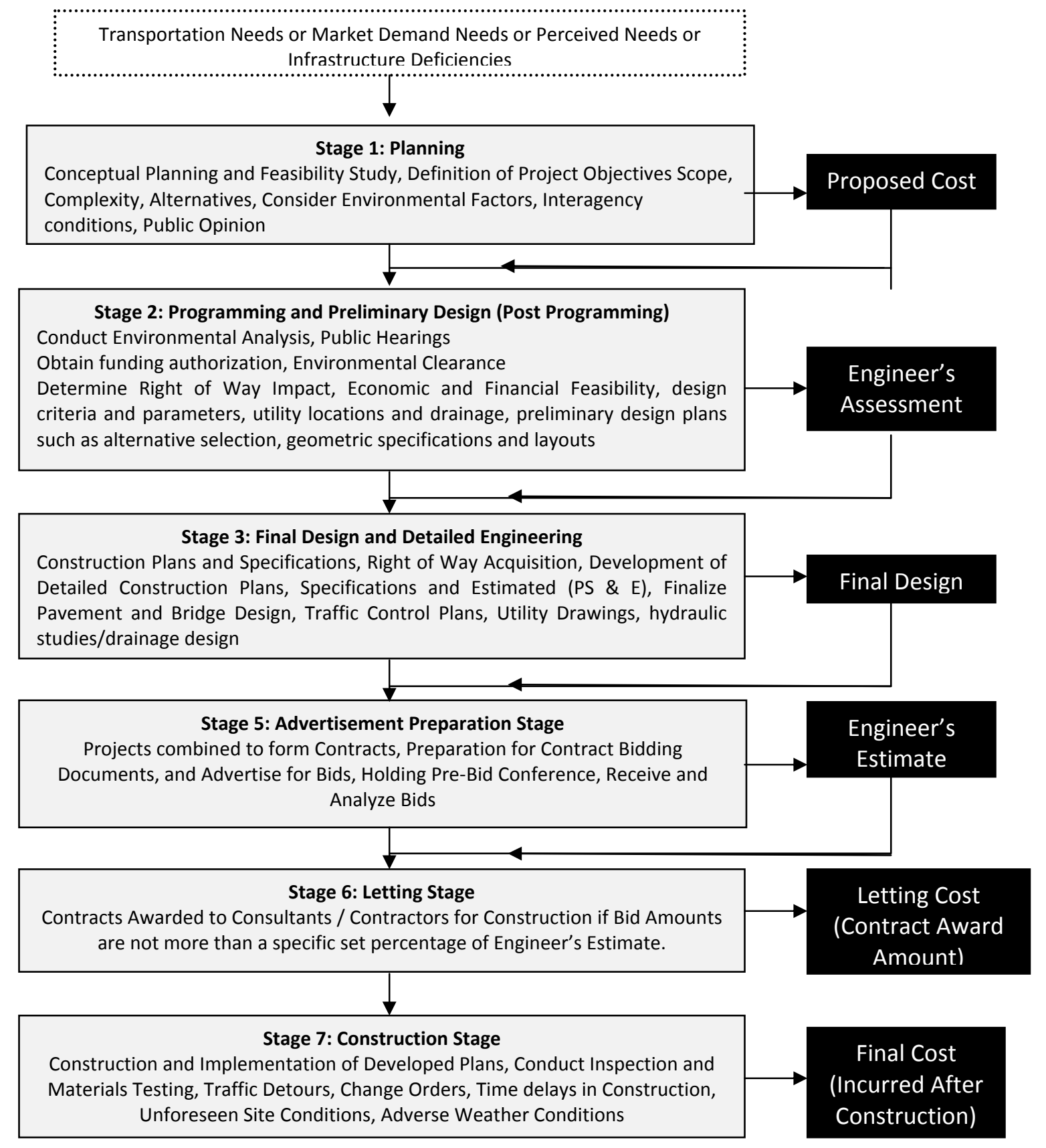

Figure 3.1: Stages of the Project Development Process

A preliminary engineering design is prepared for the project once it has been included into the state's transportation improvement program. By the end of the preliminary design phase, in most cases, the scope of the project becomes clear and the project is ready for the development of a detailed engineering design. This marks the beginning of the design stage where a blueprint for construction is prepared and the individual items and construction plans are finalized. The final design stage is followed by the project 
advertisement for letting. Projects at the same location or involving the same type of work are often lumped together to form a "contract" for advertisement.

The project development process described above reflects the general practice only, specific details vary across state highway agencies where the process may comprise more or fewer stages, depending upon the type of project and the time available to plan and prepare the project (Hendrickson and $\mathrm{Au}, 1998)$. In addition to differences in the structure of the project development process, type of activities, and the methodologies used, the process of allocation of the work during the project development process can also vary across agencies. Most agencies retain direct control of the work that is carried out at the planning and programming stages. Some agencies hire the services of planners, consultants, and financial experts outside the agency at various stages of project development particularly for complex projects. Again, the exact nature of the state of practice differs between agencies and is influenced by the type, scope, and complexity of project.

\subsection{Construction Cost Estimation}

The estimation of highway project cost involves the use of engineering judgment, experience, and scientific principles and techniques to determine the value of the goods and services that are purchased for implementation of the project. The life-cycle agency cost of a project includes the initial capital cost and the subsequent operation/maintenance costs. The capital cost of the project can broadly be divided into two categories: a) cost of non-construction related activities and b) cost of construction.

Non-construction activities associated with a project include items such as preliminary engineering, right-of-way acquisition, preparation of legal documents, project engineering and architecture work, third party collaboration (utility/railroad), transportation demand and supply management, and construction engineering and management. These activities generally involve several agencies and stakeholders. The preliminary engineering cost comprises of costs for activities such as field investigation, management of the preliminary design work, preparation of environmental documentation, and cost of any external consultant(s) (INDOT, 2005). Administrative and right-of-way costs include cost of activities such as storm water management, wetland mitigation, and costs of any contractual obligations with property owners (FHWA, 2007). Also, costs corresponding to construction contingencies, construction administration, and public outreach are determined.

The present study focuses on the estimation of construction cost only. Construction costs often can represent approximately 60 to 80 percent of total agency costs in most projects (Anderson et al., 2007). The estimation of construction cost of a project is a continuous process that is carried out at all the stages of the project development process shown in Figure 3.1. The estimates are prepared at each stage after taking into account all available information at that phase of project development. The first estimate is prepared at the planning stage and is referred to as the proposed cost. Then an engineer's assessment of the proposed 
project and its cost is carried out after the project has been programmed in the statewide transportation improvement program. Several cost estimates are prepared during the design stage; the final estimate (prepared at the end of the design stage with completed plans) is referred to as the design cost. An engineer's estimate is prepared at the advertisement stage before a project is let. This cost estimate is used for administrative and legal purposes and also as a benchmark for bid evaluation at the letting stage. Overall, the estimates at each stage are developed to keep track of the construction cost of the project, make decisions, formulate the long-term spending plans, and most importantly for accounting and control purposes (Anderson et al., 2007). The prepared estimates serve as a basis for the management and performance of a project.

Construction cost estimates tend to become more accurate as a project evolves from planning stage to letting stage (Meyer and Miller, 2001). Figure 3.2 presents schematically the level of uncertainty associated with the estimate of the construction cost at each stage of project development. The quantifiable component of the construction cost increases with project development as more detailed information about the construction activities and processes becomes available. A contingency amount is set aside to account for the unknown construction costs at each stage. The contingency (as a percentage of the estimate) reduces as the project progresses through the various development stages.

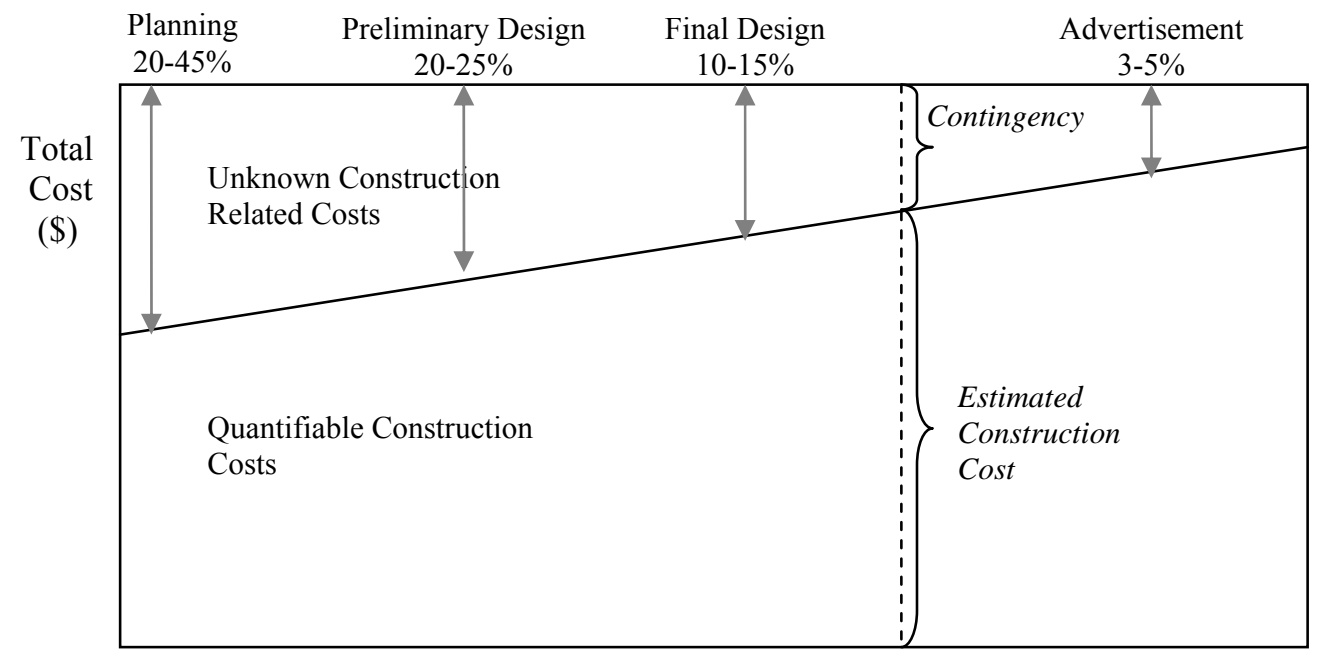

Figure 3.2: Typical Progression of Cost Uncertainty Across the Stages of Project Development

\subsection{Planning Stage}

The State department of transportation (DOT) is the central agency that administers all State highway projects within a state. The program development division of the department issues a call to the districts, MPOs, and local highway agencies to submit new project proposals for their respective jurisdictions. The call for proposals initiates the concept development and planning process. The recipients of the call identify 
highway transportation needs and requirements within their respective jurisdictions. A list of projects to be undertaken is prepared on the basis of the needs, goals and objectives of all partners involved, and the transportation improvement program of the local highway agency or MPO.

A proposal is prepared for all the identified projects. These proposals are required to include sufficient descriptive information such as need / justification for project, type of work, scope of project, location, and the basic design concept. Early consultation meetings are held with the respective stakeholders and public opinion is sought. Alternatives are defined, studied, and evaluated. Environmental factors are considered. Public involvement and participation is facilitated to take public opinion further into consideration. Regulating agencies are notified about the proposed action. Certain DOTs have specific requirements that need to be addressed at the planning stage. In California for example, all projects initiated by Caltrans are required to satisfy the California Environmental Quality Act. All DOTs require an environmental clearance as mandated by the FHWA. A project scoping report is prepared on the basis of the findings of such assessments.

The specific procedures within the planning process can vary from one highway agency to another and even from one project to another depending upon the type of construction activities involved, size and scope of the project, geographic location of the project, methods of procuring professional services, nature of construction contract award process, and financing mechanisms.

\subsubsection{Estimation of Proposed Costs - State of Practice}

The proposed cost (the first estimate of the construction cost) is prepared for each feasible project and is prepared at the planning stage using limited information such as: project length, project work type, number of lanes, pavement type, type of bridge, etc. The prepared estimate is used for programming a project into the state transportation improvement program (Caltrans, 2008). The proposed cost is considered as an "order of magnitude" estimate and is generally prepared using average unit costs that are typically determined using historical costs (costs of similar facilities constructed in the past) (Meyer and Miller, 2001). The Maryland State Highway Administration uses an Excel-based tool for preparing an estimate of the proposed roadway cost using historical costs per mile (Rummel et al, 2002). The Alabama DOT uses a regression-based tool for estimating proposed costs. The regression model, based on the bid data from historical projects, gives the unit average costs (Sanders et al., 1992). The Florida Department of Transportation updates a Transportation Costs Report periodically with cost data from historical highway projects and calculates the unit costs per centerline mile to estimate the proposed cost for roadway projects (FDOT, 2002).

Planners and engineers often use their own personal engineering judgment and experience to prepare the proposed cost estimate (AACE, 1997). Several agencies depend heavily on experienced estimation professionals to estimate the construction cost at the planning stage. Schexnayder et al. (2003) 
found that twenty-six state highway agencies in the United States had a dedicated section of experienced professionals for cost estimation. The other twenty-four highway agencies use the services of persons in the engineering design and contract preparation units to prepare estimates.

The California Department of Transportation uses a systematic approach of grouping basic work functions together for preparing proposed cost estimates (Caltrans, 2008). Cost information on basic work items such as earthwork, drainage, traffic, pavement structural section materials, and other structural items that are easy to identify is acquired. A systematic field review is conducted to identify the typically overlooked work, so as to minimize the difference between proposed cost and final design estimates. Highcost items such as utility relocation costs, hazardous waste mitigation costs, requirements for noise barriers, retaining walls, drainage facilities, traffic handling, etc., are identified in the field. Information on geotechnical conditions on the site, environmental issues, pavement structural information, right of way, and the possibility of utilizing any existing resources is also sought.

As the uncertainty associated with the prepared proposed costs is often high, a large contingency amount is set aside at the planning stage. The contingency can vary between 20 - 45\% depending upon the type of the project and the level of detail that was used to estimate the proposed cost (Meyer and Miller, 2001; PennDOT, 2007). A graduated contingency scale that allows for the provision of setting the contingency percentage on the basis of criteria such as project size or project type is popularly used for setting the contingency amount at the planning stage. Several state highway agencies have established a separate contingency account to fund projects with construction contingencies. For example, in Kentucky, a highway construction contingency account has been created within the road fund (KLRC, 2009). The money is appropriated to the account by the State's General Assembly.

\subsubsection{Research Studies on Estimating Proposed Cost}

Kim et al. (2008) proposed a case-based reasoning model for estimating proposed cost. This approach utilizes project specific factors that are available at the planning stage, such as project location, project type (new / existing), contract type (lowest price, pre-qualified completion, or design-build), construction period, and length and width of highway. The model, developed using data from 90 historical highway projects, provided decision-makers with a tool to conduct feasibility studies and to make budgetary allocation decisions more effectively.

Sodikov (2005) proposed a methodology for estimating proposed costs using artificial neural networks. Hegazy and Ayed (1998) also used the neural network approach to develop parametric cost estimation models for highway projects on the basis of project location and highway length. Cost estimation models based on artificial neural network concepts have been found to be more effective in dealing with the uncertainty associated with cost estimation at the planning stage compared to regression models, because they provide a superior framework to structure the relationships between cost and its 
significant influential factors (Smith et al., 1997). On the other hand, regression models may provide reasonable approximations and are easy to use and interpret.

\subsubsection{Accuracy of Proposed Cost Estimates}

The Virginia Department of Transportation (JLARC, 2001) found that the initial estimates of project cost tend to be significantly lower than those made at subsequent phases of project development. Factors found responsible for underestimation included: a) augmentation of project scope, b) exclusion of inflation at the planning stage, and c) failure to account for several cost items relating to site conditions. The transferability of the average unit costs used to prepare the proposed cost estimates has also been indicated as a possible source of error (AASHTO, 2006). Urban area projects are likely to have higher unit costs as the construction process is carried out in confined workspaces with a large volume of traffic and limited hours of operation (nighttime work). However, the factors that lead to higher costs at urban areas may be outweighed by factors such as the extensive availability of local contractors, equipment, material, and personnel in urban areas.

Wachs (1982) conducted interviews of several transportation planners, public officials, and consultants to determine the source of inaccuracy in cost forecasts for highway and transit projects. Based on the interviews, it was concluded that forecasts were often manipulated to get the projects approved. In one case, a transportation planner was asked to revise her transit patronage estimates so that the project could be justified to receive the federal grant. Such deliberate manipulations in the estimation of benefits and costs add uncertainty to the planning stage.

In cost overrun studies conducted abroad (Flyvbjerg et al., 2002; Flyvbjerg et al., 2003) it has been found that cost escalation is a pervasive phenomenon across transportation project types, geographical locations, and historical periods. Based on an analysis of 258 transportation infrastructure projects (worth U.S. $\$ 90$ billion) from around the world, Flyvbjerg et al. (2002) concluded that the cost estimates that were used to decide whether these projects should be built are highly misleading and inaccurate. Approximately $80 \%$ of the projects were found to have a cost overrun, about $50 \%$ of these projects were found to have an overrun in excess of $10 \%$. Flyvbjerg et al. (2004) found that cost escalation is strongly influenced by the implementation phase length and project type, and it was suggested that decision-makers and planners should be duly concerned about delays and long implementation phases. The sample of 258 projects comprised of 167 road projects that experienced an average cost overrun of $20.4 \%$ (with a standard deviation of $30 \%$ ). Also, 33 bridge and tunnel projects were analyzed and found to have an average cost escalation of $34 \%$ (with a standard deviation of $62 \%$ ). A total of 58 rail projects were analyzed and the average cost escalation across those projects was found to be $45 \%$ (with a standard deviation of $38 \%$ ). Figure 3.3 shows the distribution of cost escalation percentage across the 258 contracts. 


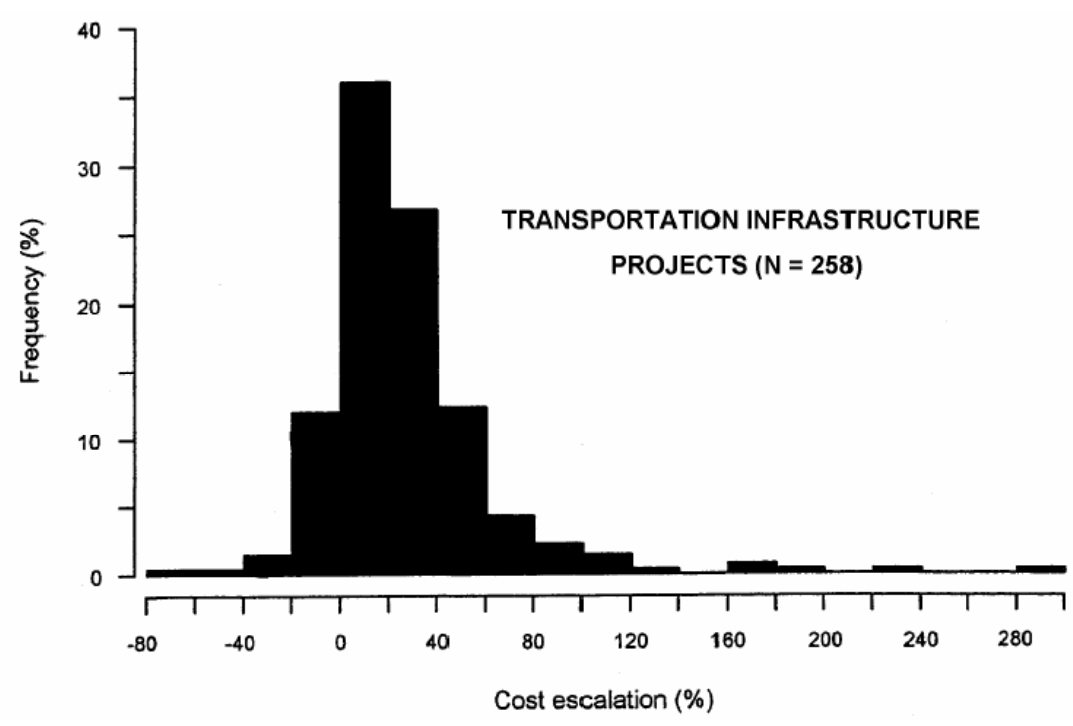

Figure 3.3: Inaccuracy in Cost Estimates at the Time of Decision to Build (Flyvbjerg, 2002)

\subsection{Programming and Preliminary Design Stages}

The objective of the programming phase is to determine the optimal set of projects from the larger universe of proposed projects to be included in the DOT's transportation improvement program. In Indiana for example, after the project proposals have been prepared and submitted, the Indiana Department of Transportation (INDOT) engages its sections or divisions responsible for budget and finance, planning and programming, etc. to evaluate and verify the project proposals. Early meetings are conducted to prepare a prioritized list of proposed projects. The MPOs are required to ensure that their respective regional transportation plans (RTP) are in conformance with the statewide transportation plan (STP). The Division

of Program Development summons the bridge, pavement, and other program management groups to analyze the proposals within their respective jurisdictions. This marks the beginning of the programming phase. Table 3.1 shows the steps during the programming phase followed at INDOT. 
Table 3.1: Steps Involved in the Programming Phase of Project Development (INDOT, 2004)

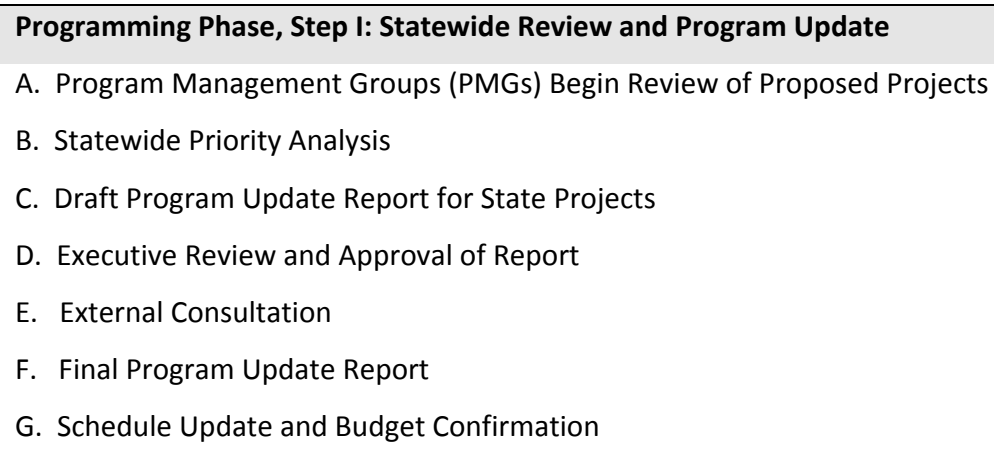

The basic framework of the programming process is similar for most state highway agencies in the United States. The programming phase starts with the review of the project proposal that explains the project needs, justification, and the costs. The review is conducted to ensure that the recommended projects are in accordance with the criteria, requirements, and objectives set forth by the highway agency. The proposed cost of the project is validated during the review, and after the review is completed, all the projects are prioritized on the basis of the recommendations from the review. A draft program report is prepared to update the state's existing transportation improvement program with new project proposals and to present an account of the impact of including the new projects on the budget. The updated program report is submitted for executive review. The districts and MPOs are consulted for their comments and a 
final program report is prepared after addressing the issues and concerns of all parties. The state's directory of all the highway projects is updated. The directory is used for preparing a draft of the state's transportation improvement program (STIP) that contains a list of projects that are: (i) planned for implementation during the next three to five years and (ii) that seek federal funding. The draft STIP is developed in consultation with the districts and the MPOs. Public review and comments are also sought on the STIP before submission to the FHWA and the FTA for review, comments, and approval. If approved, the projects scheduled in the first three years of the STIP are considered as committed projects and applicable federal funds are allocated to these projects. Thereafter, more detailed planning and design work is undertaken for the committed projects.

\subsubsection{Programming and Preliminary Design Stage Cost Estimation}

At the programming stage, the estimates of proposed cost of submitted projects are reviewed, evaluated, and revised if, required. After programming, the preliminary design stage commences and detailed information on the project is sought for the preparation of preliminary construction plans. An estimate of the cost is prepared based on the preliminary design specifications and the additional details acquired about the project scope and complexity. This estimate is often referred to as the engineer's assessment cost. The techniques that are used to prepare this estimate vary significantly in complexity across the DOTs. Widelyused techniques are categorized as: (a) detailed estimation methods and (b) historical bid-based cost estimation methods.

The detailed estimation method uses information such as the procedures used for construction, labor cost, material cost, and market conditions specific to the project location. The time required to prepare such estimates increases depending upon the level of detail being considered. The time required is significantly greater compared to that derived using methods based on average unit costs used at the planning stage. The detailed estimation method is a cost-based approach, as compared to the bid-based pricing method where average unit costs are estimated based on historical bids. The historical bid price estimation method is, however, simple, fast, and the most widely used method for cost estimation (Damnjanovic et al., 2008). This method can be used to estimate the cost of projects that are similar to those undertaken in the past with similar items, quantities, and locations (AASHTO, 2006).

The New Jersey Department of Transportation uses the Cost Estimation Software (CES) for estimating construction costs (NJDOT, 2006). This software can be used to estimate cost at various stages of project development depending upon the level of detailed information available. At the preliminary engineering stage, the construction cost estimate is prepared based on factors such as project length, work type, number of lanes, pavement type, and type of bridge. There are several categories of the type of work that are used by NJDOT at the preliminary design stage: new construction, reconstruction/widening, widening and resurfacing, resurfacing, bridge repair, intersection improvements, electrical safety and traffic 
control, intelligent transportation systems, demolition, and drainage. A separate form is used for estimating the cost of each work type. For each project work type, cost groups are formed depending upon the profile of the project. The corresponding cost of each cost group is determined using the bid-based pricing method.

\subsubsection{Accuracy of Programmed Amount}

The California Department of Transportation conducted performance reviews to measure the agency's success in planning and delivering projects within the specified budget (Caltrans, 2002). The contract award amount was measured as a percentage of the programmed amount and the agency strived to have this percentage fall within the $85-100 \%$ range. Figure 3.4 shows a comparison of the awarded amount as a percentage of the project budget for each year during the period 1998-2002. Caltrans was successful in letting contracts at $85 \%$ of the programmed amount during the four years.

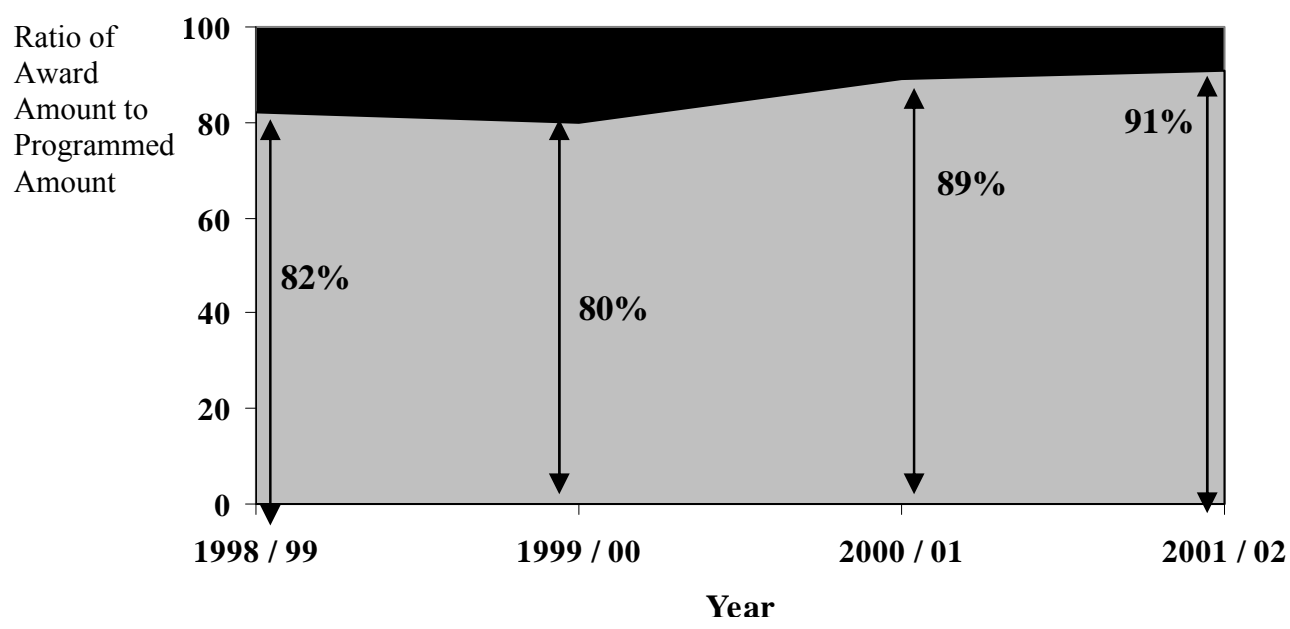

Figure 3.4: Comparison of Contract Award Amount to Programmed Amount for Contracts in California

(Caltrans, 2002)

The Missouri Department of Transportation uses a tracking system to assess their performance and to determine how well services and products are delivered to customers; the system tracks the percentage of projects that are completed within the programmed amount (MoDOT, 2008). Figure 3.5 shows the percentage of projects that were delivered within the programmed amount by project size. Large size projects (over \$1 million) were found to be delivered within the budgeted amount more frequently. 


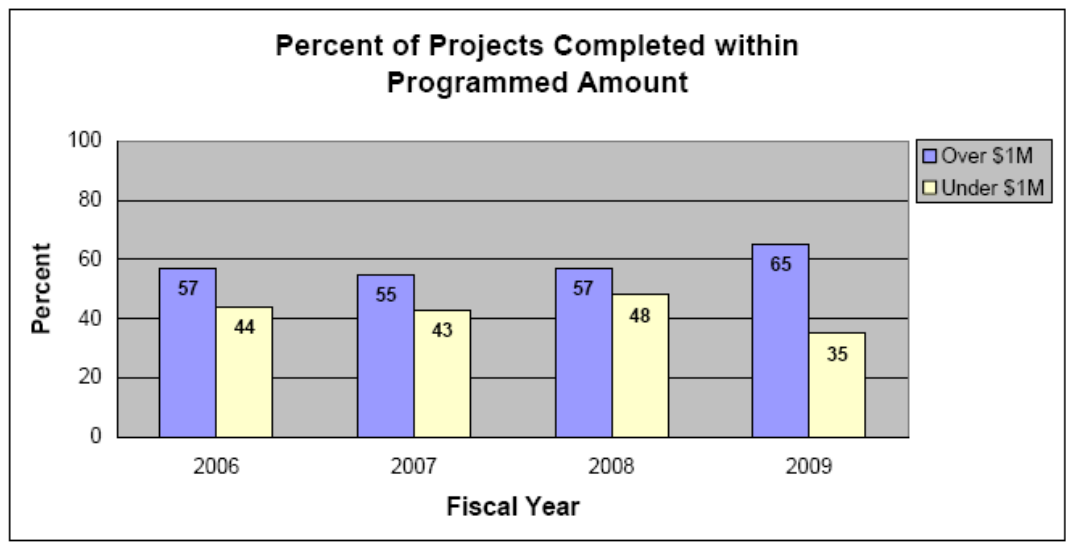

Figure 3.5: Percent of Projects Delivered Within the Programmed Amount in Missouri (MoDOT, 2008)

\subsection{Final Design Stage}

During the final design stage, detailed construction plans, and specifications are developed and finalized, and specific items to be used in construction and the corresponding quantities are determined. A design estimate of the construction cost is prepared either in-house or by a consultant as the construction plans and specifications are being developed. However, a consistent methodology is not in place for controlling the estimate of construction cost that is prepared at this stage in most of the DOTs (Schexnayder et al., 2003). Estimates prepared at the design stage vary significantly from those prepared at the planning and preliminary design stages. The methods and the tools used for the estimation of the final design cost are discussed in this section.

\subsubsection{Estimation of Design Cost at Highway Agencies}

Estimates of construction cost established at the design stage are generally prepared using computer software. Item level details are fed into the software and the unit costs for each item are adopted either from the software, based on default settings, or specified by the estimator based on current trends. Information on the quantities of each item is available from the detailed design plans. AASHTO's TRNS*PORT is the most widely used computer software for estimation (Schexnayder et al., 2003). In addition to TRNS*PORT several other software are used for the estimation of construction cost. Bid Tabs Professional by Oman Systems Inc. (Schexnayder et al., 2003) is one of the available systems in use by several agencies. TRACER is another software package that is in use; it uses parametric cost estimation methods with minimal user input (AASHTO, 2009). Models that define the relationship between the parameters and the detailed quantities of construction requirements are the basis for the computation of estimates.

TRNS*PORT can be used to prepare parametric or item-level project cost estimates based on project work types and other project characteristics. The software has four modules namely: a) CES, b) 
PES, c) LAS, and d) CAS. The Cost Estimation System (CES) module of the software is used for cost estimation. Figure 3.6 shows the framework of the TRNS*PORT software. In the New Jersey Department of Transportation (NJDOT, 2006), the CES module starts to be used at the preliminary design stage. Because itemized details are not available at that stage, those cells are left blank and are filled at the final design stage. The software uses unit bid prices for the preparation of the estimate. Historical bid prices are used to update the database. The Proposal and Estimates System (PES) module is used after the final design at the advertisement stage. The cost estimate prepared in CES is passed to PES. The Letting and Awards System (LAS) module is used for the analysis of the bids and the Construction Administration System (CAS) module is used at the construction stage. The database that stores information about the historical bids, average unit prices, and other analysis models is stored at the back-end in the decision support system (BAMS/DSS) data warehouse.

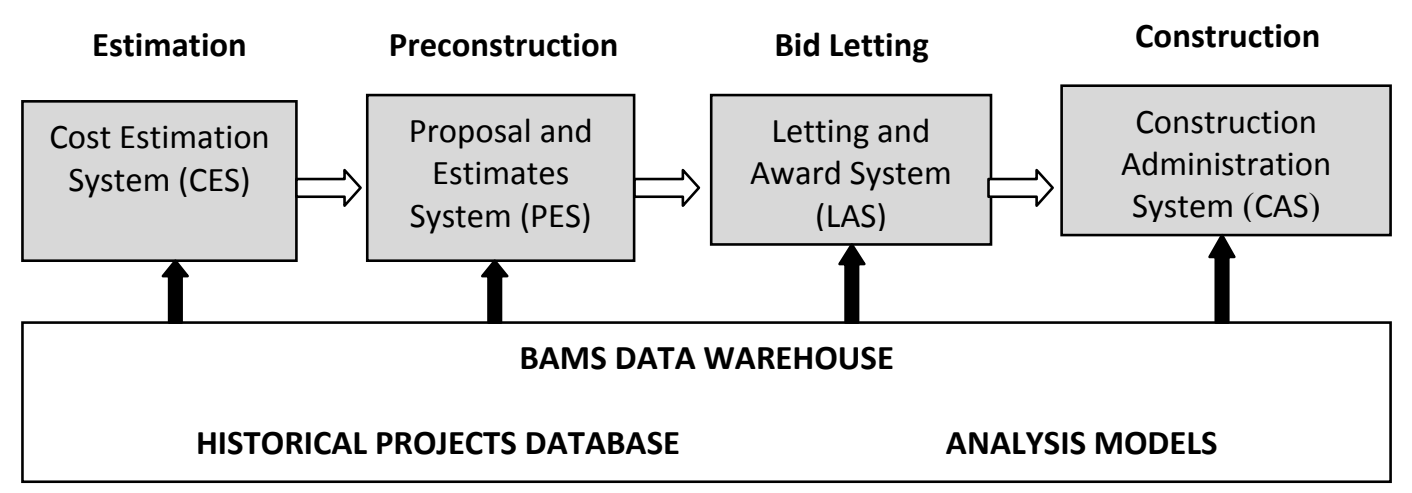

Figure 3.6: Framework of the TRNS*PORT Software (AASHTO, 2009)

\subsubsection{Accuracy of Design Estimates}

In a study involving approximately 300 projects by the Virginia Department of Transportation (JLARC, 2001), it was concluded that cost estimates are underestimated prior to final design completion. VDOT develops cost estimates at four points prior to the final design completion: a) scoping, b) preliminary field review, c) field inspection, and d) approval of right-of-way plans. It was found that the final design estimate for construction cost was $74 \%$ higher than the project scoping estimate, $53 \%$ higher than the estimate prepared after preliminary field review, 45\% higher than the estimate prepared after field inspection, and 19\% higher than the estimate prepared after submission of right-of-way plans. Furthermore, it was found that the contract award amount was fairly close to the final design estimate. The final construction cost was found to exceed the budgeted amount by an average of $19 \%$ for Interstate projects, $16 \%$ for primary projects, $9 \%$ for secondary projects, and $8 \%$ for urban projects. On an average, the final cost exceeded the budgeted cost by an average of $11 \%$. The additional funds set aside for contingency were also exceeded. Several factors were identified that explained the low cost estimates: requests by localities 
for additions to the project, non-adjustment for inflation, unforeseen site circumstances, increases in property values as a result of project development, inconsistency in inclusion of contingencies, etc. The inherent incentive in the system to inadvertently underestimate the project costs at the design phase was identified as one of the factors.

The Washington Department of Transportation analyzed 360 highway construction projects completed in 2003-05 and found that 93 were "over budget" (MacDonald et al., 2005). A project was considered over budget if the final cost exceeded the total project cost (listed in the last legislative budget) by over $5 \%$. Of the projects that went over budget, $80 \%$ were low cost projects with cost less than $\$ 1$ million. Approximately $15 \%$ of the over budget projects were in the range of $\$ 1-\$ 5$ million and only $5 \%$ of the projects were greater than $\$ 5$ million. The actual causal factors of cost overrun were analyzed, and it was found that cost overrun in $70 \%$ (65 of 93) of the projects resulted from estimation of inaccurate quantities of material at the design phase. For approximately $11 \%$ (10 of 93) of the projects, overrun was due to changed or unforeseen site conditions, and for 19\% (18 of 93) of the projects, overrun was due to factors such as weather, environment, utilities and emergencies.

The revisions in designs were attributed as one of the main reasons for cost overrun in a FHWA study of seventy-four projects each worth more than $\$ 10$ million, the average cost overrun rate exceeded $25 \%$ (Jocoby, 2001). However, unexpected site conditions were also cited as one of the reasons, and could be the cause for most of the design revisions. The Indiana Department of Transportation (INDOT) classifies the change orders related to highway construction projects in two categories: a) preventable and b) non-preventable. Preventable change orders are those that occur due to errors and omissions during the design phase, scope changes, or changes in constructability of a project. Non-preventable change orders occur due to changed field conditions, failed materials, or changes in standards or specifications.

Bordat et al. (2004) analyzed 822 contracts implemented in 1996-2001 and found that of the total amount associated with change orders ( $\$ 65$ Million), the design-related errors and omissions were responsible for $15 \%$ ( $\$ 9.5$ Million) and the constructability of the design was found responsible for approximately 5\% (\$3.4 Million). Inadequate time to produce quality designs and no accountability for project's construction performance are the two reasons that were cited as root causes for design errors and omissions. Table 3.2 presents a summary of the main factors that were found responsible for change orders. These included: 'construction-related constructability', 'design-related constructability', 'design-related errors and omissions', and 'quantity-related errors and omissions'. Design related errors and omissions accounted for $\$ 9.5$ million of the $\$ 12$ million associated with change orders in this category. 
Table 3.2: Factors Responsible for Change Orders in Highway Construction (Bordat et al., 2004)

\begin{tabular}{lccc}
\hline Factor Responsible for Change Order & $\begin{array}{c}\text { Number of } \\
\text { Contracts }\end{array}$ & $\begin{array}{c}\text { Number of } \\
\text { Change Orders }\end{array}$ & $\begin{array}{c}\text { Increase in Cost Due to } \\
\text { Change Orders (Million \$) }\end{array}$ \\
\hline No Recorded Reason & 224 & 6024 & $\$ 29$ \\
\hline Errors and Omissions & 476 & 3937 & $\$ 12$ \\
\hline Constructability & 410 & 3227 & $\$ 10$ \\
\hline Scope Changes & 278 & 2093 & $\$ 7$ \\
\hline Changed Field Conditions & 324 & 1813 & $\$ 2$ \\
\hline Failed Materials & 251 & 392 & $\$ 0.70$ \\
\hline Standard / Specifications Updates & 94 & 390 & $\$ 60$ \\
\hline
\end{tabular}

\subsection{Contract Preparation and Advertisement Stage}

During the advertisement stage, preparations for the letting the projects are made and documents are prepared for the bidding. Often, several projects in the same geographic location or involving the same kind of work are lumped together to form a contract so that they can be let together. The contracts are advertised for bids, pre-bid conferences are held, and the bids are received and analyzed at this stage. An engineer's estimate of the cost is prepared at this stage to serve as an estimate of the project cost for legal purposes and to be used as a benchmark to evaluate the bid estimates of the construction cost at the contract letting stage.

\subsubsection{Preparation of Engineer's Estimate}

An engineer's estimate of the construction cost is prepared before a contract is advertised for bidding. The engineer's estimate is based on the completed plans and specifications as compared to the design estimate that was prepared when the construction plans were being finalized. State departments of transportation often use the services of design consultants for preparing the engineer's estimate of the cost. Another important distinction between the engineer's estimate and the final design estimate is that the engineer's estimate is generally prepared by taking into account the contractors overheads and profits (Hendrickson and $\mathrm{Au}, 1998$ ). Schexnayder et al. (2003) found that sixteen DOTs reviewed and analyzed the estimate prepared by the consultants and changes were made wherever necessary. Twenty-six DOTs used estimates prepared by consultants to cross-check the engineer's estimate that was prepared in-house before the final engineer's estimate was recorded. The estimates produced by the consultants were used without any substantial changes by the remaining eight DOTs. Irrespective of whether the estimate was prepared inhouse or by an external consultant, the historical bid based approach was the most commonly used approach for the computation of the engineer's estimate. Often, a combination of the historical bid based approach and the detailed estimation approach is used wherein the cost of the major items of work is estimated using the detailed approach and may constitute $50-80 \%$ of the total construction cost depending upon project type. The rest of the items are estimated using the historical bid based approach. 
The use of software for computing the engineer's estimate is common practice at several DOTs. For example, NJDOT uses the PES module (Figure 3.6) of the TRNS*PORT software to import the estimates of cost prepared during the project development phases and develop a final cost estimate based on the additional design information that is entered after the project plans have been finalized. Once the engineer's estimate has been computed the PES module prepares an electronic bid letting package. This package is provided to the contractors electronically using software called Expedite. The contractors submit their bids electronically using this software and the bids are made available to the DOTs for analyses.

\subsubsection{Accuracy of Engineer's Estimate}

The Washington State Department of Transportation (WSDOT, 2008) compared the final construction cost with the engineer's estimate to determine the reliability of the in-house procedures for cost estimation (Table 3.3). The final cost exceeded the engineer's estimate by approximately $6 \%$ in 2004 resulting in an overrun of nearly $\$ 18$ million. In each of the fiscal years 2004, 2005, and 2006, approximately $25 \%$ of the contracts had a final cost that exceeded engineer's estimate by more than $10 \%$. The percentage of contracts having an overrun of greater than $10 \%$ was found to increase to about $30 \%$ and $32 \%$ in the years 2006 and 2007, respectively. Figure 3.7 presents the cost overrun trend from 2004 to 2008.

Table 3.3: Annual Report of Accuracy of Engineer's Estimate at Washington DOT (WSDOT, 2008)

\begin{tabular}{cccccc}
\hline $\begin{array}{l}\text { Fiscal } \\
\text { Year }\end{array}$ & $\begin{array}{l}\text { Number of } \\
\text { Contracts }\end{array}$ & $\begin{array}{l}\text { Total Engineer's } \\
\text { Estimated Cost }\end{array}$ & $\begin{array}{l}\text { Total Final } \\
\text { Cost }\end{array}$ & $\begin{array}{l}\text { Annual } \\
\text { Overrun (\$) }\end{array}$ & $\begin{array}{l}\text { Annual } \\
\text { Overrun (\%) }\end{array}$ \\
\hline 2004 & 159 & $\$ 302,276,645$ & $\$ 320,356,211$ & $\$ 18,079,566$ & $5.98 \%$ \\
\hline 2005 & 165 & $\$ 303,266,277$ & $\$ 305,253,750$ & $\$ 1,987,473$ & $0.66 \%$ \\
\hline 2006 & 125 & $\$ 228,945,165$ & $\$ 231,324,283$ & $\$ 2,379,118$ & $1.04 \%$ \\
\hline 2007 & 136 & $\$ 286,993,516$ & $\$ 290,728,546$ & $\$ 3,735,030$ & $1.30 \%$ \\
\hline 2008 & 131 & $\$ 298,200,264$ & $\$ 310,216,164$ & $\$ 12,015,900$ & $4.03 \%$ \\
\hline Total & 716 & $\$ 1,419,681,867$ & $\$ 1,457,878,954$ & $\$ 38,197,087$ & $2.69 \%$ \\
\hline
\end{tabular}




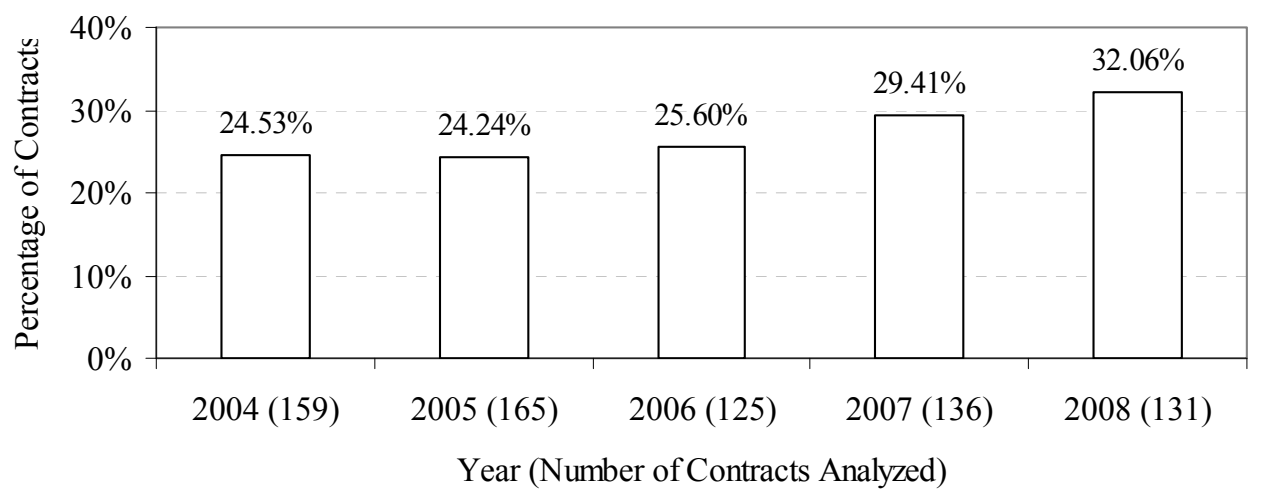

Figure 3.7: Percentage of Contracts for which Final Cost Exceeded the Engineer's Estimate by Over 10\%

(WSDOT, 2008)

Figure 3.8 shows a plot of the percentage difference that was observed for 131 contracts in year 2005. The percentage difference is plotted against contract size. The number of contracts for which the final cost exceeded the engineer's estimate by more than $10 \%$ was found similar to those for which the engineer's estimate exceeded the final cost by $10 \%$ or higher.

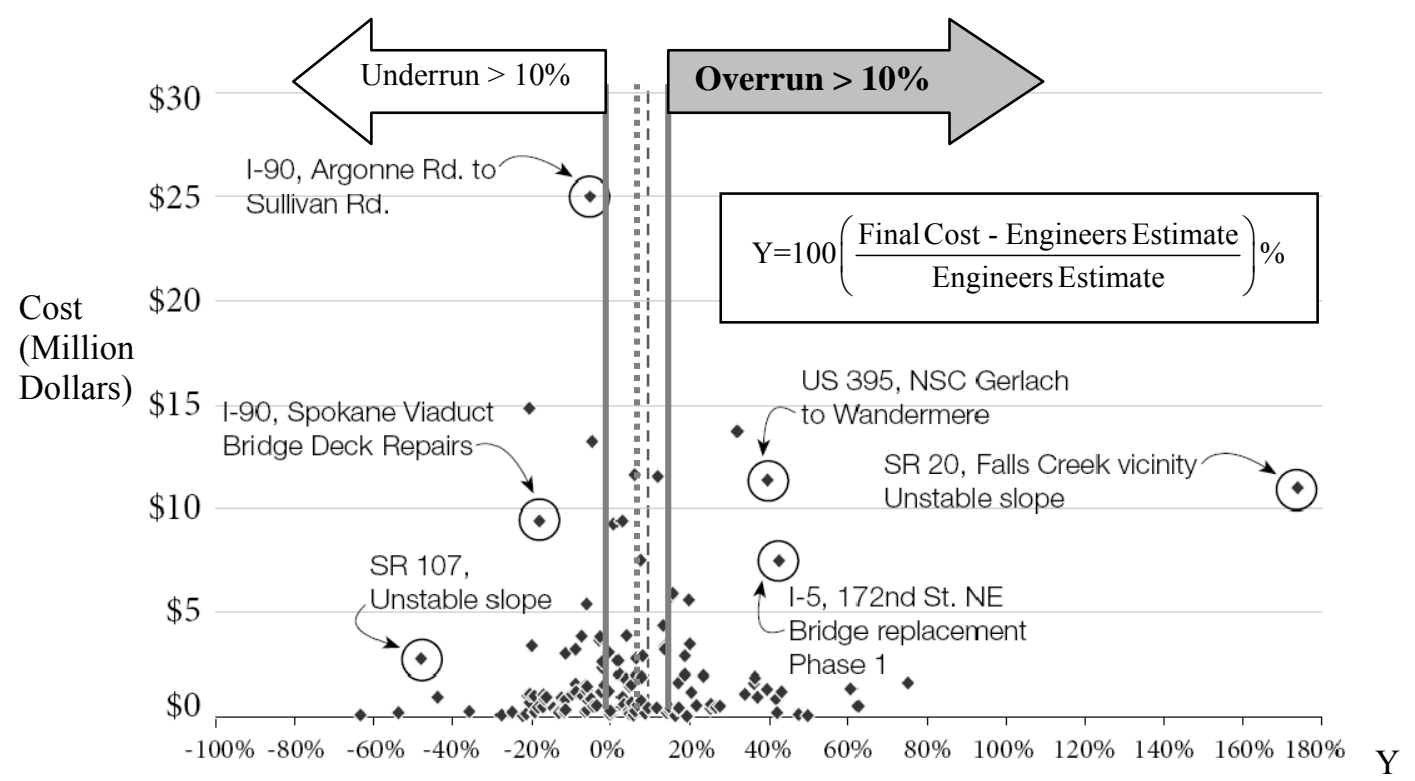

Figure 3.8: Comparison of Final Cost with Engineer's Estimate by Contract Size (WSDOT, 2008) 


\subsubsection{Determining Cost Overrun at Advertisement Stage}

Several researchers indicated that the overrun of the final construction cost can be determined by studying the difference between the contract award amount and the engineer's estimate (Jacoby, 2001; Jahren and Ashe, 1990). Also, Hendrickson and Au (1998) noted that cost overrun could result from mismanagement and lack of coordination and communication between the planners, designers, decision-makers, and contractors. The impact is particularly severe for larger and more complex contracts. Rowland (1981) indicated that as the size of a contract increases, the rate of cost overrun also tends to increase. The factors that are responsible include enhanced complexity of large contracts, increased number of communication channels, and possible distortion of information as it is exchanged between the various participants in the process. Contracts that experienced such factors during the planning and design phase can be identified before advertising the contract for bidding. Also, projects that are lumped together to be let as a single contract can be studied to determine if such an approach increases the number of communication channels and creates management issues.

\subsection{Letting Stage}

After a contract has been advertised and the bids have been received by the DOT, a letting date is set for the contract to be awarded. The time period between the programming stage and the letting stage may vary from three to ten years depending upon the type of contract. The cost estimate is prepared by the contractors in a short time-span and with the objective of winning the contract. The bid amounts are compared to the engineer's estimate and the contract is often awarded to the contractor with the lowest bid, as long as it is not lower and / or higher than the engineer's estimate by a certain specified percentage. The Letting and Award System (LAS) module of TRNS*PORT software is used by several agencies to analyze and manage bids.

\subsubsection{Estimation of Letting Cost}

Estimating the letting cost involves an assessment of the construction duration, labor requirements, construction methods, equipments, and material quantities. Inaccurate estimation of any one of these inputs could result in incorrect estimation. For example, underestimation of the construction duration will generally result in underestimation of the labor hours required for construction, which in turn would result in a relatively lower than normal bid by the contractor. Labor availability, productivity, and quality are also taken into consideration in preparing the bid estimate.

The bid estimate is generally prepared by either using historical price data or by estimating the cost using the prevalent market prices and trends. Stern (1994) argued that the latter is a better approach as prices of goods and commodities depend on a number of market factors and economic conditions. The 
overall condition of the economy, prices of individual items, construction equipments, methods, and technology are likely to change with time and from one project location to another. The duration of a project may play an important role in determining the expenditures during the construction process. Contracts constructed over longer durations are likely to have high labor costs and become more susceptible to changes in the prices of commodities. Finally, in a competitive and declining market, contractors often decide to bid with a lower profit margin, which may cause the agency's estimate to be significantly higher than the bid amount.

\subsubsection{Accuracy of Letting Cost}

Gkritza and Labi (2008) found that the likelihood of overrun of final cost compared to letting cost is influenced by project size and contract duration. Larger and longer-duration projects were more likely to result in cost overrun. Bordat et al. (2004) conducted a survey across several states to collect information about the overrun of the final cost compared to the letting cost. The states were asked to share information about the percentage of contracts with cost overrun, average cost overrun rates, annual amount spent on cost overrun, and causes of overrun. A summary of responses is presented in Table 3.4. The percentage of contracts exceeding letting cost was found to vary between $33 \%$ and $92 \%$ across the states. It was found that the Ohio and Texas DOTs had spent the most amount of money on cost overrun annually compared to other states. The average cost overrun rate was found to be less than $10 \%$ across all the states. However, this average figure does not indicate that high cost overrun did not occur in these states. The amount of money spent on cost overrun may have been compensated for by the cost underrun, which explains the low overall cost overrun rate. However, both cost overrun and underrun exceeding $10 \%$ suggest inaccuracies in cost estimation and therefore need to be addressed separately.

Table 3.4: Rate of Cost Overrun and Annual Cost Overrun Expenditure of Selected States

(Bordat et al., 2004)

\begin{tabular}{lllll}
\hline State & Period & $\begin{array}{l}\text { Percentage of Projects } \\
\text { with Overrun }\end{array}$ & $\begin{array}{l}\text { Cost Overrun } \\
\text { Rate }\end{array}$ & $\begin{array}{l}\text { Annual Amount Spent on } \\
\text { Cost Overrun }\end{array}$ \\
\hline Arkansas & 1997 to 2002 & $55 \%-62 \%$ & $2 \%-11 \%$ & \\
\hline Idaho & 1997 to 2001 & $55 \%-67 \%$ & $5 \%-11 \%$ & $\$ 5-$ \$9 Million \\
\hline Indiana & 1996 to 2002 & $55 \%$ & $5 \%$ & $\$ 26-$ \$45 Million \\
\hline Missouri & 1999 to 2002 & $60-64 \%$ & & $\$ 2-$ \$42 Million \\
\hline New Mexico & 2002 & $62 \%$ & $4 \%$ & $\$ 12$ Million \\
\hline Ohio & 1994 to 2001 & $80 \%-92 \%$ & & $\$ 76-$ \$196 Million \\
\hline Oregon & 1998 to 2002 & $18 \%-33 \%$ & $6 \%$ & $\$$ - \$5.7 Million \\
\hline Tennessee & 1998 to 2002 & $61 \%$ & $4 \%-7 \%$ & $\$ 68$ Million \\
\hline Texas & 1998 to 2002 & $66-75 \%$ & & \\
\hline
\end{tabular}

In an economic and efficiency audit study, Wagner (1998) found that the Delaware Department of Transportation (DOT) experienced cost overrun averaging 13.9\% between 1994 and 1996 due to changes in 
the work scope and incorrect estimates of work quantities in the original bid specifications. Jahren and Ashe (1990) found that the risk of high cost overrun rates was greater when the winning bid amount was less than the engineer's estimate, and further identified some cost overrun factors such as the contract document quality, nature of interpersonal relations on the project, and contractor policies. Other reasons found to be related with cost overrun included the rising costs of labor and materials, inadequate analysis (e.g., poor costing methods), poor control and scheduling, and inadequate information (Akran and Igwe, 2001). Kaming et al. (1997) identified variables that have an impact upon construction time and cost overrun using factor analysis techniques. It was found that the main causes for cost overrun were: (i) the complexity of the project, (ii) inflationary increases in material costs, and (iii) inaccurate material estimates.

Crossett and Hines (2007) compared final cost with letting cost for contracts from twenty-one states. The final and letting costs were acquired for contracts that were greater than $\$ 1$ million in size and were scheduled to finish between 2001 and 2005. Information was obtained from the states of Arizona, California, Delaware, Florida, Illinois, Kentucky, Louisiana, Maine, Michigan, Minnesota, Missouri, New Mexico, North Carolina, Ohio, Pennsylvania, South Dakota, Tennessee, Vermont, Virginia, and Washington. Percentage of contracts for which final cost exceeded letting cost was determined for each state was found to be between $36 \%-69 \%$. Across all the states, on average, the final cost exceeded the letting cost for approximately $55 \%$ of the projects. The percentage of contracts for which the final cost exceeded 110 percent of the letting cost was found to vary between 11 and 48 percent (Figure 3.9). 


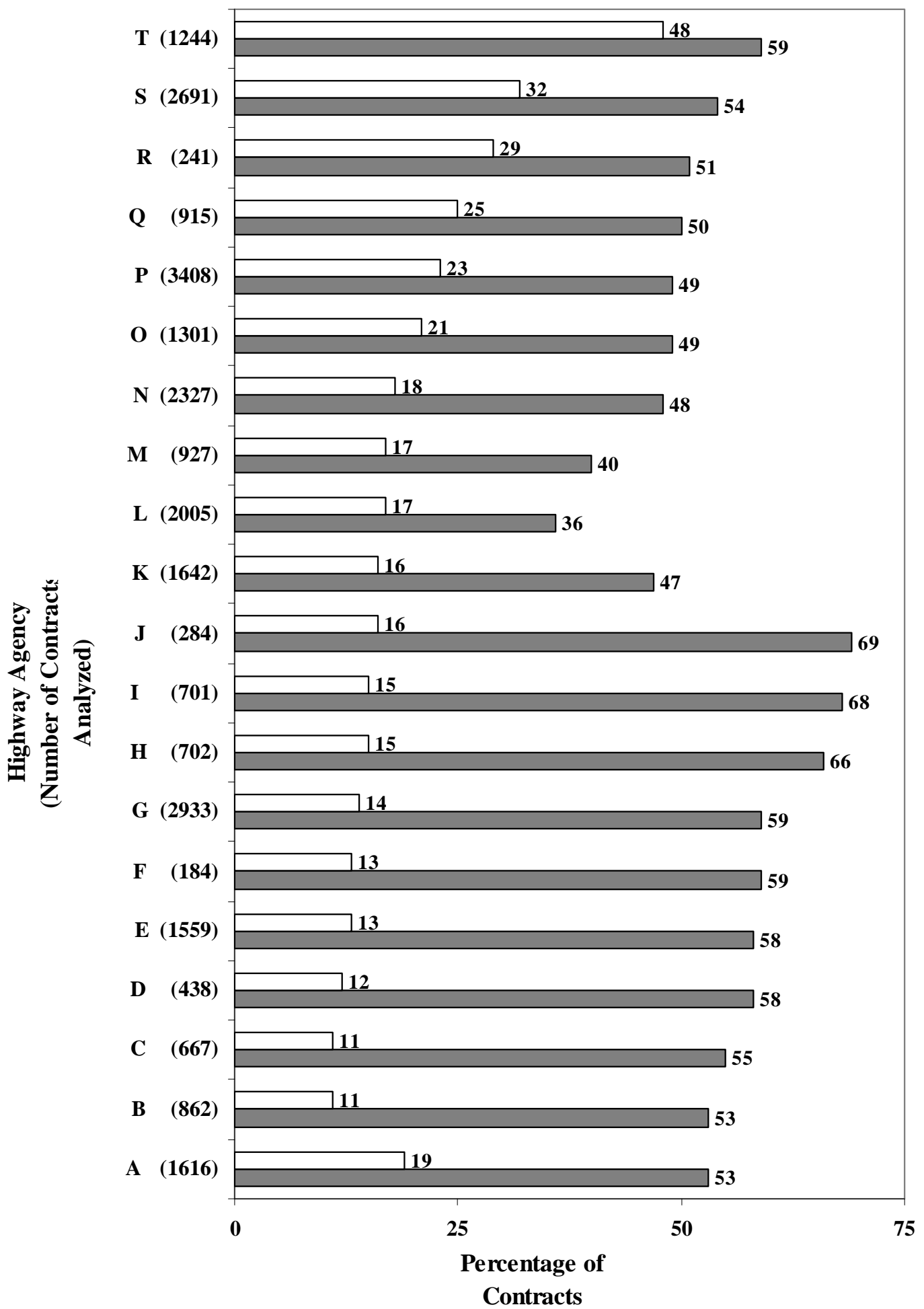

$\square$ Final Cost $>$ Letting Cost $\quad \square$ Final Cost $>110 \%$ (Letting Cost)

Figure 3.9: Percentage of Contracts (Exceeding \$1 Million) for which Final Cost Exceeded Letting Cost (Crossett and Hines, 2007) 
The Washington State Department of Transportation (WSDOT, 2008) compared the final cost with the letting cost for the contracts that were completed during the period $2002-2005$. A total of 122 contracts in 2002, 175 contracts in 2003, 147 contracts in 2004, and 155 contracts in 2005 were analyzed. The total final cost for the 599 contracts exceeded the letting cost (award amount) by approximately $\$ 76$ Million. Figure 3.10 shows the annual comparison of the final and letting cost during this period.

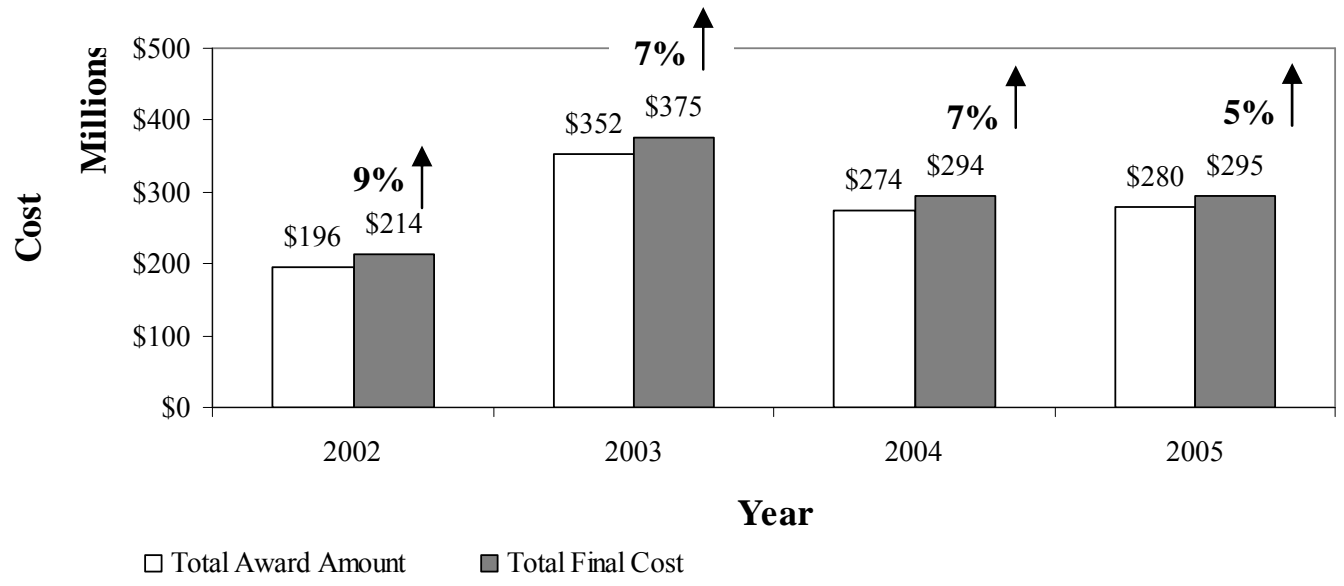

Figure 3.10: Comparison of Final Cost and Letting Cost in Washington State (WSDOT, 2008)

Figure 3.11 shows comparison of final and letting costs for 122 contracts completed in year 2005 . The final cost exceeded the letting cost for a large number of contracts.

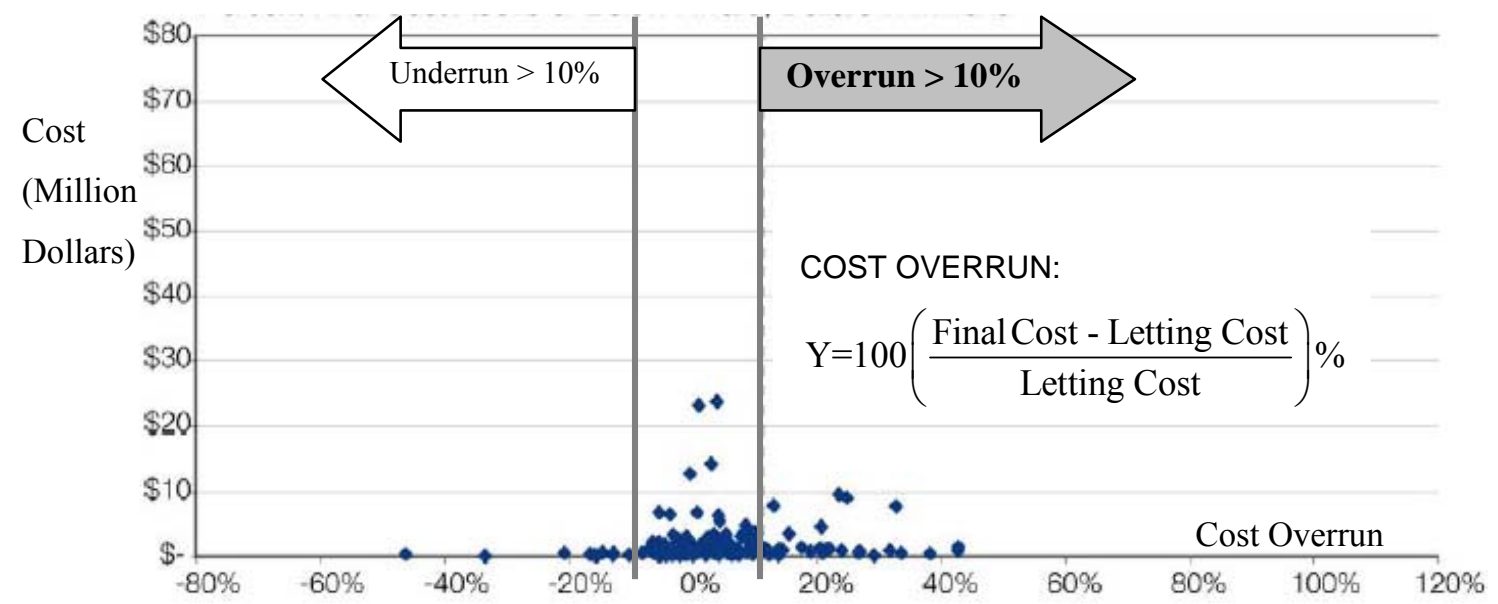

Figure 3.11: Distribution of Contracts with Cost Overrun (WSDOT, 2008) 


\subsection{Chapter Summary}

The chapter discussed the issues in cost estimation of the various phases of highway project development. The first estimate of the construction cost at the planning stage is generally based on unit (e.g., lane-mile) averages. After the project is included in the state's transportation improvement program, the engineer assessment estimate is prepared. Then, the preliminary design work starts and the project scope, work type, and complexity are defined more clearly. A preliminary design estimate of the cost is prepared on the basis of preliminary plans. The preliminary design stage is followed by the final design stage as greater detail on construction practices, material, and equipment becomes available. At this stage, a design estimate of the construction cost is prepared. When the project plans are finalized, an engineer's estimate of the cost is prepared based on the basis of the final plans and specifications. This estimate is used to advertise the project for legal purposes and to analyze the bids from constructors. After bids are received and analyzed, the contract is awarded - this is the letting stage. The winning bid cost is recorded as the letting cost. Most departments of transportation use software such as TRNS*PORT for estimating the preliminary design cost, final design cost, and engineer's estimate. The historical bid-based pricing approach is the most common method for estimation of cost at the preliminary design, final design, and the advertisement phase. The item level details are not available at the preliminary design stage, but greater detail becomes available at the final design stage and also when the engineer's estimate is prepared. The extent of phase-to-phase variation of these estimates varies across the DOTs largely due to differences in the level of detail used in estimating these costs.

The pervasive problem of overrun of final cost, compared to letting cost, has been studied by several highway agencies. Most of these studies found that early cost estimates are significantly lower than the final cost. Inaccuracies have also been found at the design stage and with the engineer's estimate. Agencies have focused on average differences between final cost and cost estimates to determine the reliability of the cost estimates. Low values of average cost overruns do not indicate that the cost estimation process was efficient because the final cost may be significantly higher than the cost estimate for some contracts, and significantly lower than the cost estimate for others. If the final cost exceeds the cost estimate for a large number of projects, the funding of future transportation improvement programs is affected. The Virginia Department of Transportation had to postpone or cancel 166 projects because the cost estimates were underestimated (Kyte et al., 2004). On the other hand, if the cost estimate is higher than the final cost, the opportunity to implement other projects is jeopardized. Agencies do not have a methodological framework to identify projects where final cost is likely to exceed the cost estimate, or where the cost estimate is likely to exceed the final cost. This deficiency is addressed in Chapter 4, where a methodological framework is presented to study the reliability of the cost estimates in detail and identify projects that are likely to experience reliability issues. 


\section{CHAPTER 4. RESEARCH METHODOLOGY}

\subsection{Introduction}

Reliability of construction cost estimates at each project development stage is critical for decision-making. Chapter 2 presented various studies that have been conducted in the United States and abroad on this topic. At several highway agencies, the final construction cost has been found to be significantly different from the estimated cost for a large number of contracts.

Analysis of cost overrun and underrun associated with historical contracts allows agencies to determine the accuracy of cost estimates. Most agencies have so far focused on comparison of final construction cost with letting cost and cost overruns have been given more importance than underruns. Average percentage differences between final and letting cost across all the contracts in a state have been used to report the overall inaccuracy of cost estimates. In such, average cost overrun is compensated by cost underrun, and the low average suggests erroneously that the overall impact of cost inaccuracy is insignificant. While some agencies have used the distribution of cost overrun and underrun, factors that can lead to identification of contracts with high cost overrun and underrun at an early stage of project development have not been studied extensively. Factors such as contract size, geographic location, and work category have been identified as some of the factors that can be used to identify contracts susceptible to cost overrun and underrun. However, variability across contracts from the same geographic location, or of the same size has not been studied in the past. Also, the inter-relationship between such factors has not been explored.

In the present study, a methodology has been proposed for use by highway agencies to overcome these deficiencies. The methodology analyzes historical contracts, studies the variability of cost overrun across districts, counties, urban and rural areas, contract sizes, types, work categories, highway functional classes, NHS status, and any other factors that are available during the initial planning stages and are believed to have an impact on cost overrun. The following section presents a framework for the probabilistic analysis of cost overrun and underrun associated with the cost estimates. 


\subsection{Methodological Framework}

4.2.1. Step 1: Study Design, Data Acquisition, and Pre-processing

The study design and the type of information that has to be collected in a cost overrun analysis study is largely determined based on the goals and objectives of the study. For studies that require a basic analysis of cost overrun, information on the various cost estimates and the final construction cost is sufficient. The estimates (proposed, engineer's assessment, design, engineer's estimate, and letting), and the final cost information that is sought includes the date when the estimate was prepared and if it was inflation-adjusted or non-adjusted (Figure 4.1).

\begin{tabular}{|c|c|c|c|c|c|}
\hline $\begin{array}{l}\text { Proposed } \\
\text { Cost } \\
\text { PCost }\end{array}$ & $\begin{array}{c}\text { Engineer's } \\
\text { Assessment } \\
\text { EACost }\end{array}$ & $\begin{array}{l}\text { Design } \\
\text { Cost } \\
\text { DCost }\end{array}$ & $\begin{array}{c}\text { Engineer's } \\
\text { Estimate } \\
\text { EECost }\end{array}$ & $\begin{array}{l}\text { Letting } \\
\text { Cost } \\
\text { LCost }\end{array}$ & $\begin{array}{c}\text { Final Cost } \\
\text { FCost }\end{array}$ \\
\hline $\begin{array}{c}\text { First } \\
\text { Estimate } \\
\text { (Stage 1) }\end{array}$ & $\begin{array}{l}\text { Second } \\
\text { Estimate } \\
\text { (Stage 2) }\end{array}$ & $\begin{array}{l}\text { Third } \\
\text { Estimate } \\
\text { (Stage 3) }\end{array}$ & $\begin{array}{l}\text { Fourth } \\
\text { Estimate } \\
\text { (Stage 4) }\end{array}$ & $\begin{array}{c}\text { Fifth } \\
\text { Estimate } \\
\text { (Stage 5) }\end{array}$ & $\begin{array}{l}\text { Incurred } \\
\text { Cost } \\
\text { (Stage 6) }\end{array}$ \\
\hline Date 1 & Date 2 & Date 3 & Date 4 & Date 5 & Date 6 \\
\hline
\end{tabular}

Figure 4.1: Information about Cost Estimates and Final Cost Sought for a Cost Overrun Study

Additional information that may be sought includes: information on the methods and procedure used for preparation of the estimates, level of detail to which each estimate was prepared, the contingency included in each estimate, and whether any adjustments for inflation were made. Such information is generally used to determine whether inflation played a role or whether appropriate contingencies were included in the estimates.

Detailed information on contract-specific factors should be sought when seeking to identify contracts that are more likely to experience cost overrun. Such factors can be broadly divided into two categories, namely: a) actual causal factors and b) surrogate causal factors. The actual causal factors include factors such as: scope changes, unforeseen site work, inflation, change orders, limited information during planning and development stages, inadequate methods for estimation, etc. Surrogate causal factors, on the other hand, are factors that point towards the actual underlying causal factors, and can be used as indicators in the absence of actual causal factors to identify contract types that are likely to experience high cost overrun or underruns. Such factors may include geographic location, contract size, contract work category, route type, highway functional class, area type, NHS status, population, and other socio-economic characteristics of the region in which the project is planned. In addition, surrogate factors that measure the efficiency and characteristics of the planning process such as schedule delays, number, size and nature of initial scope changes, and escalation pattern of the previous cost estimates may prove to be indicators of the underlying problems causing a cost overrun. 
For example, the district, county, and area type provide information about the geographic location of a contract and may indicate towards the economic characteristics of the region that lead to overrun. The 'route type', 'functional class' and 'NHS status' indicate the importance of the highway route on which the contract is implemented and can point towards site conditions, such as traffic management issues. The contract size and type point towards the planning, development and construction procedures that are used to prepare the estimates. The contract work category may indicate towards the unforeseen construction activities likely to be experienced during construction. Schedule delays, initial scope changes, and escalation pattern of prior cost estimates may indicate the complexity and uncertainty associated with cost estimation.

The present study presents a methodology for analyzing cost overrun based on surrogate causal factors, as information on these factors is available to planners at the initial planning and development stages. It is expected that an analysis based on these factors can provide planners with a tool to identify contract types that are likely to experience high cost overrun.

For each contract, information on all potential surrogate causal factors is collected. Each factor is tested for its significance in identifying contracts with cost overrun. Factors that are discrete in nature are broken down into their respective factor levels (Table 4.1). For example, all the districts within a state represent the district factor levels. The factor levels for route type are State Roads, U.S. roads, and Interstate roads. The functional class factor levels provide information about the functional class of the highway on which a contract is implemented, such as urban Interstate, rural Interstate, urban arterial, rural arterial, etc. The NHS status factor has factor levels such as: Non-NHS, Non-Interstate NHS, and Interstate. The factor levels corresponding to contract size and those corresponding to work category may be defined differently across different states. The work category factor levels are defined by combining contracts involving similar construction work. For example, all bridge-related contracts, such as bridge rehabilitation, replacement and removal, can fall under the factor level 'bridge work', whereas all pavement-related contracts can fall under the factor level 'pavement work'. On the other hand, some states may decide to analyze bridge rehabilitation and bridge replacement as two different factor levels. The factor levels corresponding to area type can be represented by urban or rural areas. Contracts that comprise of more than one project are called kin contracts, whereas those that comprise of a single project are called stand-alone contracts. The kin or stand-alone contract specifications represent the contract type factor levels. 
Table 4.1: Factor Levels Corresponding to Discrete Contract-Specific Factors

\begin{tabular}{|c|c|c|}
\hline \# & Contract Specific Factor & Contract Specific Factor Levels \\
\hline 1 & District & $\begin{array}{l}\text { District Type ' } 1 \text { ' } \\
\cdot \\
\cdot \\
\cdot \\
\text { District Type ' } i \text { ' } \\
\cdot \\
\cdot \\
\cdot \\
\text { District Type ' } N \text { ' }\end{array}$ \\
\hline 2 & Route Type & $\begin{array}{l}\text { Route Type ' } 1 \text { ' } \\
\cdot \\
\cdot \\
\text { Route Type ' } i \text { ' } \\
\cdot \\
\cdot \\
\text { Route Type 'N' }\end{array}$ \\
\hline 3 & Work Category & $\begin{array}{l}\text { Work Category ' } 1 \text { ' } \\
\cdot \\
\cdot \\
\text { Work Category ' } i \text { ' } \\
\cdot \\
\cdot \\
\text { ' Work Category ' } N \text { ' }\end{array}$ \\
\hline \multirow{2}{*}{4} & \multirow{2}{*}{ Area Type } & Urban Area \\
\hline & & Rural Area \\
\hline 3 & Functional Class (FC) & $\begin{array}{l}\text { FC Category ' } 1 \text { ' } \\
\cdot \\
\cdot \\
\text { FC Category ' } i \text { ' } \\
\cdot \\
\cdot \\
\text { FC Category ' } N \text { ' }\end{array}$ \\
\hline 5 & NHS Status (NHS) & $\begin{array}{l}\text { NHS Category ' } 1 \text { ' } \\
\cdot \\
\cdot \\
\text { NHS Category ' } i \text { ' } \\
\cdot \\
\cdot \\
\text { NHS Category ' } N \text { ' }\end{array}$ \\
\hline 6 & $\begin{array}{l}\text { Project Size } \\
\text { (Size Based on Proposed } \\
\text { Cost of the Project) }\end{array}$ & $\begin{array}{l}\text { Category } 1 \text { - Low Cost Projects } \\
\cdot \\
\cdot \\
\text { Category ' } i \text { ' - Intermediate Cost Projects } \\
\cdot \\
\cdot \\
\text { Category } N \text { - High Cost Projects } \\
\end{array}$ \\
\hline & & Kin Contract - Several Projects lumped together \\
\hline 7 & Contract Type & Standalone Contract - Single Project Contract \\
\hline
\end{tabular}


A uniform distribution of the contracts across all the factor levels is sought so that a sufficient number of observations is available for statistical analysis and the development of risk-based econometric models as demonstrated in the proposed methodology. An analysis of the one-way and two-way distribution of the contracts by the factor levels was conducted to determine if a sufficient number of contracts are available in the dataset. The one-way distribution of the contracts by factor level is expected to yield at least 50 contracts corresponding to each factor level. If a particular factor level does not meet the criteria, it is can be combined with another similar factor level by redefining the factor levels corresponding to the factor under consideration.

Next, the two-way distribution of the contracts by all pairs of factors was analyzed to ensure that all contract types are uniformly represented. The two-way distributions are helpful in interpreting the conclusions about cost overrun. For example, an average cost overrun of $60 \%$ across Interstate pavement contracts acquires a completely different interpretation, depending upon the number of contracts which this average was calculated. If information is available only for two Interstate pavement contracts, the average overrun of $60 \%$ may indicate an aberration from the normal. However, if the average overrun across 40 contracts is $60 \%$, such contracts become an issue of concern. Table 4.2 presents the framework for the twoway distribution analysis of the contracts, given seven factors (as presented in Table 4.1). There are ${ }^{7} \mathrm{C}_{2}$ (that is, 21) ways of selecting any two factors and analyzing the distribution of the contracts by their respective factor levels. Table 4.3 presents a sample two-way distribution table when contract size and work category are the two factors that are selected. Such two-way distribution analysis of the contracts in the database helps in conducting a comprehensive analysis of the cost overrun associated with historical highway infrastructure projects, using the statistical methods and concepts as described in subsequent sections.

Table 4.2: Framework for the Two-Way Distribution Analysis of the Contracts

\begin{tabular}{|c|c|c|c|c|c|c|c|}
\hline & $\begin{array}{c}\text { Work } \\
\text { Category }\end{array}$ & $\begin{array}{c}\text { Contract } \\
\text { Size }\end{array}$ & $\begin{array}{c}\text { Contract } \\
\text { Type }\end{array}$ & $\begin{array}{c}\text { Route } \\
\text { Type }\end{array}$ & $\begin{array}{c}\text { Area } \\
\text { Type }\end{array}$ & District & NHS Status \\
\hline $\begin{array}{c}\text { Work } \\
\text { Category }\end{array}$ & - & $*$ & & & & & \\
\hline Contract Size & & - & & & & & \\
\hline Contract Type & & & - & & & & \\
\hline Route Type & & & & - & & & \\
\hline Area Type & & & & & - & & \\
\hline District & & & & & & - & \\
\hline NHS Status & & & & & & & \\
\hline
\end{tabular}

* Refer to Table 4.3 for a sample of two way distribution analysis by Contract Size and Work Category 
Table 4.3: Illustrating the Distribution of Contracts by Contract Size and Work Category

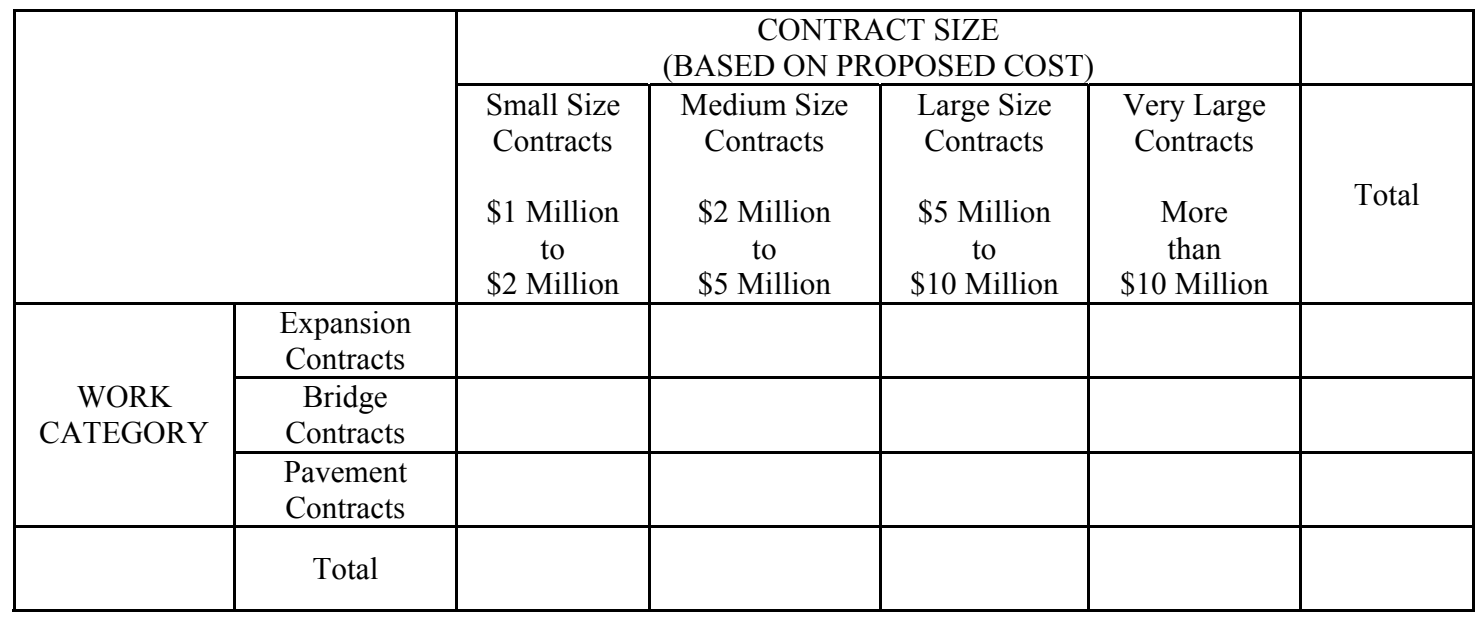

\subsubsection{Step 2: Analyzing Accuracy of Cost Estimates}

The methodology for determining the accuracy of the proposed, engineer's assessment, design, engineer's estimate, and letting cost estimates is discussed in this section. The cost estimates that were not adjusted for inflation at the time of preparations are analyzed in Steps 2 and 3. Where the non-inflated cost estimates are not available, Steps 2 and 3 are skipped and the analysis proceeds to Step 4.

\subsubsection{Step 2.1: Calculation and Preliminary Analysis of Cost Overrun}

The cost overrun $\left(\mathrm{Y}_{1}\right)$ of the final construction cost compared to the proposed cost estimate is referred to as the planning stage cost overrun. The planning stage cost overrun can be calculated as follows:

Planning Stage Cost Overrun:

$$
Y_{1}=100\left(\frac{\text { Final Cost-Proposed Cost }}{\text { Proposed Cost }}\right) \%
$$

The engineer's assessment estimate which is the second estimate of the construction cost is prepared after the programming phase. The cost overrun $\left(\mathrm{Y}_{2}\right)$ of the final cost compared to the engineer's assessment cost is referred to as the post programming stage cost overrun. The post programming stage cost overrun can be calculated as follows:

Post Programming Stage Cost Overrun:

$$
Y_{2}=100\left(\frac{\text { Final Cost-Engineer's Assessment Cost }}{\text { Engineer's Assessment Cost }}\right) \%
$$

The cost overrun $\left(\mathrm{Y}_{3}\right)$ of the final cost compared to the design cost is referred to as the design stage cost overrun and is calculated as follows: 
Design Stage Cost Overrun:

$$
Y_{3}=100\left(\frac{\text { Final Cost-Design Cost }}{\text { Design } \operatorname{Cos} t}\right) \%
$$

The cost overrun $\left(\mathrm{Y}_{4}\right)$ associated with the engineer's estimate, that is prepared before project letting, at the advertisement stage, is referred to as the advertisement stage cost overrun and can be calculated as follows:

Advertisement Stage Cost Overrun:

$$
Y_{4}=100\left(\frac{\text { Final Cost-Engineer's Estimate }}{\text { Engineer's Estimate }}\right) \%
$$

Several estimates of the final construction cost are prepared at the letting stage. The present study focuses on the comparison of the winning bid estimate or the letting cost with the final incurred construction cost to determine the cost overrun associated with the letting cost (letting stage cost overrun) The letting stage cost overrun is calculated as follows:

Letting Stage Cost Overrun:

$$
Y_{5}=100\left(\frac{\text { Final Cost-Letting } \operatorname{Cost}}{\text { Letting } \operatorname{Cos} t}\right) \%
$$

A negative value of the cost overruns $\mathrm{Y}_{1}, \mathrm{Y}_{2}, \mathrm{Y}_{3}, \mathrm{Y}_{4}$, and $\mathrm{Y}_{5}$ indicates that the final incurred construction cost is less than the corresponding cost estimate, and hence represents a cost underrun. On the other hand, a positive value of the cost overrun indicates that the final cost exceeded the proposed cost. The step-by-step procedure for preliminary analysis of cost overrun of ' $\mathrm{N}$ ' historical contracts is as follows:

(a) Calculate the planning stage cost overrun $\left(Y_{1}\right)$ for each contract ' $j$ ', and denote it by $Y_{1 j}$.

(b) Plot a histogram of $\mathrm{Y}_{1 \mathrm{j}}$ representing the planning stage cost overrun of all the ' $\mathrm{N}$ ' contracts.

(c) Determine the $25 \%, 50 \%, 75 \%$, and $100 \%$ quartiles of the planning stage cost overrun, $\mathrm{Y}_{1}$. Quartiles are points at regular intervals from the cumulative distribution of planning stage cost overrun. The value $Z_{x}$ of the $X \%$ quartile indicates that $X \%$ of the contracts have the planning stage cost overrun less than $Z_{x}$. The quartiles indicate severity of the cost overrun problem.

(d) Determine the average planning stage cost overrun $\left(\bar{Y}_{1}\right)$ across the 'N' contracts as follows:

$$
\bar{Y}_{1}=\frac{\sum_{j=1}^{N}\left(Y_{1 j}\right)}{N}
$$

A large positive average (greater than 10\%) indicates that positive cost overruns outweighed the negative cost overruns (or underruns). A small positive average (less than 10\%) indicates that the positive cost overrun marginally outweighed the negative cost overrun. A large negative value of the average cost overrun indicates that the negative cost overrun outweighed the positive cost overrun. A cost estimate within $+/-10 \%$ of the final cost is generally considered as an acceptable estimate by most state DOTs. 
(e) Determine the standard deviation $\left(\mathrm{S}_{1}\right)$ and the $95 \%$ confidence interval (C.I) of the average cost overrun. The confidence interval represents a range of likely values of the average cost overrun assuming that cost overrun is normally distributed.

$$
S_{1}=\sqrt{\frac{\sum_{j=1}^{N}\left(Y_{1 j}-\overline{Y_{1}}\right)^{2}}{N-1}} \quad 95 \% \text { C.I }: \quad \bar{Y}_{1} \pm\left(t_{\left(1-\frac{0.95}{2}, N-1\right)} \times \frac{S_{1}}{\sqrt{N}}\right)
$$

The upper and lower limits of the $95 \%$ confidence interval indicate the risk of cost overrun. The variation in the planning stage cost overrun across the ' $\mathrm{N}$ ' contracts can be calculated using the coefficient of variation (C.V), which is calculated as follows:

$$
C . V_{1}=\frac{S_{1}}{\overline{Y_{1}}}
$$

(f) Repeat steps (a)-(e) to calculate and analyze the post-programming stage cost overrun $\left(\mathrm{Y}_{2}\right)$, design stage cost overrun $\left(\mathrm{Y}_{3}\right)$, advertisement stage cost overrun $\left(\mathrm{Y}_{4}\right)$, and letting stage $\left(\mathrm{Y}_{4}\right)$ cost overrun associated with the ' $\mathrm{N}$ ' contracts. The steps (a)-(e) can also be repeated to compare two cost estimates with each other.

\subsubsection{Step 2.2: Analysis of Cost Overrun by Cost Overrun Category}

Cost overruns and underruns (defined by Step 2.1(d)) were analyzed separately to determine the inaccuracy associated with the respective cost estimate. Four categories of cost over(under)run can be further defined:

a) Category I: Contracts with 'cost overrun' $<-10 \%$ (or cost underrun $>10 \%$ ),

b) Category II: Contracts with 'cost overrun' between $-10 \% \& 0 \%$ (or cost underrun between $0 \% \& 10 \%$ ),

c) Category III: Contracts with 'cost overrun' between $0 \% \& 10 \%$, and

d) Category IV: Contracts with 'cost overrun' greater than $10 \%$.

The contracts that belong to categories II or III are referred to as belonging to the $+/-10 \%$ cost overrun bracket'. Figure 4.2 presents a schematic representation of the ' $+/-10 \%$ cost overrun bracket'.

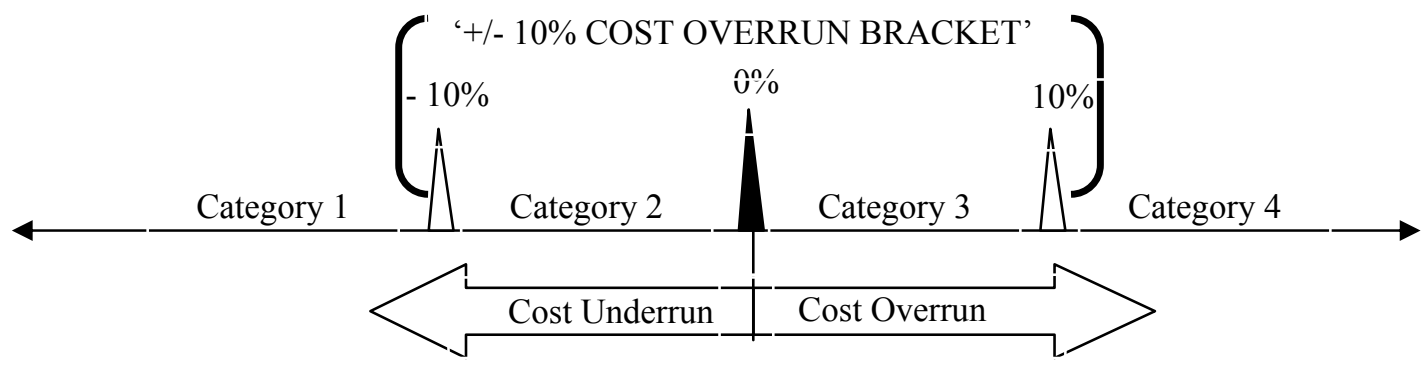

Figure 4.2: Schematic Representation of the ' $+/-10 \%$ Cost Overrun Bracket' 
The step-by-step procedure for analysis of cost overrun by cost overrun category is as follows:

(a) Start with the analysis of the planning stage cost overrun. Calculate the planning stage cost overrun, $\mathrm{Y}_{1 \mathrm{j}}$, for each contract ' $\mathrm{j}$ ' as described in Section 4.2.2.1.

(b) Categorize the contracts into the four categories of cost overrun based on the planning stage cost overrun. Determine the number of contracts ' $\mathrm{N}_{\mathrm{k}}$ ' in each cost overrun category ' $\mathrm{k}$ '.

(c) For the contracts in each cost overrun category ' $k$ ', calculate the average planning stage cost overrun $\left(\bar{Y}_{1 k}\right)$, the standard deviation $\left(\mathrm{S}_{1 \mathrm{k}}\right)$ and the $95 \%$ confidence interval $\left(\mathrm{C} . \mathrm{I}_{1 \mathrm{k}}\right)$ of the average planning stage cost overrun, as follows:

$$
\begin{aligned}
& \bar{Y}_{1 k}=\frac{\sum_{j=1}^{N_{k}}\left(Y_{1 j}\right)}{N_{k}} \quad \text { for } k=1,2,3,4 \\
& S_{1 k}=\sqrt{\frac{\sum_{j=1}^{N_{k}}\left(Y_{1 j}-\overline{Y_{1}}\right)^{2}}{N_{k}-1}} \quad \text { for } k=1,2,3,4 \\
& 95 \% \text { C.I }: \quad \overline{Y_{1 k}} \pm\left(t_{\left(1-\frac{0.95}{2}, N_{k}-1\right)} \times \frac{S_{1 k}}{\sqrt{N_{k}}}\right) \quad \text { for } k=1,2,3,4
\end{aligned}
$$

The confidence interval represents a range of likely values of the average planning stage cost overrun assuming that it is normally distributed.

(d) Tabulate the analysis results of planning stage cost overrun as shown in Table 4.4. The contracts in categories 1 and 4 are of particular interest as they are outside the $+/-10 \%$ cost overrun bracket'.

(e) Repeat steps (a)-(d) to analyze the post-programming stage cost overrun $\left(\mathrm{Y}_{2}\right)$, design stage cost overrun $\left(\mathrm{Y}_{3}\right)$, advertisement stage cost overrun $\left(\mathrm{Y}_{4}\right)$, and letting stage $\left(\mathrm{Y}_{4}\right)$ cost overrun by cost overrun category. 
Table 4.4: Illustrating the Framework for Analysis of Cost Overrun by Cost Overrun Category

\begin{tabular}{|l|l|l|l|l|}
\hline \multirow{1}{*}{} & \multicolumn{4}{|c|}{ Planning stage cost overrun } \\
& \multicolumn{4}{|c|}{$Y_{1}=100\left(\frac{\text { Final Cost - Proposed Cost }}{\text { Proposed Cost }}\right) \%$} \\
\cline { 2 - 5 } & $Y_{1}<-10 \%$ & $-10 \% \leq Y_{1}<0 \%$ & $0 \% \leq Y_{1} \leq 10 \%$ & $Y_{1}>10 \%$ \\
\cline { 2 - 5 } & & & & \\
\hline Number of Contracts & & & & \\
\hline Average Cost Overrun & & & & \\
\hline Standard Deviation & & & & \\
\hline $\begin{array}{l}\text { 95\% Confidence } \\
\text { Interval }\end{array}$ & & & & \\
\hline
\end{tabular}

\subsubsection{Step 2.3: Categorical Analysis of Cost Overrun by Contract Specific Factors}

Categorical analysis involves analysis of contracts in each cost overrun category by contract specific factors such as work category, contract size, contract type, route type, NHS status, district, and area type. The trends in frequency and severity of cost overrun across geographic locations, work categories, route types, contract types, and NHS status are examined. The step-by-step procedure for categorical analysis is presented as follows:

(a) Start with the analysis of planning stage cost overrun by work category. Determine the number of contracts $\left(\mathrm{N}_{\mathrm{kp}}\right)$ in each work category ' $\mathrm{p}$ ', that belong to planning stage cost overrun category ' $\mathrm{k}$ '.

(b) Calculate the average planning stage cost overrun, its standard deviation and $95 \%$ confidence interval by work category (' $p$ ') and cost overrun category (' $k$ ') as follows:

$$
\begin{aligned}
& \bar{Y}_{1 k p}=\frac{\sum_{j=1}^{N_{k p}}\left(Y_{1 k p j}\right)}{N_{k p}} \\
& S_{1 k p}=\sqrt{\frac{\sum_{j=1}^{N_{k p}}\left(Y_{1 k p j}-\bar{Y}_{1 k p}\right)^{2}}{N_{k p}-1}} \\
& 95 \% \text { C.I : } \bar{Y}_{1 k p} \pm\left(t_{\left(1-\frac{0.95}{2}, N_{k p}-1\right)} \times \frac{S_{1 k p}}{\sqrt{N_{k p}}}\right)
\end{aligned}
$$


where,

$\mathrm{k}=$ Cost Overrun Category; 1, 2, 3, 4

$\mathrm{P}=$ Total Number of Work Category factor Levels

$\mathrm{p}=$ Work Category Factor Level; 1, 2, ... P

$\mathrm{N}_{\mathrm{kp}}=$ Number of Contracts that belong to Cost Overrun Category $\mathrm{k}$ and

Work Category Factor Level p

$\mathrm{Y}_{1 \mathrm{kpj}}=$ Planning Stage Cost Overrun $\left(\mathrm{Y}_{1}\right)$ of Contract $\mathrm{j}$, belonging to

Cost Overrun Categoryk and Work Category Factor Levelp

$\overline{\mathrm{Y}}_{1 \mathrm{kp}}=$ Average Planning Stage Cost Overrun $\left(\mathrm{Y}_{1}\right)$, across Contracts belonging to

Cost Overrun Category k and Work Category Factor Level $p$

$\mathrm{S}_{1 \mathrm{kp}}=$ Standard Deviation of the Average Planning Stage Cost Overrun $\left(\mathrm{Y}_{1}\right)$, across Contracts

those belonging to Cost Overrun Category $k$ and Work Category Factor Level $p$

Tabulate the results as shown in Table 4.5.

Table 4.5: Illustrating the Categorical Cost Overrun Analysis by Work and Cost Overrun Categories

\begin{tabular}{|c|c|c|c|c|c|c|}
\hline & \multicolumn{4}{|c|}{$\begin{array}{c}\text { Planning stage cost overrun } \\
Y_{1}=100\left(\frac{\text { Final Cost }- \text { Proposed Cost }}{\text { Proposed Cost }}\right)\end{array}$} & \\
\hline & & \multicolumn{4}{|c|}{ PLANNING STAGE COST OVERRUN CATEGORY } & \\
\hline & & $Y_{1}<-10 \%$ & $-10 \% \leq Y_{1}<0 \%$ & $0 \% \leq Y_{1} \leq 10 \%$ & $Y_{1}>10 \%$ & $\begin{array}{l}\text { Weighted } \\
\text { Average }\end{array}$ \\
\hline \multirow{4}{*}{$\begin{array}{l}\text { WORK } \\
\text { CATEGORY } \\
\text { FACTOR } \\
\text { LEVELS }\end{array}$} & $\begin{array}{l}\text { Expansion } \\
\text { Contracts }\end{array}$ & $\begin{array}{l}\text { Average: } \\
\text { Contracts: } \\
\text { C.I: }\end{array}$ & $\begin{array}{l}\text { Average: } \\
\text { Contracts: } \\
\text { C.I: }\end{array}$ & $\begin{array}{l}\text { Average: } \\
\text { Contracts: } \\
\text { C.I: }\end{array}$ & $\begin{array}{l}\text { Average: } \\
\text { Contracts: } \\
\text { C.I: }\end{array}$ & $\begin{array}{l}\text { Average: } \\
\text { Contracts: } \\
\text { C.I: }\end{array}$ \\
\hline & $\begin{array}{c}\text { Bridge } \\
\text { Contracts }\end{array}$ & $\begin{array}{l}\text { Average: } \\
\text { Contracts: } \\
\text { C.I: }\end{array}$ & $\begin{array}{l}\text { Average: } \\
\text { Contracts: } \\
\text { C.I: }\end{array}$ & $\begin{array}{l}\text { Average: } \\
\text { Contracts: } \\
\text { C.I: }\end{array}$ & $\begin{array}{l}\text { Average: } \\
\text { Contracts: } \\
\text { C.I: }\end{array}$ & $\begin{array}{l}\text { Average: } \\
\text { Contracts: } \\
\text { C.I: }\end{array}$ \\
\hline & $\begin{array}{l}\text { Pavement } \\
\text { Contracts }\end{array}$ & $\begin{array}{l}\text { Average: } \\
\text { Contracts: } \\
\text { C.I: }\end{array}$ & $\begin{array}{l}\text { Average: } \\
\text { Contracts: } \\
\text { C.I: }\end{array}$ & $\begin{array}{l}\text { Average: } \\
\text { Contracts: } \\
\text { C.I: }\end{array}$ & $\begin{array}{l}\text { Average: } \\
\text { Contracts: } \\
\text { C.I: }\end{array}$ & $\begin{array}{l}\text { Average: } \\
\text { Contracts: } \\
\text { C.I: }\end{array}$ \\
\hline & $\begin{array}{l}\text { Weighted } \\
\text { Average }\end{array}$ & $\begin{array}{l}\text { Average: } \\
\text { Contracts: } \\
\text { C.I: }\end{array}$ & $\begin{array}{l}\text { Average: } \\
\text { Contracts: } \\
\text { C.I: }\end{array}$ & $\begin{array}{l}\text { Average: } \\
\text { Contracts: } \\
\text { C.I: }\end{array}$ & $\begin{array}{l}\text { Average: } \\
\text { Contracts: } \\
\text { C.I: }\end{array}$ & $\begin{array}{l}\text { Average: } \\
\text { Contracts: } \\
\text { C.I: }\end{array}$ \\
\hline
\end{tabular}

Contracts: Number of Contracts

C.I: $95 \%$ Confidence Interval of the Average

(c) Determine the frequency of occurrence of planning stage cost overrun that are greater than $10 \%$ in magnitude, by work category ('p'), as follows: 


$$
\begin{gathered}
\begin{array}{c}
\text { Frequency of high cost overrun for } \\
\text { contracts belonging to work category ' } \mathrm{p} \text { ' }
\end{array} \\
\sum_{\mathrm{k}=1}^{4}\left(\mathrm{~N}_{\mathrm{kp}}\right)
\end{gathered} \quad \begin{gathered}
\mathrm{k}=1,4 \\
\mathrm{~N}=1,2, \ldots . \mathrm{P}
\end{gathered}
$$

(d) For contracts that experience a positive or negative cost overrun, at the planning stage, that exceeds $10 \%$, plot the average planning stage cost overrun and its $95 \%$ confidence intervals by work category. The upper and lower limits of the $95 \%$ confidence interval indicate the severity of cost overrun. Figure 4.5 presents a hypothetical scenario where the severity of cost overrun and underrun is compared across the work categories.

(e) Repeat steps (a)-(d) to analyze planning stage cost overrun by other contract specific factors (in addition to work category) such as contract size, contract type, route type, area type, district, and NHS status.

(f) Repeat steps (a)-(e) to conduct categorical analysis of post programming stage, design stage, advertisement stage, and letting stage cost overrun. Table 4.6 presents the framework.

Table 4.6: Framework for Categorical Analysis of Cost Overrun

\begin{tabular}{|c|c|c|c|c|c|}
\hline & $\begin{array}{c}\text { Planning stage } \\
\text { cost overrun } \\
\text { Categories }\end{array}$ & $\begin{array}{c}\text { Post } \\
\text { Programming } \\
\text { Stage Cost } \\
\text { Overrun } \\
\text { Categories }\end{array}$ & $\begin{array}{c}\text { Design Stage } \\
\text { Cost Overrun } \\
\text { Categories }\end{array}$ & $\begin{array}{c}\text { Advertisement } \\
\text { Stage Cost } \\
\text { Overrun } \\
\text { Categories }\end{array}$ & $\begin{array}{c}\text { Letting Stage } \\
\text { Cost Overrun } \\
\text { Categories }\end{array}$ \\
\hline Work Category & & & \multirow{7}{*}{ Steps $(a)-(d)$} & & \\
\hline Contract Size & & & & & \\
\hline Contract Type & & & & & \\
\hline Route Type & & & & & \\
\hline Area Type & & & & & \\
\hline District & & & & & \\
\hline NHS Status & & & & & \\
\hline
\end{tabular}

In addition to the comparison of the final cost with each of the cost estimates (cost overrun analysis), Steps (a)-(e) can be used for comparison of two cost estimates as well. However, the percentage difference between two cost estimates is not referred to as cost overrun. In this study, the term cost overrun is used to represent the comparison of the final cost with one of the cost estimates. The pair-wise comparisons of the cost estimates do not provide information about the accuracy of the cost estimates but provide information about how cost estimates change from one project development stage to another. Table 4.7 presents the framework for pair-wise comparisons of costs. 
Table 4.7: Framework for Pair-wise Comparison of Cost Estimates

\begin{tabular}{|c|c|c|c|c|c|}
\hline & $\begin{array}{c}\text { Proposed } \\
\text { Cost }\end{array}$ & $\begin{array}{c}\text { Engineer's } \\
\text { Assessment }\end{array}$ & $\begin{array}{c}\text { Design } \\
\text { Cost }\end{array}$ & $\begin{array}{c}\text { Engineer's } \\
\text { Estimate }\end{array}$ & $\begin{array}{c}\text { Letting } \\
\text { Cost }\end{array}$ \\
\hline Proposed Cost & & & & & \\
\hline $\begin{array}{c}\text { Engineer's } \\
\text { Assessment Cost }\end{array}$ & - & - & - & & \\
\hline Design Cost & - & - & - & - & \\
\hline $\begin{array}{c}\text { Engineer's } \\
\text { Estimate }\end{array}$ & - & - & - & & \\
\hline Letting Cost & - & - & & & \\
\hline
\end{tabular}

\subsubsection{Step 3: Analyses of Escalation Pattern of Cost Estimates}

A methodology for analysis of the escalation pattern of the cost estimates from planning to final construction is presented in this section (Step 3). Using the proposed methodology, common trends in the escalation pattern can be identified and compared across the contract-specific factor levels. The noninflated cost estimates are analyzed in Step 3. If the non-inflated estimates are not available Step 3 is skipped and the analysis proceeds to Step 4. The procedure for analysis in Step 3 is as follows:

\section{(a) Define the Cost Escalation Patterns}

Define the escalation patterns that are expected to be most commonly exhibited by the contracts. For example, contracts may exhibit a pattern (say Pattern 'A', Figure 4.3), wherein the cost estimate increases or remains constant from the planning stage until the advertisement stage, decreases from the advertisement stage to the letting stage, and then increases or remains constant from letting to final construction. That is, the estimate prepared at a later stage is higher or the same compared to the estimate prepared at the immediate preceding stage, except at the letting stage when the letting cost is lower than the preceding estimate. Such patterns are likely in an extremely competitive bidding scenario. Identification of contracts that exhibit this pattern can provide insights about the reliability of low bidding estimates. For example, if contracts of a certain type exhibit pattern ' $A$ ' more frequently than other contract types, then the low bids for such contracts can be dealt with appropriately in the future. 


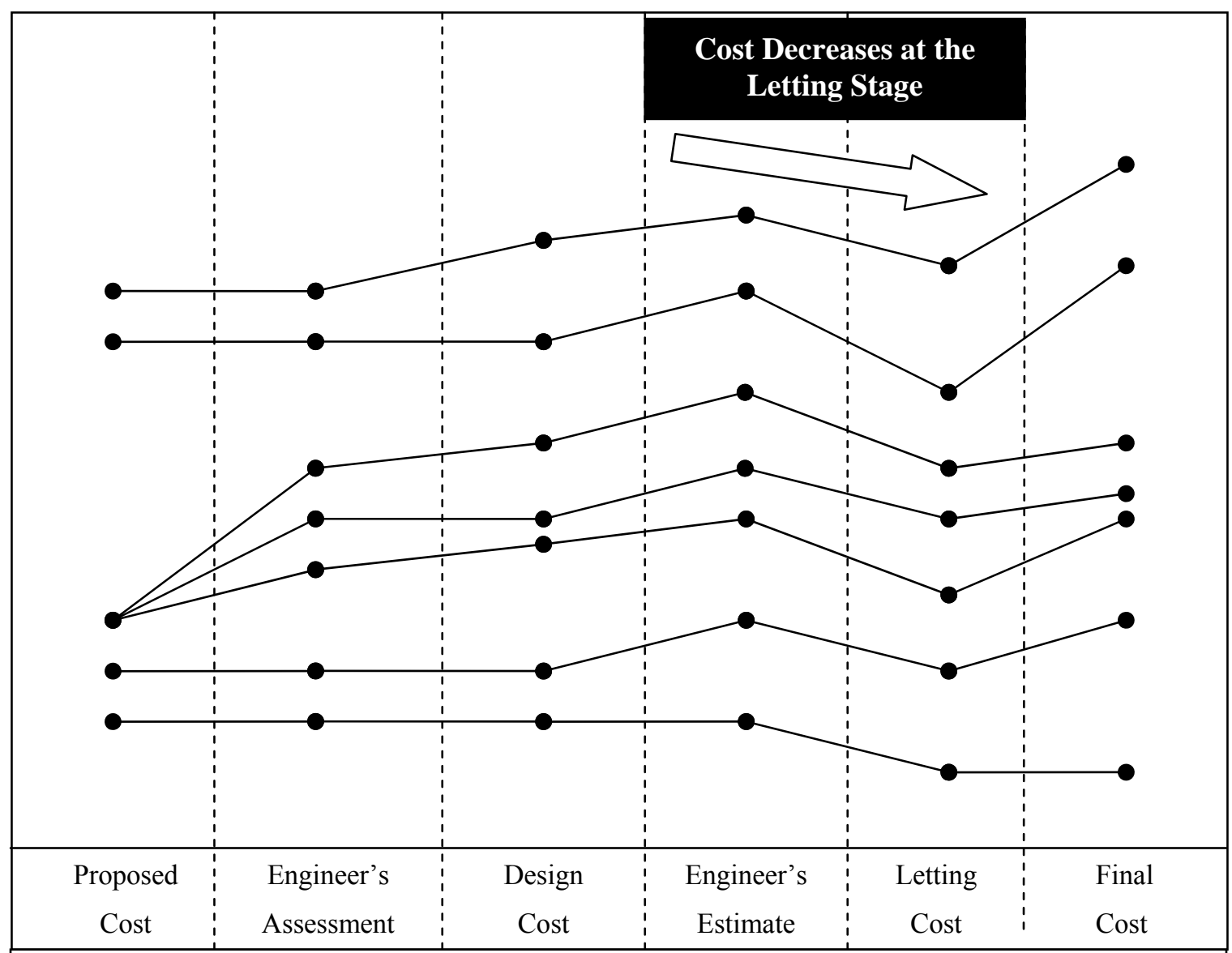

Estimated cost increases or remains the same between any two stages of project development, except between Advertisement (Engineer's Estimate) and Bidding Stage (Letting Cost)

Figure 4.3: Graphical Representation of Cost Escalation Pattern 'A'

The escalation patterns may also be defined from the perspective of the level of interest planners and decision-makers have in any particular trend that is shown by the cost estimates. For example, a pattern, say Pattern 'B' (Figure 4.4), wherein the cost estimate increases or remains constant from the planning stage until the final construction is considered to be an important pattern from the point of view of the risk of cost overrun, and from the point of view of budget management. Once the contracts that exhibit such a pattern have been identified, studies can be carried out to determine the nature of such contracts. The percentage difference between final cost and proposed cost is likely to be high for the contracts that exhibit this pattern. Moreover, contracts that exhibit pattern ' $\mathrm{B}$ ' may be the ones that generally undergo scope changes as they proceed through the planning and development phase. Also, contracts which are deliberately underestimated at the planning stage so that they can be programmed in the statewide transportation improvement program may exhibit such a pattern. Such assumptions can be validated by defining pattern 'B' and conducting exploratory studies about the contracts that exhibit it. 


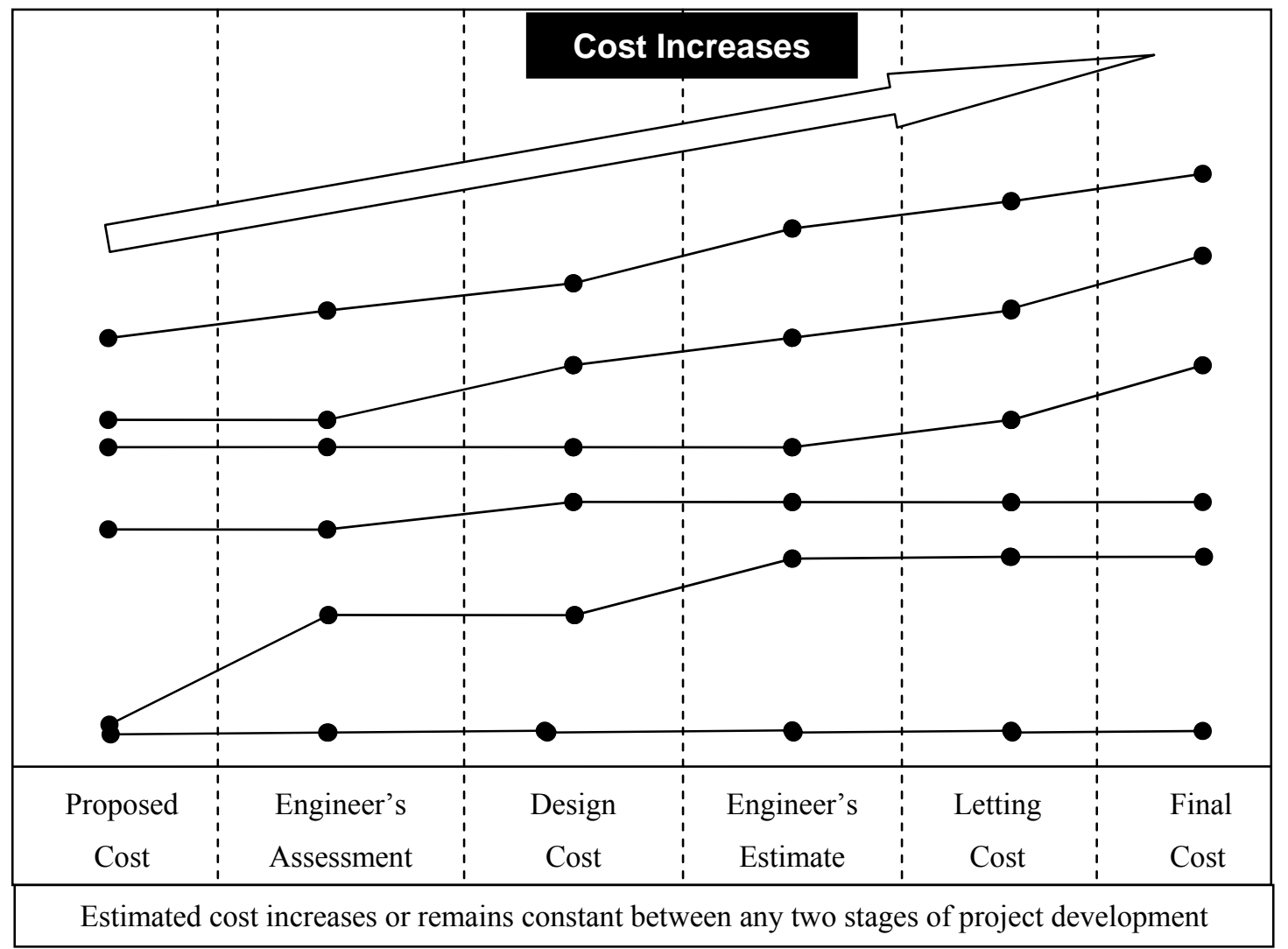

Figure 4.4: Graphical Representation of Cost Escalation Pattern 'B'

Figure 4.5 shows another pattern (herein called Pattern ' $C$ ') that may interest decision-makers. For the contracts that exhibit this pattern, the cost estimate increases or remains constant from the planning stage to the letting stage, but the final incurred cost is less than the letting cost. Identification of such contracts can help planners and decision-makers in determining the type of contracts that are overestimated by contractors. Contractors may overestimate to cover potential losses due to uncertainty associated with the construction process. If overestimation on the part of the contractor is found to be the reason for the high letting cost, then such construction risk-related uncertainties can be identified and incorporated in the in-house estimates of proposed cost, engineer's assessment, and design estimates to ensure proper budget planning in case the uncertainties were to occur. On the other hand, the construction process may be responsible for the completion of the project below the awarded amount. In such a scenario, those contracts that exhibit this pattern can be set as role models. The identification of contracts that exhibit such a pattern can allow planners and contractors to study why they were completed below the contracted amount. 


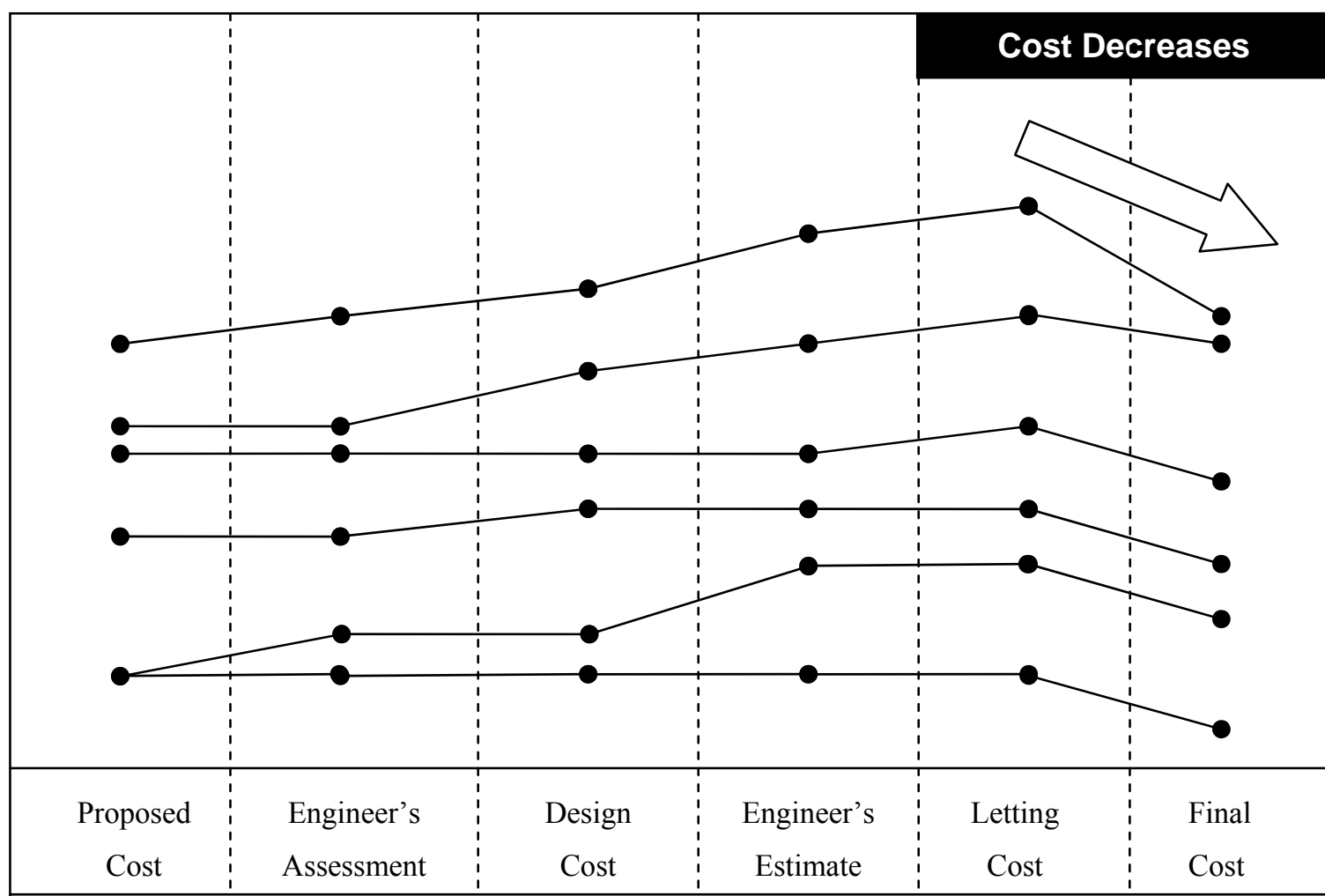

Estimated cost increases or remains constant between any two stages of project development except between Bidding Stage (Letting Cost) and Construction Stage (Final Cost)

Figure 4.5: Graphical Representation of Cost Escalation Pattern 'C'

\subsubsection{Step 4: Impact of Inflation}

The impact of inflation is determined using the with / without approach (cost overrun with inflation vs. cost overrun without inflation). Under this approach, first, the cost estimates at each stage are compared to the final cost without adjusting for inflation and their accuracy is recorded. The percentage overrun of the final cost compared to each estimate is determined using the equations 4.1 to 4.5 as discussed in Section 4.2.2. Second, the cost estimates corresponding to each stage are adjusted to the year when the final construction cost is incurred using the construction price index (CPI). The adjusted cost estimates are recorded as inflated cost estimates. The $\mathrm{i}^{\text {th }}$ inflated cost estimate (proposed, engineer's assessment, design, engineer's estimate, and letting) is calculated as follows:

$$
\text { Inflated Estimate }(\mathrm{i})=\text { Non-Inflated Estimate }(\mathrm{i}) \times\left(\frac{\text { Construction Price Index }\left(\text { Date }_{6}\right)}{\text { Construction Price Index }\left(\text { Date }_{i}\right)}\right)
$$

where,

Date $_{6}=$ Date when the final construction cost is incurred (refer to Figure 4.1)

Date $_{\mathrm{i}}=$ Date when the $\mathrm{i}^{\text {th }}$ cost estimate was prepared 
Equations 4.1 to 4.5 are used again, but this time with inflated cost estimates to calculate the overrun of the final cost. Figure 4.6 presents this framework for determining the overrun corresponding to inflated and non-inflated cost estimates.

The inflated cost estimates may be obtained directly from the highway agency instead of using the construction price index to calculate the inflated estimates. The impact of inflation cannot be determined if the inflated cost estimates are available but the non-inflated cost estimates are not. The methodology in Steps 2 and 3 is then used to analyze the inflated cost estimates only.

Once the inflated and non-inflated cost estimates have been calculated, the role played by inflation is determined by comparing the 'without inflation cost overrun' results with the 'with inflation cost overrun' results. The impact of inflating the cost estimate is studied by plotting the 'non-inflated cost estimate', the 'inflated cost estimate', and the 'final construction cost'. Six possible cases are analyzed depending upon the relative location of these numbers (as shown in Figure 4.7).

The first case represents a scenario in which the final cost is significantly higher than the noninflated proposed cost estimate. After adjusting the proposed cost for inflation, the inflated proposed cost accounts for some of the overrun of the final cost but is still less than the final cost. While this case is expected to be the most commonly exhibited, the possibility of occurrence of other cases should also be studied. The second case represents a scenario in which the final cost is higher than the non-inflated proposed cost (as in Case 1). However, after adjusting for inflation, the inflated proposed cost exceeds the final cost. That is, without inflation adjustment a cost overrun is observed and with inflation adjustment a cost underrun is observed. The third case represents a scenario in which the final cost is lower than the noninflated proposed cost. After adjustment for inflation the inflated proposed cost becomes even higher. That is, inflation adjustment magnifies the cost underrun that was observed corresponding to the non-inflated cost estimate.

The first three cases represent scenarios where inflation adjustment results in increasing the noninflated cost estimate, reflecting the growing trend of construction price index. However, construction price index may also experience a decreasing trend across some years during a certain time period. Consequently, the adjustment of non-inflated cost estimate for inflation will result in a lower inflated cost estimate. Such scenarios, while rare, should also be considered for the sake of completeness. Cases 4, 5, and 6 represent such scenarios. In Case 4, the non-inflated cost estimate is lower than the final cost and becomes even lower after inflation adjustment. In Case 5, the non-inflated cost estimate is greater than the final cost (indicating negative cost overrun or cost underrun) but becomes lower than the final cost after inflation adjustment (indicating positive cost overrun). In Case 6, the non-inflated cost estimate is greater than the final cost (as in Case 5) but remains greater than the final cost after inflation adjustment. 


\begin{tabular}{|c|c|c|c|c|c|}
\hline $\begin{array}{c}\text { Proposed } \\
\text { Cost } \\
\text { PCost }\end{array}$ & $\begin{array}{c}\text { Engineer's } \\
\text { Assessment } \\
\text { EACost }\end{array}$ & $\begin{array}{l}\text { Design } \\
\text { Cost } \\
\text { DCost }\end{array}$ & $\begin{array}{l}\text { Engineer's } \\
\text { Estimate } \\
\text { EECost }\end{array}$ & $\begin{array}{l}\text { Letting } \\
\text { Cost } \\
\underline{\text { LCost }}\end{array}$ & $\begin{array}{c}\text { Final Cost } \\
\text { FCost }\end{array}$ \\
\hline $\begin{array}{c}\text { First } \\
\text { Estimate } \\
\text { (Stage 1) }\end{array}$ & $\begin{array}{l}\text { Second } \\
\text { Estimate } \\
\text { (Stage 2) }\end{array}$ & $\begin{array}{c}\text { Third } \\
\text { Estimate } \\
\text { (Stage 3) }\end{array}$ & $\begin{array}{c}\text { Fourth } \\
\text { Estimate } \\
\text { (Stage 4) }\end{array}$ & $\begin{array}{c}\text { Fifth } \\
\text { Estimate } \\
\text { (Stage 5) }\end{array}$ & $\begin{array}{c}\text { Incurred } \\
\text { Cost } \\
\text { (Stage 6) }\end{array}$ \\
\hline
\end{tabular}

Date 1

Date 2

Date 3

Date 4

Date 5

Date 6

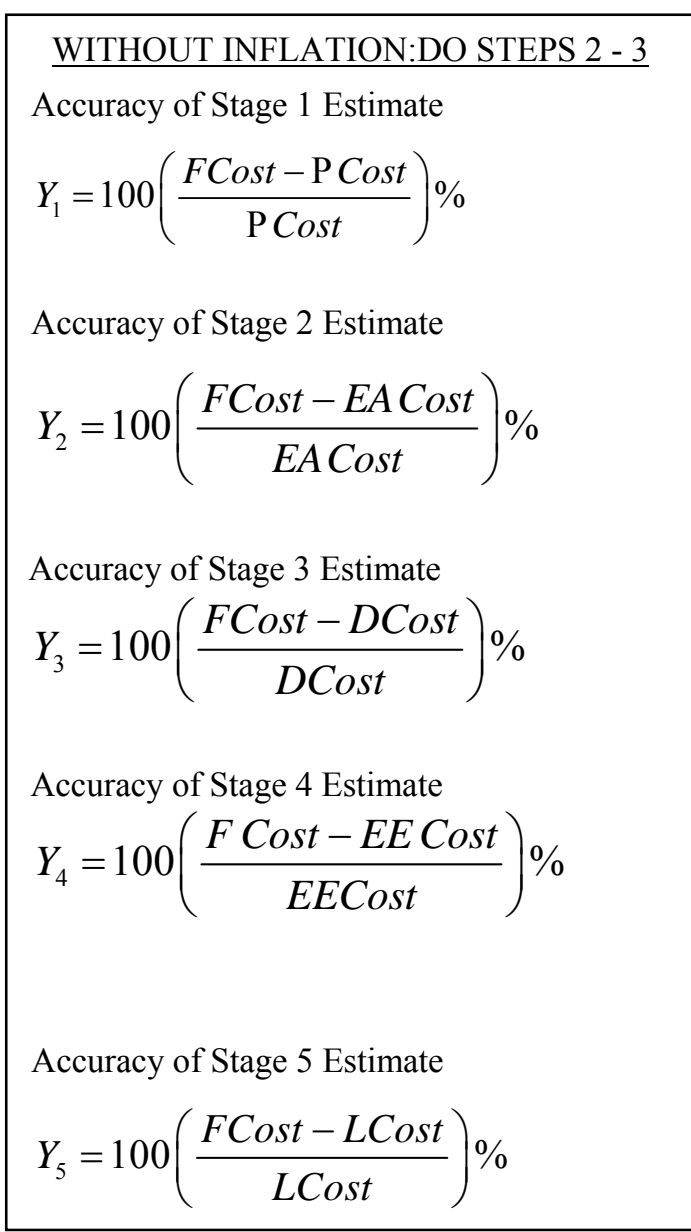

\section{WITH INFLATION: DO STEPS $2-3$}

Accuracy of Stage 1 Estimate

$Y_{1}^{*}=100\left(\frac{\text { FCost }- \text { PCost } *}{P \operatorname{Cost}^{*}}\right) \%$

Accuracy of Stage 2 Estimate

$Y_{2}^{*}=100\left(\frac{\text { FCost }- \text { EACost }}{*}\right) \%$

Accuracy of Stage 3 Estimate

$Y_{3}^{*}=100\left(\frac{F \operatorname{Cos} t-D \operatorname{Cost}^{*}}{D \operatorname{Cos}^{*}}\right) \%$

Accuracy of Stage 4 Estimate

$Y_{4}^{*}=100\left(\frac{F \operatorname{Cos} t-E E \operatorname{Cos} t^{*}}{E E \operatorname{Cos} t^{*}}\right) \%$

Accuracy of Stage 5 Estimate

$Y_{5}^{*}=100\left(\frac{F \operatorname{Cos} t-L \operatorname{Cos} t^{*}}{L \operatorname{Cos} t^{*}}\right) \%$

* Indicates the Inflated Estimate

Figure 4.6: Analysis Framework for Calculating Cost Overrun With / Without Inflation

The number of contracts exhibiting each case is determined. The most commonly exhibited case is identified. If Case 1 is the most commonly exhibited scenario, it is concluded that the cost estimate is an underestimate of the final cost, but the extent of underestimation decreases with inflation adjustment. The impact of inflation is calculated as follows: 


$$
\begin{aligned}
& \% \text { Deviation of } \% \text { Deviation of } \\
& \text { Impact of Inflation }=\text { Final Cost from }- \text { Final Cost from } \\
& \text { Non-Inflated Estimate Inflated Estimate } \\
& \underset{\text { Inflation }\left(I_{1}^{* *}\right)}{\text { Impact of }}=\left|\frac{\text { Final Cost - Non Inflated Estimate }}{\text { Non Inflated Estimate }}\right|-\left|\frac{\text { Final Cost - Inflated Estimate }}{\text { Inflated Estimate }}\right|
\end{aligned}
$$

On the other hand, if contracts exhibiting other cases are significantly more than contracts exhibiting Case 1, the data implied that non-inflated estimates were possibly better estimates of final cost than the inflated estimates were. In order to verify this implication, the methodology used for preparation of non-inflated cost estimates is studied to determine if any inflation adjustments were made implicitly.

\subsubsection{Step 5: Development of Risk-Based Econometric Analysis Framework}

In Steps 2 and 3, a methodology for analysis of the accuracy and escalation pattern of the historical cost estimates was presented. This methodology involved a macroscopic statistical analysis to study the trends in cost overrun and underrun associated with historical contracts. However, in order to examine and elucidate any relationships, theories, or principles corresponding to the observed cost difference, there is a need to conduct econometric analysis of the historical contract data. Econometric models can throw more light on the possible relationships between cost overrun and the contract-specific factors.

Several studies have been conducted to relate cost overrun with contract-specific factors such as geographic location, contract size, contract classification, contract work characteristics, contract schedule, and contract letting characteristics. Some of these studies went further to develop models so as to predict cost overrun or to simply relate cost overrun with one or more contract specific factors, so that cost overruns could be mitigated in the future. Some of these studies are described as follows. 


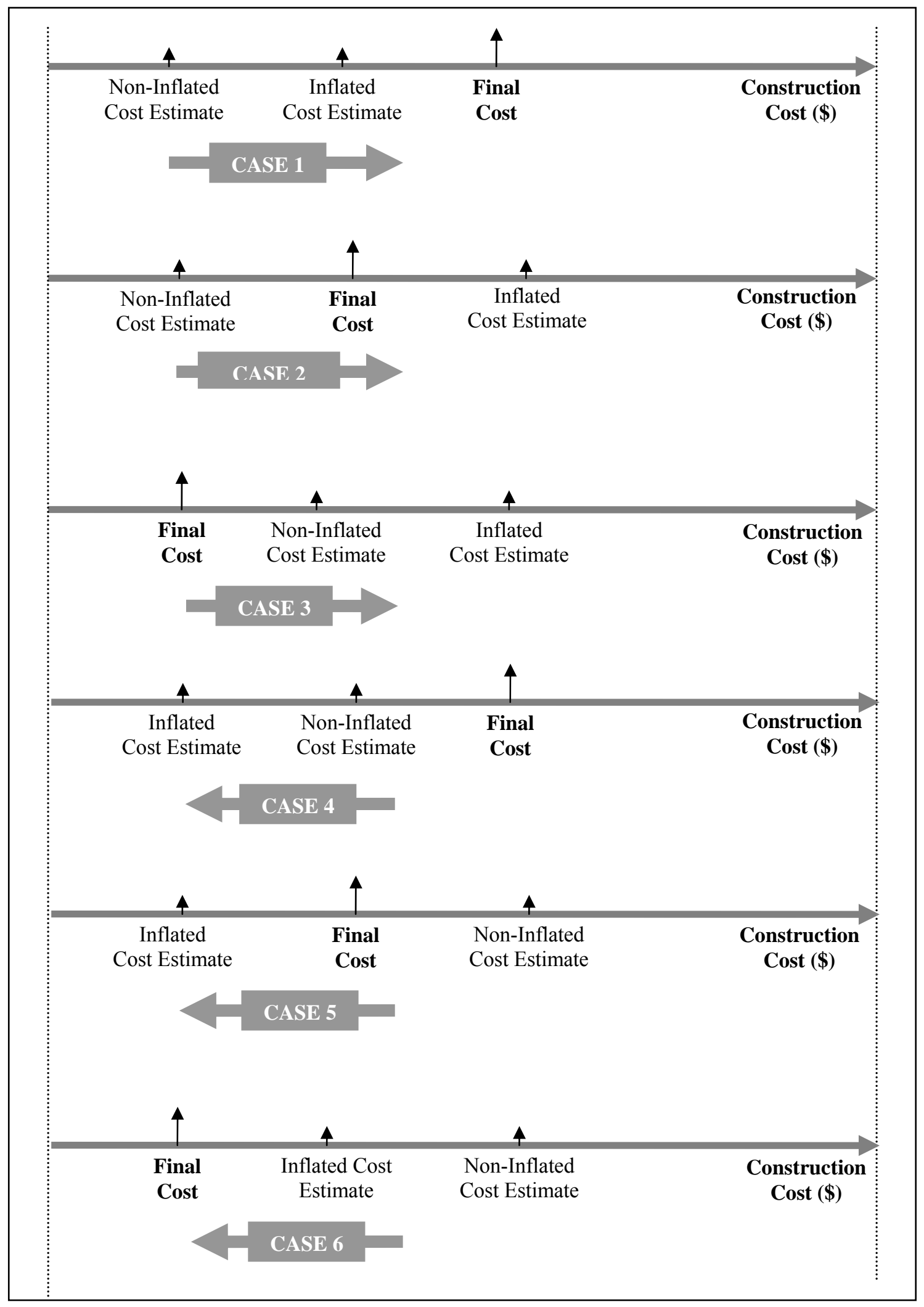

Figure 4.7: Framework for Analyzing of the Impact of Inflation 
Bordat et al. (2004) found that project type, location, weather, difference between first and second lowest bids, difference between engineer's estimate and lowest bid, and project duration were significant factors that explained cost overrun in Indiana during the period 1996-2001. In a subsequent study, ordinary least square regression models were developed to predict cost overrun as a function of these projectspecific factors. Gkritza and Labi (2008) found that contracts with larger size and longer construction contracts were more likely to incur cost overrun. Further, it was found that for contracts that incur cost overrun, the cost overrun rate decreases non-linearly with increasing contract size until a certain point after which the cost overrun rate increases with increasing contract size. Several other researchers found that cost overrun tends to increase with the size of the project (Hinze et al., 1992; Korman and Daniel, 1998).

In addition to analyzing statistical relationships, Williams (2001) developed neural network and regression models to predict the completed cost of highway construction projects using the bidding data. The bid variables that were found significant in the prediction models included: lowest bid, median bid, standard deviation of the bids, expected project construction duration, and number of bids. The models which were developed for the New Jersey Department of Transportation and were found to produce good predictions of final cost, and generally had good R-squared values.

Schexnayder et al. (2003) observed that the schedule of the project development phases plays an important role in determining whether the final cost is higher than the proposed cost. Projects that are planned, designed, and developed over a long period of time generally tend to have more room for scope changes and consequently cost overruns.

The nature of work at construction sites has also been identified as a factor of cost overrun. Thurgood et al. (1990) found that rehabilitation and reconstruction projects are more likely to have greater cost overrun compared to maintenance projects. Bhargava et al. (2008) and Bordat et al., (2004) developed models by work category to analyze and predict cost overrun. Across contracts of similar work categories and work types, the changes in design that eventually lead to change orders and cost overrun during construction are likely to be of a similar nature. Such changes in design are often one of the major causes of cost overrun (Flyvbjerg et al., 2002; JLARC, 2001; MacDonald et al., 2005; Jacoby, 2001).

In the present study, a methodology is proposed for the development of econometric models that can be used to study the relationship of cost overrun and underrun with deterministic and random contractspecific factors. The deterministic factors include: geographic location, work category, highway functional class, area type, NHS status, and contract size. The random contract-specific factors include: probability of occurrence of an escalation pattern and variability in the occurrence probability of an escalation pattern. The probability of an escalation pattern and its variability indicate the risk of a contract to experience cost overrun. The econometric models that are developed using such random variables as independent variables are therefore referred to as 'risk-based econometric models' in this study. Consequently, the framework comprising of such models is referred to as 'risk-based econometric analysis framework'. Figure 4.8, the proposed framework, comprises three modules each of which uses a set of econometric models to 
determine an aspect related to cost overrun / underrun. Module I's econometric models determine the probability and variability in probability of an escalation pattern based on the deterministic contract specific factors; Module II's econometric models determine probability of cost overrun based on deterministic and random variables; Module III's econometric models determine magnitude of cost overrun.

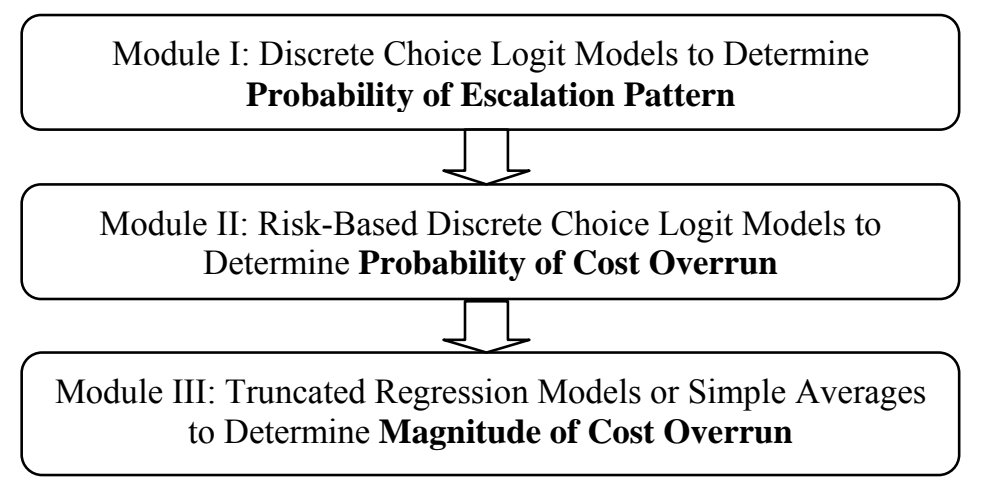

Figure 4.8: Proposed Risk-Based Econometric Analysis Framework

The step-by-step procedures used in this study for developing of the econometric models in each module are outlined in Sections 4.2.5.1 to 4.2.5.4. The methodology can be replicated by planners and decision-makers for analyzing of cost overruns at each stage of project development. Before developing the econometric models, it is useful to identify the deterministic contract-specific factors.

The quantity and quality of information on the deterministic contract-specific factors increases as the contract evolves through the planning and development stages. Therefore, the econometric models corresponding to the three modules can be developed for each project development stage using the contract-specific factors that are available at that stage. Table 4.8 shows the contract-specific factors that are typically available in Indiana at each project development stage. For example, at the letting stage, information on time taken to complete design plans and time taken to let a project are available. Models developed on the basis of such data are more useful in attempts to predict probability and magnitude of cost overrun compared to those based on information available at planning stage.

Figure 4.9 presents the preliminary steps that are carried out before proceeding to the development of the risk-based econometric analysis framework. First, the project development stage (planning, or postprogramming or design or letting), for which the econometric models have to be developed, is selected. Next, the deterministic contract-specific factors that are available at the selected stage are identified from Table 4.8 and information on historical highway contracts is selected corresponding to each of the identified factors. Once the deterministic contract-specific factors have been identified, development of the econometric models corresponding to the three modules can begin. 


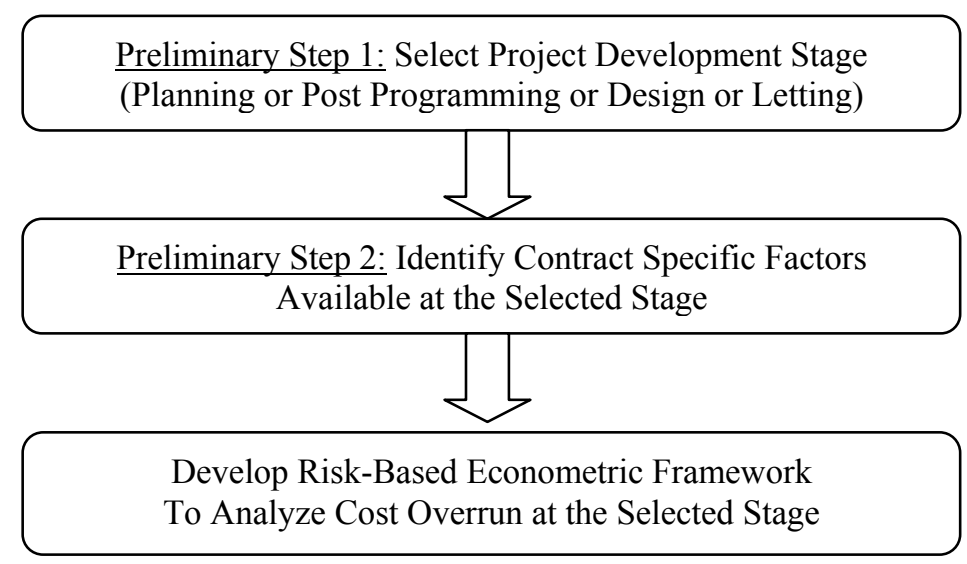

Figure 4.9: Steps Involved in Preparing for the Development of Econometric Analysis Framework 
Table 4.8: Contract-Specific Factors for Econometric Analysis Framework

\begin{tabular}{|c|c|c|c|c|c|}
\hline \multirow{2}{*}{\multicolumn{2}{|c|}{ Contract-Specific Factor }} & \multicolumn{4}{|c|}{$\begin{array}{l}\text { Project Development Stage for which the } \\
\text { Econometric Analysis Framework is being Developed }\end{array}$} \\
\hline & & $\begin{array}{l}\text { Planning } \\
\text { Stage }\end{array}$ & $\begin{array}{l}\text { Post } \\
\text { Programming } \\
\text { Stage }\end{array}$ & $\begin{array}{l}\text { Final Design } \\
\text { Stage }\end{array}$ & $\begin{array}{l}\text { Letting } \\
\text { Stage }\end{array}$ \\
\hline \multirow{5}{*}{$\begin{array}{l}\text { Geographic } \\
\text { Location }\end{array}$} & District & & & & \\
\hline & County & & & & \\
\hline & North / South / East / West & & & & \\
\hline & Urban vs. Rural Area & & & & \\
\hline & $\begin{array}{l}\text { FMIS Area (Based on } \\
\text { Population ) }\end{array}$ & - & - & & \\
\hline \multirow{5}{*}{$\begin{array}{c}\text { Contract } \\
\text { Classification }\end{array}$} & & & & & \\
\hline & Highway Functional Class & & & & \\
\hline & Route Type & & & & \\
\hline & NHS Status & & & & \\
\hline & Program Class & - & - & & \\
\hline \multirow{4}{*}{$\begin{array}{c}\text { Work } \\
\text { Characteristics }\end{array}$} & & & & & \\
\hline & $\begin{array}{l}\text { Work Category (Bridge, } \\
\text { Pavement, etc) }\end{array}$ & & & & \\
\hline & $\begin{array}{l}\text { Work Type (Pavement } \\
\text { Resurfacing, Rehabilitation, } \\
\text { Bridge Rehab / Replacement) }\end{array}$ & & & & \\
\hline & $\begin{array}{l}\text { Basic Nature of Site Work } \\
\text { (Paving, Excavation, Utilities, } \\
\text { RW etc) }\end{array}$ & - & - & & \\
\hline \multirow{6}{*}{ Cost Estimate } & & & & & \\
\hline & Proposed Cost & & & & \\
\hline & Engineer's Assessment & - & & & \\
\hline & Design Cost & - & - & & \\
\hline & Engineer's Estimate & - & - & - & \\
\hline & Bid Amounts & - & - & - & \\
\hline \multirow{3}{*}{ Time Schedule } & $\begin{array}{l}\text { Project Proposal to Design } \\
\text { Completion }\end{array}$ & - & - & & \\
\hline & Project Proposal to Letting & - & - & & \\
\hline & Expected Construction Duration & - & - & & \\
\hline \multirow{5}{*}{$\begin{array}{c}\text { Letting } \\
\text { Characteristics }\end{array}$} & Number of Bids Received & - & - & - & \\
\hline & Bid Amounts & - & - & - & \\
\hline & $\begin{array}{l}\text { Time Allotted for Bid } \\
\text { Preparation }\end{array}$ & - & - & - & \\
\hline & $\begin{array}{l}\text { Contract Completion Deadline } \\
\text { Specification (AD, DT, CD) }\end{array}$ & - & - & - & \\
\hline & $\begin{array}{l}\text { Contract Classification } \\
\text { (Standalone vs. Kin) }\end{array}$ & - & - & - & \\
\hline
\end{tabular}




\subsubsection{Step 5.1: Development of Module I for Analysis of Escalation Patterns}

The procedure for the development of Module I discrete choice models is as follows:

a) Determine the escalation pattern of the cost estimates for each of the ' $N$ ' historical contracts in the database. Section 4.2.3 described the procedure for determining the escalation pattern.

b) For each historical contract, tabulate the observed escalation pattern and the corresponding contract specific factors that are believed to influence the escalation pattern.

c) The discrete choice modeling framework is based on the premise, that, given a set of possible escalation patterns, $\{\mathrm{A}, \mathrm{B}, \ldots, \mathrm{K}\}$, the cost estimates of a contract are likely to exhibit each pattern with a certain probability. For each historical contract, the pattern that was exhibited was the one which had the maximum probability for this contract. The extent to which a contract is likely to exhibit a particular pattern depends upon the 'U-function' of the pattern. The ' $U$-function' of a pattern is a function of contract specific factors $(X)$. Mathematically, the U-function of a pattern ' $i$ ' can be expressed as follows:

$$
\bar{U}_{\text {Pattern ' } i '}=\sum_{r=1}^{R_{i}} \eta_{i r} X_{i r} \quad i \in\{A, B, \ldots, K\}
$$

where,

$\mathrm{i}=$ Indicates the escalation pattern of the cost estimates, $i \hat{I}\{\mathrm{~A}, \mathrm{~B}, \ldots, \mathrm{K}\}$

$r=$ Indicates the contract specific factor in the U-Function of pattern 'i', $r \hat{I}\left\{1,2, \ldots, R_{i}\right\}$

$\overline{\mathrm{U}}_{\text {Pattern i' }}=\mathrm{U}-$ Function of Pattern 'i'

$\mathrm{X}_{\mathrm{ir}}=$ Contract specific factor ' $\mathrm{r}$ ' that affects probability of contract exhibiting pattern 'i'

$\eta_{\mathrm{ir}}=$ Coefficient of the contract specific factor ' $r$ ' in the U-function of pattern 'i'

$\mathrm{R}_{\mathrm{i}}=$ Number of statistically significant contract specific factors in the U-function of pattern ' $\mathrm{i}$ '

d) Using the multinomial logit regression approach, the contract specific factors that significantly influence the U-function of an escalation pattern are identified and the coefficients of each of these factors in the corresponding U-function equation are calibrated using data from historical contracts. Statistical software such as SAS, NLogit, Minitab, and Limdep can be used for calibration. The calibrated U-function equations are used to calculate the U-function of each pattern given the contract type. The probability of a contract to exhibit pattern ' $i$ ' is calculated as follows:

$$
\bar{P}_{\text {Pattern'i' }}=\frac{e^{\bar{U}_{\text {Pattern'i' }^{\prime}}}}{\sum_{i=A}^{K} e^{\bar{U}_{\text {Pattern' } i^{\prime}}}} \quad \text { for } i=\{A, B, \ldots ., K\}
$$

e) Use the nested logit regression approach to calibrate the U-function equations if two or more patterns are expected to be significantly correlated to each other. The nested logit approach accounts for the Independence of Irrelevant Alternatives (IIA) limitation of the multinomial logit approach in a scenario when the patterns are highly correlated. The nested logit modeling technique classifies the patterns into categories based on the common characteristics of the patterns. For example, the non-decreasing 
escalation pattern of the cost estimates from the proposed cost to the engineer's estimate is a common characteristic between the patterns ' $A$ ', ' $B$ ' and ' $C$ ' that were defined in Figures 4.3 through 4.5. Therefore, these patterns could be nested as shown in Figure 4.10, with pattern ' $\mathrm{D}$ ' representing any escalation pattern not covered by patterns 'A', 'B', and ' $C$ ', and the nested logit approach can be used to calibrate the U-function equations. Statistical software such as SAS and Limdep can be used to test the appropriateness of the nesting structure. If the nesting structure is found to be inappropriate, it can be concluded that the correlation between the nested patterns is not significant and therefore the calibrated multinomial logit U-function equations (in Step (d)) can be used to study the impact of contract-specific factors. However, if the nesting structure is found to be significant, the calibrated multinomial logit model in Step (d) is discarded.

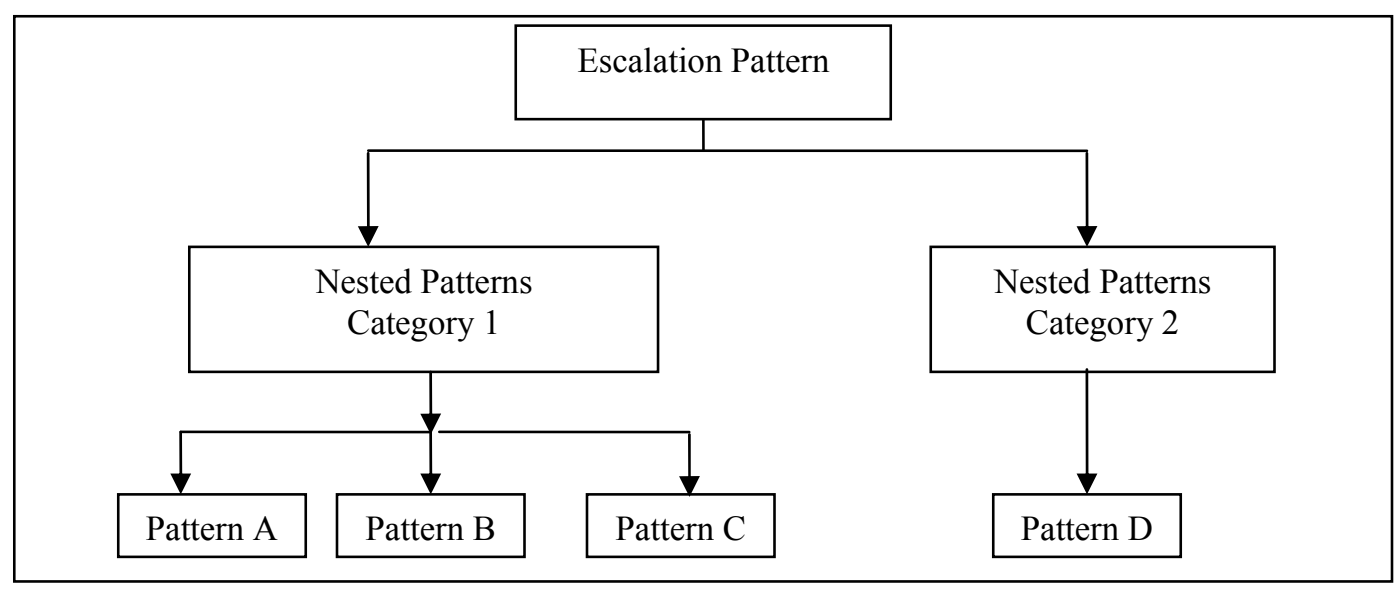

Figure 4.10: A Hypothetical Nested Structure of Four Cost Escalation Patterns

f) Use the mixed logit regression approach for calibrating the U-function equations if the coefficients of the U-function equations are expected to vary randomly across the contracts. The multinomial logit regression approach in Step (d) assumes that the coefficients of the contract-specific factors in the Ufunction equations are the same for all the historical contracts. The validity of this assumption is tested by calibrating the U-function equations using the mixed logit approach. If the standard deviation corresponding to a coefficient that is randomly varied across the contracts is found to be significant, the mixed logit models are used to study the influence of contract-specific factors on the probability of escalation pattern. However, if the coefficients are not found to vary randomly, the multinomial logit models or nested logit models are used depending upon whichever is appropriate in Step (e).

g) The transferability of the parameters of the developed model across the factor levels such as the various districts, the different work categories, or the different contract types is then ascertained. Therefore, the Steps (d), (e) and (f) are repeated to calibrate the discrete choice econometric models separately for each work category, contract type (stand-alone vs. kin contract), or contract size. Separate models are developed for each factor level corresponding to any contract-specific factor using 
the methodology in Steps (d), (e), and (f). A likelihood ratio test (Washington et al., 2003) is conducted to determine if 'separate' models are required by factor level (say work category types) or if a 'single model' for all factor levels explains the cost escalation patterns better. The likelihood test is conducted by comparing the log-likelihoods (LL) of the models. The log-likelihood of the 'single model' for all factor levels (say, work categories) is compared with the log-likelihood of the 'separate' models corresponding to the ' $I$ ' different factor levels (say, work categories). The comparison is done by computing the following test-statistic:

$$
D=2 \times\left\{L L\left(\begin{array}{l}
\text { Single Model } \\
\text { for all factor levels }
\end{array}\right)-\sum_{i=1}^{I} L L\left(\begin{array}{l}
\text { Model for } \\
\text { factor level ' } i '
\end{array}\right)\right\}
$$

The test statistic ' $\mathrm{D}$ ' is chi-squared distributed with ' $d f$ ' degrees of freedom (DF). The degree of freedom is calculated as:

$$
d f=\left\{D F\left(\begin{array}{l}
\text { Single Model } \\
\text { for all factor levels }
\end{array}\right)-\sum_{i=1}^{I} D F\left(\begin{array}{l}
\text { Model for } \\
\text { factor level ' } i \text { ' }
\end{array}\right)\right\}
$$

The p-value corresponding to the test-statistic ' $\mathrm{D}$ ' is computed and if less than 0.05 , it is concluded that separate models by factor level are required to explain the cost overrun, that is the parameters of the econometric model are not transferable across the factor levels.

Econometric models are calibrated using the Steps (a)-(g) for all the risk-based econometric frameworks using the contract specific factors that are available corresponding to that stage. The predictive capability of each framework is determined using the McFadden R-squared value (Washington et al., 2003). The economic relationships between cost overrun and the contract specific factors are studied using the calibrated coefficients of the various contract specific factors that are found significant in the econometric models (at 95\% confidence level).

\subsubsection{Step 5.2: Development of Module II to Analyze Probability of Cost Overrun}

Module II comprises of a set of discrete choice econometric models that are used to analyze the probability of overrun of the final cost compared to the proposed estimate, engineer's assessment, design estimate, engineer's estimate, and letting cost. The models are used to determine the probability and to study the factors that influence the probability of a contract type having a cost overrun of less than $-10 \%$ (cost overrun category ' 1 '), between $-10 \%$ and $0 \%$ (cost overrun category ' 2 '), between $0 \%$ and $10 \%$ (cost overrun category ' 3 '), and greater than $10 \%$ (cost overrun category ' 4 '). Calibration of the models is done based on the observed cost overrun corresponding to the historical contracts. The contract-specific factors and the risk of a contract to exhibit a particular cost escalation pattern (as measured in Module I) are used as independent variables in the model calibration. The step-by-step procedure for the development of the models is presented in this section. The methodology for determining the risk associated with predicting 
whether a contract has a cost overrun of greater than $10 \%$, between $-10 \%$ and $10 \%$ or less than $-10 \%$, has also been presented.

The methodology presented in this section can also be used to develop models for comparison of cost estimates with final cost as well as for pair-wise comparison of cost estimates. The framework for pairwise comparison of any two cost estimates is discussed in Section 4.2.2 (Table 4.7). The procedure for development of the discrete choice models for Module II is:

a) For all the ' $\mathrm{N}$ ' historical contracts that were used for calibrating the models in Module I, determine the risk that a contract will exhibit each of the ' $\mathrm{K}$ ' cost escalation patterns.

\section{Calculation of Risk of Occurrence of a Cost Escalation Pattern (Based on Module I Models)}

The risk of occurrence of a cost escalation pattern is measured by the probability of its occurrence. The probability of occurrence of an escalation pattern is estimated using the econometric models in Module I. However, the calibrated discrete choice models in Module I use the contract-specific factors as independent variables to predict a point estimate of the probability of a contract to exhibit a certain cost escalation pattern. The contract-specific factors such as district, area, size, work category, route, and functional class define a category of contract types instead of a specific contract. The predicted point estimate of the probability (based on the contract-specific factors) is therefore an estimate of the average probability that is expected across all the contracts that fit the specified type. Because each contract is unique, the probability of cost overrun may vary across contracts of the same type. Therefore, there is a risk associated in using the same deterministic point estimate of the predicted probability across all the contracts of a particular type. For each contract type, Monte Carlo simulation is carried out to randomly select the coefficients of the calibrated models from their respective distributions and to predict the probability of a particular escalation pattern in each simulation run. The multivariate normal distribution of the calibrated coefficients is expressed as:

$$
\bar{\eta} \sim N\left(\eta, \Sigma_{\eta}\right)
$$

where,

$\eta=$ Mean vector comprising of the calibrated model coefficients

$\Sigma_{\mathrm{n}}=$ Variance Covariance Matrix of the model coeffcients

$$
\vec{\eta}=\left[\begin{array}{l}
\eta_{A 1} \\
\cdot \\
\eta_{i r} \\
\cdot \\
\eta_{K R_{K}}
\end{array}\right] \quad \Sigma_{\eta}=\left[\begin{array}{ccccc}
\operatorname{Var}\left(\eta_{A 1}\right) & \cdot & \operatorname{Cov}\left(\eta_{A 1}, \eta_{i r}\right) & . & \operatorname{Cov}\left(\eta_{A 1}, \eta_{K R_{K}}\right) \\
\cdot & \cdot & \cdot & \cdot & \cdot \\
\operatorname{Cov}\left(\eta_{i r}, \eta_{A 1}\right) & \cdot & \operatorname{Var}\left(\eta_{i r}\right) & \cdot & \operatorname{Cov}\left(\eta_{i r}, \eta_{K R_{K}}\right) \\
\cdot & \cdot & \cdot & \cdot & \cdot \\
\operatorname{Cov}\left(\eta_{K R_{K}}, \eta_{A 1}\right) & \cdot & \operatorname{Cov}\left(\eta_{K R_{K}}, \eta_{i r}\right) & \cdot & \operatorname{Var}\left(\eta_{K R_{K}}\right)
\end{array}\right]
$$




$$
\begin{aligned}
& \eta_{\mathrm{ir}}=\text { Calibrated coefficient of factor ' } r \text { ' in the U-Function of pattern ' } \mathrm{i} \text { ' } \\
& \operatorname{Var}\left(\eta_{\mathrm{ir}}\right)=\text { Variance of the coefficient ' } \eta_{\mathrm{ir}}{ }^{\prime} \\
& \operatorname{Cov}\left(\eta_{\mathrm{ir}}, \eta_{\mathrm{A} 1}\right)=\text { Covariance of the coefficients ' } \eta_{\mathrm{ir}}{ }^{\prime} \text { and ' } \eta_{\mathrm{A} 1}{ }^{\prime}
\end{aligned}
$$

The calibrated coefficients of the U-function equations in Steps (d), (e), and (f) are the mean of the normal distribution corresponding to the respective coefficient. The variance-covariance matrix of the coefficients is obtained from the software that is used to calibrate the models. For each contract type, repeated random sampling of the coefficients is done from the multivariate normal distribution of the coefficients. Based on the value of the coefficients in each draw, the point estimate of the U-function of each pattern is calculated, and consequently the probability of the contract exhibiting the corresponding escalation pattern is determined. However, the computation time with this approach can be very high as the time required for repeated random sampling from a multivariate normal distribution is directly proportional to the dimension of the vector of the calibrated coefficients. As the number of contract-specific factors that are found significant in the pattern U-function equations increase, the number of calibrated coefficients increases, and consequently the multivariate normal distribution of the coefficients achieves a higher dimension and becomes more complicated. Repeated random sampling from such a multivariate normal distribution takes significantly more time.

Hsu and Wilcox (2000) suggested a dimensionality reduction technique for multinomial logit models (MNL). For each contract, the calibrated MNL model coefficients are used to determine the value of the U-function for each pattern. Since the calibrated coefficients are normally distributed, the values of the U-functions are also normally distributed. The values of the U-functions that are calculated using the calibrated coefficients are mean values corresponding to their normal distributions. This is because the calibrated coefficients in Steps (d), (e), and (f) were mean values corresponding to the normal distributions of the coefficients. The variance-covariance matrix of the Ufunctions is calculated from the variance-covariance matrix of the model coefficients and the contractspecific factors $(\mathrm{X})$, as follows:

$$
\begin{aligned}
& \operatorname{Var}\left(U_{\text {Pattern }^{\prime} i^{\prime}}\right)=\sum_{r=1}^{A_{i}} X_{r i}^{2} \operatorname{Var}\left(\eta_{i r}\right)+2 \times \sum_{r=1}^{A_{i}} \sum_{r^{\prime}<r}^{A_{i}} X_{r i} X_{r^{\prime} i} \operatorname{Cov}\left(\eta_{i r}, \eta_{i r^{\prime}}\right) \\
& \operatorname{Cov}\left(\bar{U}_{\text {Pattern }^{\prime} i^{\prime}}, \bar{U}_{\text {Pattern }^{\prime} j^{\prime}}\right)=\sum_{r=1}^{A_{i}} \sum_{r^{\prime}=1}^{A_{j}} X_{r i} X_{r^{\prime} j} \operatorname{Cov}\left(\eta_{i r}, \eta_{j r^{\prime}}\right)
\end{aligned}
$$

Based on the calculated value and variance-covariance matrix of the U-functions, their multivariate normal distribution can be specified as follows: 


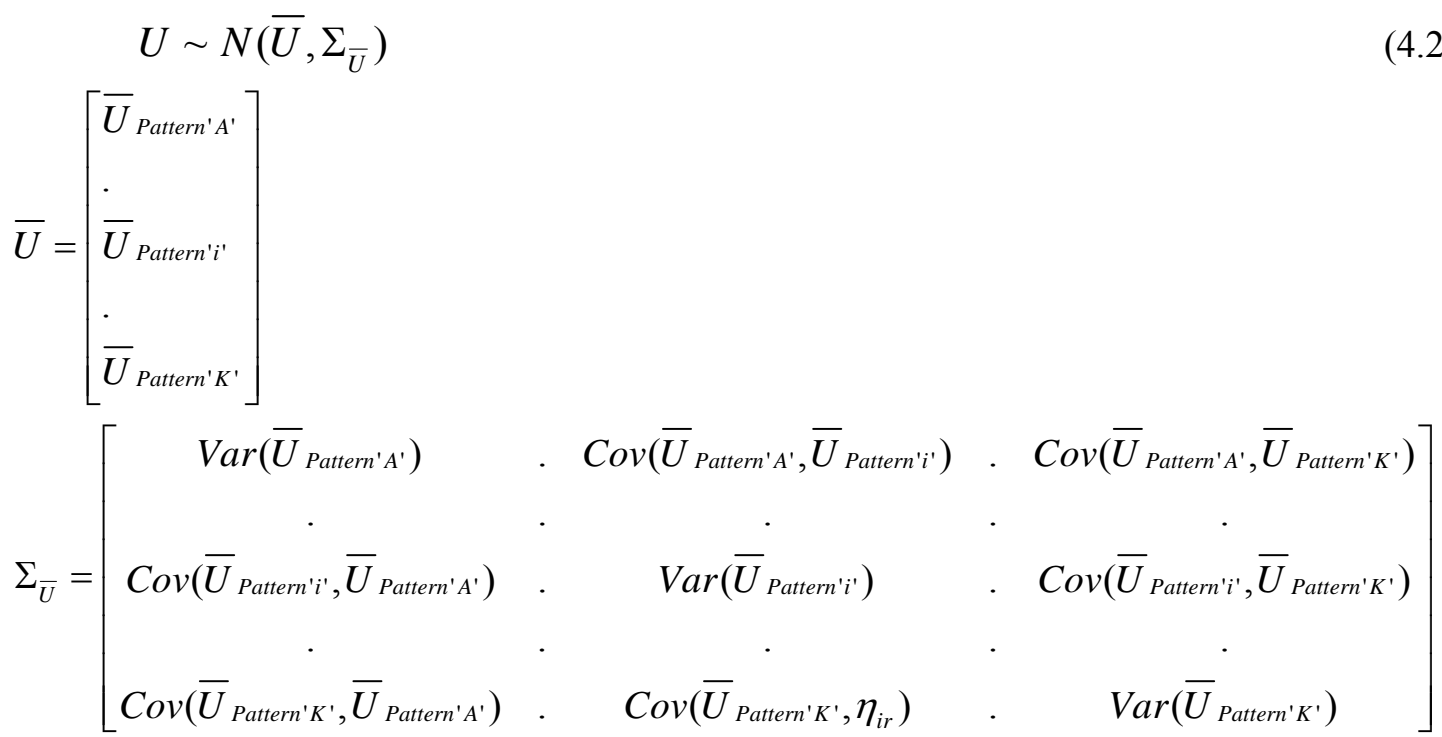

where,

$\overline{\mathrm{U}}=$ Mean Vector comprising of Mean Values of the U-Functions

$\Sigma_{\mathrm{U}}=$ Variance Covariance Matrix of the Pattern U-Functions

$\operatorname{Var}\left(\overline{\mathrm{U}}_{\text {Pattern }}{ }^{1}{ }^{\prime}\right)=$ Variance of U-Function of Pattern 'i'

$\operatorname{Cov}\left(\overline{\mathrm{U}}_{\text {Pattern' }}{ }^{\mathrm{i}}, \overline{\mathrm{U}}_{\text {Pattern' }}{ }^{\prime}\right)=$ Covariance of U-Functions of Patterns 'i' and 'j'

The variance-covariance matrix of the U-functions is a function of the contract-specific factors. Therefore, for each contract type a unique multivariate normal distribution is obtained. Figure 4.11 shows an illustration of a hypothetical 2-dimensional multivariate normal distribution of the Ufunction, corresponding to a particular contract type. Repeated random sampling of the value of Ufunction from the multivariate normal distribution of each contract type is conducted to determine the variability across the contracts of the same type to exhibit pattern 'i'. In each draw, the probability of the pattern is calculated on the basis of the randomly sampled value of the U-function. For any contract, the probability of pattern ' $\mathrm{i}$ ' in the ' $\mathrm{d}$ ' ' draw, is calculated as follows:

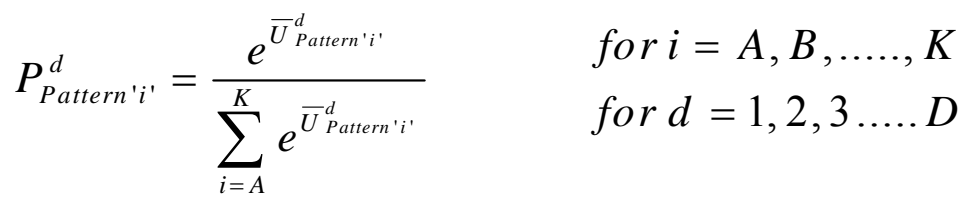

where, $\mathrm{D}=$ Total number of random draws 


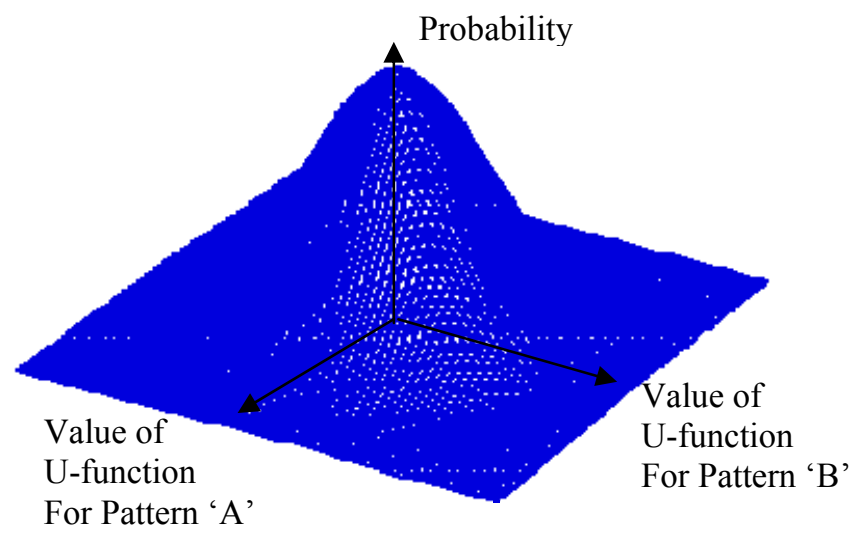

Figure 4.11: 3-Dimensional Illustration of a Multivariate Normal Distribution of the U-functions

For the given contract type, based on the 'D' draws in the Monte Carlo Simulation (MCS) process, the mean and standard deviation of the probability to exhibit pattern 'i' are calculated as:

$$
\begin{aligned}
& \mathrm{P}_{\text {Pattern } \mathrm{i}^{\mathrm{i}}}^{\mathrm{MCS}}=\frac{\sum_{d=1}^{D}\left(\mathrm{P}_{\text {Pattern 'i' }}^{\mathrm{d}}\right)}{D} \quad \text { for } \mathrm{i}=A, B, \ldots ., K \\
& \mathrm{~S}_{-} \mathrm{P}_{\text {Pattern 'i' }}^{\mathrm{MCS}}=\sqrt{\frac{\sum_{i=1}^{D}\left(\mathrm{P}_{\text {Pattern 'i' }}^{\mathrm{d}}-\mathrm{P}_{\text {Pattern 'i' }}^{\mathrm{MCS}}\right)^{2}}{D-1}}
\end{aligned}
$$

where,

$\mathrm{D}=$ Total number of draws

$\mathrm{P}_{\text {Pattern i' }}^{\mathrm{d}}=$ Probability of a contract to exhibit Pattern 'i' in ' $\mathrm{d}^{\text {th' }}$ draw

$\mathrm{P}_{\mathrm{Pattern} \mathrm{i}}^{\mathrm{MCS}}=$ Mean Probability of a contract to exhibit Pattern 'i' (MCS Based)

S_P $\mathrm{P}_{\text {Pattern } \mathrm{Mi}}^{\mathrm{MCS}}=$ Standard deviation of the probability of a contract to exhibit Pattern 'i'

The Monte Carlo Simulation (MCS) based mean probability, $P_{\text {Pattern'i' }}^{M C S}$, approaches the point estimate of the probability, $\bar{P}_{\text {Pattern'i' }}$, as the number of draws in Monte Carlo Simulation is increased. The risk associated with the probability of a contract to exhibit a pattern ' $\mathrm{i}$ ' is determined based on the variability of the probability across the ' $\mathrm{D}$ ' repeated random draws. In addition to the standard deviation, the coefficient of variation and the $95 \%$ confidence interval of the mean probability are used as measures of the variability. The $95 \%$ confidence interval of the mean probability indicates the reliability of the mean probability by specifying the interval in which the mean probability is likely to be. The coefficient of variation measures the dispersion of the true distribution of the probability of a contract type to exhibit pattern ' $i$ '. 
The coefficient of variation and the $95 \%$ confidence intervals are calculated as follows:

$$
\begin{aligned}
& \text { C.V__P Pattern 'i': S_P Pattern 'i' } / \mathrm{P}_{\text {Pattern i' }}^{\mathrm{MCS}} \\
& \text { C.I_P Pattern 'i': } \quad \mathrm{P}_{\text {Pattern } \mathrm{i}^{\prime}}^{\mathrm{MCS}} \pm\left(\mathrm{t}_{\left(1-\frac{0.95}{2}, \mathrm{D}-1\right)} \times \frac{\mathrm{S}_{-} \mathrm{P}_{\text {Pattern 'i' }}^{\mathrm{MCS}}}{\sqrt{\mathrm{D}}}\right)
\end{aligned}
$$

where,

C.V_P Patterni' ${ }^{\mathrm{MCS}}=$ Coefficient of Variation of the Probability of a contract to exhibit Pattern 'i'

C.I_ $\mathrm{P}_{\mathrm{Patterni}}^{\mathrm{MCS}}=95 \%$ Confidence Interval of the Mean Probability of a contract to exhibit Pattern 'i'

The true distribution of the probability of a particular contract type to exhibit pattern ' $\mathrm{i}$ ' is specified based on the Monte Carlo Simulation results as follows:

$$
P_{\text {Pattern'i' }} \sim N\left(\mathrm{P}_{\text {Pattern }^{\prime} \mathrm{i}^{\prime}}^{\mathrm{MCS}}, \mathrm{S} \_\mathrm{P}_{\text {Pattern 'i' }}^{\mathrm{MCS}}\right) \quad \text { for } i=A, B, \ldots . ., K
$$

b) For each of the ' $\mathrm{N}$ ' historical contracts, calculate the observed cost overrun of the final cost compared to the proposed cost (planning stage cost overrun), engineer's assessment cost (post-programming stage cost overrun), design cost (design stage cost overrun), engineer's estimate (advertisement stage cost overrun), and letting cost (letting stage cost overrun).

c) Determine the cost overrun category $(<-10 \%,-10 \%$ to $0 \%, 0 \%$ to $10 \%$, and $>10 \%)$, in which each of the ' $\mathrm{N}$ ' historical contracts lie, on the basis of each of the computed cost overrun in Step (b).

d) Tabulate the results of Steps (a), (b), and (c) for each of the ' $N$ ' historical contracts. Also, tabulate the contract-specific factors. This database will be used for calibrating the discrete choice models in this module.

e) The discrete choice modeling framework is based on the premise that given the four cost overrun categories $(<-10 \%,-10 \%$ to $0 \%, 0 \%$ to $10 \%$, and $>10 \%)$, the cost overrun of a contract is likely to lie in each of the categories with a certain probability. The probability of a contract to have a cost overrun in the cost overrun category ' $\mathrm{c}$ ' is influenced by the contract specific factors $(\mathrm{X})$ and the probability of occurrence of an escalation pattern. Mathematically, the U-function of a cost overrun category ' $c$ ' is expressed as:

$$
\begin{array}{r}
\bar{U}_{\text {Category'c' }}=f_{c}\left[X_{r}, P_{\text {Pattern'i' }}^{M C S}, S_{-} P_{\text {Pattern'i' }}^{M C S}, C . I_{-} P_{\text {Pattern'i' }}^{M C S}\right]=\sum_{a=1}^{A_{c}} \omega_{c a} Z_{c a} \\
\text { for } c=1,2,3,4
\end{array}
$$


where,

$\mathrm{i}=$ Indicates the escalation pattern of cost estimates, $\mathrm{i} \in\{\mathrm{A}, \mathrm{B}, \ldots ., \mathrm{K}\}$

$\mathrm{r}=$ Indicates the contract specific factor $\mathrm{X}, \mathrm{r} \in\{1,2, \ldots, R\}$

$\mathrm{c}=$ Indicates the Cost Overun Category, $\mathrm{c} \in\{1,2,3,4\}$

$\overline{\mathrm{U}}_{\text {Category ' } \mathrm{c}}=$ Mean Value of U-Function for cost overrun category ' $\mathrm{c}$ '

$\mathrm{X}_{\mathrm{r}}=$ Contract specific factor ' $\mathrm{r}$ '

$Z_{\mathrm{ca}}=$ Factor 'a' that significantly affects the U-Function of cost overrun category 'c'

$\omega_{\mathrm{ca}}=$ Coefficient of the factor ' $\mathrm{c}$ ' in the U-Function equation of cost overrun category 'c'

$A_{c}=$ Number of statistically significant factors in the U-Function equation of cost overrun category 'c'

f) Using the multinomial logit regression approach, identify the factors ' $Z$ ', that significantly influence the U-function of a cost overrun category. Calibrate the coefficients of each of these factors in the corresponding U-function equations using the historical contract database prepared in Step (d). Statistical software such as SAS, NLogit, and Minitab can be used for calibration. The procedure is carried out to calibrate discrete choice models corresponding to the planning stage, post-programming stage, design stage, advertisement stage, and letting stage cost overruns. The calibrated U-function equations are used to calculate the probability of each cost overrun category given the factors ' $Z$ ' corresponding to a contract. The probability of a contract to lie in cost overrun category ' $c$ ' is calculated as follows:

$$
\bar{P}_{{\text {Category' }{ }^{\prime}}^{\prime}}=\frac{e^{\bar{U}_{\text {Category'c' }}}}{\sum_{I=1}^{K} e^{\bar{U}_{\text {Category 'c' }}}} \quad \text { for } c=1,2,3,4
$$

g) Use the nested logit regression approach to calibrate the U-function equations if two or more cost overrun categories are expected to be correlated to each other. The nested logit approach accounts for the Independence of Irrelevant Alternatives (IIA) limitation of the multinomial logit approach in such a scenario. The cost overun categories are classified into one nest depending upon the common characteristics that are believed to exist between any two categories. For example, the cost overrun categories ' 1 ' (cost overrun $<-10 \%$ ) and ' 2 ' (cost overrun between $-10 \%$ and $0 \%$ ) can be nested together, as both of them represent a negative cost overrun (i.e., a cost underrun); similarly, the categories ' 3 ' (cost overrun between $0 \%$ and 10\%) and ' 4 ' (cost overrun $>10 \%$ ) as both categories represent a cost overrun. Figure 4.12 shows the schematic representation of this nesting structure. The nested logit regression approach can be used to calibrate the U-function equations using such nested 
structures. Statistical software such as SAS and Limdep can be used to test the appropriateness of the nesting structure. If the nesting structure is found to be inappropriate, it is concluded that the correlation between the nested categories is not significant and therefore the calibrated multinomial logit U-function equations (in Step (f)) are used. However, if the nesting structure is found to be significant, the calibrated multinomial logit model in Step (f) is discarded.

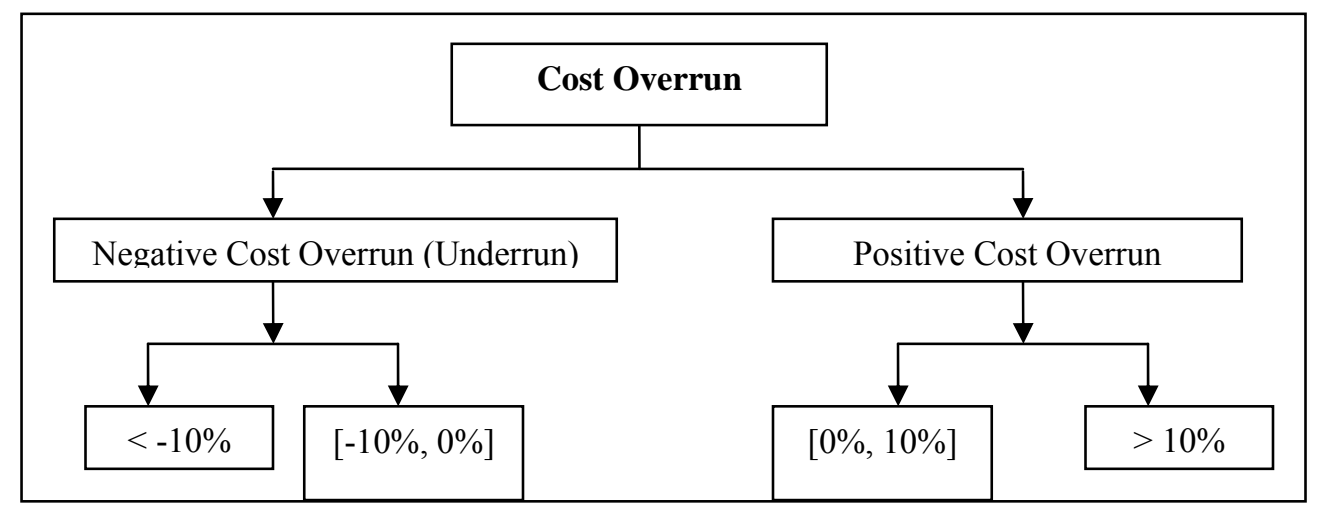

Figure 4.12: A Hypothetical Nested Structure of Cost Overrun Categories

h) Use the mixed logit regression approach for calibrating the U-function equations if the coefficients of the U-function equations are expected to vary randomly across the contracts. The multinomial logit regression approach in Step (f) assumes that the coefficients of the contract-specific factors in the Ufunction equations are the same for all the historical contracts. The validity of this assumption is tested by calibrating the U-function equations using the mixed logit approach. If the standard deviation corresponding to a coefficient that is randomly varied across the contracts is found to be significant, the mixed logit models are used to study the influence of the factors ' $Z$ ', on the probability of cost overrun. However, if the coefficients are not found to vary randomly, the multinomial logit models or nested logit models are used depending upon whichever is found appropriate in Step (g).

i) Repeat Steps (f), (h), and (i) to calibrate the discrete choice econometric models separately for each work category, contract type, or contract size. Separate models can be developed for each factor level corresponding to any contract-specific factor using the same methodology as described in Steps (d), (e), and (f). A likelihood test is conducted as described in Step (g) of Module I, to determine if 'separate' models are required by factor level or if a 'single model' for all factor levels explains the cost escalation patterns better. 


\subsubsection{Step 5.3: Development of Module III for Analyzing Severity of Cost Overrun}

Module III comprises of a set of regression models that are used to analyze the severity of overrun of the final cost compared to the proposed estimate, engineer's assessment, design estimate, engineer's estimate, and letting cost. The severity of cost overrun is measured as the expected value of the percentage overrun. The models are calibrated on the basis of the observed cost overrun corresponding to the historical contracts. The contract-specific factors and the risk of a contract to exhibit a particular cost escalation pattern (as measured using the econometric models in Module I) are used as independent variables in the model calibration. The cost estimate corresponding to which the overrun models have to be developed is selected first. The methodology presented in this section can also be used to develop models for pair-wise comparison of two cost estimates as well. The step-by-step procedure for the calibration of the econometric models in this module is as follows:

a) For all the ' $\mathrm{N}$ ' historical contracts that were used for calibrating the models in Modules $I$ and II, determine the risk of a contract to exhibit each of the ' $\mathrm{K}$ ' cost escalation patterns. The risk is calculated as described in Step (b) in the procedure for development of Module II econometric models.

b) Calculate the percentage cost overrun ( $\mathrm{Y}_{\mathrm{i}}$ : final cost vs. the selected cost estimate) for all the ' $\mathrm{N}$ ' historical contracts and then categorize the contracts by cost overrun category (as shown in Table 4.9 for Planning stage cost overrun). Also, determine the average cost overrun and the $95 \%$ confidence interval of the average cost overrun across contracts in each category.

Table 4.9: Planning Stage Cost Overrun by Cost Overrun Category

\begin{tabular}{|c|c|c|c|}
\hline \multicolumn{2}{|c|}{ Planning stage cost overrun } & Final Cost - Proposed Cost & $\%$ \\
\hline Category 1 & Category 2 & Category 3 & Category 4 \\
\hline$Y_{1}<-10 \%$ & $-10 \% \leq Y_{1}<0 \%$ & $0 \% \leq Y_{1} \leq 10 \%$ & $Y_{1}>10 \%$ \\
\hline $\begin{array}{l}\text { Average: } \\
\text { No. of Contracts: } \\
\text { C.I: }\end{array}$ & $\begin{array}{l}\text { Average: } \\
\text { No. of Contracts: } \\
\text { C.I: }\end{array}$ & $\begin{array}{l}\text { Average: } \\
\text { No. of Contracts: } \\
\text { C.I: }\end{array}$ & $\begin{array}{l}\text { Average: } \\
\text { No. of Contracts: } \\
\text { C.I: }\end{array}$ \\
\hline
\end{tabular}

C.I: Confidence Interval

c) Calibrate truncated regression models for the contracts in each cost overrun category 'c'. Truncated regression models are calibrated since contracts in each category are bounded by their respective cost overrun limits. The contract-specific factors and the risk of a contract to exhibit a particular cost escalation pattern are used as independent variables to calibrate the models.

$$
\begin{array}{lr}
E\left(Y_{i} \mid \text { Cost Overrun Category } C^{\prime}\right)=f_{c}\left[X_{r}, P_{\text {Pattern' } i^{\prime}}^{M C S}, S_{-} P_{\text {Pattern' } i^{\prime}}^{M C S}, C_{-} P_{\text {Pattern' } i^{\prime}}^{M C S}\right] \\
E\left(Y_{i} \mid \text { Cost Overrun Category }{ }^{\prime} C^{\prime}\right)=\sum_{a=1}^{A_{c}} \beta_{c a} F_{c a} & \text { for } c=1,2,3,4
\end{array}
$$


Here, $\mathrm{E}[\mid]$ represents the expected value which is obtained from the calibrated regression model.

\subsubsection{Step 6: Determining Cost Overrun Relationships}

A sensitivity analysis is conducted to determine the relationships between cost overrun at any stage with the various contract-specific factors. Each of the contract-specific factors are varied and the impact on the following is studied:

- probability that cost estimates of a contract will exhibit a particular escalation pattern (Using Module I Discrete Choice Econometric Models),

- probability that a contract will have a cost overrun less than $-10 \%$, between $-10 \%$ and $0 \%$, between $0 \%$ and 10\%, and greater than 10\% (Using Module II Discrete Choice Econometric Models),

- expected percentage cost overrun (Using Module II Discrete Choice Econometric Models and Module III Truncated Regression Models corresponding to each cost overrun category ' $c$ ').

\subsubsection{Calculating Probability of Escalation Pattern}

The probability of occurrence of an escalation pattern is estimated using the econometric models in Module I. Given a specific contract type, a Monte Carlo simulation is conducted as described in Section 4.2.5.2.

\subsubsection{Calculating Probability of Cost Overrun Categories}

The calibrated discrete choice models in Module II, regardless of whether they are multinomial logit (Step (f)), nested logit (Step (g)), or mixed logit (Step (h)) involve the use of the contract-specific factors and the risk associated with occurrence of a cost escalation pattern (from Module I) as independent variables. These variables are used to predict a point estimate of the probability of cost overrun for a particular contract type. The contract-specific factors such as district, area, size, work category, route, and functional class define a category of contract types instead of identifying a specific contract. The predicted point estimate of the probability of cost overrun (based on the contract-specific factors) is therefore an estimate of the average probability across all the contracts that fit the specified type. Because each contract is unique, probability of cost overrun may vary across the contracts of the same type. Therefore, there is a risk associated in using the same deterministic point estimate of the probability across all the contracts of a particular type. In order to account for the risk, the standard deviation and the $95 \%$ confidence interval of the probability of cost 
overrun are determined using Monte Carlo Simulation (MCS). Repeated random sampling of the model coefficients from a multivariate normal distribution is carried out in Monte Carlo Simulation. The multivariate normal distribution of the calibrated coefficients is expressed as:

$$
\bar{\omega} \sim N\left(\omega, \Sigma_{\omega}\right)
$$

where, $\omega=$ Parameter vector comprising of coefficients of Module II econometric models

The parameter vector and the variance-covariance matrix corresponding to Module II U-function equations are specified as:

$$
\vec{\omega}=\left[\begin{array}{l}
\omega_{11} \\
\cdot \\
\omega_{c r} \\
\cdot \\
\omega_{4 R_{4}}
\end{array}\right] \quad \Sigma_{\omega}=\left[\begin{array}{ccccc}
\operatorname{Var}\left(\omega_{11}\right) & \cdot & \operatorname{Cov}\left(\omega_{11}, \omega_{c r}\right) & \cdot & \operatorname{Cov}\left(\omega_{11}, \omega_{4 R_{4}}\right) \\
\cdot & \cdot & \cdot & \cdot & . \\
\operatorname{Cov}\left(\omega_{c r}, \omega_{11}\right) & \cdot & \operatorname{Var}\left(\omega_{c r}\right) & \cdot & \operatorname{Cov}\left(\omega_{c r}, \omega_{4 R_{4}}\right) \\
\cdot & \cdot & \cdot & \cdot & \cdot \\
\operatorname{Cov}\left(\omega_{4 R_{4}}, \omega_{11}\right) & \cdot & \operatorname{Cov}\left(\omega_{4 R_{4}}, \omega_{c r}\right) & \cdot & \operatorname{Var}\left(\omega_{4 R_{4}}\right)
\end{array}\right]
$$

where,

$$
\begin{aligned}
& \omega_{\mathrm{cr}}=\text { Calibrated coefficient of factor ' } r \text { ' in the U-function of cost overrun category 'c' } \\
& \omega=\text { Mean vector comprising of the calibrated model coefficients } \\
& \Sigma_{\omega}=\text { Variance Covariance Matrix of the model coeffcients } \\
& \operatorname{Var}\left(\omega_{\mathrm{cr}}\right)=\text { Variance of the coefficient ' } \omega_{\mathrm{cr}}{ }^{\prime} \\
& \operatorname{Cov}\left(\omega_{\mathrm{cr}}, \omega_{11}\right)=\text { Covariance of the coefficients ' } \omega_{\mathrm{cr}}{ }^{\prime} \text { and ' } \omega_{11}{ }^{\prime}
\end{aligned}
$$

The calibrated coefficients of the U-function equations in steps (f), (g), and (h) are used to construct the mean vector $\omega$. The variance-covariance matrix $\left(\Sigma_{\omega}\right)$ of the coefficients is obtained from the software that is used to calibrate the models. For each contract type, repeated random sampling of the coefficients is done from the multivariate normal distribution of the coefficients. Based on the value of the coefficients in each draw, the point estimate of the U-function of each cost overrun category is calculated, and consequently the probability of the contract to have a cost overrun in that category is determined. Because the number of coefficients in the developed discrete choice models is likely to be high, the dimension of the multivariate normal distribution of the coefficients is large. Repeated random sampling from such a distribution takes a lot of computation time. For multinomial logit models, the dimensionality reduction technique (Hsu and Wilcox, 2000) is used as discussed in Section 4.3.1.2. The variancecovariance matrix of the U-functions corresponding to cost overrun categories is calculated from the variance-covariance matrix of the model coefficients $\left(\Sigma_{\omega}\right)$, and the factors $(Z)$ that affect the U-functions. The calculations are carried out as follows: 


$$
\begin{aligned}
& \operatorname{Var}\left(U_{\text {Category'c }^{\prime}}\right)=\sum_{r=1}^{A_{c}} Z_{r c}^{2} \operatorname{Var}\left(\omega_{c r}\right)+2 \times \sum_{r=1}^{A_{c}} \sum_{r^{\prime}<r}^{A_{c}} Z_{r c} Z_{r^{\prime} c} \operatorname{Cov}\left(\omega_{c r}, \omega_{c r^{\prime}}\right) \\
& \operatorname{Cov}\left(U_{\text {Category 'i' }^{\prime},} U_{{\text {Category } j^{\prime}}^{\prime}}\right)=\sum_{r=1}^{A_{i}} \sum_{r^{\prime}=1}^{A_{j}} Z_{r i} Z_{r^{\prime} j} \operatorname{Cov}\left(\omega_{i r}, \omega_{j r^{\prime}}\right)
\end{aligned}
$$

Based on the calculated point estimates, variances, and covariances the multivariate normal distribution of the utilities corresponding to the cost overrun categories is specified as:

$$
\begin{aligned}
& U \sim N\left(\bar{U}, \Sigma_{U}\right) \\
& \bar{U}=\left[\begin{array}{l}
\bar{U}_{\text {Category'1' }} \\
\bar{U}_{\text {Category'2' }} \\
\bar{U}_{\text {Category' } 3^{\prime}} \\
\bar{U}_{\text {Category'4' }}
\end{array}\right]
\end{aligned}
$$

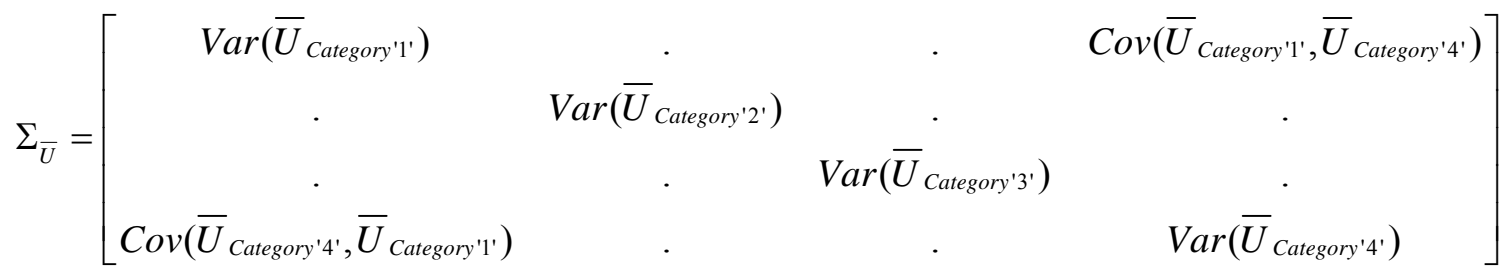

where,

$$
\begin{aligned}
& \bar{U}=\text { Mean Vector comprising of the point estimates of the pattern utilities } \\
& \sum_{\mathrm{U}}=\text { Variance Covariance Matrix of the pattern utilities } \\
& \operatorname{Var}\left(\overline{\mathrm{U}}_{\text {Category'c' }}\right)=\text { Variance of the Utility of Cost Overrun Category 'c' } \\
& \operatorname{Cov}\left(\overline{\mathrm{U}}_{\text {Categoryi' }}, \overline{\mathrm{U}}_{\text {Category }}\right)=\text { Covariance of the Utility of Cost Overrun Categories 'i' and 'j' }
\end{aligned}
$$

The U-functions of the cost overrun categories also follow a multivariate normal distribution similar to the U-function of the pattern probabilities. Monte Carlo simulation is conducted to randomly draw the value of the U-Functions from the multivariate normal distribution and determine the probability of cost overrun in each draw. For any contract, the probability of cost overrun being in category ' $c$ ', in the ' $\mathrm{d}^{\text {th, }}$ draw, is calculated as follows:

$$
P_{\text {Category 'c' }}^{d}=\frac{e^{U_{\text {Category 'c' }}^{d}}}{\sum_{c=1}^{4} e^{U_{\text {Category'c' }}^{d}}} \quad \text { for } c=1,2,3,4
$$

For the given contract type, based on the ' $D$ ' draws in the Monte Carlo Simulation (MCS) process, the mean and standard deviation of the probability of cost overrun being in category ' $c$ ' are calculated as: 


$$
\begin{array}{r}
\mathrm{P}_{\text {Category 'c' }}^{\mathrm{MCS}}=\frac{\sum_{d=1}^{D}\left(\mathrm{P}_{\text {Category' } \mathrm{c}^{\mathrm{c}}}^{\mathrm{d}}\right)}{D} \quad \text { for } \mathrm{C}=1,2, \ldots, 4 \\
\mathrm{~S}_{-} \mathrm{P}_{\text {Category } \mathrm{c}^{\prime}}^{\mathrm{MCS}}=\sqrt{\frac{\sum_{c=1}^{D}\left(\mathrm{P}_{\text {Category } \mathrm{c}^{\prime}}^{\mathrm{d}}-\mathrm{P}_{\text {Category'i' }}^{\mathrm{MCS}}\right)^{2}}{D-1}}
\end{array}
$$

where,

$\mathrm{D}=$ Total number of draws

$\mathrm{P}_{\text {Category'c' }}^{\mathrm{d}}=$ Probability of a contract to be in Cost Overrun Category ' $\mathrm{c}^{\prime}$ in ' $\mathrm{d}^{\text {th' }}$ draw

$\mathrm{P}_{\text {Category'c' }}^{\mathrm{MCS}}=$ Mean Probability of a contract to be in Cost Overrrun Category 'c' (MCS Based)

S_P $\mathrm{P}_{\text {Category'c' }}^{\mathrm{MCS}}=$ Standard deviation of the probability of a contract to be in Cost Overrun Category 'c' (MCS Based)

As the number of draws in Monte Carlo Simulation (MCS) are increased, the simulation-based mean probability, $P_{\text {Category'c' }}^{M C S}$, approaches the point estimate of the probability, $\bar{P}_{\text {Category'c', that was }}$ calculated using the calibrated models. The risk involved in associating a contract with a certain cost overrun category is assessed by calculating the variability of its probability to belong to cost overrun category ' $c$ '. The variability can be studied using standard deviation, coefficient of variation, or the $95 \%$ confidence interval of the mean probability $P_{\text {Category'c' }}^{M C S}$, as in Module $I$. The calculations are carried out as follows:

$$
\begin{aligned}
& \mathrm{C} . \mathrm{V}_{-} \mathrm{P}_{\text {Category 'c' }}^{\mathrm{MCS}}: \mathrm{S} \mathrm{P}_{\text {Category' 'c' }}^{\mathrm{MCS}} / \mathrm{P}_{\text {Category 'c' }}^{\mathrm{MCS}} \\
& \text { C.I_P } \mathrm{P}_{\text {Category 'c' }}^{\mathrm{MCS}}: \quad \mathrm{P}_{\text {Category 'c' }}^{\mathrm{MCS}} \pm\left(\mathrm{t}_{\left(1-\frac{0.95}{2}, \mathrm{D}-1\right)} \times \frac{\mathrm{S}_{-} \mathrm{P}_{\text {Category'c' }}^{\mathrm{MCS}}}{\sqrt{\mathrm{D}}}\right)
\end{aligned}
$$

where,

$$
\begin{aligned}
\text { C.V__ } & \mathrm{P}_{\text {Category }}^{\mathrm{MCS}}= \\
& \text { Coefficient of Variation of the Mean Probability of a contract } \\
& \text { to be in Cost Overrun Category 'c' (Based on MCS) } \\
\text { C.I_P } \mathrm{P}_{\text {Category 'c' }}^{\mathrm{MCS}}= & 95 \% \text { Confidence Interval of the Mean Probability of a contract } \\
& \text { to be in Cost Overrun Category 'c' (Based on MCS) }
\end{aligned}
$$

The true distribution of the probability of a particular contract type to be in cost overrun category ' $c$ ' is determined based on the Monte Carlo Simulation results as follows:

$$
P_{\text {Category'c' }} \sim N\left(\mathrm{P}_{\text {Category'c' }}^{\mathrm{MCS}}, \mathrm{S} \_\mathrm{P}_{\text {Category'c' }}^{\mathrm{MCS}}\right) \quad \text { for } c=1,2,3,4
$$


The expected percentage cost overrun, for any contract type, is calculated as follows:

1) Expected Value of Cost Overrun $\left(Y_{i}\right)$ given the contract type has cost overrun in category ' $c$ ' and

2) Probability that the contract will have cost overrun in category ' $c$ '.

Because the coefficients of the models in Modules II and III are normally distributed, a Monte Carlo simulation is done to randomly draw coefficients corresponding to each of these models from their respective distributions. The coefficients drawn in each draw ' $d$ ' are used to calculate:

$$
\begin{aligned}
& \mathrm{E}^{\mathrm{d}}\left(\mathrm{Y}_{\mathrm{i}} \mid \text { Cost Overrun Category 'c') }=\left[\begin{array}{l}
\text { Expected Value of Cost Overrun }\left(\mathrm{Y}_{\mathrm{i}}\right) \\
\text { given the contract type has } \\
\text { cost overrun in category ' } \mathrm{c} \text { ' }
\end{array}\right]\right. \\
& \mathrm{P}_{\text {Category'c' }}^{\mathrm{d}}=\left[\begin{array}{l}
\text { Probability that the contract will } \\
\text { have cost overrun in category 'c', }
\end{array}\right]
\end{aligned}
$$

Bayes' probability principle is then used to calculate the expected value of the percentage overrun $\left(\mathrm{Y}_{\mathrm{i}}\right)$, in each draw ' $d$ ', as follows:

$$
E^{d}\left(Y_{i}\right)=\left[\sum_{c=1}^{4} E^{d}\left(Y_{i} \mid \text { Cost Overrun Category' 'c ' }\right) \times \mathrm{P}_{\text {Category'c' }}^{\mathrm{d}}\right]
$$

The procedure for random sampling of the regression model coefficients is the same as the procedure that was used for random sampling of the discrete choice model coefficients.

The information on the three modules comprising the risk-based econometric analysis framework that are used to study the cost overrun relationships is summarized in Table 4.10. 


\begin{tabular}{|c|c|c|c|}
\hline $\begin{array}{l}\text { MODULE - } \\
\text { OBJECTIVE }\end{array}$ & ANALYZE & OUTPUT & $\begin{array}{c}\text { ECONOMETRIC } \\
\text { MODEL }\end{array}$ \\
\hline $\begin{array}{l}\text { Module I- } \\
\text { Determine } \\
\text { Probability of Cost } \\
\text { Escalation Pattern } \\
\text { Based on } \\
\text { a) Contract specific } \\
\text { factors }\end{array}$ & $\begin{array}{l}\text { Escalation Pattern } \\
\text { of Cost Estimates }\end{array}$ & $\begin{array}{l}\text { Output: } \\
\text { (a) Probability of a contract exhibiting } \\
\text { a particular cost escalation pattern } \\
\text { (b) Standard deviation \& } 95 \% \\
\text { Confidence Interval of the probability }\end{array}$ & $\begin{array}{l}\text { Discrete Choice } \\
\text { Logit Models }\end{array}$ \\
\hline $\begin{array}{l}\text { Module II - } \\
\text { Determine } \\
\text { Probability of Cost } \\
\text { Overrun in each Overrun }\end{array}$ & $\begin{array}{l}\text { Planning stage } \\
\text { cost overrun } \\
\left(\mathrm{Y}_{1}\right)\end{array}$ & $\begin{array}{l}\text { Probability }\left(\mathrm{Y}_{1}<-10 \%\right) \\
\text { Probability }\left(-10 \% \leq \mathrm{Y}_{1}<0 \%\right) \\
\text { Probability }\left(0 \% \leq \mathrm{Y}_{1} \leq 10 \%\right) \\
\text { Probability }\left(\mathrm{Y}_{1}>10 \%\right)\end{array}$ & $\begin{array}{l}\text { Discrete Choice } \\
\text { Logit Models }\end{array}$ \\
\hline
\end{tabular}




\begin{tabular}{|c|c|c|}
\hline $\begin{array}{l}\text { Category } \\
\text { Based on } \\
\text { a) Contract specific } \\
\text { factors and. }\end{array}$ & $\begin{array}{l}\text { Post-Programming } \\
\text { Stage Cost } \\
\text { Overrun } \\
\left(\mathrm{Y}_{2}\right)\end{array}$ & $\begin{array}{l}\text { Probability }\left(\mathrm{Y}_{2}<-10 \%\right) \\
\text { Probability }\left(-10 \% \leq \mathrm{Y}_{2}<0 \%\right) \\
\text { Probability }\left(0 \% \leq \mathrm{Y}_{2} \leq 10 \%\right) \\
\text { Probability }\left(\mathrm{Y}_{2}>10 \%\right)\end{array}$ \\
\hline $\begin{array}{l}\text { b) Probability of Cost } \\
\text { Escalation Pattern } \\
\text { (from Module 1) and, } \\
\text { c) Variability (Standard }\end{array}$ & $\begin{array}{l}\text { Design Stage Cost } \\
\text { Overrun } \\
\left(\mathrm{Y}_{3}\right)\end{array}$ & $\begin{array}{l}\text { Probability }\left(\mathrm{Y}_{3}<-10 \%\right) \\
\text { Probability }\left(-10 \% \leq \mathrm{Y}_{3}<0 \%\right) \\
\text { Probability }\left(0 \% \leq \mathrm{Y}_{3} \leq 10 \%\right) \\
\text { Probability }\left(\mathrm{Y}_{3}>10 \%\right)\end{array}$ \\
\hline $\begin{array}{l}\text { Deviation) in } \\
\text { Probability of } \backslash \text { Cost } \\
\text { Escalation Pattern }\end{array}$ & $\begin{array}{l}\text { Advertisement } \\
\text { Stage Cost } \\
\text { Overrun } \\
\left(\mathrm{Y}_{4}\right)\end{array}$ & $\begin{array}{l}\text { Probability }\left(\mathrm{Y}_{4}<-10 \%\right) \\
\text { Probability }\left(-10 \% \leq \mathrm{Y}_{4}<0 \%\right) \\
\text { Probability }\left(0 \% \leq \mathrm{Y}_{4} \leq 10 \%\right) \\
\text { Probability }\left(\mathrm{Y}_{4}>10 \%\right)\end{array}$ \\
\hline & $\begin{array}{l}\text { Letting Stage Cost } \\
\text { Overrun } \\
\left(\mathrm{Y}_{5}\right)\end{array}$ & $\begin{array}{l}\text { Probability }\left(\mathrm{Y}_{5}<-10 \%\right) \\
\text { Probability }\left(-10 \% \leq \mathrm{Y}_{5}<0 \%\right) \\
\text { Probability }\left(0 \% \leq \mathrm{Y}_{5} \leq 10 \%\right) \\
\text { Probability }\left(\mathrm{Y}_{5}>10 \%\right)\end{array}$ \\
\hline
\end{tabular}

Table 4.10: Risk-Based Econometric Analysis Framework for Analysis of Cost Overrun

\subsection{Chapter Summary}

In this chapter, a methodology for analyzing cost overrun was presented for: a) comprehensively studying the accuracy of the various cost estimates that are prepared during the planning and development phase based on data from historical contracts and b) developing an econometric analysis framework comprising of statistical models to determine the influence of contract-specific factors on the probability and the expected percentage overrun of the final cost. The models in the developed framework can also be used to predict the probability and the expected value of cost overrun at various stages of project development, on

\begin{tabular}{|c|c|c|c|}
\hline $\begin{array}{l}\text { Module III - } \\
\text { Determine } \\
\text { Percentage Overrun of } \\
\text { Final Cost over the Cost } \\
\text { Estimate }\end{array}$ & $\begin{array}{l}\text { Planning stage } \\
\text { cost overrun } \\
\left(\mathrm{Y}_{1}\right)\end{array}$ & $\begin{array}{l}\text { Expected }\left(\mathrm{Y}_{1} \mid \mathrm{Y}_{1}<-10 \%\right) \\
\text { Expected }\left(\mathrm{Y}_{1} \mid-10 \% \leq \mathrm{Y}_{1}<0 \%\right) \\
\text { Expected }\left(\mathrm{Y}_{1} \mid 0 \% \leq \mathrm{Y}_{1} \leq 10 \%\right) \\
\text { Expected }\left(\mathrm{Y}_{1} \mid \mathrm{Y}_{1}>10 \%\right)\end{array}$ & \multirow{5}{*}{$\begin{array}{l}\text { Truncated } \\
\text { Regression Models } \\
\text { or } \\
\text { Average Percentage } \\
\text { Overrun Values } \\
\text { corresponding to } \\
\text { each overrun } \\
\text { category }\end{array}$} \\
\hline \multirow{4}{*}{$\begin{array}{l}\text { Based on } \\
\text { a) Contract specific } \\
\text { factors and, } \\
\text { d) Probability of Cost } \\
\text { Escalation Pattern } \\
\text { (from Module 1) and, } \\
\text { e) Variability (Standard } \\
\text { Deviation) in } \\
\text { Probability of } \backslash \text { Cost } \\
\text { Escalation Pattern }\end{array}$} & $\begin{array}{l}\text { Post-Programming } \\
\text { Stage Cost } \\
\text { Overrun } \\
\left(\mathrm{Y}_{2}\right) \\
\end{array}$ & $\begin{array}{l}\text { Expected }\left(\mathrm{Y}_{2} \mid \mathrm{Y}_{2}<-10 \%\right) \\
\text { Expected }\left(\mathrm{Y}_{2} \mid-10 \% \leq \mathrm{Y}_{2}<0 \%\right) \\
\text { Expected }\left(\mathrm{Y}_{2} \mid 0 \% \leq \mathrm{Y}_{2} \leq 10 \%\right) \\
\text { Expected }\left(\mathrm{Y}_{2} \mid \mathrm{Y}_{2}>10 \%\right)\end{array}$ & \\
\hline & $\begin{array}{l}\text { Design Stage Cost } \\
\text { Overrun } \\
\left(\mathrm{Y}_{3}\right)\end{array}$ & $\begin{array}{l}\text { Expected }\left(\mathrm{Y}_{3} \mid \mathrm{Y}_{3}<-10 \%\right) \\
\text { Expected }\left(\mathrm{Y}_{3} \mid-10 \% \leq \mathrm{Y}_{3}<0 \%\right) \\
\text { Expected }\left(\mathrm{Y}_{3} \mid 0 \% \leq \mathrm{Y}_{3} \leq 10 \%\right) \\
\text { Expected }\left(\mathrm{Y}_{3} \mid \mathrm{Y}_{3}>10 \%\right)\end{array}$ & \\
\hline & $\begin{array}{l}\text { Advertisement } \\
\text { Stage Cost } \\
\text { Overrun } \\
\left(\mathrm{Y}_{4}\right) \\
\end{array}$ & $\begin{array}{l}\text { Expected }\left(\mathrm{Y}_{4} \mid \mathrm{Y}_{4}<-10 \%\right) \\
\text { Expected }\left(\mathrm{Y}_{4} \mid-10 \% \leq \mathrm{Y}_{4}<0 \%\right) \\
\text { Expected }\left(\mathrm{Y}_{4} \mid 0 \% \leq \mathrm{Y}_{4} \leq 10 \%\right) \\
\text { Expected }\left(\mathrm{Y}_{4} \mid \mathrm{Y}_{4}>10 \%\right)\end{array}$ & \\
\hline & $\begin{array}{l}\text { Letting Stage Cost } \\
\text { Overrun } \\
\left(\mathrm{Y}_{5}\right) \\
\end{array}$ & 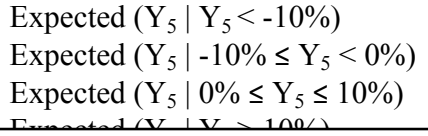 & \\
\hline
\end{tabular}


the premise that the predictive capability (which is a function of the contract-specific factors that are used for calibration of models) of the framework is appropriate.

The econometric framework developed using the proposed methodology has two distinct features. First, the framework is risk-based. The econometric models use probability distribution function of random variables that characterize the cost overrun to determine the probability of cost overrun and the expected value of cost overrun. The use of random variables as independent variables for the calibration of models is a rare and unique approach. Second, the methodology acknowledges that the calibrated model coefficients are randomly distributed and takes the randomness into consideration by conducting a Monte-Carlo simulation to randomly draw the calibrated coefficients from their respective distributions, and analyze cost overrun. 


\section{CHAPTER 5. DESCRIPTIVE ANALYSIS OF COST OVERRUN IN INDIANA}

\subsection{Introduction}

This chapter presents a comprehensive numerical analysis of cost overrun in the state of Indiana. Cost data was obtained for 419 contracts from the Management Information Portal of the Indiana Department of Transportation. The data came from a period of 1990 through 2005 during which the project was initiated and completed. All these contracts included those with a proposed cost of $\$ 1$ million or more for which consistent data was available from the planning to the completion stage. Other data that were collected include contract-specific characteristics that are available to planners at the planning stage such as district, route type, work category, area type, highway functional class, NHS status, and contract size and type. Section 5.2 describes the dataset. Section 5.3 presents an analysis of the overrun (and underrun) of the final construction cost compared to the estimates prepared during the project development phase. Section 5.4 presents an analysis of the escalation pattern of the cost estimates in current dollars over the cycle of project development.

In order to analyze the impact of inflation, information on the dates corresponding to proposed cost, design cost, letting cost, and the final construction cost was also extracted from the Information Management Portal. The estimates prepared during the project development stages were inflated to the year when the final construction cost was borne and a comparative analysis of the inflated estimate and the final

construction cost was done. The results of this analysis are shown in Section 5.5. The methodology discussed in Chapter 4 was used for the analysis.

\subsection{Dataset Description}

The distribution of the 419 contracts by route type, work category, area type, highway functional class, NHS status, contract size, and contract type are shown in Table 5.1. The 419 contracts that were analyzed in the present study comprised 270 stand-alone contracts and 149 kin contracts. The contracts were approximately uniformly distributed across the six districts in Indiana as follows: Crawfordsville (66), Fort Wayne (67), Greenfield (71), Laporte (74), Seymour (73), and Vincennes (68). The 419 contracts comprised of 71 Interstate contracts, 139 U.S. Road contracts, and 209 State Road contracts. 
Table 5.1: Distribution of the 419 Contracts in the Sample Set

\begin{tabular}{|c|c|c|c|}
\hline No. & Factor & Factor Levels & $\begin{array}{l}\text { Number of } \\
\text { Contracts }\end{array}$ \\
\hline \multirow{6}{*}{1} & \multirow{6}{*}{ District } & Crawfordsville & 66 \\
\hline & & Fort Wayne & 67 \\
\hline & & Greenfield & 71 \\
\hline & & Laporte & 74 \\
\hline & & Seymour & 73 \\
\hline & & Vincennes & 68 \\
\hline \multirow{3}{*}{2} & \multirow{3}{*}{ Route Type } & Interstate (I) & 71 \\
\hline & & U.S. Roads (U.S.) & 139 \\
\hline & & State Roads (SR) & 209 \\
\hline \multirow{3}{*}{3} & \multirow{3}{*}{ Work Category } & Expansion Contracts & 73 \\
\hline & & Bridge Contracts & 107 \\
\hline & & Pavement Contracts & 239 \\
\hline \multirow{2}{*}{4} & \multirow{2}{*}{ Area Type } & Urban Area & 136 \\
\hline & & Rural Area & 283 \\
\hline \multirow{6}{*}{5} & \multirow{6}{*}{$\begin{array}{l}\text { Highway } \\
\text { Functional Class }\end{array}$} & Rural Interstate & 31 \\
\hline & & Rural Principal Arterial & 90 \\
\hline & & Rural Minor Arterial & 61 \\
\hline & & $\begin{array}{l}\text { Rural Major Collector } \\
\text { Rural Minor Collector / Rural Local Road }\end{array}$ & 101 \\
\hline & & $\begin{array}{l}\text { Urban Interstate } \\
\text { Urban Freeways and Expressways }\end{array}$ & 52 \\
\hline & & $\begin{array}{l}\text { Urban Other Principal Arterial } \\
\text { Urban Minor Arterial Street } \\
\text { Urban Collector Street } \\
\end{array}$ & 84 \\
\hline \multirow{3}{*}{6} & \multirow{3}{*}{ NHS Status } & Interstate & 71 \\
\hline & & Non-Interstate NHS & 112 \\
\hline & & Non-NHS & 236 \\
\hline \multirow{4}{*}{7} & \multirow{4}{*}{$\begin{array}{l}\text { Contract Size } \\
\text { (Based on } \\
\text { Proposed Cost) }\end{array}$} & $\$ 1$ Million to $\$ 2$ Million & 190 \\
\hline & & $\$ 2$ Million to $\$ 5$ Million & 138 \\
\hline & & $\$ 5$ Million to $\$ 10$ Million & 53 \\
\hline & & $>\$ 10$ Million & 38 \\
\hline \multirow{2}{*}{8} & \multirow{2}{*}{ Contract Type } & Kin Contract (Projects lumped together) & 149 \\
\hline & & Standalone Contract (Only One Project) & 270 \\
\hline
\end{tabular}


The work categories represented include: added travel lanes, new road construction, interchange modification, bridge rehabilitation, replacement or removal, and major pavement projects (Table 5.2). Contracts were grouped by work category. Major pavement contracts, district pavement contracts, and road reconstruction contracts comprised the pavement contracts category. Bridge replacement, rehabilitation, and removal contracts comprised the bridge contracts category. Also, added travel lanes, new road construction, and interchange modification contracts comprised the expansion work contracts category. The 419 contracts comprised of 73 expansion contracts, 107 bridge contracts, and 239 pavement contracts.

Table 5.2: Classification and Distribution of 419 Contracts by Work Category

\begin{tabular}{|c|c|c|c|}
\hline $\begin{array}{c}\text { Work } \\
\text { Category }\end{array}$ & Work Category Description & $\begin{array}{c}\text { No. of } \\
\text { Contracts }\end{array}$ & $\begin{array}{c}\text { Total No. of } \\
\text { Contracts }\end{array}$ \\
\hline \multirow{3}{*}{$\begin{array}{l}\text { Expansion } \\
\text { Contracts }\end{array}$} & Added Travel Lanes & 35 & \multirow{3}{*}{73} \\
\hline & New Road Construction or Road Construction & 30 & \\
\hline & Interchange Modification or New Interchange & 8 & \\
\hline \multirow{6}{*}{$\begin{array}{l}\text { Bridge } \\
\text { Contracts }\end{array}$} & Bridge Rehabilitation - Historical & 24 & \multirow{6}{*}{107} \\
\hline & Bridge Replacement - Historical & 27 & \\
\hline & District Bridge (Rehabilitation) & 30 & \\
\hline & District Bridge (Removal) & 23 & \\
\hline & District Bridge (Replacement) & 2 & \\
\hline & Major Bridge (New Bridge/Grade Separation) & 1 & \\
\hline \multirow{5}{*}{$\begin{array}{l}\text { Pavement } \\
\text { Contracts }\end{array}$} & District Pavement (Non-I) & 167 & \multirow{5}{*}{239} \\
\hline & Major Pavement (Interstate) & 32 & \\
\hline & Major Pavement (NHS) & 4 & \\
\hline & Major Pavement (Non-NHS) & 29 & \\
\hline & Road Reconstruction & 7 & \\
\hline
\end{tabular}

The 419 contracts comprised 136 and 283 contracts from urban and rural areas, respectively. The distribution by highway functional class shows that 151 contracts were implemented on rural principal and minor arterials, 101 contracts on rural major/minor collector and rural local roads, 84 contracts on urban principal and minor arterials, 52 contracts on urban Interstates, freeways and expressways, and 31 contracts on rural Interstates. The distribution of contracts by NHS status shows that 71 contracts were implemented on the Interstate system, 112 contracts on the Non-Interstate NHS system, and 236 contracts on the NonNHS system. The size of a contract was determined on the basis of the proposed cost of the contract at the planning stage. Four categories of contract size were defined:
a) Category 1: proposed cost in between $\$ 1-\$ 2$ million (190 contracts),
b) Category 2: proposed cost in between $\$ 2-\$ 5$ million (138 contracts),
c) Category 3: proposed cost in between $\$ 5-\$ 10$ million (53 contracts), and
d) Category 4: proposed cost greater than $\$ 10$ million (38 contracts). 
Contracts were analyzed first by work category, then by contract size, contract type, route type, and area type. Table 5.3 shows the distribution of the contracts by these distributions. The distribution of the contracts by work category and contract size indicates that over $50 \%$ of the pavement contracts (122 of 239 ) and bridge contracts (64 of 107) have a proposed cost in between $\$ 1-\$ 2$ million. Approximately $87 \%$ of the pavement contracts and $95 \%$ of the bridge contracts had proposed costs less than $\$ 5$ million. There were no bridge contracts with over $\$ 10$ million proposed costs and only $6 \%$ of the pavement contracts had a proposed cost worth over $\$ 10$ million. On the contrary, 75\% (55 of 73) of the expansion contracts had a proposed cost greater than $\$ 5$ million and 33\% (24 of 73) had a proposed cost greater than $\$ 10$ million.

The distribution of the 419 contracts by work category and contract type is also shown in Table 5.3. Approximately $90 \%$ (65 of 73 ) of the expansion contracts were kin contracts, whereas only $28 \%$ ( 30 of 107) bridge contracts, and 23\% (54 of 239) of pavement contracts were kin contracts. That is, expansion projects were generally let as a group of projects (in each contract), whereas most pavement and bridge contracts were let as stand-alone contracts.

The distribution of the 419 contracts by work category and route type (Table 5.3) indicates a similar trend across all three work categories: the number of State Road contracts exceeds that of U.S. roads which in turn exceeds the number of Interstate contracts. In spite of this trend, the distribution of expansion contracts across the three route types is approximately uniform. However, only 17\% (18 of 107) of the bridge contracts and only 13\% (32 of 239) of the pavement contracts were implemented on Interstates. More than $50 \%$ of the pavement contracts in the dataset were implemented on state roads. The number of bridge contracts on U.S. roads only marginally exceeds that on State Roads. Approximately $70 \%$ (141 of 209) of the contracts on State Roads were pavement contracts, whereas the percentage of pavement contracts on U.S. roads is $47 \%$ (66 of 139), and on Interstates is $45 \%$ (32 of 71 ).

The distribution of the 419 contracts by work category and area type (Table 5.3) shows that approximately $78 \%$ (187 of 239) of the pavement contracts were implemented in the rural areas; in the rural areas the corresponding percentages of bridge and expansion contracts were $64 \%$ and $38 \%$, respectively. Most of the expansion contracts $(62 \%$, or 45 of 73$)$ in the database were implemented in urban areas. Approximately 66\% (187 of 283) of the contracts implemented in rural areas were pavement contracts. On the other hand, the distribution of contracts in the urban areas was approximately uniform with $38 \%$ (52 of 136) pavement contracts, $33 \%$ ( 45 of 136) expansion contracts, and $29 \%$ (39 of 136) bridge contracts. 
Table 5.3: Distribution of Contracts in each Work Category by Size, Area, Route, and Contract Type

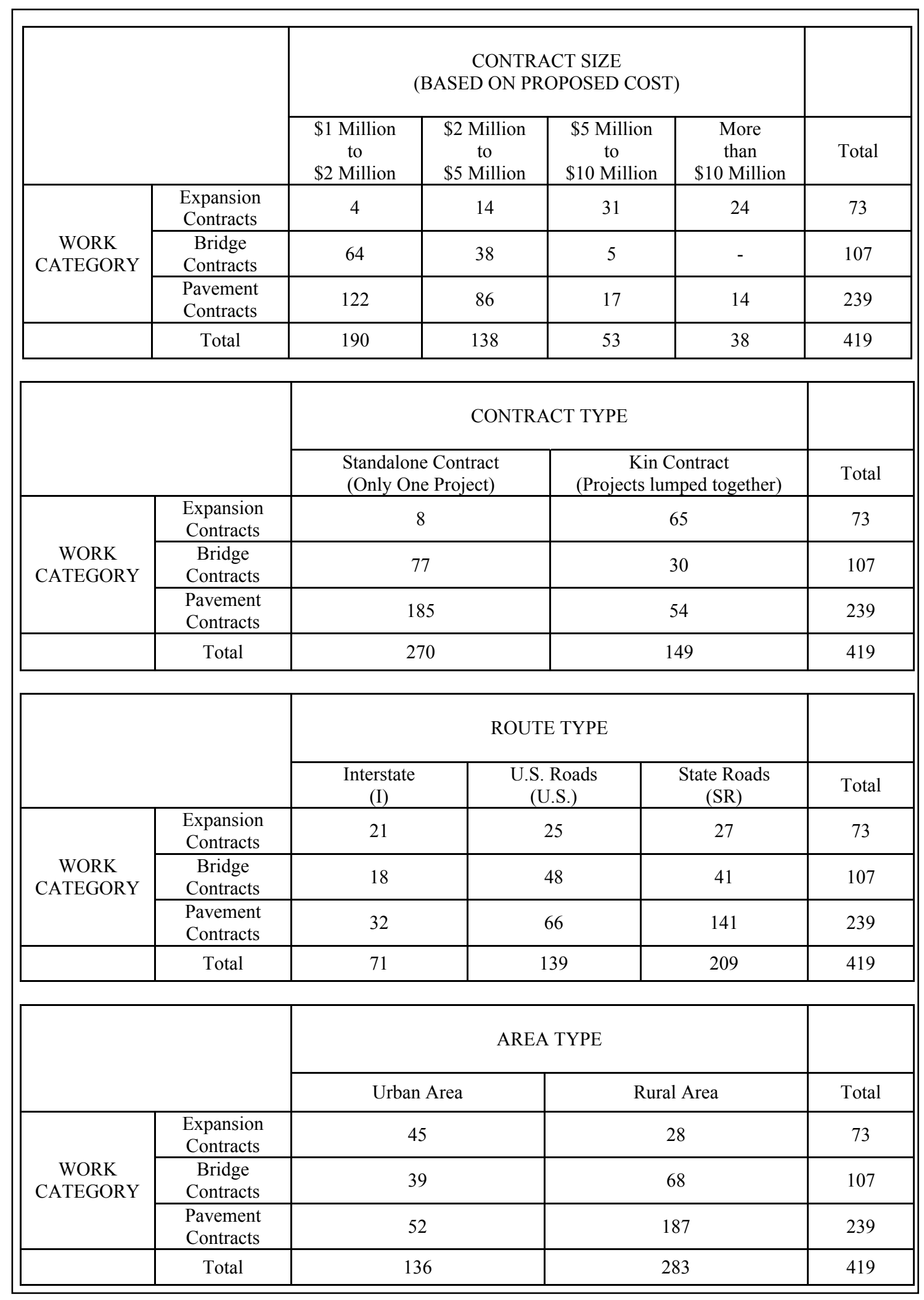


The size of a contract often plays an important role in the decision-making process. In the present study, the size of a contract was determined on the basis of the proposed cost of the contract. Most (190 of 419 ) of the contracts were in the \$1-\$2 million category. Thirty-eight of the 419 contracts had a proposed cost greater than $\$ 10$ million. The distribution of the 419 contracts in the database, by contract size and area type, by contract size and route type, and by contract size and contract type is shown in Table 5.4. The analysis of the distribution of the 419 contracts by contract size and work category was presented in Table 5.3 and the distribution by contract size and district is shown in Table 5.5.

Table 5.4: Distribution of Contracts of all Sizes by Area Type, Route Type, and Contract Type

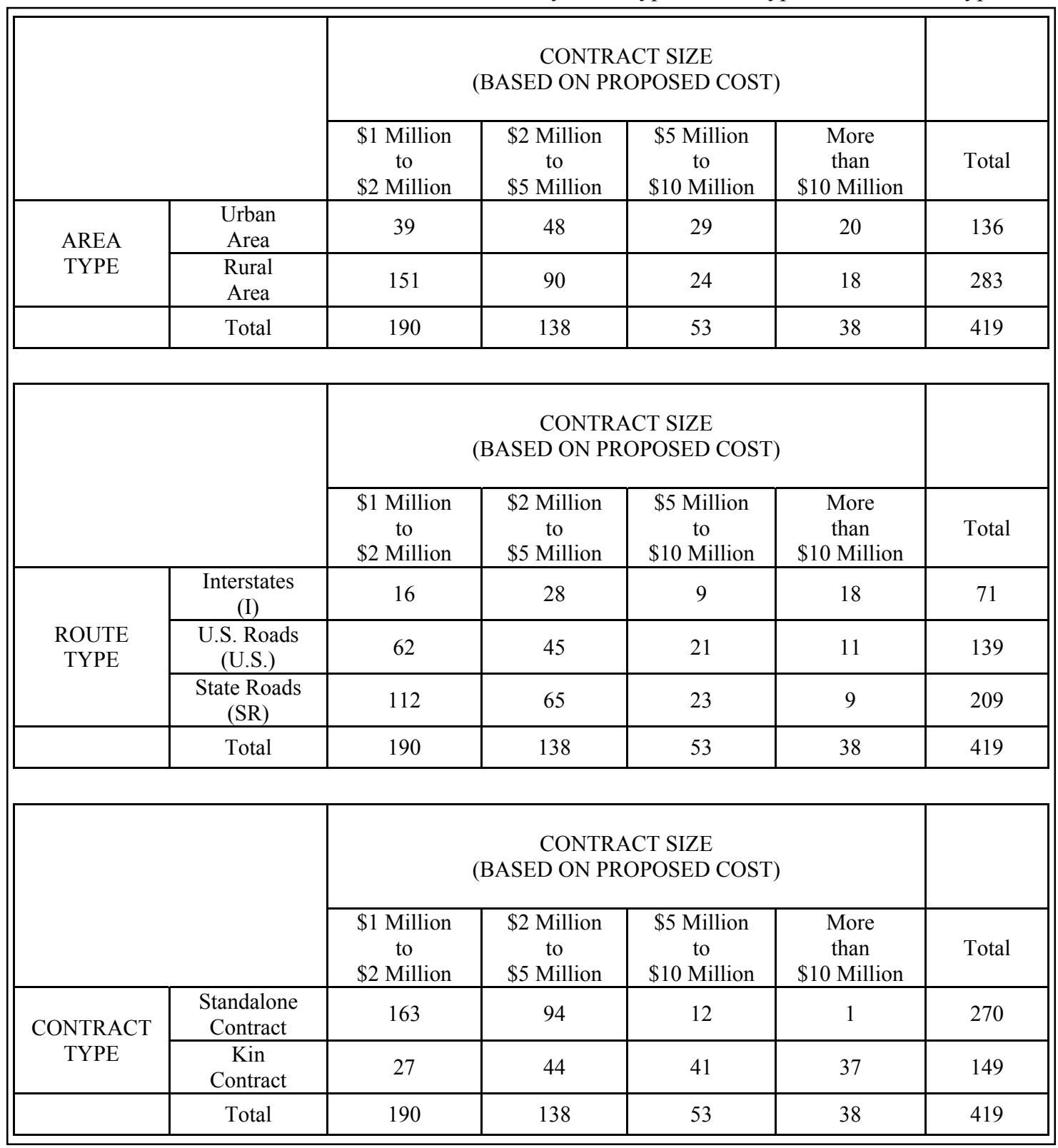


The distribution of the contracts by contract size and area type (Table 5.4) indicated that $64 \%$ ( 87 of 136) of the contracts implemented in urban areas were less than $\$ 5$ million in size. The percentage of contracts in rural areas that were less than $\$ 5$ million was $85 \%$ (241 of 283). Approximately $80 \%$ (151 of $190)$ of the contracts in the $\$ 1-\$ 2$ million contract size category were implemented in rural areas. The percentage of contracts in the $\$ 2-\$ 5$ million category that were implemented in areas is $65 \%$. On the other hand, large-sized contracts (greater than $\$ 5$ million) were distributed uniformly between urban (54\%, 49 of $91)$ and rural areas $(46 \%, 42$ of 91$)$.

The distribution of the 419 contracts by contract size and route type is also shown in Table 5.4. Of the 190 contracts in the $\$ 1-\$ 2$ million size category, approximately $60 \%$ (112 of 190) were implemented on the State Roads and only 8\% (16 of 190) of the contracts were implemented on Interstates. For contracts of size less than $\$ 5$ million, approximately 54\% (177 of 328) were implemented on State Roads and only about 13\% were on Interstates. On the other hand, of the 38 contracts that were greater than $\$ 10$ million in size, $47 \%$ (18 of 38 ) of the contracts were implemented on Interstates, and only about $24 \%$ of the contracts were on State Roads.

Based on the distribution of contracts by contract size and contract type, it was found that most ( $95 \%, 257$ of 270 ) of the stand-alone contracts were in the $\$ 1-\$ 5$ million size category. Only 5\% (13 of 270 ) of the stand-alone contracts were greater than $\$ 5$ million in size and only one stand-alone contract was greater than $\$ 10$ million in size. That is, almost all (37 of 38) of the large size contracts (greater than $\$ 10$ million) were kin contracts. However, the analysis of the distribution of the kin contracts reveals that 149 kin contracts comprised of: 18\% (27 of 149) of contracts in the \$1-\$2 million category, 30\% (44 of 149) of contracts in the $\$ 2-\$ 5$ million category, $28 \%$ (41 of 149) of contracts in the $\$ 5-\$ 10$ million category, and $25 \%$ (37 of 149) of contracts of size greater than $\$ 10$ million. Therefore, the kin contracts comprise contracts of all sizes and almost all the contracts greater than $\$ 10$ million in size were let as kin contracts.

The geographic location of a contract often has an impact on cost overrun as was discussed in Chapter 3. Therefore, the distributions of the 419 contracts by district and contract size, by district and work category, by district and area type, and by district and route type were analyzed (Table 5.5). In all the districts in Indiana (except Laporte) the number of contracts implemented decreased with an increase in contract size. Laporte district was the only district where the number of contracts in the $\$ 2-\$ 5$ million category exceed that of the \$1-\$2 million category. Also, Laporte had the highest percentage $(20 \%, 15$ of 74) of contracts in the $\$ 5-\$ 10$ million category, whereas all the other districts had approximately $10 \%$ contracts in the $\$ 5-\$ 10$ million category. Contracts greater than $\$ 10$ million (38 contracts) were distributed uniformly across all the districts except Crawfordsville, which had only three contracts in this category.

An analysis of the contracts by district and work category (Table 5.5) shows that most (29\%, 21 of 73) of the expansion contracts were implemented in Laporte District. An analysis of the contract size and work category (Table 5.3) revealed that $63 \%$ (24 of 38) of the large contracts (greater than $\$ 10$ million) contracts were expansion contracts. Also, it was found that $72 \%$ (48 of 67) of the contracts in the Fort 
Wayne district were pavement contracts whereas only 26\% (19 of 74) of the contracts in Laporte district were pavement contracts. Approximately 46\% (34 of 74) of the contracts in Laporte district were bridge contracts and 29\% (21 of 74) were expansion contracts. Seymour and Crawfordsville districts showed similar distribution of contracts as Fort Wayne district with respect to the dominance of the pavement contracts in these districts. Greenfield and Laporte accounted for $50 \%$ of the large scale (greater than $\$ 10$ million) expansion contracts.

The distribution of the 419 contracts by area type is shown in Table 5.5. The districts of Greenfield and Laporte accounted for 58\% (78 of 136) of the contracts implemented in the urban areas. This finding is not surprising considering that Greenfield and Laporte comprise largely of urban areas. For the other four districts, on average, approximately $80 \%$ of the contracts in these districts were implemented in the rural areas.

The analysis of the distribution of the contracts by district and route type indicated that approximately 50\% (35 of 71) of the Interstate contracts were taken up in the districts of Greenfield and Laporte. Approximately 54\% (40 of 74) of the contracts in the Laporte district were implemented on U.S. roads. The Seymour and Vincennes district accounted for 44\% (91 of 209) of the State Roads contracts. 
Table 5.5: Distribution of Contracts by Size, Work Category, and Area and Route Type in Each District

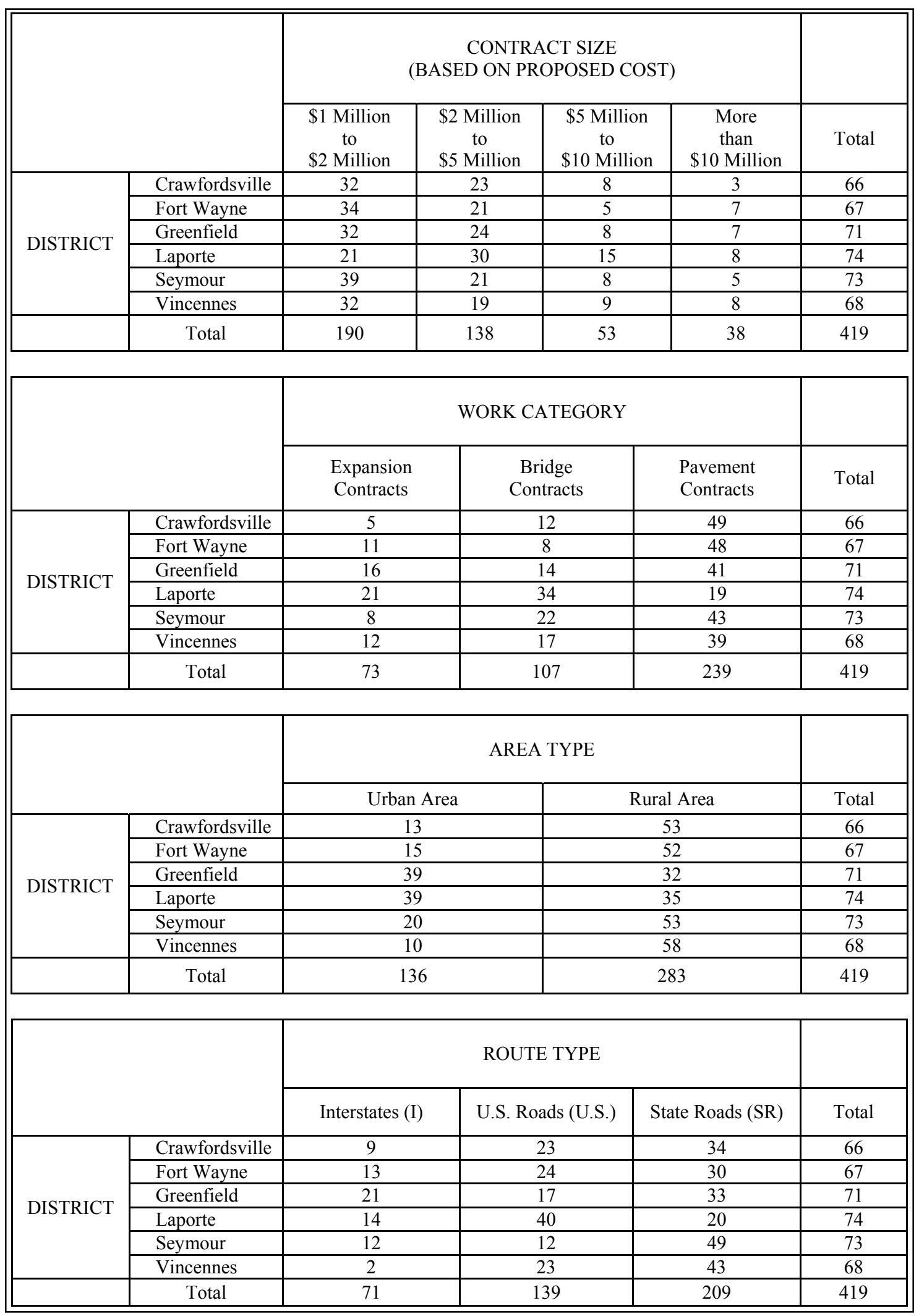




\subsection{Accuracy of Cost Estimates}

For the cost estimates prepared at each stage of project development, accuracy was determined by comparing the corresponding estimate with the final cost. The following comparisons were made: (a) Final cost vs. Proposed cost, (b) Final cost vs. Engineer's Assessment cost, (c) Final cost vs. Design cost, and (d) Final cost vs. Letting cost. The cost overrun associated with each stage was analyzed by work category, contract size, contract type, route type, NHS status, and district and area type. In particular, an emphasis was placed on the analysis of the contracts that had a cost overrun of greater than $10 \%$ or a cost overrun of less than $-10 \%$ (i.e., cost underrun $>10 \%$ ). The results presented in this section are based on the comparison of these costs in current dollars. The impact of inflation is presented in Section 5.5.

\subsubsection{Final Cost vs. Proposed Cost}

The cost overrun associated with the planning stage estimate was calculated as follows:

$$
\text { Planning Stage Cost Overrun : } Y_{1}=100\left(\frac{\text { Final Cost }- \text { Proposed Cost }}{\text { Proposed Cost }}\right) \%
$$

Figure 5.1 shows the distribution of the planning stage cost overrun for 419 contracts. The average planning stage cost overrun was $4.51 \%$ and the standard deviation was $27 \%$. The $95 \%$ confidence interval of the average planning stage cost overrun was $[1.9 \%, 7.1 \%]$. The low value of the average planning stage cost overrun is because positive cost overrun is compensated by the negative cost overrun (i.e. cost underrun). The positive value of average planning stage cost overrun (4.51\%) and the $95 \%$ confidence interval $[1.9 \%, 7.1 \%]$ indicated a dominance of cost overrun at the planning stage.

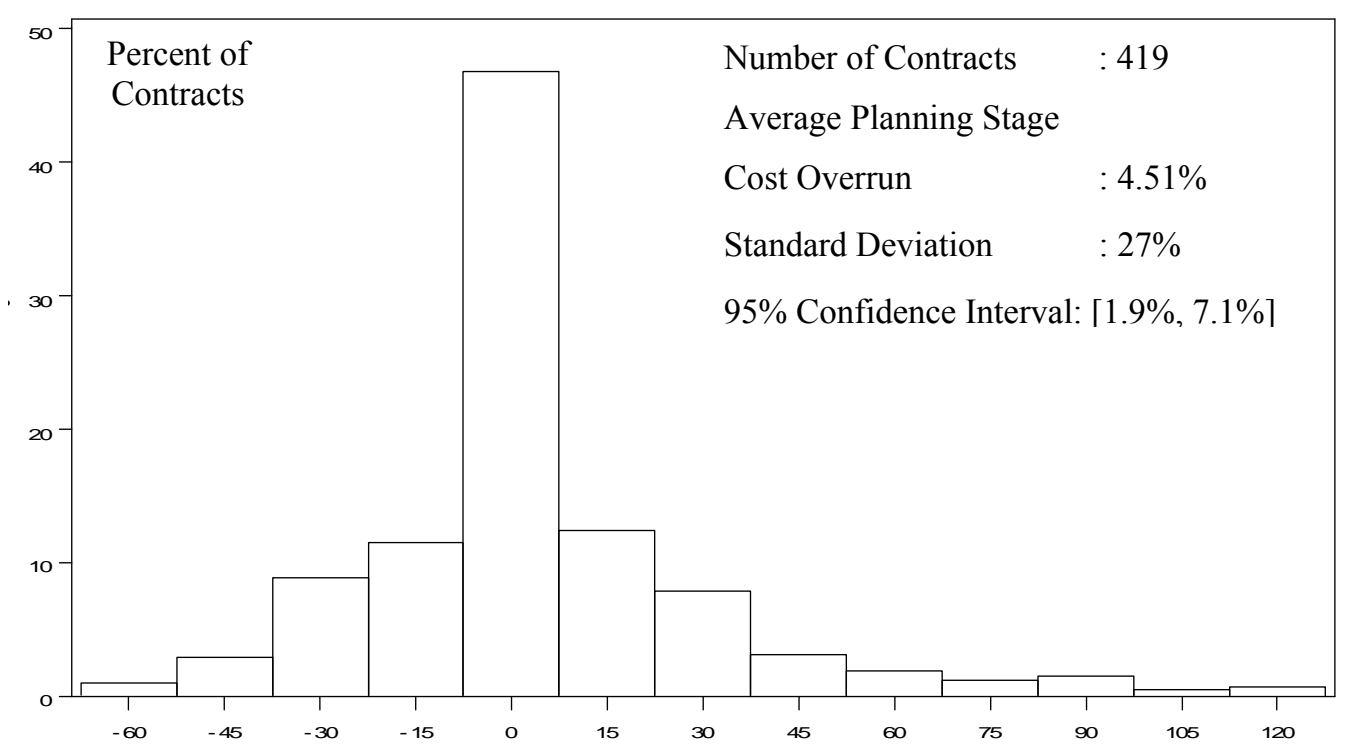

Figure 5.1: Histogram Distribution of Planning Stage Cost Overrun

$$
\mathrm{Y}_{1}=100\left(\frac{\text { Final Cost }- \text { Proposed Cost }}{\text { Proposed Cost }}\right) \%
$$


To determine the inaccuracy of the proposed cost estimate, the contracts were analyzed by cost overrun category (defined in Chapter 4). Table 5.6 presents an analysis of the average planning stage cost overrun by cost overrun category. It was found that for $27 \%$ of the contracts (112 of the 419 contracts), the final cost exceeded the proposed cost by over $10 \%$. For $22 \%$ of the contracts ( 91 of the 419 contracts), the proposed cost exceeded the final cost by more than $10 \%$. That is, $49 \%$ of the contracts (203 of 419 contracts) were outside ' $+/-10 \%$ cost overrun bracket'.

Table 5.6: Analysis of Average Planning Stage Cost Overrun by Cost Overrun Category

\begin{tabular}{|l|c|c|c|c|c|}
\hline & \multicolumn{3}{|c|}{$Y_{1}=100\left(\frac{\text { Final Cost - Proposed Cost }}{\text { Proposed Cost }}\right) \%$} & \\
\cline { 2 - 6 } & $Y_{1}<-10 \%$ & $-10 \% \leq Y_{1}<0 \%$ & $0 \% \leq Y_{1} \leq 10 \%$ & $Y_{1}>10 \%$ & \\
\hline Number of Contracts & 91 & 93 & 123 & 112 & 419 \\
\hline Weighted Average & $-26 \%$ & $-2.4 \%$ & $2.7 \%$ & $37 \%$ & $4.5 \%$ \\
\hline $\begin{array}{l}\text { 95\% Confidence } \\
\text { Interval }\end{array}$ & {$[-29 \%,-23 \%]$} & {$[-3 \%,-1.8 \%]$} & {$[2.2 \%, 3.2 \%]$} & {$[32 \%, 42 \%]$} & {$[1.9 \%, 7.1 \%]$} \\
\hline
\end{tabular}

For the 112 contracts with planning stage cost overrun exceeding $10 \%$, the average overrun was $37 \%$, and the $95 \%$ confidence interval of the average was [32\%, 42\%] (Figure 5.2). For the 91 contracts where planning stage cost underrun exceeded $10 \%$, the average underrun was $26 \%$ and the $95 \%$ confidence interval was $[23 \%, 29 \%]$. The contracts that lie within the ' $+/-10 \%$ cost overrun bracket' did not have a significant cost overrun at the planning stage, as indicated by the confidence interval. The lower limit of the confidence interval indicates that contracts that have a planning stage cost overrun of greater than $10 \%$ are expected to have a cost overrun of at least $32 \%$. Also, contracts that have a cost underrun of greater than $10 \%$ are expected to have a cost underrun of at least $23 \%$.

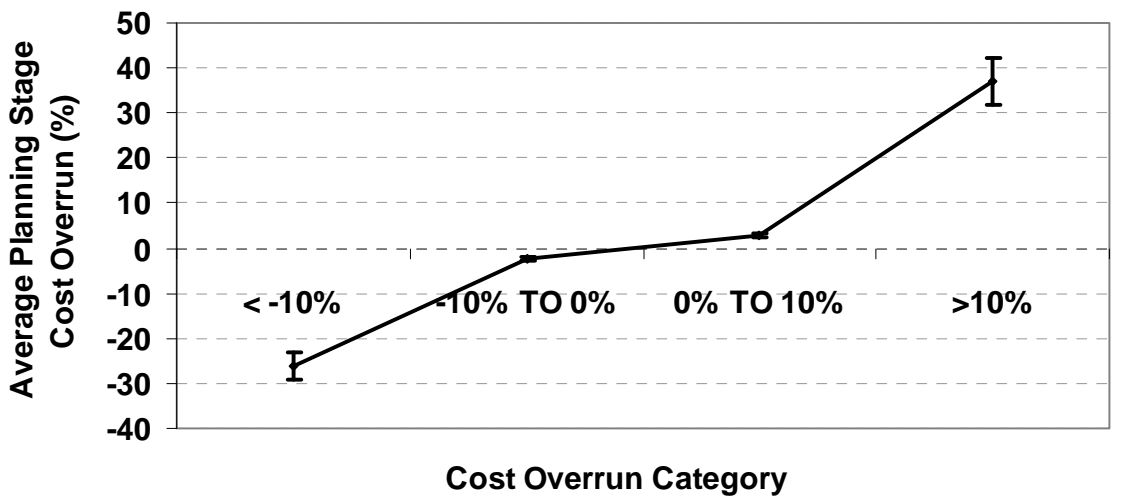

Figure 5.2: Analysis of Average Planning Stage Cost Overrun by Cost Overrun Category 
Sections 5.3.1.1 through 5.3.1.7 present a detailed analysis of the contracts for which the cost estimate at the planning stage exceeds the ' $+/-10 \%$ cost overrun bracket'. The objective was to determine the work category, contract size, contract type, route type, NHS status, area type, and district to which such contracts belong.

\subsubsection{Descriptive Analysis by Work Category}

The average planning stage cost overrun for the 73 expansion contracts, 107 bridge contracts, and 239 pavement contracts is as shown in Table 5.7, as well as the corresponding 95\% confidence intervals. The average planning stage cost overrun was highest for pavement contracts (6.4\%) and the $95 \%$ confidence interval of this average $[2.5 \%, 10.2 \%]$ indicated that the cost overrun was dominant compared to cost underrun for pavement contracts. The average planning stage cost overrun for expansion and bridge contracts was $2.3 \%$ and $1.8 \%$, respectively, and the corresponding $95 \%$ confidence intervals of [$3.6 \%, 8.2 \%]$ and $[-1.9 \%, 5.6 \%]$, respectively, indicated that the probability of cost overrun was marginally higher than that of a cost underrun.

Table 5.7: Analysis of Planning Stage Cost Overrun by Work Category and Cost Overrun Category

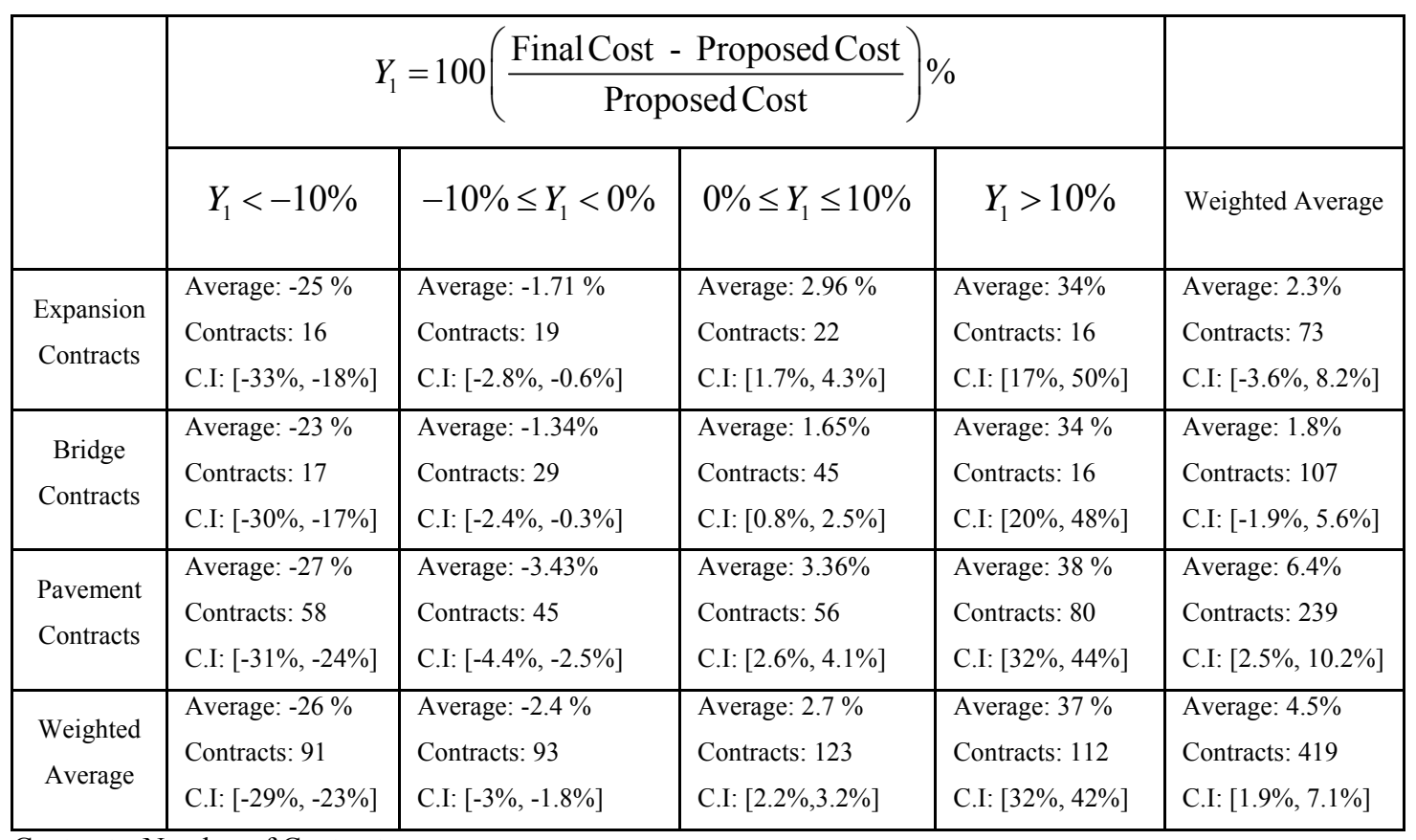

Contracts: Number of Contracts

C.I: 95\% Confidence Interval (Estimated Using One Sample t-Test)

\section{(A) Frequency of Planning Stage Cost Overrun / Underrun}

The expansion, bridge, and pavement contracts for which the planning stage cost overrun was outside the ' $+/-10 \%$ cost overrun bracket' were analyzed in greater detail to determine whether 'extreme' cost overruns 
and underruns are more frequent across contracts of any particular work type. The following conclusions were made (Figure 5.3):

i. The percentage of bridge contracts that were outside the ' $+/-10 \%$ cost overrun bracket' was $31 \%$ (33 of the 107 contracts), which was less than the corresponding percentage for expansion contracts (44\%: 32 of 73) and pavement (58\%: 138 of 239) contracts.

ii. The percentage of bridge contracts for which the planning stage cost overrun was greater than $10 \%$ was $15 \%$ ( 16 of 107 ), whereas the corresponding percentage for expansion contracts was $22 \%$ (16 of 73 ) and for pavement contracts was $34 \%$ ( 80 of 239 contracts).

iii. The percentage of bridge contracts for which the planning stage cost underrun was greater than $10 \%$ was $16 \%$ (17 of 107), whereas the corresponding percentage for expansion contracts was $22 \%$ ( 16 of 73 ) and for pavement contracts was $24 \%$ (58 of 239 contracts).

Based on these findings it was concluded that planning stage cost overrun and underrun were more frequent among pavement contracts and least frequent amongst bridge contracts.

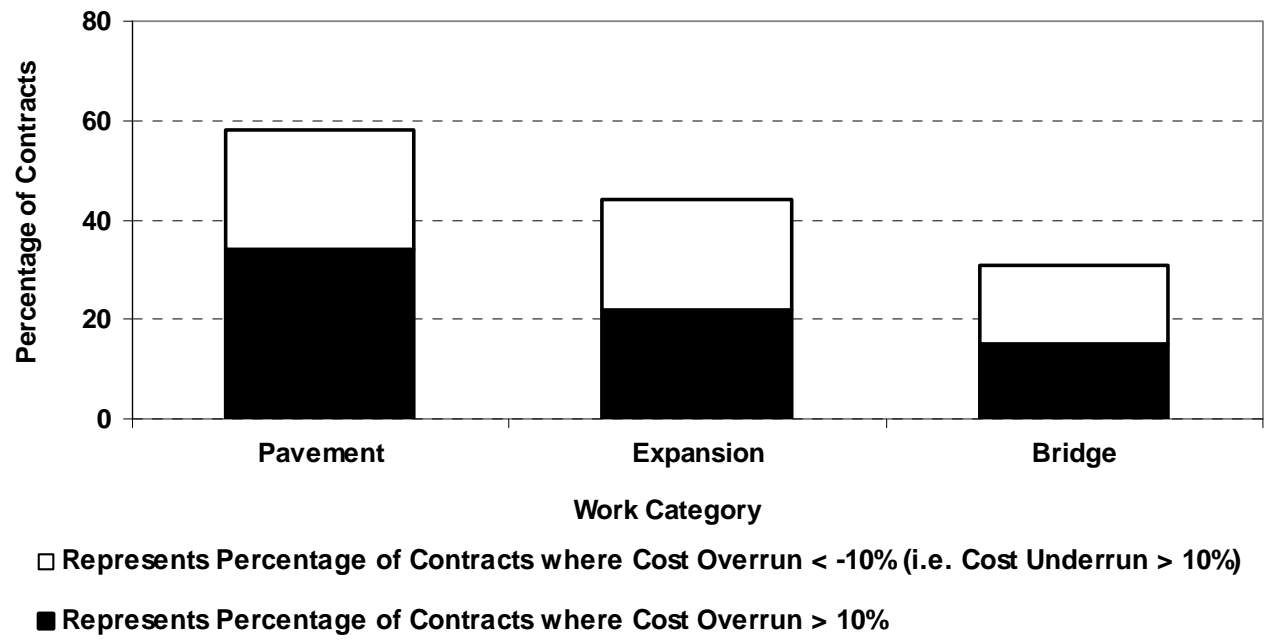

Figure 5.3: Percentage of Contracts Outside the ' $+/-10 \%$ Cost Overrun Bracket' at the Planning Stage by Work Category

\section{(B) Severity of Planning Stage Cost Overrun / Underrun}

The average planning stage cost overrun was determined for contracts that lie outside the $+/-10 \%$ cost overrun bracket' by work category. The objective of this analysis was to determine whether contracts belonging to any particular work category had a higher average percentage cost overrun (i.e., more severe cost overrun) compared to others. The conclusions made on the basis of cost overrun severity were as follows: 
i. For Contracts with Cost Overrun $>10 \%$ : The average planning stage cost overrun was $34 \%$ for expansion and bridge contracts, with a $95 \%$ confidence interval of the average $[17 \%, 50 \%]$ and [20\%, 48\%], respectively. Therefore, in this respect, the expansion and bridge contracts were found not to differ significantly. The pavement contracts, on the other hand, had a higher average planning stage cost overrun (38\%) and a narrower 95\% confidence interval of [32\%, 42\%] compared to expansion and bridge contracts. The 95\% confidence intervals indicated that expansion and bridge contracts had an average overrun between $20 \%$ and $30 \%$, whereas pavement contracts had an average overrun between $30 \%$ and $40 \%$ (Figure 5.4).

ii. For Contracts with Cost Overrun $<-10 \%$ (i.e. Cost Underrun $>10 \%$ ): The average planning stage cost underrun was $27 \%, 25 \%$, and $23 \%$ for pavement, expansion, and bridge contracts, respectively (Table 5.7). The $95 \%$ confidence interval of these average cost underrun was $[24 \%$, $31 \%],[18 \%, 33 \%]$, and $[17 \%, 30 \%]$ for pavement, expansion, and bridge contracts respectively. Expansion and bridge contracts are not significantly different in terms of underrun. Pavement contracts, on the other hand, had a consistently high cost underrun (Figure 5.4).

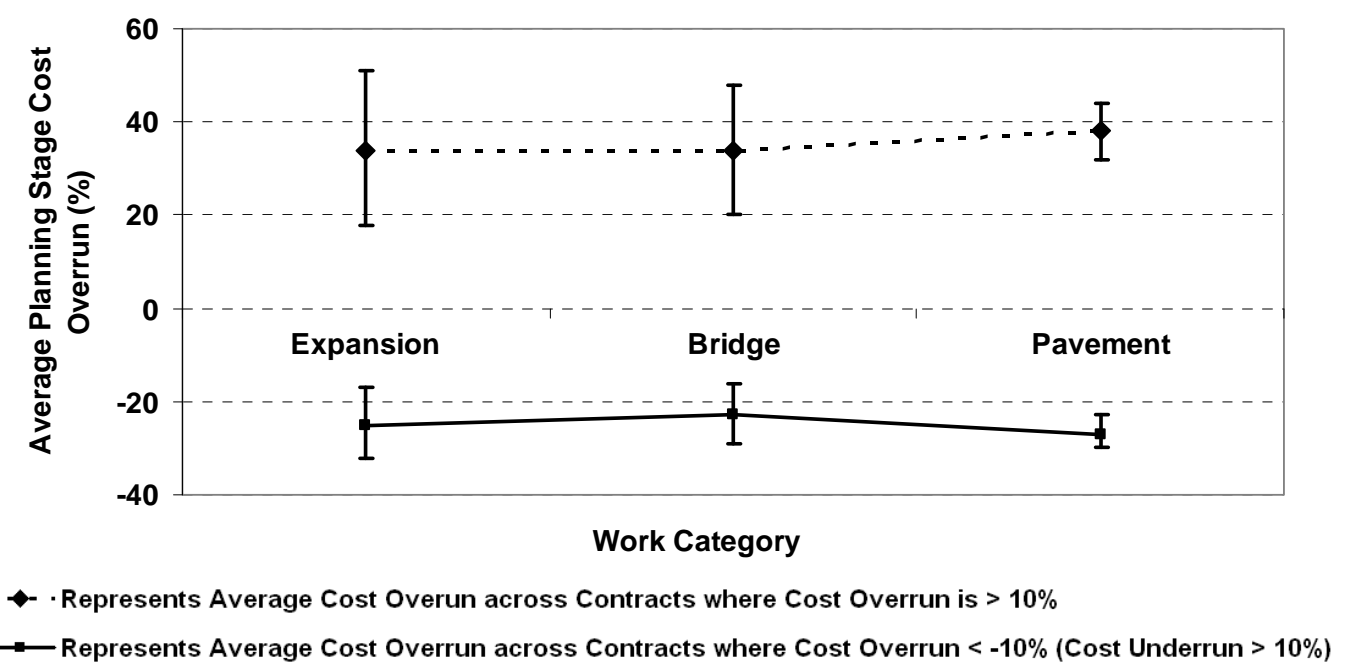

Figure 5.4: Average Planning Stage Cost Overrun for Contracts Outside the ' $+/-10 \%$ Cost Overrun Bracket' by Work Category

\subsubsection{Descriptive Analysis by Contract Size}

The statistics of the average planning stage cost overrun by contract size and cost overrun category are as shown in Table 5.8. The 190 contracts with proposed cost of \$1-\$2 million had an average planning stage cost overrun of $8.8 \%$ and a $95 \%$ confidence interval of $[4.8 \%, 13 \%]$. For contracts in this category, the positive value of average cost overrun and its confidence interval indicate that cost overruns generally outweigh cost underruns in this category. It was observed that at the planning stage, contracts with 
proposed cost $\$ 2-\$ 5$ million had a comparatively lower average cost overrun (2.5\%) and a 95\% confidence interval $[-2.4 \%, 7.3 \%]$. The upper limit of the confidence interval indicates that cost overrun of higher magnitude is possible for contracts in this category. The contracts with proposed cost in between $\$ 5-\$ 10$ million and the contracts with proposed cost greater than $\$ 10$ million had similar average planning stage cost overrun (-1.4\%). The $95 \%$ confidence interval $[-7.5 \%, 4.8 \%]$ for the average planning stage cost overrun was also similar indicating that contracts in these categories experienced similar cost overruns. Further, the lower limit of the $95 \%$ confidence interval indicates that the cost underruns were marginally more prominent for contracts greater than $\$ 5$ million in size.

Table 5.8: Analysis of Planning Stage Cost Overrun by Contract Size and Cost Overrun Category

\begin{tabular}{|c|c|c|c|c|c|}
\hline & \multicolumn{3}{|c|}{$Y_{1}=100$} & $\%$ & \multirow[b]{2}{*}{$\begin{array}{l}\text { Weighted } \\
\text { Average }\end{array}$} \\
\hline & $Y_{1}<-10 \%$ & $-10 \% \leq Y_{1}<0 \%$ & $0 \% \leq Y_{1} \leq 10 \%$ & $Y_{1}>10 \%$ & \\
\hline $\begin{array}{l}\$ 1 \mathrm{M}- \\
\$ 2 \mathrm{M}\end{array}$ & $\begin{array}{l}\text { Average: }-23 \% \\
\text { Contracts: } 31 \\
\text { C.I: }[-27 \%,-20 \%]\end{array}$ & $\begin{array}{l}\text { Average: }-2 \% \\
\text { Contracts: } 49 \\
\text { C.I: }[-2.8 \%,-1 \%]\end{array}$ & $\begin{array}{l}\text { Average: } 3 \% \\
\text { Contracts: } 52 \\
\text { C.I: }[1.7 \%, 3.3 \%]\end{array}$ & $\begin{array}{l}\text { Average: } 41 \% \\
\text { Contracts: } 58 \\
\text { C.I: }[33 \%, 48 \%]\end{array}$ & $\begin{array}{l}\text { Average: } 8.8 \% \\
\text { Contracts: } 190 \\
\text { C.I: }[4.8 \%, 13 \%]\end{array}$ \\
\hline $\begin{array}{l}\$ 2 \mathrm{M}- \\
\$ 5 \mathrm{M}\end{array}$ & $\begin{array}{l}\text { Average: }-28 \% \\
\text { Contracts: } 34 \\
\text { C.I: }[-33 \%,-23 \%]\end{array}$ & $\begin{array}{l}\text { Average: }-3 \% \\
\text { Contracts: } 29 \\
\text { C.I: }[-4.5 \%, 2 \%]\end{array}$ & $\begin{array}{l}\text { Average: } 2 \% \\
\text { Contracts: } 42 \\
\text { C.I: }[1.3 \%, 3 \%]\end{array}$ & $\begin{array}{l}\text { Average: } 39 \% \\
\text { Contracts: } 33 \\
\text { C.I: }[28 \%, 50 \%]\end{array}$ & $\begin{array}{l}\text { Average: } 2.5 \% \\
\text { Contracts: } 138 \\
\text { C.I: }[-2.4 \%, 7.3 \%]\end{array}$ \\
\hline $\begin{array}{l}\$ 5 \mathrm{M}- \\
\$ 10 \mathrm{M}\end{array}$ & $\begin{array}{l}\text { Average: }-29 \% \\
\text { Contracts: } 14 \\
\text { C.I: }[-38 \%,-22 \%]\end{array}$ & $\begin{array}{l}\text { Average: }-2 \% \\
\text { Contracts: } 12 \\
\text { C.I: }[-4 \%,-0.8 \%]\end{array}$ & $\begin{array}{l}\text { Average: } 2.9 \% \\
\text { Contracts: } 14 \\
\text { C.I: }[1.3 \%, 4.5 \%]\end{array}$ & $\begin{array}{l}\text { Average: } 25 \% \\
\text { Contracts: } 13 \\
\text { C.I: }[18 \%, 33 \%]\end{array}$ & $\begin{array}{l}\text { Average: }-1.3 \% \\
\text { Contracts: } 53 \\
\text { C.I: }[-7.4 \%, 4.7 \%]\end{array}$ \\
\hline$>\$ 10 \mathrm{M}$ & $\begin{array}{l}\text { Average: }-25 \% \\
\text { Contracts: } 12 \\
\text { C.I: }[-31 \%,-19 \%]\end{array}$ & $\begin{array}{l}\text { Average: }-1 \% \\
\text { Contracts: } 3 \\
\text { C.I: }[-4 \%, 1.9 \%]\end{array}$ & $\begin{array}{l}\text { Average: } 4.3 \% \\
\text { Contracts: } 15 \\
\text { C.I: }[2.9 \%, 5.8 \%]\end{array}$ & $\begin{array}{l}\text { Average: } 23 \% \\
\text { Contracts: } 8 \\
\text { C.I: }[16 \%, 30 \%]\end{array}$ & $\begin{array}{l}\text { Average:-1.4\% } \\
\text { Contracts: } 38 \\
\text { C.I:[-7.6\%, } 4.8 \%]\end{array}$ \\
\hline $\begin{array}{l}\text { Weighted } \\
\text { Average }\end{array}$ & $\begin{array}{l}\text { Average: }-26 \% \\
\text { Contracts: } 91 \\
\text { C.I: }[-29 \%,-23 \%]\end{array}$ & $\begin{array}{l}\text { Average: }-2.4 \% \\
\text { Contracts: } 93 \\
\text { C.I: }[-3 \%,-1.8 \%]\end{array}$ & $\begin{array}{l}\text { Average: } 2.7 \% \\
\text { Contracts: } 123 \\
\text { C.I: }[2.2 \%, 3.2 \%]\end{array}$ & $\begin{array}{l}\text { Average: } 37 \% \\
\text { Contracts: } 112 \\
\text { C.I: }[32 \%, 42 \%]\end{array}$ & $\begin{array}{l}\text { Average: } 4.5 \% \\
\text { Contracts: } 419 \\
\text { C.I: }[1.9 \%, 7.1 \%]\end{array}$ \\
\hline
\end{tabular}

Contracts: Number of Contracts

C.I: 95\% Confidence Interval (Estimated Using One Sample t-Test)

\section{(A) Frequency of Planning Stage Cost Overrun / Underrun}

The contracts that lie outside the ' $+/-10 \%$ cost overrun bracket' were analyzed by contract size to determine whether high cost overrun / underrun were more frequent for contracts of any particular size. The following conclusions were made (Figure 5.5):

i. Approximately $49 \%$ (89 of 190 ) of $\$ 1-\$ 2$ million contracts were outside the ' $+/-10 \%$ ' planning stage cost overrun bracket and this percentage was higher for bigger contract sizes as follows 
(Figure 5.5): 49\% (67 of 138) for contracts with size \$2-\$5 million, 51\% (27 of 53) for contracts with size $\$ 5$ to $\$ 10$ million; and 53\% (20 of 38) for contracts greater than $\$ 10$ million in size.

ii. The percentage of \$1-\$2 million contracts for which the planning stage cost overrun exceed $10 \%$ was 31\% (58 of 190) and it decreased with increase in contract size as follows (Figure 5.5): 24\% (33 of 138) for contracts with size \$2-\$5 million, 24\% (13 of 53) for contracts with size $\$ 5$ to $\$ 10$ million, and 21\% ( 8 of 38 ) for contracts greater than $\$ 10$ million in size.

iii. The percentage of $\$ 1-\$ 2$ million contracts for which the planning stage cost underrun was greater than $10 \%$ was $16 \%$ (31 of 190) and it increased with increase in contract size as follows (Figure 5.5): $25 \%$ (34 of 138) for contracts with size $\$ 2-\$ 5$ million, $26 \%$ (14 of 53) for contracts with size $\$ 5$ to $\$ 10$ million, and $32 \%$ (12 of 38) for contracts greater than $\$ 10$ million in size.

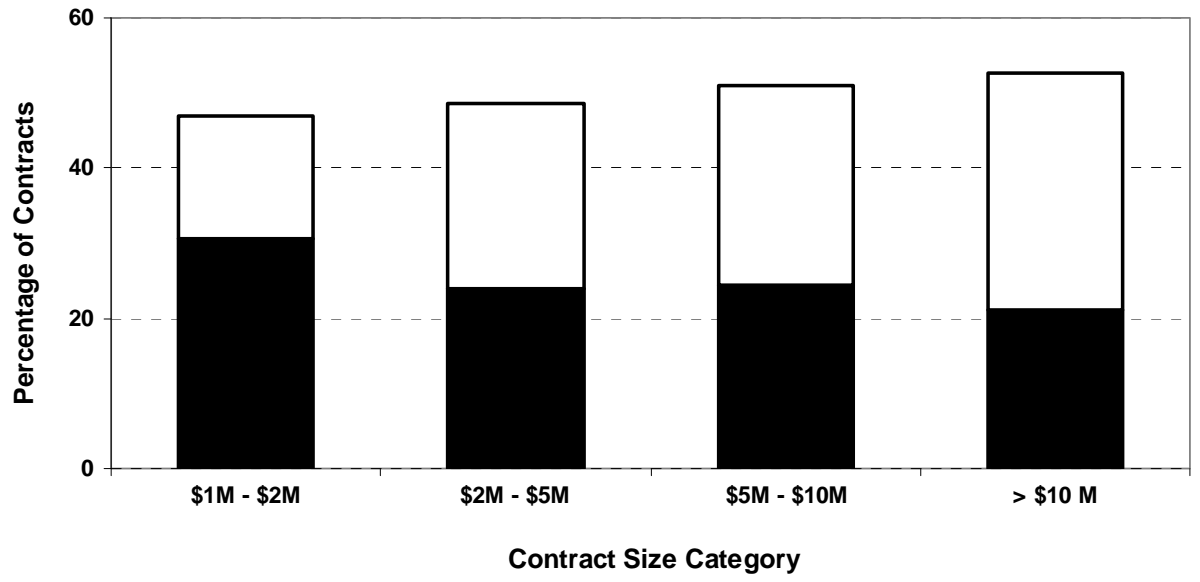

$\square$ Represents Percentage of Contracts where Cost Overrun $<-10 \%$ (i.e. Cost Underrun $>10 \%$ )

Represents Percentage of Contracts where Cost Overrun > 10\%

Figure 5.5: Percentage of Contracts Outside the ' $+/-10 \%$ Cost Overrun Bracket' at the Planning Stage by Contract Size

\section{(B) Severity of Planning Stage Cost Overrun / Underrun}

The average planning stage cost overrun was determined for contracts that lie outside the ${ }^{~}+/-10 \%$ cost overrun bracket' by contract size to analyze if there were differences in cost overrun severity across work categories. The following findings were made:

i. For Contracts with Cost Overrun $>10 \%$ : The average planning stage cost overrun decreases with increased contract size (Figure 5.6): $41 \%$ for contracts with proposed cost between $\$ 1-\$ 2 \mathrm{M}, 39 \%$ for $\$ 2-\$ 5 \mathrm{M}$ contracts, $25 \%$ for $\$ 5-\$ 10 \mathrm{M}$ contracts, and $23 \%$ for contracts greater than $\$ 10 \mathrm{M}$ contracts. The length of the $95 \%$ confidence interval (Table 5.8) of the average planning stage cost overrun did not vary significantly across the various categories of contract size. This indicates that the variance in the planning stage cost overrun was the same across all contract sizes. However, it was found that the $95 \%$ confidence interval for $\$ 1-\$ 2$ million contracts $[33 \%, 48 \%]$ and the $\$ 2-\$ 5$ 
million $[28 \%, 50 \%]$ contracts exceeded that for $\$ 5 \mathrm{M}-\$ 10 \mathrm{M}[18 \%, 33 \%]$ and was greater than $\$ 10 \mathrm{M}[16 \%, 30 \%]$ contracts. This indicates that the planning stage cost overrun is expected to be higher for relatively small-sized contracts (proposed cost $<\$ 5$ Million).

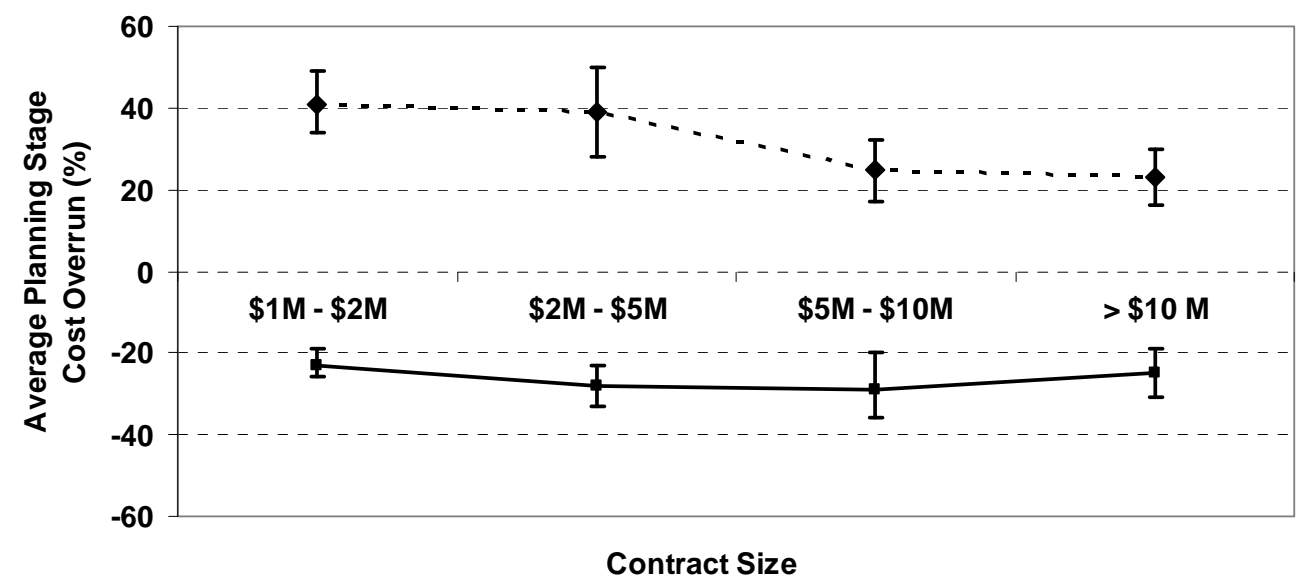

- $\downarrow$ - Represents Average Cost Overun across Contracts where Cost Overrun is $>10 \%$

$\longrightarrow$ Represents Average Cost Overrun across Contracts where Cost Overrun $<-10 \%$ (Cost Underrun $>10 \%)$

Figure 5.6: Average Planning Stage Cost Overrun for Contracts Outside the ' $+/-10 \%$ Cost Overrun Bracket' by Contract Size

ii. For Contracts with Cost Overrun $<-10 \%$ (i.e., Cost Underrun $>10 \%$ ): The average planning stage cost underrun increases with increase in contract size up to $\$ 10$ million (Figure 5.6). The average planning stage cost underrun was $23 \%$ for contracts with proposed cost in between $\$ 1-\$ 2 \mathrm{M}, 28 \%$ for contracts with size in between $\$ 2-\$ 5 \mathrm{M}, 29 \%$ for contracts with size in between $\$ 5-\$ 10 \mathrm{M}$, and $25 \%$ for contracts with size greater than $\$ 10 \mathrm{M}$. The $95 \%$ confidence interval (Table 5.8) for of these average cost underruns was [20\%, 27\%], [23\%, 33\%], [22\%, 38\%], and [19\%, 31\%] for contracts with size $\$ 1-\$ 2$ million, $\$ 2-\$ 5$ million, $\$ 5-\$ 10$ million and greater than $\$ 10$ million, respectively. The length of the confidence interval increases with an increase in contract size up to $\$ 10$ million. The upper limit of the confidence interval also increases with increase in contract size (up to $\$ 10$ million), which indicates that large-sized contracts are susceptible to higher cost underruns at the planning stage (Figure 5.4).

\subsubsection{Descriptive Analysis by Contract Type}

The average planning stage cost overrun by contract type and cost overrun category is presented in Table 5.9. The 270 stand-alone contracts have an average planning stage cost overrun of $4.7 \%$ and a $95 \%$ 
confidence interval of $[1.6 \%, 7.7 \%]$. The positive cost overrun and confidence interval indicates that cost overrun is more prominent compared to cost underrun for contracts in this category. The kin contracts had a similar average planning stage cost overrun (4.2\%) and a 95\% confidence interval $[-0.6 \%, 9 \%]$.

Table 5.9: Analysis of Planning Stage Cost Overrun by Contract Type and Cost Overrun Category

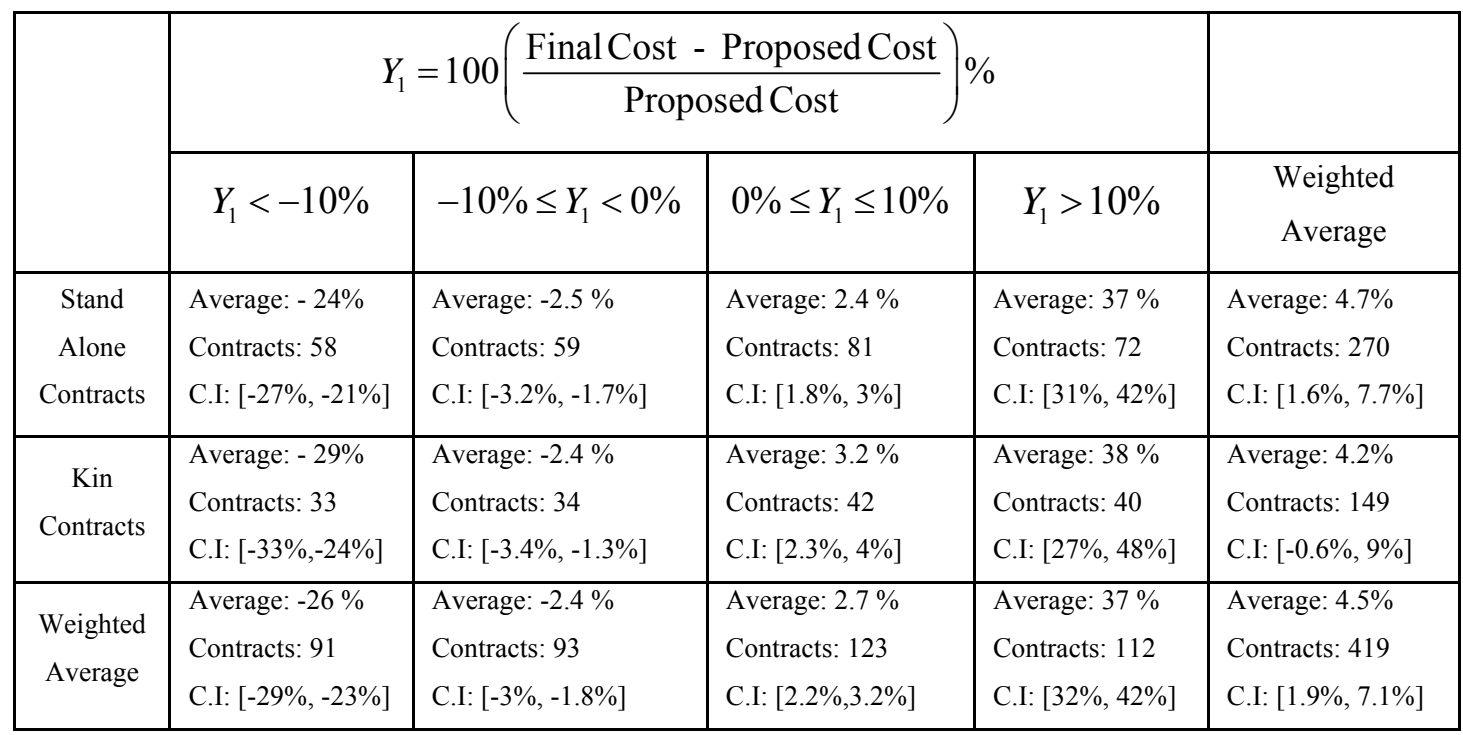

Contracts: Number of Contracts

C.I: 95\% Confidence Interval (Estimated Using One Sample t-Test)

\section{(A) Frequency of Planning stage cost overrun / Underrun}

The contracts that lie outside the ' $+/-10 \%$ cost overrun bracket' were analyzed by contract type to determine the frequency of cost overrun and underrun across kin and stand-alone contracts.

i. The percentage of stand-alone and kin contracts that were outside the ' $+/-10 \%$ ' planning stage cost overrun bracket was $48 \%$ (130 of 270) and 49\% (73 of 149), respectively (Table 5.9).

ii. The percentage of stand-alone and kin contracts for which the planning stage cost overrun was greater than $10 \%$ was $27 \%$ (72 of 270 ) and $27 \%$ (49 of 149), respectively.

iii. The percentage of stand-alone and kin contracts for which the planning stage cost underrun was greater than $10 \%$ was $21 \%$ (58 of 270 ) and $22 \%$ (33 of 149 ), respectively.

Therefore, frequency of planning stage cost overrun and underrun did not vary by contract type.

\section{(B) Severity of Planning Stage Cost Overrun / Underrun}

Based on the analysis of the average planning stage cost overrun of the kin and stand-alone contracts that lie outside the ' $+/-10 \%$ cost overrun bracket', the following findings were made:

i. $\quad$ For Contracts with Cost Overrun $>10 \%$ : The average planning stage cost overrun for stand-alone and kin contracts was $37 \%$ and $38 \%$, respectively. The length of $95 \%$ confidence interval of the 
average planning stage cost overrun for stand-alone contracts [31\%, 42\%] was half the length of the confidence interval for kin contracts $[27 \%, 48 \%]$. In other words, the variability of average cost overrun at the planning stage cost for kin contracts exceeded that for stand-alone contracts. The upper limit of the confidence interval for kin contracts (48\%) was higher compared to that of stand-alone contracts (42\%), which indicated that kin contracts experienced higher planning stage cost overrun compared to stand-alone contracts.

ii. For Contracts with Cost Overrun $<-10 \%$ (i.e. Cost Underrun $>10 \%$ ): The average planning stage cost underrun for kin contracts (29\%) was higher compared to stand-alone contracts $(24 \%)$. The $95 \%$ confidence interval of the average planning stage cost overrun for kin contracts [24\%, 33\%] and stand-alone contracts $[21 \%, 27 \%]$ indicated that the kin contracts are expected to have more severe cost underrun. This is because upper and lower limits of the confidence interval for kin contracts were higher compared to those for stand-alone contracts.

\subsubsection{Descriptive Analysis by Route Type}

There were 71 Interstate contracts, 139 U.S. Road contracts, and 209 State Road contracts. The average planning stage cost overrun and 95\% confidence interval of the average are shown in Table 5.10. The average planning stage cost overrun was highest for State Road contracts (5.8\%) and the 95\% confidence interval was $[2.2 \%, 9.4 \%]$. This indicated that the cost overrun is more prominent compared to cost underrun for State Road contracts. The average planning stage cost overrun for U.S. Road contracts was $4.6 \%$, and the $95 \%$ confidence interval was $[0.3 \%, 9 \%$ implying that the U.S. Road contracts had similar behavior as the State Road contracts. The average planning stage cost overrun was smallest for Interstate contracts $(0.5 \%)$ and the $95 \%$ confidence interval $[-6.7 \%, 7.7 \%]$ was symmetrically distributed around zero, thereby indicating that the cost overrun is balanced by the cost underrun for Interstate contracts. 
Table 5.10: Analysis of Planning Stage Cost Overrun by Route Type and Cost Overrun Category

\begin{tabular}{|c|c|c|c|c|c|}
\hline & $Y_{1}=100$ & $=100\left(\frac{\text { Final Cost }}{\text { Prop }}\right.$ & $\frac{\text { roposed Cost }}{d \text { Cost }}$ & $1 / 0$ & \multirow[b]{2}{*}{$\begin{array}{l}\text { Weighted } \\
\text { Average }\end{array}$} \\
\hline & $Y_{1}<-10 \%$ & $-10 \% \leq Y_{1}<0 \%$ & $0 \% \leq Y_{1} \leq 10 \%$ & $Y_{1}>10 \%$ & \\
\hline Interstates & $\begin{array}{l}\text { Average: }-31 \% \\
\text { Contracts: } 18 \\
\text { C.I: }[-39 \%,-23 \%]\end{array}$ & $\begin{array}{l}\text { Average: }-2 \% \\
\text { Contracts: } 16 \\
\text { C.I: }[-3.5 \%,-0.4 \%]\end{array}$ & $\begin{array}{l}\text { Average: } 3 \% \\
\text { Contracts: } 24 \\
\text { C.I: }[1.9 \%, 4.2 \%]\end{array}$ & $\begin{array}{l}\text { Average: } 42 \% \\
\text { Contracts: } 13 \\
\text { C.I: }[18 \%, 66 \%]\end{array}$ & $\begin{array}{l}\text { Average: } 0.5 \% \\
\text { Contracts: } 71 \\
\text { C.I:[-6.7\%,7.7\%] }\end{array}$ \\
\hline U.S. Roads & $\begin{array}{l}\text { Average: }-22 \% \\
\text { Contracts: } 31 \\
\text { C.I: }[-26 \%,-18 \%]\end{array}$ & $\begin{array}{l}\text { Average: }-2.4 \% \\
\text { Contracts: } 32 \\
\text { C.I: }[-3.5 \%,-1.4 \%]\end{array}$ & $\begin{array}{l}\text { Average: } 2.54 \% \\
\text { Contracts: } 40 \\
\text { C.I: }[1.6 \%, 3.5 \%]\end{array}$ & $\begin{array}{l}\text { Average: } 36 \% \\
\text { Contracts: } 36 \\
\text { C.I: }[27 \%, 46 \%]\end{array}$ & $\begin{array}{l}\text { Average: } 4.6 \% \\
\text { Contracts: } 139 \\
\text { C.I: }[0.3 \%, 9 \%]\end{array}$ \\
\hline $\begin{array}{l}\text { State } \\
\text { Roads }\end{array}$ & $\begin{array}{l}\text { Average: }-27 \% \\
\text { Contracts: } 42 \\
\text { C.I: }[-30 \%,-23 \%]\end{array}$ & $\begin{array}{l}\text { Average: }-2.6 \% \\
\text { Contracts: } 45 \\
\text { C.I: }[-3.5 \%,-1.6 \%]\end{array}$ & $\begin{array}{l}\text { Average: } 2.6 \% \\
\text { Contracts: } 59 \\
\text { C.I: }[1.8 \%, 3.3 \%]\end{array}$ & $\begin{array}{l}\text { Average: } 36 \% \\
\text { Contracts: } 63 \\
\text { C.I: }[31 \%, 42 \%]\end{array}$ & $\begin{array}{l}\text { Average: } 5.8 \% \\
\text { Contracts: } 209 \\
\text { C.I: }[2.2 \%, 9.4 \%]\end{array}$ \\
\hline $\begin{array}{l}\text { Weighted } \\
\text { Average }\end{array}$ & $\begin{array}{l}\text { Average: }-26 \% \\
\text { Contracts: } 91 \\
\text { C.I: }[-29 \%,-23 \%]\end{array}$ & $\begin{array}{l}\text { Average: }-2.4 \% \\
\text { Contracts: } 93 \\
\text { C.I: }[-3 \%,-1.8 \%]\end{array}$ & $\begin{array}{l}\text { Average: } 2.7 \% \\
\text { Contracts: } 123 \\
\text { C.I: }[2.2 \%, 3.2 \%]\end{array}$ & $\begin{array}{l}\text { Average: } 37 \% \\
\text { Contracts: } 112 \\
\text { C.I: }[32 \%, 42 \%]\end{array}$ & $\begin{array}{l}\text { Average: } 4.5 \% \\
\text { Contracts: } 419 \\
\text { C.I: }[1.9 \%, 7.1 \%]\end{array}$ \\
\hline
\end{tabular}

Contracts: Number of Contracts

C.I: 95\% Confidence Interval (Estimated Using One Sample t-Test)

\section{(A) Frequency of Planning Stage Cost Overrun / Underrun}

The Interstate, U.S. Road, and State Road contracts for which the planning stage cost overrun was outside the ' $+/-10 \%$ cost overrun bracket' were analyzed to investigate differences in cost overrun across route types. The following observations were made (Figure 5.7):

i. The percentage of Interstate contracts that were outside the ' $+/-10 \%$ cost overrun bracket' was $44 \%$ (31 of the 71 contracts), which was less than the corresponding percentage for U.S. Road contracts (48\%, 67 of 139) and State Road (50\%, 105 of 209) contracts.

ii. The percentage of Interstate contracts for which the planning stage cost overrun exceeded $10 \%$ was $18 \%$ (13 of 71), whereas the corresponding percentage for U.S. Road contracts was $26 \%$ (36 of 139) and for State Road contracts was 30\% (63 of 209 contracts).

iii. The percentage of Interstate contracts for which the planning stage cost underrun was greater than $10 \%$ was $25 \%$ ( 18 of 71 ), whereas the corresponding percentage for U.S. Road contracts was $22 \%$ (31 of 139) and for State Road contracts was 20\% (42 of 209 contracts). 


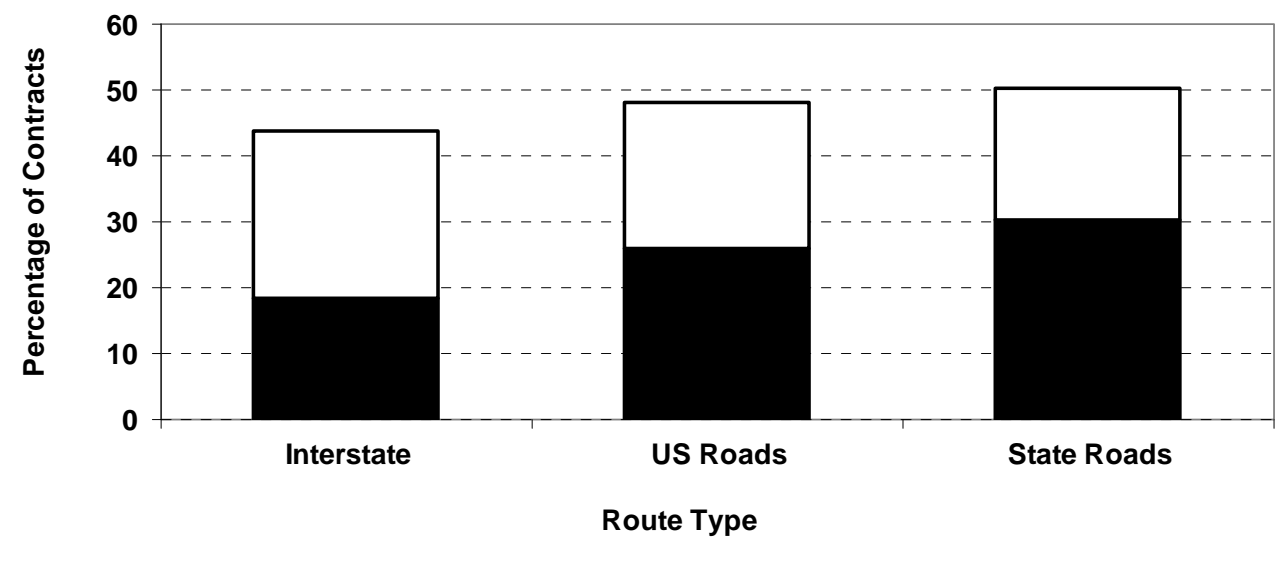

$\square$ Represents Percentage of Contracts where Cost Overrun $<-10 \%$ (i.e. Cost Underrun $>10 \%$ )

Depresents Percentage of Contracts where Cost Overrun $>10 \%$

Figure 5.7: Percentage of Contracts Outside the ' $+/-10 \%$ Cost Overrun Bracket' at the Planning Stage by Route Type

\section{(B) Severity of Planning Stage Cost Overrun / Underrun}

The average planning stage cost overrun was determined for contracts that lie outside the $+/-10 \%$ cost overrun bracket' by route type. The objective of this analysis was to determine whether contracts of any particular route type had a higher average planning stage cost overrun (i.e., more severe cost overrun) compared to others. The following conclusions were made:

i. $\quad$ For Contracts with Cost Overrun $>10 \%$ : The average planning stage cost overrun was $42 \%, 38 \%$ and $36 \%$ for Interstate, State Road, and U.S. Road contracts, respectively. While the average planning stage cost overrun was not significantly different across the route types, an analysis of the $95 \%$ confidence intervals indicated that the Interstate contracts $[18 \%, 66 \%]$ experience a wider range of cost overrun compared to State Road [31\%, 42\%] and U.S. Road [27\%, 46\%] contracts (Figure 5.8). The upper limit of the $95 \%$ confidence interval for Interstate contracts was $66 \%$ compared to $46 \%$ for U.S. Road and $42 \%$ for State Road contracts, which indicated that Interstate contracts experienced high cost overrun more frequently compared to U.S. and State Road contracts. Also, the width of the confidence interval for State Road contracts was less than the corresponding width of U.S. Road and Interstate contracts, indicating that State Road contracts experienced less variability in cost overrun.

ii. For Contracts with Cost Overrun $<-10 \%$ (i.e. Cost Underrun $>10 \%$ ): The average planning stage cost underrun for Interstate contracts (31\%) was higher compared to State Road (27\%) and U.S. Road (22\%) contracts. The $95 \%$ confidence intervals corresponding to these averages were [23\%, 
$39 \%$ ], [23\%, 30\%], and [18\%, 26\%] for Interstate, State Road, and U.S. Road contracts, respectively. Based on the plot of the $95 \%$ confidence intervals and the average planning stage cost overrun (Figure 5.8), it was concluded that the Interstate contracts are more susceptible to high cost underrun, compared to State Road and U.S. Road contracts.

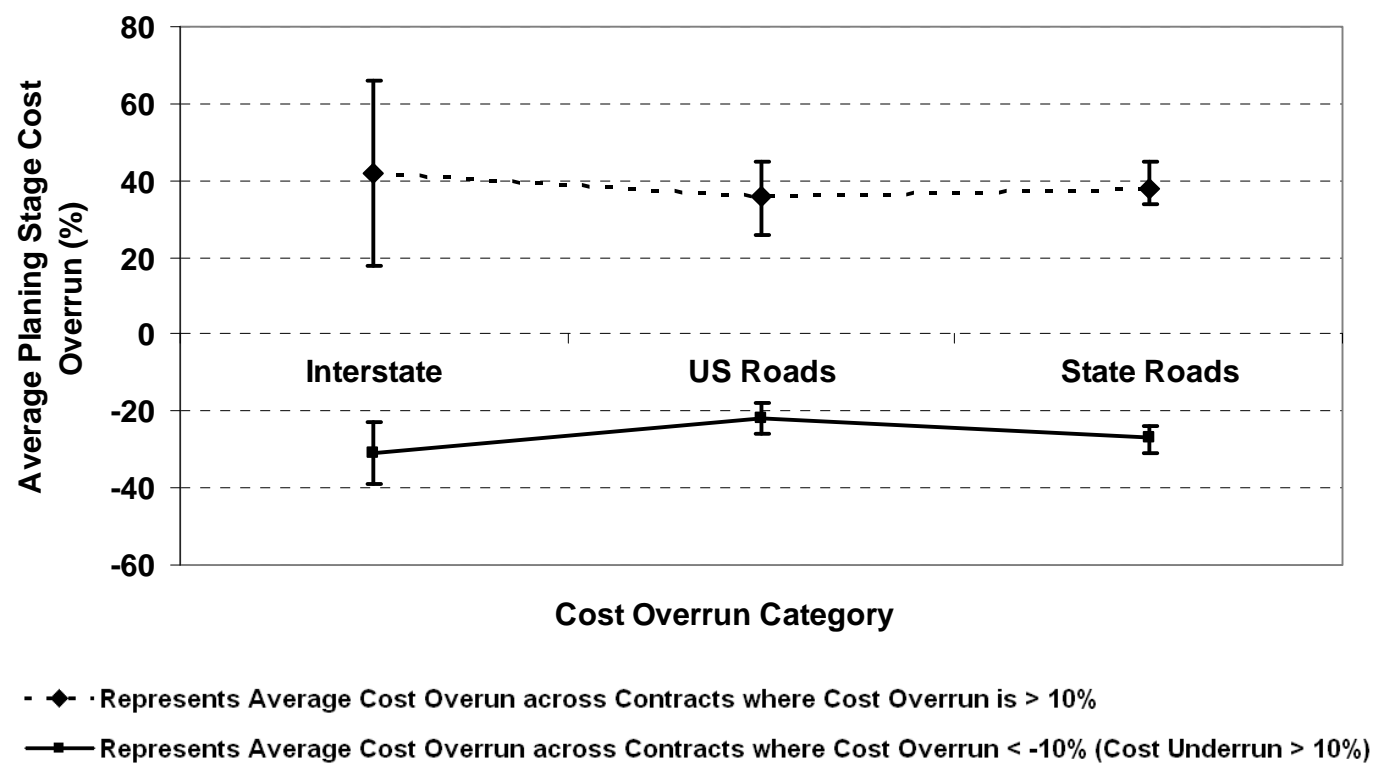

Figure 5.8: Average Planning Stage Cost Overrun for Contracts Outside the ' $+/-10 \%$ Cost Overrun Bracket' by Route Type

\subsubsection{Descriptive Analysis by NHS Status}

The average planning stage cost overrun for the 71 Interstate contracts, 112 Non-Interstate NHS contracts, and 236 Non-NHS contracts is as shown in Table 5.11. The 95\% confidence interval of the average planning stage cost overrun is also shown in the table. Both Non-Interstate NHS and Non-NHS contracts experienced an average planning stage cost overrun of 5.4\%. The $95 \%$ confidence intervals of the average planning stage cost overrun were also similar for Non-Interstate NHS $[0.6 \%, 10.2 \%]$ and Non-NHS $[1.9 \%$, $8.7 \%$ ] contracts. The positive average and $95 \%$ confidence intervals indicated that cost overruns are more prominent compared to cost underrun for Non-Interstate NHS and Non-NHS contracts. The average planning stage cost overrun was least for Interstate contracts $(0.5 \%)$ and the $95 \%$ confidence interval $[-6.7 \%, 7.7 \%]$ was symmetrically distributed around zero, thereby indicating that the cost overrun is balanced by the cost underrun for Interstate contracts. 
Table 5.11: Planning Stage Cost Overrun by NHS Status and Cost Overrun Category

\begin{tabular}{|c|c|c|c|c|c|}
\hline & $Y_{1}=100$ & $=100\left(\frac{\text { Final Cost }-}{\text { Propo }}\right.$ & $\left.\frac{\text { Proposed Cost }}{\text { ed Cost }}\right)$ & $\%$ & \multirow[b]{2}{*}{$\begin{array}{l}\text { Weighted } \\
\text { Average }\end{array}$} \\
\hline & $Y_{1}<-10 \%$ & $-10 \% \leq Y_{1}<0 \%$ & $0 \% \leq Y_{1} \leq 10 \%$ & $Y_{1}>10 \%$ & \\
\hline Interstate & $\begin{array}{l}\text { Average: }-31 \% \\
\text { Contracts: } 18 \\
\text { C.I: }[-39 \%,-23 \%]\end{array}$ & $\begin{array}{l}\text { Average: }-2 \% \\
\text { Contracts: } 16 \\
\text { C.I: }[-3.5 \%,-0.4 \%]\end{array}$ & $\begin{array}{l}\text { Average: } 3 \% \\
\text { Contracts: } 24 \\
\text { C.I: }[2 \%, 4 \%]\end{array}$ & $\begin{array}{l}\text { Average: } 42 \% \\
\text { Contracts: } 13 \\
\text { C.I: }[18 \%, 66 \%]\end{array}$ & $\begin{array}{l}\text { Average: } 0.5 \% \\
\text { Contracts: } 71 \\
\text { C.I:[-6.7\%,7.7\%] }\end{array}$ \\
\hline $\begin{array}{c}\text { Non } \\
\text { Interstate } \\
\text { NHS }\end{array}$ & $\begin{array}{l}\text { Average: }-23 \% \\
\text { Contracts: } 23 \\
\text { C.I: }[-28 \%,-18 \%]\end{array}$ & $\begin{array}{l}\text { Average: }-2.2 \% \\
\text { Contracts: } 24 \\
\text { C.I: }[-3.4 \%,-1 \%]\end{array}$ & $\begin{array}{l}\text { Average: } 2.9 \% \\
\text { Contracts: } 35 \\
\text { C.I: }[1.9 \%, 3.9 \%]\end{array}$ & $\begin{array}{l}\text { Average: } 36 \% \\
\text { Contracts: } 30 \\
\text { C.I: }[26 \%, 46 \%]\end{array}$ & $\begin{array}{l}\text { Average: } 5.4 \% \\
\text { Contracts: } 112 \\
\text { C.I: }[0.6 \%, 10.2 \%]\end{array}$ \\
\hline $\begin{array}{l}\text { Non } \\
\text { NHS }\end{array}$ & $\begin{array}{l}\text { Average: }-26 \% \\
\text { Contracts: } 50 \\
\text { C.I: }[-29 \%,-23 \%]\end{array}$ & $\begin{array}{l}\text { Average: }-2.7 \% \\
\text { Contracts: } 53 \\
\text { C.I: }[-3.5 \%,-1.8 \%]\end{array}$ & $\begin{array}{l}\text { Average: } 2.4 \% \\
\text { Contracts: } 64 \\
\text { C.I: }[1.7 \%, 3.1 \%]\end{array}$ & $\begin{array}{l}\text { Average: } 36 \% \\
\text { Contracts: } 69 \\
\text { C.I: }[31 \%, 42 \%]\end{array}$ & $\begin{array}{l}\text { Average: } 5.4 \% \\
\text { Contracts: } 236 \\
\text { C.I:[1.9\%,8.7\%] }\end{array}$ \\
\hline $\begin{array}{l}\text { Weighted } \\
\text { Average }\end{array}$ & $\begin{array}{l}\text { Average: }-26 \% \\
\text { Contracts: } 91 \\
\text { C.I: }[-29 \%,-23 \%]\end{array}$ & $\begin{array}{l}\text { Average: }-2.4 \% \\
\text { Contracts: } 93 \\
\text { C.I: }[-3 \%,-1.8 \%]\end{array}$ & $\begin{array}{l}\text { Average: } 2.7 \% \\
\text { Contracts: } 123 \\
\text { C.I: }[2.2 \%, 3.2 \%]\end{array}$ & $\begin{array}{l}\text { Average: } 37 \% \\
\text { Contracts: } 112 \\
\text { C.I: }[32 \%, 42 \%]\end{array}$ & $\begin{array}{l}\text { Average: } 4.5 \% \\
\text { Contracts: } 419 \\
\text { C.I:[1.9\%,7.1\%] }\end{array}$ \\
\hline
\end{tabular}

Contracts: Number of Contracts

C.I: 95\% Confidence Interval (Estimated Using One Sample t-Test)

\section{(A) Frequency of Planning Stage Cost Overrun / Underrun}

The Interstate, Non-Interstate NHS, and Non-NHS contracts, for which the planning stage cost overrun was outside the ' $+/-10 \%$ cost overrun bracket', were analyzed in more detail to determine if 'extreme' cost overrun and underrun are more frequent across contracts of any particular NHS status type. The following conclusions were made (Figure 5.9):

i. The percentage of Interstate contracts that were outside the ' $+/-10 \%$ cost overrun bracket' was $44 \%$ ( 31 of the 71 contracts), which was less than the corresponding percentage for Non-Interstate NHS contracts $(47 \%, 53$ of 112) and Non-NHS (50\%, 119 of 236) contracts.

ii. The percentage of Interstate contracts for which the planning stage cost overrun exceeded $10 \%$ was $18 \%$ (13 of 71), whereas the corresponding percentage for Non-Interstate NHS contracts was $27 \%$ (30 of 112) and for Non-NHS contracts was 36\% (69 of 236 contracts).

iii. The percentage of Interstate contracts for which the planning stage cost underrun was greater than $10 \%$ was $25 \%$ (18 of 71 ), whereas the corresponding percentage for Non-Interstate NHS contracts was $21 \%$ (23 of 112) and for Non-NHS contracts was $21 \%$ (50 of 236 contracts).

Based on these findings, it was concluded that the planning stage cost overrun is more frequent for Non-NHS contracts, followed by Non-Interstate NHS and Interstate contracts. Cost underrun on the other 
hand are marginally more frequent among Interstate contracts, compared to Non-Interstate NHS and NonNHS contracts.

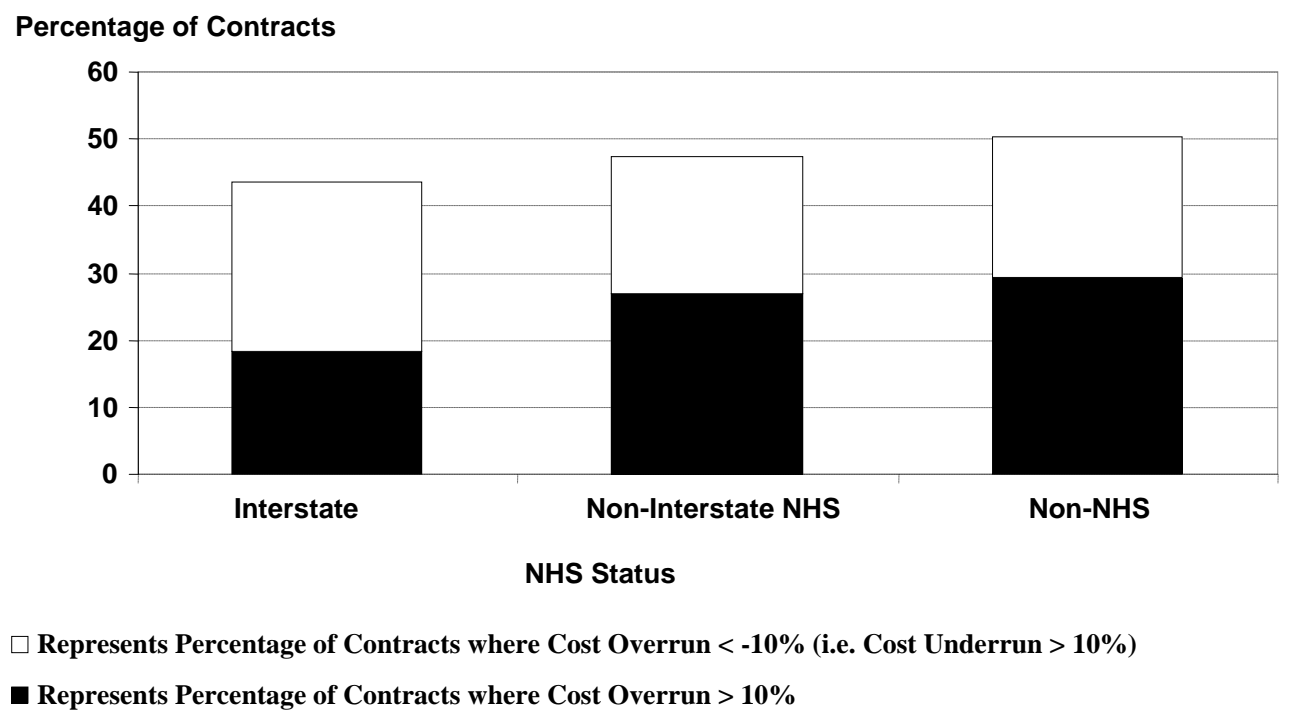

Figure 5.9: Percentage of Contracts Outside the ' $+/-10 \%$ Cost Overrun Bracket' at the Planning Stage by

\section{NHS Status}

\section{(B) Severity of Planning Stage Cost Overrun / Underrun}

The average planning stage cost overrun was calculated for contracts that lie outside the $+/-10 \%$ cost overrun bracket' for each NHS status to analyze severity. The following observations were made:

i. For Contracts with Cost Overrun $>10 \%$ : The average planning stage cost overrun was $42 \%$ for Interstate contracts, $36 \%$ for Non-Interstate NHS contracts, and 36\% for Non-NHS contracts. While the average planning stage cost overrun was not significantly different across the three NHS status level, an analysis of the $95 \%$ confidence intervals indicated that the Interstate contracts $[18 \%, 66 \%]$ experience a wider range of cost overrun compared to Non-Interstate NHS [26\%, $46 \%]$ and Non-NHS [31\%, 42\%] contracts (Figure 5.10). The upper limit of the 95\% confidence interval for Interstates contracts was $66 \%$ compared to $46 \%$ for Non-Interstate NHS contracts and $42 \%$ for Non-NHS, which implied that Interstate contracts were more susceptible to higher cost overrun compared to Non-Interstate NHS and Non-NHS contracts. Also, the lower limit of the confidence interval for Non-NHS (31\%) contracts exceeded that for Non-Interstate NHS (26\%) and Interstate (18\%) contracts: this indicates that Non-NHS and Non-Interstate NHS contracts experienced comparatively lower cost overrun than Interstate contracts.

ii. For Contracts with Cost Overrun $<-10 \%$ (i.e., Cost Underrun $>10 \%$ ): The average planning stage cost underrun for Interstate contracts (31\%) was higher compared to Non-NHS (26\%) and Non- 
Interstate NHS (23\%) contracts. The 95\% confidence intervals corresponding to these averages were [23\%, 39\%], [23\%, 29\%], and [18\%, 28\%] for Interstate, Non-NHS, and Non-Interstate NHS contracts respectively. Based on the $95 \%$ confidence intervals and the average planning stage cost overrun (Figure 5.10) it was concluded that the Interstate contracts were more susceptible to severe cost underrun, compared to Non-NHS and Non-Interstate NHS contracts.

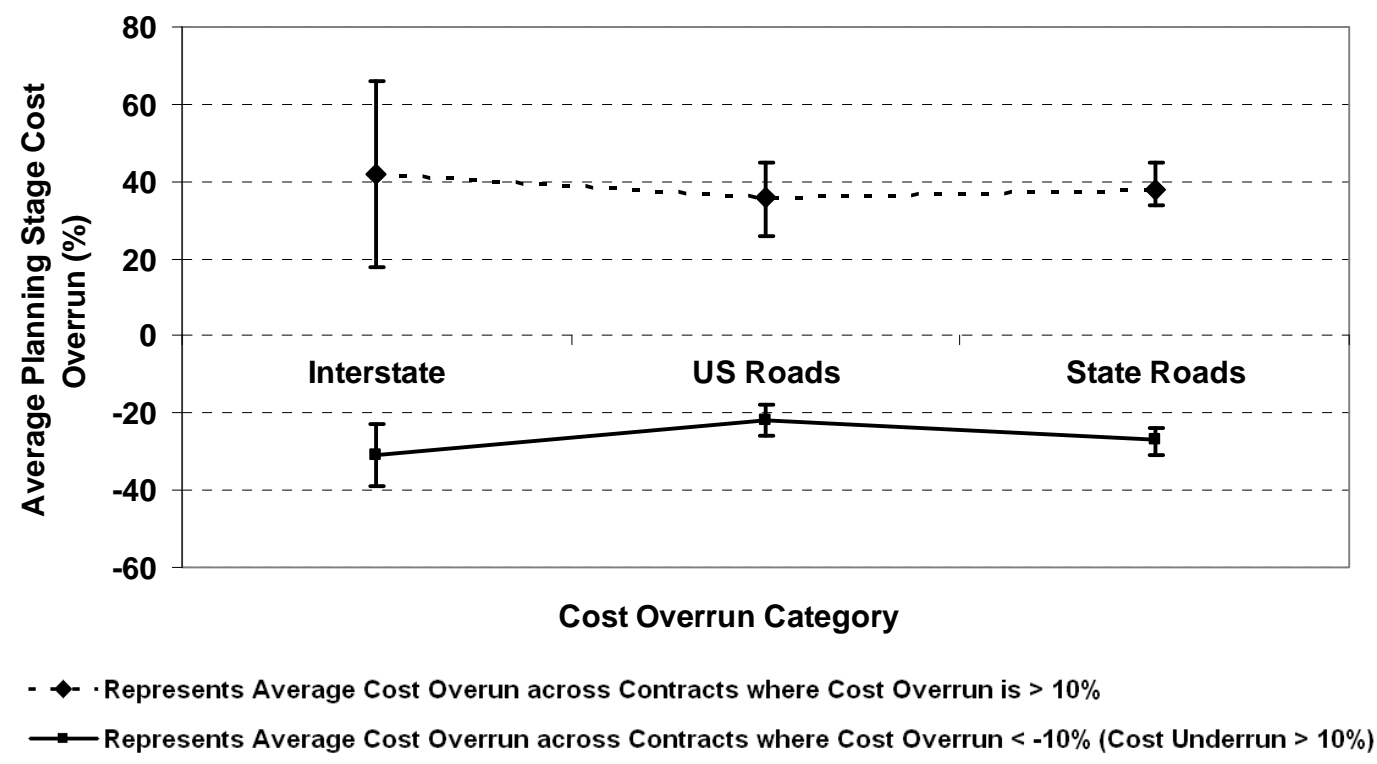

Figure 5.10: Average Planning Stage Cost Overrun for Contracts Outside the ‘ $+/-10 \%$ Cost Overrun Bracket' by NHS Status

\subsubsection{Descriptive Analysis by Administrative District}

Table 5.12 shows the average planning stage cost overrun for all districts. The Greenfield district had the highest average planning stage cost overrun (9.4\%), followed by Crawfordsville (6.2\%), Vincennes (5.3\%), Seymour (3.4\%), Fort Wayne (2.9\%), and Laporte (0.18\%). The 95\% confidence interval of the average planning stage cost overrun in the Greenfield and Crawfordsville districts was $[1.6 \%, 17 \%]$ and $[-0.4 \%$, $13 \%$ ] which indicated that cost overrun is significantly more prominent than cost underrun in both districts, with Greenfield in particular. In the districts of Seymour, Fort Wayne, and Vincennes, the 95\% confidence interval of the average planning stage cost overrun indicated that cost overrun is marginally prominent than cost underrun but the average overrun is not significantly different from zero. 
Table 5.12: Analysis of Planning Stage Cost Overrun by District and Cost Overrun Category

\begin{tabular}{|c|c|c|c|c|c|}
\hline & & $100\left(\frac{\text { Final Cost }}{\text { Prop }}\right.$ & $\frac{\text { Proposed Cost }}{\text { ed Cost }}$ & $\%$ & \\
\hline & $Y_{1}<-10 \%$ & $-10 \% \leq Y_{1}<0 \%$ & $0 \% \leq Y_{1} \leq 10 \%$ & $Y_{1}>10 \%$ & $\begin{array}{l}\text { Weighted } \\
\text { Average }\end{array}$ \\
\hline CRAWF & $\begin{array}{l}\text { Average: }-26.4 \% \\
\text { Contracts: } 13 \\
\text { C.I: }[-32 \%,-21 \%]\end{array}$ & $\begin{array}{l}\text { Average: }-4.1 \% \\
\text { Contracts: } 12 \\
\text { C.I: }[-6.4 \%,-1.9 \%]\end{array}$ & $\begin{array}{l}\text { Average: } 2.7 \% \\
\text { Contracts: } 19 \\
\text { C.I: }[1.4 \%, 4.1 \%]\end{array}$ & $\begin{array}{l}\text { Average: } 34 \% \\
\text { Contracts: } 22 \\
\text { C.I: }[23 \%, 45 \% \text { ] }\end{array}$ & $\begin{array}{l}\text { Average: } 6.2 \% \\
\text { Contracts: } 66 \\
\text { C.I:[-0.4\%,13\%] }\end{array}$ \\
\hline FW & $\begin{array}{l}\text { Average: }-30.5 \% \\
\text { Contracts: } 12 \\
\text { C.I: }[-41 \%,-20 \%]\end{array}$ & $\begin{array}{l}\text { Average: }-2.8 \% \\
\text { Contracts: } 15 \\
\text { C.I: }[-4.6 \%,-1 \%]\end{array}$ & $\begin{array}{l}\text { Average: } 2.5 \% \\
\text { Contracts: } 24 \\
\text { C.I: }[1.4 \%, 3.5 \%]\end{array}$ & $\begin{array}{l}\text { Average: } 34 \% \\
\text { Contracts: } 16 \\
\text { C.I: }[19 \%, 49 \%]\end{array}$ & $\begin{array}{l}\text { Average: } 2.9 \% \\
\text { Contracts: } 67 \\
\text { C.I:[-3.4\%,9.2\%] }\end{array}$ \\
\hline GRE & $\begin{array}{l}\text { Average: }-21.5 \% \\
\text { Contracts: } 17 \\
\text { C.I: }[-27 \%,-16 \%]\end{array}$ & $\begin{array}{l}\text { Average: }-1.4 \% \\
\text { Contracts: } 16 \\
\text { C.I: }[-2.6 \%,-0.1 \%]\end{array}$ & $\begin{array}{l}\text { Average: } 3.5 \% \\
\text { Contracts: } 18 \\
\text { C.I: }[1.9 \%, 5.0 \%]\end{array}$ & $\begin{array}{l}\text { Average: } 49 \% \\
\text { Contracts: } 20 \\
\text { C.I: }[33 \%, 65 \%]\end{array}$ & $\begin{array}{l}\text { Average: } 9.4 \% \\
\text { Contracts: } 71 \\
\text { C.I:[1.6\%,17\%] }\end{array}$ \\
\hline LAP & $\begin{array}{l}\text { Average: }-23.6 \% \\
\text { Contracts: } 17 \\
\text { C.I: }[-31 \%,-16 \%]\end{array}$ & $\begin{array}{l}\text { Average: }-1.4 \% \\
\text { Contracts: } 19 \\
\text { C.I: }[-2.4 \%,-0.4 \%]\end{array}$ & $\begin{array}{l}\text { Average: } 2.5 \% \\
\text { Contracts: } 27 \\
\text { C.I: }[15 \%, 3.6 \%]\end{array}$ & $\begin{array}{l}\text { Average: } 34 \% \\
\text { Contracts: } 11 \\
\text { C.I: }[21 \%, 46 \%]\end{array}$ & $\begin{array}{l}\text { Average: } 0.18 \% \\
\text { Contracts: } 74 \\
\text { C.I:[-4.5\%,4.8\%] }\end{array}$ \\
\hline SEY & $\begin{array}{l}\text { Average: }-26.8 \% \\
\text { Contracts: } 15 \\
\text { C.I: }[-31 \%,-22 \%]\end{array}$ & $\begin{array}{l}\text { Average: }-2.4 \% \\
\text { Contracts: } 18 \\
\text { C.I: }[-3.9 \%,-0.9 \%]\end{array}$ & $\begin{array}{l}\text { Average: } 1.1 \% \\
\text { Contracts: } 18 \\
\text { C.I: }[.2 \%, \% 2]\end{array}$ & $\begin{array}{l}\text { Average: } 31 \% \\
\text { Contracts: } 22 \\
\text { C.I: }[19 \%, 42 \%]\end{array}$ & $\begin{array}{l}\text { Average: } 3.4 \% \\
\text { Contracts: } 73 \\
\text { C.I:[-2.5\%,9.3\%] }\end{array}$ \\
\hline VIN & $\begin{array}{l}\text { Average: }-28.3 \% \\
\text { Contracts: } 17 \\
\text { C.I: }[-35 \%,-21 \%]\end{array}$ & $\begin{array}{l}\text { Average: }-3.2 \% \\
\text { Contracts: } 13 \\
\text { C.I: }[-5.3 \%,-1.2 \%]\end{array}$ & $\begin{array}{l}\text { Average: } 3.9 \% \\
\text { Contracts: } 17 \\
\text { C.I: }[2 \%, 5.7 \% \text { ] }\end{array}$ & $\begin{array}{l}\text { Average: } 39 \% \\
\text { Contracts: } 21 \\
\text { C.I: }[28 \%, 51 \%]\end{array}$ & $\begin{array}{l}\text { Average: } 5.3 \% \\
\text { Contracts: } 68 \\
\text { C.I:[-2\%,12.3\%] }\end{array}$ \\
\hline $\begin{array}{l}\text { Weighted } \\
\text { Average }\end{array}$ & $\begin{array}{l}\text { Average: }-26 \% \\
\text { Contracts: } 91 \\
\text { C.I: }[-29 \%,-23 \%]\end{array}$ & $\begin{array}{l}\text { Average: }-2.4 \% \\
\text { Contracts: } 93 \\
\text { C.I: }[-3 \%,-1.8 \%]\end{array}$ & $\begin{array}{l}\text { Average: } 2.7 \% \\
\text { Contracts: } 123 \\
\text { C.I: }[2.2 \%, 3.2 \%]\end{array}$ & $\begin{array}{l}\text { Average: } 37 \% \\
\text { Contracts: } 112 \\
\text { C.I: }[32 \%, 42 \% \text { ] }\end{array}$ & $\begin{array}{l}\text { Average: } 4.5 \% \\
\text { Contracts: } 419 \\
\text { C.I:[1.9\%,7.1\%] }\end{array}$ \\
\hline
\end{tabular}

Contracts: Number of Contracts

C.I: 95\% Confidence Interval (Estimated Using One Sample t-Test)

\section{(A) Frequency of Planning Stage Cost overrun / Underrun}

The distribution of the contracts that lie outside the ' $+/-10 \%$ planning stage cost overrun bracket' by district is shown in Figure 5.11. The following observations were made:

i. The percentage of contracts outside the $+/-10 \%$ cost overrun bracket was least in Laporte district (38\%) followed by Fort Wayne (42\%), Seymour (51\%), Greenfield (52\%), Crawfordsville (53\%) and Vincennes (56\%). On the average, approximately $49 \%$ of contracts across all districts have a planning stage cost overrun outside the ' $+/-10 \%$ cost overrun bracket'.

ii. Approximately $30 \%$ of contracts in each of the three districts of Crawfordsville, Seymour, and Vincennes had a cost overrun greater than $10 \%$. Only $15 \%$ of the contracts in the Laporte district 
had a planning stage cost overrun greater than $10 \%$. In the districts of Fort Wayne and Greenfield $24 \%$ of the contracts had a planning stage cost overrun of greater than $10 \%$.

iii. The percentage of contracts having a cost underrun of greater than $10 \%$ was found to be least for the Fort Wayne district (18\%). The percentage of contracts having a cost underrun of greater than $10 \%$ was $20 \%$ for Crawfordsville, $21 \%$ for Seymour, $23 \%$ for Laporte, $24 \%$ for Greenfield, and $25 \%$ for Vincennes districts.

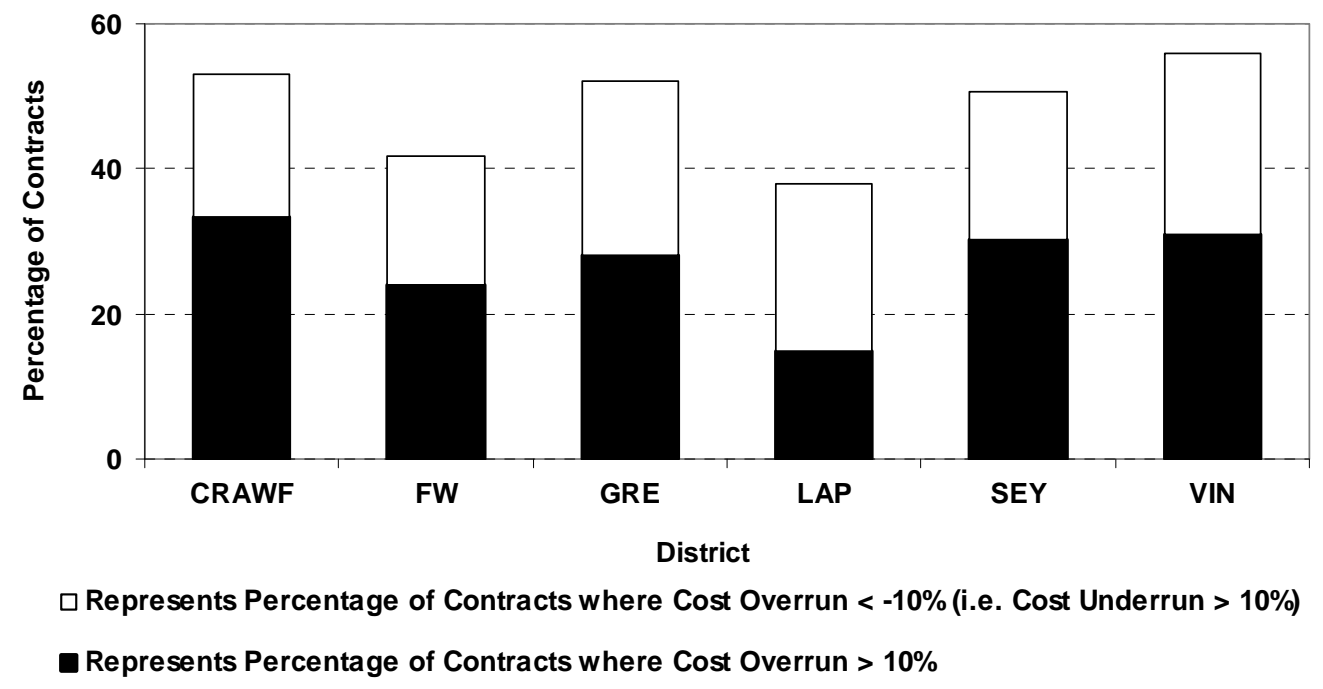

Figure 5.11: Percentage of Contracts Outside the ' $+/-10 \%$ Cost Overrun Bracket' at the Planning Stage by Administrative District

\section{(B) Severity of Planning Stage Cost Overrun / Underrun}

The average planning stage cost overrun was determined for contracts that lie outside the $+/-10 \%$ cost overrun bracket' by administrative district. The objective of this analysis was to identify the districts with high cost overrun at the planning stage.

i. For Contracts with Cost Overrun $>10 \%$ : The average planning stage cost overrun was highest for Greenfield district (49\%), followed by Vincennes (39\%), Crawfordsville (34\%), Fort Wayne (34\%), Laporte (34\%), and Seymour (34\%). The 95\% confidence intervals of the average planning stage cost overrun were also plotted for each district (Figure 5.12). The analysis of the $95 \%$ confidence intervals indicated that the average planning stage cost overrun for Greenfield district was high compared to all the other districts. Other districts did not have significant differences.

ii. For Contracts with Cost Overrun $<-10 \%$ (i.e. Cost Underrun $>10 \%$ ): The average planning stage cost underrun was $31 \%$ in Fort Wayne, $28 \%$ in Vincennes, $27 \%$ in Seymour, $26 \%$ in Crawfordsville, $24 \%$ in Laporte, and $22 \%$ in Greenfield district. An analysis of the $95 \%$ confidence interval of these average planning stage cost underrun indicates that the contracts in 
Fort Wayne district were more susceptible to high planning stage cost underrun. The upper limit of the average planning stage cost under run in all the other districts was comparatively lower and in the range of 31\%-35\%. Hence, contracts in Fort Wayne had more frequent high cost underrun.

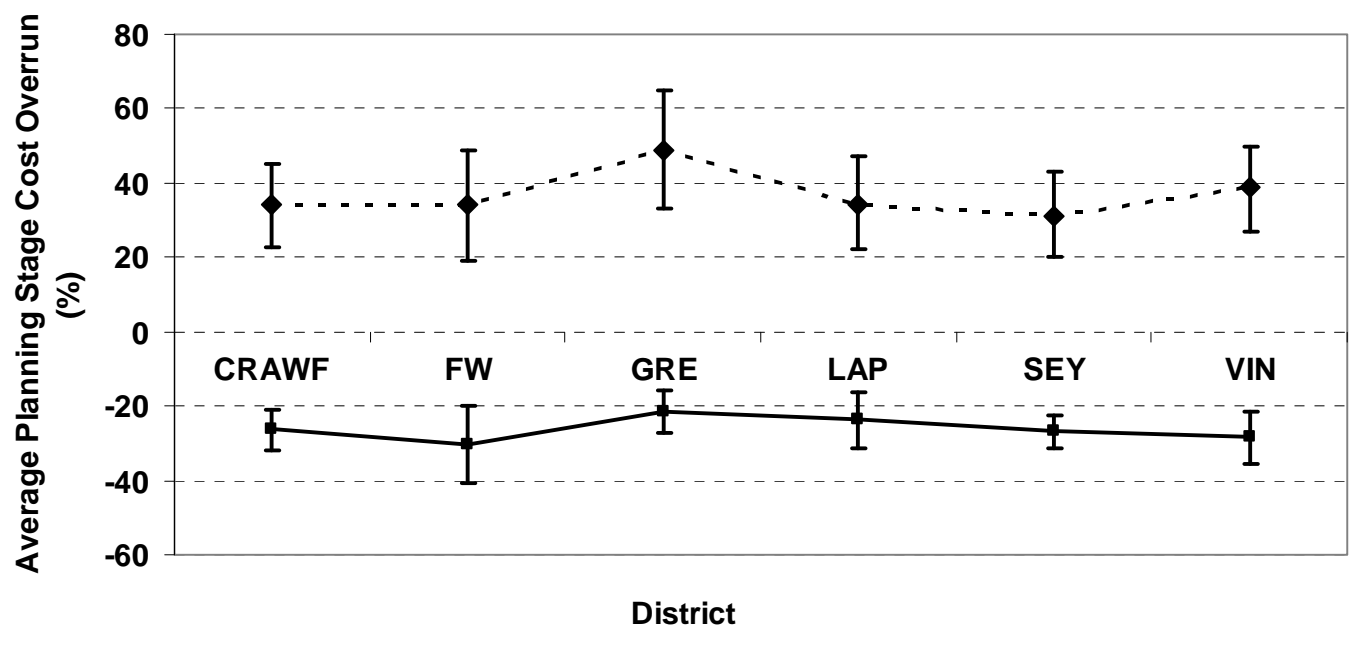

- $\downarrow$ - Represents Average Cost Overun across Contracts where Cost Overrun is $>10 \%$

$\longrightarrow$ Represents Average Cost Overrun across Contracts where Cost Overrun $<-10 \%($ Cost Underrun $>10 \%)$

Figure 5.12: Average Planning Stage Cost Overrun for Contracts Outside the ‘ $+/-10 \%$ Cost Overrun Bracket' by District

\subsubsection{Descriptive Analysis by Area Type}

The average planning stage cost overrun in the urban area was $7.4 \%$ and the $95 \%$ confidence interval of the average was $[2.5 \%, 12 \%]$ (Table 5.13). The average planning stage cost overrun in the rural area was $3.2 \%$ and the $95 \%$ confidence interval of the average was $[0.1 \%, 6.2 \%]$. Based on the comparison of the averages and the upper limits of the $95 \%$ confidence interval, it was seen that urban areas had more cost overrun compared to rural areas. 
Table 5.13: Analysis of Planning Stage Cost Overrun by Area Type and Cost Overrun Category

\begin{tabular}{|c|c|c|c|c|c|}
\hline & $Y_{1}=100$ & \multicolumn{3}{|c|}{$\left(\frac{\text { Final Cost }- \text { Proposed Cost }}{\text { Proposed Cost }}\right) \%$} & \multirow[b]{2}{*}{$\begin{array}{l}\text { Weighted } \\
\text { Average }\end{array}$} \\
\hline & $Y_{1}<-10 \%$ & $-10 \% \leq Y_{1}<0 \%$ & $0 \% \leq Y_{1} \leq 10 \%$ & $Y_{1}>10 \%$ & \\
\hline Urban & $\begin{array}{l}\text { Average: }-23.4 \% \\
\text { Contracts: } 23 \\
\text { C.I: }[-29 \%,-18 \%]\end{array}$ & $\begin{array}{l}\text { Average: }-2.3 \% \\
\text { Contracts: } 37 \\
\text { C.I: }[-3.3 \%,-1.2 \%]\end{array}$ & $\begin{array}{l}\text { Average: } 2.5 \% \\
\text { Contracts: } 43 \\
\text { C.I: }[1.7 \%, 3.4 \%]\end{array}$ & $\begin{array}{l}\text { Average: } 46 \% \\
\text { Contracts: } 33 \\
\text { C.I: }[35 \%, 57 \%]\end{array}$ & $\begin{array}{l}\text { Average: } 7.4 \% \\
\text { Contracts: } 136 \\
\text { C.I:[2.5\%,12\%] }\end{array}$ \\
\hline Rural & $\begin{array}{l}\text { Average: }-27 \% \\
\text { Contracts: } 68 \\
\text { C.I: }[-30 \%,-24 \%]\end{array}$ & $\begin{array}{l}\text { Average: }-2.5 \% \\
\text { Contracts: } 56 \\
\text { C.I: }[-3.3 \%,-1.7 \%]\end{array}$ & $\begin{array}{l}\text { Average: } 2.7 \% \\
\text { Contracts: } 80 \\
\text { C.I: }[2.1 \%, 3.4 \% \text { ] }\end{array}$ & $\begin{array}{l}\text { Average: } 33 \% \\
\text { Contracts: } 79 \\
\text { C.I: }[28 \%, 39 \% \text { ] }\end{array}$ & $\begin{array}{l}\text { Average: } 3.2 \% \\
\text { Contracts: } 283 \\
\text { C.I:[0.1\%,6.2\%] }\end{array}$ \\
\hline $\begin{array}{l}\text { Weighted } \\
\text { Average }\end{array}$ & $\begin{array}{l}\text { Average: }-26 \% \\
\text { Contracts: } 91 \\
\text { C.I: }[-29 \%,-23 \%]\end{array}$ & $\begin{array}{l}\text { Average: }-2.4 \% \\
\text { Contracts: } 93 \\
\text { C.I: }[-3 \%,-1.8 \%]\end{array}$ & $\begin{array}{l}\text { Average: } 2.7 \% \\
\text { Contracts: } 123 \\
\text { C.I: }[2.2 \%, 3.2 \%]\end{array}$ & $\begin{array}{l}\text { Average: } 37 \% \\
\text { Contracts: } 112 \\
\text { C.I: }[32 \%, 42 \% \text { ] }\end{array}$ & $\begin{array}{l}\text { Average: } 4.5 \% \\
\text { Contracts: } 419 \\
\text { C.I:[1.9\%,7.1\%] }\end{array}$ \\
\hline
\end{tabular}

Contracts: Number of Contracts

C.I: 95\% Confidence Interval (Estimated Using One Sample t-Test)

\section{(A) Frequency of Planning Stage Cost Overrun / Underrun}

The contracts that lie outside the ' $+/-10 \%$ cost overrun bracket' were analyzed by area type. The following observations were made based on the results presented in Table 5.13:

i. The planning stage cost overrun was outside the ' $+/-10 \%$ cost overrun bracket' for $41 \%$ (56 of 136) of the urban area contracts and $52 \%$ (147 of 283) of the rural area contracts.

ii. The planning stage cost overrun exceeded $10 \%$ for $24 \%$ (33 of 136) of the urban area contracts and $28 \%$ ( 79 of 283 ) of the rural area contracts.

iii. The planning stage cost underrun exceeded 10\% for 17\% (23 of 136) of the urban area contracts and $24 \%$ (68 of 283 ) of the rural area contracts. 


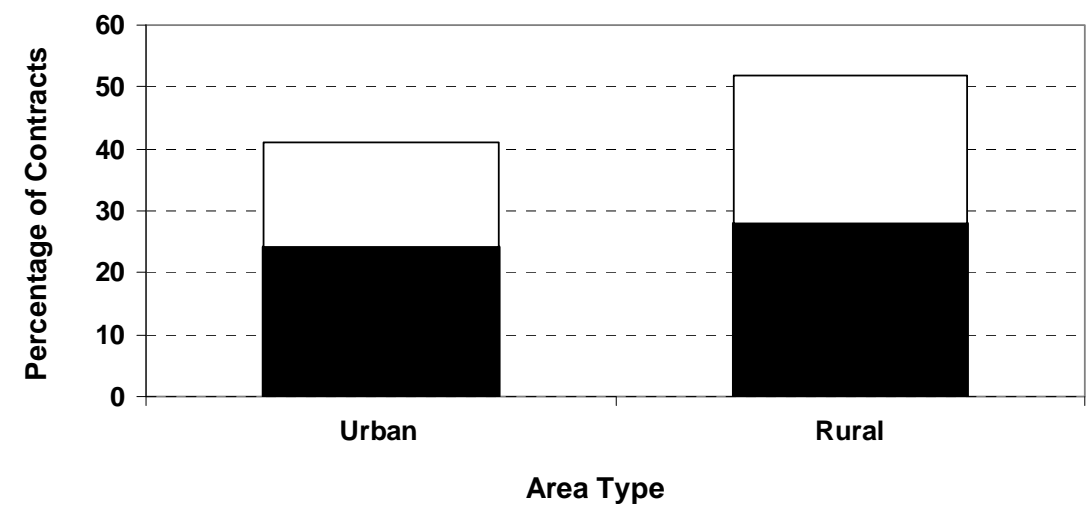

$\square$ Represents Percentage of Contracts where Cost Overrun $<-10 \%$ (i.e. Cost Underrun $>10 \%$ )

Represents Percentage of Contracts where Cost Overrun $>10 \%$

Figure 5.13: Percentage of Contracts Outside the ' $+/-10 \%$ Cost Overrun Bracket' at the Planning Stage by Area Type

\section{(B) Severity of Planning Stage Cost Overrun / Underrun}

The analysis of the average planning stage cost overrun for urban and rural area contracts that lie outside the ' $+/-10 \%$ cost overrun bracket' is presented in Figure 5.14. The following observations were made:

i. For Contracts with Cost Overrun $>10 \%$ : The average planning stage cost overrun in urban and rural areas was $46 \%$ and $33 \%$, respectively. The length of $95 \%$ confidence interval of the average planning stage cost overrun for urban area contracts [35\%, 57\%] was twice the length of the confidence interval for rural area contracts $[28 \%, 39 \%]$. In other words, the variability of the planning stage cost overrun was greater for urban area contracts. The upper limit of the confidence interval for urban area contracts (57\%) was higher compared to that of rural area contracts (39\%), which indicated that urban area contracts experienced higher planning stage cost overrun compared to rural area contracts.

ii. For Contracts with Cost Overrun $<-10 \%$ (i.e. Cost Underrun $>10 \%$ ): The average planning stage cost underrun in the urban and rural areas was $23 \%$. The $95 \%$ confidence interval of the average planning stage cost underrun for urban area contracts $[18 \%, 29 \%]$ and for rural area contracts $[24 \%, 30 \%]$ indicated that rural area contracts higher cost underrun compared to urban area contracts. 


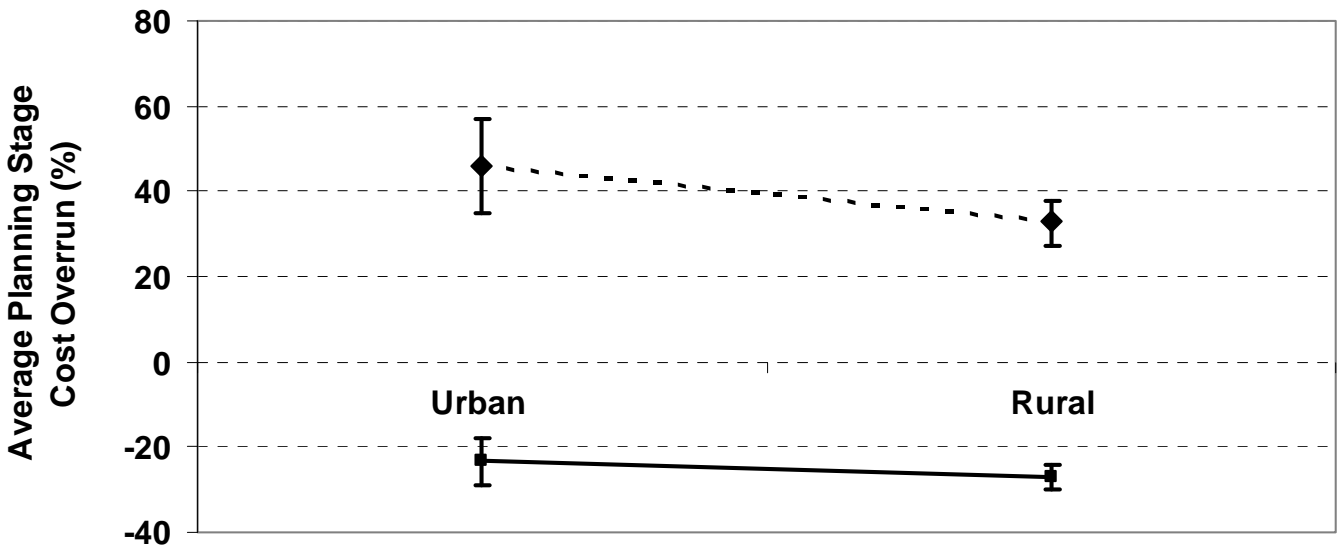

Area Type

- $\downarrow$ - Represents Average Cost Overun across Contracts where Cost Overrun is $>10 \%$

$\rightarrow-$ Represents Average Cost Overrun across Contracts where Cost Overrun $<-10 \%($ Cost Underrun $>10 \%)$

Figure 5.14: Average Planning Stage Cost Overrun for Contracts Outside the " $+/-10 \%$ Cost Overrun Bracket' by Area Type

\subsubsection{Final Cost vs. Engineer's Assessment Cost}

The overrun of the final construction cost compared to the engineer's assessment cost was calculated to determine the accuracy of the estimate prepared after the project has been programmed. The overrun was calculated as:

$$
Y_{2}=100\left(\frac{\text { Final Cost-Engineer's Assessment Cost }}{\text { Engineer's Assessment Cost }}\right) \%
$$

The overrun of the final cost over the engineer's assessment cost was analyzed by contract size, work category, district, area type, route type, NHS status, and contract type. The results were similar to those for the planning stage cost overrun, which implied that the engineer's assessment cost was not significantly different from the proposed cost. In order to verify this implication, the proposed cost was compared to the engineer's assessment cost. The percentage difference between the engineer's assessment cost and proposed cost was calculated as follows:

$$
Y=100\left(\frac{\text { Engineer's Assessment Cost-Proposed Cost }}{\text { Proposed Cost }}\right) \%
$$

Table 5.14 presents the difference between the proposed cost and the engineer's assessment cost by cost overrun category and work category. It was found that the proposed cost and engineer's assessment cost did not differ significantly from each other for 394 of the 419 contracts. The average percentage 
difference was greater than $+/-10 \%$ for only 22 of the 419 contracts; nineteen of these 22 contracts were pavement contracts. Because of the similarity in the engineer's assessment cost and the proposed cost for most of the contracts in the state, results of the detailed analysis of the overrun of the final construction cost over the engineer's assessment cost were not presented in this report.

Table 5.14: Analyzing the Difference between Proposed Cost and Engineer's Assessment Cost

\begin{tabular}{|c|c|c|c|c|c|}
\hline & \multicolumn{4}{|c|}{$Y=100\left(\frac{\text { Engineer's Assessment Cost }- \text { Proposed Cost }}{\text { Proposed Cost }}\right) \%$} & \\
\hline & $Y<-10 \%$ & $-10 \% \leq Y<0 \%$ & $0 \% \leq Y \leq 10 \%$ & $Y>10 \%$ & $\begin{array}{l}\text { Weighted } \\
\text { Average }\end{array}$ \\
\hline Expansion & $\begin{array}{l}\text { Average: }-36 \% \\
\text { Contracts: } 1\end{array}$ & - & $\begin{array}{l}\text { Average: } 0.11 \% \\
\text { Contracts: } 72\end{array}$ & - & $\begin{array}{l}\text { Average: } 0.21 \% \\
\text { Contracts: } 73\end{array}$ \\
\hline Bridge & - & $\begin{array}{l}\text { Average: }-4.8 \% \\
\text { Contracts: } 1\end{array}$ & $\begin{array}{l}\text { Average: } 0.04 \% \\
\text { Contracts: } 102\end{array}$ & $\begin{array}{l}\text { Average: } 21 \% \\
\text { Contracts: } 4\end{array}$ & $\begin{array}{l}\text { Average: } 0.77 \% \\
\text { Contracts: } 107\end{array}$ \\
\hline Pavement & $\begin{array}{l}\text { Average: }-28 \% \\
\text { Contracts: } 6\end{array}$ & $\begin{array}{l}\text { Average: }-5.5 \% \\
\text { Contracts: } 2\end{array}$ & $\begin{array}{l}\text { Average: } 0.02 \% \\
\text { Contracts: } 220\end{array}$ & $\begin{array}{l}\text { Average: } 39 \% \\
\text { Contracts: } 11\end{array}$ & $\begin{array}{l}\text { Average: } 1.04 \% \\
\text { Contracts: } 239\end{array}$ \\
\hline $\begin{array}{l}\text { Weighted } \\
\text { Average }\end{array}$ & $\begin{array}{l}\text { Average: }-30 \% \\
\text { Contracts: } 7\end{array}$ & $\begin{array}{l}\text { Average: }-5.26 \% \\
\text { Contracts: } 3\end{array}$ & $\begin{array}{l}\text { Average: } 0.04 \% \\
\text { Contracts: } 394\end{array}$ & $\begin{array}{l}\text { Average: } 37 \% \\
\text { Contracts: } 15\end{array}$ & $\begin{array}{l}\text { Average: } 0.82 \% \\
\text { Contracts: } 419\end{array}$ \\
\hline
\end{tabular}

Contracts: Number of Contracts

\subsubsection{Final Cost vs. Design Cost}

The overrun of the final construction cost over the design estimate of the construction cost was calculated to determine the accuracy of the estimate prepared at the final design stage. This cost overrun is referred to as the design stage cost overrun. The design stage cost overrun was calculated as follows:

$$
\text { Design Stage Cost Overrun : } Y_{3}=100\left(\frac{\text { Final Cost }- \text { Design Cost }}{\text { Design Cost }}\right) \%
$$

The distribution of design stage cost overrun is shown in Figure 5.15 for 419 contracts. The average design stage cost overrun was $1.85 \%$ and the standard deviation was $24 \%$. The $95 \%$ confidence interval of the average design stage cost overrun was $[-0.4 \%, 4.1 \%]$. However, these numbers are not a true reflection of the accuracy of the cost estimate prepared at the design stage. This is because the positive cost overrun is compensated by the negative cost overrun. The positive value of average design stage cost overrun $(1.85 \%)$ and the $95 \%$ confidence interval $[-0.4 \%, 4.1 \%]$ indicated that the cost overrun are either more severe or more frequent compared to cost underrun at the design stage. Table 5.15 presents the average design stage cost overrun by design stage cost overrun category (as defined in Chapter 4). 


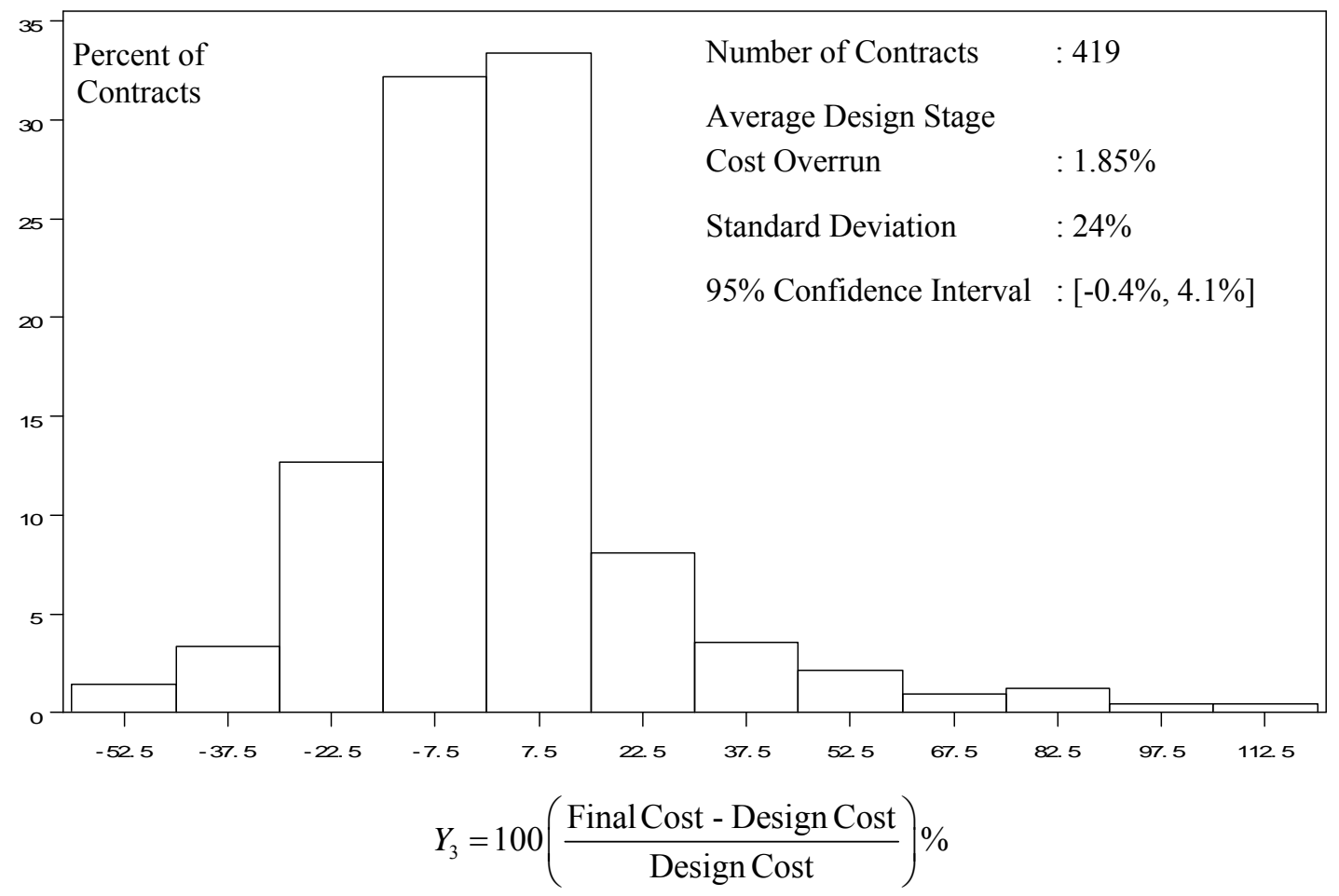

Figure 5.15: Histogram Distribution of Design Stage Cost Overrun

The design stage cost overrun exceeded $10 \%$ for $22 \%$ of the contracts ( 94 of the 419 contracts). For $25 \%$ of the contracts ( 105 of the 419 contracts) the design stage cost overrun was less than $-10 \%$ (i.e., the design stage cost underrun exceeded 10\%). Overall, for $47 \%$ of the contracts (199 of 419 contracts) the difference between the design estimate and the final cost was outside ' $+/-10 \%$ cost overrun bracket'.

Table 5.15: Analysis of Average Design Stage Cost Overrun by Cost Overrun Category

\begin{tabular}{|l|c|c|c|c|c|}
\hline \multirow{2}{*}{} & \multicolumn{4}{|c|}{$Y_{3}=100\left(\frac{\text { Final Cost - Design Cost }}{\text { Design Cost }}\right) \%$} & \\
\cline { 2 - 6 } & $Y_{3}<-10 \%$ & $-10 \% \leq Y_{3}<0 \%$ & $0 \% \leq Y_{3} \leq 10 \%$ & $Y_{3}>10 \%$ & Total \\
\hline $\begin{array}{l}\text { Number of } \\
\text { Contracts }\end{array}$ & 105 & 103 & 117 & 94 & 419 \\
\hline $\begin{array}{l}\text { Weighted } \\
\text { Average }\end{array}$ & $-22.97 \%$ & $-2.58 \%$ & $2.66 \%$ & $33.44 \%$ & $1.85 \%$ \\
\hline $\begin{array}{l}95 \% \\
\text { Confidence } \\
\text { Interval }\end{array}$ & {$[-25 \%,-21 \%]$} & {$[-3.15 \%,-2.01 \%]$} & {$[2.12 \%, 3.19 \%]$} & {$[28 \%, 38 \%]$} & {$[-0.4 \%, 4.1 \%]$} \\
\hline
\end{tabular}


For the 94 contracts which had the design stage cost overrun greater than $10 \%$, it was found that the average design stage cost overrun across these contracts was $33 \%$ and the $95 \%$ confidence interval of the average was $[28 \%, 38 \%$ ] (Figure 5.16). For the 105 contracts which had the design stage cost underrun of greater than $10 \%$, the average design stage cost underrun was $23 \%$ and the $95 \%$ confidence interval was $[21 \%, 25 \%]$. The average design stage cost overrun and the limits of the $95 \%$ confidence interval were less than $5 \%$ for the contracts that lie within the ' $+/-10 \%$ cost overrun bracket'. Therefore, contracts that fall outside the ' $+/-10 \%$ cost overrun bracket' were those that resulted in a high cost overrun or underrun at the design stage. Sections 5.3.3.1 through 5.3.3.7 present a detailed analysis of the contracts that exceed the ' $+/-10 \%$ cost overrun bracket' at the design stage.

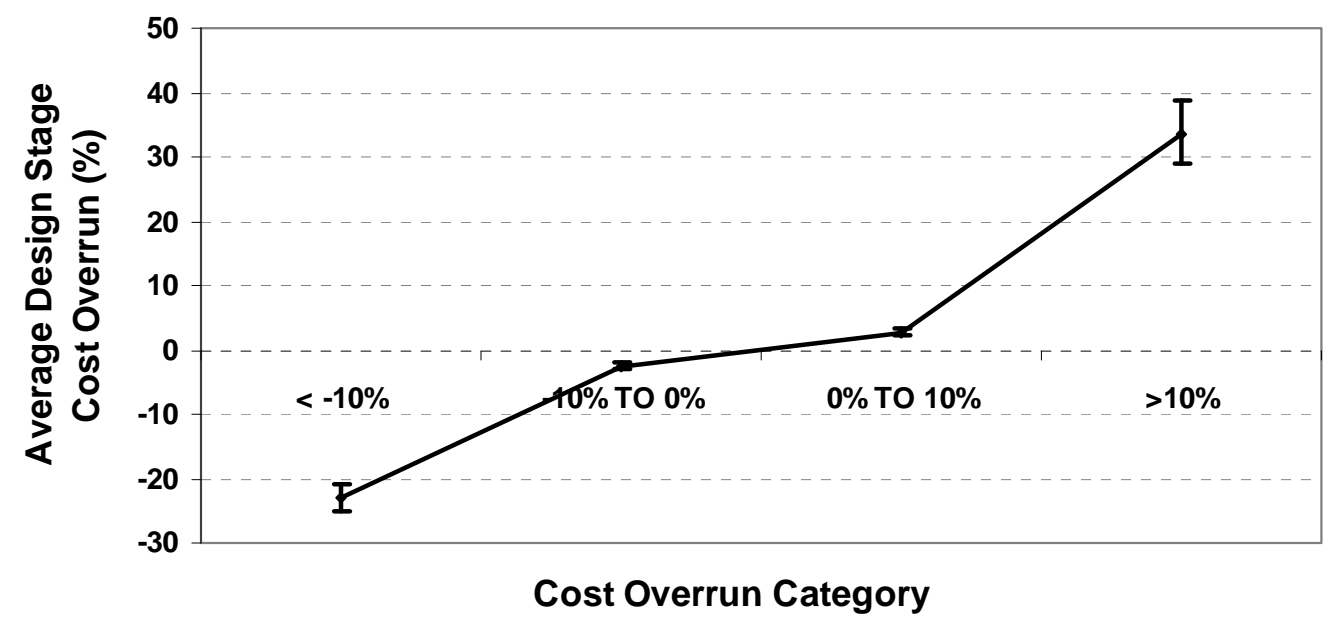

Figure 5.16: Analysis of Average Design Stage Cost Overrun by Cost Overrun Category

\subsubsection{Descriptive Analysis by Work Category}

The average design stage cost overrun for the 73 expansion contracts, 107 bridge contracts and 239 pavement contracts is as shown in Table 5.16, as well as the corresponding 95\% confidence interval of the averages. The average design stage cost overrun was highest for pavement contracts (4\%) and the $95 \%$ confidence interval of the average $[0.5 \%, 7 \%]$ indicated that the cost overrun is more dominant than cost underrun for pavement contracts. For expansion contracts, the average design stage cost overrun $(0.7 \%)$ and the $95 \%$ confidence interval $[-4.0 \%, 5.5 \%]$ of the average, indicated that cost overrun and underrun balance each other. For bridge contracts, the average design state cost overrun (-2\%) and the 95\% confidence interval of the average $[-5 \%, 1 \%]$ indicated that cost underrun are dominant over cost overrun for the contracts in this work category. 
Table 5.16: Analysis of Average Cost Overrun of Final Cost over Design Cost by Work Category

\begin{tabular}{|c|c|c|c|c|c|}
\hline & \multicolumn{3}{|c|}{$Y_{3}=100$} & & \multirow[b]{2}{*}{$\begin{array}{l}\text { Weighted } \\
\text { Average }\end{array}$} \\
\hline & $Y_{3}<-10 \%$ & $-10 \% \leq Y_{3}<0 \%$ & $0 \% \leq Y_{3} \leq 10 \%$ & $Y_{3}>10 \%$ & \\
\hline $\begin{array}{l}\text { Expansion } \\
\text { Contracts }\end{array}$ & $\begin{array}{l}\text { Average: }-26 \% \\
\text { Contracts: } 15 \\
\text { C.I: }[-35 \%,-18 \%]\end{array}$ & $\begin{array}{l}\text { Average: }-2.1 \% \\
\text { Contracts: } 21 \\
\text { C.I: }[-3 \%,-1 \%]\end{array}$ & $\begin{array}{l}\text { Average: } 3.1 \% \\
\text { Contracts: } 22 \\
\text { C.I: }[1.7 \%, 4.6 \%]\end{array}$ & $\begin{array}{l}\text { Average: } 28 \% \\
\text { Contracts: } 15 \\
\text { C.I: }[18 \%, 38 \%]\end{array}$ & $\begin{array}{l}\text { Average: } 0.7 \% \\
\text { Contracts: } 73 \\
\text { C.I:[-4\%,5.5\%] }\end{array}$ \\
\hline $\begin{array}{c}\text { Bridge } \\
\text { Contracts }\end{array}$ & $\begin{array}{l}\text { Average: }-20 \% \\
\text { Contracts: } 24 \\
\text { C.I: }[-25 \%,-16 \%]\end{array}$ & $\begin{array}{l}\text { Average: }-1.89 \% \\
\text { Contracts: } 30 \\
\text { C.I: }[-3 \%,-0.7 \%]\end{array}$ & $\begin{array}{l}\text { Average: } 1.45 \% \\
\text { Contracts: } 45 \\
\text { C.I: }[0.7 \%, 2.1 \%]\end{array}$ & $\begin{array}{l}\text { Average: } 33 \% \\
\text { Contracts: } 8 \\
\text { C.I: }[11 \%, 55 \%]\end{array}$ & $\begin{array}{l}\text { Average: }-2 \% \\
\text { Contracts: } 107 \\
\text { C.I:[-5\%,1\%] }\end{array}$ \\
\hline $\begin{array}{l}\text { Pavement } \\
\text { Contracts }\end{array}$ & $\begin{array}{l}\text { Average: }-23 \% \\
\text { Contracts: } 66 \\
\text { C.I: }[-26 \%,-21 \%]\end{array}$ & $\begin{array}{l}\text { Average: }-3.1 \% \\
\text { Contracts: } 52 \\
\text { C.I: }[-3.9 \%,-2.4 \%]\end{array}$ & $\begin{array}{l}\text { Average: } 3.5 \% \\
\text { Contracts: } 50 \\
\text { C.I: }[2.7 \%, 4.3 \%]\end{array}$ & $\begin{array}{l}\text { Average: } 35 \% \\
\text { Contracts: } 71 \\
\text { C.I: }[29 \%, 41 \%]\end{array}$ & $\begin{array}{l}\text { Average: } 4 \% \\
\text { Contracts: } 239 \\
\text { C.I:[0.5\%,7\%] }\end{array}$ \\
\hline $\begin{array}{l}\text { Weighted } \\
\text { Average }\end{array}$ & $\begin{array}{l}\text { Average: }-23 \% \\
\text { Contracts: } 105 \\
\text { C.I: }[-25 \%,-21 \%]\end{array}$ & $\begin{array}{l}\text { Average: }-2.6 \% \\
\text { Contracts: } 103 \\
\text { C.I: }[-3.1 \%, 2.0 \%]\end{array}$ & $\begin{array}{l}\text { Average: } 2.7 \% \\
\text { Contracts: } 117 \\
\text { C.I: }[2.1 \%, 3.2 \%]\end{array}$ & $\begin{array}{l}\text { Average: } 33 \% \\
\text { Contracts: } 94 \\
\text { C.I: }[28 \%, 38 \%]\end{array}$ & $\begin{array}{l}\text { Average: } 1.85 \% \\
\text { Contracts: } 419 \\
\text { C.I:[-0.4\%,4\%] }\end{array}$ \\
\hline
\end{tabular}

Contracts: Number of Contracts

C.I: 95\% Confidence Interval (Estimated Using One Sample t-Test)

(A) Frequency of Design Stage Cost Overrun / Underrun

The expansion, bridge, and pavement contracts for which the design stage cost overrun was outside the ' + $10 \%$ cost overrun bracket' were analyzed in greater detail to determine if cost overrun or underrun was more frequent across contracts of any particular work type. The following findings were made (Figure 5.17):

i. The percentage of bridge contracts that fell outside the ' $+/-10 \%$ ' design stage cost overrun bracket was $30 \%$ (32 of the 107 contracts), which was less than the corresponding percentage for expansion contracts (41\%: 30 of 73 ) and pavement (57\%: 137 of 239) contracts.

ii. The percentage of bridge contracts for which the design stage cost overrun exceeded $10 \%$ was $7 \%$ ( 8 of 107), whereas the corresponding percentage for expansion contracts was $21 \%$ (15 of 73 ) and for pavement contracts was $30 \%$ (71 of 239 contracts).

iii. The percentage of bridge contracts for which the design stage cost underrun exceeded $10 \%$ was $22 \%$ ( 24 of 107), whereas the corresponding percentage for expansion contracts was $21 \%$ (15 of 73 ) and for pavement contracts was $28 \%$ ( 66 of 239 contracts). 
Based on these findings it was concluded that the design stage cost overrun and underrun are more frequent amongst pavement contracts and least frequent amongst bridge contracts.

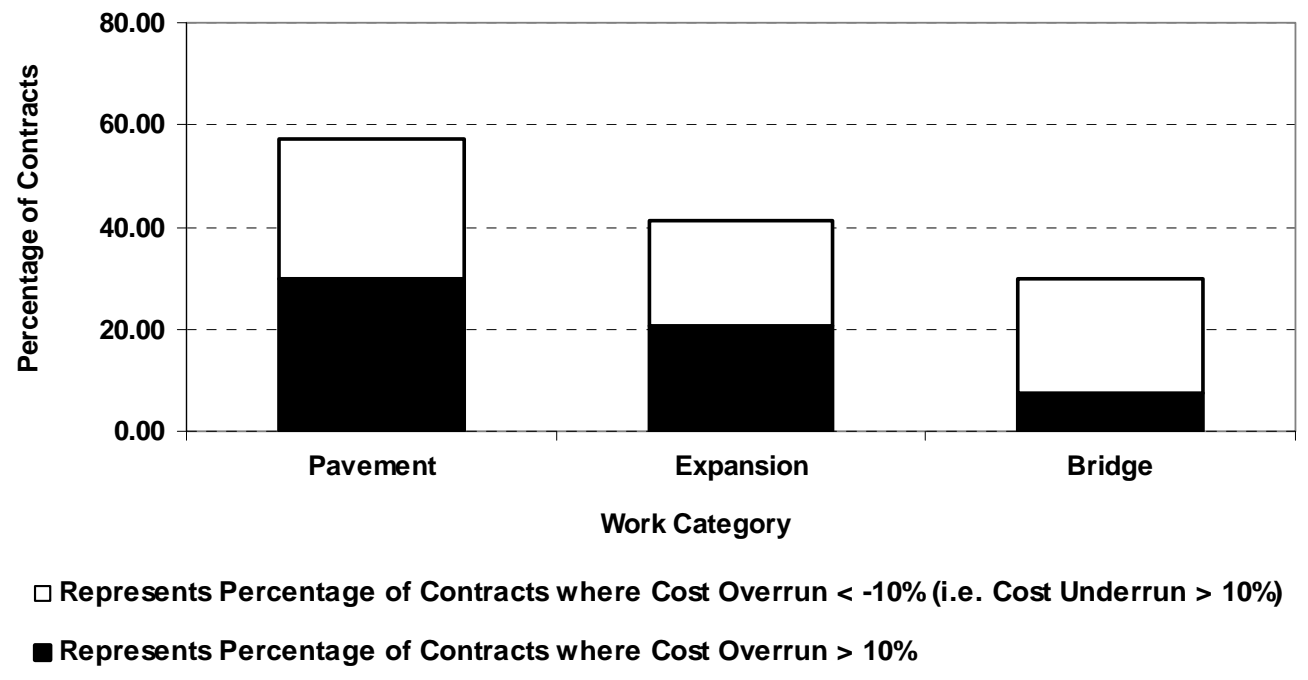

Figure 5.17: Percentage of Contracts Outside the ' $+/-10 \%$ ' Design Stage Cost Overrun Bracket by Work

$$
\text { Category }
$$

\section{(B) Severity of Design Stage Cost Overrun / Underrun}

The average design stage cost overrun was determined by work category. The following findings were made based on the analysis of the severity of cost overrun:

i. For Contracts with Cost Overrun $>10 \%$ : The average design stage cost overrun was $28 \%, 33 \%$, and 35\% for expansion, bridge, and pavement contracts, respectively (Table 5.16). The 95\% confidence interval of these averages was $[18 \%, 38 \%],[11 \%, 55 \%]$, and $[29 \%, 41 \%]$ for expansion, bridge, and pavement contracts, respectively. The confidence intervals indicated that pavement contracts experienced lower variability in cost overrun compared to expansion and bridge contracts. The upper limit of the confidence interval for bridge contracts $(55 \%)$ was significantly larger compared to the upper limit of expansion (38\%) and pavement (41\%) contracts, which implied that bridge contracts were more susceptible to high design stage cost overrun.

ii. For Contracts with Cost Overrun $<-10 \%$ (i.e. Cost Underrun $>10 \%$ ): The average design stage cost underrun was $26 \%, 23 \%$, and $20 \%$ for expansion, pavement, and bridge contracts, respectively (Table 5.16). The $95 \%$ confidence interval of these average cost underrun was $[18 \%$, $35 \%],[21 \%, 26 \%]$, and [16\%, 25\%] for expansion, pavement, and bridge contracts, respectively. The confidence intervals indicated that expansion contracts experienced higher cost underrun 
compared to pavement and bridge contracts (Figure 5.18), while pavement contracts tend to exhibit a low variability of cost underrun.

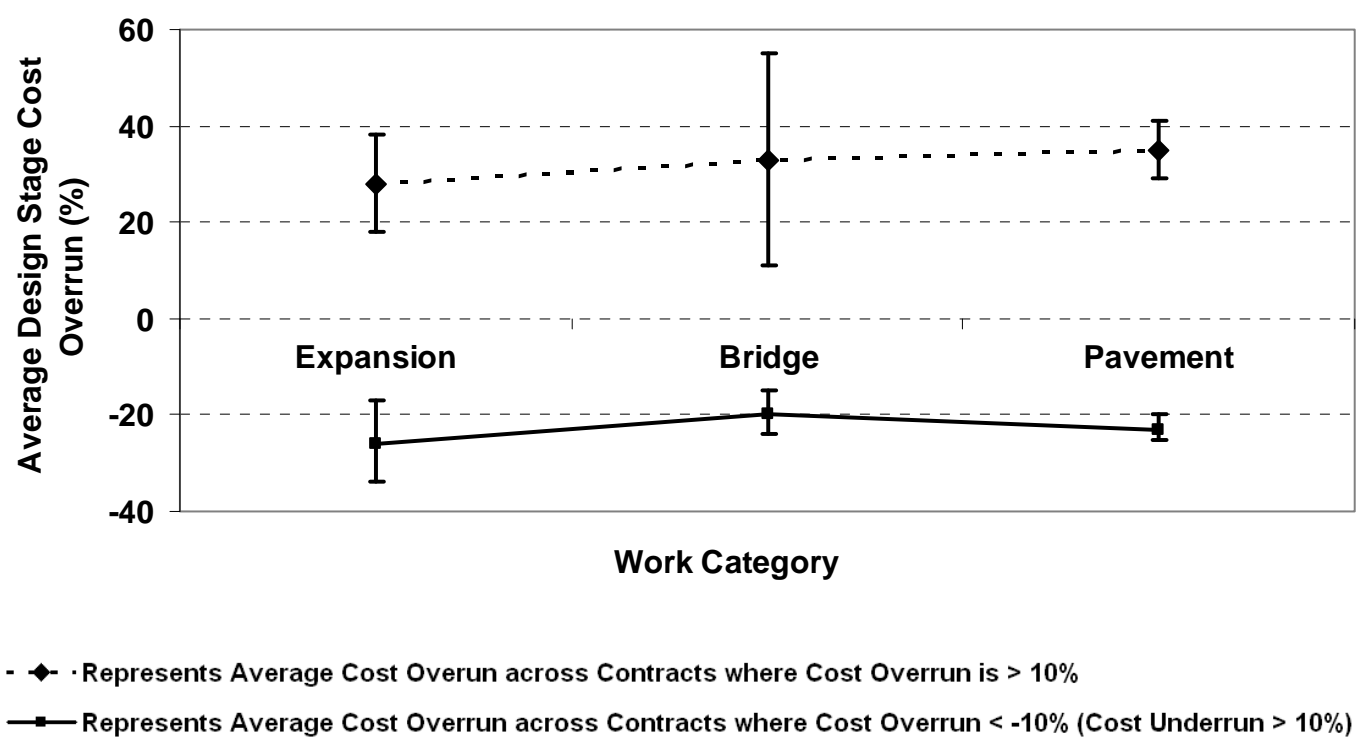

Figure 5.18: Average Design Stage Cost Overrun for Contracts Outside the ' $+/-10 \%$ Cost Overrun Bracket' by Work Category

\subsubsection{Descriptive Analysis by Contract Size}

The analysis of the design stage cost overrun by contract size and cost overrun category is illustrated in Table 5.17. The 190 contracts with proposed cost between $\$ 1-\$ 2$ million have an average design stage cost overrun of $3.8 \%$ and a $95 \%$ confidence interval of $[0.5 \%, 7 \%]$. The positive cost overrun and confidence interval indicates that cost overrun is more significant compared to cost underrun for contracts in this category. The contracts with proposed cost $\$ 2-\$ 5$ million have a comparatively lower average design stage cost overrun (1.5\%) and 95\% confidence interval $[-2.8 \%, 6 \%]$. The upper limit of the confidence interval indicated that cost overrun is marginally more likely for contracts in this category. The contracts with proposed cost between $\$ 5-\$ 10$ million and the contracts with proposed cost greater than $\$ 10$ million have average design stage cost overrun of $-1 \%$ and $-2.6 \%$, respectively. The $95 \%$ confidence interval of the average design stage cost overrun was similar for contracts in these categories, $[-7 \%, 5 \%]$ and $[-9 \%, 4 \%]$, respectively. Further, the lower limit of the $95 \%$ confidence interval indicates that contracts exceeding $\$ 5$ million were more susceptible to cost underrun.

Table 5.17: Analysis of Average Design Stage Cost Overrun by Contract Size and Cost Overrun Category 


\begin{tabular}{|c|c|c|c|c|c|}
\hline & \multicolumn{4}{|c|}{$Y_{3}=100\left(\frac{\text { Final Cost }- \text { Design Cost }}{\text { Design Cost }}\right) \%$} & \multirow[b]{2}{*}{$\begin{array}{l}\text { Weighted } \\
\text { Average }\end{array}$} \\
\hline & $Y_{3}<-10 \%$ & $-10 \% \leq Y_{3}<0 \%$ & $0 \% \leq Y_{3} \leq 10 \%$ & $Y_{3}>10 \%$ & \\
\hline $\begin{array}{l}\$ 1 \mathrm{M}- \\
\$ 2 \mathrm{M}\end{array}$ & $\begin{array}{l}\text { Average: }-19.5 \% \\
\text { Contracts: } 42 \\
\text { C.I: }[-22 \%,-17 \%]\end{array}$ & $\begin{array}{l}\text { Average: }-2 \% \\
\text { Contracts: } 56 \\
\text { C.I: }[-2.9 \%,-1.3 \%]\end{array}$ & $\begin{array}{l}\text { Average: } 2.5 \% \\
\text { Contracts: } 48 \\
\text { C.I: }[1.6 \%, 3.3 \%]\end{array}$ & $\begin{array}{l}\text { Average: } 35 \% \\
\text { Contracts: } 44 \\
\text { C.I: }[27 \%, 43 \%]\end{array}$ & $\begin{array}{l}\text { Average: } 3.8 \% \\
\text { Contracts: } 190 \\
\text { C.I:[0.5\%,7\%] }\end{array}$ \\
\hline $\begin{array}{l}\$ 2 \mathrm{M}- \\
\$ 5 \mathrm{M}\end{array}$ & $\begin{array}{l}\text { Average: }-23.7 \% \\
\text { Contracts: } 37 \\
\text { C.I: }[-28 \%,-20 \%]\end{array}$ & $\begin{array}{l}\text { Average: }-3.5 \% \\
\text { Contracts: } 30 \\
\text { C.I: }[-4.7 \%,-2.4 \%]\end{array}$ & $\begin{array}{l}\text { Average: } 2.1 \% \\
\text { Contracts: } 41 \\
\text { C.I: }[1.3 \%, 3 \%]\end{array}$ & $\begin{array}{l}\text { Average: } 37 \% \\
\text { Contracts: } 30 \\
\text { C.I: }[27 \%, 47 \%]\end{array}$ & $\begin{array}{l}\text { Average: } 1.54 \% \\
\text { Contracts: } 138 \\
\text { C.I:[-2.8\%,6\%] }\end{array}$ \\
\hline $\begin{array}{l}\$ 5 \mathrm{M}- \\
\$ 10 \mathrm{M}\end{array}$ & $\begin{array}{l}\text { Average: }-28.4 \% \\
\text { Contracts: } 14 \\
\text { C.I: }-37 \%,-20 \% \text { ] }\end{array}$ & $\begin{array}{l}\text { Average: }-2.6 \% \\
\text { Contracts: } 11 \\
\text { C.I: }[-4.3 \%,-0.9 \%]\end{array}$ & $\begin{array}{l}\text { Average: } 3.3 \% \\
\text { Contracts: } 15 \\
\text { C.I: }[1.5 \%, 5 \%]\end{array}$ & $\begin{array}{l}\text { Average: } 25 \% \\
\text { Contracts: } 13 \\
\text { C.I: }[17 \%, 33 \%]\end{array}$ & $\begin{array}{l}\text { Average:-1.0\% } \\
\text { Contracts: } 53 \\
\text { C.I:[-7\%,5\%] }\end{array}$ \\
\hline$>\$ 10 \mathrm{M}$ & $\begin{array}{l}\text { Average: }-26.2 \% \\
\text { Contracts: } 12 \\
\text { C.I: }-34 \%,-19 \% \text { ] }\end{array}$ & $\begin{array}{l}\text { Average: }-2.3 \% \\
\text { Contracts: } 6 \\
\text { C.I: }[-4.3 \%,-0.4 \%]\end{array}$ & $\begin{array}{l}\text { Average: } 4.1 \% \\
\text { Contracts: } 13 \\
\text { C.I: }[2.5 \%, 5.8 \%]\end{array}$ & $\begin{array}{l}\text { Average: } 25 \% \\
\text { Contracts: } 7 \\
\text { C.I: }[15 \%, 35 \%]\end{array}$ & $\begin{array}{l}\text { Average:-2.6\% } \\
\text { Contracts: } 38 \\
\text { C.I:[-9.2\%,4\%] }\end{array}$ \\
\hline $\begin{array}{l}\text { Weighted } \\
\text { Average }\end{array}$ & $\begin{array}{l}\text { Average: }-23 \% \\
\text { Contracts: } 105 \\
\text { C.I: }[-25 \%,-21 \%]\end{array}$ & $\begin{array}{l}\text { Average: }-2.6 \% \\
\text { Contracts: } 103 \\
\text { C.I: }[-3.1 \%, 2.0 \%]\end{array}$ & $\begin{array}{l}\text { Average: } 2.7 \% \\
\text { Contracts: } 117 \\
\text { C.I: }[2.1 \%, 3.2 \%]\end{array}$ & $\begin{array}{l}\text { Average: } 33 \% \\
\text { Contracts: } 94 \\
\text { C.I: }[28 \%, 38 \%]\end{array}$ & $\begin{array}{l}\text { Average: } 1.85 \% \\
\text { Contracts: } 419 \\
\text { C.I:[-0.4\%,4\%] }\end{array}$ \\
\hline
\end{tabular}

Contracts: Number of Contracts

C.I: 95\% Confidence Interval (Estimated Using One Sample t-Test)

\section{(A) Frequency of Design Stage Cost Overrun / Underrun}

The following conclusions were made based on the analysis of design stage cost overrun by contract size (Figure 5.19):

i. The percentage of $\$ 1-\$ 2$ million contracts that were outside the ' $+/-10 \%$ ' design stage cost overrun bracket was $45 \%$ ( 86 of 190), which was smaller compared to $49 \%$ (67 of 138) for contracts of size $\$ 2-\$ 5$ million, 51\% (27 of 53) for contracts of size $\$ 5-\$ 10$ million, and 50\% (19 of 38) for contracts exceeding $\$ 10$ million.

ii. The percentage of $\$ 1-\$ 2$ million contracts for which the design stage cost overrun exceeded $10 \%$ was $23 \%$ (44 of 190), and this percentage decreased with increase in contract size as follows (Figure 5.19): 22\% (30 of 138) for contracts with size $\$ 2-\$ 5$ million, $22 \%$ (13 of 53) for contracts of size $\$ 5$ to $\$ 10$ million, and $18 \%$ (7 of 38) for contracts greater than $\$ 10$ million in size.

iii. The percentage of $\$ 1-\$ 2$ million contracts for which the design stage cost underrun exceeded $10 \%$ was $22 \%$ (42 of 190), and this percentage increased with increase in contract size as follows (Figure 5.19): 26\% (37 of 138) for contracts of size \$2-\$5 million, 26\% (14 of 53) for contracts of size $\$ 5$ to $\$ 10$ million, and 32\% (12 of 38) for contracts exceeding $\$ 10$ million. 


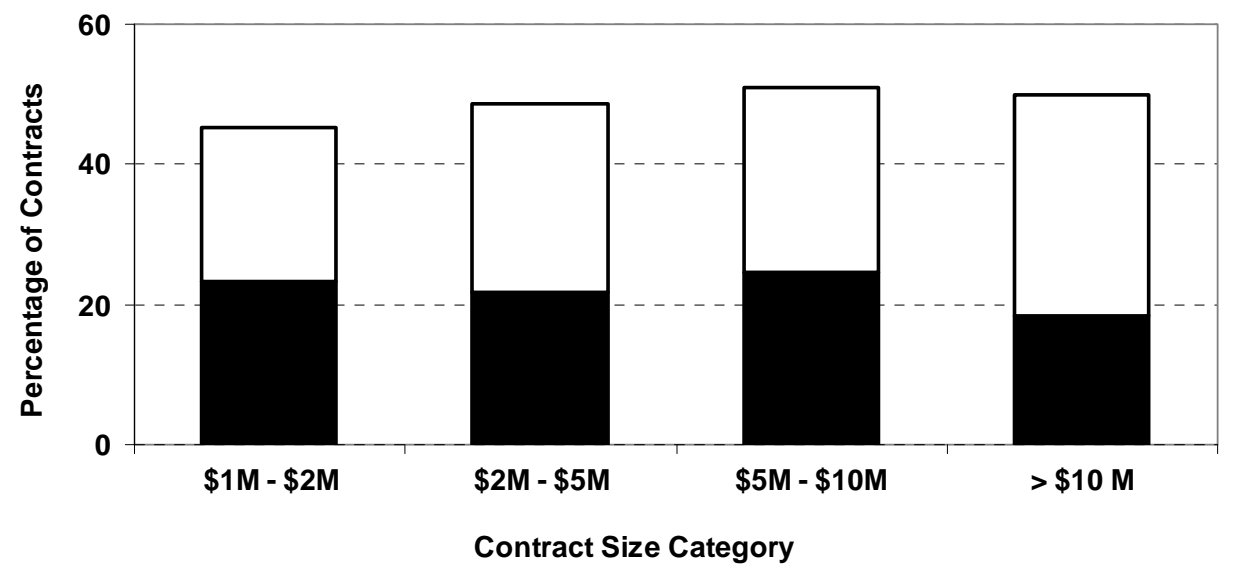

$\square$ Represents Percentage of Contracts where Cost Overrun < -10\% (i.e. Cost Underrun > 10\%)

Depresents Percentage of Contracts where Cost Overrun $>10 \%$

Figure 5.19: Percent Contracts Outside the ‘ $+/-10 \%$ ’ Design Stage Cost Overrun Bracket by Contract Size

\section{(B) Severity of Design Stage Cost Overrun / Underrun}

The average design stage cost overrun was determined for contracts that lie outside the $+/-10 \%$ cost overrun bracket' by contract size. The following observations were made based on the analysis of the severity of cost overrun were as follows:

i. For Contracts with Cost Overrun $>10 \%$ : The average design stage cost overrun decreases with an increase in contract size (Figure 5.20). The average design stage cost overrun was 35\% for contracts with a proposed cost between $\$ 1-\$ 2 \mathrm{M}, 37 \%$ for contracts with size between $\$ 2-\$ 5 \mathrm{M}$, $25 \%$ for contract sizes between $\$ 5-\$ 10 \mathrm{M}$, and $25 \%$ for contracts with size greater than $\$ 10 \mathrm{M}$. The width of the $95 \%$ confidence interval (Table 5.17) for the average design stage cost overrun did not vary significantly across the various categories of contract size, indicating that the variance in the design stage cost overrun was the same across contract sizes. However, it was found that for contracts with proposed cost between $\$ 1-\$ 2$ million [27\%, 43\%] and between $\$ 2-\$ 5$ million [27\%, $47 \%$ ], was higher compared to the $95 \%$ confidence interval for contracts with proposed cost between $\$ 5 \mathrm{M}-\$ 10 \mathrm{M}[17 \%, 33 \%]$ and for contracts with a proposed cost greater than $\$ 10 \mathrm{M}[15 \%$, $35 \%]$. This indicates that the design stage cost overrun is expected to be higher for small-sized contracts (proposed cost $<\$ 5$ Million).

ii. For Contracts with Cost Overrun $<-10 \%$ (i.e. Cost Underrun $>10 \%$ ): It was observed that average design stage cost underrun increased as contract size increased from $\$ 1$ million to $\$ 10$ million (Figure 5.20). The average design stage cost underrun was $20 \%$ for contracts with size in between $\$ 1-\$ 2 \mathrm{M}, 24 \%$ for contract sizes between $\$ 2-\$ 5 \mathrm{M}, 28 \%$ for contract sizes between $\$ 5-\$ 10 \mathrm{M}$, and $26 \%$ for contracts with size greater than $\$ 10 \mathrm{M}$. The $95 \%$ confidence intervals of the averages were [17\%, 22\%], [20\%, 28\%], [20\%,37\%], and [19\%, 34\%] for contracts with size \$1-\$2 million, \$2- 
$\$ 5$ million, \$5-\$10 million, and greater than $\$ 10$ million, respectively. The upper limit of the confidence interval also increased with an increase in contract size from \$1 million to \$10 million, which indicated that large contracts were susceptible to higher design stage cost underrun (Figure $5.20)$.

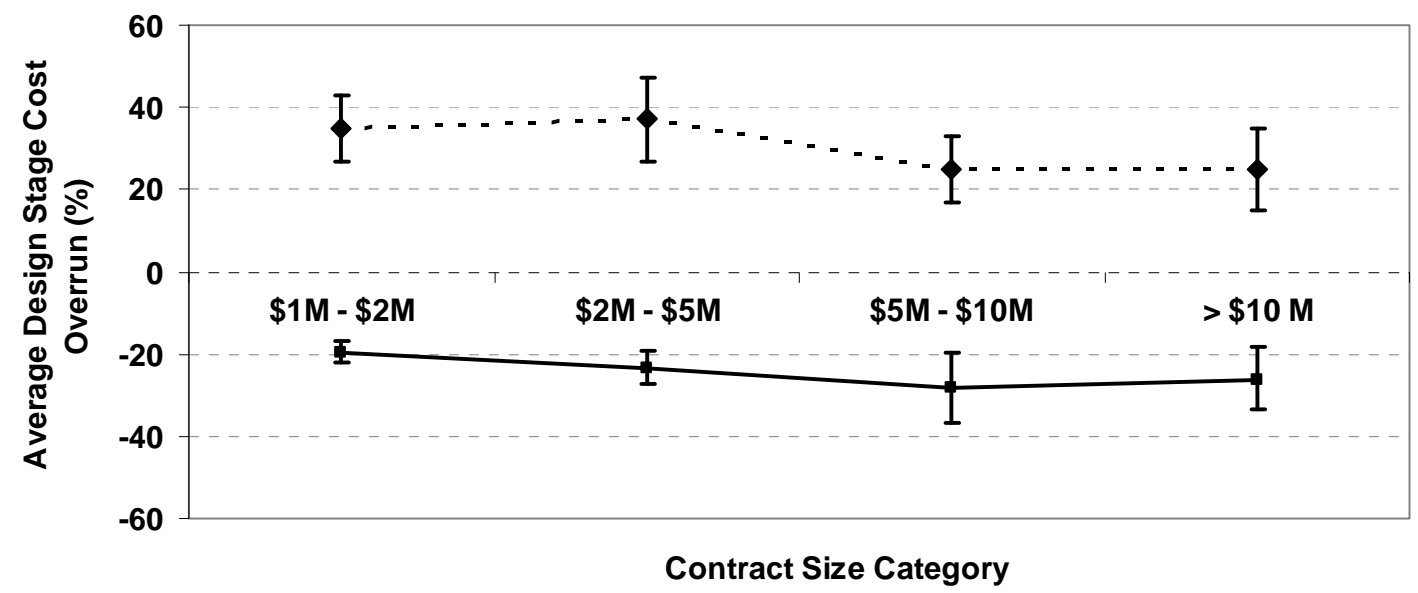

\section{$-\downarrow-$ Represents Average Cost Overun across Contracts where Cost Overrun is $>10 \%$ \\ $\longrightarrow$ Represents Average Cost Overrun across Contracts where Cost Overrun $<-10 \%$ (Cost Underrun $>10 \%)$}

Figure 5.20: Average Design Stage Cost Overrun for Contracts Outside the ‘ $+/-10 \%$ Cost Overrun Bracket' by Contract Size

\subsubsection{Descriptive Analysis by Contract Type}

The analysis of the average design stage cost overrun by contract type and cost overrun category is presented in Table 5.18. The 270 stand-alone contracts have an average design stage cost overrun of $2 \%$ and a $95 \%$ confidence interval of $[0.6 \%, 4.6 \%]$. The positive cost overrun and confidence interval indicates that cost overrun is more prominent compared to cost underrun for stand-alone contracts. The kin contracts had an average design stage cost overrun of $1.6 \%$ and a $95 \%$ confidence interval of $[-2.7 \%, 6 \%]$. 
Table 5.18: Analysis of Average Cost Overrun of Final Cost over Design by Contract Type

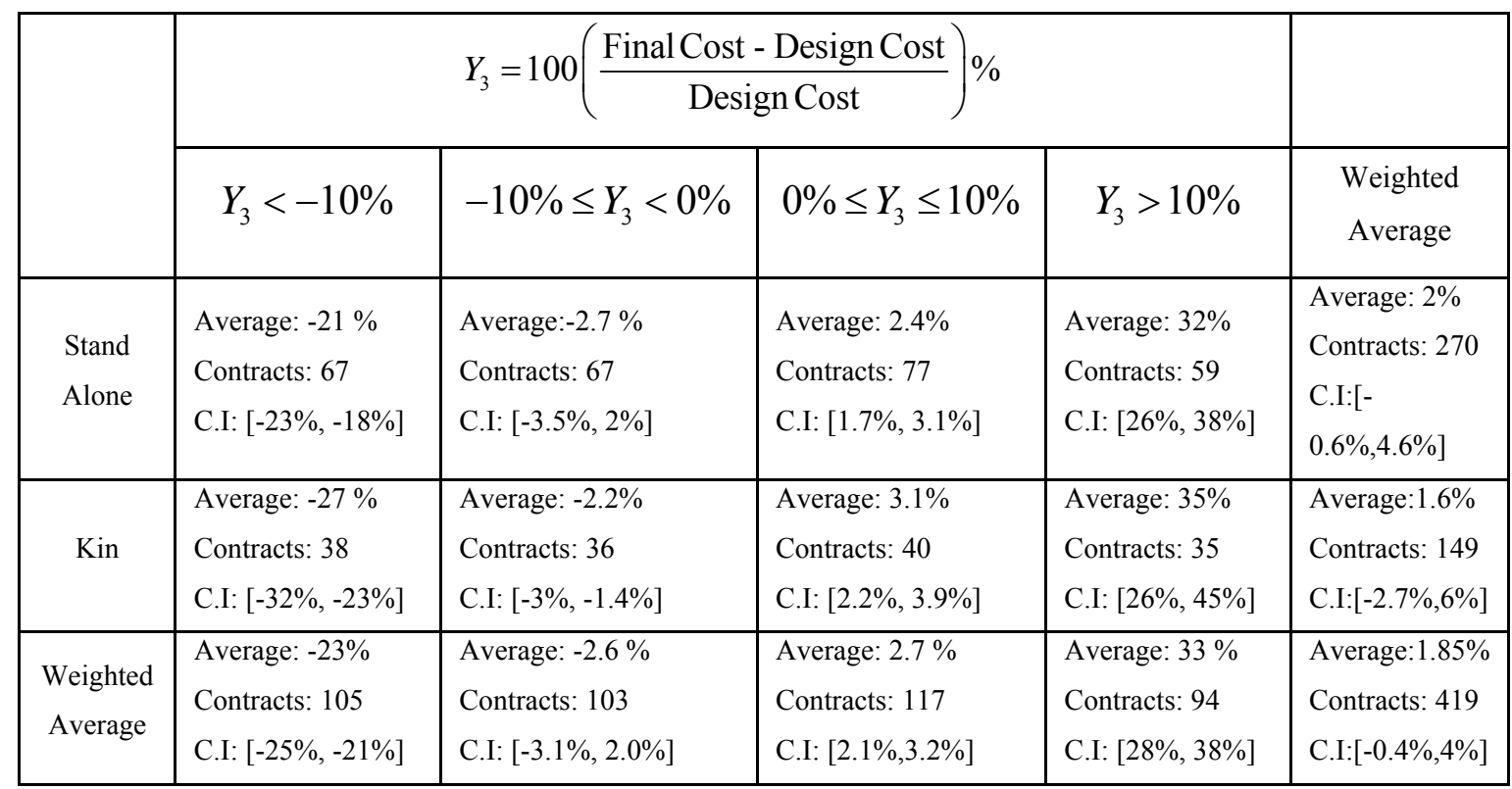

Contracts: Number of Contracts

C.I: 95\% Confidence Interval (Estimated Using One Sample t-Test)

\section{(A) Frequency of Design Stage Cost Overrun / Underrun}

Standalone and kin contracts were analyzed and following observations were made regarding the frequency of occurrence of high cost overrun and underrun (Figure 5.21):

i. The percentage of stand-alone and kin contracts that were outside the ' $+/-10 \%$ ' design stage cost overrun bracket was 47\% (126 of 270) and 49\% (73 of 149), respectively.

ii. The percentage of stand-alone and kin contracts for which the design stage cost overrun exceeded $10 \%$ was $22 \%$ (59 of 270 ) and $24 \%$ (35 of 149 ), respectively.

iii. The percentage of stand-alone and kin contracts for which the design stage cost underrun exceeded $10 \%$ was $25 \%$ ( 67 of 270 ) and $26 \%$ (38 of 149 ), respectively.

Therefore, the frequency of design stage cost overrun and underrun was not found to vary by contract type. 


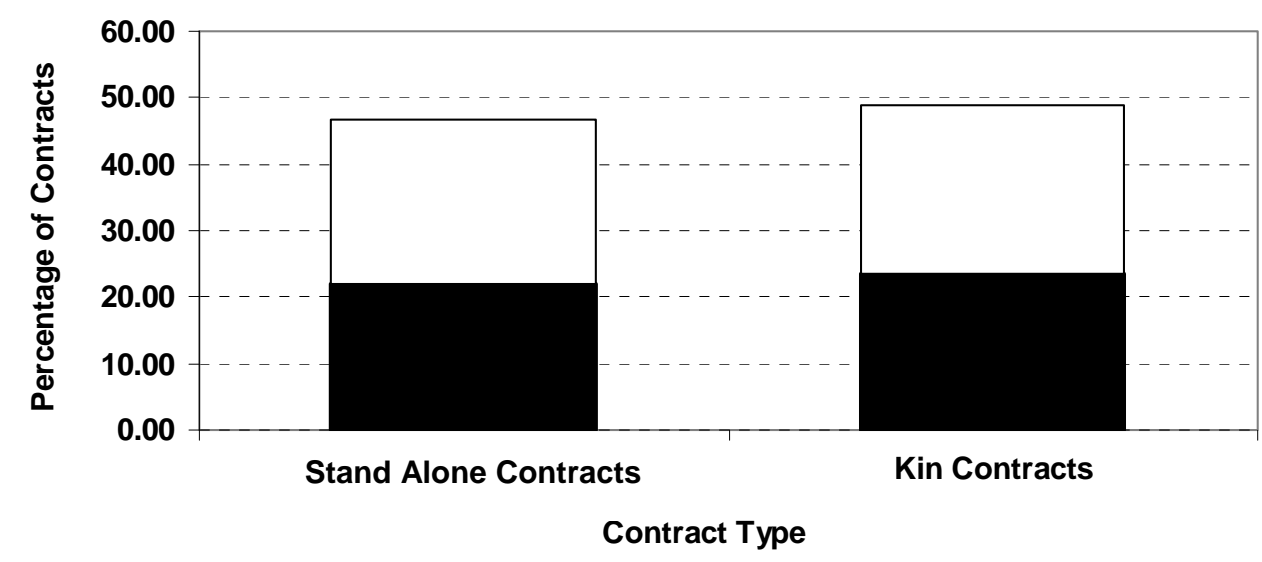

$\square$ Represents Percentage of Contracts where Cost Overrun < -10\% (i.e. Cost Underrun > 10\%)

Depresents Percentage of Contracts where Cost Overrun $>10 \%$

Figure 5.21: Percentage of Contracts Outside the ‘ + /-10\%’ Design Stage Cost Overrun Bracket by Contract Size

\section{(B) Severity of Design Stage Cost Overrun / Underrun}

The following observations were made based on the analysis of average design stage cost overrun of standalone and kin contacts (Figure 5.22):

i. For Contracts with Cost Overrun $>10 \%$ : The average design stage cost overruns for stand-alone and kin contracts were $32 \%$ and $35 \%$, respectively. The width of the $95 \%$ confidence interval of the average design stage cost overrun for stand-alone contracts [26\%,38\%] was half the width of the confidence interval for kin contracts [26\%, 45\%]. That is, the variability of the average design stage cost overrun for kin contracts was more compared to stand-alone contracts. The upper limit of the confidence interval for kin contracts (45\%) was higher compared to that of stand-alone contracts (38\%), which indicated that kin contracts were susceptible to higher design stage cost overrun compared to stand-alone contracts.

ii. For Contracts with Cost Overrun $<-10 \%$ (i.e. Cost Underrun $>10 \%$ ): The average design stage cost underrun for kin contracts (27\%) was higher compared to stand-alone contracts $(21 \%)$. The $95 \%$ confidence interval of the average design stage cost overrun for kin contracts [23\%, 32\%] and stand-alone contracts $[18 \%, 23 \%]$ indicated that the kin contracts have more severe cost underrun. This is because upper and lower limits of the confidence interval for kin contracts were higher compared to those for stand-alone contracts. 


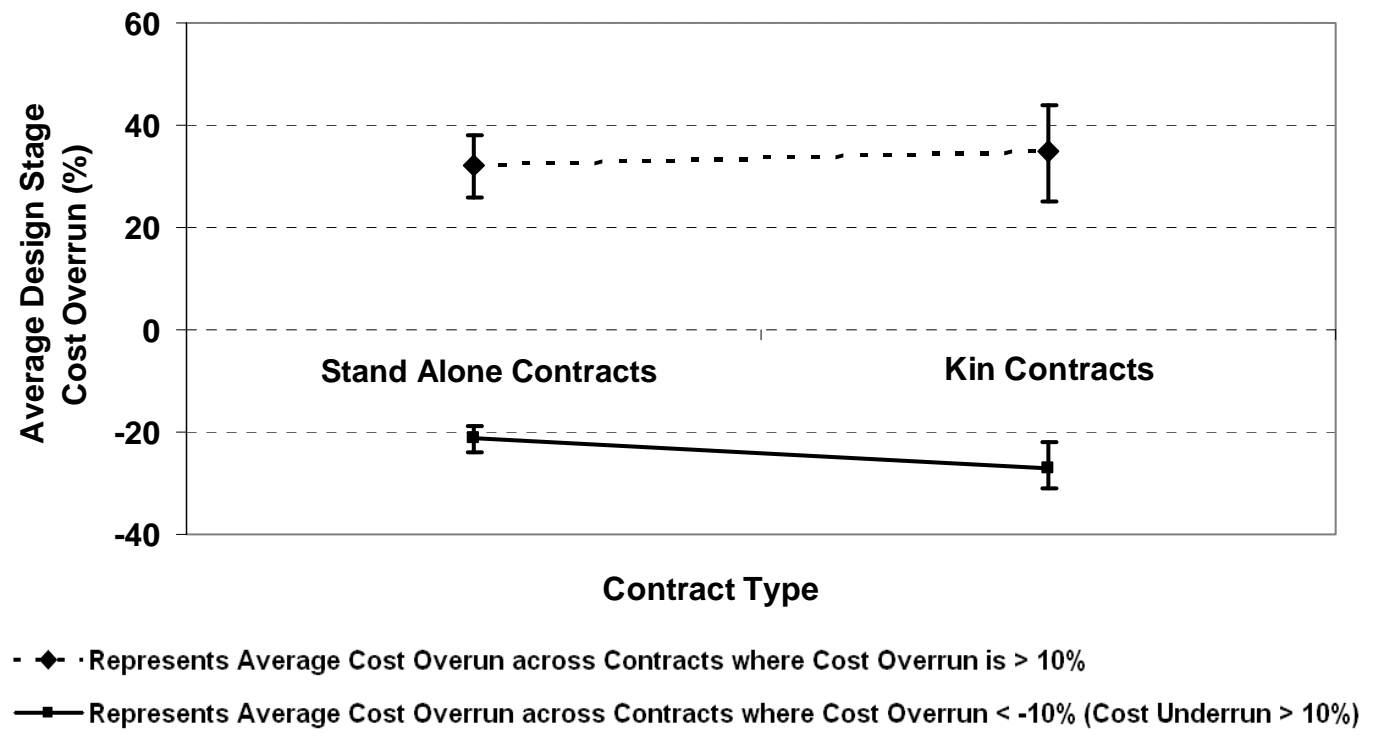

Figure 5.22: Average Design Stage Cost Overrun for Contracts Outside the ' $+/-10 \%$ Cost Overrun Bracket' by Contract Type

\subsubsection{Descriptive Analysis by Route Type}

The average design stage cost overrun for the 71 Interstate contracts, 139 U.S. Road contracts, and 209 State Road contracts and corresponding 95\% confidence intervals are as shown in Table 5.19. The average design stage cost overrun was highest for State Road contracts (3.5\%) and the $95 \%$ confidence interval of the average $[0.3 \%, 6.8 \%]$ indicated that the cost overrun is more prominent compared to cost underrun for State Road contracts. The analysis showed that the average design stage cost overrun for U.S. Road contracts is $1 \%$, and the $95 \%$ confidence interval of the average is $[-2.6 \%, 4.6 \%]$. The average design stage cost overrun was least for Interstate contracts $(-1.5 \%)$ and the $95 \%$ confidence interval $[-7.5 \%, 4.6 \%]$ indicated that cost overrun is more prominent for Interstate contracts.

\section{(A) Frequency of Design Stage Cost Overrun / Underrun}

The Interstate, U.S. Road and State Road contracts for which the design stage cost overrun was outside the ' $+/-10 \%$ cost overrun bracket' were analyzed to determine if cost overrun and underrun are more frequent across contracts of any particular route type. The following conclusions were made (Figure 5.23):

i. The percentage of Interstate contracts that were outside the ' $+/-10 \%$ cost overrun bracket' was $44 \%$ ( 31 of the 71 contracts), which was less than the corresponding percentage for U.S. Road contracts (48\%, 66 of 139) and State Road (49\%, 102 of 209) contracts.

ii. The percentage of Interstate contracts for which the design stage cost overrun exceeded $10 \%$ was $14 \%$ (10 of 71), whereas the corresponding percentage for U.S. Road contracts was $22 \%$ ( 31 of 139 ) and for State Road contracts was $25 \%$ (53 of 209 contracts). 
iii. The percentage of Interstate contracts for which the design stage cost underrun exceeded $10 \%$ was $29 \%$ ( 21 of 71 ), whereas the corresponding percentage for U.S. Road contracts was $25 \%$ (35 of 139 ) and for State Road contracts was $23 \%$ (49 of 209 contracts).

Table 5.19: Analysis of Average Cost Overrun of Final Cost over Design Cost by Route Type

\begin{tabular}{|c|c|c|c|c|c|}
\hline & \multicolumn{4}{|c|}{$Y_{3}=100\left(\frac{\text { Final Cost }- \text { Design Cost }}{\text { Design Cost }}\right) \%$} & \multirow[b]{2}{*}{$\begin{array}{l}\text { Weighted } \\
\text { Average }\end{array}$} \\
\hline & $Y_{3}<-10 \%$ & $-10 \% \leq Y_{3}<0 \%$ & $0 \% \leq Y_{3} \leq 10 \%$ & $Y_{3}>10 \%$ & \\
\hline Interstates & $\begin{array}{l}\text { Average: }-26 \% \\
\text { Contracts: } 21 \\
\text { C.I: }[-32 \%,-20 \%]\end{array}$ & $\begin{array}{l}\text { Average: }-2.4 \% \\
\text { Contracts: } 18 \\
\text { C.I: }[-4 \%,-0.9 \%]\end{array}$ & $\begin{array}{l}\text { Average: } 2.8 \% \\
\text { Contracts: } 22 \\
\text { C.I: }[1.6 \%, 4 \%]\end{array}$ & $\begin{array}{l}\text { Average: } 42 \% \\
\text { Contracts: } 10 \\
\text { C.I: }[18 \%, 66 \%]\end{array}$ & $\begin{array}{l}\text { Average:- } 1.5 \% \\
\text { Contracts: } 71 \\
\text { C.I:[-7.5\%,4.6\%] }\end{array}$ \\
\hline U.S. Roads & $\begin{array}{l}\text { Average: }-22 \% \\
\text { Contracts: } 35 \\
\text { C.I: }[-26 \%,-18 \%]\end{array}$ & $\begin{array}{l}\text { Average: }-2.4 \% \\
\text { Contracts: } 36 \\
\text { C.I: }[-3.2 \%, 1.6 \%]\end{array}$ & $\begin{array}{l}\text { Average: } 2.5 \% \\
\text { Contracts: } 37 \\
\text { C.I: }[1.5 \%, 3.4 \%]\end{array}$ & $\begin{array}{l}\text { Average: } 29 \% \\
\text { Contracts: } 31 \\
\text { C.I: }[20 \%, 38 \%]\end{array}$ & $\begin{array}{l}\text { Average: } 1 \% \\
\text { Contracts: } 139 \\
\text { C.I:- }-6 \%, 4.6 \%]\end{array}$ \\
\hline $\begin{array}{l}\text { State } \\
\text { Roads }\end{array}$ & $\begin{array}{l}\text { Average: }-23 \% \\
\text { Contracts: } 49 \\
\text { C.I: }[-26 \%,-20 \%] \\
\end{array}$ & $\begin{array}{l}\text { Average: }-2.8 \% \\
\text { Contracts: } 49 \\
\text { C.I: }[-3.6 \%, 1.9 \%]\end{array}$ & $\begin{array}{l}\text { Average: } 2.8 \% \\
\text { Contracts: } 58 \\
\text { C.I: }[2 \%, 3.5 \%] \\
\end{array}$ & $\begin{array}{l}\text { Average: } 34 \% \\
\text { Contracts: } 53 \\
\text { C.I: }[28 \%, 41 \%]\end{array}$ & $\begin{array}{l}\text { Average: } 3.5 \% \\
\text { Contracts: } 209 \\
\text { C.I: } 0.3 \%, 6.8 \%] \\
\end{array}$ \\
\hline $\begin{array}{l}\text { Weighted } \\
\text { Average }\end{array}$ & $\begin{array}{l}\text { Average: }-23 \% \\
\text { Contracts: } 105 \\
\text { C.I: }[-25 \%,-21 \%]\end{array}$ & $\begin{array}{l}\text { Average: }-2.6 \% \\
\text { Contracts: } 103 \\
\text { C.I: }[-3.1 \%, 2.0 \%]\end{array}$ & $\begin{array}{l}\text { Average: } 2.7 \% \\
\text { Contracts: } 117 \\
\text { C.I: }[2.1 \%, 3.2 \%]\end{array}$ & $\begin{array}{l}\text { Average: } 33 \% \\
\text { Contracts: } 94 \\
\text { C.I: }[28 \%, 38 \%]\end{array}$ & $\begin{array}{l}\text { Average: } 1.85 \% \\
\text { Contracts: } 419 \\
\text { C.I:[-0.4\%,4\%] }\end{array}$ \\
\hline
\end{tabular}

Contracts: Number of Contracts

C.I: 95\% Confidence Interval (Estimated Using One Sample t-Test)

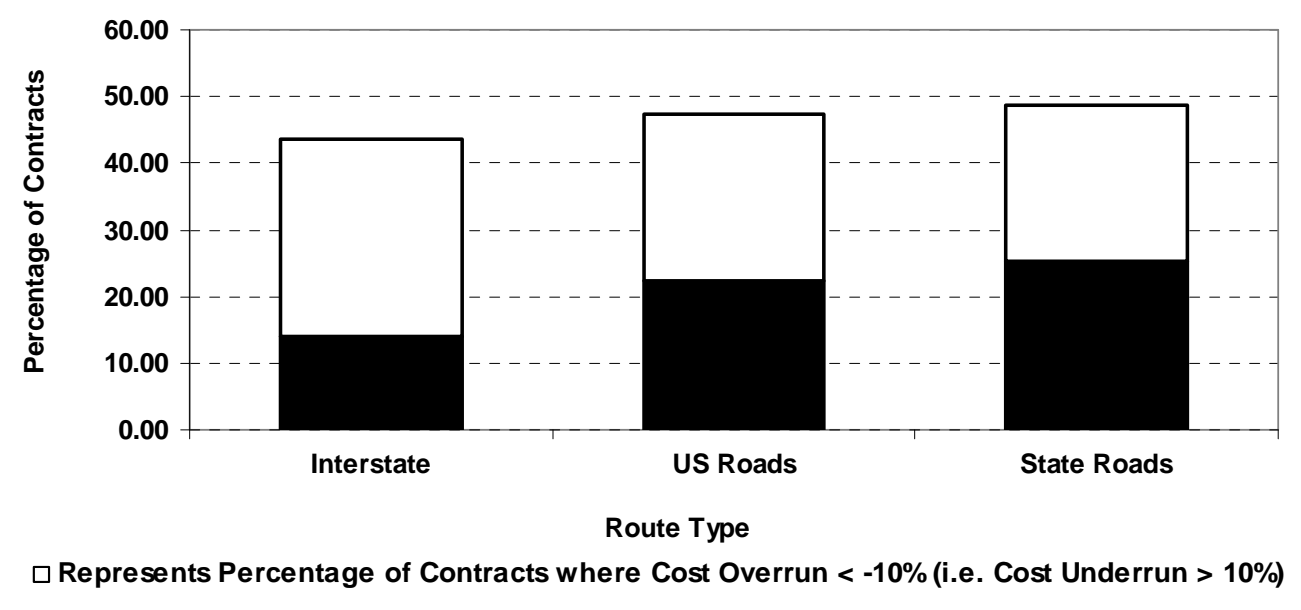

Depresents Percentage of Contracts where Cost Overrun > 10\%

Figure 5.23: Percentage of Contracts Outside the ‘ $+/-10 \%$ ’ Design Stage Cost Overrun Bracket by Route Type 
(B) Severity of Design Stage Cost Overrun / Underrun

The average design stage cost overrun was determined for contracts that lie outside the $+/-10 \%$ cost overrun bracket' by route type. This was to determine whether there were differences in cost overrun across route types.

i. $\quad$ For Contracts with Cost Overrun $>10 \%$ : The average design stage cost overrun was $42 \%, 34 \%$, and $29 \%$ for Interstate, State Road, and U.S. Road contracts, respectively. The 95\% confidence intervals indicated that the Interstate contracts [18\%, 66\%] experience a wider range of cost overrun compared to State Road [28\%, 41\%] and U.S. Road [20\%, 38\%] contracts (Figure 5.24). The upper limit of the $95 \%$ confidence interval for Interstate contracts was $66 \%$ compared to $38 \%$ for U.S. Road and $41 \%$ for State Road contracts. This indicated that Interstate contracts were more susceptible to high cost overrun compared to U.S. Road and State Road contracts. Also, the lower limit of the confidence interval for State Road (28\%) contracts was more than that of U.S. Road (20\%) and Interstate Road (18\%) contracts which indicated that State Road contracts experienced lower design stage cost overrun.

ii. For Contracts with Cost Overrun $<-10 \%$ (i.e. Cost Underrun $>10 \%$ ): The average design stage cost underrun for Interstate road contracts (26\%) was higher compared to State Roads (23\%) and U.S. Roads (22\%). The $95 \%$ confidence interval of the average was [20\%, 32\%], [20\%, 26\%], and [18\%, 26\%] for Interstate, State Road, and U.S. Road contracts, respectively. Based on the plot of the $95 \%$ confidence intervals and the average design stage cost overrun (Figure 5.24), it was concluded that the Interstate contracts are more vulnerable to high design stage cost underrun compared to State Road and U.S. Roads contracts.

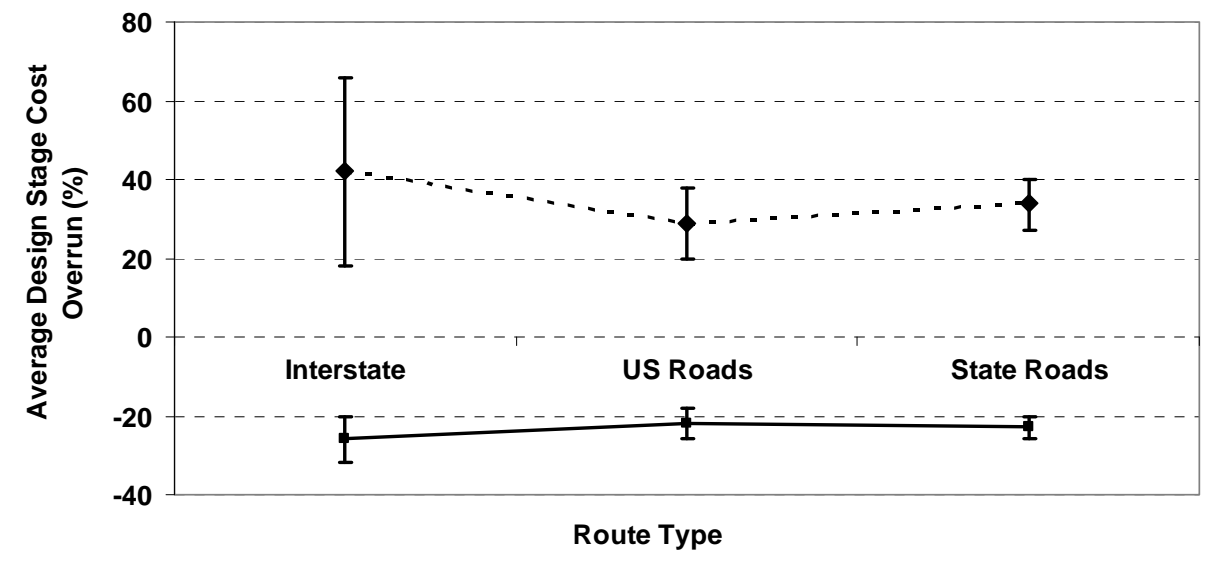

$-\downarrow-$ Represents Average Cost Overun across Contracts where Cost Overrun is $>10 \%$

$\rightarrow-$ Represents Average Cost Overrun across Contracts where Cost Overrun $<-10 \%($ Cost Underrun $>10 \%)$

Figure 5.24: Average Design Stage Cost Overrun for Contracts Outside the ' $+/-10 \%$ Cost Overrun Bracket' by Route Type 


\subsubsection{Analysis by NHS Status}

The average design stage cost overrun for the 71 Interstate contracts, 112 Non-Interstate NHS contracts, and 236 Non-NHS contracts is as shown in Table 5.20, as well as the corresponding 95\% confidence interval of these average design stage cost overrun. Non-Interstate NHS and Non-NHS contracts experienced an average design stage cost overrun of $2.1 \%$ and $2.7 \%$, respectively. The $95 \%$ confidence intervals of the average design stage cost overrun were similar for Non-Interstate NHS [-1.5\%, 5.8\%] and Non-NHS $[-0.4 \%, 5.9 \%]$ contracts. The positive average and the largely positive $95 \%$ confidence interval indicated that the cost overrun is more prominent compared to cost underrun for Non-Interstate NHS and Non-NHS contracts. For Interstate contracts, the average design stage cost overrun (-1.5\%) and the 95\% confidence interval $[-7.6 \%, 4.5 \%]$ indicated that the cost underruns are relatively more prominent compared to cost overruns.

Table 5.20: Analysis of Average Design Stage Cost Overrun by Cost Overrun Category and NHS Status

\begin{tabular}{|c|c|c|c|c|c|}
\hline & & $Y_{3}=100\left(\frac{\text { Final Cost }}{\text { Desi }}\right.$ & $\left.\frac{\text { Design Cost }}{\text { n Cost }}\right) \%$ & & \\
\hline & $Y_{3}<-10 \%$ & $-10 \% \leq Y_{3}<0 \%$ & $0 \% \leq Y_{3} \leq 10 \%$ & $Y_{3}>10 \%$ & $\begin{array}{l}\text { Weighted } \\
\text { Average }\end{array}$ \\
\hline Interstate & $\begin{array}{l}\text { Average: }-26 \% \\
\text { Contracts: } 21 \\
\text { C.I: }[-32 \%,-20 \%]\end{array}$ & $\begin{array}{l}\text { Average: }-2.4 \% \\
\text { Contracts: } 18 \\
\text { C.I: }[-4 \%,-0.9 \%]\end{array}$ & $\begin{array}{l}\text { Average: } 2.8 \% \\
\text { Contracts: } 22 \\
\text { C.I: }[1.6 \%, 4 \%]\end{array}$ & $\begin{array}{l}\text { Average: } 42 \% \\
\text { Contracts: } 10 \\
\text { C.I: }[18 \%, 66 \%]\end{array}$ & $\begin{array}{l}\text { Average:-1.5\% } \\
\text { Contracts: } 71 \\
\text { C.I:[-7.6\%,4.5\%] }\end{array}$ \\
\hline $\begin{array}{l}\text { Non- } \\
\text { Interstate } \\
\text { NHS }\end{array}$ & $\begin{array}{l}\text { Average: }-21 \% \\
\text { Contracts: } 24 \\
\text { C.I: }[-27 \%,-16 \%]\end{array}$ & $\begin{array}{l}\text { Average: }-2 \% \\
\text { Contracts: } 26 \\
\text { C.I: }[-3 \%,-1 \%]\end{array}$ & $\begin{array}{l}\text { Average: } 3.1 \% \\
\text { Contracts: } 36 \\
\text { C.I: }[2.1 \%, 4.1 \%]\end{array}$ & $\begin{array}{l}\text { Average: } 27 \% \\
\text { Contracts: } 26 \\
\text { C.I: }[19 \%, 34 \%]\end{array}$ & $\begin{array}{l}\text { Average: } 2.1 \% \\
\text { Contracts: } 112 \\
\text { C.I:[-1.5\%,5.8\%] }\end{array}$ \\
\hline $\begin{array}{l}\text { Non } \\
\text { NHS }\end{array}$ & $\begin{array}{l}\text { Average: }-23 \% \\
\text { Contracts: } 60 \\
\text { C.I: }[-25 \%,-20 \%]\end{array}$ & $\begin{array}{l}\text { Average: }-2.9 \% \\
\text { Contracts: } 59 \\
\text { C.I: }[-3.7 \%,-2 \%]\end{array}$ & $\begin{array}{l}\text { Average: } 2.3 \% \\
\text { Contracts: } 59 \\
\text { C.I: }[1.6 \%, 3.1 \%]\end{array}$ & $\begin{array}{l}\text { Average: } 35 \% \\
\text { Contracts: } 58 \\
\text { C.I: }[29 \%, 41 \%]\end{array}$ & $\begin{array}{l}\text { Average: } 2.7 \% \\
\text { Contracts: } 236 \\
\text { C.I:[-0.4\%,5.9\%] }\end{array}$ \\
\hline $\begin{array}{l}\text { Weighted } \\
\text { Average }\end{array}$ & $\begin{array}{l}\text { Average: }-23 \% \\
\text { Contracts: } 105 \\
\text { C.I: }[-25 \%,-21 \%]\end{array}$ & $\begin{array}{l}\text { Average: }-2.6 \% \\
\text { Contracts: } 103 \\
\text { C.I: }[-3.1 \%, 2.0 \%]\end{array}$ & $\begin{array}{l}\text { Average: } 2.7 \% \\
\text { Contracts: } 117 \\
\text { C.I: }[2.1 \%, 3.2 \%]\end{array}$ & $\begin{array}{l}\text { Average: } 35 \% \\
\text { Contracts: } 94 \\
\text { C.I: }[28 \%, 38 \%]\end{array}$ & $\begin{array}{l}\text { Average: } 1.85 \% \\
\text { Contracts: } 419 \\
\text { C.I:[-0.4\%,4\%] }\end{array}$ \\
\hline
\end{tabular}

Contracts: Number of Contracts

C.I: 95\% Confidence Interval (Estimated Using One Sample t-Test)

\section{(A) Frequency of Design Stage Cost Overrun / Underrun}

The Interstate, Non-Interstate NHS, and Non-NHS contracts were analyzed and following observations were made (Figure 5.25):

i. The percentage of Interstate contracts that were outside the ' $+/-10 \%$ cost overrun bracket' was $44 \%$ ( 31 of the 71 contracts), which was less than the corresponding percentage for Non-Interstate NHS contracts $(45 \%, 50$ of 112) and Non-NHS (50\%, 118 of 236) contracts. 
ii. The percentage of Interstate contracts for which the design stage cost overrun exceeded $10 \%$ was $14 \%$ ( 10 of 71 ), whereas the corresponding percentage for Non-Interstate NHS contracts was $23 \%$ (26 of 112) and for Non-NHS contracts was $25 \%$ (58 of 236 contracts).

iii. The percentage of Interstate contracts for which the design stage cost underrun exceeded $10 \%$ was $30 \%$ ( 21 of 71 ), whereas the corresponding percentage for Non-Interstate NHS contracts was $21 \%$ (24 of 112) and for Non-NHS contracts was $25 \%$ (60 of 236 contracts).

Based on these findings, it was found that the design stage cost overrun is more frequent for NonNHS contracts followed by Non-Interstate NHS and Interstate contracts. Cost underruns on the other hand are more frequent amongst Interstate contracts, compared to Non-Interstate NHS and Non-NHS contracts.

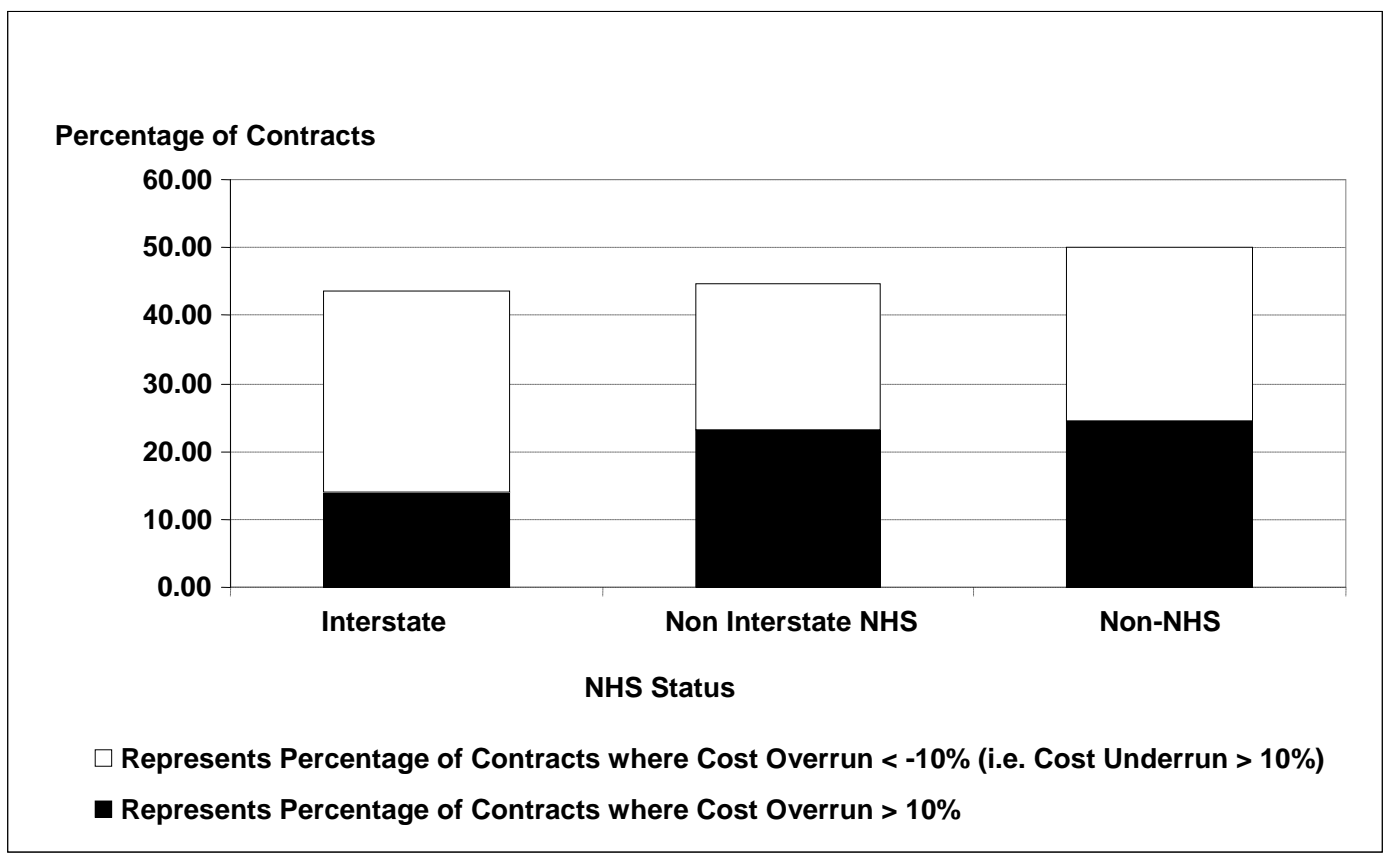

Figure 5.25: Percentage of Contracts Outside the ‘ $+/-10 \%$ ’ Design Stage Cost Overrun Bracket by NHS Status

\section{(A) Severity of Design Stage Cost Overrun / Underrun}

The average design stage cost overrun was determined for contracts that lie outside the $+/-10 \%$ cost overrun bracket' by NHS status. The objective of this analysis was to determine whether contracts belonging to any particular NHS status experienced a higher average design stage cost overrun or underrun compared to others. The following conclusions were made:

i. For Contracts with Cost Overrun $>10 \%$ : The average design stage cost overrun was $42 \%$ for Interstate contracts, $27 \%$ for Non-Interstate NHS contracts, and 35\% for Non-NHS contracts. An analysis of the $95 \%$ confidence intervals indicated that the Interstate contracts [18\%, 66\%] experience a wider range of cost overrun compared to Non-Interstate NHS [19\%, 34\%] and Non- 
NHS $[29 \%, 41 \%]$ contracts (Figure 5.26). The upper limit of the $95 \%$ confidence interval for Interstates-NHS contracts was $66 \%$ compared to $34 \%$ for Non-Interstate NHS contracts and $41 \%$ for Non-NHS, which implied that Interstate contracts experienced higher cost overrun compared to Non-Interstate NHS and Non-NHS contracts.

ii. For Contracts with Cost Overrun $<-10 \%$ (i.e. Cost Underrun $>10 \%$ ): The average design stage cost underrun for Interstate contracts (26\%) was higher compared to Non-NHS (23\%) and NonInterstate NHS $(21 \%)$ contracts. The $95 \%$ confidence intervals corresponding to these averages were [20\%,32\%], [20\%, 25\%], and [16\%, 27\%] for Interstate, Non-NHS, and Non-Interstate NHS contracts, respectively. Based on the plot of the $95 \%$ confidence intervals and the average design stage cost overrun (Figure 5.26), it was found that the Interstate contracts were more vulnerable to high cost underrun, compared to Non-NHS and Non-Interstate NHS contracts.

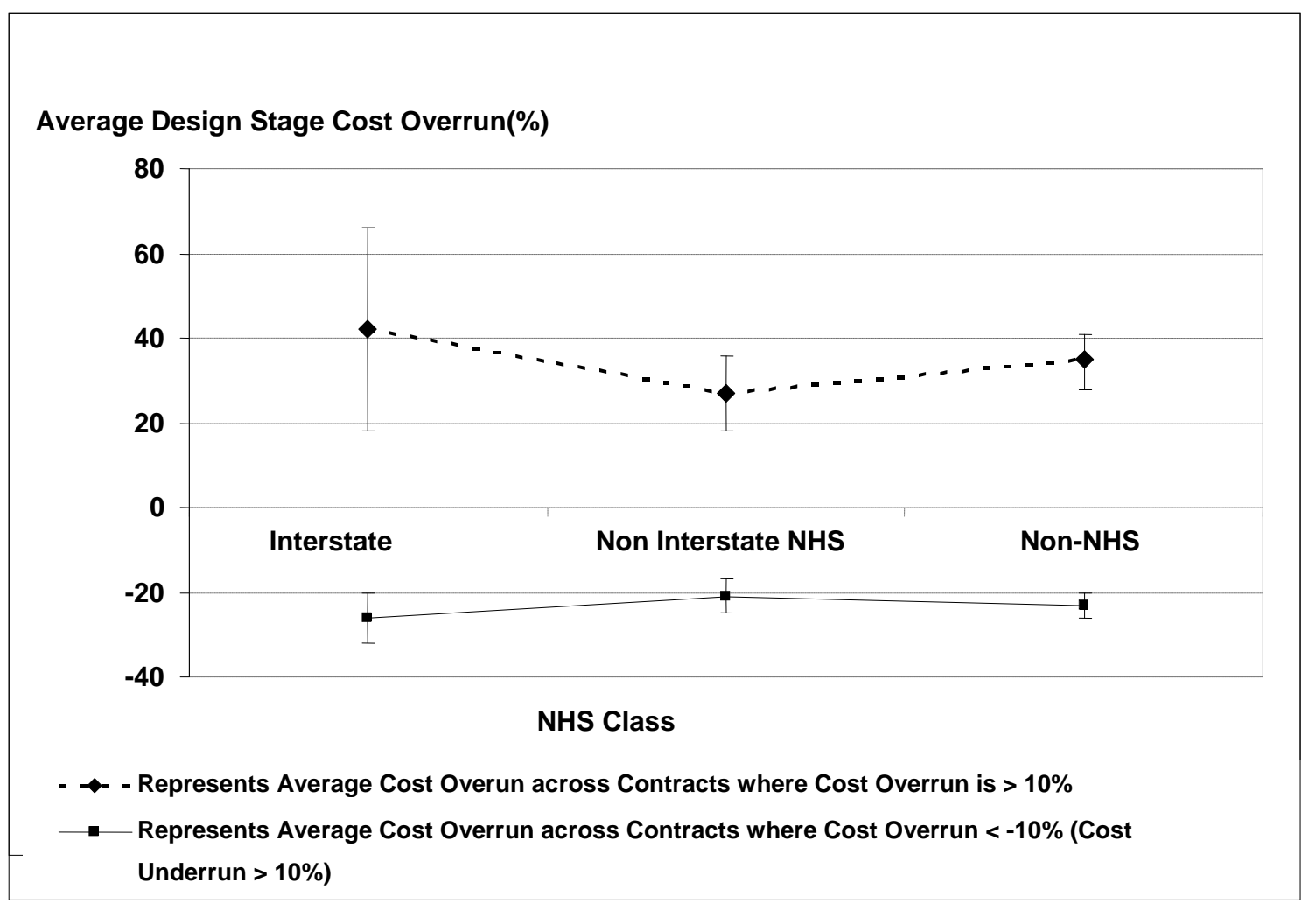

Figure 5.26: Average Design Stage Cost Overrun for Contracts Outside the ‘ $+/-10 \%$ Cost Overrun Bracket' by NHS Status

\subsubsection{Descriptive Analysis by District}

Table 5.21 shows the average design stage cost overrun for all districts. The Greenfield district had the highest average design stage cost overrun (9.4\%), followed by Crawfordsville (6.2\%), Vincennes (5.3\%), 
Seymour (3.4\%), Fort Wayne (2.9\%), and Laporte $(0.18 \%)$. The $95 \%$ confidence interval of the average design stage cost overrun in the Greenfield and Crawfordsville districts was $[1.6 \%, 17 \%]$ and $[-0.4 \%$, $13 \%$ ], which indicated that cost overrun is significantly more prominent than cost underrun in both these districts, particularly in Greenfield. In the districts of Seymour, Fort Wayne, and Vincennes, the 95\% confidence interval of the average design stage cost overrun indicated that cost overrun is marginally more prominent than cost underrun, but the average overrun is not significantly different from zero.

Table 5.21: Analysis of Average Cost Overrun of Final Cost over Design Cost by District

\begin{tabular}{|c|c|c|c|c|c|}
\hline & \multicolumn{4}{|c|}{$Y_{3}=100\left(\frac{\text { Final Cost }- \text { Design Cost }}{\text { Design Cost }}\right) \%$} & \multirow[b]{2}{*}{$\begin{array}{l}\text { Weighted } \\
\text { Average }\end{array}$} \\
\hline & $Y_{3}<-10 \%$ & $-10 \% \leq Y_{3}<0 \%$ & $0 \% \leq Y_{3} \leq 10 \%$ & $Y_{3}>10 \%$ & \\
\hline CRAWF & $\begin{array}{l}\text { Average: }-23.6 \% \\
\text { Contracts: } 18 \\
\text { C.I: }[-29 \%,-19 \%]\end{array}$ & $\begin{array}{l}\text { Average: }-3.8 \% \\
\text { Contracts: } 11 \\
\text { C.I: }[5.8 \%,-1.7 \%]\end{array}$ & $\begin{array}{l}\text { Average: } 3 \% \\
\text { Contracts: } 18 \\
\text { C.I: }[1.4 \%, 4.6 \%]\end{array}$ & $\begin{array}{l}\text { Average: } 33 \% \\
\text { Contracts: } 19 \\
\text { C.I: }[22 \%, 44 \%]\end{array}$ & $\begin{array}{l}\text { Average: } 3.2 \% \\
\text { Contracts: } 66 \\
\text { C.I:[-3\%,9.5\%] }\end{array}$ \\
\hline $\mathrm{FW}$ & $\begin{array}{l}\text { Average: }-22 \% \\
\text { Contracts: } 12 \\
\text { C.I: }[-30 \%,-14 \%]\end{array}$ & $\begin{array}{l}\text { Average: }-2.2 \% \\
\text { Contracts: } 17 \\
\text { C.I: }[-3.6 \%,-0.7 \%]\end{array}$ & $\begin{array}{l}\text { Average: } 2.5 \% \\
\text { Contracts: } 22 \\
\text { C.I: }[1.4 \%, 3.7 \%]\end{array}$ & $\begin{array}{l}\text { Average: } 31 \% \\
\text { Contracts: } 16 \\
\text { C.I: }[18 \%, 43 \%]\end{array}$ & $\begin{array}{l}\text { Average: } 3.7 \% \\
\text { Contracts: } 67 \\
\text { C.I:[-1.6\%,8.9\%] }\end{array}$ \\
\hline GRE & $\begin{array}{l}\text { Average: }-20 \% \\
\text { Contracts: } 18 \\
\text { C.I:[-25\%,-14\%] }\end{array}$ & $\begin{array}{l}\text { Average: }-2.4 \% \\
\text { Contracts: } 21 \\
\text { C.I: }[-3.8 \%,-1 \%]\end{array}$ & $\begin{array}{l}\text { Average: } 3.2 \% \\
\text { Contracts: } 16 \\
\text { C.I: }[1.5 \%, 4.9 \%]\end{array}$ & $\begin{array}{l}\text { Average: } 37 \% \\
\text { Contracts: } 16 \\
\text { C.I: }[22 \%, 52 \%]\end{array}$ & $\begin{array}{l}\text { Average: } 3.3 \% \\
\text { Contracts: } 71 \\
\text { C.I:[-2.5\%, } 9.1 \%]\end{array}$ \\
\hline LAP & $\begin{array}{l}\text { Average: }-21.6 \% \\
\text { Contracts: } 19 \\
\text { C.I:[-28\%,-16\%] }\end{array}$ & $\begin{array}{l}\text { Average: }-2.3 \% \\
\text { Contracts: } 21 \\
\text { C.I: }[-3.6 \%,-1 \%]\end{array}$ & $\begin{array}{l}\text { Average: } 2.6 \% \\
\text { Contracts: } 28 \\
\text { C.I: }[1.5 \%, 3.8 \%]\end{array}$ & $\begin{array}{l}\text { Average: } 34 \% \\
\text { Contracts: } 6 \\
\text { C.I: }[10 \%, 57 \%]\end{array}$ & $\begin{array}{l}\text { Average:-2.4\% } \\
\text { Contracts: } 74 \\
\text { C.I:[-6.4\%, } 1.5 \%]\end{array}$ \\
\hline SEY & $\begin{array}{l}\text { Average: }-25.3 \% \\
\text { Contracts: } 17 \\
\text { C.I:[-30\%,-21\%] }\end{array}$ & $\begin{array}{l}\text { Average: }-2.5 \% \\
\text { Contracts: } 18 \\
\text { C.I: }[-4 \%,-1 \%]\end{array}$ & $\begin{array}{l}\text { Average: } 1.4 \% \\
\text { Contracts: } 18 \\
\text { C.I: }[0.4 \%, 2.5 \%]\end{array}$ & $\begin{array}{l}\text { Average: } 32 \% \\
\text { Contracts: } 20 \\
\text { C.I: }[19 \%, 44 \%]\end{array}$ & $\begin{array}{l}\text { Average: } 2.5 \% \\
\text { Contracts: } 73 \\
\text { C.I:[-3.4\%,8.4\%] }\end{array}$ \\
\hline VIN & $\begin{array}{l}\text { Average: }-25 \% \\
\text { Contracts: } 21 \\
\text { C.I:[-31\%,-19\%] }\end{array}$ & $\begin{array}{l}\text { Average: }-2.9 \% \\
\text { Contracts: } 15 \\
\text { C.I: }[-4.5 \%,-1.2 \%]\end{array}$ & $\begin{array}{l}\text { Average: } 3.3 \% \\
\text { Contracts: } 15 \\
\text { C.I: }[1.5 \%, 5.2 \%]\end{array}$ & $\begin{array}{l}\text { Average: } 35 \% \\
\text { Contracts: } 17 \\
\text { C.I: }[23 \%, 48 \%]\end{array}$ & $\begin{array}{l}\text { Average: } 1.2 \% \\
\text { Contracts: } 68 \\
\text { C.I:[-5.2\%,7.7\%] }\end{array}$ \\
\hline
\end{tabular}

Contracts: Number of Contracts

C.I: 95\% Confidence Interval (Estimated Using One Sample t-Test)

\section{(A) Frequency of Design Stage Cost Overrun / Underrun}

The distribution of the contracts that lie outside the ' $+/-10 \%$ ' design stage cost overrun bracket by district is shown in Figure 5.27.

i. The percentage of contracts outside the ' $+/-10 \%$ cost overrun bracket' was least in Laporte district (33\%), followed by Fort Wayne (42\%), Greenfield (48\%), Seymour (51\%), Crawfordsville (56\%), and Vincennes (56\%). On average, approximately $48 \%$ of contracts have a design stage cost overrun outside the ' $+/-10 \%$ cost overrun bracket'. 
ii. The percentage of contracts having a cost overrun of greater than $10 \%$ was least in Laporte district (8\%), followed by Greenfield (23\%), Vincennes (25\%), Seymour (27\%), Crawfordsville (29\%), and Fort Wayne (44\%).

iii. The percentage of contracts having a cost underrun exceeding $10 \%$ was least in the Fort Wayne district (18\%), followed by Seymour (23\%), Greenfield (25\%), Laporte (26\%), Crawfordsville (27\%), and Vincennes (30\%).

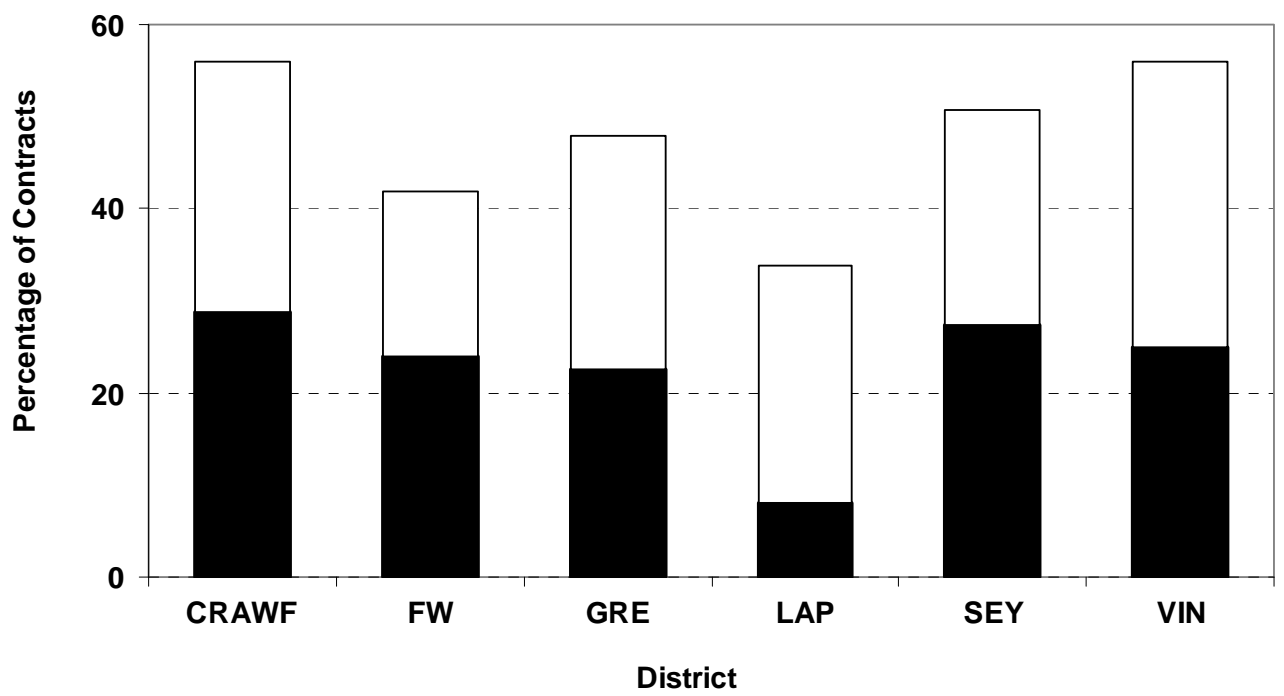

$\square$ Represents Percentage of Contracts where Cost Overrun < -10\% (i.e. Cost Underrun > 10\%)

Depresents Percentage of Contracts where Cost Overrun $>10 \%$

Figure 5.27: Percentage of Contracts Outside the ‘ $+/-10 \%$ ' Design Stage Cost Overrun Bracket by District

\section{(B) Severity of Design Stage Cost Overrun / Underrun}

The average design stage cost overrun was determined for contracts that lie outside the $+/-10 \%$ cost overrun bracket' by district. The objective was to identify the districts with high design stage cost overrun.

i. For Contracts with Cost Overrun $>10 \%$ : The average design stage cost overrun was largest for Greenfield district (37\%), as compared to Vincennes (35\%), Laporte (34\%), Crawfordsville (33\%), Seymour (32\%), and Fort Wayne (31\%). Based on the plot of the average design stage cost overrun and the corresponding 95\% confidence interval (Figure 5.28), it was concluded that the cost overrun is not significantly different across the districts at the design stage.

ii. For Contracts with Cost Overrun $<-10 \%$ (i.e. Cost Underrun $>10 \%$ ): The average design stage cost underrun was 20\% in Greenfield, 22\% in Laporte and Fort Wayne, 24\% in Crawfordsville, and $25 \%$ in Vincennes and Seymour districts. An analysis of the $95 \%$ confidence interval indicates no significant difference in average design stage cost overrun across the districts. 


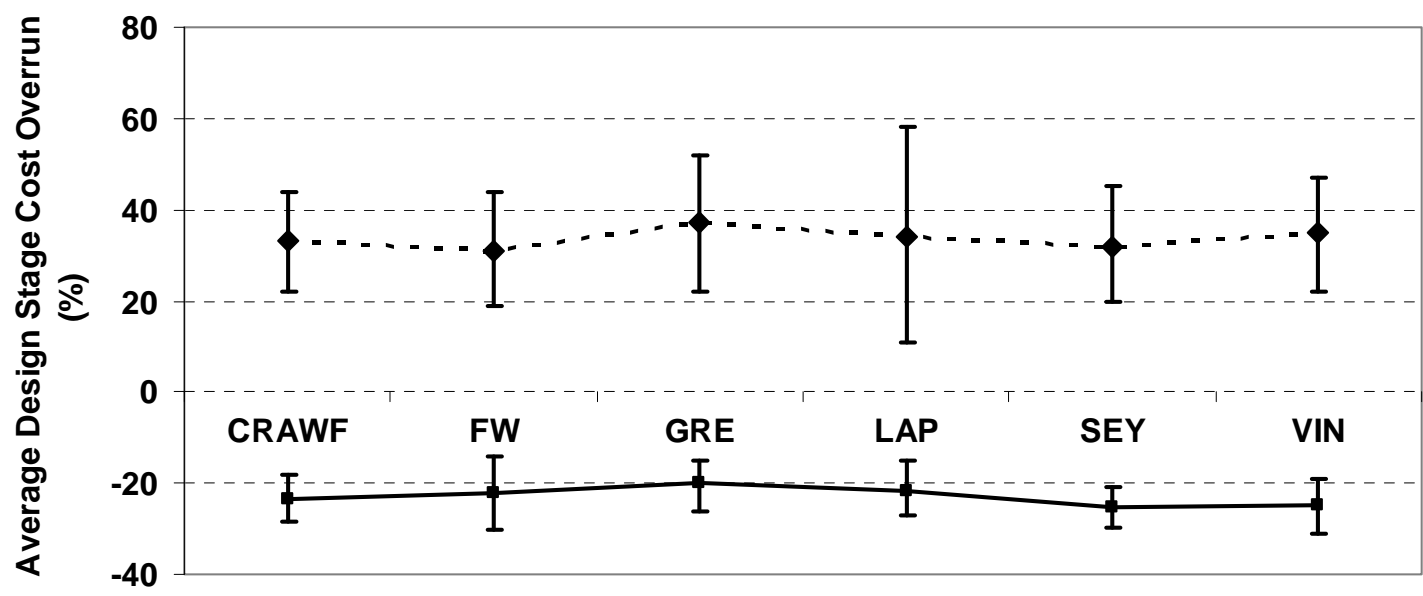

District

$-\leftrightarrow$ Represents Average Cost Overun across Contracts where Cost Overrun is $>10 \%$

$\longrightarrow-$ Represents Average Cost Overrun across Contracts where Cost Overrun $<-10 \%$ (Cost Underrun $>10 \%$ )

Figure 5.28: Average Design Stage Cost Overrun for Contracts Outside the ' $+/-10 \%$ Cost Overrun Bracket' by District

\subsubsection{Descriptive Analysis by Area Type}

The analysis of the average design stage cost overrun by area type and cost overrun category is presented in Table 5.22. Design stage cost overrun in urban areas was not significantly different from that in rural areas. The average design stage cost overrun in the urban area was $2.7 \%$ with a $95 \%$ confidence interval of $[-1.5 \%, 6.8 \%]$. The average design stage cost overrun in the rural area was $1.5 \%$ and the $95 \%$ confidence interval of the average was $[-1.2 \%, 4.2 \%]$.

Table 5.22: Average Design Stage Cost Overrun by Cost Overrun Category and Area Type

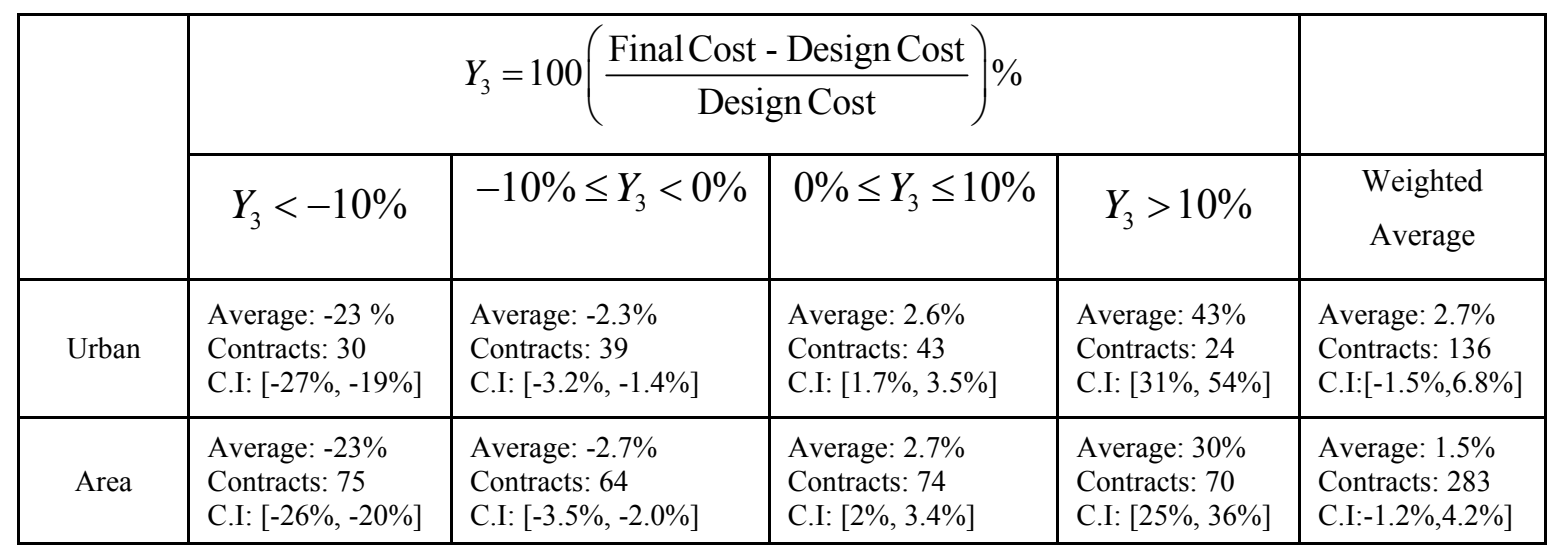

Contracts: Number of Contracts

C.I: 95\% Confidence Interval (Estimated Using One Sample t-Test) 


\section{(A) Frequency of Design Stage Cost Overrun / Underrun}

The contracts that were outside the ' $+/-10 \%$ cost overrun bracket' were analyzed by area type. The following observations were made based on the results presented in Table 5.22 and Figure 5.29:

1. The design stage cost overrun was outside the ' $+/-10 \%$ cost overrun bracket' for $40 \%$ (54 of 136) of the urban area contracts and for 51\% (145 of 283) of the rural area contracts.

2. The design stage cost overrun exceeded $10 \%$ for $17 \%$ (24 of 136) of the urban area contracts and $24 \%$ (70 of 283) of the rural area contracts.

3. The design stage cost underrun exceeded $10 \%$ for $22 \%$ (30 of 136) of the urban area contracts and $27 \%$ ( 75 of 283 ) of the rural area contracts.

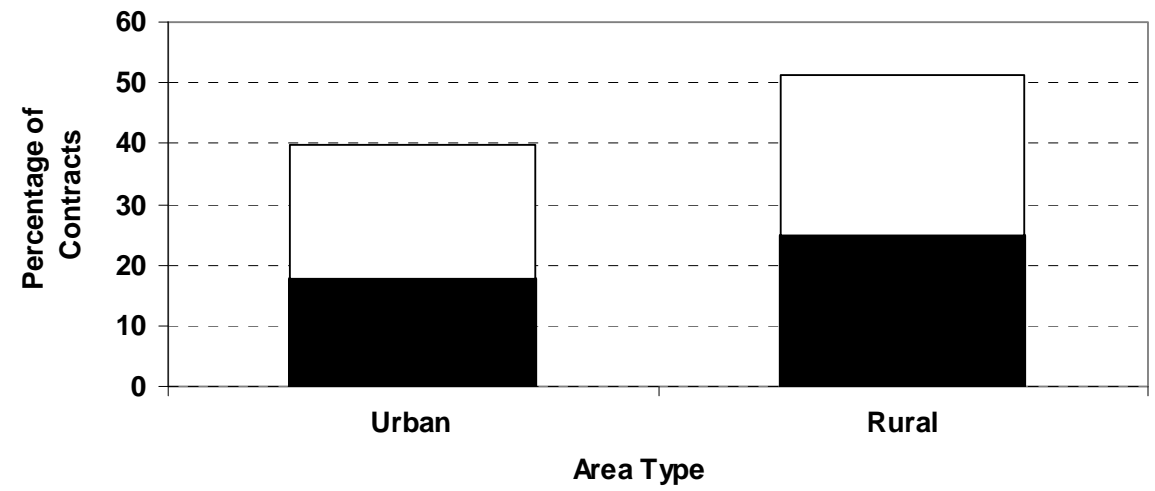

$\square$ Represents Percentage of Contracts where Cost Overrun < -10\% (i.e. Cost Underrun > 10\%)

Represents Percentage of Contracts where Cost Overrun $>10 \%$

Figure 5.29: Percent Contracts Outside the ‘ $+/ 10 \%$ ’ Design Stage Cost Overrun Bracket by Area Type

\section{(B) Severity of Design Stage Cost Overrun / Underrun}

The average design stage cost overrun was plotted for urban and rural area contracts that lie outside the ' $+/-10 \%$ cost overrun bracket' (Figure 5.30). The findings were as follows:

i. For Contracts with Cost Overrun $>10 \%$ : The average design stage cost overrun in the urban and rural areas was $43 \%$ and $30 \%$, respectively. The width of $95 \%$ confidence interval of the average design stage cost overrun for urban area contracts [31\%, 54\%] was twice the width of the confidence interval for rural area contracts $[25 \%, 36 \%]$. That is, the variability of the design stage cost overrun was greater for the urban area contracts. The upper limit of the confidence interval for urban area contracts (54\%) was higher than that of rural area contracts (36\%), which indicated that urban area contracts experienced higher design stage cost overrun compared to rural area contracts.

ii. For Contracts with Cost Overrun $<-10 \%$ (i.e. Cost Underrun $>10 \%$ ): The average design stage cost underruns for the urban and rural areas was are both approximately $23 \%$, and the $95 \%$ confidence interval is $[19 \%, 27 \%]$ and $[20 \%, 26 \%]$, respectively. Therefore, cost underrun at the design stage was not significantly different for contracts in the urban and rural areas. 


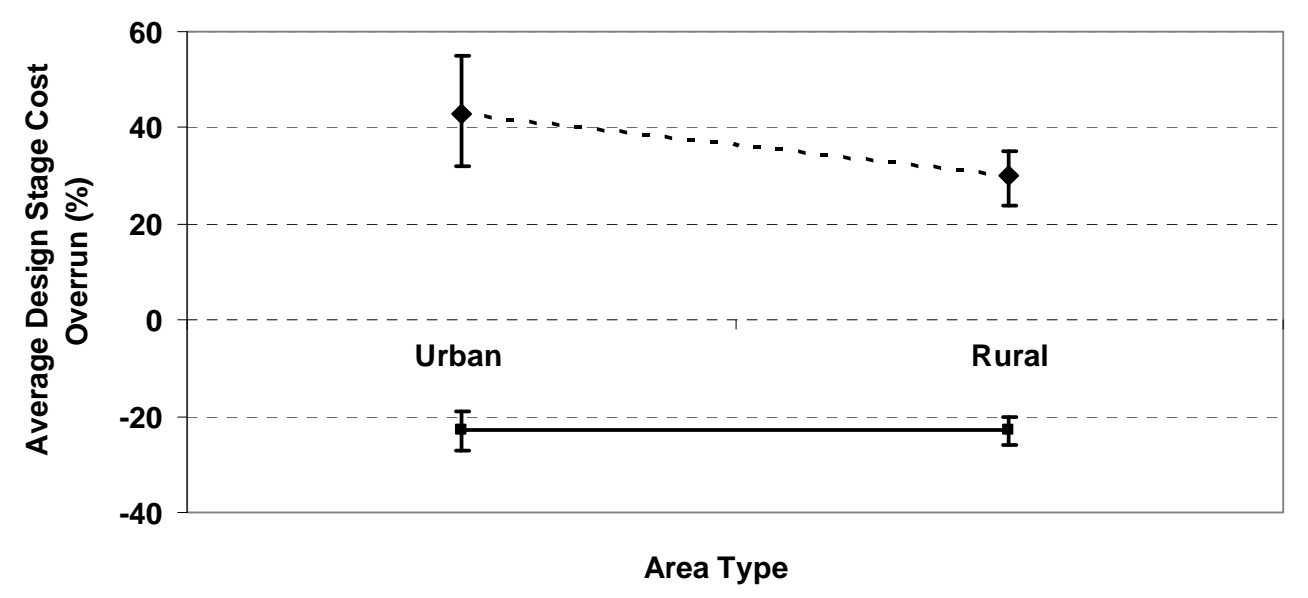

$-\bullet$ Represents Average Cost Overun across Contracts where Cost Overrun is $>10 \%$
$\rightarrow-$ Represents Average Cost Overrun across Contracts where Cost Overrun $<-10 \%$ (Cost Underrun $>10 \%$ )

Figure 5.30: Average Design Stage Cost Overrun for Contracts Outside the ' $+/-10 \%$ Cost Overrun Bracket' by Area Type

\subsubsection{Final Cost vs. Letting Cost}

The difference between the final construction cost and the letting cost (winning bid amount) was calculated to determine the accuracy of the cost estimate at the letting stage. The letting stage cost overrun was calculated as:

$$
\text { Letting Stage Cost Overrun : } Y_{4}=100\left(\frac{\text { Final Cost - Letting Cost }}{\text { Letting Cost }}\right) \%
$$

The distribution of letting stage cost overrun is shown in Figure 5.31 for 419 contracts. The average letting stage cost overrun was $6.3 \%$ and the standard deviation was $13 \%$. The $95 \%$ confidence interval of the average letting stage cost overrun was $[5.1 \%, 7.6 \%]$. The low value of the average letting stage cost overrun is because the positive cost overrun is compensated by the negative cost overrun (i.e. cost underrun). However, the positive value of average letting stage cost overrun (6.3\%) and the 95\% confidence interval $[5.1 \%, 7.6 \%]$ indicated that overruns outweighs underruns at the letting stage. 


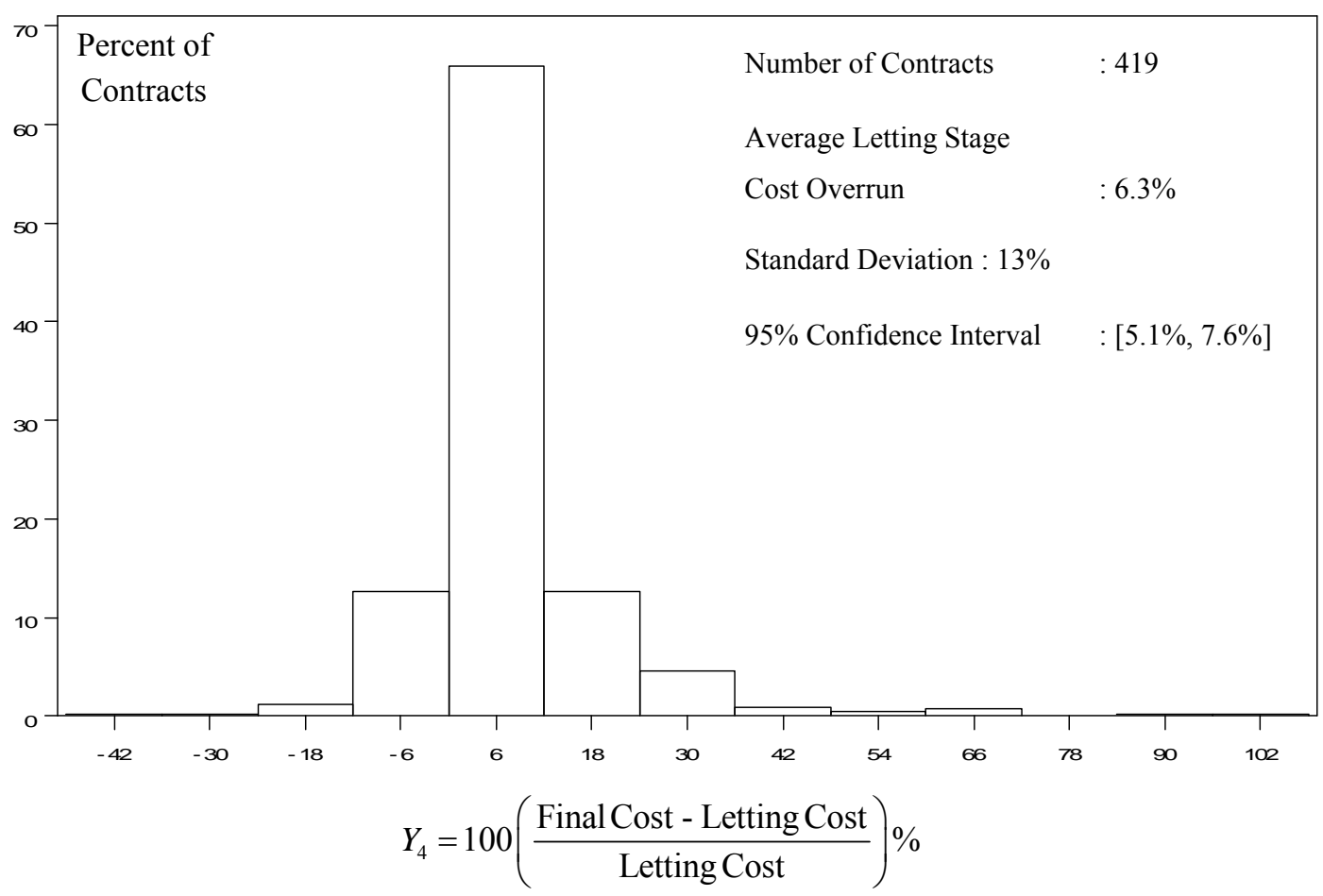

Figure 5.31: Histogram Distribution of Letting Stage Cost Overrun

Table 5.23 presents the average letting stage cost overrun by cost overrun category (as defined in Chapter 4). The final cost exceeded the letting cost by over $10 \%$ (cost overrun) for $25 \%$ of the contracts (104 of the 419 contracts); the letting cost exceeded the final cost (cost underrun) by over $10 \%$ for only $3 \%$ of the contracts (13 of the 419 contracts). That is, for $72 \%$ of the contracts (302 of 419 contracts) the difference between the final cost and the letting cost was within the ' $+/-10 \%$ cost overrun bracket' and only $28 \%$ of the contracts were outside the bracket.

Table 5.23: Analysis of Average Letting Stage Cost Overrun by Cost Overrun Category

\begin{tabular}{|l|c|c|c|c|c|}
\hline & \multicolumn{3}{|c|}{$Y_{4}=100\left(\frac{\text { Final Cost - Letting Cost }}{\text { Letting Cost }}\right) \%$} & \\
\cline { 2 - 6 } & $Y_{4}<-10 \%$ & $-10 \% \leq Y_{4}<0 \%$ & $0 \% \leq Y_{4} \leq 10 \%$ & $Y_{4}>10 \%$ & Total \\
\hline Number of Contracts & 13 & 47 & 255 & 104 & 419 \\
\hline Weighted Average & $-17 \%$ & $-3.74 \%$ & $2.82 \%$ & $22 \%$ & $3.91 \%$ \\
\hline $\begin{array}{l}95 \% \text { Confidence } \\
\text { Interval }\end{array}$ & {$[-23 \%,-11 \%]$} & {$[-4.6 \%,-2.9 \%]$} & {$[2.4 \%, 3.2 \%]$} & {$[19 \%, 25 \%]$} & {$[5.1 \%, 7.6 \%]$} \\
\hline
\end{tabular}




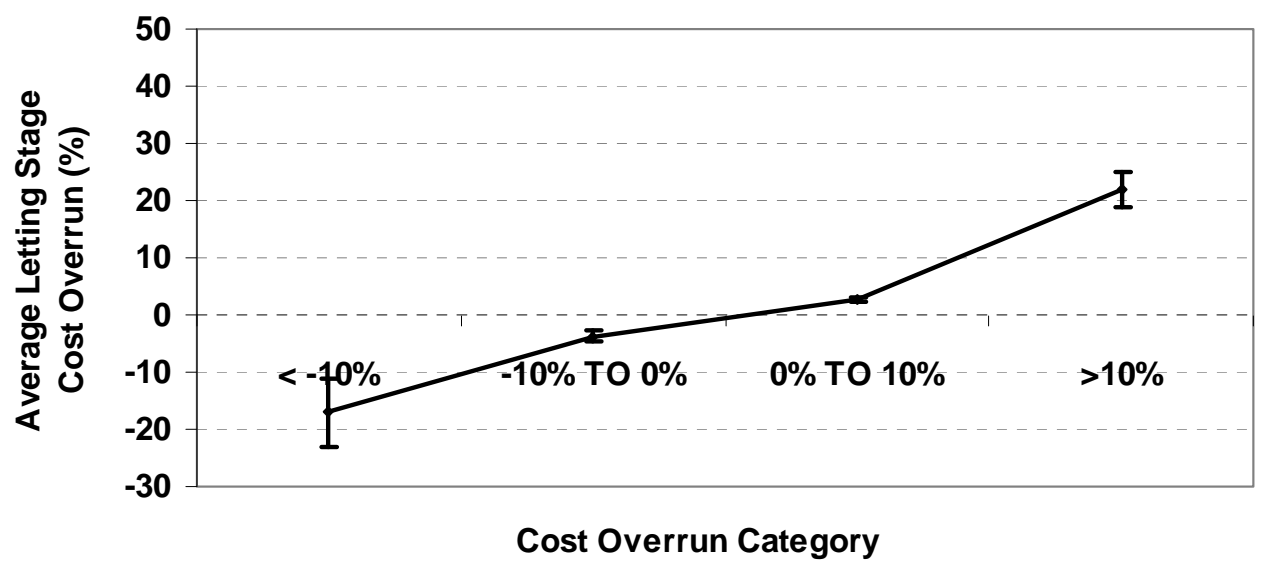

Figure 5.32: A 95\% Confidence Interval Analysis of Average Letting Stage Cost Overrun by Cost Overrun Category

Figure 5.32 shows the average letting stage cost overrun and the $95 \%$ confidence intervals for the contracts in each cost overrun category. For the 104 contracts for which the letting stage cost overrun exceeds $10 \%$, it was found that the average letting stage cost overrun for these contracts was $22 \%$. Further, it was determined with $95 \%$ confidence that the average letting stage cost overrun for contracts that belong to this category fall between $19 \%$ and $25 \%$. Cost underrun of greater than $10 \%$ (i.e. cost overrun $<-10 \%$ ) were found to be infrequent (only 13 of 419 contracts) at the letting stage. For these 13 contracts, the average letting stage cost underrun was $17 \%$ and the $95 \%$ confidence interval was $[11 \%, 23 \%]$. The contracts that lie within the ' $+/-10 \%$ cost overrun bracket' did not have a significant cost overrun / underrun at the letting stage. The average letting stage cost overrun and the limits of the $95 \%$ confidence interval were less than $5 \%$ for these contracts. Chapter 6 presents models that were developed to determine the probability of a contract belonging to any one of the four categories of letting stage cost overrun.

Sections 5.3.4.1 through 5.3.4.7 present a detailed analysis of the contracts that have a cost overrun of greater than $10 \%$ by contract size, type, work category, area type, route type, NHS status, and administrative district.

\subsubsection{Descriptive Analysis by Work Category}

The average letting stage cost overrun and the $95 \%$ confidence interval of the average are shown in Table 5.24 by work category. The average letting stage cost overrun $(8.8 \%)$ and the $95 \%$ confidence interval $[8.8 \%, 12.2 \%]$ of the expansion contracts exceeded that for pavement contracts $(5.6 \%$; $[3.0 \%, 8.2 \%])$ and bridge contracts $(5.9 \%,[4.4 \%, 7.4 \%])$. 
Table 5.24: Analysis of Average Letting Stage Cost Overrun by Cost Overrun and Work Category

\begin{tabular}{|c|c|c|c|c|c|}
\hline & & $Y_{4}=100\left(\frac{\text { Final Co }}{\mathrm{Le}}\right.$ & \multicolumn{2}{|c|}{$\left(\frac{\text { Final Cost }- \text { Letting Cost }}{\text { Letting Cost }}\right) \%$} & \multirow[b]{2}{*}{$\begin{array}{l}\text { Weighted } \\
\text { Average }\end{array}$} \\
\hline & $Y_{4}<-10 \%$ & $-10 \% \leq Y_{4}<0 \%$ & $0 \% \leq Y_{4} \leq 10 \%$ & $Y_{4}>10 \%$ & \\
\hline $\begin{array}{c}\text { Expansion } \\
\text { Contracts }\end{array}$ & $\begin{array}{l}\text { Average: }-10 \% \\
\text { Contracts: } 1\end{array}$ & $\begin{array}{l}\text { Average: }-2.8 \% \\
\text { Contracts: } 9 \\
\text { C.I: }[-4.8 \%, 0.8 \%]\end{array}$ & $\begin{array}{l}\text { Average: } 3.2 \% \\
\text { Contracts: } 42 \\
\text { C.I: }[2.2 \%, 4.1 \%]\end{array}$ & $\begin{array}{l}\text { Average: } 26 \% \\
\text { Contracts: } 21 \\
\text { C.I: }[17 \%, 35 \%]\end{array}$ & $\begin{array}{l}\text { Average: } 8.8 \% \\
\text { Contracts: } 73 \\
\text { C.I:[5.2\%,12.5\%] }\end{array}$ \\
\hline $\begin{array}{c}\text { Bridge } \\
\text { Contracts }\end{array}$ & $\begin{array}{l}\text { Average: - } 44 \% \\
\text { Contracts: } 1\end{array}$ & $\begin{array}{l}\text { Average: }-4 \% \\
\text { Contracts: } 11 \\
\text { C.I: }[-6 \%,-1.8 \%]\end{array}$ & $\begin{array}{l}\text { Average: } 2.9 \% \\
\text { Contracts: } 75 \\
\text { C.I: }[2.3 \%, 3.5 \%]\end{array}$ & $\begin{array}{l}\text { Average: } 23 \% \\
\text { Contracts: } 20 \\
\text { C.I: }[13 \%, 33 \%]\end{array}$ & $\begin{array}{l}\text { Average: } 5.6 \% \\
\text { Contracts: } 107 \\
\text { C.I: }[3 \%, 8.2 \%]\end{array}$ \\
\hline $\begin{array}{l}\text { Pavement } \\
\text { Contracts }\end{array}$ & $\begin{array}{l}\text { Average: }-16 \% \\
\text { Contracts: } 11 \\
\text { C.I:[-19\%,-12\%] }\end{array}$ & $\begin{array}{l}\text { Average: }-4 \% \\
\text { Contracts: } 27 \\
\text { C.I: }[-5 \%,-2.9 \%]\end{array}$ & $\begin{array}{l}\text { Average: } 2.7 \% \\
\text { Contracts: } 138 \\
\text { C.I: }[2.1 \%, 3.2 \%]\end{array}$ & $\begin{array}{l}\text { Average: } 21 \% \\
\text { Contracts: } 63 \\
\text { C.I: }[18 \%, 24 \%]\end{array}$ & $\begin{array}{l}\text { Average: } 5.9 \% \\
\text { Contracts: } 239 \\
\text { C.I:[4.4\%,7.4\%] }\end{array}$ \\
\hline $\begin{array}{l}\text { Weighted } \\
\text { Average }\end{array}$ & $\begin{array}{l}\text { Average: }-17 \% \\
\text { Contracts: } 13 \\
\text { C.I:[-23\%,-11\%] }\end{array}$ & $\begin{array}{l}\text { Average: }-3.7 \% \\
\text { Contracts: } 47 \\
\text { C.I: }[-4.6 \%,-2.9 \%]\end{array}$ & $\begin{array}{l}\text { Average: } 2.8 \% \\
\text { Contracts: } 255 \\
\text { C.I: }[2.4 \%, 3.2 \%]\end{array}$ & $\begin{array}{l}\text { Average: } 22 \% \\
\text { Contracts: } 104 \\
\text { C.I: }[19 \%, 25 \%]\end{array}$ & $\begin{array}{l}\text { Average: } 6.3 \% \\
\text { Contracts: } 419 \\
\text { C.I:[5.1\%,7.6\%] }\end{array}$ \\
\hline
\end{tabular}

Contracts: Number of Contracts

C.I: 95\% Confidence Interval (Estimated Using One Sample t-Test)

The letting stage cost overrun exceeded $10 \%$ for $19 \%$ (20 of 107) of the bridge contracts, $26 \%$ (63 of 239) of the pavement contracts, and 29\% (21 of 73 contracts) of the expansion contracts (Figure 5.33). For contracts with letting stage cost overrun exceeding $10 \%$, the average letting stage cost overrun was $26 \%, 23 \%$, and $21 \%$ for expansion, bridge, and pavement contracts, respectively (Figure 5.34). This indicates that pavement contracts had the least average letting stage cost overrun. The $95 \%$ confidence intervals of the average letting stage cost overrun was [17\%, 35\%], [13\%, 33\%], and [18\%, 24\%] for expansion, bridge, and pavement contracts, respectively. The upper limit of the confidence interval for pavement contracts (24\%) was less than that of expansion (35\%) and bridge (33\%) contracts (Figure 5.34), which implied that the pavement contracts were less susceptible to high letting stage cost overrun compared to expansion and bridge contracts. The $95 \%$ confidence also indicated that the variability of the letting stage cost overrun was lowest for pavement contracts. 


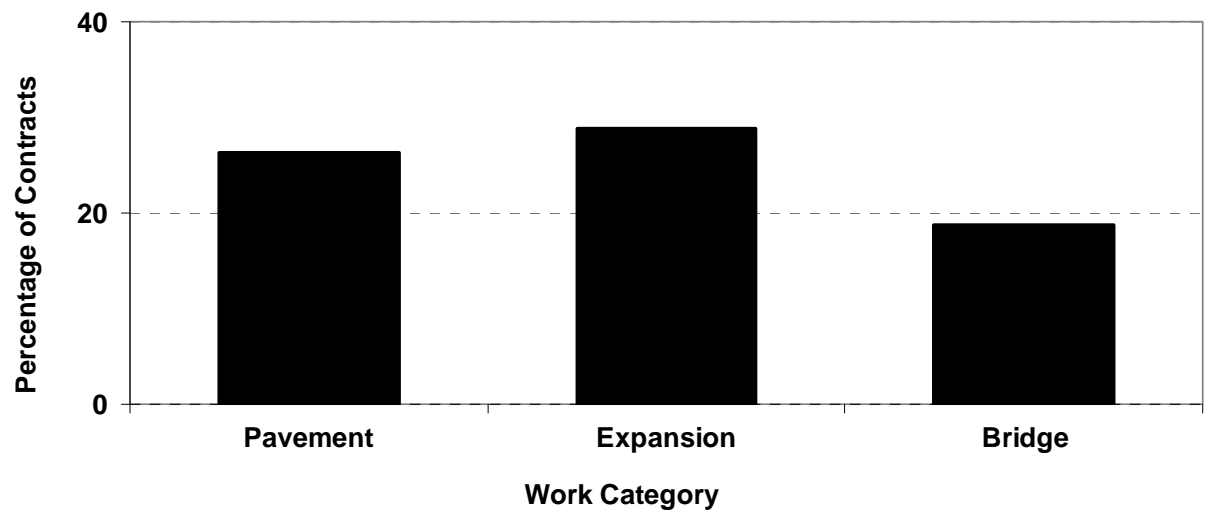

Figure 5.33: Percent Contracts with Letting Stage Cost Overrun $>10 \%$ by Work Category

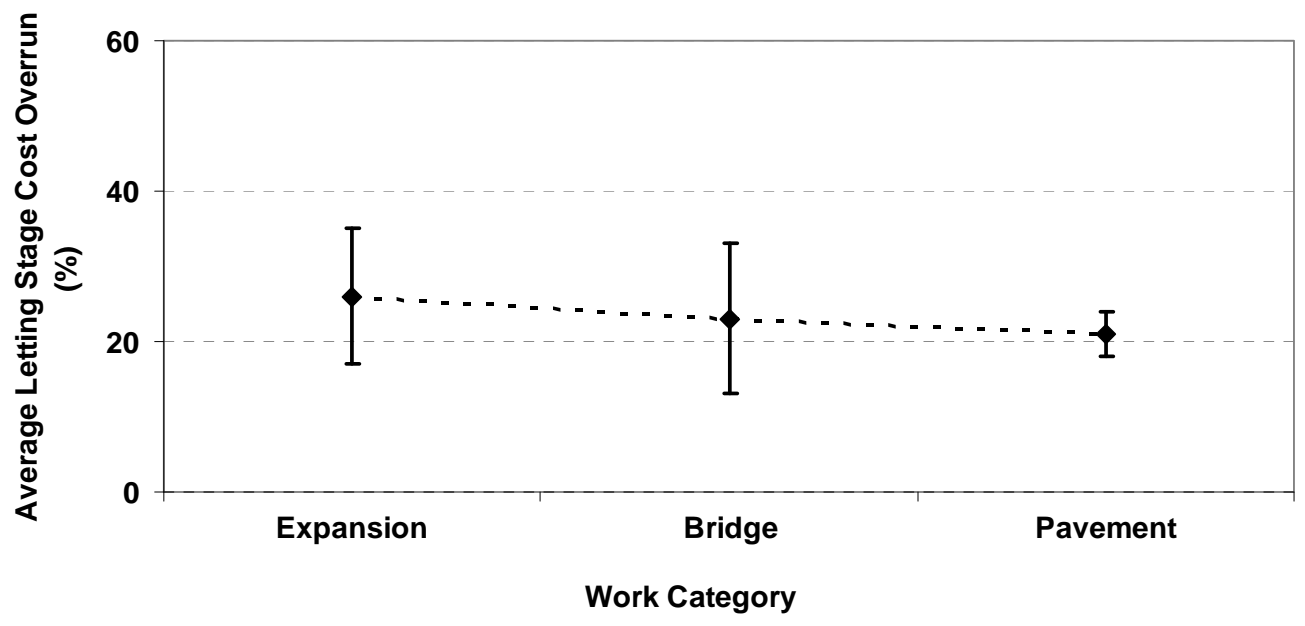

Figure 5.34: Average Letting Stage Cost Overrun for Contracts with Overrun $>10 \%$ by Work Category

\subsubsection{Descriptive Analysis by Contract Size}

The average letting stage cost overrun increased with increase in contract size from $\$ 1$ million to $\$ 10$ million (Table 5.25). The average letting stage cost overrun was $4.5 \%$ for contracts of size $\$ 1-\$ 2$ million, $7.2 \%$ for contracts of size $\$ 2-\$ 5$ million, and 9.3\% for contracts sized $\$ 5-\$ 10$ million. The $95 \%$ confidence intervals of the average letting stage cost overrun was [3.2\%, 5.9\%], [4.6\%, 9.7\%], and [4\%, 14.7\%] for contracts in the $\$ 1-\$ 2$ million, $\$ 2-\$ 5$ million, and $\$ 5-\$ 10$ million size categories, respectively. The upper limit of the $95 \%$ confidence interval increased with an increase in contract size from $\$ 1-\$ 10$ million, suggesting that large-sized contracts are more vulnerable to cost overrun at the letting stage. The contracts with proposed cost exceeding \$10 million had an average letting stage cost overrun of $8 \%$ and a $95 \%$ confidence interval of $[5 \%, 11 \%]$, which were marginally lower than the corresponding values for contracts 
in the $\$ 5$ - $\$ 10$ million size category, but higher than the corresponding values for contracts in the $\$ 1-\$ 5$ million size category.

Table 5.25: Average Letting Stage Cost Overrun by Contract Size and Cost Overrun Category

\begin{tabular}{|c|c|c|c|c|c|}
\hline & \multicolumn{4}{|c|}{$Y_{4}=100\left(\frac{\text { Final Cost }- \text { Letting Cost }}{\text { Letting Cost }}\right) \%$} & \multirow[b]{2}{*}{$\begin{array}{l}\text { Weighted } \\
\text { Average }\end{array}$} \\
\hline & $Y_{4}<-10 \%$ & $-10 \% \leq Y_{4}<0 \%$ & $0 \% \leq Y_{4} \leq 10 \%$ & $Y_{4}>10 \%$ & \\
\hline $\begin{array}{l}\$ 1 \mathrm{M}- \\
\$ 2 \mathrm{M}\end{array}$ & $\begin{array}{l}\text { Average: }-14.5 \% \\
\text { Contracts: } 4 \\
\text { C.I: [-24\%, - } \\
5.5 \%]\end{array}$ & $\begin{array}{l}\text { Average: }-3.3 \% \\
\text { Contracts: } 28 \\
\text { C.I: }[-4.4 \%,-2.1 \%]\end{array}$ & $\begin{array}{l}\text { Average: } 2.5 \% \\
\text { Contracts: } 121 \\
\text { C.I: }[1.9 \%, 3 \%]\end{array}$ & $\begin{array}{l}\text { Average: } 19 \% \\
\text { Contracts: } 37 \\
\text { C.I: }[16 \%, 22 \%]\end{array}$ & $\begin{array}{l}\text { Average: } 4.5 \% \\
\text { Contracts: } 190 \\
\text { C.I: }[3.2 \%, 5.9 \%]\end{array}$ \\
\hline $\begin{array}{l}\$ 2 \mathrm{M}- \\
\$ 5 \mathrm{M}\end{array}$ & $\begin{array}{l}\text { Average: }-17.5 \% \\
\text { Contracts: } 8 \\
\text { C.I: }[-27 \%,-8 \%]\end{array}$ & $\begin{array}{l}\text { Average: }-4.5 \% \\
\text { Contracts: } 11 \\
\text { C.I: }[-6.2 \%,-2.8 \%]\end{array}$ & $\begin{array}{l}\text { Average: } 2.8 \% \\
\text { Contracts: } 78 \\
\text { C.I: }[-2 \%, 3.5 \%]\end{array}$ & $\begin{array}{l}\text { Average: } 23.3 \% \\
\text { Contracts: } 41 \\
\text { C.I: }[18 \%, 29 \%]\end{array}$ & $\begin{array}{l}\text { Average: } 7.2 \% \\
\text { Contracts: } 138 \\
\text { C.I:[4.6\%,9.7\%] }\end{array}$ \\
\hline $\begin{array}{l}\$ 5 \mathrm{M}- \\
\$ 10 \mathrm{M}\end{array}$ & $\begin{array}{l}\text { Average: }-27.5 \% \\
\text { Contracts: } 1\end{array}$ & $\begin{array}{l}\text { Average: }-3.5 \% \\
\text { Contracts: } 6 \\
\text { C.I:[- } 6.3 \%,-0.8 \%]\end{array}$ & $\begin{array}{l}\text { Average: } 3.3 \% \\
\text { Contracts: } 32 \\
\text { C.I: }[2.4 \%, 4.2 \%]\end{array}$ & $\begin{array}{l}\text { Average: } 31.3 \% \\
\text { Contracts: } 14 \\
\text { C.I: }[16 \%, 46 \%]\end{array}$ & $\begin{array}{l}\text { Average: } 9.3 \% \\
\text { Contracts: } 53 \\
\text { C.I:[4\%, } 14.7 \%]\end{array}$ \\
\hline$>\$ 10 \mathrm{M}$ & - & $\begin{array}{l}\text { Average: }-6.8 \% \\
\text { Contracts: } 2 \\
\text { C.I: }[-8.5 \%,-5 \%]\end{array}$ & $\begin{array}{l}\text { Average: } 3.9 \% \\
\text { Contracts: } 24 \\
\text { C.I: }[2.6 \%, 5.2 \%]\end{array}$ & $\begin{array}{l}\text { Average: } 18.6 \% \\
\text { Contracts: } 12 \\
\text { C.I: }[14 \%, 24 \%]\end{array}$ & $\begin{array}{l}\text { Average: } 8.0 \% \\
\text { Contracts: } 38 \\
\text { C.I:[ } 5 \%, 11 \%]\end{array}$ \\
\hline
\end{tabular}

Contracts: Number of Contracts

C.I: 95\% Confidence Interval (Estimated Using One Sample t-Test)

The letting stage cost overrun exceeded $10 \%$ for $19 \%$ (37 of 190) of the $\$ 1-\$ 2$ million contracts, $30 \%$ (41 of 138) of $\$ 2-\$ 5$ million contracts, $26 \%$ (14 of 53) of $\$ 2-\$ 5$ million contracts, and 32\% (12 of 38 contracts) of contracts greater than $\$ 10$ million (Figure 5.35). Therefore, letting stage cost overrun greater than $10 \%$ was found to be least frequent for small-sized contracts.

For the contracts with letting stage cost overrun greater than $10 \%$, the average letting stage cost overrun was 19\% for contracts with size \$1-\$2 million, 23\% for contracts of size $\$ 2-\$ 5$ million, 31\% for contracts with size $\$ 5-\$ 10$ million, and 19\% for contracts of size exceeding $\$ 10$ million (Figure 5.36). Therefore, the average letting stage cost overrun increased with contract size from $\$ 1-\$ 10$ million. The $95 \%$ confidence interval of the average letting stage cost overrun for contracts of size in between $\$ 1-\$ 2$ million [16\%, 22\%], for contracts of size $\$ 2-\$ 5$ million [18\%, 29\%], and for contracts of size $\$ 5-\$ 10$ million $[16 \%, 46 \%]$, also indicated that cost overruns generally increase with contract size (Figure 5.36). However, for contracts of size exceeding $\$ 10 \mathrm{M}$, the average letting stage cost overrun (19\%) and the $95 \%$ confidence interval $[14 \%, 24 \%]$ were lower compared to $\$ 1-\$ 10$ million contracts. 


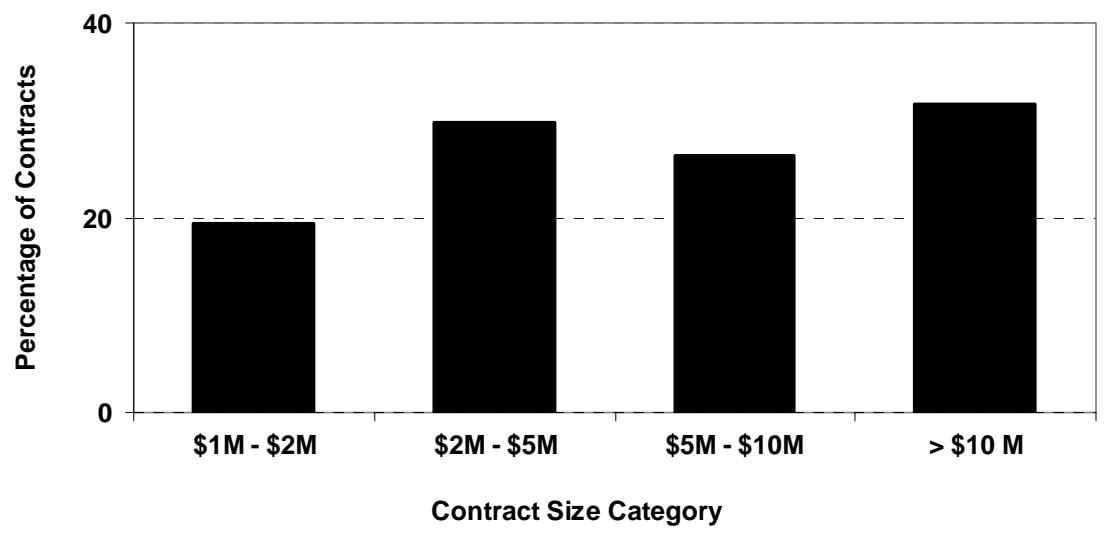

Figure 5.35: Percent Contracts with Letting Stage Cost Overrun $>10 \%$ by Contract Size

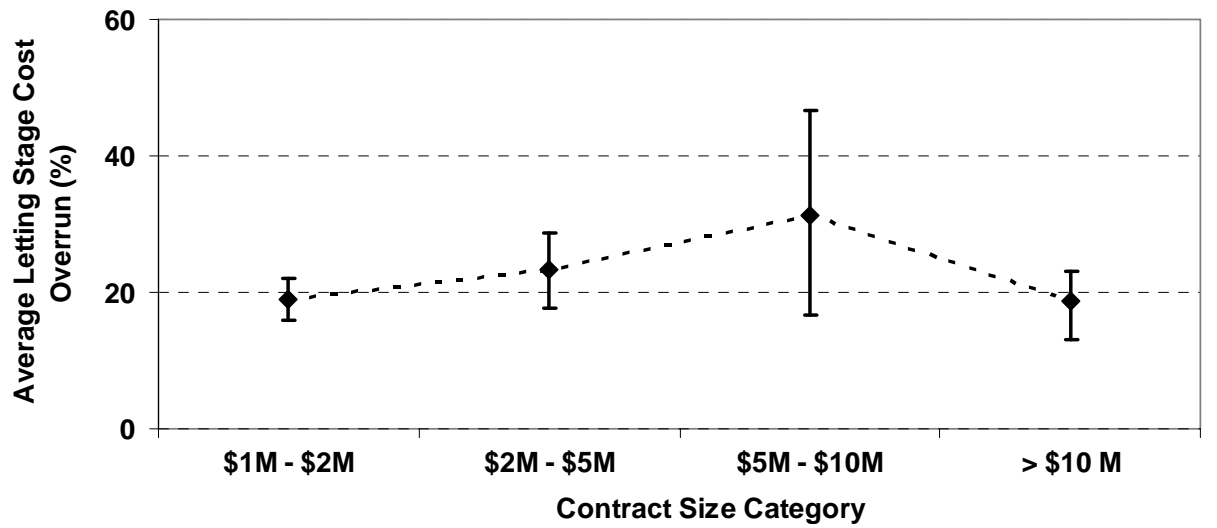

Figure 5.36: Average Letting Stage Cost Overrun for Contracts with Cost Overrun $>10 \%$ by Contract Size

\subsubsection{Analysis by Contract Type}

The average letting stage cost overrun by contract type and cost overrun category is shown in Table 5.26. The average letting stage cost overrun was higher for stand-alone contracts $(8.3 \%)$ compared to kin contracts $(5.2 \%)$. The $95 \%$ confidence intervals of the average letting stage cost overrun was $[4 \%, 6.4 \%]$ and $[5.5 \%, 11 \%]$ for kin and stand-alone contracts, respectively, which further confirmed that cost overrun are more significant for stand-alone contracts, as the upper limit of the confidence interval was higher for stand-alone contracts. 
Table 5.26: Analysis of Average Cost Overrun of Final Cost over Letting Cost by Contract Type

\begin{tabular}{|c|c|c|c|c|c|}
\hline & $Y_{4}=100$ & \multicolumn{3}{|c|}{$\left.\frac{\text { Final Cost }- \text { Letting Cost }}{\text { Letting Cost }}\right) \%$} & \multirow[b]{2}{*}{$\begin{array}{l}\text { Weighted } \\
\text { Average }\end{array}$} \\
\hline & $Y_{4}<-10 \%$ & $-10 \% \leq Y_{4}<0 \%$ & $0 \% \leq Y_{4} \leq 10 \%$ & $Y_{4}>10 \%$ & \\
\hline Kin & $\begin{array}{l}\text { Average: }-15 \% \\
\text { Contracts: } 7 \\
\text { C.I: }[-20 \%,-9.3 \%]\end{array}$ & $\begin{array}{l}\text { Average: }-3.4 \% \\
\text { Contracts: } 32 \\
\text { C.I: }[-4.3 \%,-2.5 \%]\end{array}$ & $\begin{array}{l}\text { Average: } 2.7 \% \\
\text { Contracts: } 169 \\
\text { C.I: }[2.2 \%, 3.1 \%]\end{array}$ & $\begin{array}{l}\text { Average: } 18.9 \% \\
\text { Contracts: } 62 \\
\text { C.I: }[17 \%, 21 \%]\end{array}$ & $\begin{array}{l}\text { Average: } 5.2 \% \\
\text { Contracts: } 270 \\
\text { C.I:[4\%, } 6.4 \%]\end{array}$ \\
\hline $\begin{array}{l}\text { Stand } \\
\text { Alone }\end{array}$ & $\begin{array}{l}\text { Average: }-20 \% \\
\text { Contracts: } 6 \\
\text { C.I: }[-34 \%,-6.8 \%]\end{array}$ & $\begin{array}{l}\text { Average: }-4.5 \% \\
\text { Contracts: } 15 \\
\text { C.I: }[-6.2 \%,-2.7 \%]\end{array}$ & $\begin{array}{l}\text { Average: } 3.1 \% \\
\text { Contracts: } 86 \\
\text { C.I: }[2.5 \%, 3.7 \%]\end{array}$ & $\begin{array}{l}\text { Average: } 27.5 \% \\
\text { Contracts: } 42 \\
\text { C.I: }[21 \%, 34 \%]\end{array}$ & $\begin{array}{l}\text { Average: } 8.3 \% \\
\text { Contracts: } 149 \\
\text { C.I:[5.5\%, } 11 \%]\end{array}$ \\
\hline $\begin{array}{l}\text { Weighted } \\
\text { Average }\end{array}$ & $\begin{array}{l}\text { Average: }-17 \% \\
\text { Contracts: } 13 \\
\text { C.I: }[-23 \%,-11 \%]\end{array}$ & $\begin{array}{l}\text { Average: }-3.7 \% \\
\text { Contracts: } 47 \\
\text { C.I: }[-4.6 \%,-2.9 \%]\end{array}$ & $\begin{array}{l}\text { Average: } 2.8 \% \\
\text { Contracts: } 255 \\
\text { C.I: }[2.4 \%, 3.2 \%]\end{array}$ & $\begin{array}{l}\text { Average: } 22 \% \\
\text { Contracts: } 104 \\
\text { C.I: }[19 \%, 25 \%]\end{array}$ & $\begin{array}{l}\text { Average: } 6.3 \% \\
\text { Contracts: } 419 \\
\text { C.I:[5.1\%,7.6\%] }\end{array}$ \\
\hline
\end{tabular}

Contracts: Number of Contracts

C.I: 95\% Confidence Interval (Estimated Using One Sample t-Test)

The letting stage cost overrun exceeded $10 \%$ for $23 \%$ (62 of 270 ) of the kin contracts and for $28 \%$ (42 of 149) of the stand-alone contracts. This indicates that cost overruns exceeding $10 \%$ are more frequent for stand-alone contracts (Figure 5.37).

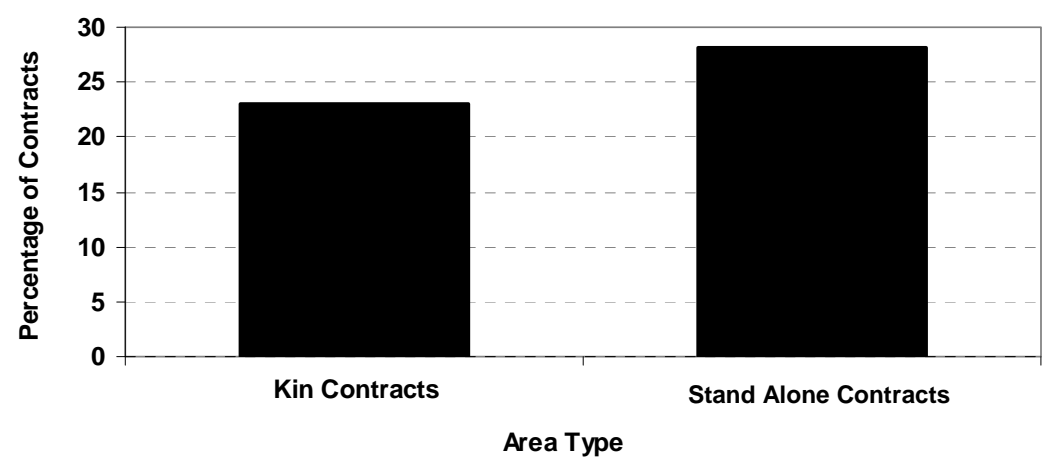

Figure 5.37: Percent Contracts with Letting Stage Cost Overrun $>10 \%$ by Contract Type

For the contracts with letting stage cost overrun exceeding $10 \%$, the average letting stage cost overrun was $19 \%$ for kin contracts and $28 \%$ for stand-alone contracts. The $95 \%$ confidence interval of the average letting stage cost overrun for stand-alone contracts [21\%,34\%] was also higher than that of kin contracts $[17 \%, 21 \%]$, thereby indicating that letting stage cost overrun exceeding $10 \%$ are more severe for stand-alone contracts (Figure 5.38). 


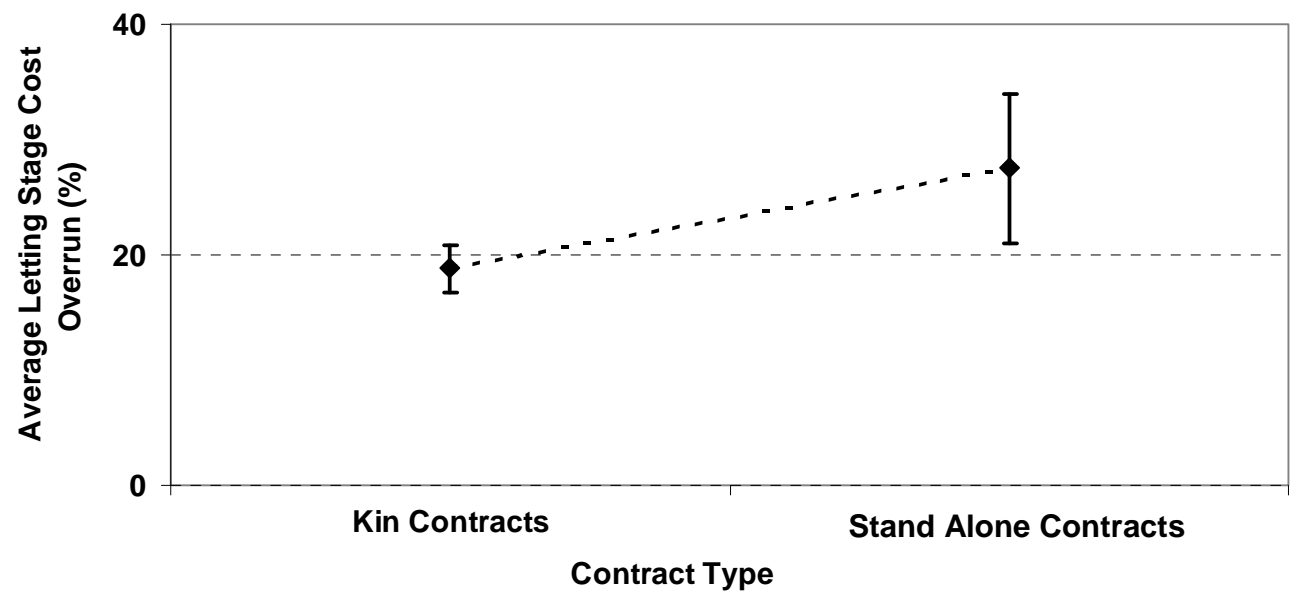

Figure 5.38: Average Letting Stage Cost Overrun for Contracts with Cost Overrun $>10 \%$ by Contract Type

\subsubsection{Descriptive Analysis by Route Type}

The average letting stage cost overrun was $7.1 \%$ for U.S. road contracts, $6.2 \%$ for state road contracts, and $5.4 \%$ for Interstate contracts (Table 5.27). The $95 \%$ confidence intervals of the average letting stage cost overrun was $[4.6 \%, 9.6 \%],[4.6 \%, 7.7 \%]$, and $[2 \%, 8.7 \%]$ for U.S. Road, State Road, and Interstate contracts, respectively. The average and the $95 \%$ confidence intervals indicated that cost overrun is more prominent than cost underrun across the three route categories. U.S. Road contracts had a marginally higher average and upper limit of the $95 \%$ confidence interval which indicated that U.S. road contracts had more significant cost overrun compared to State Road and Interstate contracts.

The frequency of high cost overrun at the letting stage was not significantly different across the three route types (Figure 5.39). The average letting stage cost overrun exceeded $10 \%$ for $26 \%$ (55 of 209) of the State Road contracts, 24\% (17 of 71) of the Interstate contracts, and 23\% (32 of 139) of U.S. road contracts. 
Table 5.27: Analysis of Average Cost Overrun of Final Cost over Letting Cost by Route Type

\begin{tabular}{|c|c|c|c|c|c|}
\hline & $Y_{4}=100$ & \multicolumn{3}{|c|}{$\left(\frac{\text { Final Cost }- \text { Letting Cost }}{\text { Letting Cost }}\right) \%$} & \multirow[b]{2}{*}{$\begin{array}{l}\text { Weighted } \\
\text { Average }\end{array}$} \\
\hline & $Y_{4}<-10 \%$ & $-10 \% \leq Y_{4}<0 \%$ & $0 \% \leq Y_{4} \leq 10 \%$ & $Y_{4}>10 \%$ & \\
\hline Interstates & $\begin{array}{l}\text { Average: }-27 \% \\
\text { Contracts: } 2\end{array}$ & $\begin{array}{l}\text { Average: }-4.6 \% \\
\text { Contracts: } 5 \\
\text { C.I: }[-8.6 \%,-0.6 \%]\end{array}$ & $\begin{array}{l}\text { Average: } 2.67 \% \\
\text { Contracts: } 47 \\
\text { C.I: }[1.9 \%, 3.5 \%]\end{array}$ & $\begin{array}{l}\text { Average: } 20 \% \\
\text { Contracts: } 17 \\
\text { C.I: }[9 \%, 30 \%]\end{array}$ & $\begin{array}{l}\text { Average: } 5.4 \% \\
\text { Contracts: } 71 \\
\text { C.I:[2\%, } 8.7 \%]\end{array}$ \\
\hline $\begin{array}{l}\text { U.S. } \\
\text { Roads }\end{array}$ & $\begin{array}{l}\text { Average: }-15 \% \\
\text { Contracts: } 5 \\
\text { C.I: [-20\%,- } \\
8.8 \%] \\
\end{array}$ & $\begin{array}{l}\text { Average: }-3.6 \% \\
\text { Contracts: } 14 \\
\text { C.I: }[-5.2 \%,-2.2 \%]\end{array}$ & $\begin{array}{l}\text { Average: } 3.2 \% \\
\text { Contracts: } 88 \\
\text { C.I: }[2.5 \%, 3.8 \%]\end{array}$ & $\begin{array}{l}\text { Average: } 26 \% \\
\text { Contracts: } 32 \\
\text { C.I: }[19 \%, 33 \%]\end{array}$ & $\begin{array}{l}\text { Average: } 7.1 \% \\
\text { Contracts: } 139 \\
\text { C.I:[4.6\%,9.6\%] }\end{array}$ \\
\hline $\begin{array}{l}\text { State } \\
\text { Roads }\end{array}$ & $\begin{array}{l}\text { Average: }-16 \% \\
\text { Contracts: } 6 \\
\text { C.I:[-24\%,-9\%] } \\
\end{array}$ & $\begin{array}{l}\text { Average: }-3.6 \% \\
\text { Contracts: } 28 \\
\text { C.I: }[-4.7 \%,-2.5 \%]\end{array}$ & $\begin{array}{l}\text { Average: } 2.6 \% \\
\text { Contracts: } 120 \\
\text { C.I: }[2 \%, 3 \%]\end{array}$ & $\begin{array}{l}\text { Average: } 21 \% \\
\text { Contracts: } 55 \\
\text { C.I: [18\%, } \\
24 \%] \\
\end{array}$ & $\begin{array}{l}\text { Average: } 6.2 \% \\
\text { Contracts: } 209 \\
\text { C.I:[4.6\%,7.7\%] }\end{array}$ \\
\hline $\begin{array}{l}\text { Weighted } \\
\text { Average }\end{array}$ & $\begin{array}{l}\text { Average: }-17 \% \\
\text { Contracts: } 13 \\
\text { C.I: }[-23 \%,-11 \%]\end{array}$ & $\begin{array}{l}\text { Average: }-3.7 \% \\
\text { Contracts: } 47 \\
\text { C.I: }[-4.6 \%,-2.9 \%]\end{array}$ & $\begin{array}{l}\text { Average: } 2.8 \% \\
\text { Contracts: } 255 \\
\text { C.I: }[2.4 \%, 3.2 \%]\end{array}$ & $\begin{array}{l}\text { Average: } 22 \% \\
\text { Contracts: } 104 \\
\text { C.I: [19\%, } \\
25 \% \text { ] }\end{array}$ & $\begin{array}{l}\text { Average: } 6.3 \% \\
\text { Contracts: } 419 \\
\text { C.I:[5.1\%,7.6\%] }\end{array}$ \\
\hline
\end{tabular}

Contracts: Number of Contracts

C.I: 95\% Confidence Interval (Estimated Using One Sample t-Test)

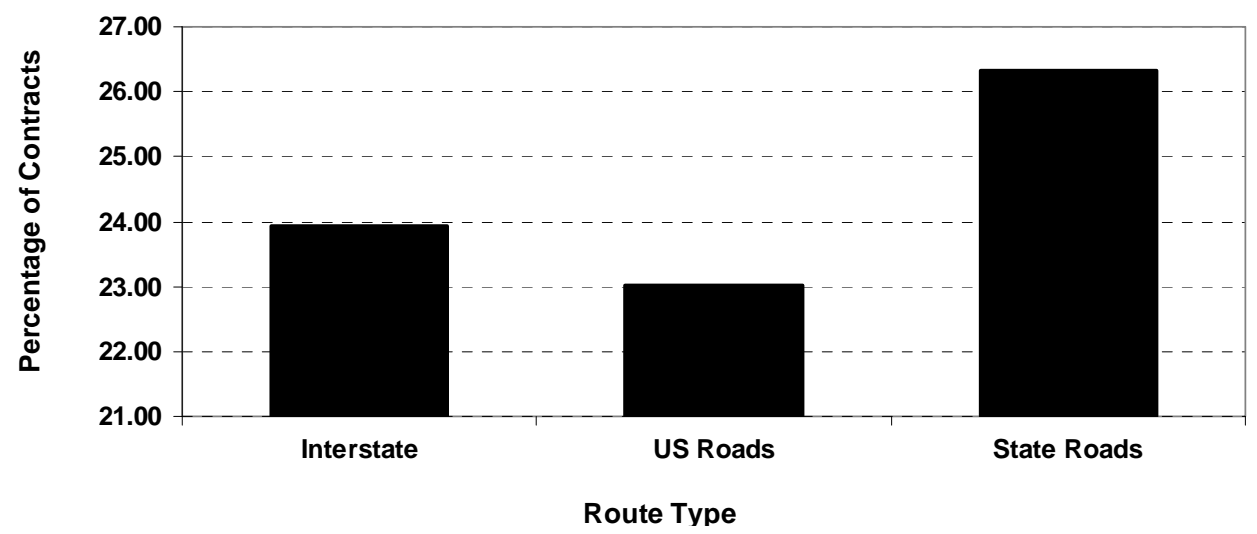

Figure 5.39: Percent Contracts with Letting Stage Cost Overrun $>10 \%$ by Route Type

For the contracts with letting stage cost overrun greater than $10 \%$, the average letting stage cost overrun was $26 \%$ for U.S. road contracts, $21 \%$ for State Road contracts, and $20 \%$ for Interstate contracts. The $95 \%$ confidence intervals of the average letting stage cost overrun for U.S. road contracts [19\%, 33\%], State Road contracts $[18 \%, 24 \%]$, and Interstate road contracts $[9 \%, 30 \%]$ are plotted in Figure 5.40 . The upper limit of the confidence interval was lower for State Road contracts indicating that State Road contracts did not experience high cost overrun. Also, the width of the confidence interval was least for State Road contracts indicating a propensity of State Road contracts to exhibit lower variability of cost overruns. 


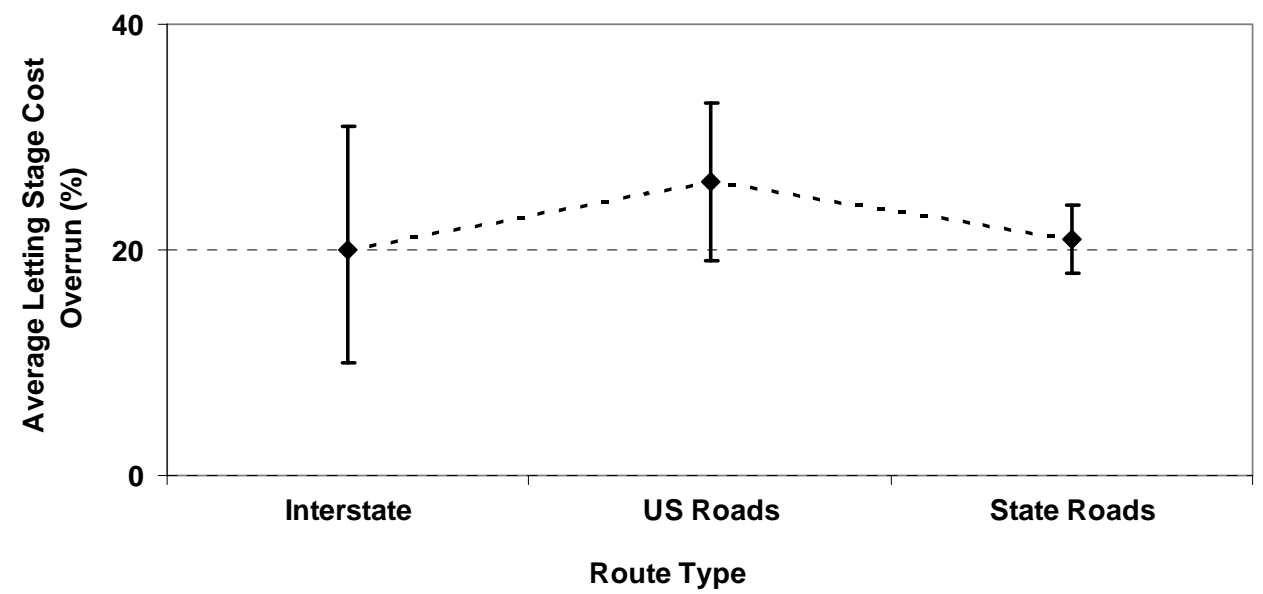

Figure 5.40: Average Letting Stage Cost Overrun for Contracts with Overrun $>10 \%$ by Route Type

\subsubsection{Descriptive Analysis by NHS Status}

The analysis of average letting stage cost overrun by NHS status and cost overrun category is presented in Table 5.28. The average letting stage cost overrun was $6.8 \%$ for Non-NHS contracts, $6.0 \%$ for NonInterstate NHS contracts, and $5.4 \%$ for Interstate contracts. The $95 \%$ confidence intervals of the average letting stage cost overrun was $[5 \%, 8.5 \%],[4 \%, 8 \%]$, and $[2 \%, 8.7 \%]$ for Non-NHS, Non-Interstate NHS, and Interstate contracts, respectively. The average and the $95 \%$ confidence intervals indicated that cost overrun is not significantly different across the three levels of NHS status. 
Table 5.28: Analysis of Average Cost Overrun of Final Cost over Letting Cost by NHS Status

\begin{tabular}{|c|c|c|c|c|c|}
\hline & & $Y_{4}=100\left(\frac{\text { Final Cos }}{\text { Let }}\right.$ & \multicolumn{2}{|c|}{$\%$} & \multirow[b]{2}{*}{$\begin{array}{l}\text { Weighted } \\
\text { Average }\end{array}$} \\
\hline & $Y_{4}<-10 \%$ & $-10 \% \leq Y_{4}<0 \%$ & $0 \% \leq Y_{4} \leq 10 \%$ & $Y_{4}>10 \%$ & \\
\hline Interstate & $\begin{array}{l}\text { Average: }-27 \% \\
\text { Contracts: } 2\end{array}$ & $\begin{array}{l}\text { Average: }-4.6 \% \\
\text { Contracts: } 5 \\
\text { C.I: }[-8.6 \%,-0.6 \%]\end{array}$ & $\begin{array}{l}\text { Average: } 2.7 \% \\
\text { Contracts: } 47 \\
\text { C.I: }[1.9 \%, 3.5 \%]\end{array}$ & $\begin{array}{l}\text { Average: } 19.6 \% \\
\text { Contracts: } 17 \\
\text { C.I: }[9.3 \%, 30 \%]\end{array}$ & $\begin{array}{l}\text { Average: } 5.4 \% \\
\text { Contracts: } 71 \\
\text { C.I: }[2 \%, 8.7 \%]\end{array}$ \\
\hline $\begin{array}{l}\text { Non } \\
\text { Interstate } \\
\text { NHS }\end{array}$ & $\begin{array}{l}\text { Average: }-15 \% \\
\text { Contracts: } 4 \\
\text { C.I: }[-23 \%,-6.3 \%]\end{array}$ & $\begin{array}{l}\text { Average: }-3.6 \% \\
\text { Contracts: } 12 \\
\text { C.I: }[-5.3 \%,-1.8 \%]\end{array}$ & $\begin{array}{l}\text { Average: } 3.6 \% \\
\text { Contracts: } 72 \\
\text { C.I: }[2.8 \%, 4.3 \%]\end{array}$ & $\begin{array}{l}\text { Average: } 21 \% \\
\text { Contracts: } 24 \\
\text { C.I: }[17 \%, 26 \%]\end{array}$ & $\begin{array}{l}\text { Average: } 6 \% \\
\text { Contracts: } 112 \\
\text { C.I: }[4 \%, 8 \%]\end{array}$ \\
\hline $\begin{array}{l}\text { Non } \\
\text { NHS }\end{array}$ & $\begin{array}{l}\text { Average: }-16 \% \\
\text { Contracts: } 7 \\
\text { C.I: }[-22 \%,-10 \%]\end{array}$ & $\begin{array}{l}\text { Average: }-3.6 \% \\
\text { Contracts: } 30 \\
\text { C.I: }[-4.7 \%,-2.6 \%]\end{array}$ & $\begin{array}{l}\text { Average: } 2.5 \% \\
\text { Contracts: } 136 \\
\text { C.I: }[2 \%, 3 \%]\end{array}$ & $\begin{array}{l}\text { Average: } 24 \% \\
\text { Contracts: } 63 \\
\text { C.I: }[19 \%, 28 \%]\end{array}$ & $\begin{array}{l}\text { Average: } 6.8 \% \\
\text { Contracts: } 236 \\
\text { C.I: }[5 \%, 8.5 \%]\end{array}$ \\
\hline $\begin{array}{l}\text { Weighted } \\
\text { Average }\end{array}$ & $\begin{array}{l}\text { Average: }-17 \% \\
\text { Contracts: } 13 \\
\text { C.I: }[-23 \%,-11 \%]\end{array}$ & $\begin{array}{l}\text { Average: }-3.7 \% \\
\text { Contracts: } 47 \\
\text { C.I: }[-4.6 \%,-2.9 \%]\end{array}$ & $\begin{array}{l}\text { Average: } 2.8 \% \\
\text { Contracts: } 255 \\
\text { C.I: }[2.4 \%, 3.2 \%]\end{array}$ & $\begin{array}{l}\text { Average: } 22 \% \\
\text { Contracts: } 104 \\
\text { C.I: }[19 \%, 25 \%]\end{array}$ & $\begin{array}{l}\text { Average: } 6.3 \% \\
\text { Contracts: } 419 \\
\text { C.I:[5.1\%,7.6\%] }\end{array}$ \\
\hline
\end{tabular}

Contracts: Number of Contracts

C.I: 95\% Confidence Interval (Estimated Using One Sample t-Test)

The frequency of high cost overrun at the letting stage was analyzed across the levels of NHS status (Figure 5.41). It was found that high cost overrun was marginally more frequent for Non-NHS contracts. The average letting stage cost overrun exceeded $10 \%$ for $27 \%$ (63 of 236) of the Non-NHS contracts, $24 \%$ ( 17 of 71 ) of the Interstate contracts, and $21 \%$ ( 24 of 112) of Non-Interstate NHS contracts.

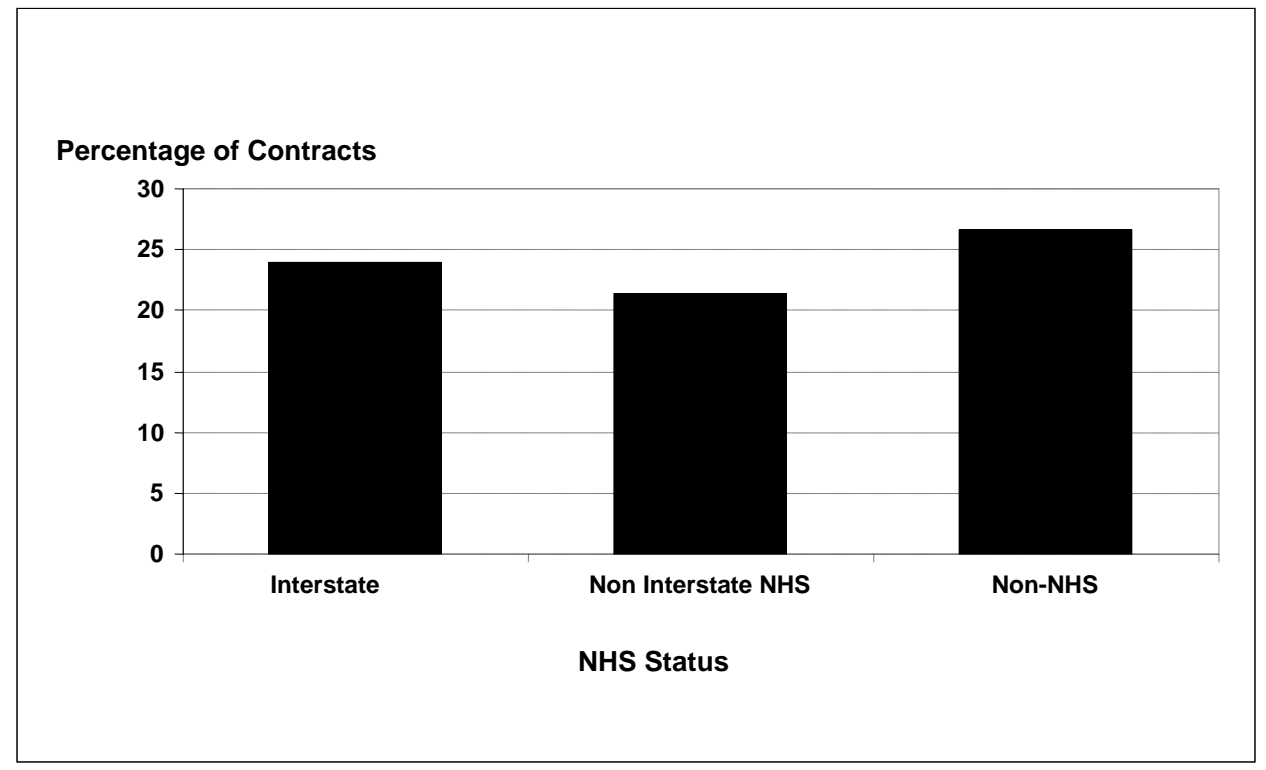

Figure 5.41: Percent Contracts with Letting Stage Cost Overrun $>10 \%$ by NHS Status 
For the contracts with letting stage cost overrun greater than $10 \%$, the average letting stage cost overrun was $24 \%$ for Non-NHS contracts, $21 \%$ for Non-Interstate NHS contracts, and $19 \%$ for Interstate contracts. The $95 \%$ confidence intervals of the average letting stage cost overrun for Non-NHS contracts [19\%, 28\%], Non-Interstate NHS contracts [17\%, 26\%], and Interstate contracts [9\%, 30\%] are plotted in Figure 5.42. The confidence intervals and the average cost overrun indicated that Non-NHS contracts were more susceptible to high cost overrun. The width of the confidence interval for Interstate contracts was significantly higher compared to that of Non-Interstate NHS and Non-NHS contracts, thereby indicating high variability of cost overrun across the Interstate contracts.

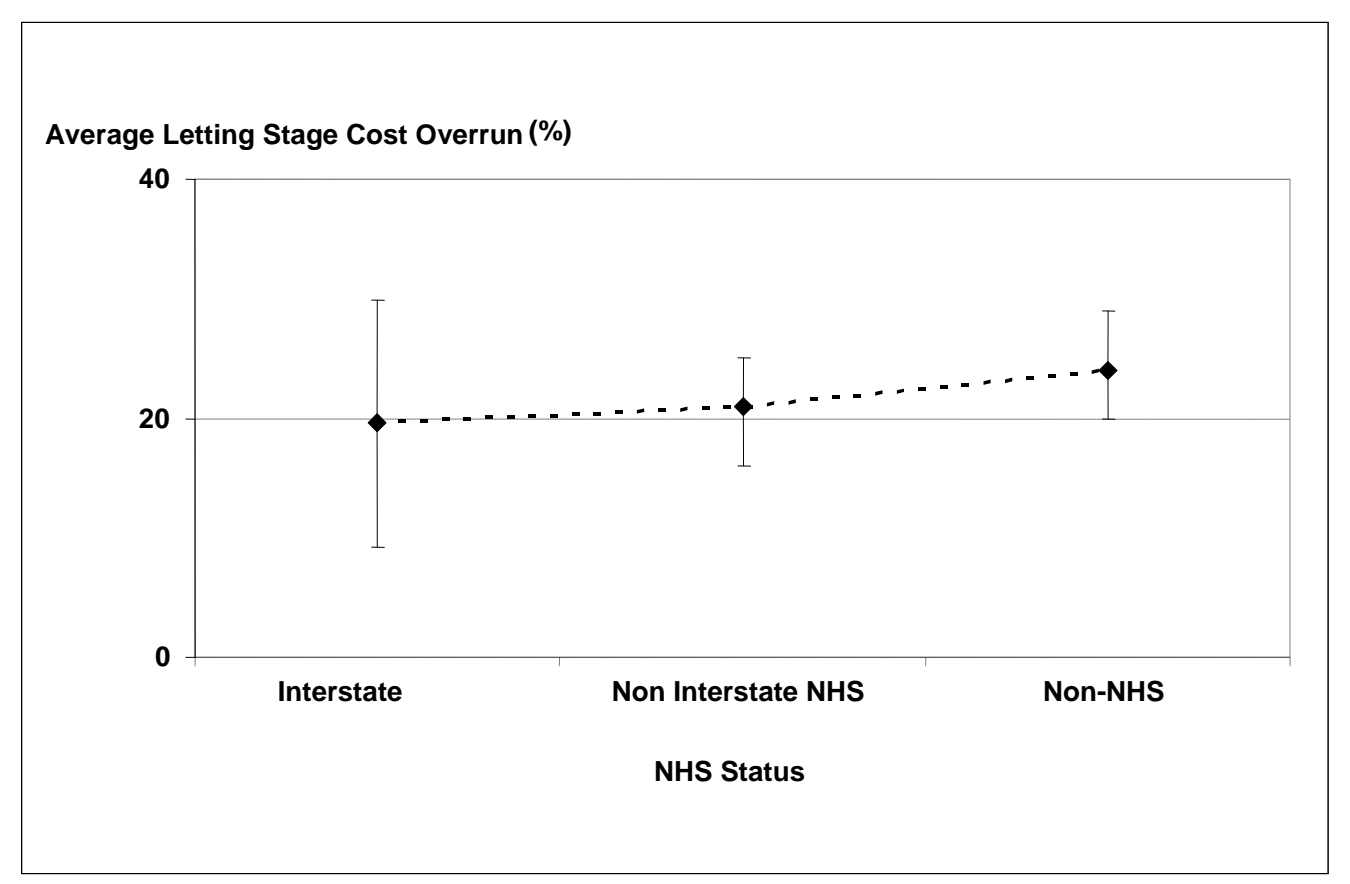

Figure 5.42: Average Letting Stage Cost Overrun for Contracts with Overrun $>10 \%$ by NHS Status

\subsubsection{Descriptive Analysis by Administrative District}

The analysis of average letting stage cost overrun by district and cost overrun category is presented in Table 5.29. The average letting stage cost overrun was found to be the least for the Laporte district $(2.0 \%)$ and highest for the Vincennes district (9.0\%). The 95\% confidence interval of the average letting stage cost overrun of contracts in the Vincennes district was $[5.8 \%, 12 \%]$ which exceeded that of the Laporte district $[0.3 \%, 4.7 \%]$. For the other districts, the average letting stage cost overrun was in the range of $5 \%-8 \%$ and the $95 \%$ confidence interval of the average was also not significantly different.

The frequency of high cost overrun at the letting stage was analyzed across the six administrative districts. The letting stage cost overrun exceeded $10 \%$ for $35 \%$ of the contracts in the Vincennes district, whereas only $8 \%$ of the contracts in the Laporte district had a cost overrun of greater than $10 \%$ at the 
letting stage. For the other districts, the frequency of cost overrun greater than $10 \%$ was in the range of 24\%-28\% (Figure 5.43).

Table 5.29: Analysis of Average Cost Overrun of Final Cost over Letting Cost by District

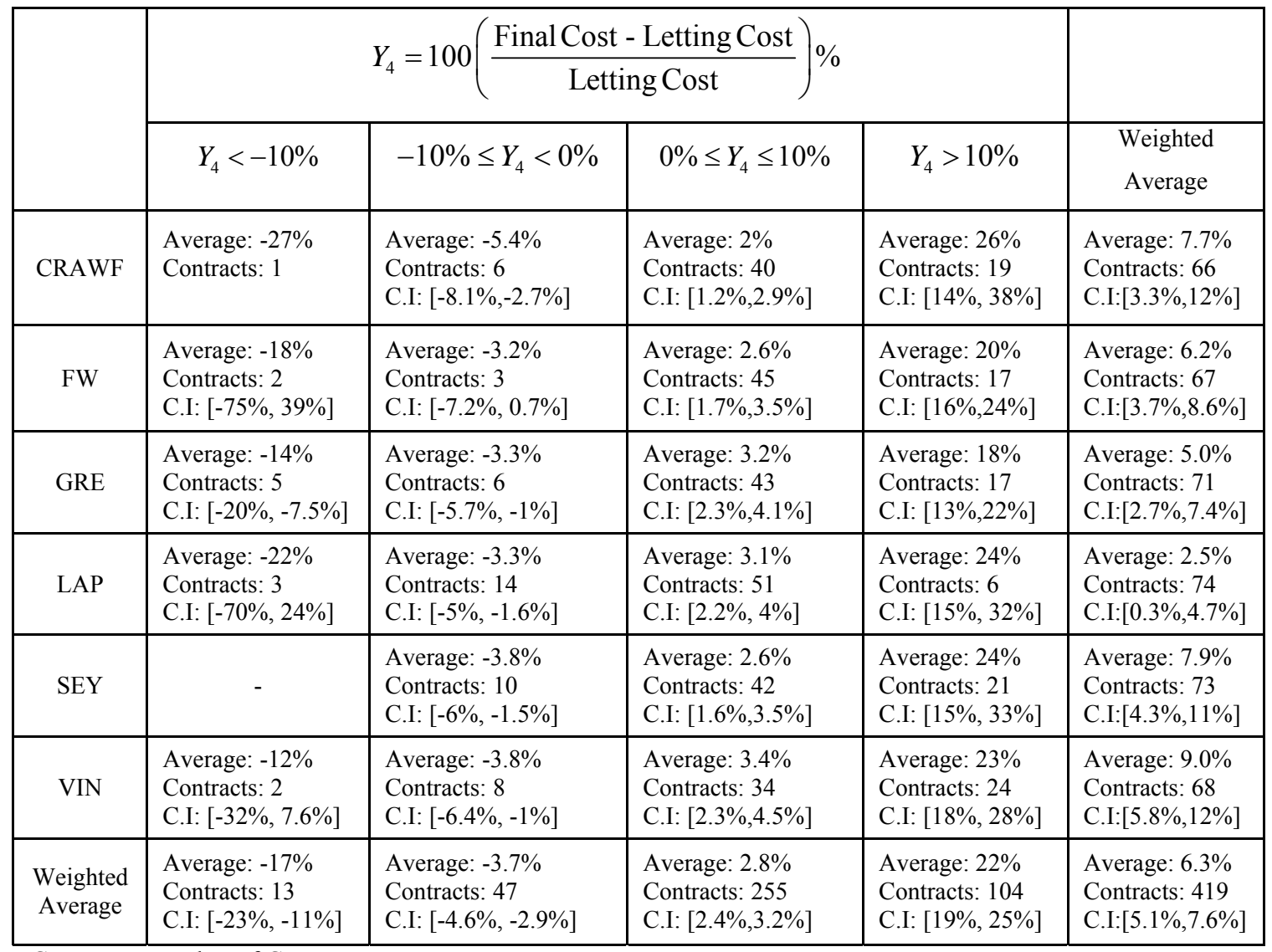

Contracts: Number of Contracts

C.I: $95 \%$ Confidence Interval (Estimated Using One Sample t-Test)

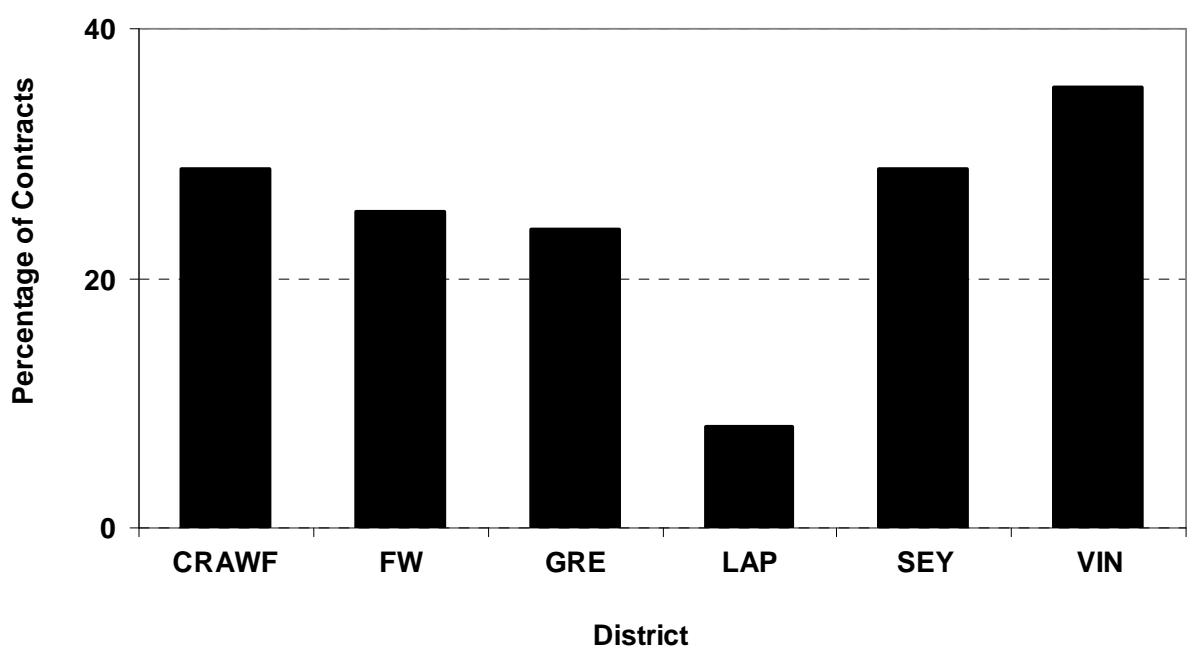

Figure 5.43: Percent Contracts with Letting Stage Cost Overrun $>10 \%$ by District 
For the contracts with letting stage cost overrun exceeding $10 \%$, the average letting stage cost overrun and the $95 \%$ confidence intervals of the averages were comparable for Greenfield (18\%) and Fort Wayne (20\%) districts (Figure 5.44). Laporte and Seymour districts had an average letting stage cost overrun of $24 \%$ and the $95 \%$ confidence interval of the average was [15\%,33\%], indicating that contracts in these districts experienced marginally higher cost overrun compared to Fort Wayne and Greenfield districts. The contracts in the Vincennes district had an average letting stage cost overrun of $23 \%$, but the variability of cost overrun was lower compared to Laporte and Seymour districts, as indicated by the confidence interval of the average [18\%,28\%]. Crawfordsville district had the highest average letting stage cost overrun (26\%) and the highest upper limit of the confidence interval (38\%), indicating that the contracts in Crawfordsville were more susceptible to high cost overrun.

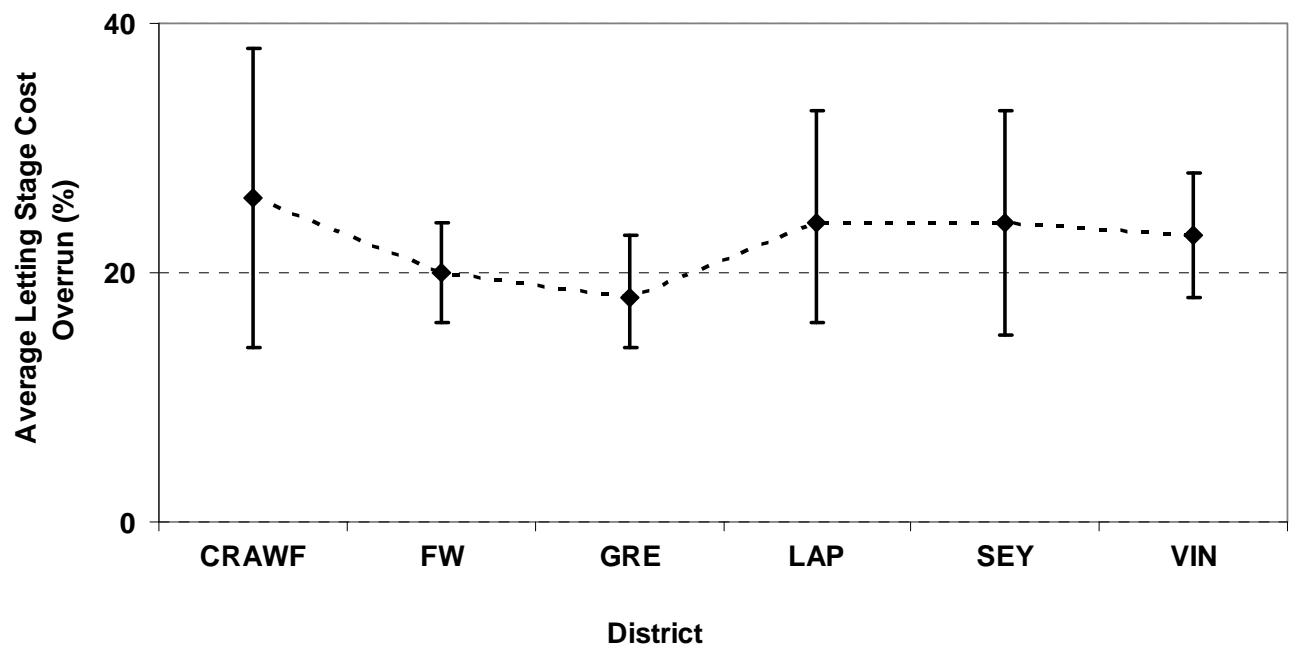

Figure 5.44: Average Letting Stage Cost Overrun for Contracts with Overrun $>10 \%$ by District

\subsubsection{Descriptive Analysis by Area Type}

As shown in Table 5.30, the average letting stage cost overrun was higher for urban area contracts $(8.1 \%)$ compared to rural area contracts $(5.5 \%)$. The $95 \%$ confidence intervals of the average letting stage cost overrun also indicated that letting stage cost overrun in the urban areas were more significant than in the rural areas. The $95 \%$ confidence interval for urban area contracts was $[5.4 \%, 11 \%]$ and for rural area contracts, $[4 \%, 6.8 \%]$. 
Table 5.30: Analysis of Average Cost Overrun of Final Cost over Letting Cost by Area Type

\begin{tabular}{|c|c|c|c|c|c|}
\hline & & $Y_{4}=100\left(\frac{\text { Final Co }}{\mathrm{Le}}\right.$ & \multicolumn{2}{|c|}{$\left(\frac{\text { Final Cost }- \text { Letting Cost }}{\text { Letting Cost }}\right) \%$} & \multirow[b]{2}{*}{$\begin{array}{l}\text { Weighted } \\
\text { Average }\end{array}$} \\
\hline & $Y_{4}<-10 \%$ & $-10 \% \leq Y_{4}<0 \%$ & $0 \% \leq Y_{4} \leq 10 \%$ & $Y_{4}>10 \%$ & \\
\hline Urban & $\begin{array}{l}\text { Average: }-14 \% \\
\text { Contracts: } 4 \\
\text { C.I: }[-24 \%,-5 \%]\end{array}$ & $\begin{array}{l}\text { Average: }-4.2 \% \\
\text { Contracts: } 12 \\
\text { C.I: }[-6 \%,-2.3 \%]\end{array}$ & $\begin{array}{l}\text { Average: } 3 \% \\
\text { Contracts: } 82 \\
\text { C.I: }[2.4 \%, 3.7 \%]\end{array}$ & $\begin{array}{l}\text { Average: } 25 \% \\
\text { Contracts: } 38 \\
\text { C.I: }[18 \%, 32 \%]\end{array}$ & $\begin{array}{l}\text { Average: } 8.1 \% \\
\text { Contracts: } 136 \\
\text { C.I:[5.4\%,11\%] }\end{array}$ \\
\hline Rural & $\begin{array}{l}\text { Average: }-19 \% \\
\text { Contracts: } 9 \\
\text { C.I: }[-27 \%,-10 \%]\end{array}$ & $\begin{array}{l}\text { Average: }-3.6 \% \\
\text { Contracts: } 35 \\
\text { C.I: }[-4.5 \%,-2.6 \%]\end{array}$ & $\begin{array}{l}\text { Average: } 2.7 \% \\
\text { Contracts: } 173 \\
\text { C.I: }[2.3 \%, 3.2 \%]\end{array}$ & $\begin{array}{l}\text { Average: } 21 \% \\
\text { Contracts: } 66 \\
\text { C.I: }[18 \%, 24 \%]\end{array}$ & $\begin{array}{l}\text { Average: } 5.5 \% \\
\text { Contracts: } 283 \\
\text { C.I: }[4 \%, 6.8 \%]\end{array}$ \\
\hline $\begin{array}{l}\text { Weighted } \\
\text { Average }\end{array}$ & $\begin{array}{l}\text { Average: }-17 \% \\
\text { Contracts: } 13 \\
\text { C.I: }[-23 \%,-11 \%]\end{array}$ & $\begin{array}{l}\text { Average: }-3.7 \% \\
\text { Contracts: } 47 \\
\text { C.I: }[-4.6 \%,-2.9 \%]\end{array}$ & $\begin{array}{l}\text { Average: } 2.8 \% \\
\text { Contracts: } 255 \\
\text { C.I: }[2.4 \%, 3.2 \%]\end{array}$ & $\begin{array}{l}\text { Average: } 22 \% \\
\text { Contracts: } 104 \\
\text { C.I: }[19 \%, 25 \%]\end{array}$ & $\begin{array}{l}\text { Average: } 6.3 \% \\
\text { Contracts: } 419 \\
\text { C.I:[5.1\%,7.6\%] }\end{array}$ \\
\hline
\end{tabular}

Contracts: Number of Contracts

C.I: 95\% Confidence Interval (Estimated Using One Sample t-Test)

Cost overruns exceeding 10\% were more frequent for urban area contracts. Approximately $28 \%$ ( 38 of 136) of the urban area contracts had a cost overrun of greater than $10 \%$, whereas $23 \%$ (66 of 283 ) of the rural area contracts had a cost overrun of greater than $10 \%$ (Figure 5.45).

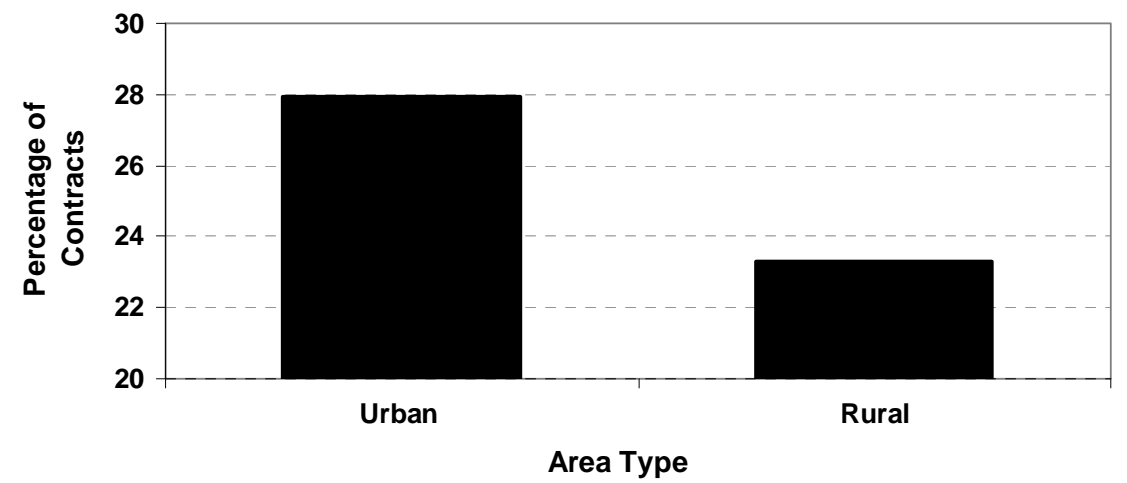

Figure 5.45: Percent Contracts with Letting Stage Cost Overrun $>10 \%$ by Area Type

For the contracts with letting stage cost overrun exceeding 10\% (Figure 5.46), the average letting stage cost overrun and the $95 \%$ confidence intervals of the averages suggested that urban area contracts are more susceptible to high cost overrun compared to rural areas. The average letting stage cost overrun was $25 \%$ across the urban area contracts and was $21 \%$ for the rural area contracts. The upper limit of the $95 \%$ confidence interval of the average was also higher for urban area contracts (32\%) compared to rural area contract (24\%), which further indicated that urban area contracts experienced higher cost overruns. 


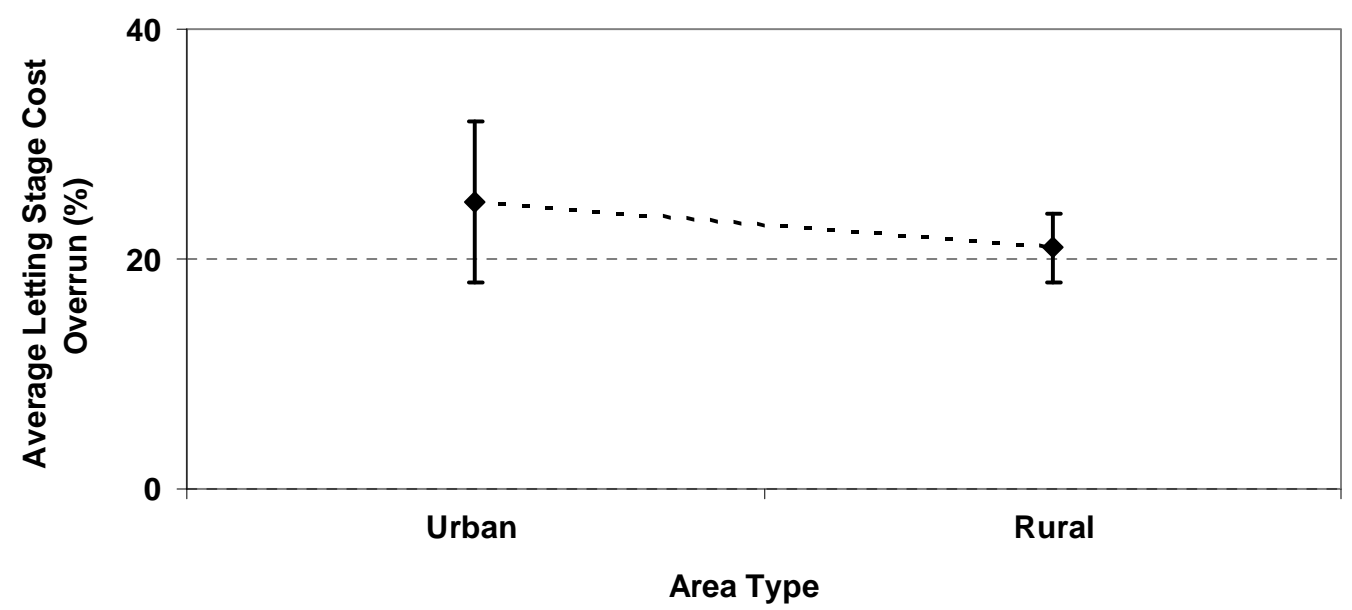

Figure 5.46: Average Letting Stage Cost Overrun for Contracts with Cost Overrun $>10 \%$ by Area Type

\subsubsection{Letting Cost vs. Proposed Cost}

The difference between the letting cost and the proposed cost was calculated to determine if contracts are delivered at the initial proposed budget and the factors affecting any deviations thereof. The percentage difference was calculated as:

$$
\text { Cost Overrun : } Y_{5}=100\left(\frac{\text { Letting Cost }- \text { Proposed Cost }}{\text { Proposed Cost }}\right) \%
$$

The average overrun of letting cost over proposed cost was found to be $-1.4 \%$ and the standard deviation was $23 \%$. The $95 \%$ confidence interval of the average letting stage cost overrun was $[-3.7 \%$, $0.8 \%]$. The negative sign of the average letting stage cost overrun value and the largely negative confidence interval indicated that letting cost was lower than the proposed cost for most of the contracts.

Table 5.31 presents the average overrun of the letting cost over proposed cost, by cost overrun category. For $61 \%$ of the contracts ( 259 of 419 contracts), the difference between letting cost and proposed cost was within the ' $+/-10 \%$ ' bracket.

The letting cost was greater than the proposed cost for 43\% (176 of 419) of the contracts but exceeded the proposed cost by more than $10 \%$ (cost overrun) for only $15 \%$ of the contracts (59 of the 419 contracts). For the remaining 28\% (117 of 419) contracts, the letting cost exceeded proposed cost by an average of less than $2 \%$. However, for the 59 contracts with letting costs greater than $10 \%$, the average overrun of the letting cost (over proposed cost) was $40.8 \%$. Further, the $95 \%$ confidence interval for the average overrun for contracts that belonged to this category ranged between $34 \%$ and $47 \%$.

The proposed cost exceeded the letting cost for 57\% (243 of 419). For 24\% (101 of 419) of the contracts the proposed cost exceeded letting cost by over $10 \%$. For the 101 contracts whose proposed cost 
exceeded the letting cost by over $10 \%$, the proposed cost was higher by an average of $28 \%$, with a $95 \%$ confidence of $25 \%-31 \%$.

Table 5.31: Analysis of Average Letting Stage Cost Overrun by Cost Overrun Category

\begin{tabular}{|l|c|c|c|c|c|}
\hline & \multicolumn{4}{|c|}{$Y_{5}=100\left(\frac{\text { Letting Cost - Proposed Cost }}{\text { Proposed Cost }}\right) \%$} & \\
\cline { 2 - 6 } & $Y_{4}<-10 \%$ & $-10 \% \leq Y_{4}<0 \%$ & $0 \% \leq Y_{4} \leq 10 \%$ & $Y_{4}>10 \%$ & Total \\
\hline $\begin{array}{l}\text { Number of } \\
\text { Contracts }\end{array}$ & 101 & 142 & 117 & 59 & 419 \\
\hline $\begin{array}{l}\text { Average } \\
\text { Overrun }\end{array}$ & $-28 \%$ & $-2.3 \%$ & $1.53 \%$ & $40.8 \%$ & $3.91 \%$ \\
\hline $\begin{array}{l}95 \% \text { Confidence } \\
\text { Interval }\end{array}$ & {$[-31 \%,-25 \%]$} & {$[-2.8 \%,-1.8 \%]$} & {$[1.1 \%, 2.0 \%]$} & {$[34 \%, 47 \%]$} & {$[5.1 \%, 7.6 \%]$} \\
\hline
\end{tabular}

\subsection{Cost Escalation across All Stages}

The estimates of the final construction cost were tracked from the planning stage until the final construction for each contract to determine the escalation pattern during the planning and development phase. On the basis of an analysis of the 419 highway contracts in Indiana, three patterns of cost escalation were found to be most widespread. This section presents an analysis of these cost escalation patterns. Contracts in each pattern category were analyzed by their work category, contract size, area type, route type, district, and NHS status to determine the influence of these factors.

\subsubsection{Cost Escalation Pattern 'A'}

A graphical representation of Pattern 'A' is presented in Figure 5.47. Contracts that exhibit this pattern are characterized as follows: the cost estimate increases or remains constant at all stages except the letting stage. The decrease in the cost estimate at the letting stage indicates that contracts that exhibit pattern ' $\mathrm{A}$ ' are generally those that experience high competition at the letting stage. Such competition is generally experienced by contracts that are straightforward construction activities. Pattern 'A' contracts tend to have more information available about the construction activities compared to contracts exhibiting any other pattern. Standard and reliable cost estimation procedures probably exist for such contracts and therefore significant cost changes due to unforeseen factors and uncertainty in cost estimation are likely to be less. This is perhaps why for such contracts, contractors submit bids that are lower than the design cost estimate, in contrast to contracts as opposed to contracts that exhibit other patterns. 


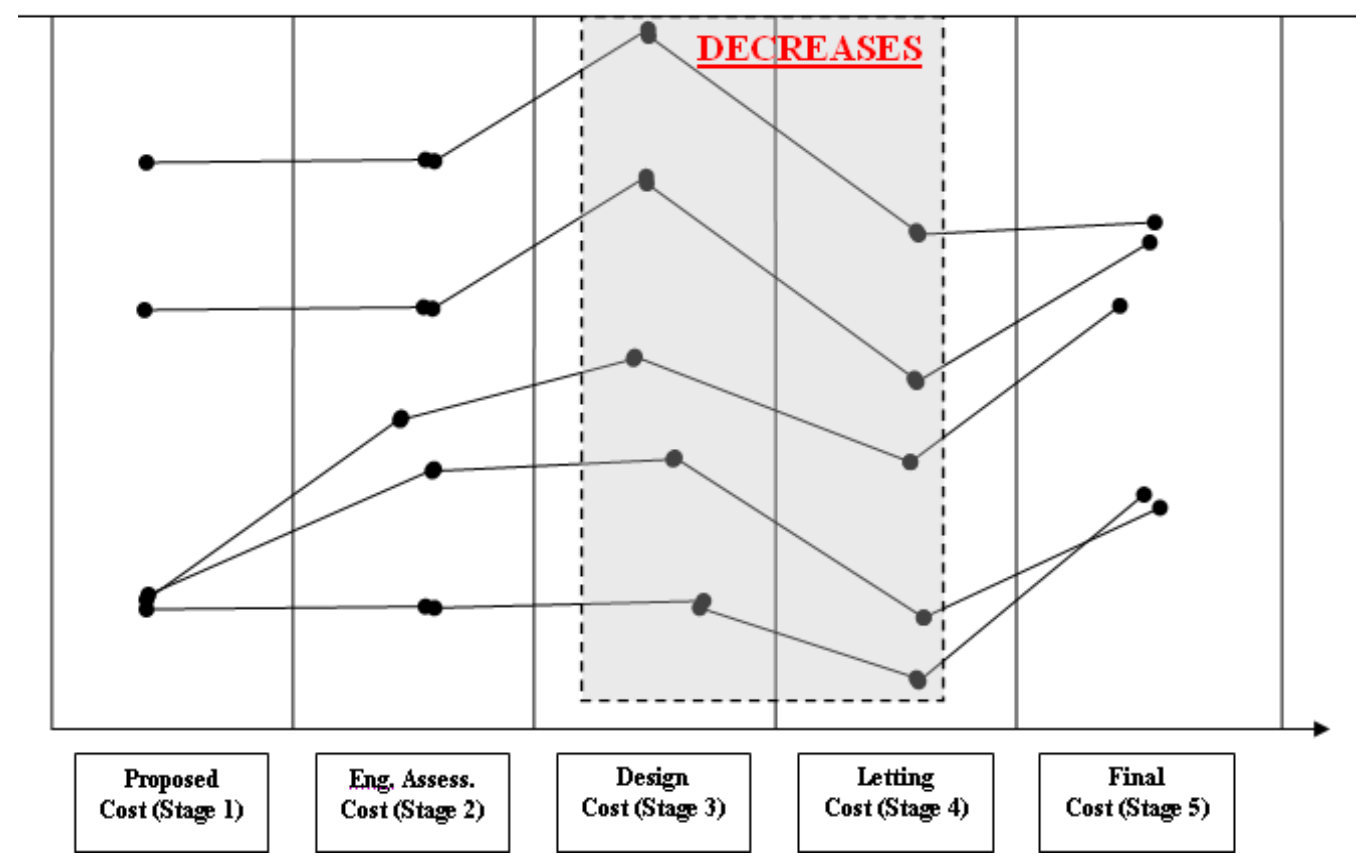

Figure 5.47: Graphical Representation of Cost Escalation Pattern 'A'

Pattern 'A' was observed in 215 of the 419 contracts. The cost escalation between two consecutive stages was analyzed by calculating the percentage increase in the cost estimate at the latter stage compared to the estimate at the preceding stage (Figure 5.48). The engineer's assessment cost and the proposed cost were generally not found to be significantly different from each other. It was found that the major cost escalation generally occurred between the programming stage (engineer's assessment estimate) and design stage, and between the letting and final construction stages. The final design cost exceeded the engineer's assessment by an average of $6.2 \%$. Further, it was determined with $95 \%$ confidence that the average difference between the two estimates is between $3.6 \%$ and $8.6 \%$. The cost escalation between letting and final construction was found to be even higher. The final construction cost was more than the letting cost by an average of $9.2 \%$. The analysis of the $95 \%$ confidence interval indicated that the final cost exceeded the letting cost by $7-11 \%$. The letting cost was less than the design estimate by an average of $12.8 \%$. The $95 \%$ confidence interval of the average difference between letting cost and the design cost indicated that letting cost was less than the design cost estimate by $11-15 \%$. 


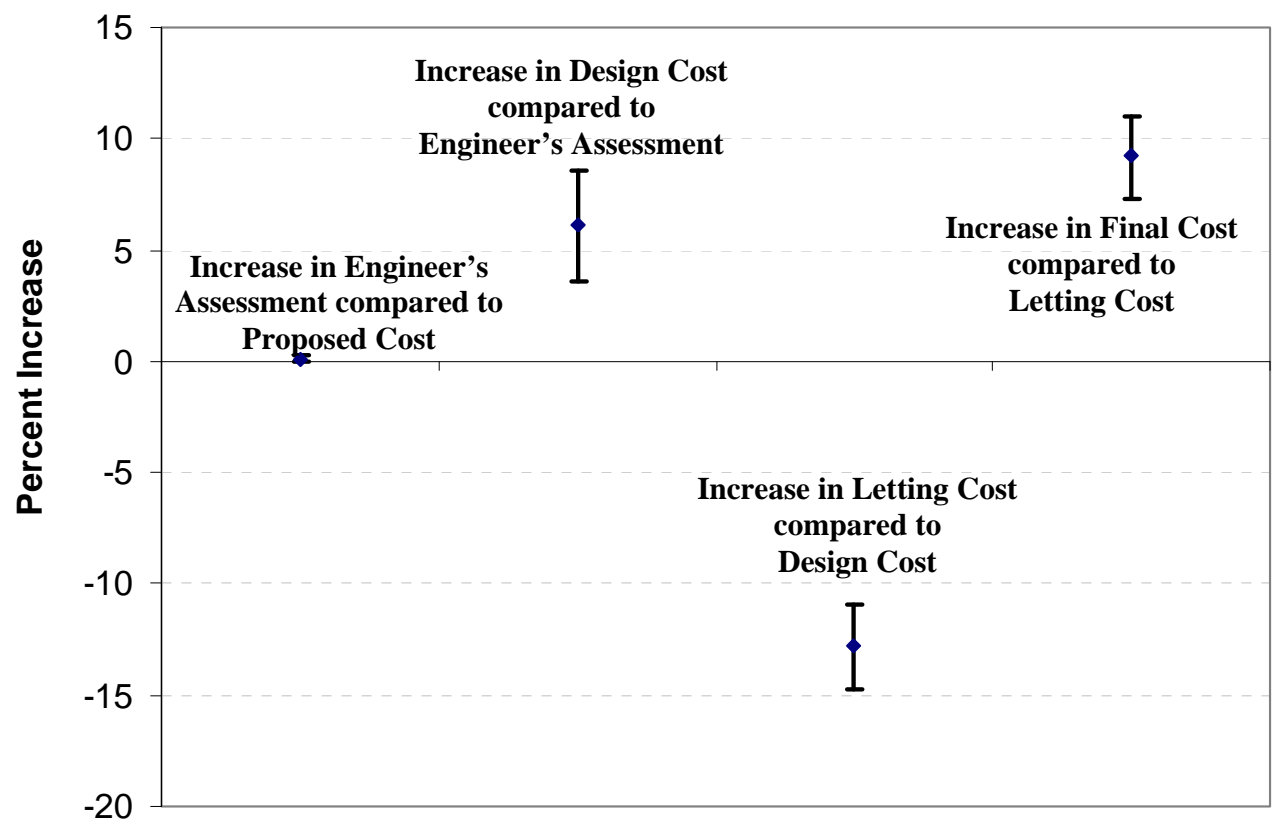

Figure 5.48: Stage-to-Stage Cost Deviations for Pattern 'A' Contracts

Figure 5.49 presents a comparison of the cost estimates at each stage with the proposed cost estimate. It was found that the cost estimate prepared after the programming phase (engineer's assessment cost) exceeded the proposed cost by an average of $0.1 \%$. After the design stage was completed, the average difference between the design cost and the proposed cost generally increased to $6.24 \%$. At the letting stage, the average difference between the letting cost and the proposed cost decreased to $-7.7 \%$. The average difference between the final construction and proposed costs was found to be between $-2.7 \%$ and $3.5 \%$ at the $95 \%$ confidence level, indicating that the final construction cost was not significantly different from the proposed cost for the contracts that exhibit Pattern 'A'. The figure could also be utilized to determine the average percentage difference between other cost estimates. For example, the design cost exceeds the proposed cost by an average of $6.24 \%$ and the final cost exceeds the proposed cost by an average of $0.4 \%$. Therefore, the design cost exceeds the final cost by $5.84 \%$ (subtracting $0.4 \%$ from $6.24 \%$ ). That is, for contracts exhibiting Pattern ' $A$ ' the design cost is generally an overestimate of the final cost whereas the letting cost is generally an underestimate of the final cost. Econometric models were developed (presented in Chapter 6) that can be used to identify contracts that are most likely to exhibit Pattern ' $A$ '. 


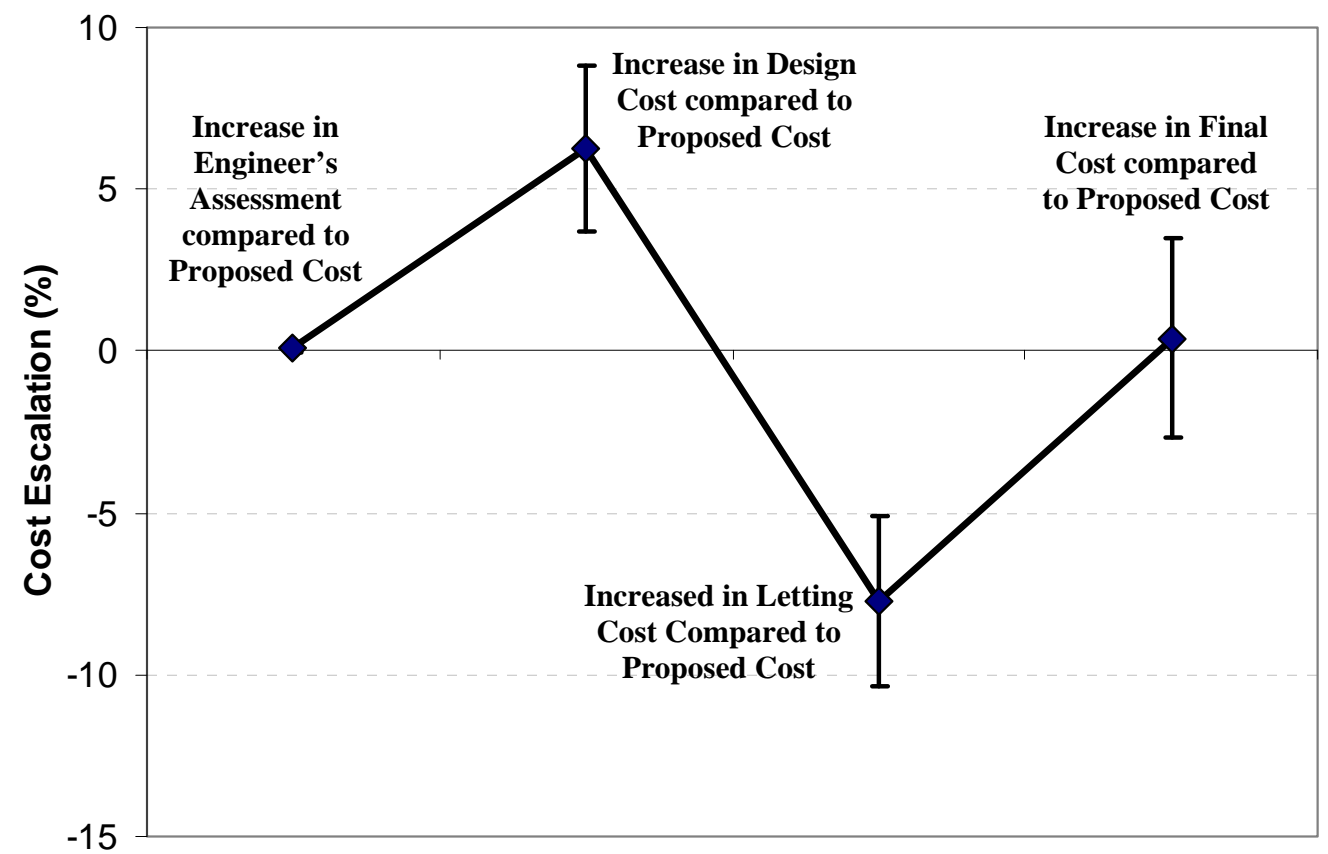

Figure 5.49: Average Cost Deviation of Each Stage Relative to Proposed Cost for Pattern 'A' Contracts

A detailed analysis was conducted to examine the frequency at which contracts of certain attributes exhibit Pattern 'A'. Section 5.4.4 presents the results.

\subsubsection{Cost Escalation Pattern 'B'}

A graphical representation of Pattern ' $\mathrm{B}$ ' is shown in Figure 5.50. For the contracts that exhibit this pattern, the cost estimate increases or remains constant from the planning stage until the final construction. Pattern 'B' was exhibited by 97 of the 419 contracts. The increasing trend of the cost estimates indicates that contracts that exhibit pattern ' $\mathrm{B}$ ' are likely to be those that are more susceptible to increase in the cost estimate, due to unforeseen costs arising from unforeseen site conditions, scope changes, and change orders. Contracts exhibiting this pattern are likely to have greater uncertainty associated with the cost estimates. It is probably because of the high risk that the contractors do not bid a low cost for such contracts despite a competitive letting environment.

Each segment of the cost escalation pattern was analyzed. The increase in each cost estimate compared to the cost estimate at the immediate preceding stage was determined. Figure 5.51 presents an analysis of the pair-wise comparisons of cost estimates. The average difference between the engineer's assessment and the proposed cost indicated that the engineer's assessment and the proposed cost estimates were similar. The average difference between the design cost and engineer's assessment was $2.5 \%(0.4 \%$ $5 \%$ with $95 \%$ confidence). Based on the $95 \%$ confidence intervals, it was concluded that the average difference between the design cost and engineer's assessment cost for contracts exhibiting Pattern 'B' (in 
the range of $0.4 \%-4.6 \%$ ) was less than that for contracts exhibiting Pattern ' $\mathrm{A}$ ' (in the range of $3.6 \%$ $8.6 \%)$.

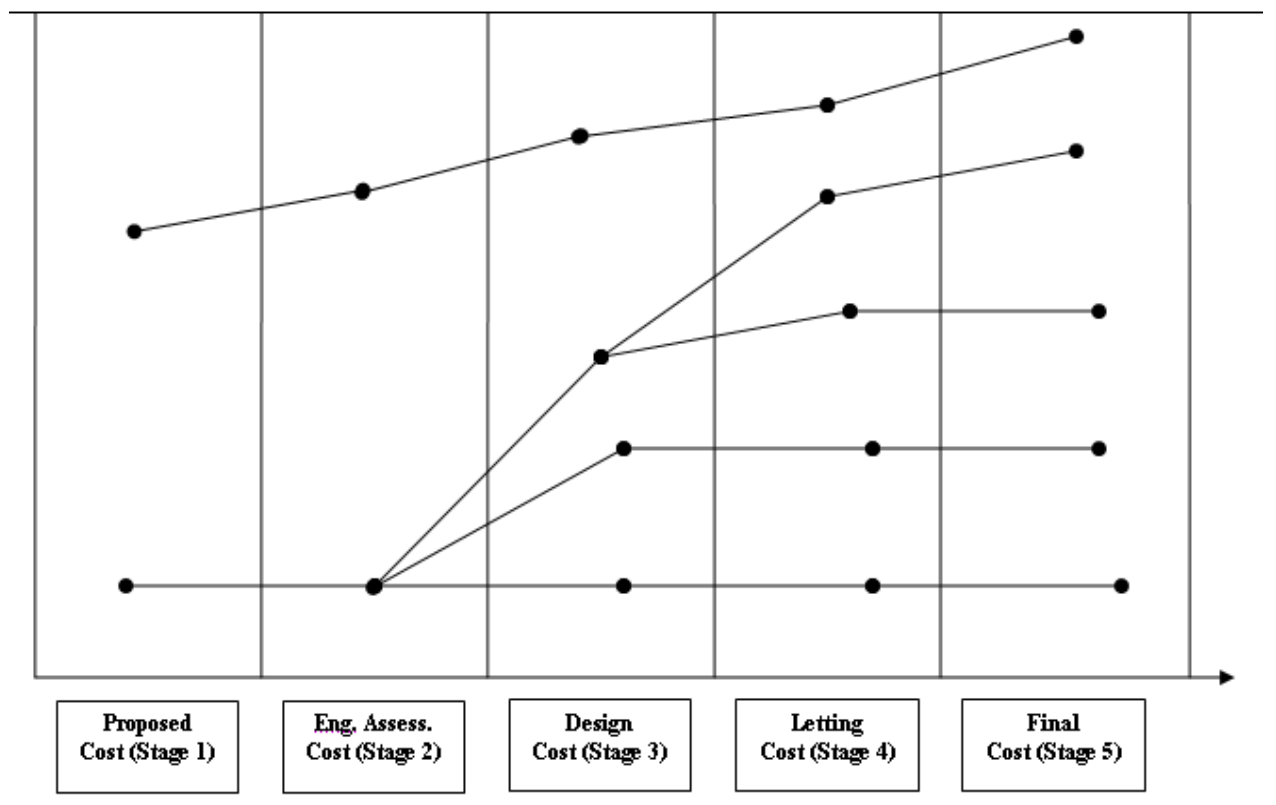

Figure 5.50: Graphical Representation of Cost Escalation Pattern 'B'

A significant increase in the estimated cost was found to occur between the design and letting stages, and between the letting and final construction stages. The cost estimate at the letting stage was found to be higher than that of the design stage by over $10 \%$ (Figure 5.51). The average difference between the cost estimate at the letting stage and the estimate at the design stage was $12 \%$ with a $95 \%$ confidence interval of $[7.5 \%, 16 \%]$. The average difference between the final cost and the letting cost was $7.5 \%$ and the $95 \%$ confidence interval of the average was $[5.3 \%, 9.7 \%]$. 


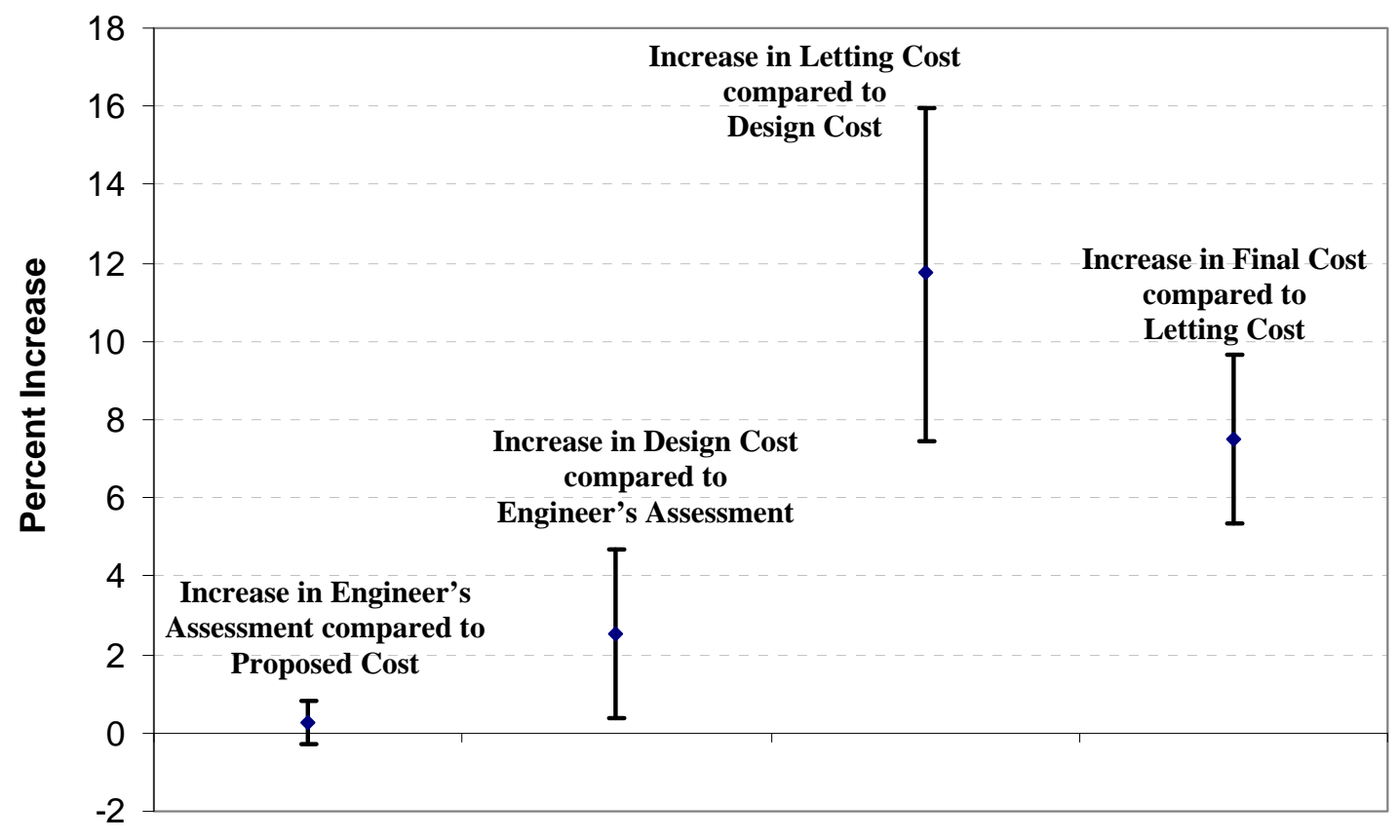

Figure 5.51: Stage-to-Stage Cost Deviations for Pattern 'B' Contracts

The cumulative impact of cost estimate increases with respect to the proposed cost at each stage is shown in Figure 5.52. The difference between the engineer's assessment cost and proposed cost was found to be negligible. The average difference between the design cost and the proposed cost was $2.8 \%$ and lay between $1 \%$ and $5 \%$ with $95 \%$ confidence. Due to two significant cost escalations from design to letting stage (an average increase of 12\%) and from letting to final construction (an average increase of $8 \%$ ), the final cost exceeded the proposed cost by an average of $24 \%$. Moreover, the average difference between the final cost and proposed cost was $18-30 \%$ with $95 \%$ confidence. This analysis suggests that contracts exhibiting Pattern 'B' were found to be associated with cost overrun to a greater extent compared to those exhibiting other patterns. 


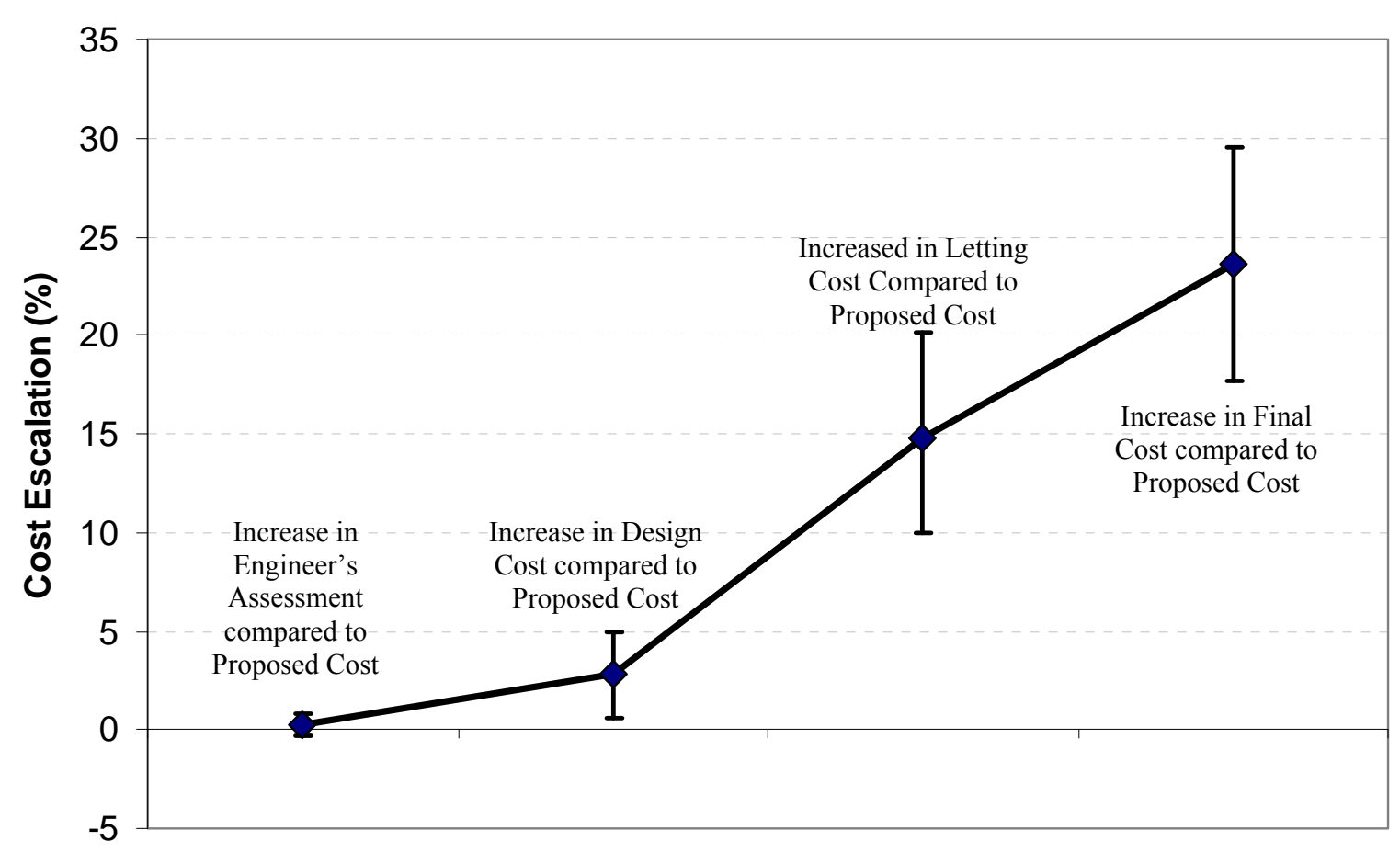

Figure 5.52: Average Cost Deviation of Each Stage Relative to Proposed Cost for Pattern 'B' Contracts

A detailed analysis was conducted to determine if contracts of certain characteristics have a greater propensity to exhibit Pattern 'B'. Section 5.4.4 presents the results. In Chapter 6, the study presents econometric models that can be used to identify contracts that are most likely to exhibit Pattern 'B' based on the contract-specific factors.

\subsubsection{Cost Escalation Pattern ' $\mathrm{C}$ '}

Figure 5.53 presents a graphical representation of Pattern ' $\mathrm{C}$ '. For the 39 of 419 contracts that exhibit this pattern, the cost estimate increases or remains constant across all stages except the final stage where it decreases. Contracts exhibiting such a pattern are likely to be those that are expected to experience contingencies and unforeseen costs arising from unforeseen site conditions, but the risk of occurrence of such uncertainties is not very high. 


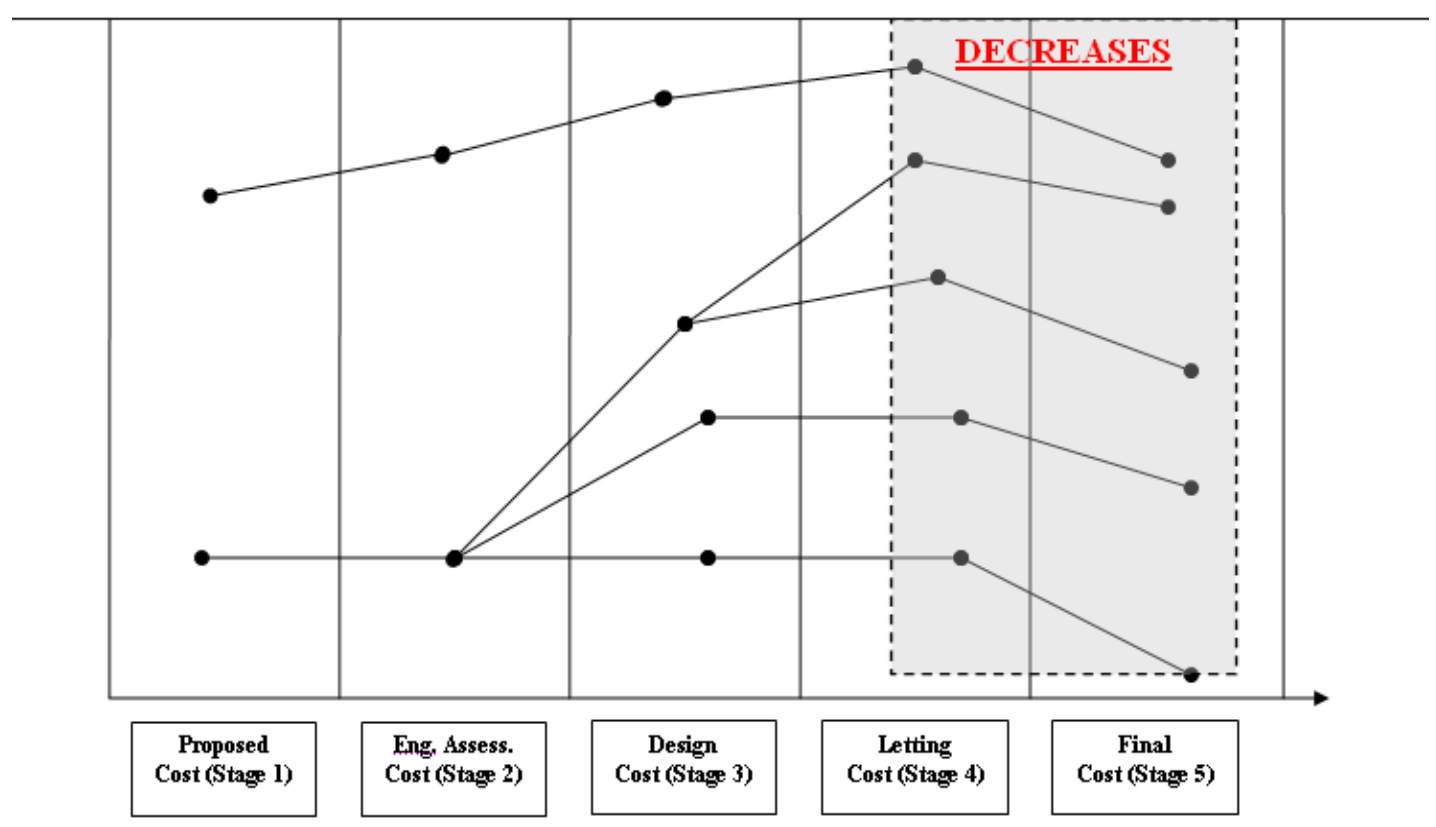

Figure 5.53: Graphical Representation of Cost Escalation Pattern 'C'

Patterns ' $\mathrm{A}$ ' and ' $\mathrm{B}$ ' were found to be the most widely exhibited patterns across the 419 randomly selected contracts. Together, they accounted for $75 \%$ of all the contracts. Pattern ' $\mathrm{C}$ ' accounted for approximately 10\% (39 of 419) of the contracts. Contracts that did not exhibit patterns 'A', 'B', or ' $\mathrm{C}$ ' were designated as exhibiting Pattern ' $D$ '. The four patterns were mutually exclusive and exhaustive. That is, no contract exhibited any two patterns at the same time and every contract exhibits one of the four cost escalation patterns. Section 5.4.4 presents the distribution of the contracts exhibiting Patterns 'A' and 'B' by contract size, work, area, and route type.

\subsubsection{Additional Analysis of Contracts Exhibiting Patterns ' $A$ ' and 'B'}

The contracts exhibiting Patterns 'A' and 'B' were analyzed by contract size, work catgory, area, and route type. Figure 5.54 presents these contracts exhibiting by contract size. The figure suggests that large-sized contracts experienced pattern 'A' or 'B' more frequently compared to small-sized contracts. Approximately $70 \%$ of contracts in the $\$ 1-\$ 2$ million contract size category (contract size based on proposed cost) exhibited either pattern 'A' or pattern 'B', as compared to $73 \%$ in the $\$ 2-\$ 5$ million category, $77 \%$ in the $\$ 5-\$ 10$ million category. and $89 \%$ in the greater than $\$ 10$ million category. Large contracts (greater than $\$ 10$ million) were found to exhibit Pattern ' $A$ ' more frequently compared to small-sized contracts: $63 \%$ of these exhibited Pattern 'A' compared to $60 \%$ in the $\$ 5-10$ million size category, $51 \%$ in the $\$ 2-\$ 5$ million size category, and $46 \%$ in the $\$ 1-\$ 2$ million size category. The small-sized contracts were found to exhibit Pattern 'B' more frequently compared to large size contracts: approximately $25 \%$ of contracts in the $\$ 1-\$ 2$ 
million size category exhibited Pattern 'B', compared to $22 \%$ of contracts in the $\$ 2-\$ 5$ million category, and $17 \%$ of contracts in the $\$ 5-\$ 10$ million category. However, approximately $26 \%$ of the contracts exceeding $\$ 10$ million size exhibited Pattern ' $\mathrm{B}$ ', this was marginally higher compared to other contract size categories.

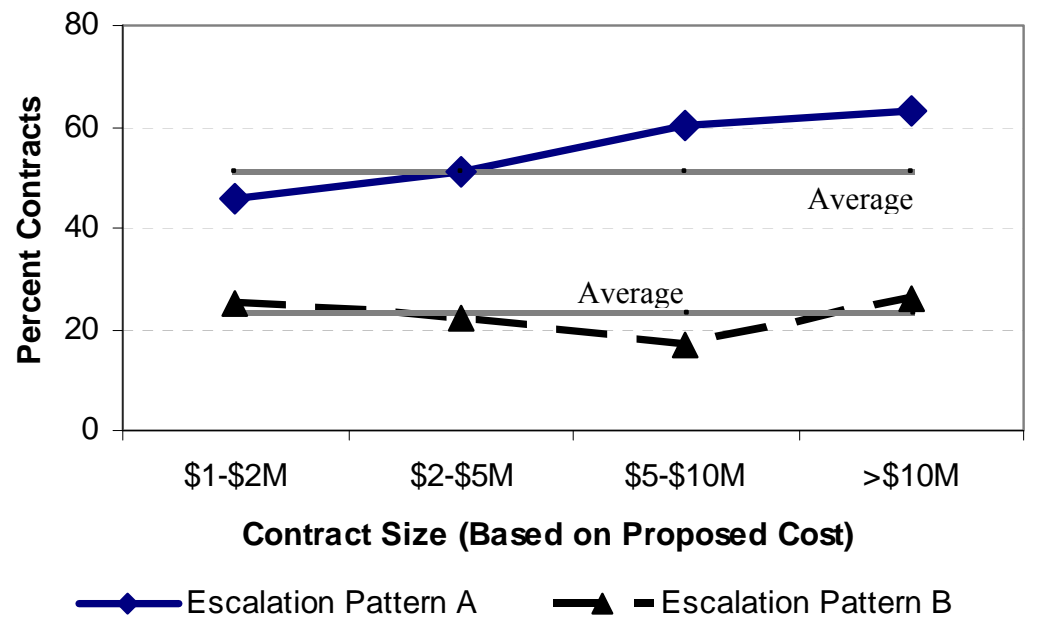

Figure 5.54: Distribution of Contracts that Exhibit Cost Escalation Patterns 'A' and 'B' by Contract Size Category

The distribution of contracts exhibiting patterns 'A' and 'B' by work category is shown in Figure 5.55. The expansion contracts exhibited Pattern ' $\mathrm{A}$ ' or ' $\mathrm{B}$ ' more frequently compared to bridge and pavement contracts: approximately $80 \%$ (58 of 73 ) of the expansion contracts exhibited either Pattern 'A' or 'B' as compared to $78 \%$ (84 of 107) of bridge contracts and 71\% (90 of 101) pavement contracts. 


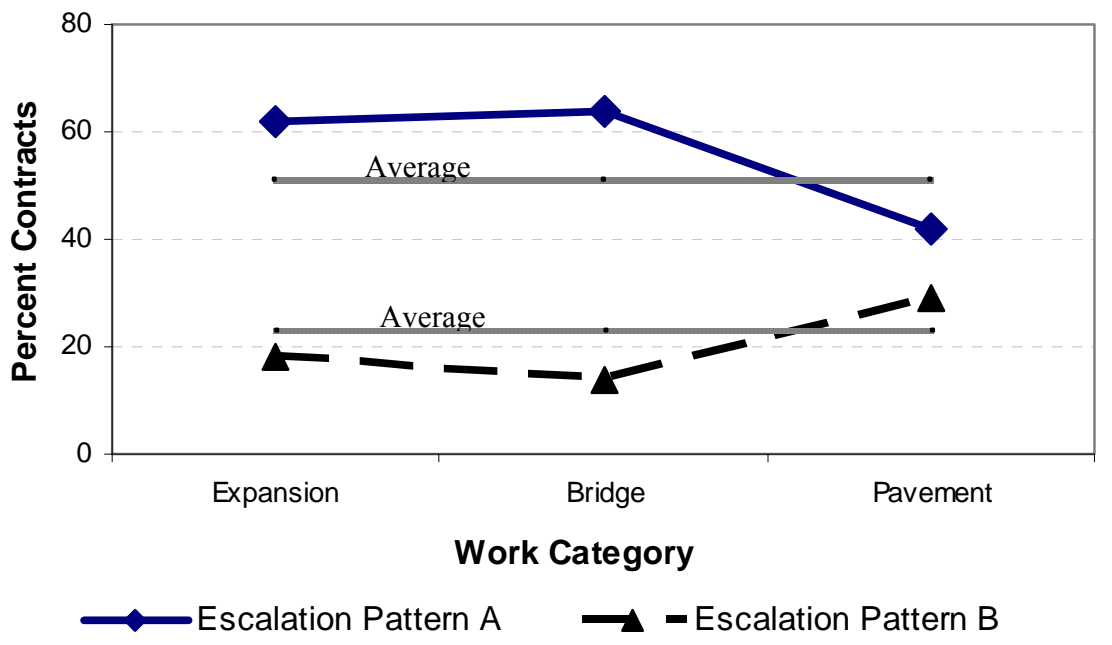

Figure 5.55: Distribution of Contracts that Exhibit Cost Escalation Patterns 'A' and 'B' by Work Category

Compared to expansion and bridge contracts, pavement contracts exhibited Pattern ' $A$ ' less frequently: approximately $62 \%$ of expansion contracts and $64 \%$ of bridge contracts exhibited Pattern 'A', compared to $42 \%$ of pavement contracts. On the other hand, pavement contracts exhibited Pattern ' $\mathrm{B}$ ' more frequently compared to expansion and bridge contracts: approximately $29 \%$ of pavement contracts exhibited Pattern 'B' compared to $18 \%$ of expansion contracts and $14 \%$ of bridge contracts. The relatively high frequency of pavement contracts exhibiting Pattern 'B' appears to be associated with their greater propensity to incur cost overrun exceeding $10 \%$ (see Sections 5.3.1.1 and 5.3.3.1).

The distribution of the contracts exhibiting Patterns ' $A$ ' and ' $B$ ' by area type is shown in Figure 5.56. The contracts in the rural areas $(49 \%, 138$ of 283) are found to exhibit Pattern 'A' less frequently compared to contracts in urban areas (57\%, 77 of 136 contracts). However, contracts in rural areas exhibit Pattern 'B' more frequently (25\%, 70 of 283$)$ compared to contracts in urban areas (20\%, 27 of 136). 


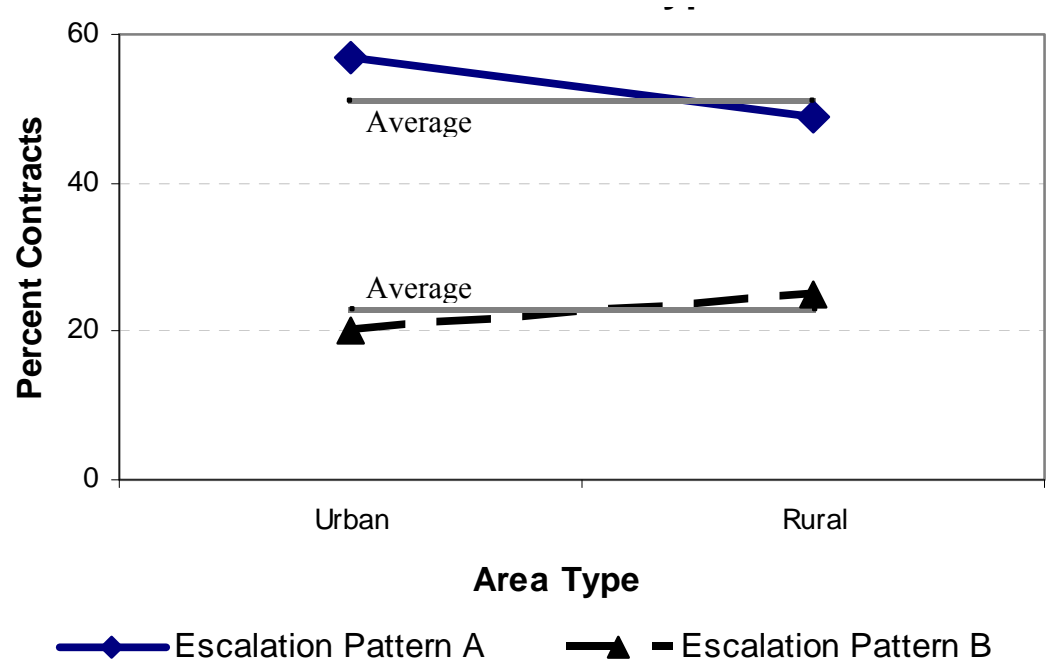

Figure 5.56: Distribution of Contracts that Exhibit Cost Escalation Patterns ' $A$ ' and 'B' by Area Type

The Interstate contracts $(65 \%, 46$ of 71$)$ were found to exhibit Pattern 'A' more frequently compared to U.S. Road (51\%, 71 of 139) or State Road (47\%, 98 of 209) contracts (Figure 5.57). The State Road contracts (26\%, 54 of 209) exhibited Pattern 'B' more frequently compared to U.S. Road (23\%, 32 of $139)$ and Interstate contracts $(15 \%, 11$ of 71$)$ (Figure 5.57$)$.

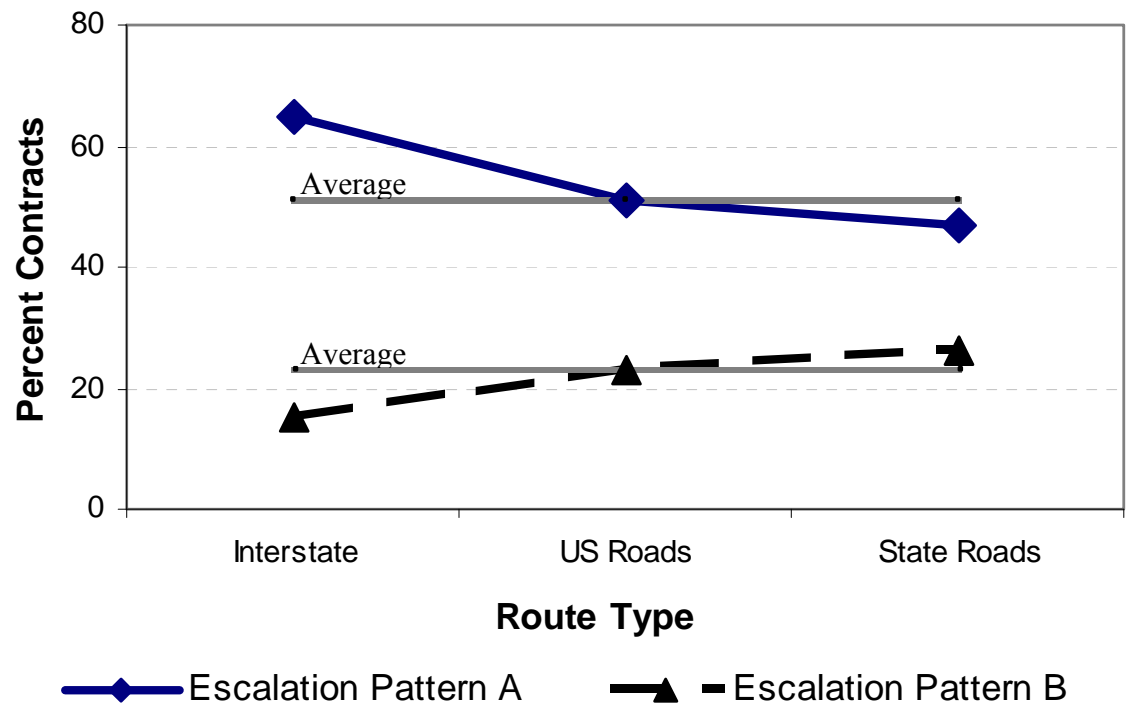

Figure 5.57: Percent Contracts Exhibiting Cost Escalation Patterns 'A' and 'B' by Route Type

Approximately 56\% of kin contracts were found to exhibit Pattern 'A' compared to $49 \%$ of standalone contracts. Also, it was found that $21 \%$ of stand-alone contracts and $24 \%$ of kin contracts exhibited Pattern 'B'. Therefore, stand-alone and kin contracts did not differ significantly with respect to exhibiting 
Pattern 'B'. This seems to be generally consistent with the finding in Sections 5.3.1.3 and 5.3.2.3 that the frequency of having a cost overrun exceeding $10 \%$ is similar for these two contract types.

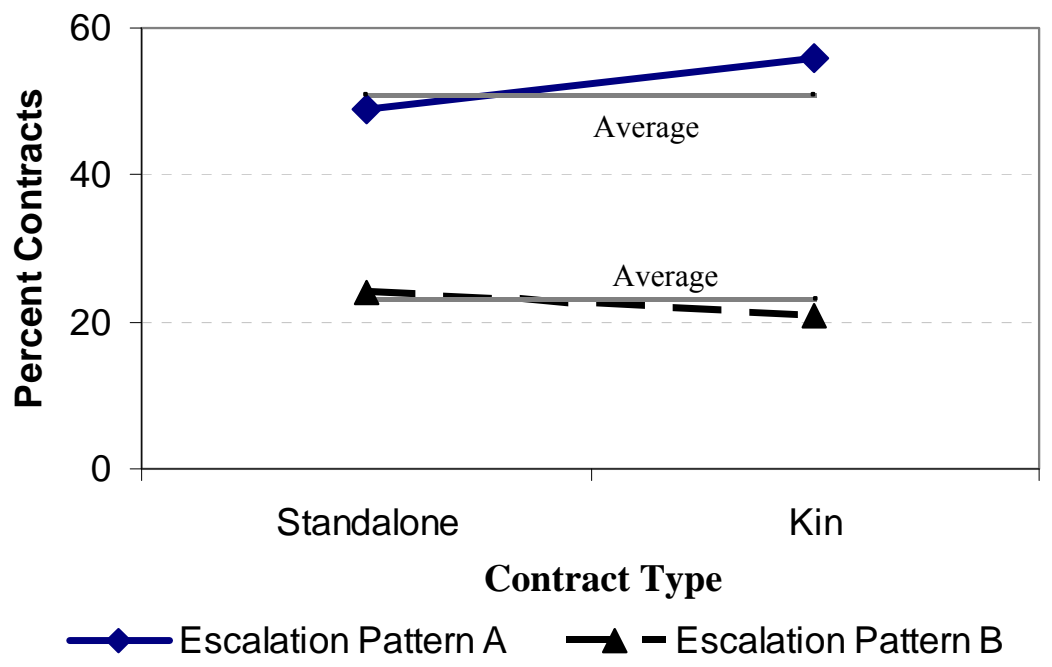

Figure 5.58: Distribution of Contracts that Exhibit Cost Escalation Patterns 'A' and 'B' by Route Type

\subsection{Impact of Inflation}

In Sections 5.3 and 5.4, cost overruns associated with the estimates prepared at the planning stage (proposed cost), design stage (design cost), and letting stage (letting cost) were determined on the basis of the value of these estimates in current dollars (that is, the value of these estimates as recorded at the time of planning, design, and letting, respectively). The annual rate of inflation (across all sectors) in the state of Indiana from 1970 to 2005 is shown in Figure 5.59. In the present study, approximately $78 \%$ (298 of 385) contracts were proposed, planned, designed, and constructed during 1992 to 2005 . The average annual inflation across all sectors during this period was approximately 3\%. In highway construction, the construction price index (CPI) is used to determine the changes in prices of the inputs to, and outputs of, the construction activity. Figure 5.60 presents a comparison of the growth in construction price index and the rate of inflation. The growth trend in the U.S. average construction price index was similar to the inflation trend in Indiana. 


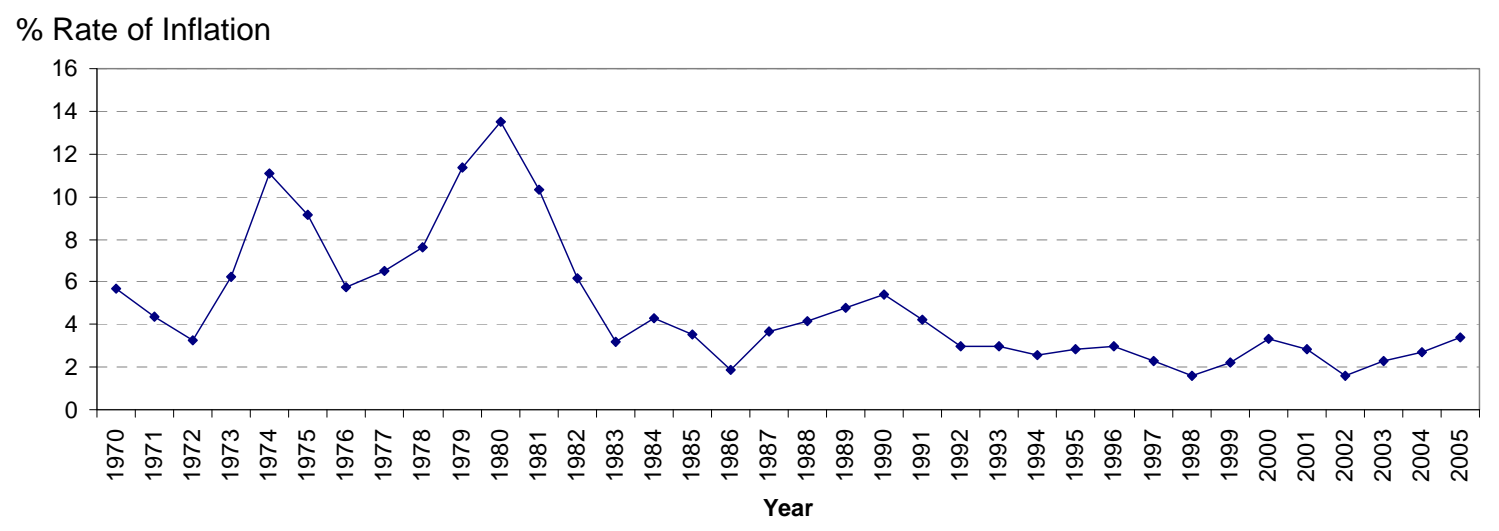

Figure 5.59: Rate of Inflation in Indiana from 1970 to 2005 (IBRC, 2008)

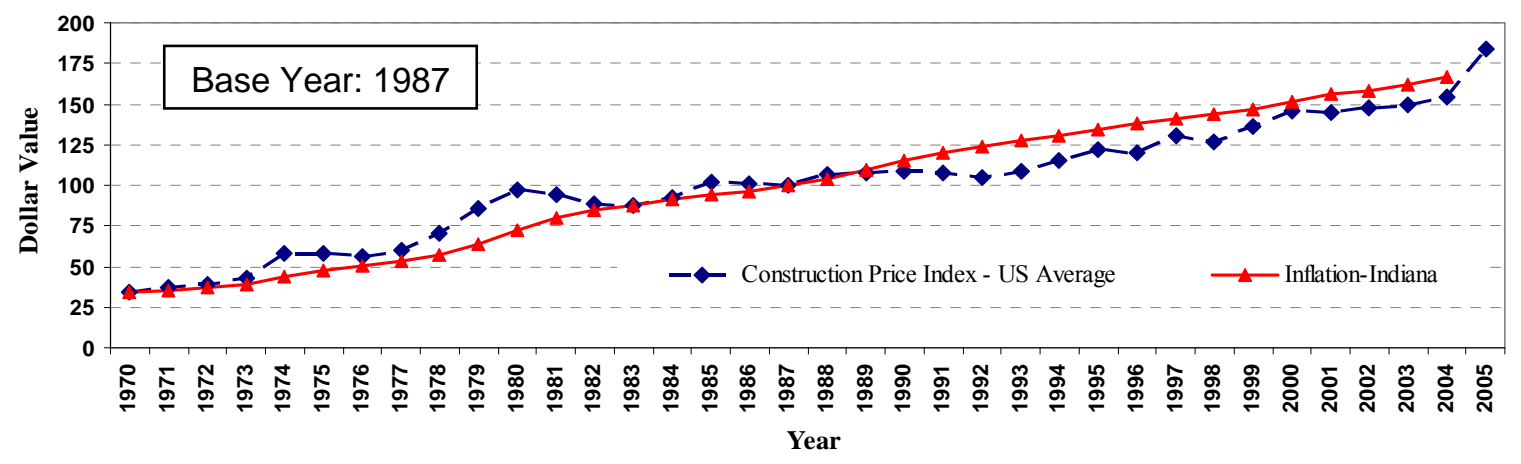

Figure 5.60: Growth of Construction Price Index (U.S.) and Inflation (Indiana) from 1970 to 2005

(IBRC, 2008)

\subsubsection{Proposed Cost Estimate vs. Final Construction Cost}

For each of the 385 contracts for which the date information was available, the non-inflated proposed cost estimate was inflated from the year it was estimated to the year when the final construction cost was incurred. The impact of inflating the proposed cost estimate was studied by plotting the 'proposed cost estimate', the 'inflated proposed cost', and the 'final construction cost'. Six possible cases were considered as described in Chapter 4. The first case represents a scenario where the final cost was significantly higher than the non-inflated proposed cost estimate, but after adjusting for inflation, the difference was smaller. It was found that only 63 of the 385 contracts showed such a pattern as shown in Figure 5.61. The final cost exceeded the proposed cost estimate (non-inflated) by an average of approximately $45 \%$. However, after the proposed cost was adjusted for inflation, the average overrun of the final cost compared to the inflated proposed cost reduced to $29 \%$, implying that the inflation $\left(I_{1}^{*}\right)$ was responsible for $16 \%$ of the overrun. 


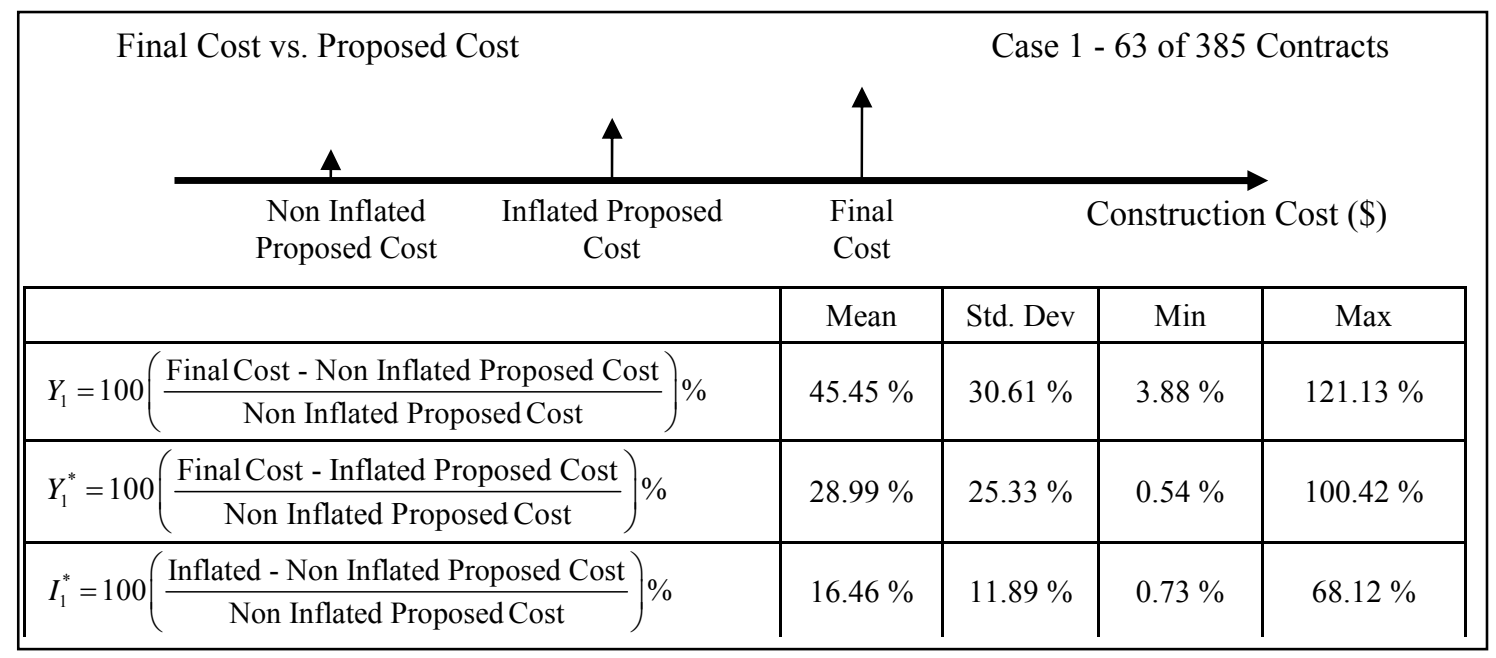

Figure 5.61: Analysis of Impact of Inflation on Proposed Cost: Case 1

For approximately $40 \%$ of the 385 contracts, the final cost marginally exceeded the non-inflated proposed cost estimate by an average of about $8 \%$ (Figure 5.62). However, after the non-inflated proposed cost was adjusted for inflation, inflated proposed cost exceeded final cost by an average of $23 \%$.

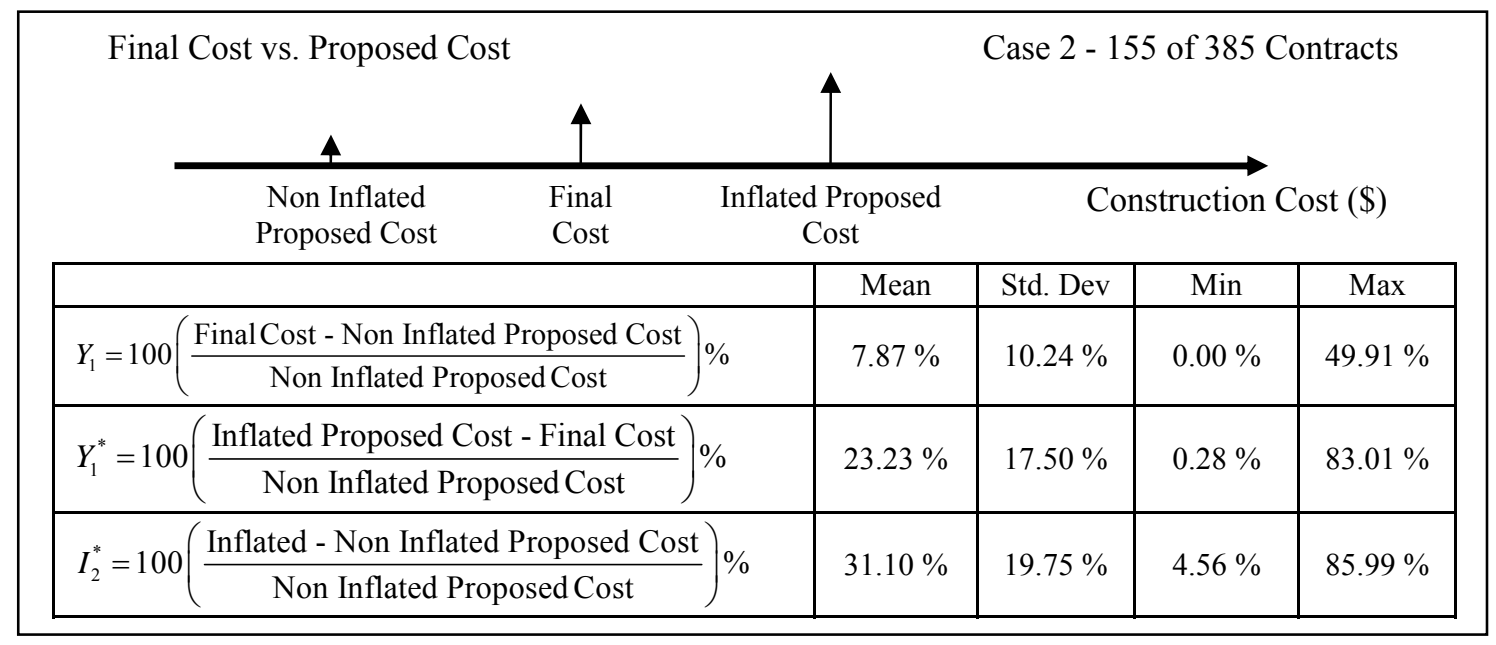

Figure 5.62: Analysis of Impact of Inflation on Proposed Cost: Case 2

Also, for 161 of the 385 contracts, the non-inflated proposed cost estimate was found to exceed the final cost by an average of approximately 13\% (Figure 5.63). By adjusting the non-inflated estimate for inflation, the average difference between inflated proposed cost and final cost increased to approximately $37 \%$. Again, this observation suggests that the non-inflated estimate is a more accurate estimate of the final cost compared to the inflated estimate. Figure 5.64 presents the number of years between project proposal 
and final construction, which indicates that inflation should have been a significant factor in affecting the accuracy of non-inflated cost estimates.

\begin{tabular}{||c|c|c|c|c|}
\hline \multicolumn{5}{|c|}{ Final Cost vs. Proposed Cost } \\
\hline $\begin{array}{c}\text { Final } \\
\text { Cost }\end{array} \quad \begin{array}{c}\text { Non Inflated } \\
\text { Proposed Cost }\end{array}$ & \multicolumn{3}{|c|}{$\begin{array}{c}\text { Inflated Proposed } \\
\text { Cost }\end{array}$} & \multicolumn{3}{c|}{ Construction Cost (\$) } \\
\hline$Y_{1}=100\left(\frac{\text { Non Inflated Proposed Cost - Final Cost }}{\text { Non Inflated Proposed Cost }}\right) \%$ & $13.08 \%$ & $14.65 \%$ & $0.00 \%$ & $62.08 \%$ \\
\hline$i Y_{1}=100\left(\frac{\text { Inflated Proposed Cost - Final Cost }}{\text { Non Inflated Proposed Cost }}\right) \%$ & $36.80 \%$ & $20.58 \%$ & $1.57 \%$ & $99.20 \%$ \\
\hline$i Y_{1}=100\left(\frac{\text { Inflated - Non Inflated Proposed Cost }}{\text { Non Inflated Proposed Cost }}\right) \%$ & $23.72 \%$ & $15.08 \%$ & $1.56 \%$ & $83.20 \%$ \\
\hline
\end{tabular}

Figure 5.63: Analysis of Impact of Inflation on Proposed Cost: Case 3

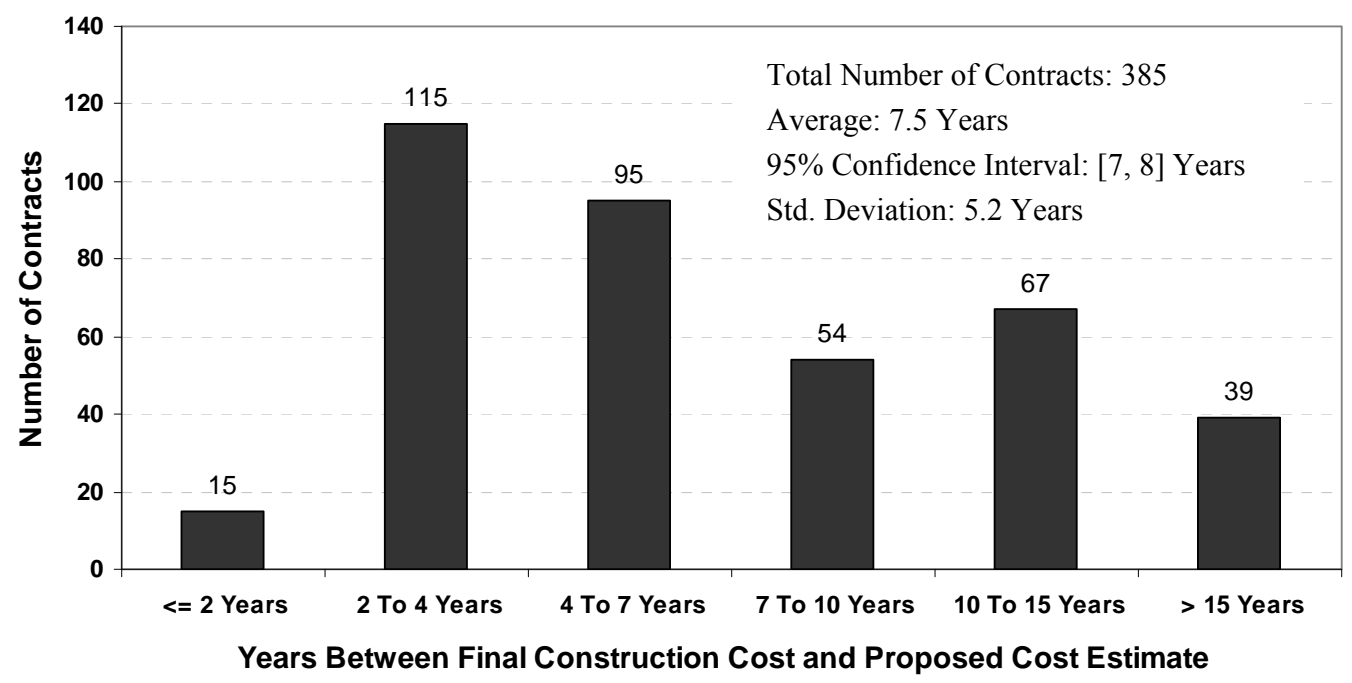

Figure 5.64: Number of Years between the Final Construction Cost and Proposed Cost

\subsubsection{Final Cost vs. Design Cost}

The analysis conducted for proposed cost was repeated with design cost. It was found that 75 contracts exhibited Case 1. Across the 75 contracts, the final cost exceeded the non-inflated design estimate by an average of approximately $31 \%$ (Figure 5.65). After the design estimate was adjusted for inflation, the 
average overrun of the final cost compared to the inflated design estimate reduced to $22 \%$, implying that inflation $\left(I_{3}^{*}\right)$ was responsible for $10 \%$ of the overrun.

Most of the contracts exhibited Cases 2 and 3. Case 2 was exhibited by $26 \%$ of the 385 contracts. For these contracts, the final cost marginally exceeded the non-inflated design cost estimate by an average of $4 \%$ (Figure 5.66). After the estimate was adjusted for inflation, the inflated design cost exceeded the final cost by an average of $9 \%$. That is, the impact of inflating the 'non-inflated' design cost estimate resulted in an average increase of $14 \%$ in the design cost estimate.

The third case (Case 3) was exhibited by 169 of the 385 contracts. Across these contracts, the noninflated design cost estimate was found to exceed the final cost by an average of approximately $11 \%$ (Figure 5.67). After the design estimate was adjusted for inflation, the average difference increased to $23 \%$. The non-inflated design cost, therefore, was found to be a better estimate of the final cost for $70 \%$ of the 385 contracts (100 contracts exhibiting Case 2 and 169 exhibiting Case 3 ).

\begin{tabular}{|c|c|c|c|c|c|}
\hline & Final Cost vs. Design Cost & $\uparrow$ & ase $1-75$ & 385 Cor & \\
\hline & $\begin{array}{c}\text { Inflated Design } \\
\text { Cost }\end{array}$ & $\begin{array}{l}\text { Final } \\
\text { Cost }\end{array}$ & & nstructio & Cost (\$) \\
\hline & & Mean & Std. Dev & Min & Max \\
\hline$Y_{3}=100$ & $\left(\frac{\text { Final Cost - Non Inflated Design Cost }}{\text { Non Inflated Design Cost }}\right) \%$ & $31.40 \%$ & $26.46 \%$ & $2.07 \%$ & $115.12 \%$ \\
\hline$Y_{3}^{*}=100$ & $\left(\frac{\text { Final Cost - Inflated Design Cost }}{\text { Non Inflated Design Cost }}\right) \%$ & $21.85 \%$ & $24.22 \%$ & $0.52 \%$ & $111.84 \%$ \\
\hline$I_{3}^{*}=100$ & $\left(\frac{\text { Inflated - Non Inflated Design Cost }}{\text { Non Inflated Design Cost }}\right) \%$ & $9.56 \%$ & $7.80 \%$ & $0.63 \%$ & $26.04 \%$ \\
\hline
\end{tabular}

Figure 5.65: Analysis of Impact of Inflation on Design Cost: Case 1 


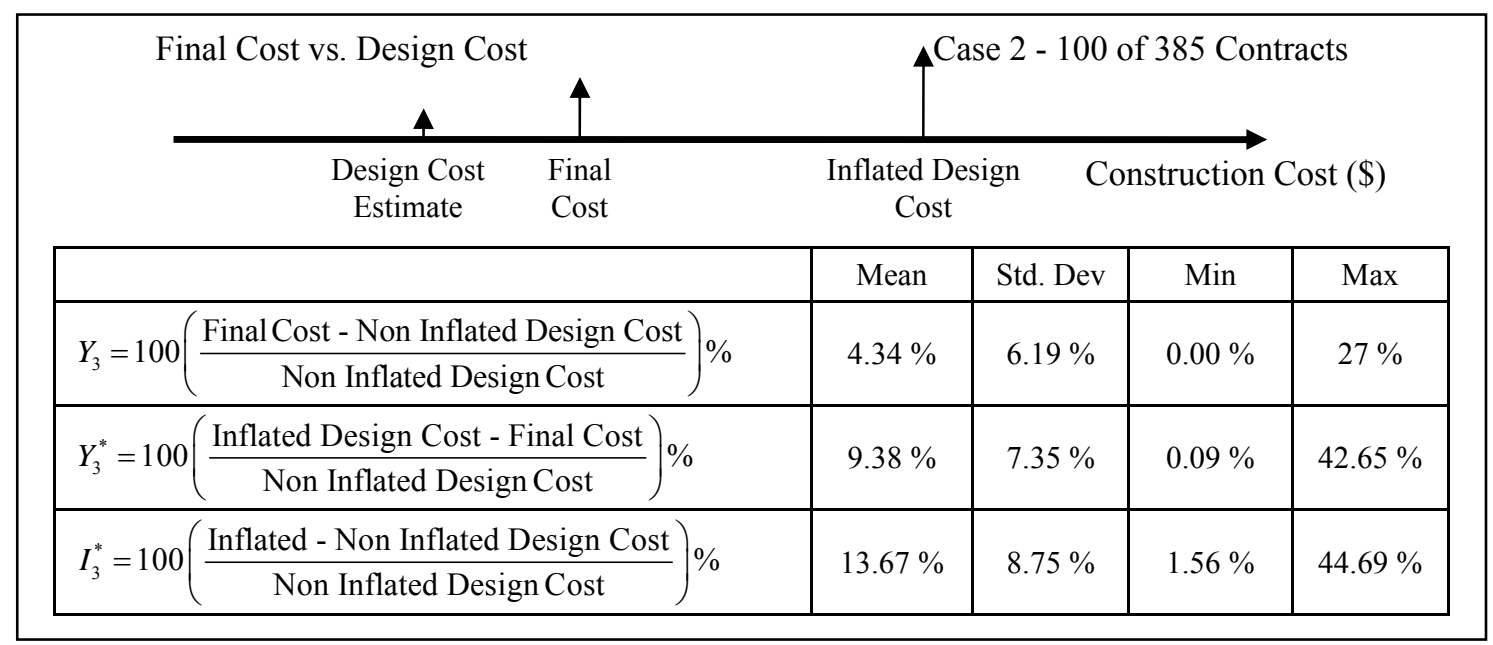

Figure 5.66: Analysis of Impact of Inflation on Design Cost: Case 2

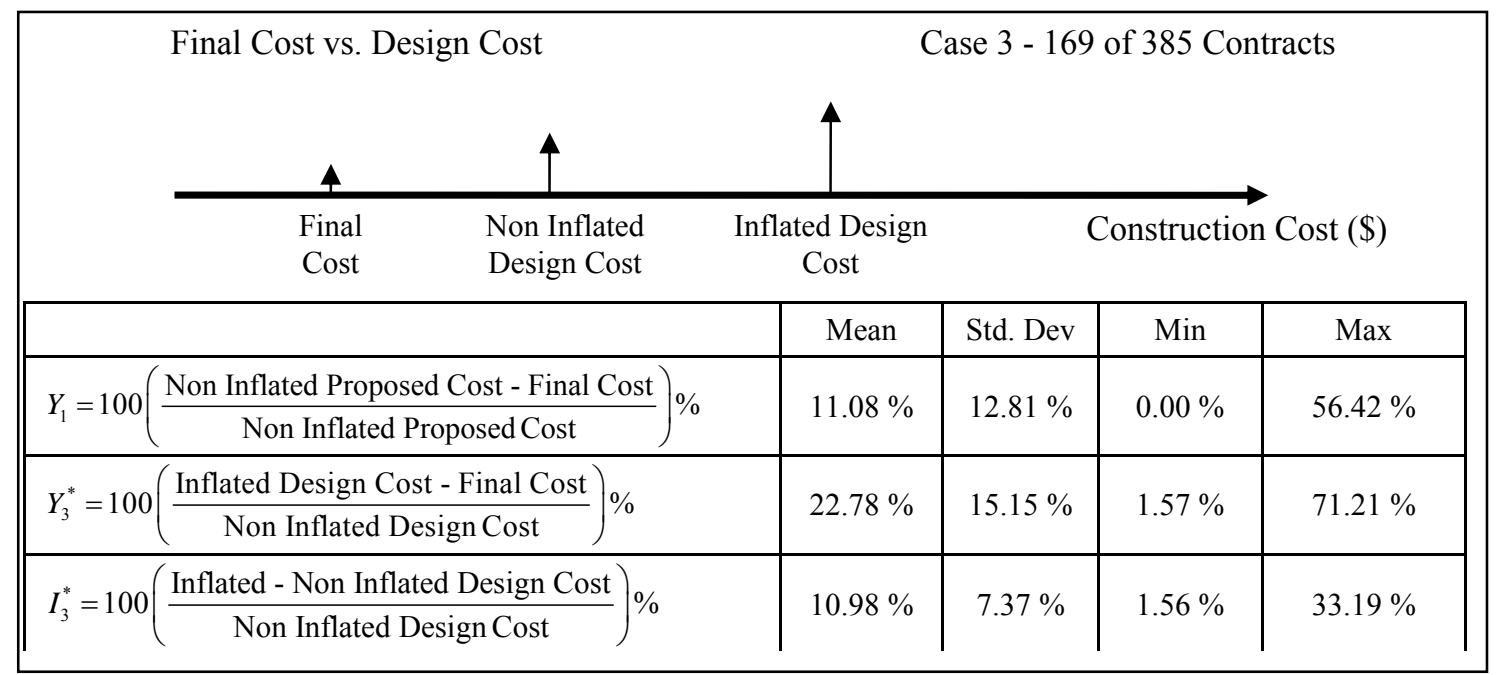

Figure 5.67: Analysis of Impact of Inflation on Design Cost: Case 3

The inflated design cost was found to be closer to the final cost compared to the inflated proposed cost because the impact of inflation on the non-inflated design cost was not as significant as it was for the inflated proposed cost. This is because average time between design completion and construction completion is significantly less than the average duration between project proposal and construction completion (Figure 5.68). 


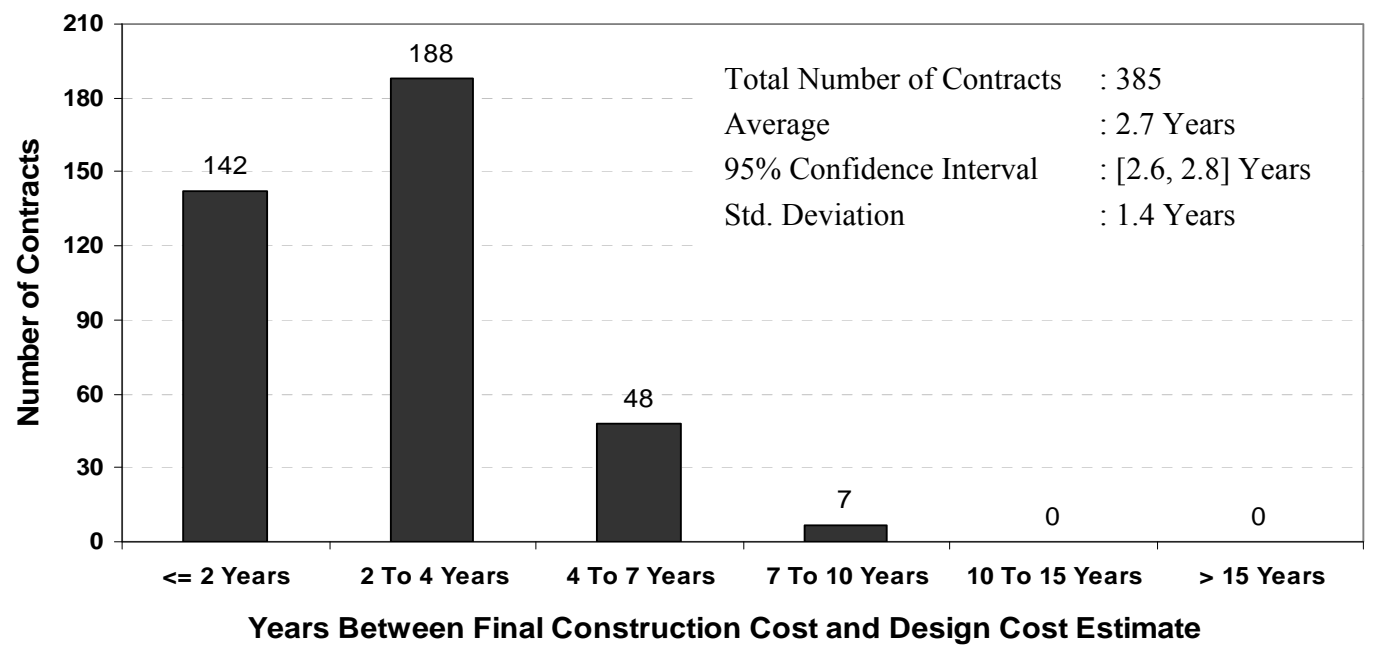

Figure 5.68: Number of Years between the Final Construction Cost and Design Cost

\subsubsection{Final Cost vs. Letting Cost}

The 'letting cost', the 'inflated letting cost' and the 'final construction cost' were plotted using the same methodology used for analyzing the design cost. Again, most of the contracts were found to exhibit Cases 2 and 3. Only 93 of the 385 contracts exhibited Case 1. Across the 93 contracts (that exhibited Case 1), the final cost exceeded the non-inflated letting cost by an average of $20 \%$. After the letting cost was adjusted for inflation, the average overrun of the final cost compared to the letting cost reduced to approximately $12.4 \%$, implying that inflation $\left(\mathrm{II}_{4}\right)$ was responsible for an average overrun of $7 \%$ (Figure 5.69 ).

\begin{tabular}{|c|c|c|c|c|c|}
\hline & 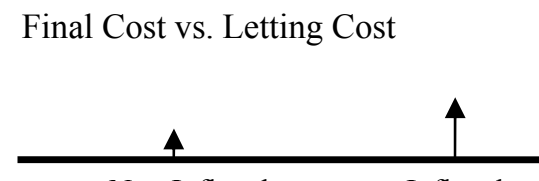 & $\hat{A}$ & ase $1-93$ & $385 \mathrm{C}$ & cts \\
\hline & $\begin{array}{l}\text { Non Inflated } \\
\text { Letting Cost }\end{array}$ & $\begin{array}{l}\text { Final } \\
\text { Cost }\end{array}$ & & struc & ost (\$) \\
\hline & & Mean & Std. Dev & Min & Max \\
\hline$Y_{4}=100$ & $\left(\frac{\text { Final Cost - Non Inflated Letting Cost }}{\text { Non Inflated Letting Cost }}\right) \%$ & $19.58 \%$ & $17.97 \%$ & $0 \%$ & $103.46 \%$ \\
\hline$Y_{4}^{*}=100$ & $\left(\frac{\text { Final Cost }- \text { Inflated Letting Cost }}{\text { Non Inflated Letting Cost }}\right) \%$ & $12.39 \%$ & $15.95 \%$ & $0 \%$ & $93.24 \%$ \\
\hline$I_{4}^{*}=100$ & $\left(\frac{\text { Inflated - Non-Inflated Letting Cost }}{\text { Non Inflated Letting Cost }}\right) \%$ & $7.18 \%$ & $6.65 \%$ & $0 \%$ & $26.04 \%$ \\
\hline
\end{tabular}

Figure 5.69: Analysis of Impact of Inflation on Letting Cost: Case 1 
For approximately $48 \%$ (184 of 385) of the contracts, the final cost exceeded the letting cost (noninflated) marginally by an average of 3.5\% (Case 2: Figure 5.70). However, after the letting cost was adjusted for inflation, the inflated letting cost exceeded the final cost by an average of approximately $9 \%$. Only 44 of the 385 contracts exhibited Case 3, wherein the non-inflated letting cost was found to exceed the final cost by an average of $7.6 \%$, and inflation adjustment resulted in increasing this average difference to $16 \%$ (Figure 5.71). Therefore, for the contracts exhibiting Cases 2 and 3, inflated letting cost was not a significant overestimate of the final cost.

\begin{tabular}{|c|c|c|c|c|c|}
\hline Final & Cost vs. Letting Cost & $\uparrow$ & Case 2 - 1 & of $385 C$ & ntracts \\
\hline & \multirow[t]{2}{*}{ Letting Cost } & Inflated Letting Cost & \multicolumn{3}{|c|}{ Construction Cost (\$) } \\
\hline & & Mean & Std. Dev & Min & Max \\
\hline$Y_{4}=100$ & $\frac{\text { Final Cost - Non Inflated Letting Cost }}{\text { Non Inflated Letting Cost }}$ & $3.48 \%$ & $6.68 \%$ & $0.00 \%$ & $24.42 \%$ \\
\hline$i Y_{4}=100$ & $0\left(\frac{\text { Final Cost - Inflated Letting Cost }}{\text { Non Inflated Letting Cost }}\right)$ & $9.06 \%$ & $7.02 \%$ & $0.05 \%$ & $42.65 \%$ \\
\hline$I I_{4}=100$ & $\left(\frac{\text { Inflated - Non-Inflated Letting Cost }}{\text { Non Inflated Letting Cost }}\right)$ & $12.54 \%$ & $7.88 \%$ & $1.25 \%$ & $43.29 \%$ \\
\hline
\end{tabular}

Figure 5.70: Analysis of Impact of Inflation on Letting Cost: Case 2

\begin{tabular}{||c|c|c|c|c|}
\hline \multicolumn{1}{|c|}{ Final Cost vs. Letting Cost } & Case 3 - 44 of 385 Contracts \\
\hline $\begin{array}{c}\text { Final } \\
\text { Cost }\end{array}$ & Mean & Std. Dev & Min & Max \\
\hline$Y_{4}=100\left(\frac{\text { Final Cost - Non Inflated Letting Cost }}{\text { Non Inflated Letting Cost }}\right) \%$ & $7.64 \%$ & $8.38 \%$ & $0.03 \%$ & $44.23 \%$ \\
\hline$Y_{4}^{*}=100\left(\frac{\text { Inflated Letting Cost - Final Cost }}{\text { Non Inflated Letting Cost }}\right) \%$ & $15.86 \%$ & $10.09 \%$ & $3.90 \%$ & $49.71 \%$ \\
\hline$I_{4}^{*}=100\left(\frac{\text { Inflated Letting Cost - Letting Cost }}{\text { Letting Cost }}\right) \%$ & $8.22 \%$ & $6.08 \%$ & $1.25 \%$ & $26.82 \%$ \\
\hline
\end{tabular}

Figure 5.71: Analysis of Impact of Inflation on Letting Cost: Case 3 
Typically, the letting costs are established shortly after the final design estimates are evaluated (Figure 5.72). Therefore, the impact of inflation on the non-inflated letting costs and design estimates was similar.

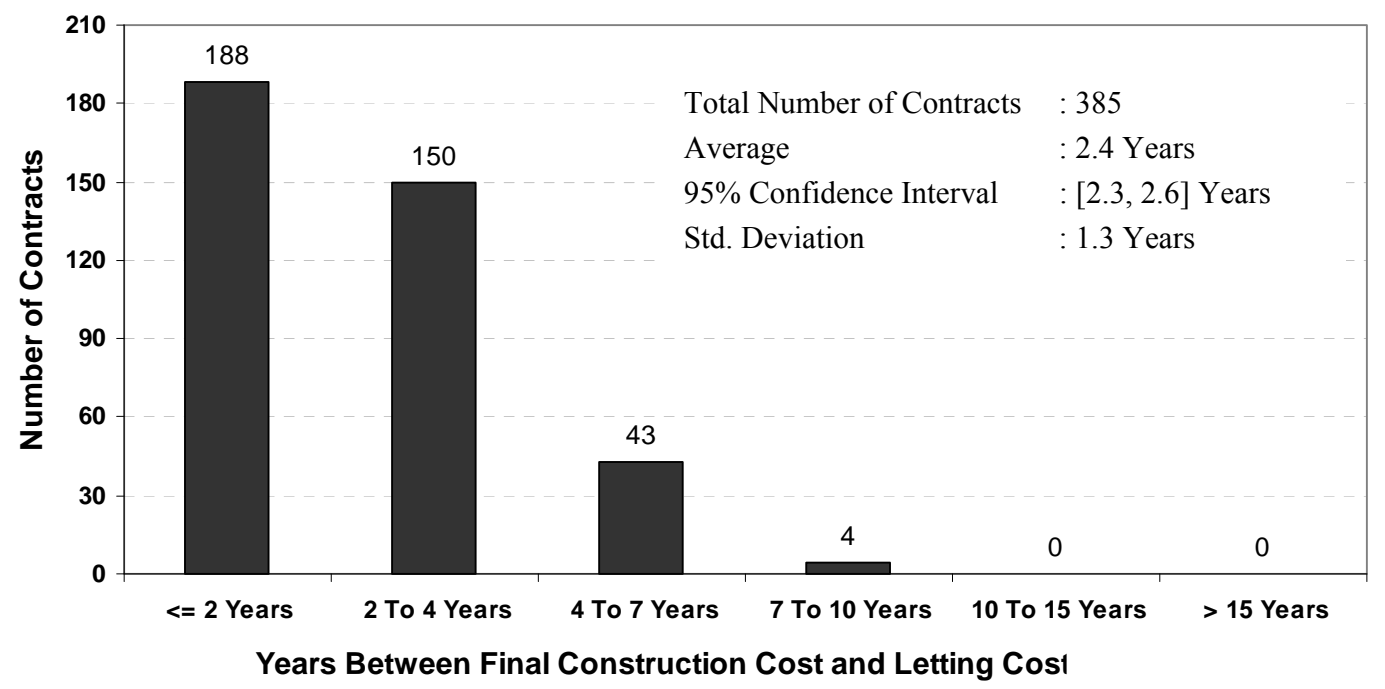

Figure 5.72: Number of Years between the Final Construction Cost and Letting Cost

Based on the analysis of the impact of inflation, it was concluded that inflation adjustment resulted in inconsistent estimates of final construction cost. The following factors could be responsible for the observed counter-intuitive trends.

(a) The non-inflated cost estimates (particularly the proposed cost) could include large contingency amounts, which are getting inflated as well.

(b) It is likely that the included contingency amounts accounted for inflation and never got used up by the contingency. Either the contingency never happened or planners and contractors learnt to deal with recurrent contingencies over the course of development of the project. Issues that were perceived as contingencies at the planning stage, perhaps no longer remained contingencies at the time of construction.

(c) Inflation was perhaps inherently taken into consideration by the methods that were used to prepare the construction cost estimate at latter stages. For example, the unit averages those were used to determine the non-inflated proposed cost estimate were calculated based on the final cost of historical contracts that had experienced high inflation.

(d) Improved technology, better construction equipment, and less number of labor hours were used in the actual construction process, which were not expected at the time when the contract was proposed. 


\subsection{Chapter Summary}

This chapter presented a statistical analysis of cost overrun in Indiana. The accuracy of the proposed cost, engineer's assessment cost, design cost, and letting cost estimates was evaluated for 419 historical contracts from Indiana. Approximately $52 \%$ of the contracts were found to have the proposed cost estimate, engineer's assessment, and design cost within $+/-10 \%$ of the final cost. The engineer's assessment cost and proposed cost estimate did not differ significantly from each other across the 419 contracts. The letting cost was found to be within $+/-10 \%$ of the final cost for $72 \%$ of the contracts. For only $14 \%$ ( 57 of 419 ) of the contracts, the final construction cost exceeded all the cost estimates (proposed, engineer's assessment, design, and letting) by more than $10 \%$. The proposed cost, engineer's assessment and design cost estimate were exceeded by more than $10 \%$ for $20 \%$ ( 85 of 419 ) of the contracts. Cost overrun and underrun were found to be equally frequent when the final cost was compared to the proposed cost, engineer's assessment, and design cost. Approximately $23 \%$ of the contracts were found to have an underrun, whereas $26 \%$ of the contracts had an overrun of final cost compared to these estimates. However, when the final cost was compared to the letting cost only 14\% (60 of 419) of the contracts were found to have an underrun, whereas $86 \%$ (359 of 419) contracts had an overrun of the final cost. But, only for approximately $25 \%$ (104 of 419) of the contracts, the final cost exceeded the letting cost by more than $10 \%$. The frequency and severity of cost overrun and underrun were also analyzed by contract-specific factors such as work category, contract size, contract type, district, area type, route type, and NHS status. Cost overrun and underrun were found to be fairly uniformly distributed across most categories within these factors. The escalation pattern of the cost estimates from planning stage to final construction stage was analyzed to determine the most commonly followed cost estimate trend during the planning and development process. It was found that approximately $60 \%$ of the contracts exhibited a pattern where the cost estimate increases from planning stage until the letting stage, but the estimate at the letting stage is lower than the design estimate. For such contracts, the final construction cost was found to be higher than the letting cost but comparable to the proposed and engineer's assessment cost and lower than the design cost estimate. The above results were based on the reported costs in current dollars (that is without specifically adjusting for inflation). It was found in the chapter that inflation was perhaps taken into consideration implicitly by the methodology used to prepare the cost estimates. In the next chapter, the observed trends and impacts of contract specific factors are tested for statistical significance and models are developed to study the relationship of cost overrun with contract-specific factors. 


\section{CHAPTER 6. RISK-BASED ECONOMETRIC ANALYSIS OF COST OVERRUN IN INDIANA}

\subsection{Introduction}

The methodology proposed in Chapter 4 was used for the development of a risk-based stochastic econometric framework for analysis of cost overrun. The econometric models comprising the framework were developed using the historical highway contracts (419) from Indiana DOT analyzed in Chapter 5. Therefore, the developed framework can be used to identify the contract types that are likely to experience cost overrun in Indiana. The framework was applied by first identifying the contract-specific factors that affect the risk of occurrence of escalation pattern. Next, models were developed to determine the probability and magnitude of planning, design, and letting stage cost overrun based on the risk of occurrence of escalation patterns and contract-specific factors.

\subsection{Econometric Analysis Framework Development \\ 6.2.1. Identification of Factors Affecting Cost Overrun}

The contract-specific factors include work category, administrative district, area type, highway functional class, NHS status, route type, and contract size (based on proposed cost). These were tested for their impact on the probability of occurrence of escalation patterns. These factors were also identified as those that could influence cost underestimation at the planning, design, and letting stage cost overrun. In addition to these factors, the impact of risk of escalation pattern on cost overrun was also studied. Additional contract specific factors are generally available at the design and letting stages. The additional factors that become available at the design stage include: a) time duration between project proposal and final design completion and b) percentage change in the design cost estimate relative to proposed cost. These factors were studied for their impact on design stage cost overrun. The additional factors that become available at letting stage include: a) time span between project proposal and letting, b) time span between letting and final design completion, and c) percentage change in the letting cost relative to proposed cost. The impact of these factors on letting stage cost overrun was studied. The relationship between the identified factors and probability of cost overrun was studied by calibrating econometric models as described in Chapter 4 . 


\subsubsection{Model Calibration}

The 419 historical contracts that were used to calibrate the models comprised of: 239 pavement contracts, 107 bridge contracts, and 73 expansion contracts. Separate models were developed for each work category. Likelihood ratio tests were also conducted to justify the development of separate models.

The methodology for the model development has been described in Chapter 4. A three-step approach was adopted. First, a multinomial logit model was developed to estimate the probability that a given contract will exhibit a given escalation pattern. The contract-specific factors that were found to affect the probability of escalation pattern at the $90 \%$ confidence level were used to calibrate the model. After the models were calibrated, a Monte Carlo simulation was conducted to determine the probability and the variability in the probability of the escalation patterns (as described in Chapter 4). The mean and the standard deviation of the probability of an escalation pattern were used as indicators of the risk associated with occurrence of an escalation pattern. Next, multinomial logit models were developed to determine the probability of planning, design, and letting stage cost overrun as a function of the deterministic contractspecific factors and the risk that a contract will exhibit a particular escalation pattern (which is a random independent variable). The model can be used to determine the probability that a contract will fall in any one of the established of cost overrun categories: less than $<-10 \%$, between $-10 \%$ and $0 \%$, between $0 \%$ and $10 \%$, and greater than $10 \%$. Finally, the expected average cost overrun for any given contract, was determined for contracts in each cost overrun category. The magnitude of cost overrun is determined using the principle of conditional probability as described in Chapter 4 .

\subsubsection{Methodology for Analyzing the Impact of Contract-Specific Using the Developed Models}

To study the impact of the factors used to develop the models on the probability of following a particular escalation patterns, and the probability and magnitude of cost overrun, a sensitivity analysis was conducted. The inter-relationships between the factors can be studied via a graphical approach. The probability of planning stage cost overrun was computed for 2,268 distinct contract types, corresponding to various combinations of the contract specific factors $(6$ districts $* 9$ functional classes $* 21$ contract sizes $* 2$ contact types). The size of expansion contracts was varied from $\$ 1 \mathrm{M}$ to $\$ 30 \mathrm{M}$, whereas the size of bridge contracts was varied from $\$ 1 \mathrm{M}$ to $\$ 7 \mathrm{M}$ and size of pavement contracts was varied from $\$ 1 \mathrm{M}$ to $\$ 10 \mathrm{M}$. The range of contract size for contracts in each work category was decided based on the range of the sizes of these contracts that was observed in practice (based on the 419 contracts).

Similarly, the probability of design stage cost overrun was computed for 181,440 distinct contract types, corresponding to various levels of contract specific factors that affect the design stage cost overrun ( 6 districts $* 9$ functional classes * 21 contract sizes * 2 contract types * 10 levels of time duration between design completion and project proposal $* 8$ levels of percentage difference between design and proposed cost). 
Finally, the probability of letting stage cost overrun was computed for 420,000 distinct contract types corresponding to various levels of contract specific factors that affect the design stage cost overrun (6 districts $* 7$ functional classes $* 8$ contract sizes $* 2$ contract types $* 5$ levels of time duration between design completion and project proposal $* 5$ levels of percentage difference between design and proposed cost $* 5$ levels of time duration between letting and project proposal $* 5$ levels of percentage difference between letting and proposed cost).

The mean probability of planning, design and letting stage cost overrun was computed by each contract-specific factor such as by: contract size, highway functional class, time duration between design and project proposal, etc. The variation in the mean probability of overrun was studied corresponding to the changing levels of the contract-specific factors.

\subsection{Econometric Models for Expansion Contracts}

The expansion contracts for which models were developed included: added travel lanes, new highway construction, interchange modification, or new interchange construction. Such contracts are significantly different from the pavement and bridge contracts that generally involve routine rehabilitation, resurfacing, and reconstruction work. Expansion contracts are particularly likely to experience comparatively higher risk of incurring unforeseen costs related to excavation, utility relocation, and design plan changes. Also, as they typically are of large scale and high profile, contracts they experience intense competition at the letting stage.

\subsubsection{Probability of Escalation Patterns}

A total of 73 expansion contracts of size ranging from $\$ 1-\$ 30 \mathrm{M}$ were used to develop multinomial logit models to determine probability of occurrence of a given escalation pattern, for such contracts. Table 6.1 presents the multinomial logit model. Contract-specific factors such as geographic location (district and area type), contract size (based on initial proposed cost), and highway functional class were found to significantly affect the probability of occurrence of each escalation pattern. The model had a McFadden Rsquare value of 0.36 , indicating that the model explains $36 \%$ of the randomness associated with the tendency of the cost estimates to exhibit a particular escalation pattern. The methodology used for the development of this model is described in Chapter 4 and can be used by highway agencies in other states for developing similar models. 
Table 6.1: Model to Estimate Probability of Occurrence of Escalation Patterns for Expansion Contracts

\begin{tabular}{|c|c|c|c|c|c|}
\hline PATTERN & Contract Specific Factor & Coefficient & Std. Err. & T-Ratio & P-Value \\
\hline \multirow{2}{*}{ PATTERN 'A' } & Constant & 3.0371 & 0.6161 & 4.93 & 0.00 \\
\hline & State Roads / Non-NHS Highways & -1.5297 & 0.5825 & -2.63 & 0.06 \\
\hline \multirow{3}{*}{ PATTERN 'B' } & Proposed Cost (\$ Millions) & 0.2048 & 0.0917 & 2.23 & 0.02 \\
\hline & Vincennes District & -2.1646 & 1.1877 & -1.82 & 0.12 \\
\hline & Square of Proposed Cost (\$ Millions) & -0.0044 & 0.0029 & -1.60 & 0.05 \\
\hline \multirow{6}{*}{ PATTERN 'C' } & Arterial Roads (Urban / Rural) & -3.9398 & 1.6786 & -2.35 & 0.04 \\
\hline & U.S. Roads / Non-Interstate NHS & 3.0957 & 1.5235 & 2.03 & 0.02 \\
\hline & Vincennes District & 6.2753 & 2.7755 & 2.26 & 0.01 \\
\hline & $\begin{array}{l}\text { Fort Wayne and Laporte Districts in } \\
\text { North }\end{array}$ & 4.5336 & 1.8462 & 2.46 & 0.11 \\
\hline & Proposed Cost (\$ Millions) & -0.3598 & 0.2013 & -1.79 & 0.07 \\
\hline & $\begin{array}{l}\text { Crawfordsville and Greenfield Districts } \\
\text { in Central Indiana }\end{array}$ & 2.4759 & 1.1463 & 2.16 & 0.09 \\
\hline PATTERN 'D' & Laporte District & 1.9429 & 0.7503 & 2.59 & 0.02 \\
\hline
\end{tabular}

Log-Likelihood (Model): -65.18; Log-Likelihood (No Coefficients): -101.20; Log-Likelihood (Constant): -78.03; Number of Observations: 73

\subsubsection{Impact of Contract Size}

Figure 6.1 shows the variation in the mean probability of each escalation pattern by contract size. The figure suggests that the probability of expansion contracts to exhibit patterns ' $A$ ' and ' $B$ ' was found to increase with an increase in contract size, but the tendency to exhibit pattern ' $\mathrm{C}$ ' was found to decrease with an increase in contract size. Pattern ' $\mathrm{D}$ ' was found least likely to be exhibited and its probability did not change with increased contract size. Large expansion contracts (greater than $\$ 10 \mathrm{M}$ ) were found more likely to exhibit pattern ' $A$ ', whereas expansion contracts less than $\$ 5 \mathrm{M}$ in size were found more likely to exhibit pattern ' $C$ '. Contracts between $\$ 5$ - $\$ 10 \mathrm{M}$ were found equally likely to exhibit patterns ' $A$ ' and ' $C$ '. Therefore, while the probability to exhibit pattern ' $A$ ' increases with increasing contract size, the probability to exhibit pattern ' $\mathrm{C}$ ' decreases (and at a higher rate) than the rate of increase in the probability of pattern 'A'. Large expansion contracts (greater than $\$ 10 \mathrm{M}$ ) generally provide contractors with more opportunity to incur a profit and therefore contractors tend to bid less than the design cost (Pattern ' $A$ '), despite the uncertainty associated with unforeseen site conditions, scope changes, and change orders. Small expansion contracts $(<\$ 5 \mathrm{M})$, on the other hand, do not provide any incentive of additional profit to compensate for the uncertainty arising due to scope changes and change orders. As a result, contractors submit bids that exceed the design cost (Pattern ' $\mathrm{C}$ ') for small contracts to account for the uncertainty. As some of the unforeseen factors and contingencies do not occur, contractors end up completing the construction for less than the overestimated letting cost. The transition between the tendencies to show 
escalation pattern ' $\mathrm{A}$ ' or ' $\mathrm{C}$ ' occurs in the contract size range in between $\$ 5-\$ 10 \mathrm{M}$. The tendency to exhibit pattern ' $C$ ', however, tends to be low for larger expansion contracts. As such, contracts are less likely to be completed within the let amount, owing to the higher risk of experiencing unforeseen construction problems. Due to the greater uncertainty, large contracts are more likely to exceed the letting cost. This is probably why they become more likely to exhibit patterns ' $\mathrm{A}$ ' and ' $\mathrm{B}$ ' as compared to pattern ' $\mathrm{C}$ '.

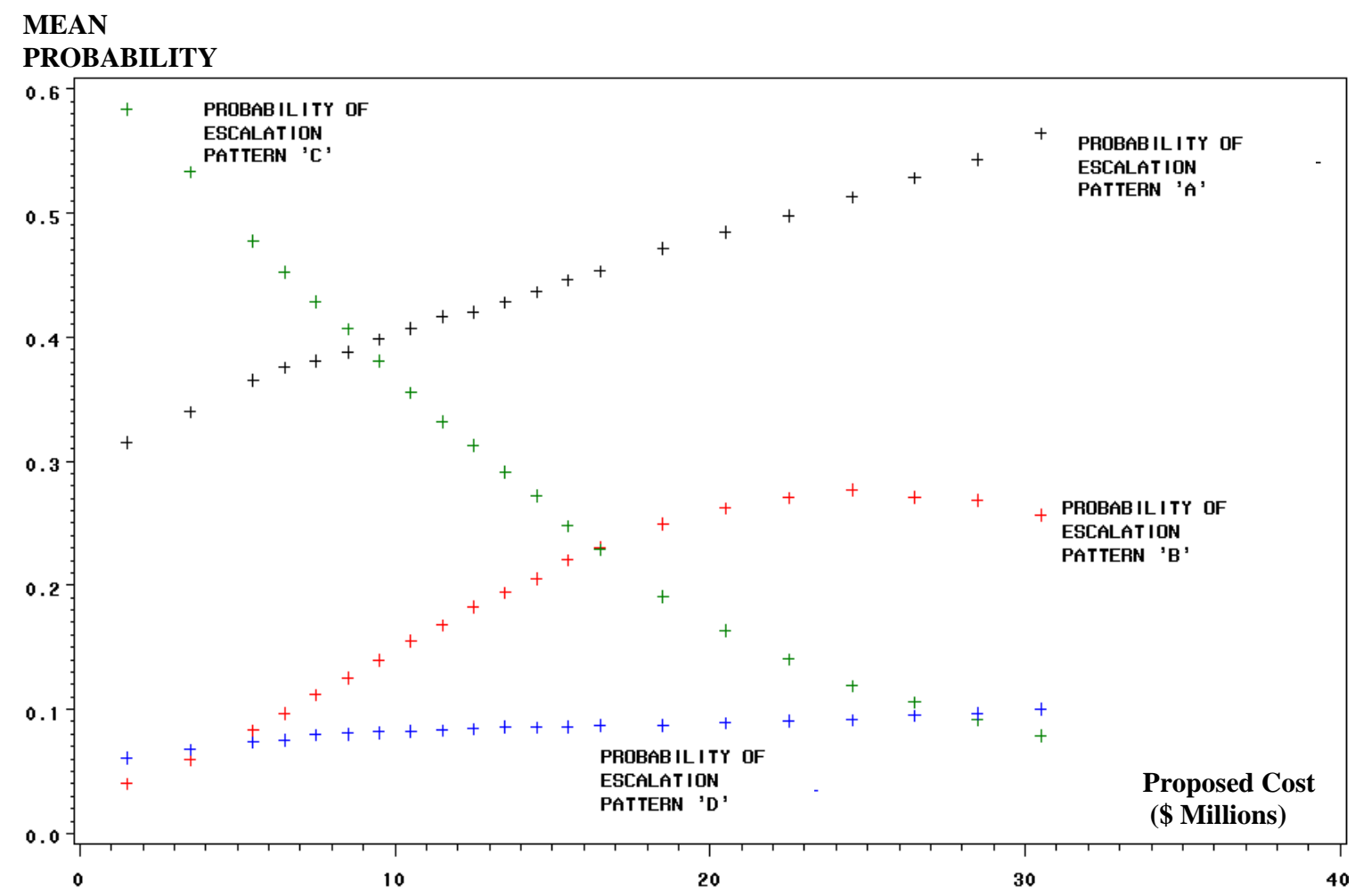

Figure 6.1: Comparison of Mean Probability of Escalation Patterns across Expansion Contracts of Different Sizes

\subsubsection{Impact of Geographic Location and Contract Size}

The trends in the mean probability of the escalation patterns were studied in further detail by geographic location (i.e., the six districts). The objective was to determine whether the increasing trend in the probability of escalation patterns ' $\mathrm{A}$ ' and ' $\mathrm{B}$ ' and the decreasing trend in the probability of escalation pattern ' $\mathrm{C}$ ' were prevalent across all districts. It was found that for the urbanized districts of Seymour, Greenfield, and Laporte, the probability of escalation pattern 'A' showed a non-increasing trend with increasing contract size (Figure 6.2). In spite of the non-increasing trend, large contracts in these districts, nevertheless, were found to be more likely to exhibit pattern 'A' compared to the other patterns. However, the tendency to exhibit pattern ' $\mathrm{B}$ ' increased at a faster rate in these districts compared to other districts, 
and therefore large contracts were only marginally more likely to exhibit pattern ' $\mathrm{A}$ ' compared to pattern ' $\mathrm{B}$ ' (Figure 6.3). In fact, contracts in the urbanized districts were found to be more likely to exhibit pattern 'B' compared to contracts in other districts. The probability to exhibit pattern 'C' was low for contracts in Seymour and Greenfield districts (Figure 6.4) even for smaller contract sizes, indicating that contracts in these two districts had a greater propensity to exhibit patterns ' $\mathrm{A}$ ' and ' $\mathrm{B}$ '.

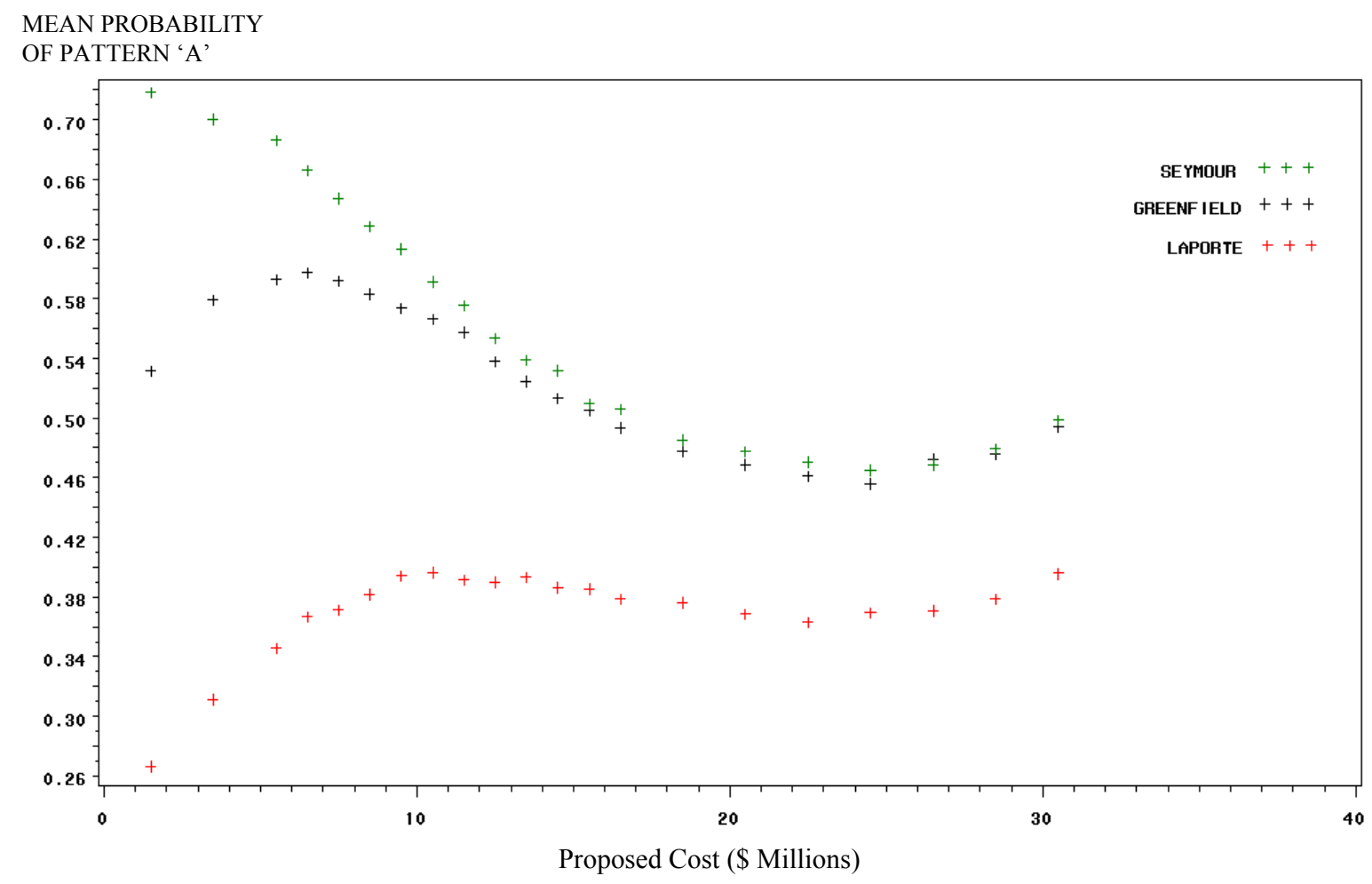

Figure 6.2: Distribution of Probability of Occurrence of Escalation Pattern 'A' for Expansion Contracts in Seymour, Greenfield, and Laporte Districts 


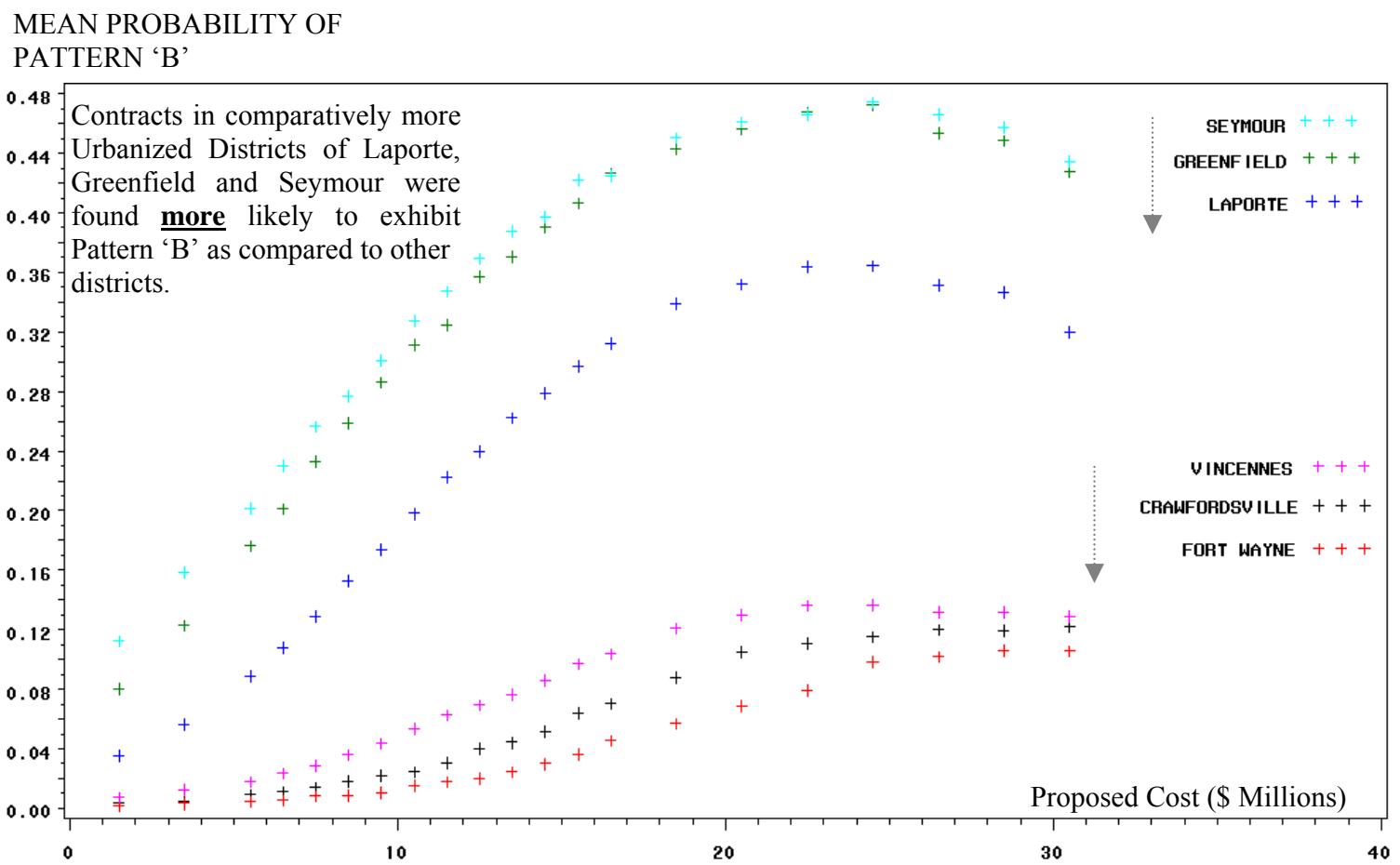

Figure 6.3: Distribution of Probability of Escalation Pattern 'B' for Expansion Contracts by District

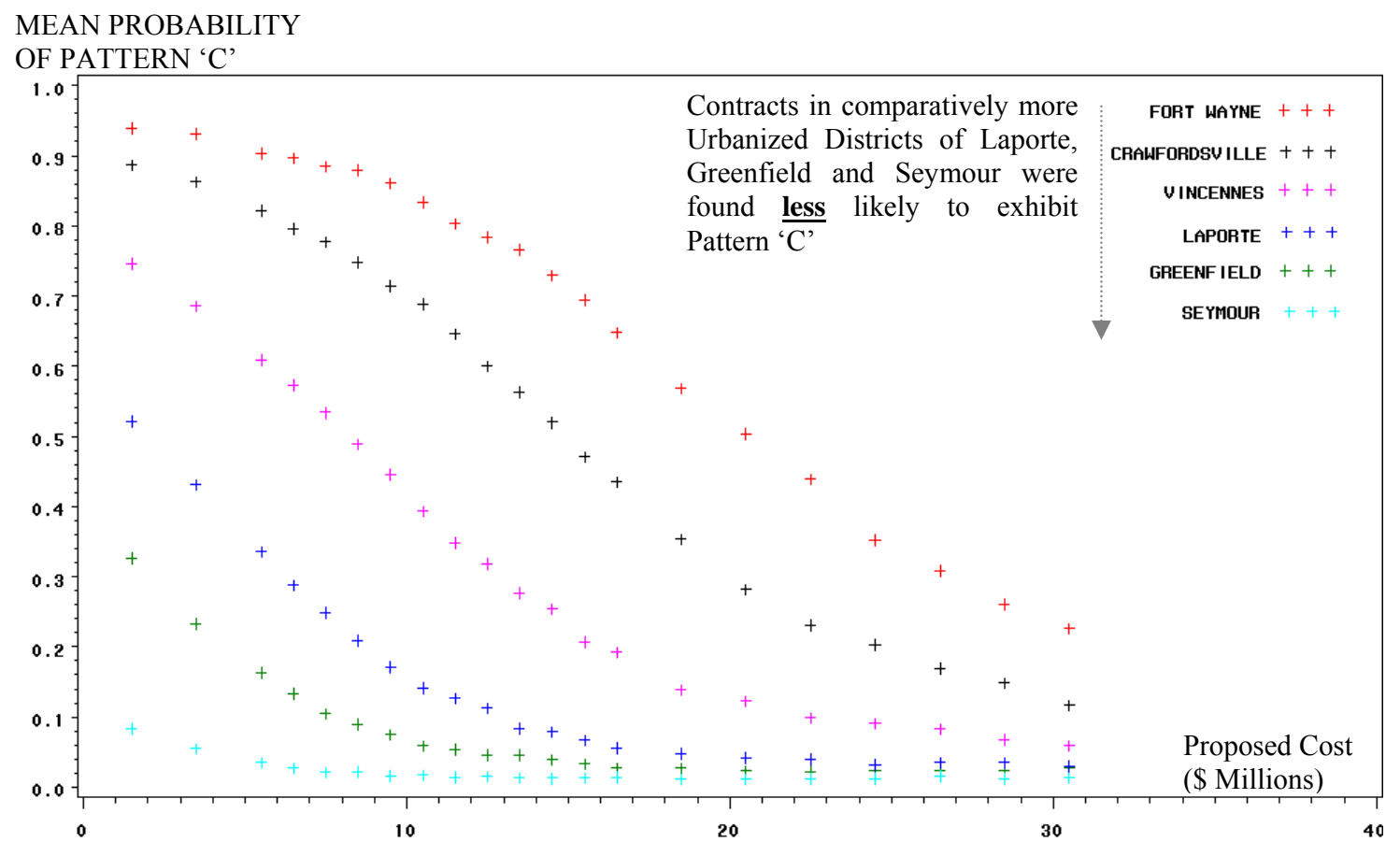

Figure 6.4: Distribution of Probability of Escalation Pattern ' $\mathrm{C}$ ' for Expansion Contracts by District 
Contracts in the relatively less urbanized districts of Vincennes, Crawfordsville, and Fort Wayne were found to exhibit increasing probability of escalation pattern ' $A$ ' with increasing contract size. Large contracts were significantly more likely to exhibit pattern 'A' (Figure 6.5). On the other hand, small-sized contracts (less than $\$ 10 \mathrm{M}$ ) in these districts were significantly more likely to exhibit pattern ' $\mathrm{C}$ ' (Figure $6.4)$.

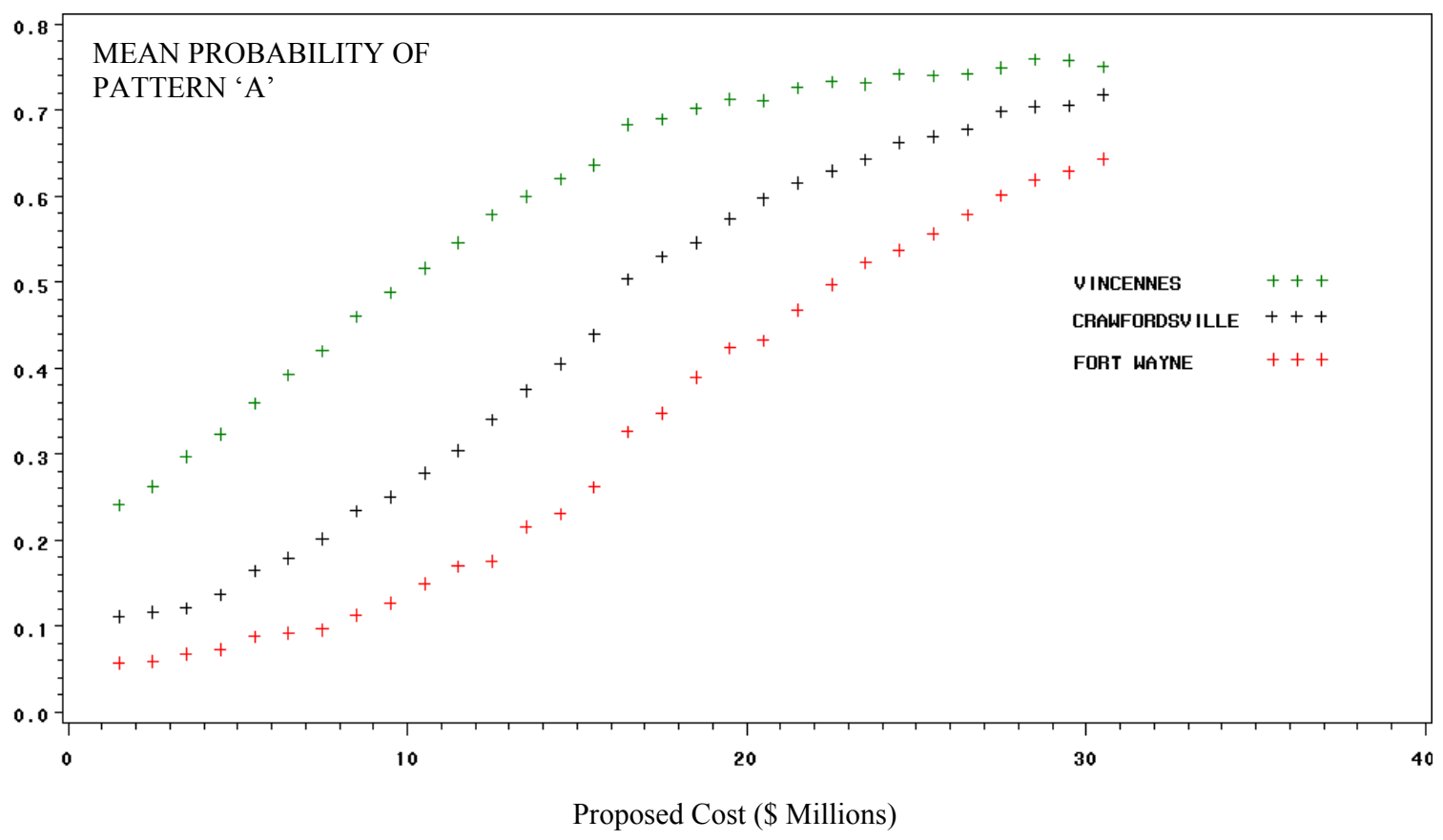

Figure 6.5: Distribution of Probability of Escalation Pattern ' $\mathrm{C}$ ' for Expansion Contracts in Vincennes, Crawfordsville, and Fort Wayne Districts

The above trends are indicative of the propensity of expansion contracts in Seymour and Greenfield districts to experience unforeseen costs (as contracts in these districts were found more likely to experience pattern 'B'). Contracts in the less urbanized districts, on the other hand, are less likely to experience unforeseen costs (as they have a higher propensity to exhibit patterns ' $\mathrm{C}$ '). Construction in urbanized districts is more likely to encounter underground utilities compared to construction in less urbanized districts, thereby resulting in higher risk of unforeseen conditions. Due to the lower risk of unforeseen conditions in the less urbanized districts, contractors bid low to win large contracts in these districts (as indicated by the tendency of large contracts to exhibit pattern 'A'). Also, above trends indicate that large expansion contracts in all the districts are more susceptible to unforeseen costs compared to small-sized contracts (as indicated by the increase in the probability of pattern ' $\mathrm{B}$ ' with contract size and decrease in the probability of pattern ' $\mathrm{C}$ ' with contract size). These findings were validated based on the analysis of the probability of cost overrun (presented in Section 6.3.2). 


\subsubsection{Impact of NHS Status and Route Type}

The NHS status or route type was found to influence the probability of escalation pattern occurrence. The tendency to exhibit pattern ' $\mathrm{A}$ ' was found to increase with increasing contract size for contracts on all route types (Figure 6.6). Large expansion contracts (greater than $\$ 5 \mathrm{M}$ ) on Interstate highways were found more likely to exhibit pattern ' $A$ ' and less (but equally) likely to exhibit patterns ' $B$ ' and 'C'. Large expansion contracts at Interstates are high profile contracts and therefore are more likely to experience greater scrutiny and competition during the programming and letting stages. As a result, such contracts are more likely to exhibit pattern 'A' compared to those at lower class highways.

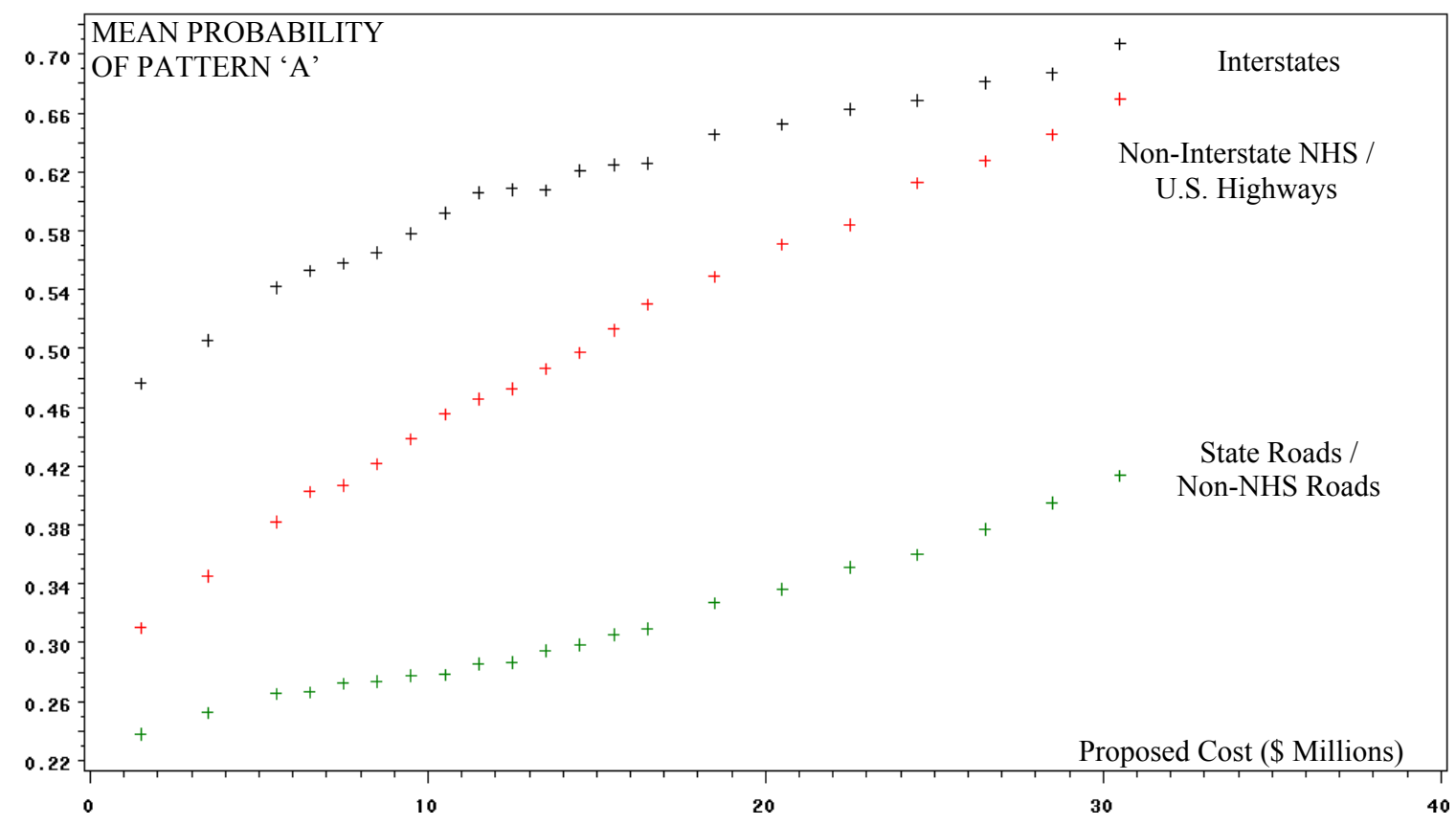

Figure 6.6: Distribution of Probability of Escalation Pattern 'A' for Expansion Contracts by NHS Status /

Route Type

The results suggest that expansion contracts at lower highway functional classes have a greater propensity to exhibit pattern ' $\mathrm{C}$ '. This suggests that the cost estimates prepared for contracts at lower class highways, even at the letting stage, tend to be conservative. Contracts at these highway functional classes are not high profile contracts and therefore a conservative approach is preferred to account for the risk of unforeseen costs. The risk of unforeseen costs is probably not high as indicated by the low propensity of Interstate contracts to exhibit pattern 'B' (Figure 6.8). In fact, small expansion contracts at Interstates, being comparatively low profile compared to large expansion contracts at these highway classes, are equally likely to exhibit patterns ' $\mathrm{A}$ ' and ' $\mathrm{C}$ ' (Figure 6.6 and Figure 6.7, respectively). This finding suggests that contractors generally accept smaller risk (and thus submit higher bids) for small expansion contracts on Interstate highways, they accept greater risk by submitting relatively low bids (in spite of the uncertainty from unforeseen costs). 


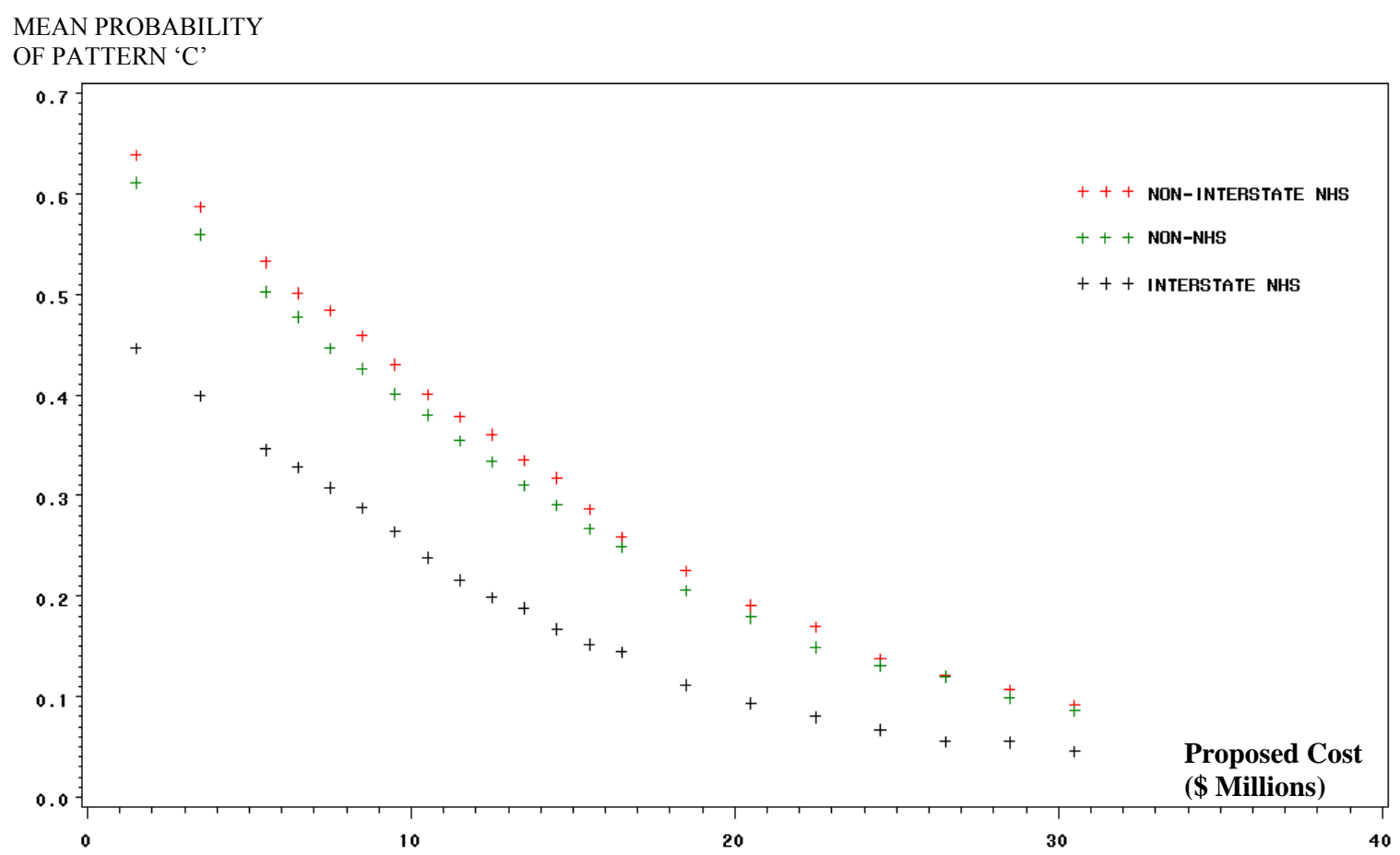

Figure 6.7: Distribution of Probability of Escalation Pattern ' $C$ ' for Expansion Contracts by NHS Status

The greater propensity of large expansion contracts on Non-NHS highways to exhibit pattern 'B' compared to contracts on NHS highways indicates that large contracts at lower functional classes are more susceptible to unforeseen costs. Large expansion contracts on Non-NHS highways, such as arterial roads, are more likely to encounter underground utilities to a greater extent compared to Interstates and therefore are more susceptible to higher unforeseen costs. On the other hand, small expansion contracts at lower functional classes are less likely to encounter underground utilities and therefore are more likely to experience pattern ' $\mathrm{C}$ ' (Figure 6.7), this represents a scenario where planning is done for unforeseen costs, but are not experienced in most cases. 


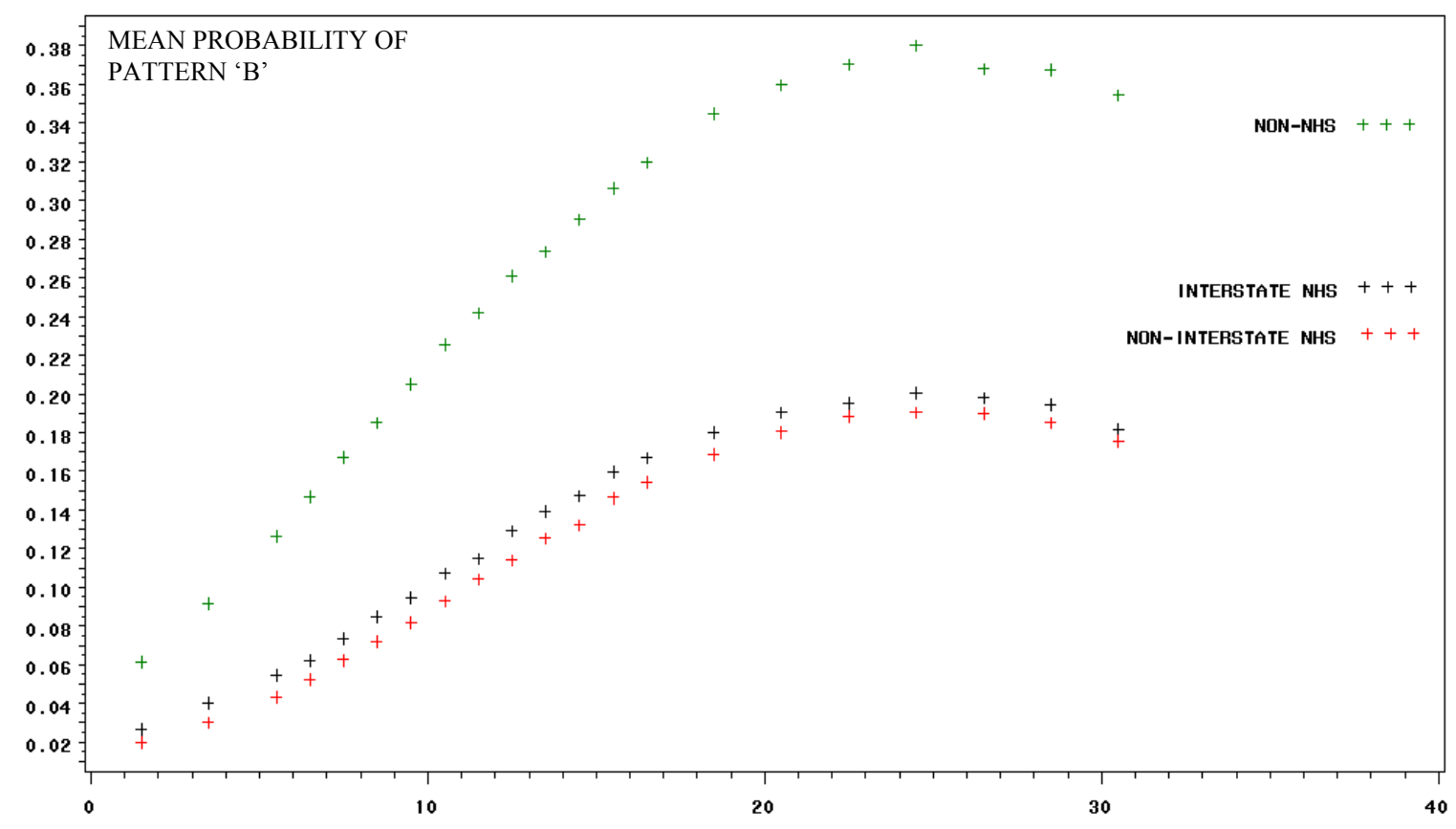

Figure 6.8: Distribution of Probability of Escalation Pattern 'B' for Expansion Contracts by NHS Status

\subsubsection{Probability of Cost Overrun Occurrence}

Discrete choice multinomial logit models were developed to determine the occurrence probability of cost overrun at planning, design, and letting stages. Table 6.2 presents the model for determining probability of planning stage cost overrun. Contract-specific factors, which included the propensity of a contract to exhibit an escalation pattern, were found to have an impact on the outcome.

Table 6.3 presents the model for estimating the occurrence of cost overrun at the design stage. A greater amount of information on the contract is available at the design stage,. The percentage difference between design estimate and proposed cost was found to affect the probability of design stage cost overrun. These factors are not available at the planning stage and therefore were not included in the model for determining planning stage cost overrun. As a result, the McFadden R-squared value of the design stage cost overrun model (0.39) was higher than that of the planning stage cost overrun model $(0.30)$. 
Table 6.2: Multinomial Logit Model for Determining Occurrence Probability of Planning Stage Cost

Overrun, Expansion Contracts

\begin{tabular}{|c|c|c|c|c|c|}
\hline $\begin{array}{c}\text { Cost } \\
\text { Overrun }\end{array}$ & Contract Specific Factor & Coeff. & Std.Err. & t-ratio & p-Value \\
\hline \multirow{2}{*}{$\begin{array}{l}\text { Category } 1 \\
<-10 \%\end{array}$} & $\begin{array}{l}\text { Seymour and Vincennes Districts in } \\
\text { South Indiana }\end{array}$ & 1.2654 & 0.6127 & 2.07 & 0.04 \\
\hline & Probability of Escalation Pattern ' $\mathrm{B}$ ' & -8.2766 & 2.9172 & -2.84 & 0.00 \\
\hline \multirow{2}{*}{$\begin{array}{l}\text { Category } 2 \\
{[<-10 \%, 0 \%)}\end{array}$} & Proposed Cost (in Million \$) & -0.1348 & 0.0458 & -2.94 & 0.00 \\
\hline & Probability of Escalation Pattern ' $C$ ' & 2.8402 & 0.9362 & 3.03 & 0.00 \\
\hline \multirow{3}{*}{$\begin{array}{l}\text { Category } 3 \\
{[0 \%, 10 \%]}\end{array}$} & Probability of Escalation Pattern 'A' & -7.1492 & 3.0458 & -2.35 & 0.02 \\
\hline & $\begin{array}{l}\text { Probability of Escalation Pattern 'A' / } \\
\text { Variability in Probability of Escalation } \\
\text { Pattern 'A' }\end{array}$ & 0.4798 & 0.2290 & 2.09 & 0.04 \\
\hline & $\begin{array}{l}\text { Variability in Probability of Escalation } \\
\text { Pattern 'A' (Measured using Std. Dev) }\end{array}$ & 8.8551 & 5.0124 & 1.77 & 0.08 \\
\hline $\begin{array}{c}\text { Category } 4 \\
>10 \%\end{array}$ & $\begin{array}{l}\text { Fort Wayne and Laporte Districts in } \\
\text { North }\end{array}$ & -2.2259 & 0.7937 & -2.80 & 0.01 \\
\hline
\end{tabular}

Log-Likelihood (Model): -82.81; Log-Likelihood (No Coefficients): -101.20; Log-Likelihood (Constant): -100.54

Table 6.3: Multinomial Logit Model for Determining Occurrence Probability of Design Stage Cost

Overrun, Expansion Contracts

\begin{tabular}{|c|c|c|c|c|c|}
\hline Cost Overrun & Contract Specific Factor & Coeff. & Std.Err. & t-ratio & P-Value \\
\hline \multirow{3}{*}{ Category 1} & $\begin{array}{l}\text { Seymour and Vincennes Districts in } \\
\text { South Indiana }\end{array}$ & 2.8686 & 1.2686 & 2.26 & 0.02 \\
\hline & Probability of Escalation Pattern 'B' & -34.0507 & 15.0947 & -2.26 & 0.02 \\
\hline & $\begin{array}{l}\text { Urban Districts of Seymour, } \\
\text { Greenfield and Laporte }\end{array}$ & 3.1787 & 1.3464 & 2.36 & 0.02 \\
\hline \multirow{6}{*}{$\begin{array}{l}\text { Category } 2 \\
{[-10 \%, 0 \%)}\end{array}$} & Proposed Cost (in Million \$) & -0.5460 & 0.1784 & -3.06 & 0.00 \\
\hline & Probability of Escalation Pattern 'C' & 5.1216 & 1.4182 & 3.61 & 0.00 \\
\hline & $\begin{array}{l}\text { Probability of Pattern 'B' relative to } \\
\text { Pattern 'D' }\end{array}$ & 1.9437 & 0.5462 & 3.56 & 0.00 \\
\hline & Laporte District & 4.6339 & 1.4915 & 3.11 & 0.00 \\
\hline & Vincennes District & 4.4344 & 1.5762 & 2.81 & 0.00 \\
\hline & $\begin{array}{l}\text { Time Between Design and Project } \\
\text { Proposal (years) }\end{array}$ & -0.1597 & 0.0842 & -1.90 & 0.06 \\
\hline $\begin{array}{l}\text { Category } 3 \\
{[0 \%, 10 \%]}\end{array}$ & $\begin{array}{l}\text { Probability of Escalation Pattern } \\
\text { 'A' / Variability in Probability of } \\
\text { Escalation Pattern 'A' }\end{array}$ & 0.1505 & 0.0981 & 1.53 & 0.12 \\
\hline \multirow{3}{*}{ Category 4} & $\begin{array}{l}\text { Fort Wayne and Laporte Districts in } \\
\text { North }\end{array}$ & -4.1188 & 1.8252 & -2.26 & 0.02 \\
\hline & Probability of Pattern 'B' & 5.9898 & 2.8466 & 2.10 & 0.04 \\
\hline & $\begin{array}{l}\text { Percentage Difference Between } \\
\text { Design and Proposed Cost }\end{array}$ & -0.1452 & 0.1002 & -1.45 & 0.15 \\
\hline
\end{tabular}

* Log-Likelihood (Model): -49.29; Log-Likelihood (No Coefficients): -80.41; Log-Likelihood (Constant): -76.80 
At the letting stage, the factors that were found to affect the probability of letting stage cost overrun include: contract size, geographic location, NHS status, contract type, percentage difference between proposed, design, and letting costs, and the time between final design completion and project proposal. In addition to these contract-specific factors, the propensity of a contract to exhibit a particular escalation pattern was also found to affect the probability of occurrence of letting stage cost overrun (Table 6.4). The McFadden R-squared value of the letting stage cost overrun model (0.40) was found to be higher than that of planning stage (0.30) and design stage models (0.39). This is because additional information is available at the letting stage, such as percentage difference between letting and proposed cost.

Table 6.4: Multinomial Logit Model for Determining Occurrence Probability of Letting Stage Cost Overrun, Expansion Contracts

\begin{tabular}{|c|c|c|c|c|c|}
\hline $\begin{array}{l}\text { Cost Overrun } \\
\text { Category }\end{array}$ & Contract Specific Factor & Coeff. & Std.Err. & t-ratio & P-Value \\
\hline \multirow{3}{*}{ Category 1} & Probability of Escalation Pattern 'B' & -27.763 & 11.881 & -2.34 & 0.02 \\
\hline & $\begin{array}{l}\text { Urban Districts of Seymour, Greenfield } \\
\text { and Laporte }\end{array}$ & 2.0229 & 1.1512 & 1.76 & 0.08 \\
\hline & $\begin{array}{l}\text { Percentage Difference Between Letting } \\
\text { and Proposed Cost }\end{array}$ & 0.0858 & 0.0498 & 1.72 & 0.08 \\
\hline \multirow[t]{2}{*}{ Category 2} & Proposed Cost (in Million \$) & -0.1098 & 0.0439 & -2.50 & 0.01 \\
\hline & $\begin{array}{l}\text { Time Between Final Design and Project } \\
\text { Proposal (Years) }\end{array}$ & 0.1799 & 0.0608 & 2.96 & 0.00 \\
\hline \multirow{3}{*}{$\begin{array}{l}\text { Category } 3 \\
(5 \%, 10 \%]\end{array}$} & $\begin{array}{l}\text { Variability in Probability of Escalation } \\
\text { Pattern 'A' (Measured using Std. Dev) }\end{array}$ & -40.7846 & 16.5534 & -2.46 & 0.01 \\
\hline & Kin Contracts & 3.7110 & 1.8226 & 2.04 & 0.04 \\
\hline & Crawfordsville District & 4.3130 & 1.7832 & 2.42 & 0.02 \\
\hline \multirow{3}{*}{ Category 4} & Fort Wayne and Laporte Districts in North & -3.0351 & 1.0549 & -2.88 & 0.00 \\
\hline & $\begin{array}{l}\text { Percentage Difference Between Design } \\
\text { and Proposed Cost }\end{array}$ & 0.7281 & 0.2748 & 2.65 & 0.01 \\
\hline & Non-NHS Highways & 1.6106 & 0.8142 & 1.98 & 0.05 \\
\hline
\end{tabular}

* Log-Likelihood (Model): -48.41; Log-Likelihood (No Coefficients): -80.41; Log-Likelihood (Constant): -70.96

The factors that were found to affect the probability of cost overrun at the planning, design, and letting stages were compared to study the impact of these factors on the accuracy of the cost estimates prepared at the various stages. Table 6.5 compares the coefficients. It is seen that the sign of the coefficients did not change across the models for the three stages. However, the magnitudes of the coefficients were found to be different. Also, contract size, geographic location, highway functional class, NHS status, and probability of escalation pattern were found to affect the probability of cost overrun occurrence at all stages. 
Table 6.5: Comparison of Coefficients of the Factors Affecting Occurrence Probability of Planning, Design and Letting Stage Cost Overrun, Expansion Contracts

\begin{tabular}{|c|c|c|c|c|c|}
\hline $\begin{array}{c}\text { Cost } \\
\text { Overrun } \\
\text { Category }\end{array}$ & Contract Specific Factor & Planning & Design & $\begin{array}{l}\text { Cost } \\
\text { Overrun } \\
\text { Category }\end{array}$ & Letting \\
\hline \multirow{4}{*}{$\begin{array}{l}\text { Category } 1 \\
\qquad-10 \%\end{array}$} & $\begin{array}{l}\text { Seymour and Vincennes Districts in South } \\
\text { Indiana }\end{array}$ & 1.2654 & 2.8686 & \multirow{10}{*}{ Category 1} & \\
\hline & Probability of Escalation Pattern 'B' & -8.2766 & -34.0507 & & -27.76 \\
\hline & $\begin{array}{l}\text { Urban Districts of Seymour, Greenfield } \\
\text { and Laporte }\end{array}$ & & 3.1787 & & 2.02 \\
\hline & $\begin{array}{l}\text { Percentage Difference Between Letting } \\
\text { and Proposed Cost }\end{array}$ & & & & 0.086 \\
\hline \multirow{6}{*}{$\begin{array}{l}\text { Category } 2 \\
{[-10 \%, 0 \%)}\end{array}$} & Proposed Cost (in Million \$) & -0.1348 & -0.546 & & \\
\hline & Probability of Escalation Pattern ' $\mathrm{C}$ ' & 2.8402 & 5.1216 & & \\
\hline & $\begin{array}{l}\text { Probability of Pattern 'B' relative to } \\
\text { Pattern 'D' }\end{array}$ & & 1.9437 & & \\
\hline & Laporte District & & 4.6339 & & \\
\hline & Vincennes District & & 4.4344 & & \\
\hline & $\begin{array}{l}\text { Time Between Design and Project } \\
\text { Proposal (years) }\end{array}$ & & -0.1597 & & \\
\hline \multirow{7}{*}{$\begin{array}{l}\text { Category } 3 \\
{[0 \%, 10 \%]}\end{array}$} & Proposed Cost (in Million \$) & & & \multirow{2}{*}{$\begin{array}{l}\text { Category } 2 \\
{[0 \%, 5 \%]}\end{array}$} & -0.1097 \\
\hline & $\begin{array}{l}\text { Time Between Design and Project } \\
\text { Proposal (years) }\end{array}$ & & & & 0.18 \\
\hline & Kin Contracts & & & \multirow{5}{*}{$\begin{array}{l}\text { Category } 3 \\
(5 \%, 10 \%]\end{array}$} & 3.7109 \\
\hline & Crawfordsville District & & & & 4.3129 \\
\hline & Probability of Escalation Pattern 'A' & -7.1492 & & & \\
\hline & $\begin{array}{l}\text { Probability of Escalation Pattern 'A'/ } \\
\text { Variability in Probability of Escalation } \\
\text { Pattern 'A' }\end{array}$ & 0.4798 & 0.1505 & & \\
\hline & $\begin{array}{l}\text { Variability in Probability of Escalation } \\
\text { Pattern 'A' (Measured using Std. Dev) }\end{array}$ & 8.8551 & & & -40.7845 \\
\hline \multirow{4}{*}{ Category 4} & Fort Wayne and Laporte Districts in North & -2.2259 & -4.1188 & \multirow{4}{*}{ Category 4} & -3.035 \\
\hline & Probability of Pattern 'B' & & 5.9898 & & \\
\hline & $\begin{array}{l}\text { Percentage Difference Between Design } \\
\text { and Proposed Cost }\end{array}$ & & -0.1452 & & 0.72814 \\
\hline & Non-NHS Highways & & & & 1.6106 \\
\hline
\end{tabular}




\subsubsection{Impact of Escalation Pattern by Geographic Location (District)}

The probability of a negative cost overrun was found to decrease with an increase in the probability of escalation pattern 'B'. Expansion contracts that were more likely to Pattern 'B' were found more likely to have a cost overrun of greater than $10 \%$. Figure 6.9 shows the increasing trend in the probability of cost overrun greater than $10 \%$ with increasing probability of pattern 'B' for contracts in each district. The plot shows the trend across the 2,268 contract types of various sizes and on various highway functional classes in the six districts of Indiana. This trend was seen in all six districts. However, the trend pattern was found to be different across the districts, suggesting that that the probability of an overrun greater than $10 \%$ is affected by several factors including the probability of exhibiting escalation pattern ' $\mathrm{B}$ ' and the administrative district.

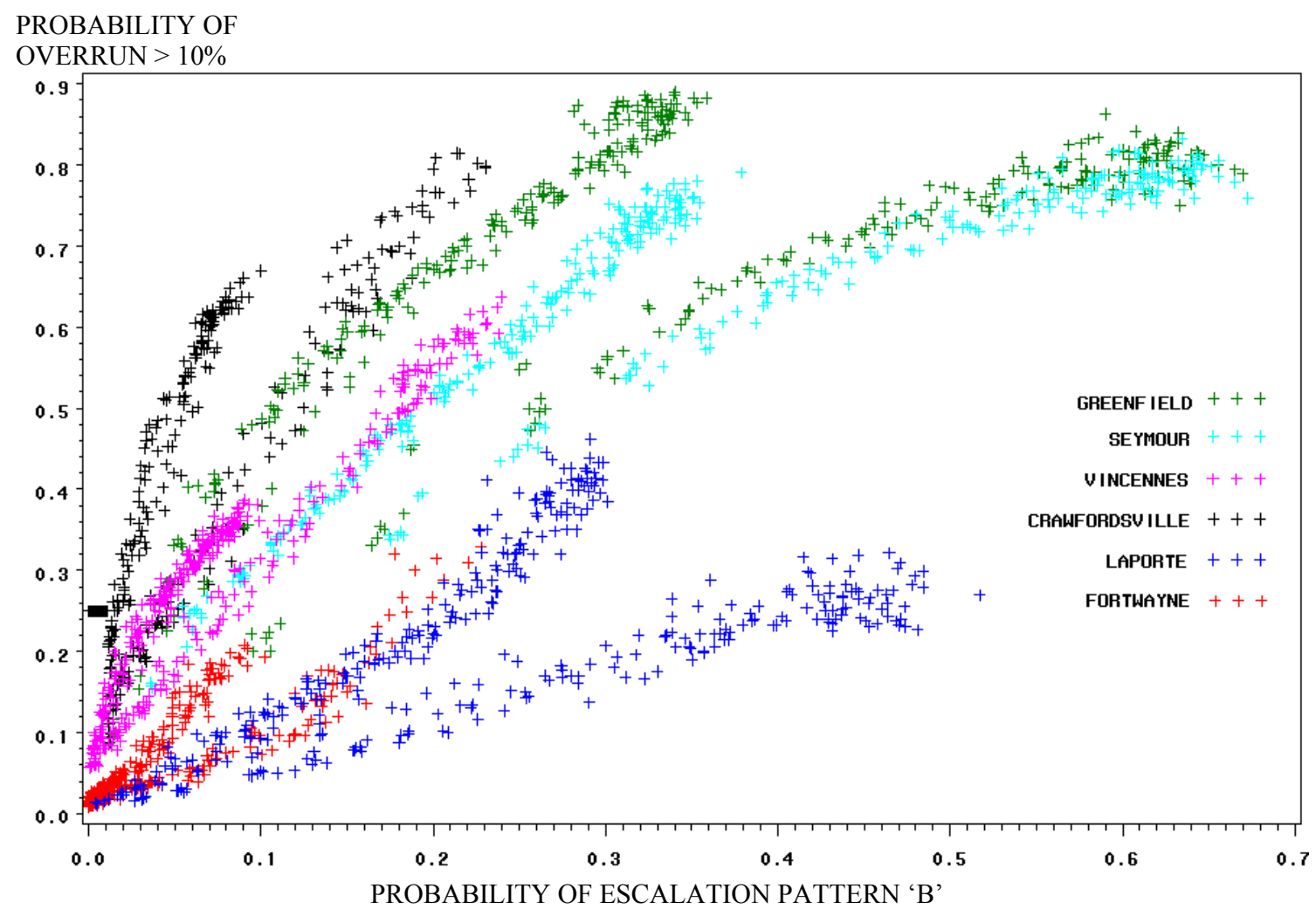

Figure 6.9: Impact of Escalation Pattern 'B' on the Probability of Planning Stage Cost Overrun $>10 \%$ (Expansion Contracts)

On the basis of the escalation patterns presented in Section 6.3.1, it was found that expansion contracts in the Seymour and Greenfield districts are more likely to exhibit pattern 'B' compared to contracts in other districts. Figure 6.9 shows that contracts in Seymour and Greenfield districts are more 
likely to have a cost overrun exceeding $10 \%$ compared to those in other districts. This finding seems to be supported by the expectation that expansion contracts in comparatively urban districts are more likely to have higher cost overruns due to a higher risk of experiencing unforeseen factors during construction.

Expansion contracts more likely to exhibit pattern ' $\mathrm{A}$ ' were found more likely to have a negative cost overrun of less than $-10 \%$. Contracts exhibiting pattern ' $A$ ' are expected to be those that are likely to experience more competition and a lower risk of unforeseen cost factors during project development. This explains the propensity of contracts exhibiting pattern ' $\mathrm{A}$ ' to have negative cost overrun. Figure 6.10 shows the tendency of contracts in each district to experience negative cost overrun because of their propensity to exhibit pattern 'A'. The contracts in the relatively urban districts of Seymour and Greenfield were found less likely to have negative cost overrun compared to contracts in urban districts. This is because contracts in these districts were found more likely to exhibit pattern 'B' and consequently are more likely to have a cost overrun exceeding $10 \%$.

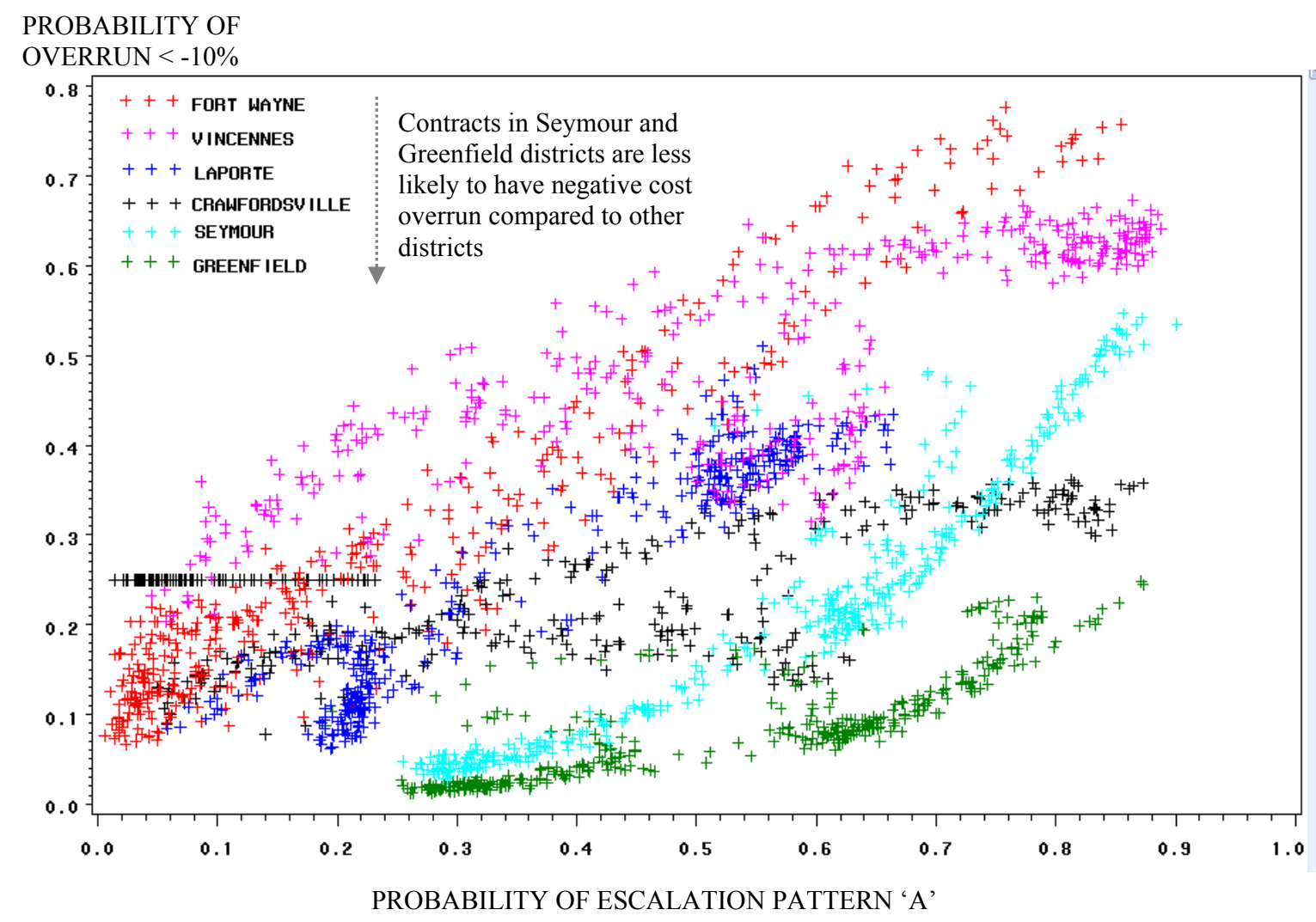

Figure 6.10: Impact of Escalation Pattern 'B' on the Probability of Planning Stage Cost Overrun $>10 \%$ (Expansion Contracts)

In addition to the probability of the escalation patterns ' $\mathrm{A}$ ' and ' $\mathrm{B}$ ', the variability in the probability of the escalation pattern ' $A$ ' was also found to be a significant factor that affects the probability 
of cost overrun. As the variability in the probability to exhibit pattern ' $A$ ' increases, the tendency to have a high cost overrun decreases. Expansion contracts, in general, were found more likely to exhibit pattern 'A' compared to other patterns (refer to Figure 6.1). As the variability increases, the upper limit of the 95\% confidence interval of the probability of pattern ' $\mathrm{A}$ ' increases and becomes closer to $100 \%$. As a result, an increase in the variability further increases the likelihood of a contract to exhibit pattern ' $A$ '. Therefore, the possibility of a scenario where a contract is more likely to experience competition during letting and less likely to experience unforeseen factors increases, thereby resulting in a negative cost overrun.

\subsubsection{Impact of Contract Size and Geographic Location (District)}

Contract size was found to have an impact on the probability of planning, design, and letting stage cost overrun. Large expansion contracts (greater than $\$ 10 \mathrm{M}$ ) were found more likely to experience high cost overrun (Figure 6.11). Large expansion contracts are more likely to experience scope changes, unforeseen and unplanned costs because of the large volume of construction activities involved and therefore tend to be more likely to have high overrun.

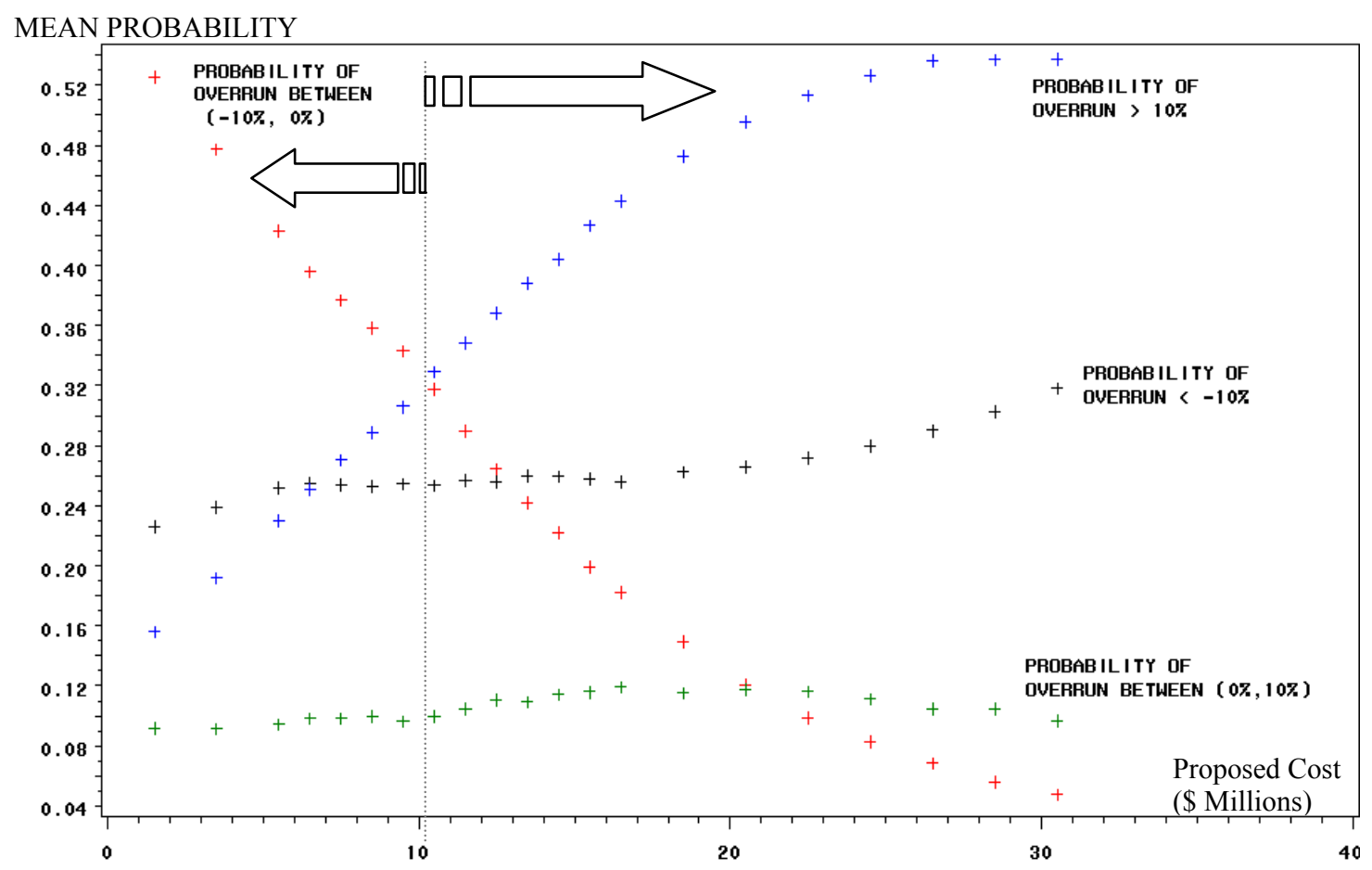

Figure 6.11: Comparison of Probability of Planning Stage Cost Overrun by Contract Size for

\section{Expansion Contracts}

An analysis of the large expansion contracts by district type indicates that large expansion contracts in the districts of Greenfield and Seymour are more likely to have cost overrun greater than $10 \%$. 
Figure 6.12 presents the tendency of large expansion contracts to have higher cost overruns compared to small expansion contracts in these districts. The difference in the propensities of large and small expansion contracts to have a high cost overrun was found to be comparatively small in the districts of Vincennes, Laporte, and Fort Wayne. Contracts in Seymour and Greenfield districts were found more likely to exhibit pattern 'B', which indicates that large expansion contracts in these districts are more likely to experience scope changes and unforeseen costs compared to the large contracts in other districts.

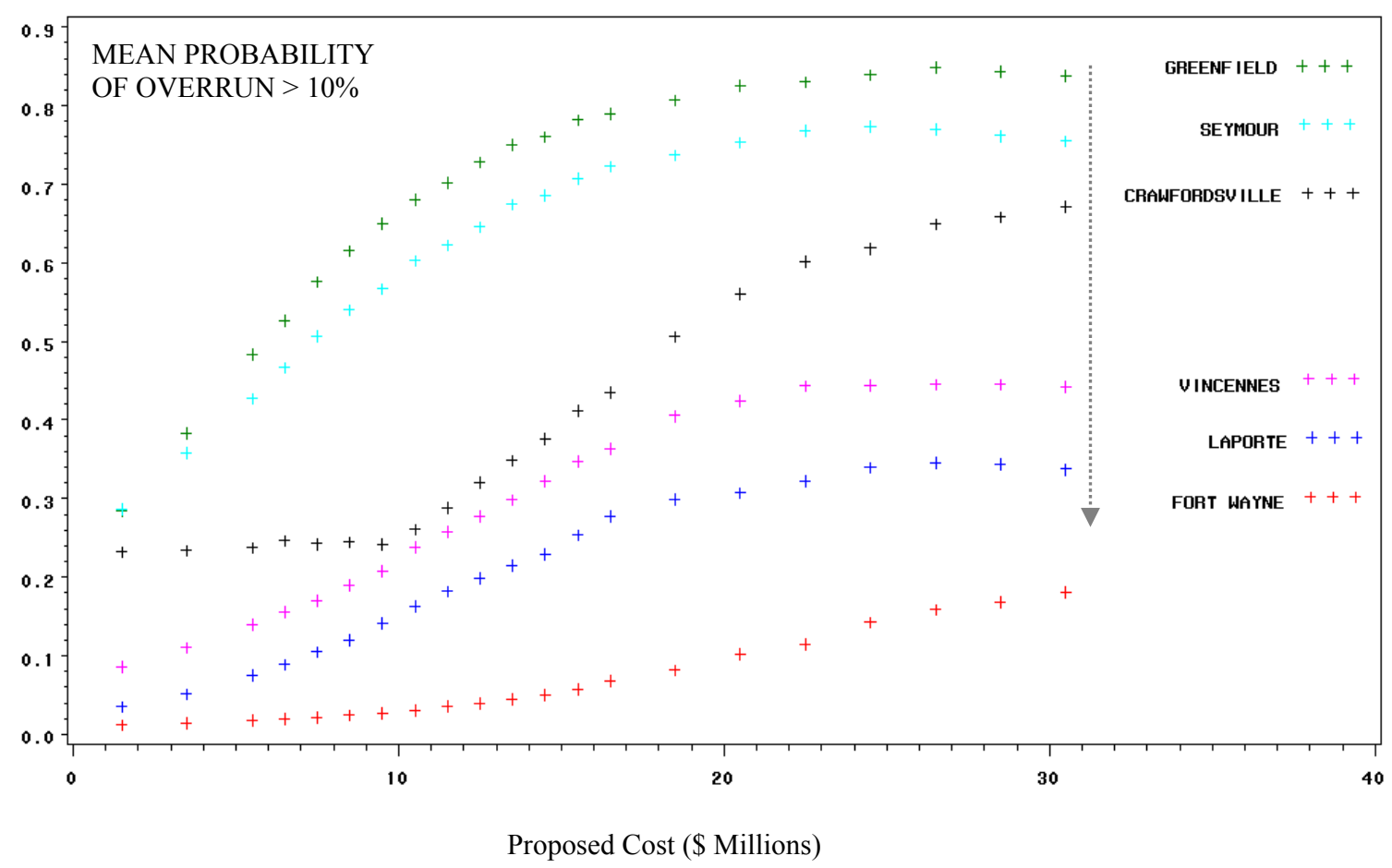

Figure 6.12: Comparison of Mean Probability of Planning Stage Cost Overrun Greater than $10 \%$ by Contract Size and Geographic Location (District)

The probability of large expansion contracts to experience a negative cost overrun of less than $-10 \%$ was found to be higher than the probability of overrun between $+/-10 \%$. In particular, large contracts in the districts of Fort Wayne and Vincennes were found more likely to experience a high negative cost overrun. Overall, across all districts, large expansion contracts were found more likely to experience cost overrun outside the ' $+/-10 \%$ cost overrun bracket'. Small expansion contracts (less than $\$ 10 \mathrm{M}$ ), on the other hand, were found more likely to have a negative planning stage cost overrun between $-10 \%$ and $0 \%$ (Figure 6.11), indicating that small expansion contracts are less likely to see unforeseen costs due to their size. 


\subsubsection{Impact of Area Type}

Urban and rural areas in Indiana were compared to determine whether the tendency of contracts in Seymour and Greenfield districts to have high cost overrun was due to comparatively more urbanization of these districts. The expansion contracts in urban and rural areas were not found to be significantly different from each other in their propensity to experience higher cost overruns $(>10 \%)$. Therefore, it was concluded other factors are responsible for the tendency of contracts in more urbanized districts to experience a high cost overrun.

\subsubsection{Impact of NHS Status}

Expansion contracts on higher levels of NHS status were found more likely to have a negative planning stage cost overrun of less than $-10 \%$. Figures 6.13 and 6.14 present a comparison of the mean probability of planning stage cost overrun across contracts of various sizes at Interstates, Non-Interstate NHS, and NonNHS highways. Contracts at Non-NHS highways were found less likely to have a negative cost overrun of less than $-10 \%$ and more likely to experience a positive cost overrun of greater than $10 \%$. Contracts at NonNHS highways were also found more likely to experience a design and letting stage cost overrun of greater than $10 \%$.

The expansion contracts at NHS highways were found less likely to experience pattern 'B' (refer to Figure 6.8) compared to Non-NHS highways, indicating that NHS highways are less likely to experience unforeseen costs. Expansion contracts at Non-NHS highways, such as urban and rural arterials, are more likely to experience underground utilities and other urban-related construction problems compared to those at Interstates, and therefore the unforeseen costs were less likely for Non-NHS highways.

\subsubsection{Impact of Contract Classification (Standalone vs. Kin Contract)}

The kin contracts were found more likely to have a letting stage cost overrun between 5\%-10\%. The estimates of cost prepared at the letting stage for kin contracts possibly do not take into account the additional costs due to lack of coordination in the construction of all the projects in the kin. Due to the low bidding at the letting stage, the impact of not considering these costs is further exacerbated. 


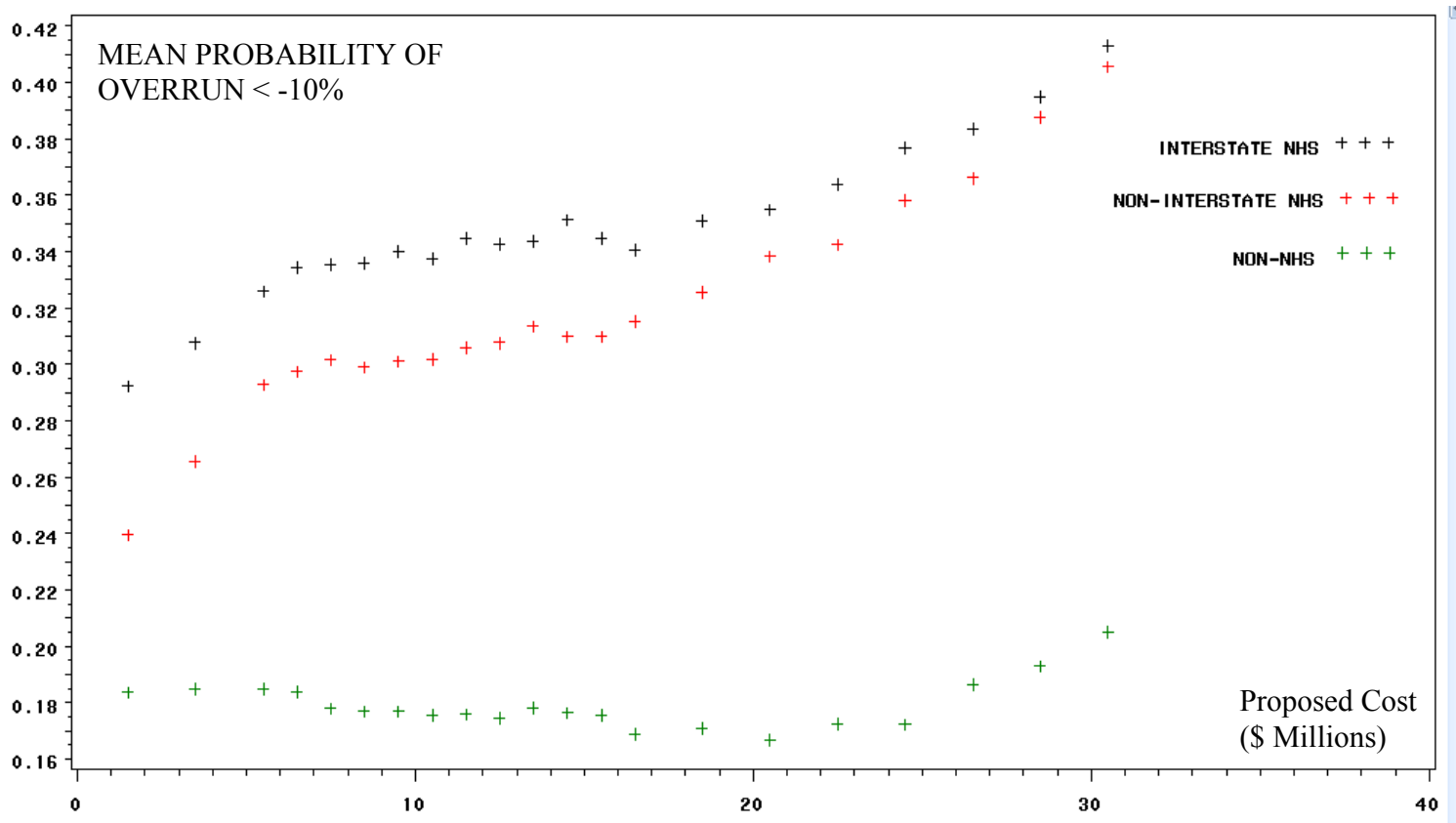

Figure 6.13: Mean Probability of Planning Stage Cost Underrun by NHS Status and Contract Size

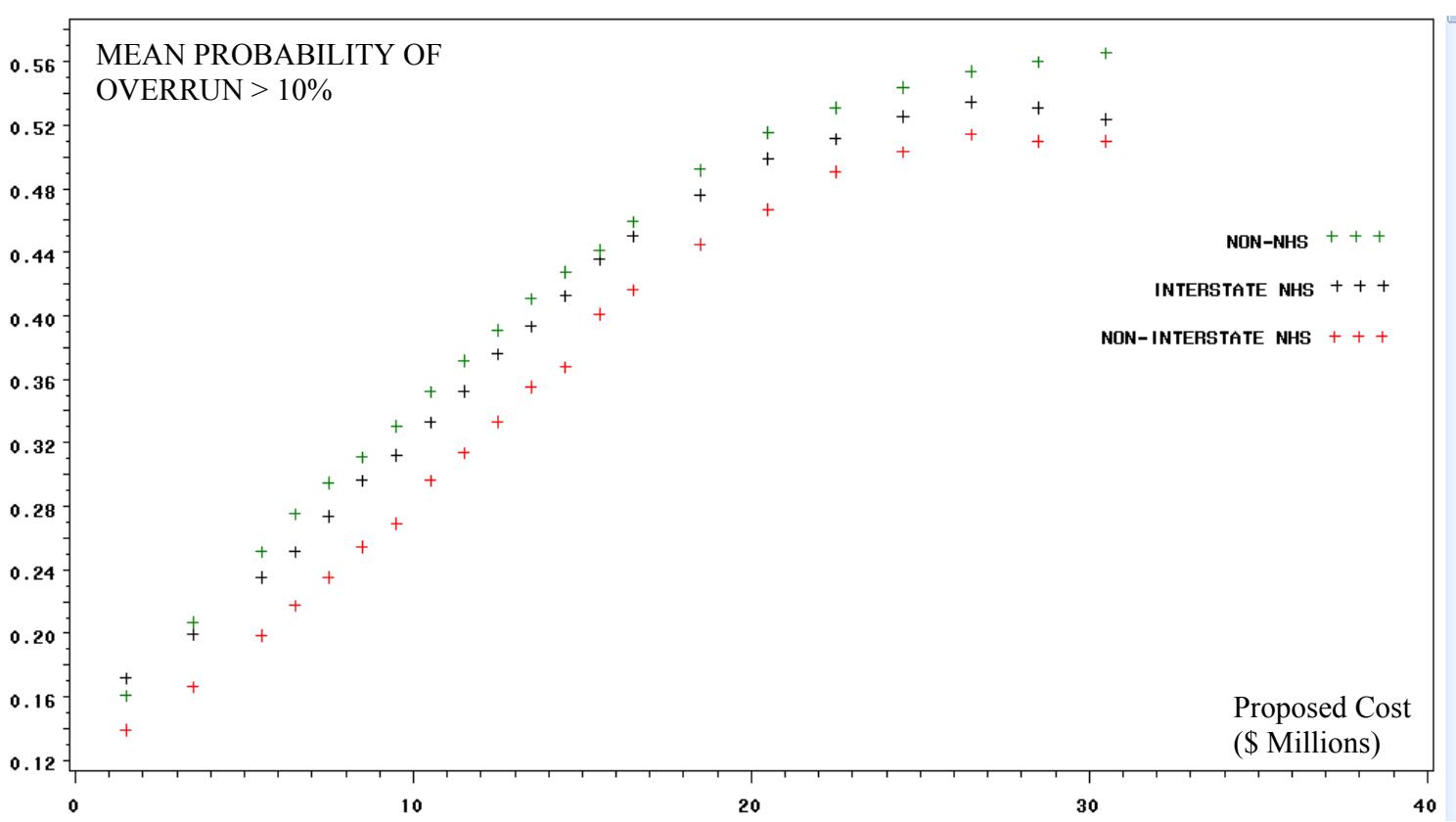

Figure 6.14: Mean Probability of Planning Stage Cost Overrun by NHS Status and Contract Size 


\subsubsection{Impact of Changes in Cost Estimates}

At any stage of the project development cycle, the change in the cost estimate from a previous stage was found to significantly influence the probability of cost overrun at that stage. It was found that as the percentage difference between design and proposed cost increases, the probability of a design stage cost overrun of greater than $10 \%$ decreases. An increase in the percentage difference between the design estimate and the proposed cost suggests that scope changes were made to the project or unforeseen costs were identified as more and more information became available about the construction process and related activities. In either scenario, an updated design cost enhances understanding of the effect of construction activities (compared to a scenario when design cost was not updated). Therefore, cost increases from the proposed stage to the design stage tend to make the design estimate more accurate.

The percentage difference between design cost and proposed cost was also found to be a significant factor in determining the probability of a letting stage cost overrun; a higher percentage difference between design and proposed cost tends to increase the probability of experiencing a letting stage cost overrun of greater than $10 \%$. An increase in the design estimate compared to proposed cost due to scope changes tends to make the contract bigger in size, and large contracts tend to have high cost overrun due to increased complexity and susceptibility to unforeseen factors. On the other hand, design estimates could also be higher than the proposed cost estimates, because unforeseen factors at the planning stage were identified during the design stage. It is possible that some of such factors were not identified by the contractors at the letting stage given the short time span within which they had to prepare the bids. As a result, the probability of a letting stage cost overrun increased.

An increase in the percentage difference between letting cost and proposed cost tends to increase the probability of experiencing a negative letting stage cost overrun. If letting cost was less than the proposed cost, a contract was more likely to have an overrun. As the percentage difference between the letting cost and the proposed cost increases, the probability of having an over-estimated letting cost decreases. This is because as letting cost increases, final cost estimate tends to become more conservative.

\subsubsection{Impact of Time between Final Design Completion and Project Proposal}

Contracts with a long time span between design and project proposal were more likely to experience a positive design stage cost overrun and less likely to experience a negative design stage cost overrun. Also, the probability of a positive letting stage cost overrun was found to increase with an increase in the time span between final design completion and project proposal. A longer time span indicates that the contract 
was a large-scale project with more complex design process, or the project had scope changes during the design process. Large-scale expansion contracts are susceptible to a large number of unforeseen factors. Complex designs may experience constructability issues, therefore as the time span increases, the occurrence probability of design and letting stage cost overrun increases.

\subsubsection{Magnitude of Cost Overrun}

The magnitude of cost overrun was determined by using the concepts and principles of conditional probability. The probabilities of cost overrun less than $-10 \%$, between $-10 \%$ and $0 \%$, between $0 \%$ and $10 \%$, and greater than $10 \%$ (as computed in Section 6.3.2) were multiplied by the expected value of cost overrun for that particular cost overrun category. Table 6.6 presents the expected value of planning, design, and letting stage cost overrun by cost overrun category. Figure 6.15 presents the expected value of planning stage cost overrun by contract size and district. As discussed in Sections 6.3.1 and 6.3.2, large expansion contracts in Seymour and Greenfield districts are more likely to have higher cost overruns.

Table 6.6: Expected Value of Cost Overrun for Expansion Contracts by Cost Overrun Category

\begin{tabular}{|c|c|c|c|c|c|}
\hline \multirow{2}{*}{$\begin{array}{l}\text { Cost } \\
\text { Overrun } \\
\text { Type }\end{array}$} & \multicolumn{4}{|c|}{ Cost Overrun Category } & \multirow[b]{2}{*}{$\begin{array}{l}\text { Weighted } \\
\text { Average }\end{array}$} \\
\hline & Category 1 & Category 2 & Category 3 & Category 4 & \\
\hline $\begin{array}{l}\text { Planning } \\
\text { Stage }\end{array}$ & $\begin{array}{l}\text { Average: }-25 \% \\
\text { Contracts: } 16 \\
\text { C.I:[-33\%, - } \\
18 \% \text { ] } \\
\end{array}$ & $\begin{array}{l}\text { Average: }-1.71 \% \\
\text { Contracts: } 19 \\
\text { C.I: }[-2.8 \%,-0.6 \%]\end{array}$ & $\begin{array}{l}\text { Average: } 2.96 \% \\
\text { Contracts: } 22 \\
\text { C.I: }[1.7 \%, 4.3 \%]\end{array}$ & $\begin{array}{l}\text { Average: } 34 \% \\
\text { Contracts: } 16 \\
\text { C.I: }[17 \%, 50 \%]\end{array}$ & $\begin{array}{l}\text { Average: } 2.3 \% \\
\text { Contracts: } 73 \\
\text { C.I: }[-3.6 \%, 8.2 \%]\end{array}$ \\
\hline $\begin{array}{l}\text { Design } \\
\text { Stage }\end{array}$ & $\begin{array}{l}\text { Average: }-26 \% \\
\text { Contracts: } 15 \\
\text { C.I:[-35\%, - } \\
18 \%]\end{array}$ & $\begin{array}{l}\text { Average: }-2.1 \% \\
\text { Contracts: } 21 \\
\text { C.I: }[-3 \%,-1 \%]\end{array}$ & $\begin{array}{l}\text { Average: } 3.1 \% \\
\text { Contracts: } 22 \\
\text { C.I: }[1.7 \%, 4.6 \%]\end{array}$ & $\begin{array}{l}\text { Average: } 28 \% \\
\text { Contracts: } 15 \\
\text { C.I: }[18 \%, 38 \%]\end{array}$ & $\begin{array}{l}\text { Average: } 0.7 \% \\
\text { Contracts: } 73 \\
\text { C.I:[-4\%,5.5\%] }\end{array}$ \\
\hline $\begin{array}{l}\text { Letting } \\
\text { Stage }\end{array}$ & $\begin{array}{l}\text { Average: }-10 \% \\
\text { Contracts: } 1\end{array}$ & $\begin{array}{l}\text { Average: }-2.8 \% \\
\text { Contracts: } 9 \\
\text { C.I: }[-4.8 \%, 0.8 \%]\end{array}$ & $\begin{array}{l}\text { Average: } 3.2 \% \\
\text { Contracts: } 42 \\
\text { C.I: }[2.2 \%, 4.1 \%]\end{array}$ & $\begin{array}{l}\text { Average: } 26 \% \\
\text { Contracts: } 21 \\
\text { C.I: }[17 \%, 35 \%]\end{array}$ & $\begin{array}{l}\text { Average: } 8.8 \% \\
\text { Contracts: } 73 \\
\text { C.I:[5.2\%,12.5\%] }\end{array}$ \\
\hline
\end{tabular}




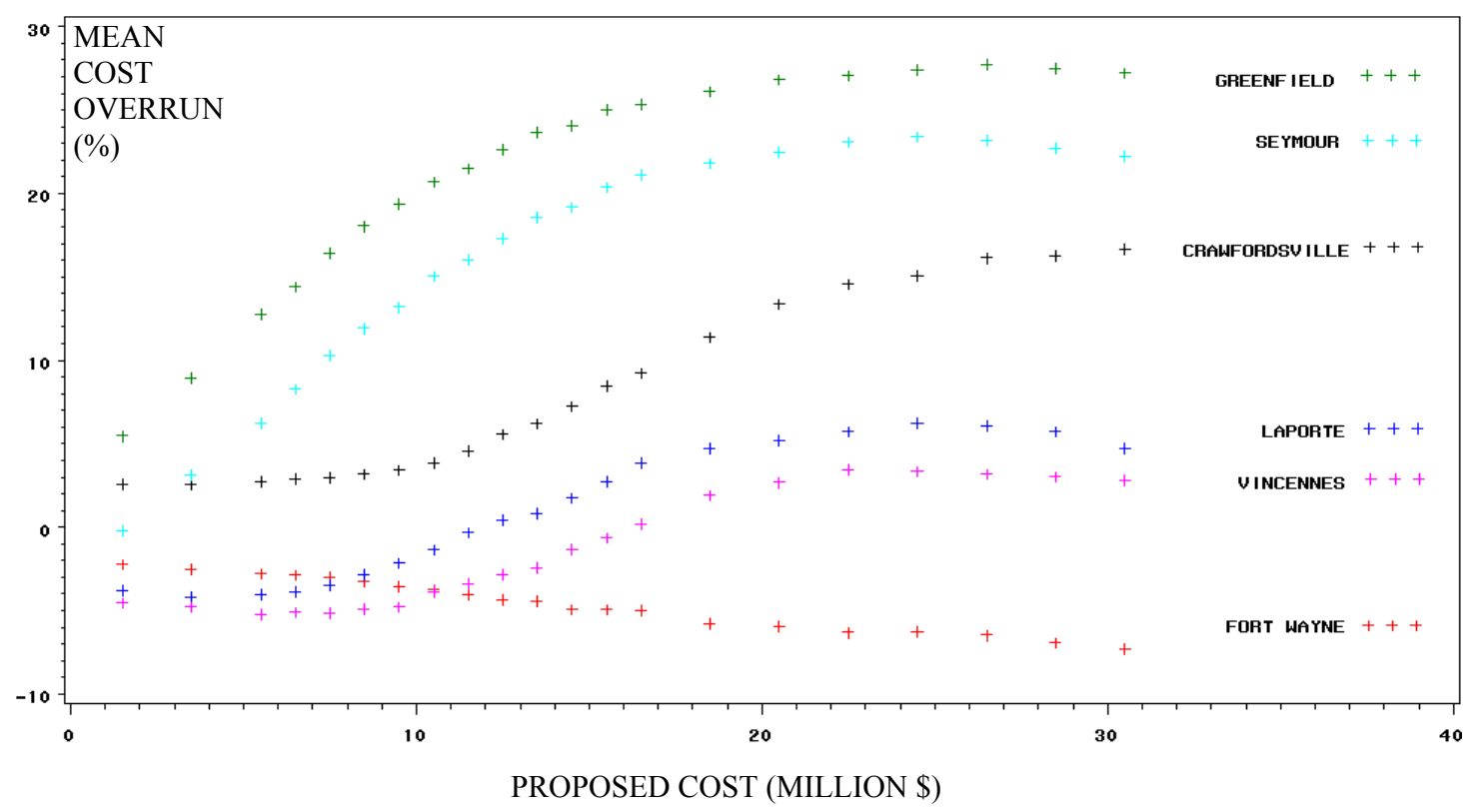

Figure 6.15: Mean Planning Stage Cost Overrun Across Expansion Contracts by Size and District

\subsection{Econometric Models for Bridge Contracts}

Models were developed for bridge contracts that involved rehabilitation, replacement, or removal work on bridges. Bridges deteriorate over time and can become either structurally or functionally deficient. Extensive information and knowledge is generally available about the nature of construction activities, costs involved, and cost estimation practices due to the periodic nature of work on bridges. Therefore, the extent of uncertainty associated with cost estimation for bridge contracts is generally lower than that for expansion contracts.

\subsubsection{Probability of Escalation Patterns}

A total of 107 bridge contracts of sizes ranging from $\$ 1-\$ 30 \mathrm{M}$ were analyzed to develop multinomial logit models (Table 6.7) to estimate the probability of occurrence of each escalation pattern. Contract-specific factors such as geographic location (district and area type), contract size (based on initial proposed cost), and highway functional class were found to significantly affect the probability of the escalation patterns. The model had a McFadden R-squared value of 0.47 , indicating that the model explains $47 \%$ of the randomness associated with the tendency of the cost estimates to exhibit a particular escalation pattern. The model can be used for determining the escalation pattern of the cost estimates associated with bridge project development cycle in Indiana. The methodology used for the model development is described in Chapter 4. This can be used for developing similar models by highway agencies in other regions. 
Table 6.7: Multinomial Logit Model for Determining Probability of Escalation Pattern for Bridge Contracts

\begin{tabular}{|c|l|c|c|c|c|}
\hline \multirow{2}{*}{ PATTERN } & \multicolumn{1}{|c|}{ Contract Specific Factor } & Coeff. & Std.Err. & T-ratio & p-value \\
\hline \multirow{4}{*}{ PATTERN A } & Constant & 5.1362 & 1.3012 & 3.95 & 0.00 \\
\cline { 2 - 6 } & Urban Area & 1.1453 & 0.5292 & 2.16 & 0.03 \\
\cline { 2 - 6 } & Greenfield District & 3.3570 & 1.5535 & 2.16 & 0.03 \\
\hline \multirow{3}{*}{ PATTERN B } & Constant & 4.7146 & 1.3301 & 3.54 & 0.00 \\
\cline { 2 - 6 } & Non-NHS Highways & -1.4383 & 0.6474 & -2.22 & 0.03 \\
\hline \multirow{5}{*}{ PATTERN C } & Laporte District & 7.8440 & 1.8862 & 4.16 & 0.00 \\
\cline { 2 - 6 } & Seymour and Vincennes in South & 6.3447 & 1.7207 & 3.69 & 0.00 \\
\cline { 2 - 6 } & Proposed Cost (\$ Millions) & -1.2470 & 0.7028 & -1.77 & 0.08 \\
\cline { 2 - 6 } & Arterial Roads (Urban / Rural) & -1.4241 & 0.7205 & -1.98 & 0.05 \\
\hline \multirow{3}{*}{ PATTERN D } & Crawfordsville and Greenfield in Central & 3.1901 & 1.3591 & 2.35 & 0.02 \\
\cline { 2 - 6 } & U.S. Highways & 2.4029 & 0.9538 & 2.52 & 0.01 \\
\cline { 2 - 6 } & Minor Arterial Roads & -4.3282 & 1.7378 & -2.49 & 0.01 \\
\cline { 2 - 6 } & Non-NHS Roads & 3.1161 & 1.2252 & 2.54 & 0.01 \\
\hline
\end{tabular}

Log-Likelihood (Model): -79.36; Log-Likelihood (No Coefficients): -148.34; Log-Likelihood (Constant): -111.03

Number of Observations: 107

\subsubsection{Impact of Contract Size}

Bridge contracts were found to be more likely to exhibit pattern ' $A$ ' compared to other patterns. The tendency of bridge contracts to exhibit pattern ' $\mathrm{A}$ ' was found to be higher than the propensity of expansion contracts to exhibit pattern 'A' (refer to Figure 6.1). Also, the tendency of bridge contracts to exhibit a pattern was not found to change significantly with increases in proposed cost or contract size (Figure 6.16).

MEAN PROBABILITY OF

ESCALATION PATTERN 


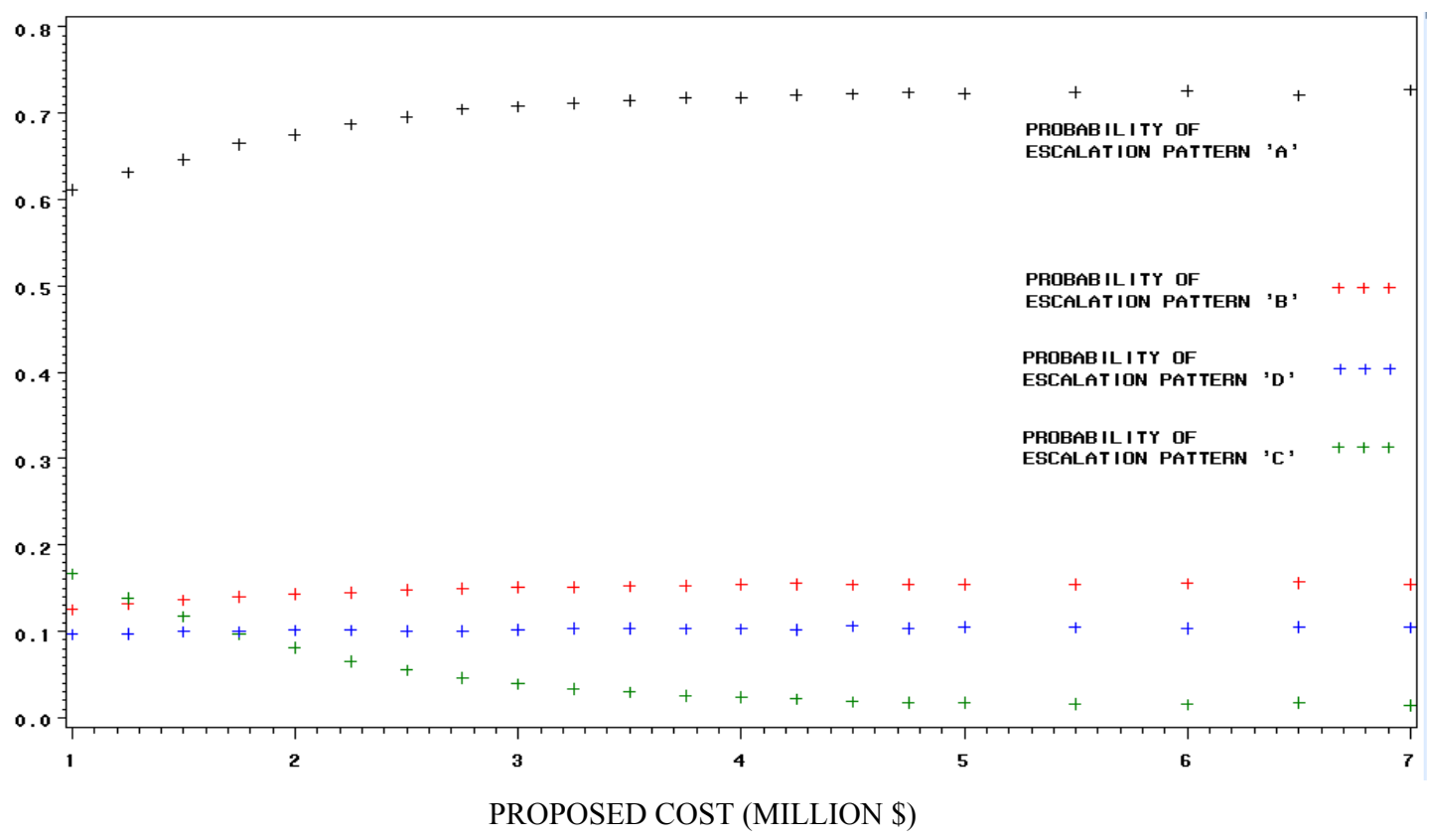

Figure 6.16: Comparison of Probability of Escalation Patterns by Contract Size for Bridge Contracts

The propensity of bridge contracts to exhibit pattern ' $A$ ' indicates that most of the bridge contracts are straightforward construction activities with standard construction practice and cost estimation process. The low tendency of bridge contracts to exhibit pattern ' $\mathrm{B}$ ' indicates that bridge contracts were less likely to experience unforeseen costs and changes in large changes in cost estimates.

\subsubsection{Impact of Contract Size and Geographic Location (District)}

A detailed analysis of the tendency of bridge contracts of various sizes to exhibit pattern 'A' was conducted by geographic location (district). The objective was to determine if the tendency of bridge contracts to exhibit pattern 'A' was prevalent in each of the six districts irrespective of the contract size. The results of the trends, seen in all the districts, are shown in Figure 6.17. Small bridge contracts (less than \$3M) in Laporte district were found to be less likely to exhibit pattern 'A' compared to large contracts in this district. Also small contracts (less than $\$ 3 \mathrm{M}$ ) in Seymour and Vincennes districts were found to be marginally less likely to exhibit pattern 'A' compared to large contracts in these districts. Across all the other districts, the propensity to exhibit pattern ' $A$ ' did not change with increasing contract sizes. Contracts in Greenfield district were found more likely to exhibit pattern ' $A$ ' and least likely to exhibit pattern 'B' compared to contracts in other districts. 


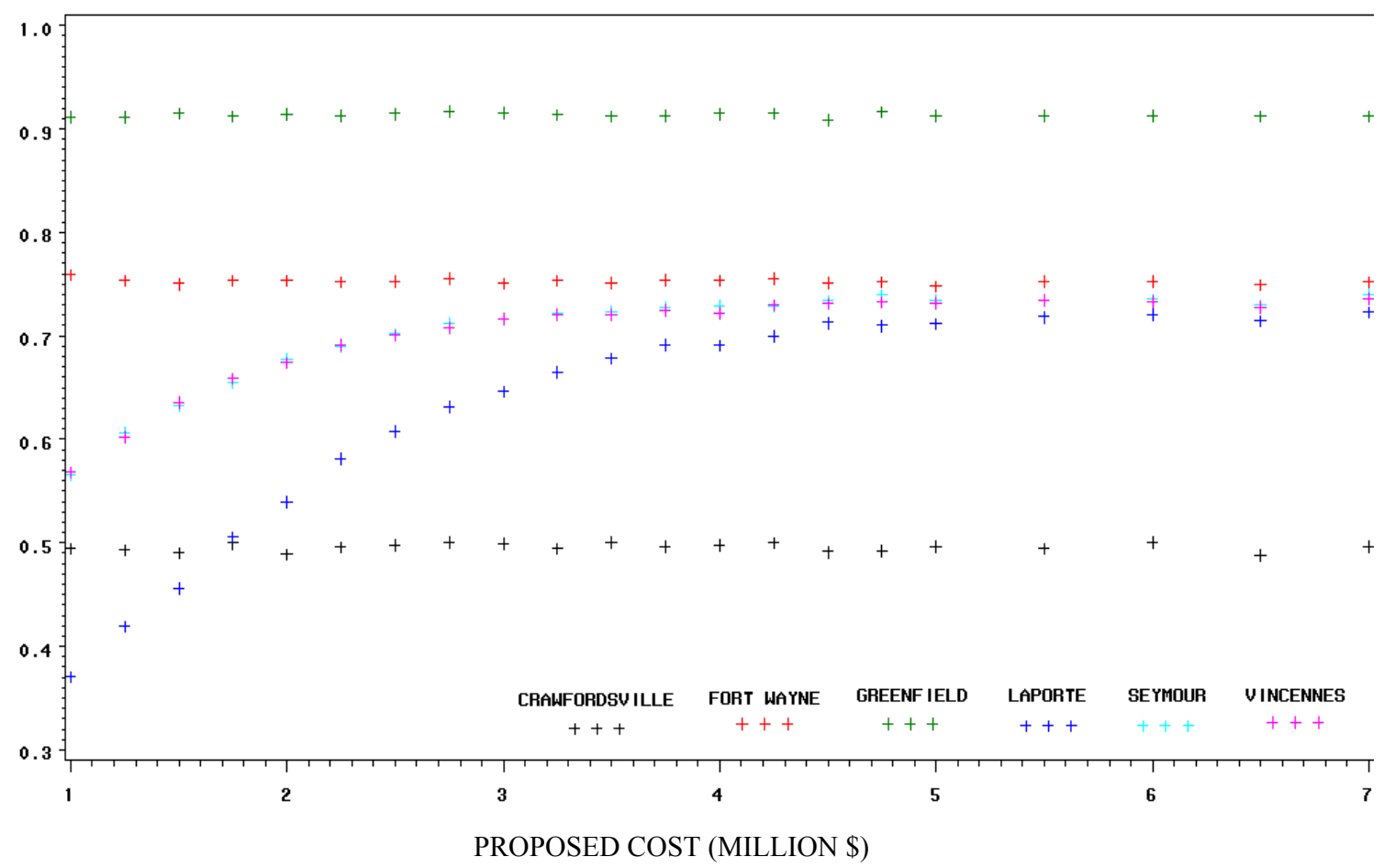

Figure 6.17: Comparison of Probability of Escalation Pattern 'A' Across Districts (Bridge Contracts)

\subsubsection{Impact of NHS Status}

An analysis of probability of escalation pattern by NHS status indicated that bridge contracts on Interstates were more likely to exhibit pattern 'B', followed by the contracts on Non-Interstate NHS and Non-NHS highways (Figure 6.18). The tendency of Interstate bridge contracts to exhibit pattern ' $\mathrm{B}$ ' indicates that such contracts are more likely to experience unforeseen costs compared to contracts on comparatively lower levels of NHS status. The probability of Non-NHS highway contracts to exhibit pattern 'B' was found to be very low. The bridges on Interstates are generally high profile as they are designed to carry more traffic as compared to bridges on Non-NHS highways. The structural and functional efficiency that is required for these bridges, makes the construction activities on these bridges more susceptible to scope changes and unforeseen costs. As a result, they become more likely to exhibit pattern 'B' compared to other NHS status level. However, most of the contracts on each of these NHS status levels were more likely to exhibit pattern 'A' as compared to pattern 'B'. The propensity to exhibit pattern 'A' was not found to be significantly different across these NHS status levels.

MEAN PROBABILITY OF ESCALATION PATTERN 'B' 


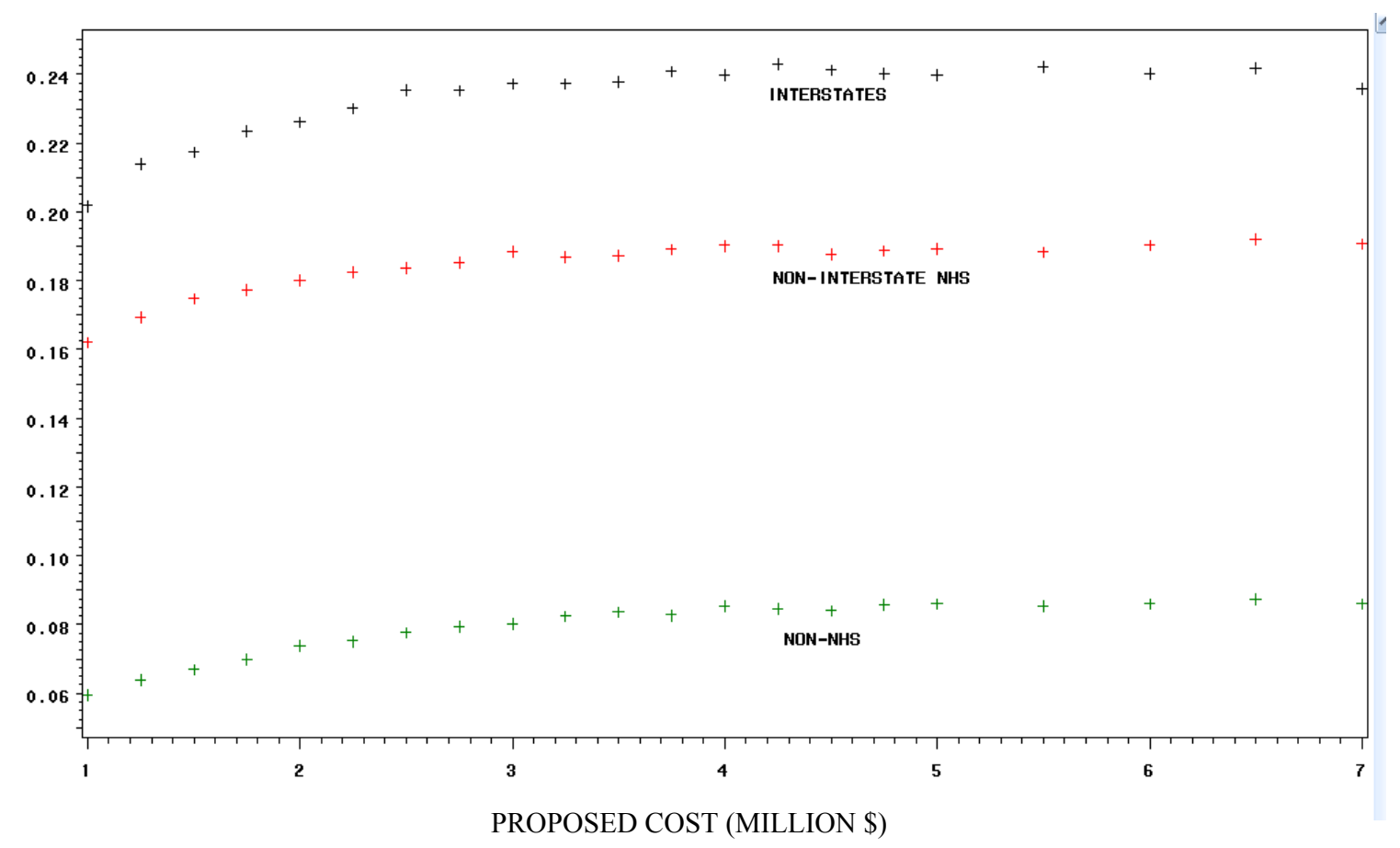

Figure 6.18: Comparison of Tendency to Exhibit Pattern 'B' Across Levels of NHS Status by Contract Size (Bridge Contracts)

\subsubsection{Probability of Cost Overrun Occurrence}

The models presented in Tables 6.8-6.10 were developed for bridge contracts to estimate the occurrence probability of planning, design, and letting stage cost overruns, respectively. Contract-specific factors such as size, geographic location, highway functional class, and the tendency of a contract to exhibit an escalation pattern were found to have an impact on the probability of planning, design, and letting stage cost overrun. Factors such as the time duration between final design completion and project proposal and the percentage difference between the design estimate and proposed cost were found to affect the probability of design stage cost overrun. These factors are not available at the planning stage and therefore were not included in the model for determining planning stage cost overrun. Because of inclusion of additional factors, the McFadden R-squared value of the design stage cost overrun model ( 0.33$)$ was higher than that of the planning stage cost overrun model $(0.26)$. The occurrence probability of letting stage cost overrun was found to be affected by additional factors (compared to planning and design stage cost overrun) as more information about contract-specific factors becomes available at the letting stage. These include: contract classification as stand-alone or kin, percentage difference between proposed, design and letting estimates, and the time between final design completion and project proposal. The propensity of a contract to exhibit an escalation pattern was also found to affect the probability of letting stage cost 
overrun. Table 6.10 presents the multinomial logit model for determining the probability of letting stage cost overrun.

Table 6.8: Multinomial Logit Model for Determining the Probability of Planning Stage Cost Overrun for Bridge Contracts

\begin{tabular}{|c|l|c|c|c|c|}
\hline $\begin{array}{c}\text { Cost Overrun } \\
\text { Category }\end{array}$ & \multicolumn{1}{|c|}{ Contract Specific Factor } & Coeff. & Std.Err. & t-ratio & p-Value \\
\hline \multirow{2}{*}{$\begin{array}{c}\text { Category } 1 \\
<-10 \%\end{array}$} & Laporte District & 1.1568 & 0.5686 & 2.03 & 0.04 \\
\cline { 2 - 6 } & Probability of Escalation Pattern 'B' & -4.6787 & 2.7052 & -1.73 & 0.08 \\
\cline { 2 - 6 } & Urban Area & -0.8711 & 0.5446 & -1.62 & 0.10 \\
\hline \multirow{2}{*}{$\begin{array}{c}\text { Category 2 } \\
{[-10 \%, 0 \%)}\end{array}$} & $\begin{array}{l}\text { Variability in Probability of Escalation } \\
\text { Pattern 'A' (Measured using Std. Dev) }\end{array}$ & 9.9976 & 4.3059 & 2.32 & 0.02 \\
\cline { 2 - 7 } & Proposed Cost (in Million \$) & -0.4943 & 0.2417 & -2.05 & 0.04 \\
\hline \multirow{2}{*}{$\begin{array}{c}\text { Category 3 } \\
{[0 \%, 10 \%]}\end{array}$} & Probability of Escalation Pattern 'B' & 2.7521 & 1.6862 & 1.63 & 0.10 \\
\cline { 2 - 6 } & Urban and Rural Collectors & 0.8772 & 0.5538 & 1.64 & 0.10 \\
\hline \multirow{2}{*}{$\begin{array}{c}\text { Category 4 } \\
>10 \%\end{array}$} & Urban Interstate, Freeway or Expressway & 2.7013 & 0.9055 & 2.98 & 0.00 \\
\cline { 2 - 6 } & Rural Arterial & 1.5655 & 0.6680 & 2.34 & 0.02 \\
\cline { 2 - 6 } & Probability of Escalation Pattern 'A' & -3.1036 & 1.0760 & -2.88 & 0.00 \\
\hline
\end{tabular}

Log-Likelihood (Model): -123.79; Log-Likelihood (No Coefficients): -148.34; Log-Likelihood (Constant): -138.51 Number of Observations: 107

Table 6.9: Multinomial Logit Model for Determining the Probability of Design Stage Cost Overrun for Bridge Contracts

\begin{tabular}{|c|l|c|c|c|c|}
\hline $\begin{array}{c}\text { Overrun } \\
\text { Category }\end{array}$ & \multicolumn{1}{|c|}{ Contract Specific Factor } & Coeff. & Std.Err. & t-ratio & P-Value \\
\hline Category 1 & $\begin{array}{l}\text { Percentage Difference Between } \\
\text { Design and Proposed Cost }\end{array}$ & 0.0468 & 0.0173 & 2.71 & 0.01 \\
\hline
\end{tabular}




\begin{tabular}{|c|c|c|c|c|c|}
\hline \multirow[t]{2}{*}{$<-10 \%$} & Kin Contract & 1.2948 & 0.5296 & 2.44 & 0.01 \\
\hline & Interstate & -1.2162 & 0.6709 & -1.81 & 0.07 \\
\hline \multirow{3}{*}{$\begin{array}{l}\text { Category } 2 \\
{[-10 \%, 0 \%)}\end{array}$} & $\begin{array}{l}\text { Variability in Probability of } \\
\text { Escalation Pattern 'A' (Measured } \\
\text { using Std. Dev) }\end{array}$ & 18.7070 & 5.2980 & 3.53 & 0.00 \\
\hline & Proposed Cost (in Million \$) & -0.3806 & 0.2141 & -1.78 & 0.08 \\
\hline & Urban and Rural Arterials & -1.1250 & 0.5208 & -2.16 & 0.03 \\
\hline \multirow{3}{*}{$\begin{array}{l}\text { Category } 3 \\
{[0 \%, 10 \%]}\end{array}$} & $\begin{array}{l}\text { Probability of Escalation Pattern 'B' } \\
\text { / Variability in Probability of } \\
\text { Escalation Pattern 'B' }\end{array}$ & 0.4543 & 0.1303 & 3.49 & 0.00 \\
\hline & Urban and Rural Collectors & 1.7873 & 0.6670 & 2.68 & 0.01 \\
\hline & Vincennes District & -1.4932 & 0.6940 & -2.15 & 0.03 \\
\hline \multirow[t]{2}{*}{ Category 4} & Probability of Escalation Pattern 'A' & -1.8551 & 0.9336 & -1.99 & 0.05 \\
\hline & $\begin{array}{l}\text { Square of Time Between Design } \\
\text { and Project Proposal (years) }\end{array}$ & 0.0054 & 0.0036 & 1.50 & 0.13 \\
\hline
\end{tabular}

* Log-Likelihood (Model): -110.96; Log-Likelihood (No Coefficients): -142.78; Log-Likelihood (Constant): -129.84

Table 6.10: Multinomial Logit Model for Determining the Probability of Letting Stage Cost Overrun for Bridge Contracts

\begin{tabular}{|c|c|c|c|c|c|}
\hline $\begin{array}{l}\text { Cost Overrun } \\
\text { Category }\end{array}$ & Contract Specific Factor & Coeff. & Std.Err. & t-ratio & P-Value \\
\hline \multirow{3}{*}{$\begin{array}{c}\text { Category } 1 \\
\quad<0 \%\end{array}$} & $\begin{array}{l}\text { Percentage Difference Between Letting } \\
\text { and Proposed Cost }\end{array}$ & 0.0462 & 0.0279 & 1.66 & 0.10 \\
\hline & Laporte District & 1.3975 & 0.6071 & 2.30 & 0.02 \\
\hline & Urban / Rural Arterials & -1.0191 & 0.6395 & -1.59 & 0.11 \\
\hline \multirow{2}{*}{$\begin{array}{c}\text { Category } 2 \\
{[0 \%, 5 \%)}\end{array}$} & Proposed Cost (\$ Millions) & 0.4420 & 0.2141 & 2.06 & 0.04 \\
\hline & $\begin{array}{l}\text { Variability in Probability of Escalation } \\
\text { Pattern 'B' (Measured using Std. Dev) }\end{array}$ & 14.9898 & 7.4202 & 2.02 & 0.04 \\
\hline \multirow{4}{*}{$\begin{array}{l}\text { Category } 3 \\
(5 \%, 10 \%]\end{array}$} & $\begin{array}{l}\text { Percentage Difference Between Design } \\
\text { and Proposed Cost }\end{array}$ & 0.0569 & 0.0201 & 2.83 & 0.00 \\
\hline & Probability of Escalation Pattern 'C' & -4.1314 & 2.4138 & -1.71 & 0.09 \\
\hline & Probability of Escalation Pattern 'B' & 5.9627 & 1.9455 & 3.06 & 0.00 \\
\hline & Kin Contracts & -2.1932 & 1.1544 & -1.90 & 0.06 \\
\hline \multirow[t]{3}{*}{ Category 4} & Crawfordsville District & 1.2388 & 0.6714 & 1.85 & 0.07 \\
\hline & Urban and Rural Interstates & 1.1354 & 0.6530 & 1.74 & 0.08 \\
\hline & Square of Proposed Cost (\$ Millions) & 0.0642 & 0.0376 & 1.71 & 0.09 \\
\hline
\end{tabular}

* Log-Likelihood (Model): -105.19; Log-Likelihood (No Coefficients): -148.34; Log-Likelihood (Constant): -145.3

Factors that were found to affect the probability of planning, design, and letting stage cost overrun were compared to study the similarity of their impact on the probability of the cost overrun. Contract size, geographic location, highway functional class, NHS status, and probability of escalation pattern were found to affect the probability of cost overrun at all stages. Table 6.11 presents a comparison of the coefficients of the factors. For the factors found to influence the probability of cost overrun at all stages, the sign of their 
coefficients was the same across the models, indicating that the impact of the factors on the probability of cost overrun was not different.

\subsubsection{Impact of Escalation Pattern by Geographic Location (District)}

The tendency to exhibit escalation patterns ' $\mathrm{A}$ ', ' $\mathrm{B}$ ', and ' $\mathrm{C}$ ' was found to have an impact on the probability of planning, letting, and design stage cost overrun. It was found that bridge contracts that are more likely to exhibit pattern 'A' were more likely to experience negative cost overrun and, consequently, less likely to experience a cost overrun of greater than $10 \%$. On the other hand, contracts that were more likely to exhibit pattern ' $\mathrm{B}$ ' were found to be more likely to have planning, design and letting stage cost overruns. As the tendency to exhibit pattern ' $\mathrm{B}$ ' increased, the probability to experience planning stage cost overrun between $0 \%$ and $10 \%$ and letting stage cost overrun between $5 \%$ and $10 \%$ increased. Consequently, the probability of a negative cost overrun decreased. Bridge contracts that were more likely to exhibit pattern 'B' were likely to be more susceptible to unforeseen factors, either due to unforeseen site conditions or due to scope changes, and therefore were more likely to have cost overrun. Contracts more likely to experience pattern ' $\mathrm{A}$ ' generally have low cost overrun as they: are straightforward construction activities that follow the routine planning process, experience competition at letting, and have efficient management during the development and construction stages so as to ensure that contracts are completed within the low letting cost.

In addition to patterns ' $\mathrm{A}$ ' and ' $\mathrm{B}$ ', pattern ' $\mathrm{C}$ ' was also found to have an impact on the probability of cost overrun for bridge contracts (unlike expansion contracts where only patterns 'A' and 'B' were found to affect the probability of cost overrun). The tendency to experience a high letting stage cost overrun was found to decrease with an increase in the probability of pattern ' $C$ '. Pattern ' $C$ ' represents a scenario where the risk of unforeseen costs exists during planning, development, and letting, but is not as high as for contracts exhibiting pattern 'B'. That is, unforeseen costs and factors resulting in design and scope changes were less likely to occur for contracts exhibiting pattern ' $\mathrm{C}$ '. As a result, the probability of cost overrun decreased with an increase in the likelihood of occurrence of pattern ' $\mathrm{C}$ '.

Table 6.11: Comparison of Coefficients of the Factors Affecting Probability of Planning, Design, and

Letting Stage Cost Overrun (Bridge Contracts)

\begin{tabular}{|c|l|c|c|c|c|}
\hline $\begin{array}{c}\text { Cost } \\
\text { Overrun }\end{array}$ & \multicolumn{1}{|c|}{ Contract Specific Factor } & Planning & Design & $\begin{array}{c}\text { Cost } \\
\text { Overrun }\end{array}$ & Letting \\
\hline Category 1 & Laporte District & 1.1568 & & Category 1 & 1.3974 \\
\hline
\end{tabular}




\begin{tabular}{|c|c|c|c|c|c|}
\hline \multirow{7}{*}{$<-10 \%$} & Probability of Escalation Pattern 'B' & -4.6787 & & \multirow{10}{*}{$<0 \%$} & \\
\hline & Urban Area & -0.8711 & & & \\
\hline & $\begin{array}{l}\text { Percentage Difference Between Design } \\
\text { and Proposed Cost }\end{array}$ & & 0.0468 & & \\
\hline & Kin Contract & & 1.2948 & & \\
\hline & Interstate Highway & & -1.2162 & & \\
\hline & $\begin{array}{l}\text { Percentage Difference Between Letting } \\
\text { and Proposed Cost }\end{array}$ & & & & 0.0461 \\
\hline & Urban / Rural Arterials & & & & -1.019 \\
\hline \multirow{3}{*}{$\begin{array}{l}\text { Category } 2 \\
{[-10 \%, 0 \%)}\end{array}$} & $\begin{array}{l}\text { Variability in Probability of Escalation } \\
\text { Pattern 'A' (Measured using Std. Dev) }\end{array}$ & 9.9976 & 18.707 & & \\
\hline & Proposed Cost (in Million \$) & -0.4943 & -0.3806 & & \\
\hline & Urban and Rural Arterials & & -1.125 & & \\
\hline \multirow{9}{*}{$\begin{array}{l}\text { Category } 3 \\
{[0 \%, 10 \%]}\end{array}$} & Urban and Rural Collectors & 0.8772 & 1.7873 & \multirow{5}{*}{$\begin{array}{l}\text { Category } 2 \\
{[0 \%, 5 \%]}\end{array}$} & \\
\hline & $\begin{array}{l}\text { Probability of Escalation Pattern 'B' / } \\
\text { Variability in Probability of Escalation } \\
\text { Pattern 'B' }\end{array}$ & & 0.4543 & & \\
\hline & Vincennes District & & -1.4932 & & \\
\hline & Proposed Cost (in Million \$) & & & & 0.442 \\
\hline & $\begin{array}{l}\text { Variability in Probability of Escalation } \\
\text { Pattern 'B' (Measured using Std. Dev) }\end{array}$ & & & & 14.9897 \\
\hline & $\begin{array}{l}\text { Percentage Difference Between Design } \\
\text { and Proposed Cost }\end{array}$ & & & \multirow{4}{*}{$\begin{array}{l}\text { Category } 3 \\
(5 \%, 10 \%]\end{array}$} & 0.05686 \\
\hline & Probability of Escalation Pattern 'C' & & & & -4.1314 \\
\hline & Probability of Escalation Pattern 'B' & 2.7521 & & & 5.9626 \\
\hline & Kin contracts & & & & \\
\hline \multirow{7}{*}{$\begin{array}{l}\text { Category } 4 \\
\quad>10 \%\end{array}$} & Urban Interstate, Freeway or Expressway & 2.7013 & & \multirow{7}{*}{$\begin{array}{l}\text { Category } 4 \\
\quad>10 \%\end{array}$} & \\
\hline & Rural Arterial & 1.5655 & & & \\
\hline & Probability of Escalation Pattern 'A' & -3.1036 & -1.8551 & & \\
\hline & $\begin{array}{l}\text { Square of Time Between Design and } \\
\text { Project Proposal (years) }\end{array}$ & & 0.0054 & & \\
\hline & Crawfordsville District & & & & 1.23875 \\
\hline & Square of Proposed Cost (\$ Millions) & & & & 0.06423 \\
\hline & Urban and Rural Interstates & & & & 1.1354 \\
\hline
\end{tabular}

In addition to the probability of the escalation patterns, the variability in the probability of an escalation pattern was also found to affect the probability of cost overrun. The variability in the probability of an escalation pattern indicates the variability across the contracts of a particular type to exhibit that escalation pattern. The contract-specific factors that are used to determine the probability of an escalation pattern define a contract type or a category of contracts. Several contracts can belong to this type and may 
experience variability in their tendency to exhibit an escalation pattern. A contract may be likely to exhibit pattern 'B' with $30 \%$ probability while another might have a $45 \%$ chance to exhibit pattern ' $\mathrm{B}$ '. It was found that as this variability in the propensity to exhibit pattern ' $\mathrm{B}$ ' increases for a particular contract type, the probability of cost overrun increases (Figure 6.19).

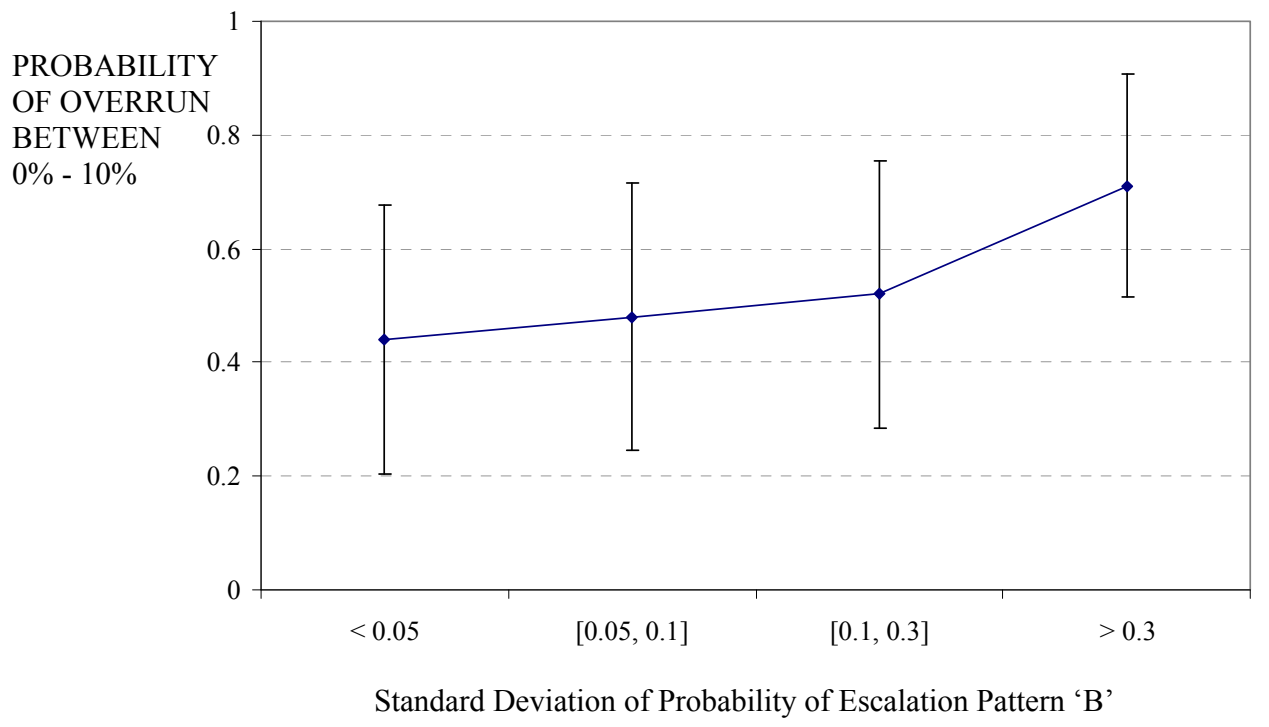

Figure 6.19: Impact of Variability in Probability of Escalation Pattern 'B' on the Probability of Cost

Overrun

Contract types that experience high variability in the probability to exhibit pattern 'B' may or may not experience pattern 'B'. That is, contracts belonging to such a contract type may or may not experience unforeseen costs. This degree of uncertainty about the occurrence of unforeseen costs indicates towards the uncertainty associated with cost estimation. As a result, the probability of cost overrun increases.

\subsubsection{Impact of Contract Size and Geographic Location (District)}

Bridge contracts were found more likely to have a cost overrun within the ' $+/-10 \%$ cost overrun bracket'. The tendency to have cost overrun between $0 \%$ and $10 \%$ was found to be higher than the tendency to have a negative cost overrun between $-10 \%$ and $0 \%$ (Figure 6.20). Moreover, large contracts were found more likely to experience cost overrun in the $0 \%$ to $10 \%$ range compared to small contracts, whereas the tendency to experience a negative cost overrun was found to decrease with a decrease in contract size. Large contracts are generally bridge replacement contracts or contracts involving significant replacement of the bridge deck or the superstructure. Such contracts are more likely to experience cost overrun compared to routine bridge maintenance and rehabilitation contracts, which are comparatively smaller in size and involve low profile construction activities. 


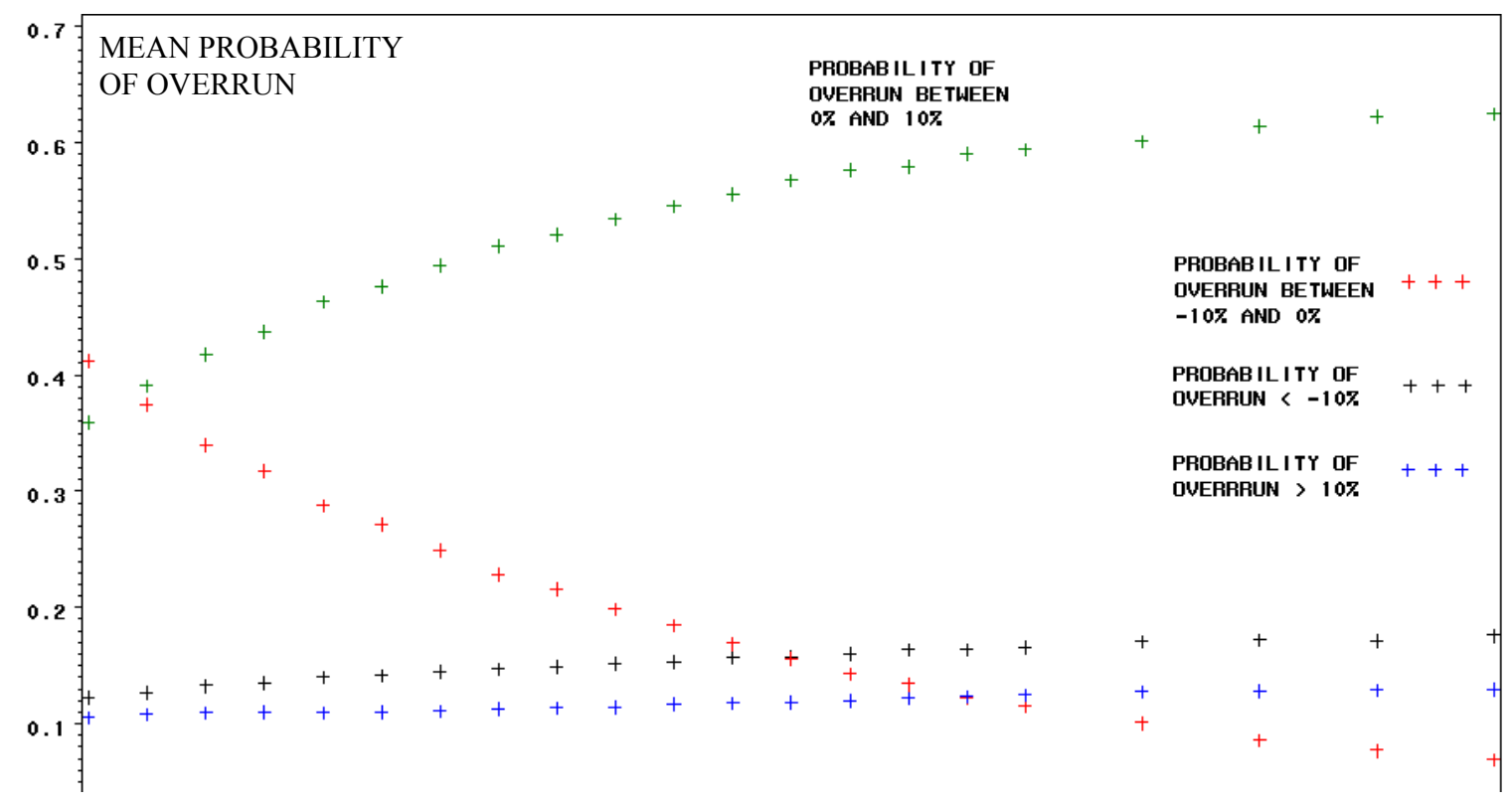

PROPOSED COST (MILLION \$)

Figure 6.20: Probability of Planning Stage Cost Overrun by Contract Size for Bridge Contracts

An analysis of the tendency of bridge contracts to experience cost overrun was conducted by district to determine if the trends in the probability of overrun shown in Figure 6.20 were prevalent across all districts. Greenfield, Laporte, and Crawfordsville districts were found more likely to have a negative cost overrun and less likely to have a cost overrun in the range of $0 \%$ to $10 \%$ compared to other districts (Figure 6.21). Contracts in Greenfield district were found least likely to exhibit pattern 'B' followed by contracts in Laporte and Crawfordsville districts. That is, contracts in these districts experienced lower risk of unforeseen costs compared to contracts in other districts. More experience with high profile bridge construction contracts and better management and construction practices are likely to be responsible for contracts in Greenfield, Laporte, and Crawfordsville districts to experience relatively low cost overrun.

MEAN PROBABILITY

OF OVERRUN BETWEEN

$0 \%$ AND $10 \%$ 


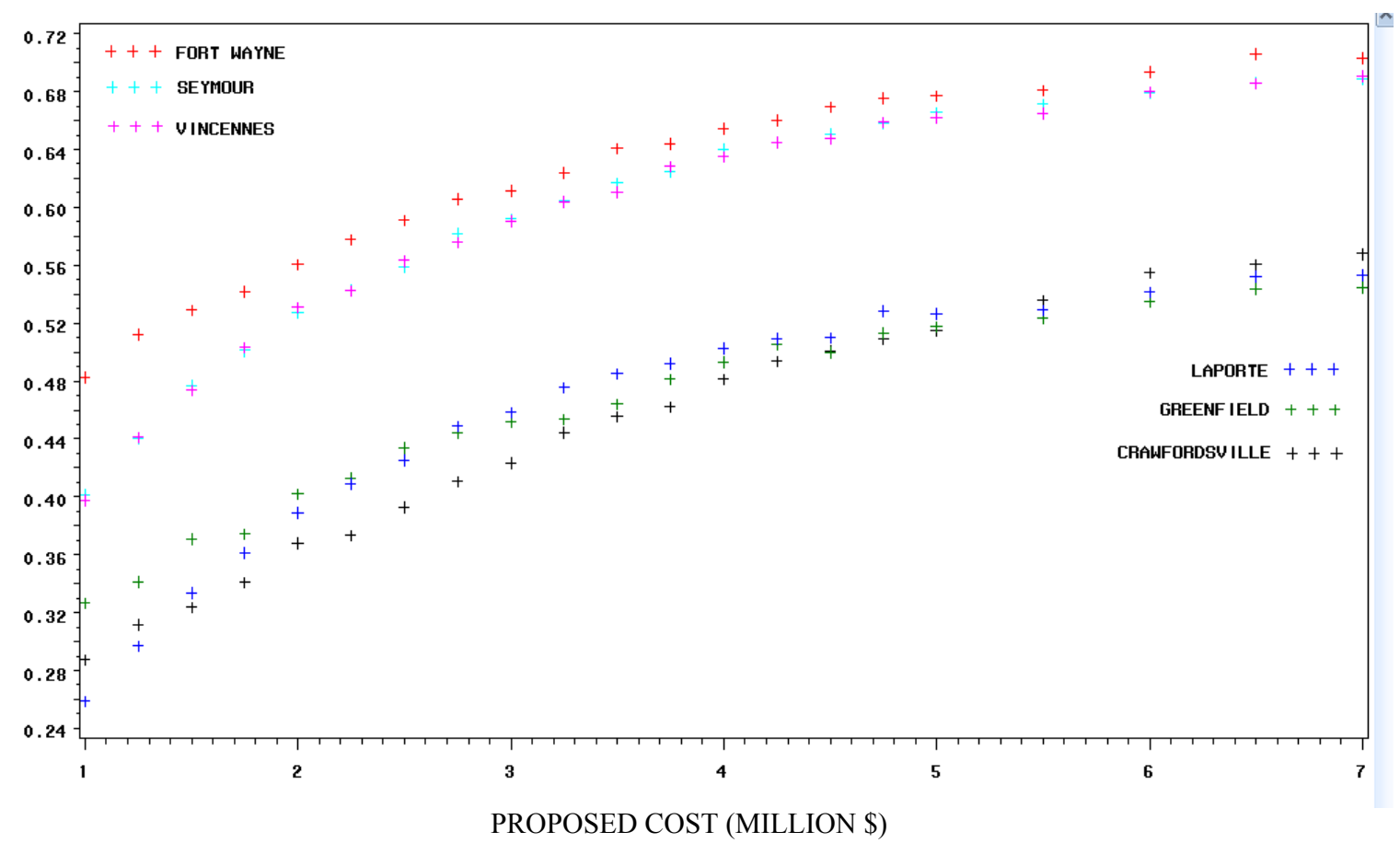

Figure 6.21: Probability of Planning Stage Cost Overrun Between $0 \%$ and $10 \%$ by Contract Size and District for Bridge Contracts

\subsubsection{Impact of Area Type}

Urban area bridge contracts were found more likely to experience planning stage cost overrun greater than $10 \%$ compared to contracts in rural areas. Contracts in rural areas were found more likely to have planning stage cost overrun of less than $10 \%$ compared to contracts in urban areas. The tendency of contracts in urban areas to experience high cost overrun was observed across contracts of all sizes. Factors such as traffic management and the availability of limited space for construction and rehabilitation work are likely to be responsible for high cost overrun in urban areas.

\subsubsection{Impact of NHS Status}

A detailed analysis of the planning, design and letting stage cost overrun was conducted by NHS status in the urban and rural areas. The planning, design and letting stage cost overrun corresponding to Interstate contracts were found more likely to be greater than $10 \%$ compared to contracts on Non-Interstate NHS highways and Non-NHS highways. Figure 6.22 presents the probability of planning stage cost overrun greater than $10 \%$ by NHS status. Across the Interstate contracts, urban Interstate contracts were found more likely to have a cost overrun of greater than $10 \%$ compared to rural Interstate contracts. The rural Interstate contracts were found more likely to have a comparatively lower cost overrun between $0 \%$ and $10 \%$ as 
opposed to urban Interstate contracts. In general, contracts on rural highway functional classes such as Interstates, principal arterials, minor arterials, and collectors were found more likely to have lower cost overruns $(0 \%$ to $10 \%)$. The contracts on urban collectors and arterials were similar to contracts on rural functional classes with respect to their tendency to have cost overruns. The increased likelihood of contracts on urban Interstates to have high cost overruns was likely due to the traffic management issues on these highways. Because of the difference between the functional classes, contracts in urban areas were found more likely to have higher cost overruns.

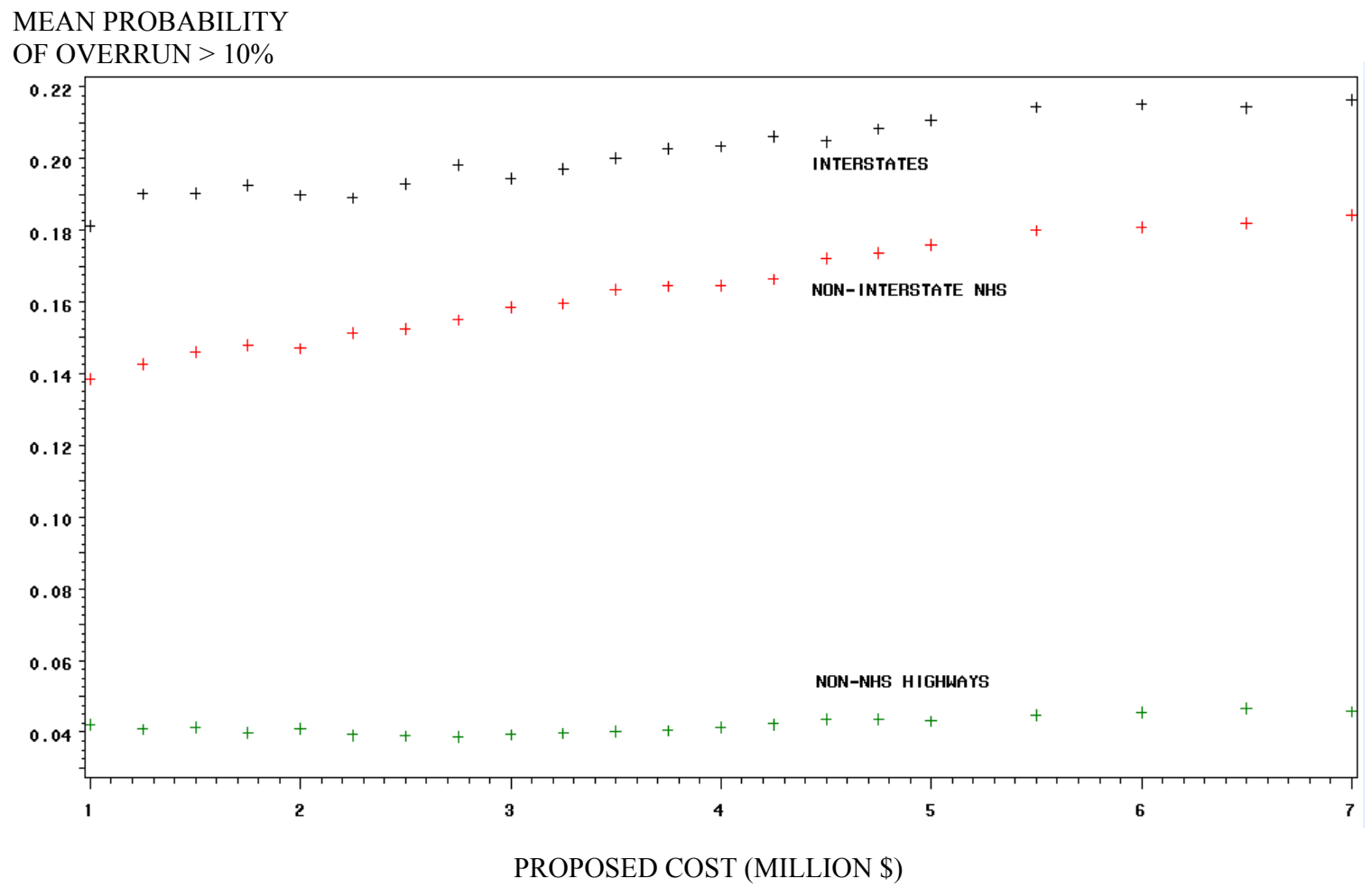

Figure 6.22: Comparison of Probability of Planning Stage Cost Overrun Greater than $10 \%$ by NHS Status and Contract Size (Bridge Contracts)

\subsubsection{Impact of Contract Classification (Standalone vs. Kin Contract)}

The letting strategy was not found to have an impact on the probability of cost overrun. Standalone and kin contracts were not found to be significantly different from each other (unlike expansion contracts where probability of letting stage cost overrun was higher for kin contracts). These contracts were found to be not different from each other with respect to their tendency to exhibit a particular escalation pattern. 


\subsubsection{Impact of Changes in Cost Estimates}

The change in the cost estimate from planning stage to final design stage was found to have an impact on the probability of cost overrun at the design and letting stages. It was found that as the percentage difference between design and proposed cost increased, there was an increase in the probability that the design stage cost overrun will be less than $-10 \%$ increased. An increase in the percentage difference between the design estimate and the proposed cost indicates that either scope changes were made to the project or unforeseen costs were identified as more information became available about the construction process and activities. In either scenario, an updated design cost is indicative of a more comprehensive understanding of the construction activities (compared to a scenario when design cost was not updated). Therefore, cost increases at the design stage tend to make the design estimate more accurate.

The percentage difference between design cost and proposed cost was also found to be a significant factor in determining the probability of a letting stage cost overrun. It was found that a higher percentage difference between design and proposed cost tends to increase the probability of letting stage cost overrun. The letting stage cost overrun becomes more likely to be in the $5 \%-10 \%$ category as the percentage difference between design and proposed cost increases. An increase in the design estimate compared to proposed cost due to scope changes tends to make the contract bigger in size; large contracts tend to have higher cost overruns due to increased complexity and susceptibility to unforeseen factors. As a result, the letting stage cost overrun increases. On the other hand, design estimates could also be higher than the proposed cost estimates because unforeseen factors at the planning stage were identified during the design stage. Some of such factors were possibly not identified by the contractors at the letting stage given the relatively short time span they had to prepare the bids. As a result the probability of a letting stage cost overrun increased.

An increase in the percentage difference between letting cost and proposed cost tends to increase the probability of experiencing letting stage cost underrun. If letting cost was less than the proposed cost, a contract was more likely to have an overrun. An increase in the letting cost (compared to proposed cost) indicates that contractors bid a higher cost. This is generally done to take into consideration the risk of unforeseen costs. Therefore, a comparatively higher letting cost suggests that a conservative approach was adopted for the preparation of the letting cost estimate. Consequently, the probability of letting stage cost underrun increases.

\subsubsection{Impact of Time between Final Design Completion and Project Proposal}

The time span between the final design completion and the project proposal was found to have a positive impact on the probability of design stage cost overrun. As the time span increases, contracts were found to be more likely to experience a cost overrun greater than $10 \%$. The time between final design completion and project proposal is a reflection of the complexity of the contract. Large time spans are generally 
experienced for: large contracts, contracts where site conditions created design challenges, or where multiple scope changes were made. Each of these factors could make a contract more susceptible to high cost overrun.

\subsubsection{Magnitude of Cost Overrun}

The magnitude of cost overrun was determined by using the conditional probability concept in the same way as for the expansion contracts. Table 6.12 presents the expected value of planning, design, and letting stage cost overrun by cost overrun category. Figure 6.15 presents the magnitude of planning stage cost overrun by contract size, area type, and highway functional class. Bridge contracts on urban Interstates, freeways, and expressways were expected to have high planning stage cost overruns (greater than 10\%) compared to contracts on rural highway functional classes.

Table 6.12: Expected Value of Cost Overrun for Bridge Contracts by Cost Overrun Category

\begin{tabular}{|c|c|c|c|c|c|}
\hline \multirow{2}{*}{$\begin{array}{c}\text { Cost } \\
\text { Overrun } \\
\text { Type }\end{array}$} & \multicolumn{4}{|c|}{ Cost Overrun Category } & \multirow[b]{2}{*}{$\begin{array}{l}\text { Weighted } \\
\text { Average }\end{array}$} \\
\hline & Category 1 & Category 2 & Category 3 & Category 4 & \\
\hline $\begin{array}{l}\text { Planning } \\
\text { Stage }\end{array}$ & $\begin{array}{l}\text { Average: }-23 \% \\
\text { Contracts: } 17 \\
\text { C.I: }[-30 \%,-17 \%]\end{array}$ & $\begin{array}{l}\text { Average: }-1.34 \% \\
\text { Contracts: } 29 \\
\text { C.I: }[-2.4 \%,-0.3 \%]\end{array}$ & $\begin{array}{l}\text { Average: } 1.65 \% \\
\text { Contracts: } 45 \\
\text { C.I: }[0.8 \%, 2.5 \%]\end{array}$ & $\begin{array}{l}\text { Average: } 34 \% \\
\text { Contracts: } 16 \\
\text { C.I: }[20 \%, 48 \%]\end{array}$ & $\begin{array}{l}\text { Average: } 1.8 \% \\
\text { Contracts: } 107 \\
\text { C.I: }[-1.9 \%, 5.6 \%]\end{array}$ \\
\hline $\begin{array}{l}\text { Design } \\
\text { Stage }\end{array}$ & $\begin{array}{l}\text { Average: }-20 \% \\
\text { Contracts: } 24 \\
\text { C.I: }[-25 \%,-16 \%]\end{array}$ & $\begin{array}{l}\text { Average: }-1.89 \% \\
\text { Contracts: } 30 \\
\text { C.I: }[-3 \%,-0.7 \%]\end{array}$ & $\begin{array}{l}\text { Average: } 1.45 \% \\
\text { Contracts: } 45 \\
\text { C.I: }[0.7 \%, 2.1 \%]\end{array}$ & $\begin{array}{l}\text { Average: } 33 \% \\
\text { Contracts: } 8 \\
\text { C.I: }[11 \%, 55 \%]\end{array}$ & $\begin{array}{l}\text { Average: }-2 \% \\
\text { Contracts: } 107 \\
\text { C.I: }[-5 \%, 1 \%]\end{array}$ \\
\hline $\begin{array}{l}\text { Letting } \\
\text { Stage }\end{array}$ & $\begin{array}{l}\text { Average: - } 44 \% \\
\text { Contracts: } 1\end{array}$ & $\begin{array}{l}\text { Average: }-4 \% \\
\text { Contracts: } 11 \\
\text { C.I: }[-6 \%,-1.8 \%]\end{array}$ & $\begin{array}{l}\text { Average: } 2.9 \% \\
\text { Contracts: } 75 \\
\text { C.I: }[2.3 \%, 3.5 \%]\end{array}$ & $\begin{array}{l}\text { Average: } 23 \% \\
\text { Contracts: } 20 \\
\text { C.I: }[13 \%, 33 \%]\end{array}$ & $\begin{array}{l}\text { Average: } 5.6 \% \\
\text { Contracts: } 107 \\
\text { C.I:[3\%, } 8.2 \%]\end{array}$ \\
\hline
\end{tabular}




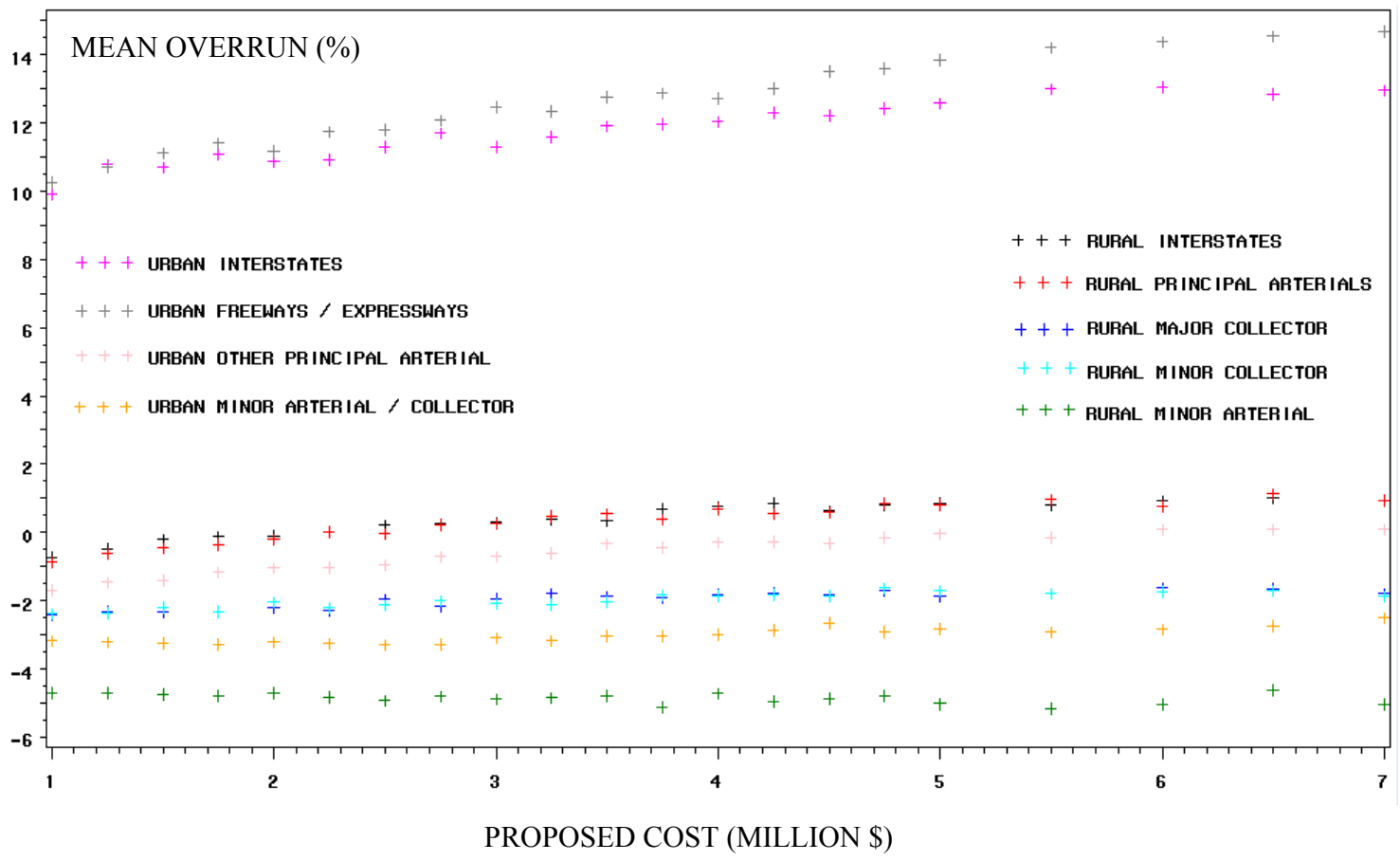

Figure 6.23: Mean Planning Stage Cost Overrun (\%) for Bridge Contracts by Size and Functional Class

\subsection{Econometric Models for Pavement Contracts}

Pavement contracts involve rehabilitation, resurfacing, replacement, or reconstruction work. The extent of uncertainty and variability associated with the construction process of a pavement contract can generally be expected to be lower than that for expansion and bridge contracts. Pavement contracts are usually straightforward, routine construction activities for which sufficient knowledge and information exists about the factors that can result in cost overrun.

\subsubsection{Probability of Escalation Patterns}

A total of 239 historical pavement contracts in the range of $\$ 1-\$ 10 \mathrm{M}$ were analyzed to develop the multinomial logit models (Table 6.13) for analysis of escalation pattern of pavement contracts. Contractspecific factors such as geographic location, contract size, and highway functional class were found to significantly affect the probability of the escalation patterns. 
Table 6.13: Multinomial Logit Model to Determine Probability of Escalation Pattern (Pavement Contracts)

\begin{tabular}{|c|l|c|c|c|}
\hline PATTERN & \multicolumn{1}{|c|}{ Contract Specific Factor } & Coeff. & Std.Err. & T-ratio \\
\hline \multirow{4}{*}{ PATTERN A } & Constant & 0.7723 & 0.2742 & 2.82 \\
\cline { 2 - 5 } & Proposed Cost (in Million \$) & 0.1109 & 0.0579 & 1.92 \\
\cline { 2 - 5 } & Proposed Cost between \$2M-\$5M & -0.6812 & 0.3036 & -2.24 \\
\hline \multirow{3}{*}{ PATTERN B } & Urban and Rural Interstates & -0.9193 & 0.5934 & -1.65 \\
\cline { 2 - 5 } & Vincennes District & -0.8684 & 0.4452 & -1.95 \\
\cline { 2 - 5 } & Proposed Cost (in Million \$) & 0.1283 & 0.0610 & 2.10 \\
\cline { 2 - 5 } & Proposed Cost between \$1M-\$2M & 0.6334 & 0.2718 & 2.33 \\
\hline \multirow{3}{*}{ PATTERN C } & Proposed Cost (in Million \$) & -0.3061 & 0.1206 & -2.54 \\
\hline & Fort Wayne and Laporte Districts in North & 0.5901 & 0.3690 & 1.60 \\
\cline { 2 - 5 } & Greenfield District & 0.7761 & 0.4241 & 1.83 \\
\cline { 2 - 5 } & Rural Principal Arterial & 0.8078 & 0.4794 & 1.68 \\
\cline { 2 - 5 } & Rural Minor Arterial & -1.7239 & 0.7571 & -2.28 \\
\cline { 2 - 5 } & U.S. Roads & -0.7939 & 0.4828 & -1.64 \\
\hline
\end{tabular}

Log-Likelihood (Model): -283.8; Log-Likelihood (No Coefficients): -331.3; Log-Likelihood (Constant): -300.9

Number of Observations: 239

\subsubsection{Impact of Contract Size}

Pavement contracts were found to be more likely to exhibit pattern 'A' compared to other patterns. Figure 6.24 presents the tendency of pavement contracts of various sizes to exhibit each escalation pattern. The probability to exhibit pattern ' $\mathrm{A}$ ' was found to increase with increases in contract size, indicating that the cost estimates of large contracts (greater than $\$ 5 \mathrm{M}$ ) were more likely to exhibit pattern 'A'. For large pavement contracts, highways may be closed to traffic and therefore the traffic management costs are smaller, thereby allowing contractors to submit bids. Small pavement contracts, on the other hand, may involve more traffic management as the road is often are not completely closed to traffic, and therefore they are expected to experience comparatively lower propensity to exhibit pattern ' $A$ '. Therefore, there is a jump observed in the probability of occurrence of pattern ' $A$ ' for contracts greater than $\$ 5 \mathrm{M}$. 


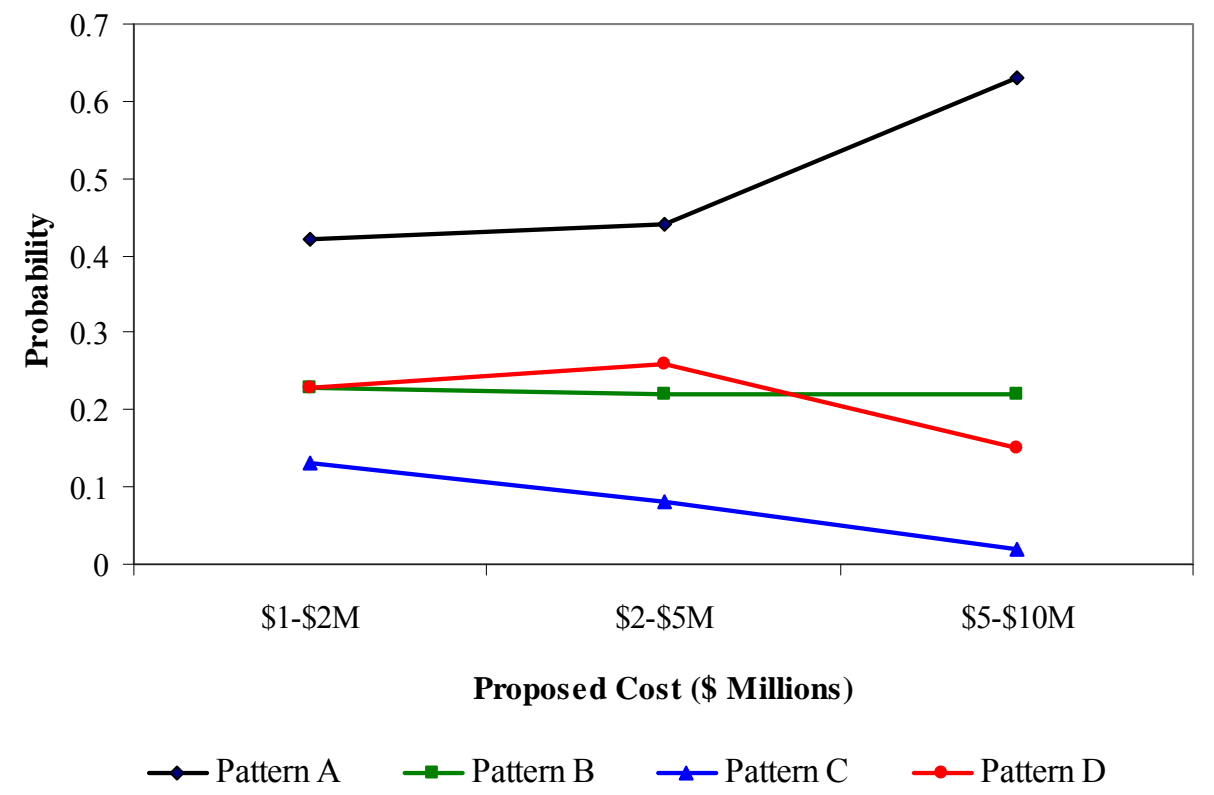

Figure 6.24: Mean Probability of Escalation Patterns by Contract Size for Pavement Contracts

\subsubsection{Impact of Contract Size and Geographic Location (District)}

Figure 6.25 presents a detailed analysis of the mean probability of escalation pattern 'A' by district and contract size. The increasing trend of the probability of pattern ' $A$ ' with contract size was found across all districts. The jump in the probability of escalation pattern ' $A$ ' for contracts greater than $\$ 5$ million was found across all districts, indicating that large contracts experience lower letting costs. The districts of Vincennes, Crawfordsville, and Fort Wayne were found to be relatively more likely to exhibit pattern 'A', followed by the relatively more urbanized districts of Seymour, Laporte and Greenfield. Contracts in urbanized districts were less likely to exhibit pattern 'A', perhaps because contractors find it difficult to quote a lower construction cost in urbanized districts owing to the difficulties in traffic management, lack of availability of space for construction, and higher labor costs. 
Mean Probability of

Escalation Pattern 'A'

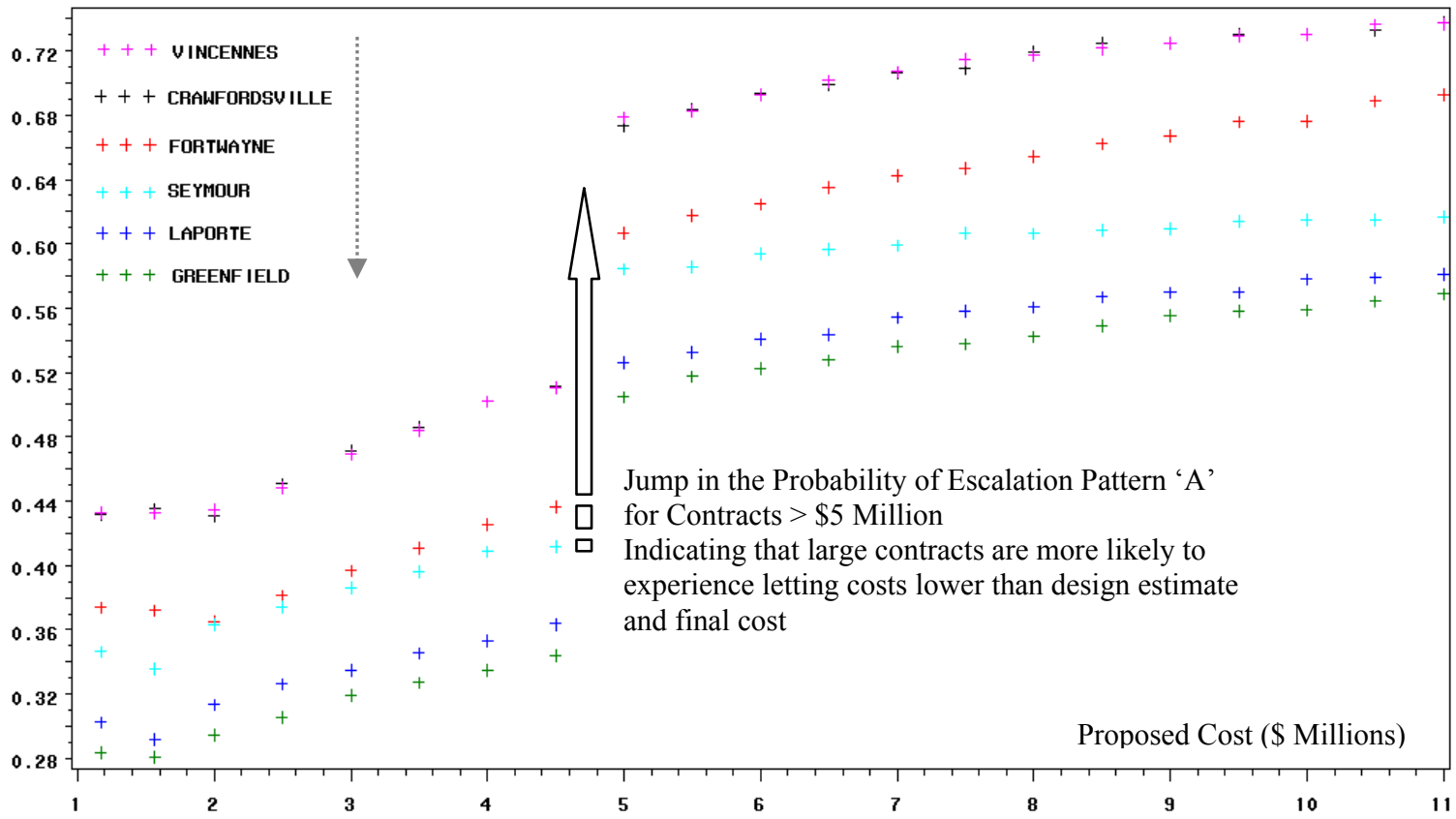

Figure 6.25: Mean Probability of Escalation Pattern 'A' by Contract Size and District for Pavement

Contracts

The probability of pattern ' $\mathrm{B}$ ' follows a step-wise increasing trend with increasing size for contracts in all districts. Figure 6.26 presents an analysis of the mean probability of escalation pattern 'B' by district and contract size. The drop in the probability of pattern ' $\mathrm{B}$ ' for contracts greater than $\$ 5 \mathrm{M}$ is because large contracts were found more likely to exhibit pattern 'A' because of the tendency of contractors to bid low. The drop was observed across all districts. Contracts less than $\$ 5 \mathrm{M}$ have comparatively lower returns due to their small size, and are likely to experience more costs because of traffic management, limited construction space, and overall management of construction process compared to large contracts. This also explains why contracts of size $\$ 1-\$ 2 \mathrm{M}$ were found to be more likely to exhibit pattern 'B' compared to contracts of larger size. 


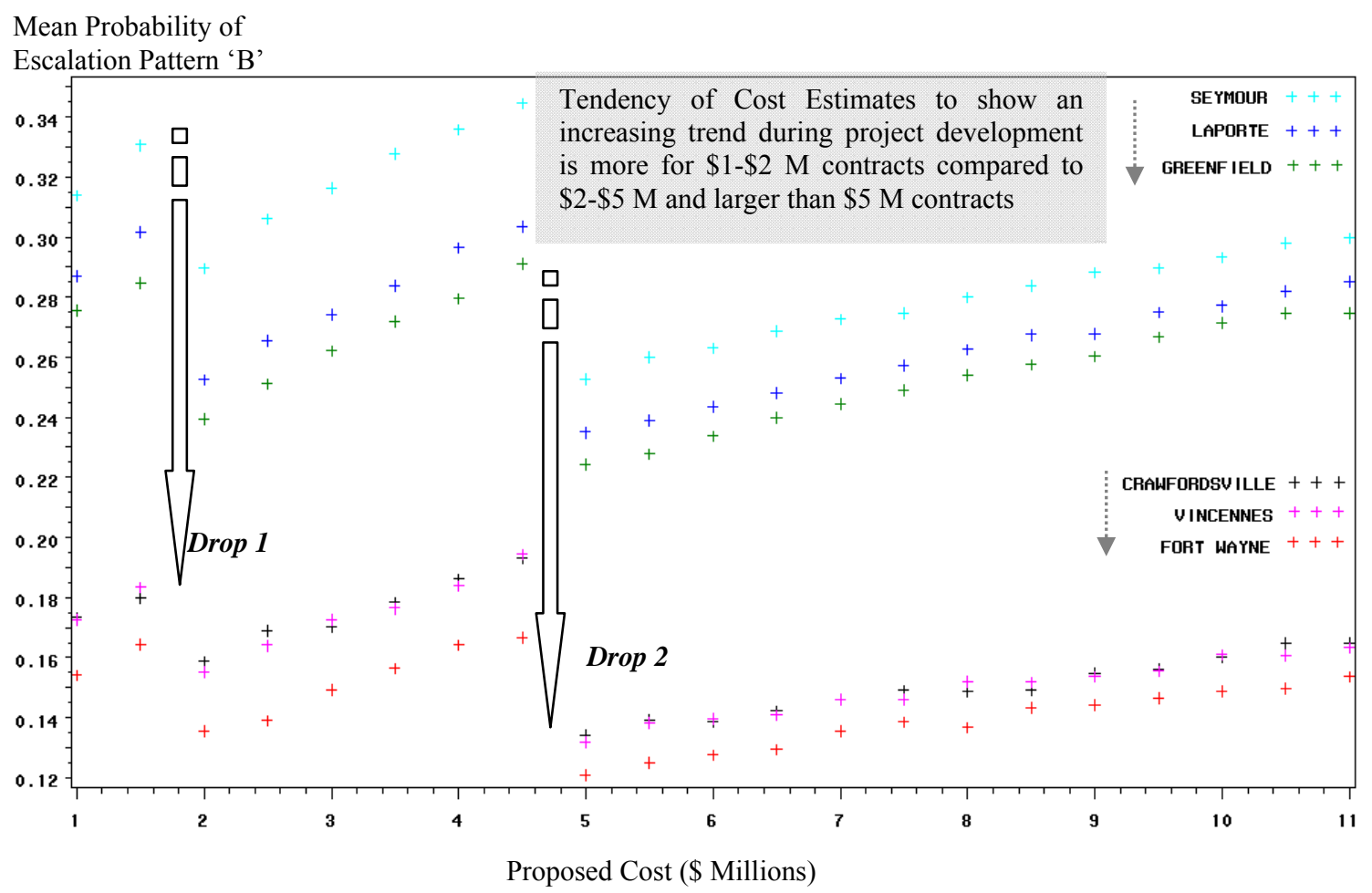

Figure 6.26: Mean Probability of Escalation Pattern 'B' by Contract Size and District for Pavement Contracts

\subsubsection{Impact of Route Type}

Figure 6.27 presents an analysis of the mean probability of pattern 'A' by route type (Interstate, U.S. highway, and State Road) and contract size. Interstate contracts were found more likely to experience escalation pattern 'A', followed by U.S. highway and State Road contracts. Interstate contracts possibly involved less traffic management costs, as they were either partially closed to traffic or underwent pavement work during non-peak hours. It is likely that pavement work on Interstates was completed faster, owing to more uniform features and less unforeseen site conditions. On the other hand, the Non-Interstate NHS highways and the Non-NHS highways would have involved more traffic management and over a longer period of time, as site conditions change from one location to another. As a result, they were found to be more likely to experience an increasing trend in the construction cost. 
Mean Probability of

Escalation Pattern 'A'

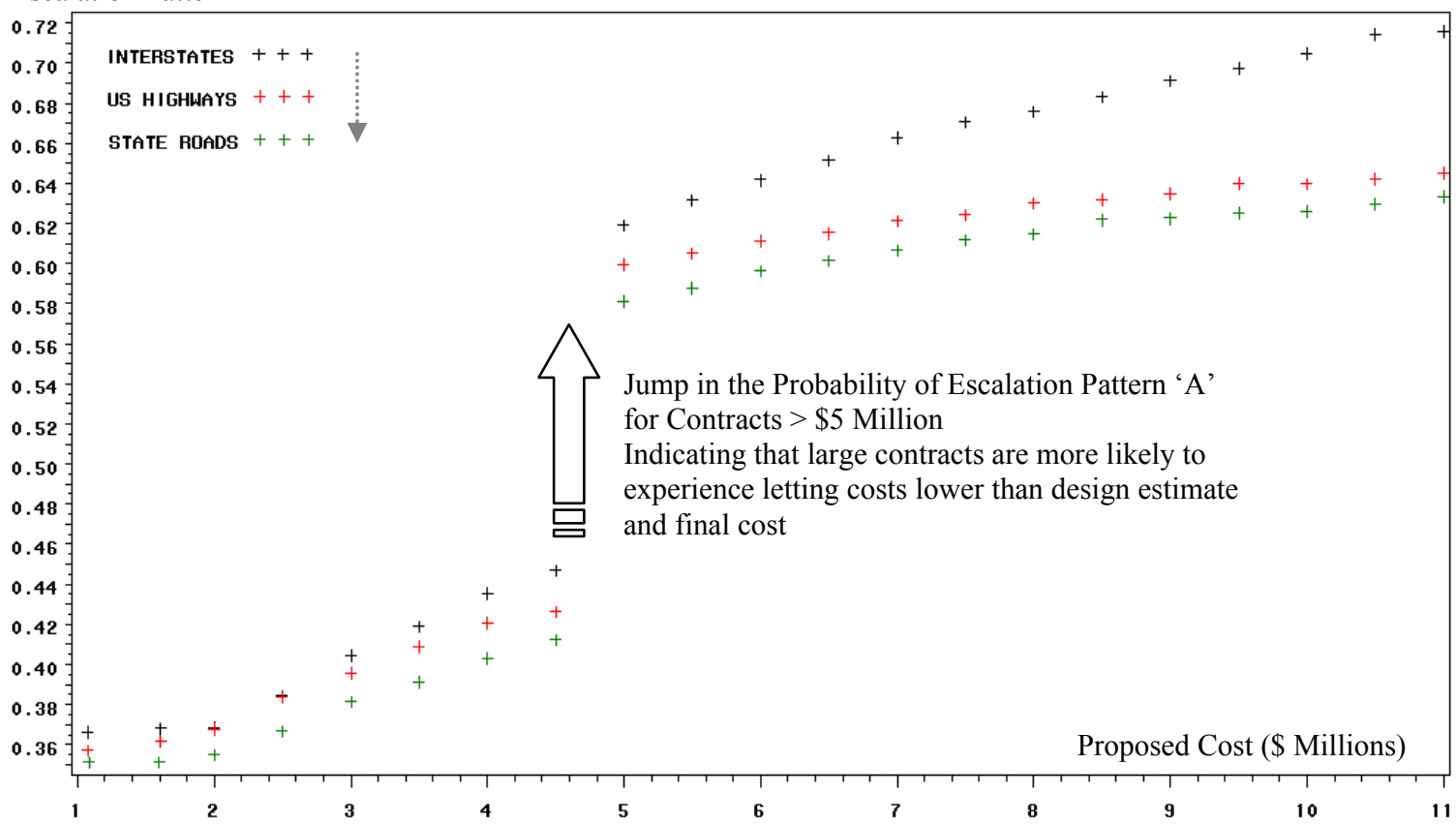

Figure 6.27: Mean Probability of Escalation Pattern 'A' by Contract Size and Route Type for Pavement Contracts

\subsubsection{Probability of Cost Overrun Occurrence}

A set of econometric models were developed for pavement contracts to determine the occurrence probability of planning, design, and letting stage cost overruns. Influential factors found to affect such probabilities include: contract size, geographic location, highway functional class, and the propensity of a contract to exhibit an escalation pattern (Table 6.14). In addition, the time span between final design completion and project proposal and the percentage difference between design estimate and proposed cost were found to affect the probability of a design stage cost overrun (Table 6.15). The occurrence probability of letting stage cost overrun was also found to be influenced by other factors such as the: time span between project proposal and letting, percentage difference between letting cost and proposed cost, and percentage difference between design cost and proposed cost (Table 6.16).

The impacts of the factors that were found to influence the probability of planning, design, and letting stage cost overruns were compared. Table 6.17 presents a comparison of the coefficients of the factors; the sign of the coefficients of these factors did not change across the models. This implies that for a given factor, the nature of its impact on planning, design, and letting stage cost overruns was not different. However, since the magnitudes of the coefficients were different, the extent of the impact varied. 
Table 6.14: Multinomial Logit Model to Determine Probability of Planning Stage Cost Overrun for Pavement Contracts

\begin{tabular}{|c|l|c|c|c|c|}
\hline $\begin{array}{c}\text { Cost } \\
\text { Overrun }\end{array}$ & \multicolumn{1}{|c|}{ Contract Specific Factor } & Coeff. & Std.Err. & t-ratio & p-Value \\
\hline \multirow{5}{*}{$<-10 \%$} & Constant & -46.8711 & 8.8960 & -5.27 & 0.00 \\
\cline { 2 - 6 } & Logarithm of Proposed Cost (in \$) & 3.2794 & 0.6131 & 5.35 & 0.00 \\
\cline { 2 - 6 } & Rural Area & 1.1117 & 0.5690 & 1.95 & 0.05 \\
\cline { 2 - 6 } & Proposed Cost between \$1M-\$2M & 1.3376 & 0.5401 & 2.48 & 0.01 \\
\cline { 2 - 6 } & $\begin{array}{l}\text { Variability in Probability of Escalation } \\
\text { Pattern B (Measured using Std. Dev) }\end{array}$ & -41.1529 & 14.9668 & -2.75 & 0.01 \\
\cline { 2 - 6 } & Urban Interstate, Freeway or Expressway & 1.5378 & 0.9036 & 1.70 & 0.09 \\
\hline$[<-10 \%, 0 \%)$ & Rural Collector (Major/Minor) & -0.7275 & 0.3475 & -2.09 & 0.04 \\
\hline \multirow{3}{*}[0\%,10\%]{} & Seymour District & -1.1384 & 0.5502 & -2.07 & 0.04 \\
\cline { 2 - 6 } & Proposed Cost (in Million \$) & 0.2216 & 0.0707 & 3.14 & 0.00 \\
\cline { 2 - 6 } & Probability of Escalation Pattern 'A' & -0.8538 & 0.4979 & -1.71 & 0.09 \\
\hline$>10 \%$ & Proposed Cost (in Million \$) & 0.1631 & 0.0632 & 2.58 & 0.01 \\
\hline
\end{tabular}

* Log-Likelihood (Model): -296; Log-Likelihood (No Coefficients): -331.32; Log-Likelihood (Constant): -326.09

Table 6.15: Multinomial Logit Model to Determine Probability of Design Stage Cost Overrun for Pavement Contracts

\begin{tabular}{|c|l|c|c|c|c|}
\hline $\begin{array}{c}\text { Cost } \\
\text { Overrun }\end{array}$ & \multicolumn{1}{|c|}{ Contract Specific Factor } & Coeff. & Std.Err. & t-ratio & P-Value \\
\hline \multirow{5}{*}{$<$} & Constant & -31.6941 & 7.5128 & -4.22 & 0.00 \\
\cline { 2 - 6 } & Logarithm of Proposed Cost (in \$) & 2.5121 & 0.5482 & 4.58 & 0.00 \\
\cline { 2 - 6 } & Proposed Cost between \$1 - \$2 M & 0.8394 & 0.5329 & 1.58 & 0.12 \\
\cline { 2 - 6 } & $\begin{array}{l}\text { Variability in Probability of } \\
\text { Escalation Pattern 'B' } \\
\text { (Measured using Std. Dev) }\end{array}$ & -74.7932 & 20.4891 & -3.65 & 0.00 \\
\cline { 2 - 6 } & $\begin{array}{l}\text { Square of Time Between Design and } \\
\text { Project Proposal (years) }\end{array}$ & -0.0126 & 0.0071 & -1.78 & 0.08 \\
\cline { 2 - 6 } & $\begin{array}{l}\text { Urban Districts of Seymour, } \\
\text { Greenfield and Laporte }\end{array}$ & -1.0584 & 0.4243 & -2.49 & 0.01 \\
\hline \multirow{2}{*}{$-10 \%, 0 \%$} & $\begin{array}{l}\text { Percentage Difference Between } \\
\text { Design and Proposed Cost }\end{array}$ & -0.0195 & 0.0106 & -1.84 & 0.07 \\
\hline \multirow{5}{*}[0\%,10\%]{} & $\begin{array}{l}\text { Percentage Difference Between } \\
\text { Design and Proposed Cost }\end{array}$ & -0.0360 & 0.0128 & -2.81 & 0.00 \\
\cline { 2 - 6 } & Seymour District & -1.1180 & 0.5560 & -2.01 & 0.04 \\
\cline { 2 - 6 } & $\begin{array}{l}\text { 2-4 years Between Design and } \\
\text { Project Proposal }\end{array}$ & 0.9686 & 0.3136 & 3.09 & 0.00 \\
\hline & $\begin{array}{l}\text { Percentage Difference Between } \\
\text { Design and Proposed Cost }\end{array}$ & -0.0500 & 0.0134 & -3.72 & 0.00 \\
\cline { 2 - 6 } & Probability of Escalation Pattern 'B' & 1.3377 & 0.6976 & 1.92 & 0.06 \\
\hline
\end{tabular}

* Log-Likelihood (Model): -274.26; Log-Likelihood (No Coefficients): -310.5; Log-Likelihood (Constant): -308.8 
Table 6.16: Multinomial Logit Model to Determine Probability of Letting Stage Cost Overrun for Pavement Contracts

\begin{tabular}{|c|l|c|c|c|c|}
\hline \multirow{2}{*}{ Cost Overrun } & \multicolumn{1}{|c|}{ Contract Specific Factor } & Coeff. & Std.Err. & t-ratio & P-Value \\
\hline \multirow{3}{*}{$0 \%$} & Laporte District & 1.0337 & 0.6023 & 1.72 & 0.09 \\
\hline \multirow{3}{*}{$0 \%, 5 \%$} & Constant & 1.3153 & 0.2253 & 5.84 & 0.00 \\
\cline { 2 - 6 } & $\begin{array}{l}\text { Percentage Difference Between Design } \\
\text { and Proposed Cost }\end{array}$ & 0.0002 & 0.0001 & 1.60 & 0.11 \\
\cline { 2 - 6 } & Interstate Highways & 0.9245 & 0.4553 & 2.03 & 0.04 \\
\cline { 2 - 6 } & $\begin{array}{l}\text { Time Between Letting and Project } \\
\text { Proposal (Years) }\end{array}$ & -0.1278 & 0.0581 & -2.20 & 0.03 \\
\hline \multirow{2}{*}{$(5 \%, 10 \%)$} & Square of Proposed Cost (\$ Millions) & 0.0042 & 0.0020 & 2.15 & 0.03 \\
\cline { 2 - 6 } & Laporte District & 1.1798 & 0.5734 & 2.06 & 0.04 \\
\hline & $\begin{array}{l}\text { Urban Districts of Seymour, Greenfield } \\
\text { and Laporte }\end{array}$ & -1.2118 & 0.5454 & -2.22 & 0.03 \\
\cline { 2 - 6 } & Kin Contracts & 0.8534 & 0.3855 & 2.21 & 0.03 \\
\cline { 2 - 6 } & Probability of Escalation Pattern 'B' & 2.5124 & 1.2491 & 2.01 & 0.04 \\
\cline { 2 - 6 } & Seymour District & 1.1356 & 0.5729 & 1.98 & 0.05 \\
\hline
\end{tabular}

* Log-Likelihood (Model): -269.64; Log-Likelihood (No Coefficients): -310.5; Log-Likelihood (Constant): -289.46 
Table 6.17: Comparison of Coefficients of the Factors Affecting Probability of Planning, Design and Letting Stage Cost Overrun (Pavement Contracts)

\begin{tabular}{|c|c|c|c|c|c|}
\hline Cost Overrun & Contract Specific Factor & Planning & Design & & Letting \\
\hline \multirow{10}{*}{$<-10 \%$} & Constant & -46.8711 & -31.694 & \multirow{13}{*}{$<0 \%$} & \\
\hline & Logarithm of Proposed Cost (in \$) & 3.2794 & 2.5121 & & \\
\hline & Proposed Cost between $\$ 1 \mathrm{M}-\$ 2 \mathrm{M}$ & 1.3376 & 0.8394 & & \\
\hline & $\begin{array}{l}\text { Urban Districts of Seymour, Greenfield } \\
\text { and Laporte }\end{array}$ & & -1.0584 & & \\
\hline & Laporte District & & & & 1.0336 \\
\hline & Kin Contract & -1.3902 & -1.2332 & & \\
\hline & Rural Area & 1.112 & & & \\
\hline & $\begin{array}{l}\text { Variability in Probability of Escalation } \\
\text { Pattern 'B' (Measured using Std. Dev) }\end{array}$ & -41.15 & -74.79 & & \\
\hline & $\begin{array}{l}\text { Urban Interstate, Freeway or } \\
\text { Expressway }\end{array}$ & 1.5378 & & & \\
\hline & $\begin{array}{l}\text { Square of Time Between Design and } \\
\text { Project Proposal (years) }\end{array}$ & & -0.0126 & & \\
\hline \multirow{3}{*}{$-10 \%, 0 \%$} & Constant & & & & \\
\hline & $\begin{array}{l}\text { Percentage Difference Between Design } \\
\text { and Proposed Cost }\end{array}$ & & -0.0195 & & \\
\hline & Rural Collector (Major/Minor) & -0.7275 & & & \\
\hline \multirow{11}{*}[0\%,10\%]{} & Constant & & & \multirow{8}{*}{$0 \%, 5 \%$} & 1.315 \\
\hline & Seymour District & -1.1384 & -1.118 & & \\
\hline & Interstate Highways & & & & 0.9245 \\
\hline & Proposed Cost (in Million \$) & 0.2216 & & & \\
\hline & $\begin{array}{l}\text { Percentage Difference Between Design } \\
\text { and Proposed Cost }\end{array}$ & & -0.036 & & \\
\hline & $\begin{array}{l}\text { Square of Percentage Difference } \\
\text { Between Design and Proposed Cost }\end{array}$ & & & & 0.0002 \\
\hline & $\begin{array}{l}\text { 2-4 years Between Design and Project } \\
\text { Proposal }\end{array}$ & & 0.9686 & & \\
\hline & $\begin{array}{l}\text { Time between Letting and Project } \\
\text { Proposal }\end{array}$ & & & & -0.1278 \\
\hline & Probability of Escalation Pattern 'A' & -0.8538 & & \multirow{3}{*}[5\%,10\%]{} & \\
\hline & Square of Proposed Cost (\$ Millions) & & & & 0.0042 \\
\hline & Laporte District & & & & 1.18 \\
\hline \multirow{6}{*}{$>10 \%$} & $\begin{array}{l}\text { Urban Districts of Seymour, Greenfield } \\
\text { and Laporte }\end{array}$ & & & \multirow{6}{*}{$>10 \%$} & -1.2112 \\
\hline & Seymour District & & & & 1.1356 \\
\hline & Kin Contracts & & & & 0.8534 \\
\hline & $\begin{array}{l}\text { Percentage Difference Between Design } \\
\text { and Proposed Cost }\end{array}$ & - & -0.05 & & \\
\hline & Probability of Escalation Pattern 'B' & & 1.3377 & & 2.512 \\
\hline & Proposed Cost (in Million \$) & 0.1631 & & & \\
\hline
\end{tabular}




\subsubsection{Impact of Contract Size}

The probability of planning stage cost overrun was found to decrease with an increase in contract size for pavement contracts (Figure 6.28). Large pavement contracts (greater than $\$ 5 \mathrm{M}$ ) were found more likely to experience a planning stage cost overrun less than $-10 \%$. The probability of experiencing planning stage cost overruns less than $-10 \%$ was lower for small contracts. Small pavement contracts were found more likely to experience cost overruns greater than $10 \%$, as opposed to large pavement contracts. In Section 6.5.1, it was found that large pavement contracts were more likely to exhibit pattern 'A' (see Figure 6.24), whereas small pavement contracts were more likely to exhibit pattern ' $\mathrm{B}$ '. This probably explains why large pavement contracts were found more likely to experience cost underruns, whereas small pavement contracts were found more susceptible to cost overruns. Large pavement contracts are perhaps managed more efficiently, because they often, unlike smaller pavement contracts, involve complete highway closures, thereby during the construction period thereby resulting in low traffic management costs.

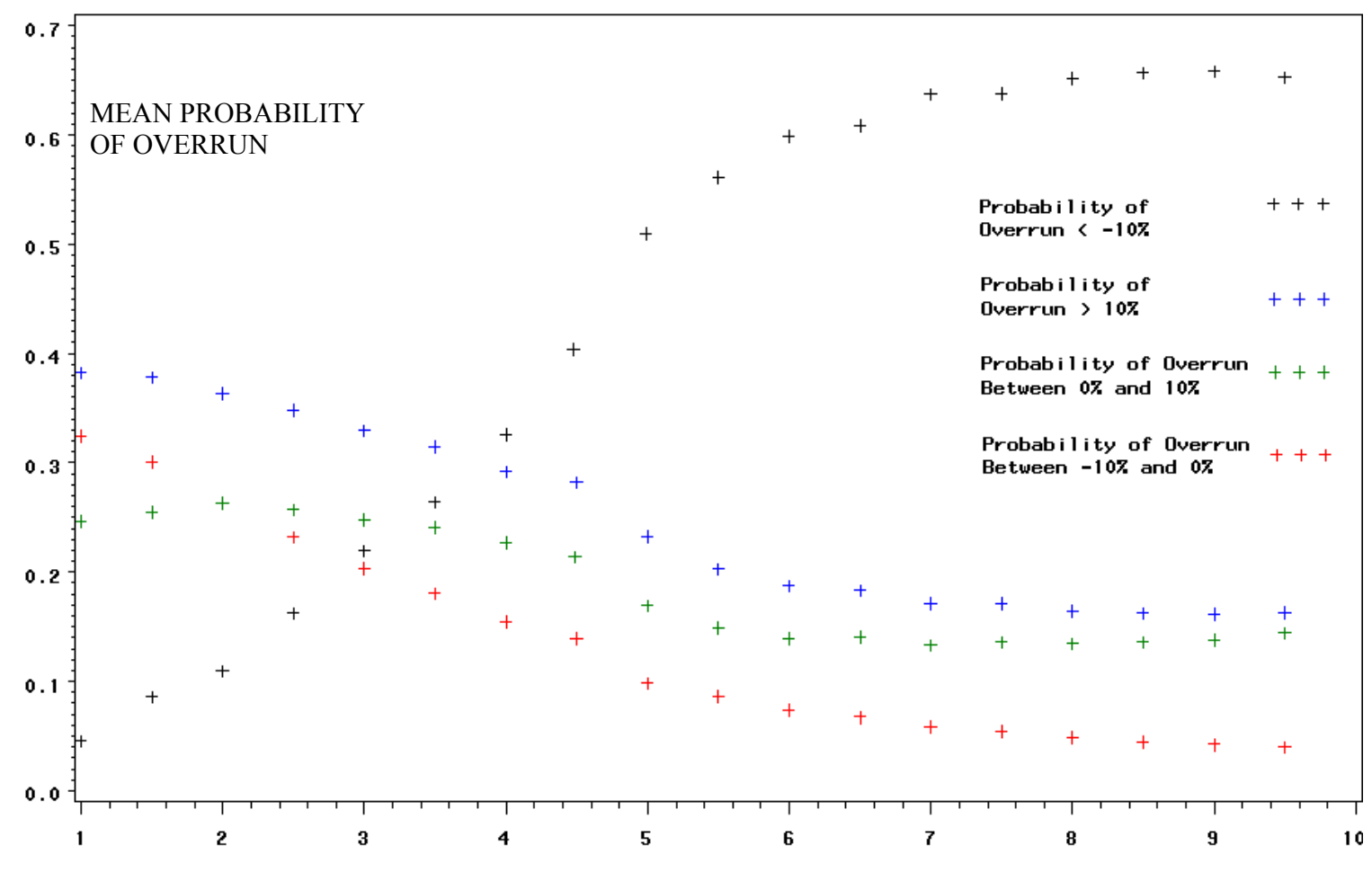

PROPOSED COST (\$ MILLIONS)

Figure 6.28: Mean Probability of Planning Stage Cost Overrun Corresponding to Various Levels of a Pavement Contract Size (Based on Proposed Cost) 


\subsubsection{Impact of Escalation Pattern}

The likelihood of occurrence of escalation pattern ' $A$ ' was found to have a decreasing effect on the probability of positive planning, design, and letting stage cost overruns. Further, it was found that as the probability of pattern ' $\mathrm{B}$ ' increases, overruns greater than $10 \%$ were more likely to occur. Contracts that are more likely to exhibit pattern ' $\mathrm{B}$ ' were found to be more likely to experience unforeseen factors, and therefore more likely to have high cost overrun. On the other hand, contracts that are more likely to exhibit pattern ' $A$ ' were found to be more likely to experience low letting costs, which indicates that such contracts were straightforward construction activities that were less likely to experience unforeseen factors and costs.

The variability in the probability of escalation pattern ' $\mathrm{B}$ ' was also found to have an impact on the probability of cost overruns. As the variability in the probability of pattern ' $\mathrm{B}$ ' increases, contracts were found to be less likely to experience negative cost overruns of less than $-10 \%$. This is because, as the variability in probability of pattern 'B' increases, the uncertainty associated with unforeseen costs that result in escalation pattern ' $\mathrm{B}$ ' increases. Contract types that experience high variability in the probability to exhibit pattern 'B' may or may not experience pattern 'B' because contracts of such types may or may not experience unforeseen costs. This degree of uncertainty surrounding the occurrence of unforeseen costs is indicative of the uncertainty associated with cost estimation. As a result, the probability of cost overrun increases.

\subsubsection{Impact of Geographic Location (Area Type)}

Large (greater than $\$ 5 \mathrm{M}$ ) pavement contracts in rural areas were found to be more likely to experience negative cost overruns, while large pavement contracts in urban areas were found more likely to experience positive overruns. Figure 6.29 presents a comparison of the mean probability of cost overruns greater than $10 \%$ for contracts of different sizes in urban and rural areas. Corresponding to each contract size, the mean probability of overruns, across contracts on all highway functional classes, in urban and rural areas was computed. The unit costs of labor, traffic management costs, and additional costs due to limited space on construction sites are some of the factors that are generally responsible for higher construction costs in urban areas.

Figure 6.30 compares the mean probability of overrun across urban and rural area contracts in each district. The mean probability of having a planning cost overrun exceeding $10 \%$ is marginally higher for urban area contracts. However, these contracts have a relatively higher upper limit of $95 \%$ confidence interval of the mean probability, which indicates that some urban area pavement contracts are likely to experience high cost overruns. 
MEAN PROBABILITY OF

OVERRUN $>10 \%$

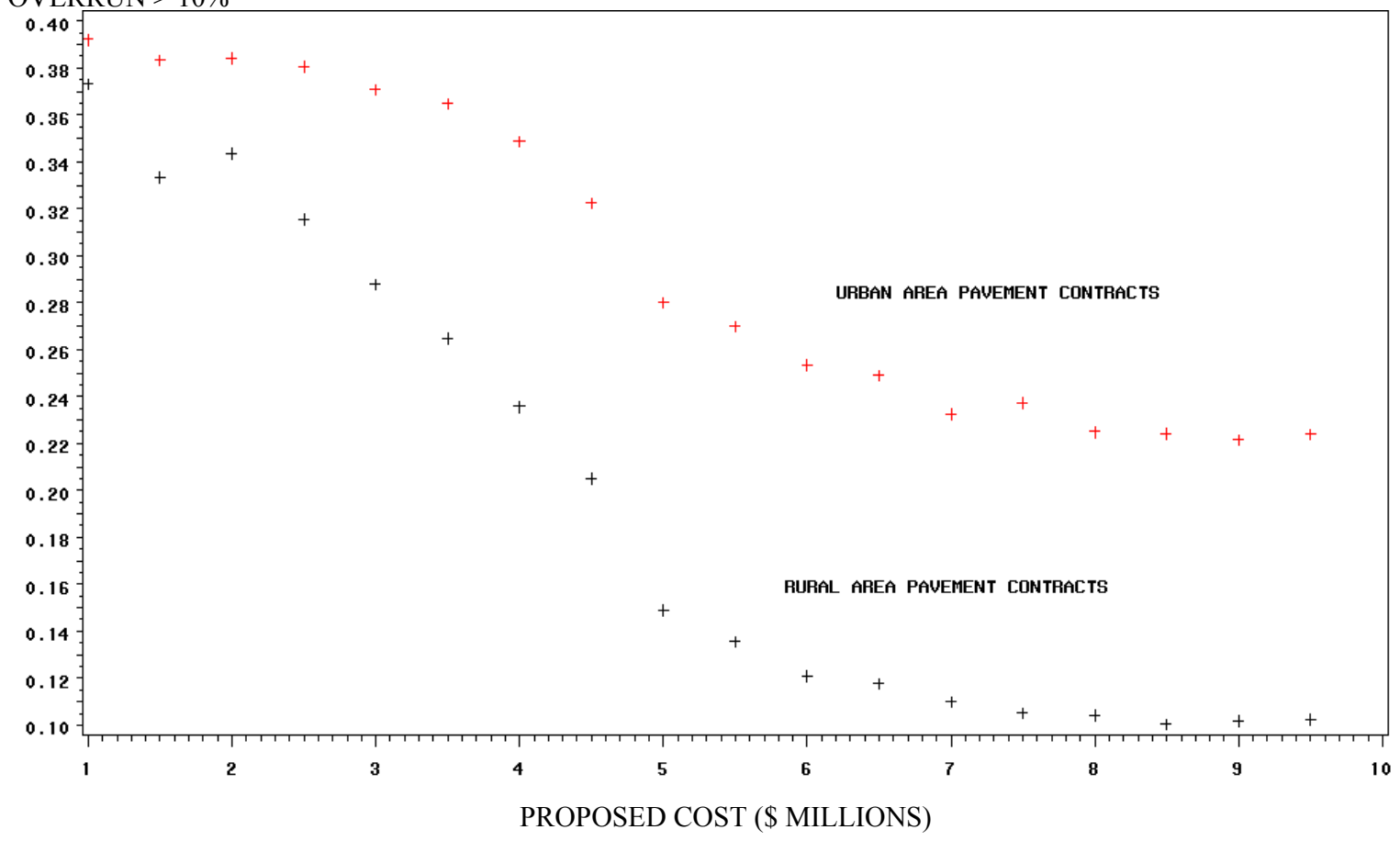

Figure 6.29: Comparison of Mean Probability of Planning Stage Cost Overrun Across Urban and Rural Area Contracts by Contract Size

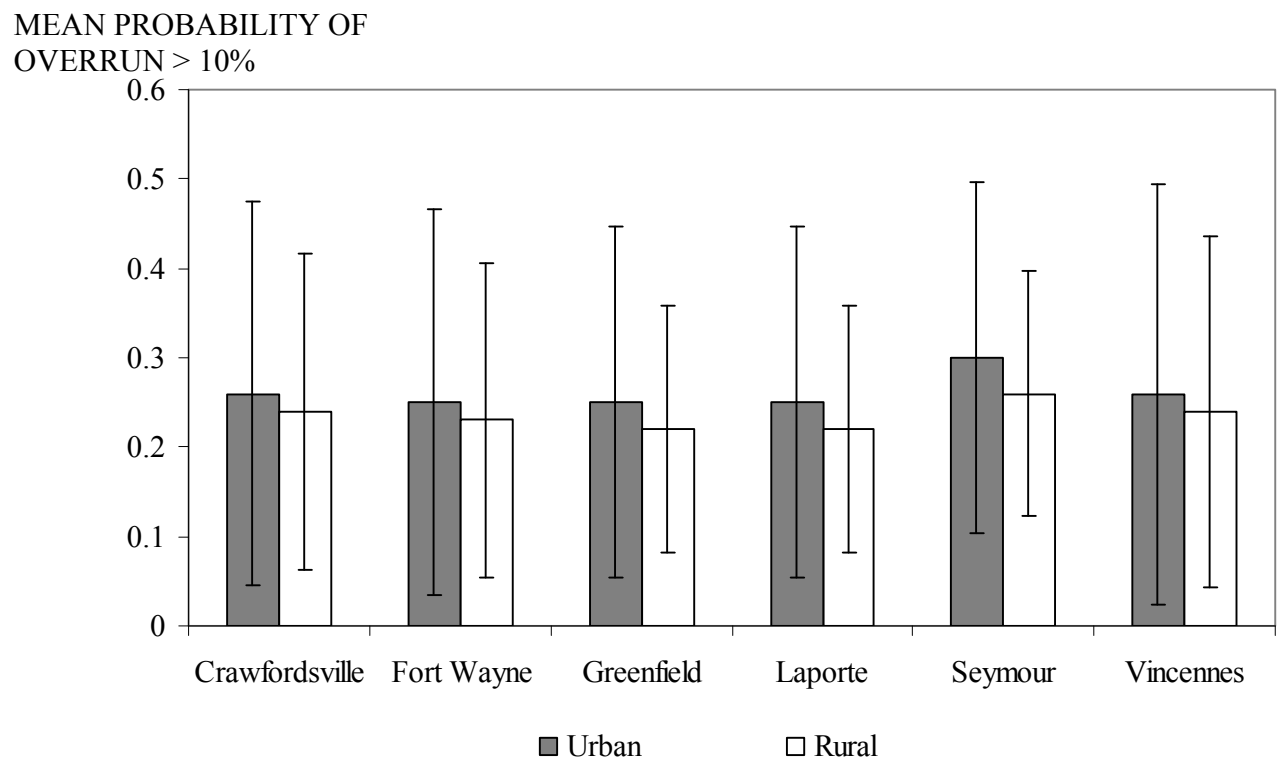

Figure 6.30: Comparison of Mean Probability of Planning Stage Cost Overrun Across Urban and Rural Area Contracts in Each District 


\subsubsection{Impact of Contract Classification (Standalone vs. Kin)}

Kin pavement contracts were found to be more likely to experience letting stage cost overruns exceeding $10 \%$, as compared to stand-alone contracts. Figure 6.31 presents a comparison of the mean probability of letting stage cost overruns greater than $10 \%$ by contract classification and administrative district. Across all six districts, the probability of a letting stage cost overrun was greater for kin contracts. The variability in the probability of cost overruns greater than $10 \%$ was also analyzed to study the difference in the propensity of stand-alone and kin contracts to experience cost overrun. The overlap of the $95 \%$ confidence intervals across all the districts, suggests that the mean probability of overruns greater than $10 \%$ is not significantly different for kin and stand-alone contracts. However, the upper and lower limits of the confidence interval indicate that kin contracts are more susceptible to high cost overruns.

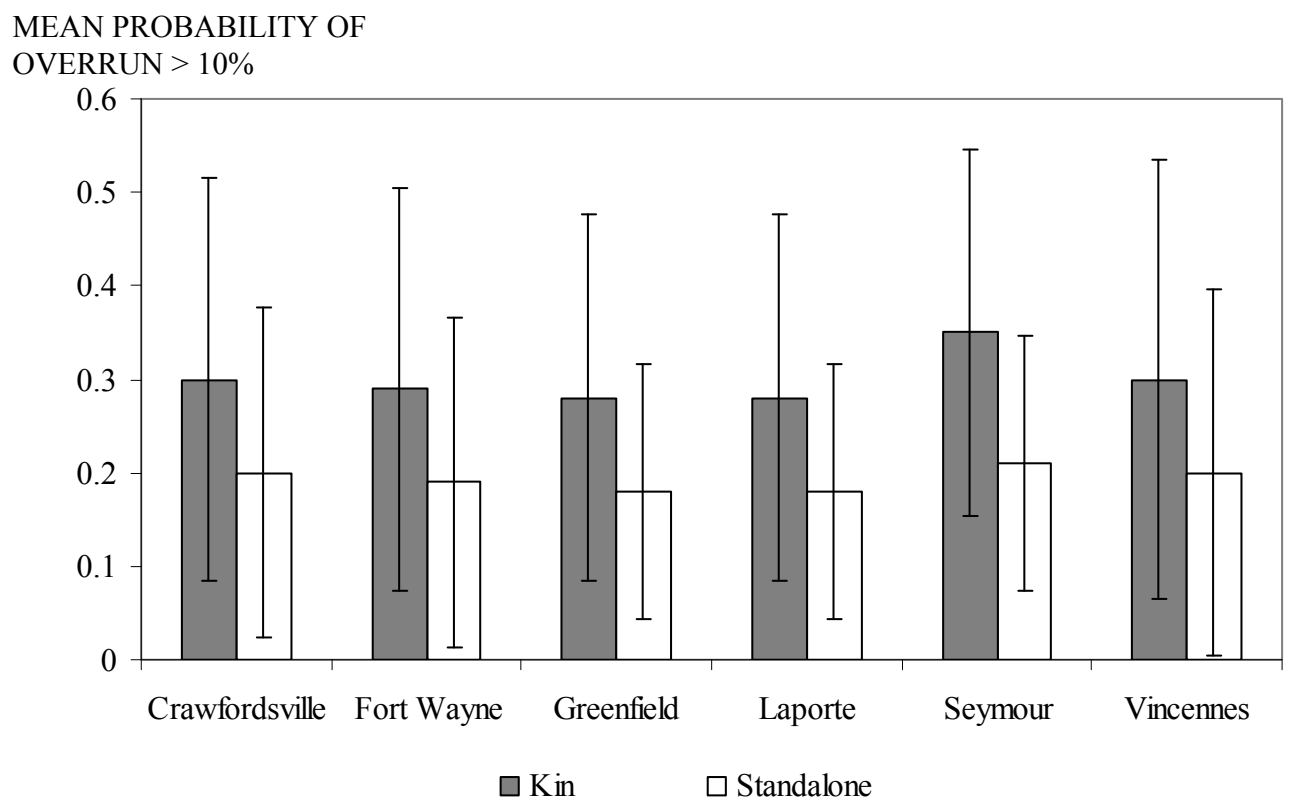

Figure 6.31: Comparison of Mean Probability of Letting Stage Cost Overrun Across Standalone and Kin Contracts in each District

\subsubsection{Impact of Geographic Location (District)}

A comparison of the mean probability of cost overrun greater than $10 \%$ across the districts indicated that contracts in Seymour district were marginally more likely to have a cost overrun of greater than $10 \%$ compared to contracts in other districts. In particular, for less than $\$ 3$ million pavement contracts, the probability of having a cost overrun greater than $10 \%$ was higher for Seymour district contracts compared to contracts in other districts. Seymour district is more urbanized compared to the districts of Crawfordsville, Fort Wayne, and Vincennes which was one of the reasons why contracts in this district were found to be more likely to have a cost overrun exceeding $10 \%$ compared to other districts. However, 
other urbanized districts of Greenfield and Laporte were not found to be significantly different than the less urbanized districts. This indicated that factors other than the urbanized nature of the Seymour district were responsible for the relatively higher tendency of contracts in this district to experience cost overrun.

\subsubsection{Impact of Highway Functional Class}

The contracts on urban Interstates, freeways, and expressways were found more likely to experience negative cost overrun of less than $-10 \%$. The contracts on these highways were also found more likely to exhibit pattern 'A' (refer to Figure 6.27) and less likely to exhibit pattern 'B' compared to other highways, which explains their tendency to have a negative cost overrun. Interstate contracts possibly involved less traffic management costs, as they were either partially closed to traffic or underwent pavement work during non-peak hours. Also, it is likely that pavement work on Interstates was completed faster, due to more consistent and less unforeseen site conditions.

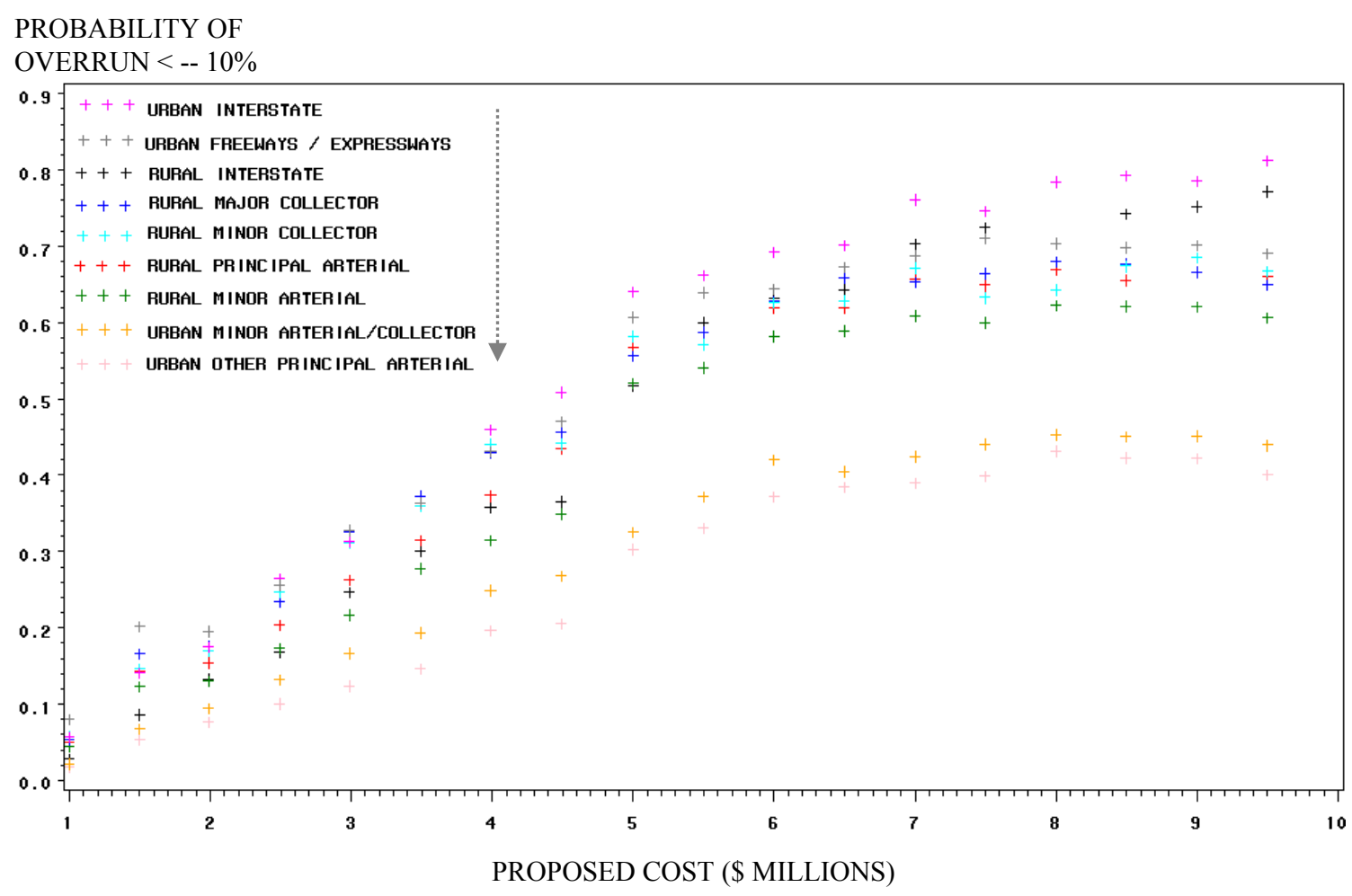

Figure 6.32: Comparison of Mean Probability of Planning Stage Cost Overrun Across Highway Functional Classes by Contract Size 


\subsubsection{Impact of Changes in Cost Estimates}

The probability of design stage cost overruns decreases with increases in the percentage difference between design cost and proposed cost. The percentage difference between design cost and proposed cost was also found to be a significant factor in determining the probability of a letting stage cost overrun. It was found that as design cost exceeds the proposed cost, the probability of experiencing a high letting stage cost overrun increases. An increase in the design cost relative to proposed cost indicates that unforeseen costs were identified during the development of the design plans. As a result, the accuracy of the design estimate improves. On the other hand, an increase in the design cost compared to proposed cost can also be due to scope changes. As the project scope is enhanced and the project becomes bigger, the tendency to experience competition at letting stage increases. As a result, contractors may bid low which would increase the probability of a letting stage cost overrun.

The probability of experiencing a letting stage cost underrun was found to increase with an increase in the percentage difference between letting cost and proposed cost. As letting cost increases relative to the proposed cost, it tends to evolve into a more conservative estimate of the construction cost, and therefore the probability of letting stage cost overrun decreases and the probability of an underrun increases.

\subsubsection{Impact of Time between Final Design Completion and Project Proposal}

Large time durations between project proposal and final design completion result in a higher tendency to experience design and letting stage cost overruns. A long time span suggests that the design process was complicated, many scope changes were made, or the contract is being constructed on a large scale. Complex designs and large contracts are generally more likely to experience constructability problems, and hence cost overrun. This explains the increase in the probability of design and letting stage cost overruns with increases in time duration.

\subsubsection{Magnitude of Cost Overrun}

Table 6.18 presents the expected value of planning, design, and letting stage cost overrun by cost overrun category. The magnitude of cost overrun is determined by using the conditional probability principle, as for expansion and bridge contracts. Pavement contracts were expected to have low planning design and letting stage cost overruns. Large pavement contracts (greater than $\$ 5 \mathrm{M}$ ) were found to have negative planning and design stage cost overruns, while smaller pavement contracts were found to have comparatively higher (between $0 \%$ and 10\%) planning and design stage cost overruns. The average letting stage cost overrun was found to be marginally higher for large pavement contracts (5-10\%) compared to small pavement contracts (0-5\%), indicating that at the letting stage, lower bids for large contracts are received. 
Table 6.18: Expected Value of Cost Overrun for Pavement Contracts by Cost Overrun Category

\begin{tabular}{|c|c|c|c|c|c|}
\hline \multirow{2}{*}{$\begin{array}{c}\text { Cost } \\
\text { Overrun } \\
\text { Type }\end{array}$} & \multicolumn{4}{|c|}{ Cost Overrun Category } & \multirow[b]{2}{*}{$\begin{array}{l}\text { Weighted } \\
\text { Average }\end{array}$} \\
\hline & $\begin{array}{c}\text { CONTRACTS } \\
\text { WHERE } \\
Y_{1}<-10 \%\end{array}$ & $\begin{array}{c}\text { CONTRACTS } \\
\text { WHERE } \\
-10 \% \leq Y_{1}<0 \%\end{array}$ & $\begin{array}{c}\text { CONTRACTS } \\
\text { WHERE } \\
0 \% \leq Y_{1} \leq 10 \%\end{array}$ & $\begin{array}{c}\text { CONTRACTS } \\
\text { WHERE } \\
Y_{1}>10 \%\end{array}$ & \\
\hline $\begin{array}{l}\text { Planning } \\
\text { Stage }\end{array}$ & $\begin{array}{l}\text { Average: }-27 \% \\
\text { Contracts: } 58 \\
\text { C.I: }[-31 \%,-24 \%]\end{array}$ & $\begin{array}{l}\text { Average: }-3.43 \% \\
\text { Contracts: } 45 \\
\text { C.I: }[-4.4 \%,-2.5 \%]\end{array}$ & $\begin{array}{l}\text { Average: } 3.36 \% \\
\text { Contracts: } 56 \\
\text { C.I: }[2.6 \%, 4.1 \%]\end{array}$ & $\begin{array}{l}\text { Average: } 38 \% \\
\text { Contracts: } 80 \\
\text { C.I: }[32 \%, 44 \%]\end{array}$ & $\begin{array}{l}\text { Average: } 6.4 \% \\
\text { Contracts: } 239 \\
\text { C.I: }[2.5 \%, 10.2 \%]\end{array}$ \\
\hline $\begin{array}{l}\text { Design } \\
\text { Stage }\end{array}$ & $\begin{array}{l}\text { Average: }-23 \% \\
\text { Contracts: } 66 \\
\text { C.I: }[-26 \%,-21 \%] \\
\end{array}$ & $\begin{array}{l}\text { Average: }-3.1 \% \\
\text { Contracts: } 52 \\
\text { C.I: }[-3.9 \%,-2.4 \%]\end{array}$ & $\begin{array}{l}\text { Average: } 3.5 \% \\
\text { Contracts: } 50 \\
\text { C.I: }[2.7 \%, 4.3 \%]\end{array}$ & $\begin{array}{l}\text { Average: } 35 \% \\
\text { Contracts: } 71 \\
\text { C.I: }[29 \%, 41 \%]\end{array}$ & $\begin{array}{l}\text { Average: } 4 \% \\
\text { Contracts: } 239 \\
\text { C.I: }[0.5 \%, 7 \%]\end{array}$ \\
\hline $\begin{array}{l}\text { Letting } \\
\text { Stage }\end{array}$ & $\begin{array}{l}\text { Average: }-16 \% \\
\text { Contracts: } 11 \\
\text { C.I:[-19\%,-12\%] }\end{array}$ & $\begin{array}{l}\text { Average: }-4 \% \\
\text { Contracts: } 27 \\
\text { C.I: }[-5 \%,-2.9 \%]\end{array}$ & $\begin{array}{l}\text { Average: } 2.7 \% \\
\text { Contracts: } 138 \\
\text { C.I: }[2.1 \%, 3.2 \%]\end{array}$ & $\begin{array}{l}\text { Average: } 21 \% \\
\text { Contracts: } 63 \\
\text { C.I: }[18 \%, 24 \%]\end{array}$ & $\begin{array}{l}\text { Average: } 5.9 \% \\
\text { Contracts: } 239 \\
\text { C.I:[4.4\%,7.4\%] }\end{array}$ \\
\hline
\end{tabular}

\subsection{Econometric Models for Comparing Letting and Proposed Cost}

Econometric models were developed using the proposed methodology to compare the cost estimates. The models helped to identify the contracts for which letting cost is significantly higher or lower than the proposed cost. Tables 6.19-6.21 present the models for expansion, bridge, and pavement contracts, respectively. Based on the sensitivity analysis, it was found that the letting cost is generally lower than the proposed cost by $0-10 \%$ for contracts in all work categories. Large expansion contracts (greater than $\$ 10$ M) were found to be more likely to have lower letting cost compared to proposed cost, opposes opposed to small expansion contracts.

Table 6.19: Model to Determine Overrun of Letting Cost Compared to Proposed Cost, Expansion Contracts

\begin{tabular}{|c|l|c|c|c|}
\hline Overrun & \multicolumn{1}{|c|}{ Contract Specific Factor } & Coeff. & Std.Err. & t-ratio \\
\hline \multirow{3}{*}{$<-10 \%$} & Seymour and Vincennes Districts in South Indiana & 1.7068 & 0.6745 & 2.53 \\
\cline { 2 - 5 } & Probability of Pattern 'B' & -8.7610 & 3.4968 & -2.51 \\
\cline { 2 - 5 } & Square of Proposed Cost (in \$ millions) & 0.0019 & 0.0012 & 1.64 \\
\hline \multirow{3}{*}[-10\%,0\%]{} & Rural Principal Arterial & 1.1347 & 0.5462 & 2.08 \\
\cline { 2 - 5 } & Greenfield District & -1.4403 & 0.7526 & -1.91 \\
\cline { 2 - 5 } & Urban Districts of Seymour, Greenfield and Laporte & 0.6221 & 0.4126 & 1.51 \\
\hline$[0 \%, 10 \%]$ & Crawfordsville and Greenfield Districts in Central Indiana & -2.2946 & 0.9146 & -2.51 \\
\cline { 2 - 5 } & Proposed Cost between \$1 M -\$ 2M & 2.0807 & 1.1871 & 1.75 \\
\hline$>10 \%$ & Constant & -1.9431 & 0.6316 & -3.08 \\
\cline { 2 - 5 } & Vincennes District & 2.3284 & 1.0823 & 2.15 \\
\hline
\end{tabular}


The probability of experiencing a lower letting cost relative to the proposed cost was found to increase with larger bridge contract sizes. Large pavement contracts (greater than $\$ 5 \mathrm{M}$ ) were found more likely to experience a lower letting cost compared to proposed cost, as opposed to small pavement contracts. More results corresponding to the comparison of letting cost with proposed cost are summarized in Appendix A.

Table 6.20: Model to Determine Overrun of Letting Cost Compared to Proposed Cost, Bridge Contracts

\begin{tabular}{|c|l|c|c|c|c|}
\hline Overrun & \multicolumn{1}{|c|}{ Contract Specific Factor } & Coeff. & Std.Err. & t-ratio & P-value \\
\hline \multirow{3}{*}{$<-10 \%$} & Probability of Pattern 'B' & -4.3647 & 2.5941 & -1.68 & 0.09 \\
\cline { 2 - 6 } & Proposed Cost (\$ Millions) & 0.4103 & 0.1847 & 2.22 & 0.03 \\
\cline { 2 - 6 } & Non-NHS Highway & 1.5649 & 0.5995 & 2.61 & 0.01 \\
\hline \multirow{3}{*}[-10\%,0\%]{} & Constant & 3.6267 & 0.7834 & 4.63 & 0.00 \\
\cline { 2 - 6 } & U.S. Highway & -1.2815 & 0.5024 & -2.55 & 0.01 \\
\cline { 2 - 6 } & Probability of Pattern 'b' & -6.6929 & 2.2536 & -2.97 & 0.00 \\
\hline \multirow{2}{*}[0\%,10\%]{} & Variability in Probability of Pattern 'C' & 15.2867 & 4.5225 & 3.38 & 0.00 \\
\cline { 2 - 6 } & State Roads & 0.9244 & 0.6020 & 1.54 & 0.12 \\
\hline \multirow{2}{*}{$>10 \%$} & Urban Interstates and Expressways & 5.0596 & 1.4881 & 3.40 & 0.00 \\
\cline { 2 - 6 } & Probability of Pattern 'A' & -4.5001 & 1.9997 & -2.25 & 0.02 \\
\cline { 2 - 6 } & Rural Minor Arterial & 2.8171 & 1.4809 & 1.90 & 0.06 \\
\hline
\end{tabular}

Table 6.21: Model to Determine Overrun of Letting Cost Compared to Proposed Cost, Pavement Contracts

\begin{tabular}{|c|l|c|c|c|c|}
\hline Overrun & \multicolumn{1}{|c|}{ Contract Specific Factor } & Coeff. & Std.Err. & t-ratio & P-value \\
\hline \multirow{5}{*}{$<-10 \%$} & Constant & -28.7780 & 5.2123 & -5.52 & 0.00 \\
\cline { 2 - 6 } & Logarithm of Proposed Cost (in \$) & 2.0747 & 0.3617 & 5.74 & 0.00 \\
\cline { 2 - 6 } & Urban Arterials and Collectors & -1.0555 & 0.5094 & -2.07 & 0.04 \\
\cline { 2 - 6 } & Variability in Probability of Escalation Pattern 'B' & -31.4144 & 12.0364 & -2.61 & 0.01 \\
\cline { 2 - 6 } & Proposed Cost $>$ \$10 M & -2.4762 & 0.9550 & -2.59 & 0.01 \\
\hline \multirow{3}{*}[-10\%,0\%]{} & Crawfordsville District & -0.7617 & 0.4025 & -1.89 & 0.06 \\
\cline { 2 - 6 } & Probability of Pattern 'B' & -1.7341 & 0.9739 & -1.78 & 0.07 \\
\hline \multirow{3}{*}[0\%,10\%]{} & Rural Minor Arterial & 0.7942 & 0.3650 & 2.18 & 0.03 \\
\cline { 2 - 6 } & Proposed Cost between \$1 M -\$ 2M & -0.8477 & 0.2960 & -2.86 & 0.00 \\
\hline$>10 \%$ & Probability of Pattern 'A' & -1.8193 & 0.5631 & -3.23 & 0.00 \\
\hline
\end{tabular}




\subsection{Conclusions}

The developed methodology was used to carry out a risk-based econometric analysis for expansion, pavement, and bridge contracts in Indiana. Econometric models were calibrated to describe the relationship of escalation pattern, planning, design, and letting stage cost overruns with contract-specific factors. The contracts that are more likely to experience a cost overrun were identified and the relationships suggested by cost overrun trends (presented in Chapter 4) in Indiana, were statistically validated using the developed models. It was demonstrated that the proposed methodology (in Chapter 4) can be used to developed riskbased econometric analysis frameworks for identification of contracts susceptible to cost overrun. Contracts that are more likely to have unfavorable escalation patterns and are more likely to experience high cost overrun can be identified by other highway agencies by developing similar frameworks.

A summary of the findings and the impact of contract-specific factors on the probability and magnitude of cost overrun is provided in Appendix A. A Cost Overrun Analysis Software was developed for Indiana that incorporates the developed risk-based econometric models for expansion, bridge, and pavement contracts. The software can be used by INDOT in the future to conduct the analysis presented in this Chapter. Moreover, the software can also be used by INDOT to identify the contracts that are currently being planned and are likely to experience cost overrun. Chapter 7 describes the features and the working of the software. 


\section{CHAPTER 7. COST OVERRUN ANALYSIS SOFTWARE}

\subsection{Introduction}

A software tool was developed for Indiana to help the state highway agency estimate the probability and magnitude of a cost overrun for a contract on the basis of its characteristics. The estimated probability and magnitude of cost overrun can be compared across a set of contracts, and the ones that are more likely to experience cost overrun can be identified. This chapter presents the software modules, framework, and an example to demonstrate the working of the software and the process of estimating the probability and magnitude of cost overrun.

\subsection{Software Modules}

The software has three modules. Figure 7.1 presents a flowchart that describes the working of the software and the flow of information from one module to another. First, a list of contracts that to be compared is prepared. The three modules are then run one by one for each contract in the list. For each contract, information on contract-specific factors is specified as input. Module $I$ is run to determine the probability and the variability in probability of an escalation pattern. The multinomial logit models presented in Chapter 6 for expansion, bridge, and pavement contracts are used to determine the probability of escalation pattern depending upon the work type of the contract being analyzed. A Monte Carlo simulation is conducted to calculate the variability in the probability of an escalation pattern. The risk that the given contract type will exhibit a particular escalation pattern is determined by calculating the mean, standard deviation, and $95 \%$ confidence interval of the probability of an escalation pattern. Next, Module II is run to determine probability of a planning, design, or letting stage cost overrun (as specified by the user). The contract-specific factors and the risk of occurrence of an escalation pattern are used as an input in the Module II models. In order to determine the variability in the probability of overrun, Monte Carlo simulation is conducted. The mean, standard deviation and $95 \%$ confidence interval of the probability of cost overrun are determined based on the Monte Carlo simulation runs. Module III is run to determine the magnitude of cost overruns based on the probability of occurrence of each cost overrun category (as computed using Module II). The conditional probability principle is used to calculate the magnitude of cost

overrun. The conditional probability principle uses the probability of cost overrun categories and the 
magnitude of overrun corresponding to each category, so as to determine the expected magnitude of cost overrun.

The modules are run for all the contracts in the list until the end of list is reached. The results corresponding to probability of escalation patterns, probability of cost overrun, and magnitude of cost overrun are stored in an Excel file for further analysis. Further analysis is conducted to compare the propensity of contracts to exhibit a particular escalation pattern and to experience a cost overrun. The contracts that are most likely to experience increasing costs and high cost overruns are identified based on this comparison. 


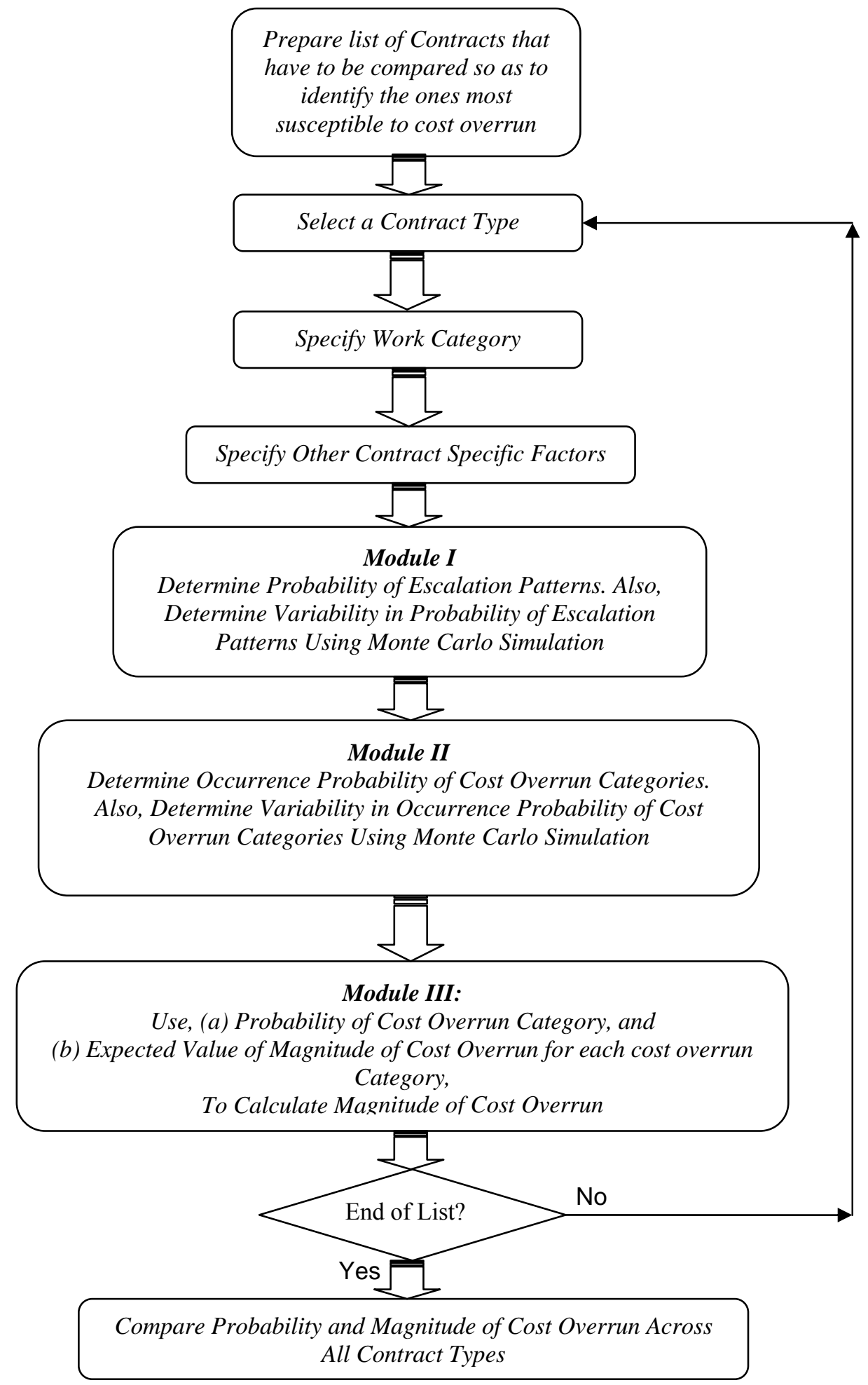

Figure 7.1: Flowchart Depicting the Working of Cost Overrun Analysis Software 


\subsection{Interface and Software Framework}

The software provides the user with three options to compare a set of contract types and consequently to identify the ones with high positive and negative cost overruns. Figure 7.2 shows the front page interface of the software with the three options.

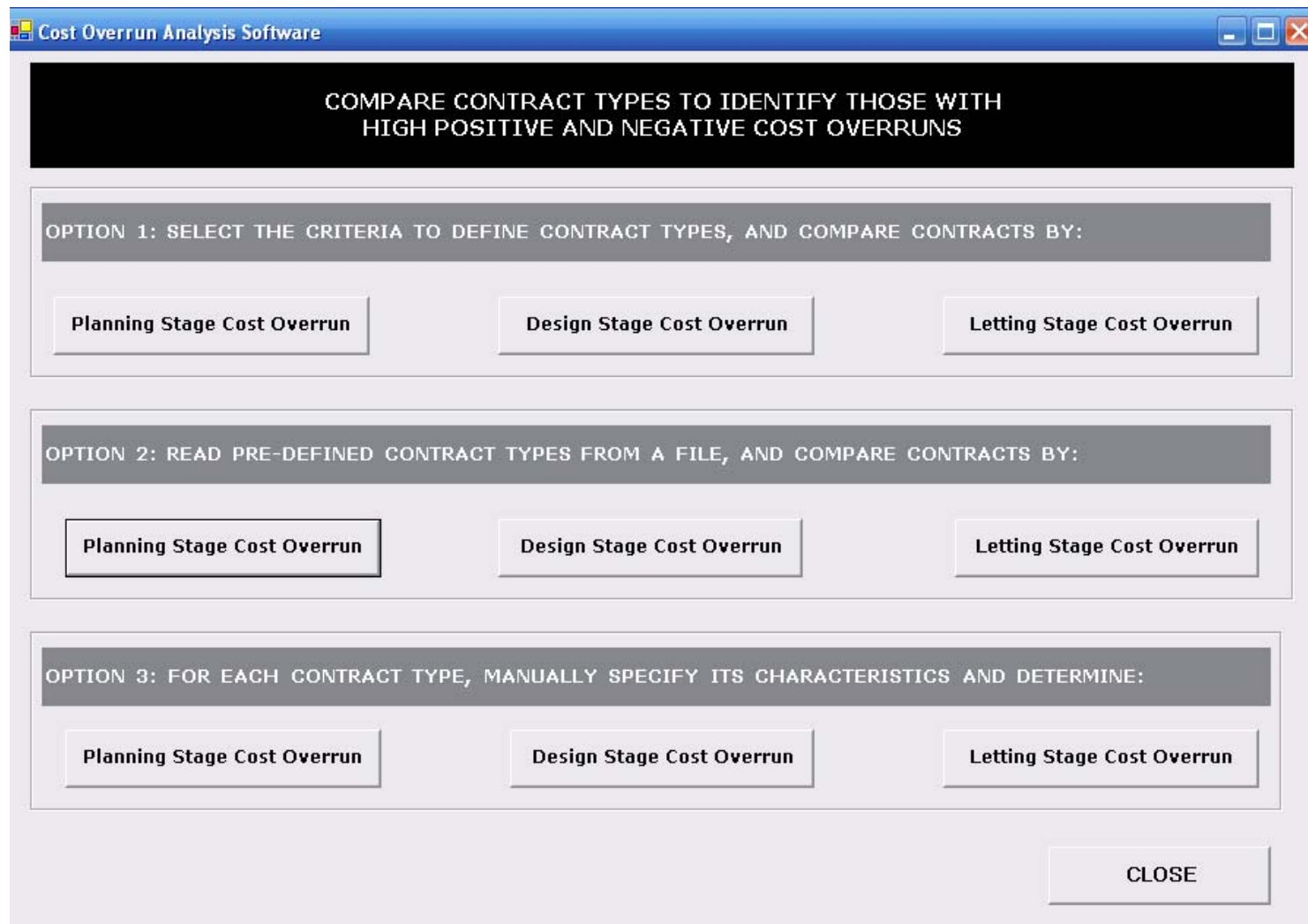

Figure 7.2: Front Page Interface Showing the Features of the Cost Overrun Analysis Software

a. Option 1: Select the criteria to define the contract types

Using this option, the user can define the contract types to be compared based on criteria such as the geographic location (district), highway functional class, area type, work category, contract size, and contract letting strategy. The option is used when it is desired to study the trends in cost overrun due to variation in these contract-specific factors. Figure 7.3 shows the user interface that provides the options to select the criteria to compare contracts based on a planning stage cost overrun. For example, contracts across all districts, highway functional classes, work categories, and contract sizes ranging from $\$ 1 \mathrm{M}$ to $\$ 20 \mathrm{M}$ can be compared by selecting the appropriate criterion. When contracts have to be compared on the basis of the design and letting stage cost overruns, additional criteria are used such as: a) time duration 
between design and project proposal, b) time duration between letting and project proposal, c) percentage difference between design and proposed cost, and d) percentage difference between letting and proposed cost.

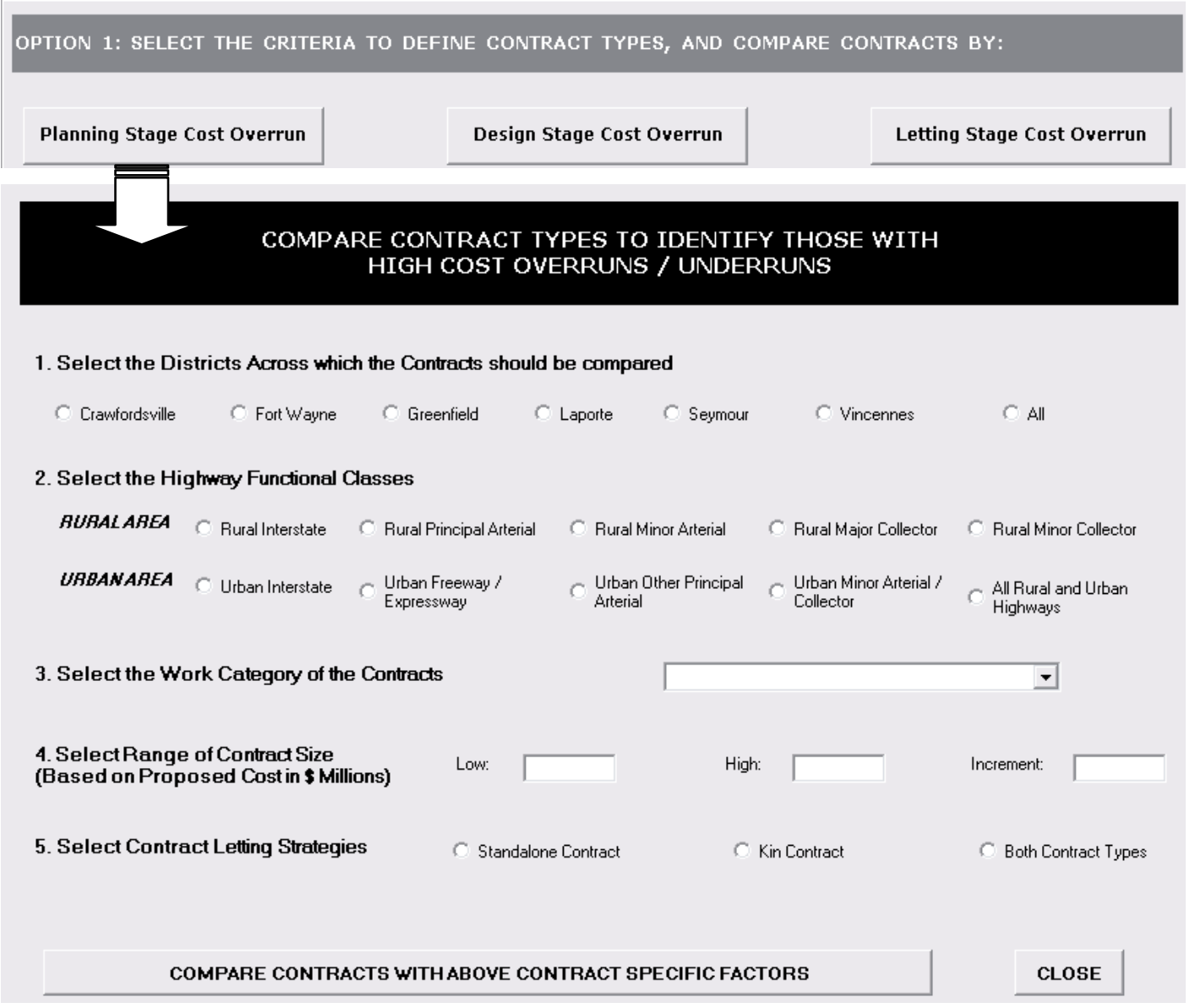

Figure 7.3: Select Criteria to Define Contract Types for Comparison Based on Planning Cost Stage Overrun

b. Option 2: Read pre-defined contract types from a file

This option allows the user to compare the tendency towards cost overruns across pre-defined contract types that are being planned, designed, or are scheduled for letting. If the accuracy of the proposed cost has to be compared the 'planning stage cost overrun' tab is selected (Figure 7.4). Information available at the planning stage is read for each contract type from a file. The information that is required includes: work category, district, highway functional class, area type, NHS status, kin vs. stand-alone contracts, and proposed cost (in \$Million). If the accuracy of final design estimate has to be compared, the 'design stage cost overrun' tab is selected. Information available at the design stage is read for each contract type. This 
includes the information available at the planning stage plus the time duration from planning to final design and the percentage difference between design estimate and proposed cost. If the accuracy of letting cost has to be compared, the 'letting stage cost overrun' tab is selected. Information in addition to that read at the design stage is read from a file. Additional information includes: time duration from planning to letting and percentage difference between letting and proposed cost.

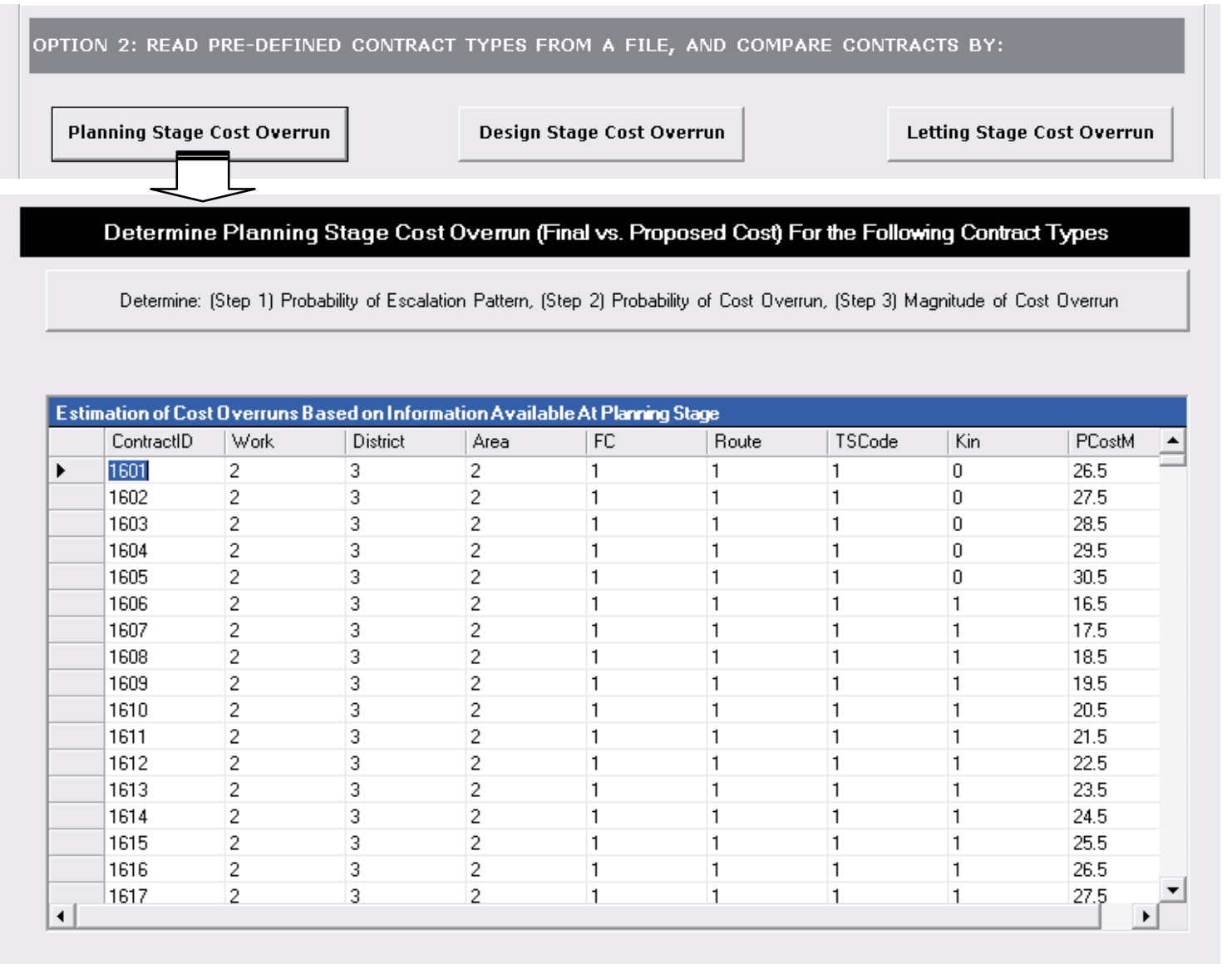

Figure 7.4: Reading Contract Types from a File for Comparison Based on Planning Cost Stage Overrun

c. Option 3: For each contract type, manually specify contract characteristics and determine cost overrun This option allows the user to compare contract types by estimating the cost overrun for each contract type, one by one. It allows the user to manually enter the data corresponding to a contract type. By selecting this option, the user is taken through each of the three modules of the software that are used for determining: a) probability of escalation pattern (Module I), b) probability of cost overrun (Module II), and c) magnitude of cost overrun (Module III). Figures 7.5-7.7 present the inputs that the user is required to provide when this option is selected, in order to determine the planning, design, and letting stage cost overruns, respectively. This option allows the user to track the workings of the software by going through each module one by one. Options 1 and 2, on the other hand, determine the cost overrun for all the specified 
contract types and stored them in a file without allowing the user to analyze the results at the end of each module. The results of each module are presented for the contract type corresponding to which information was entered. The process is repeated for all the contracts that the user wishes to analyze.

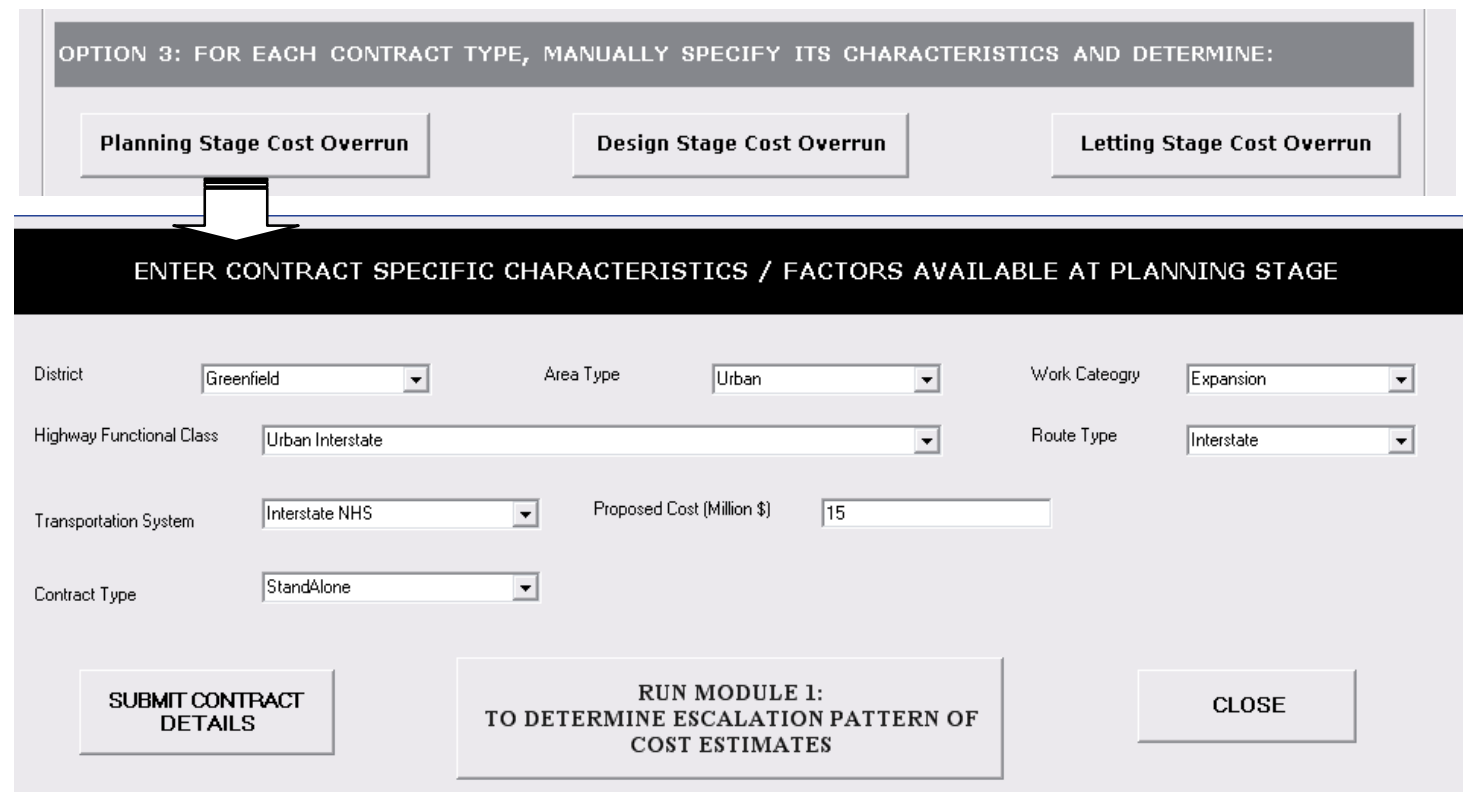

Figure 7.5: Entering Contract-Specific Factors to Determine Planning Stage Cost Overrun

OPTION 3: FOR EACH CONTRACT TYPE, MANUALLY SPECIFY ITS CHARACTERISTICS AND DETERMINE:

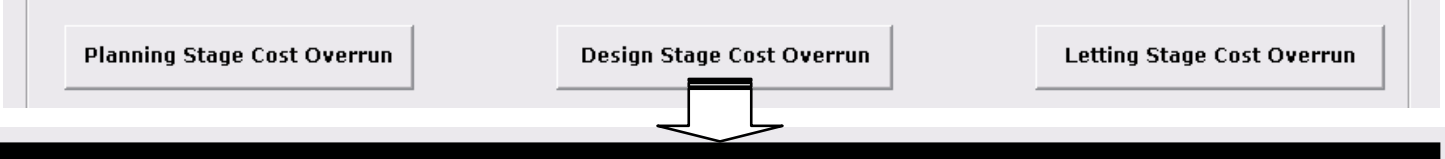

ENTER CONTRACT SPECIFIC CHARACTERISTICS / FACTORS AVAILABLE AT DESIGN STAGE

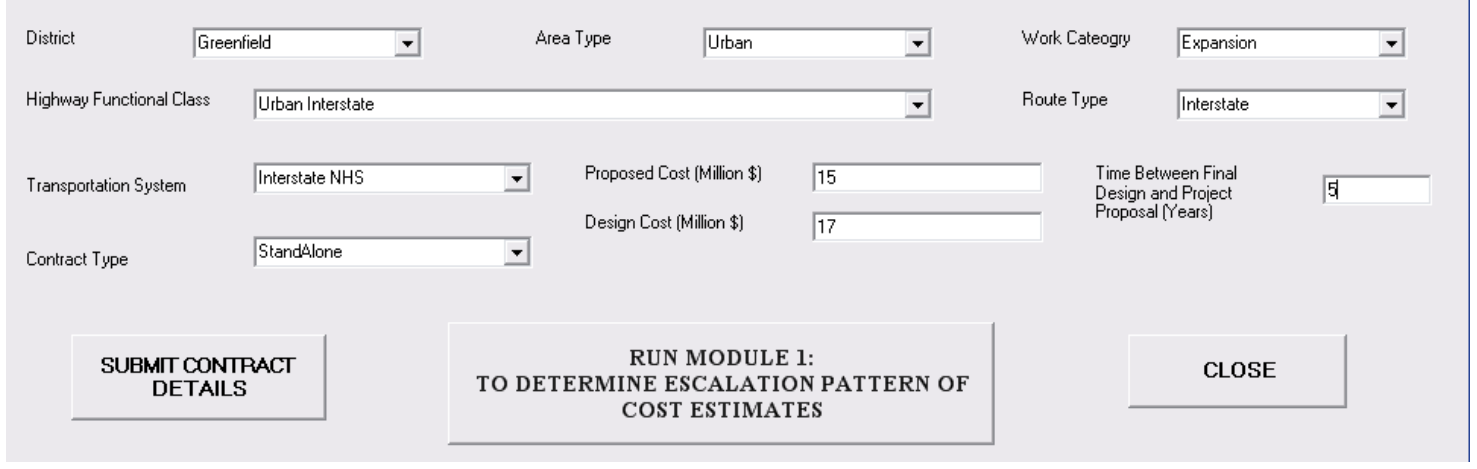

Figure 7.6: Entering Contract-Specific Factors to Determine Design Stage Cost Overrun 


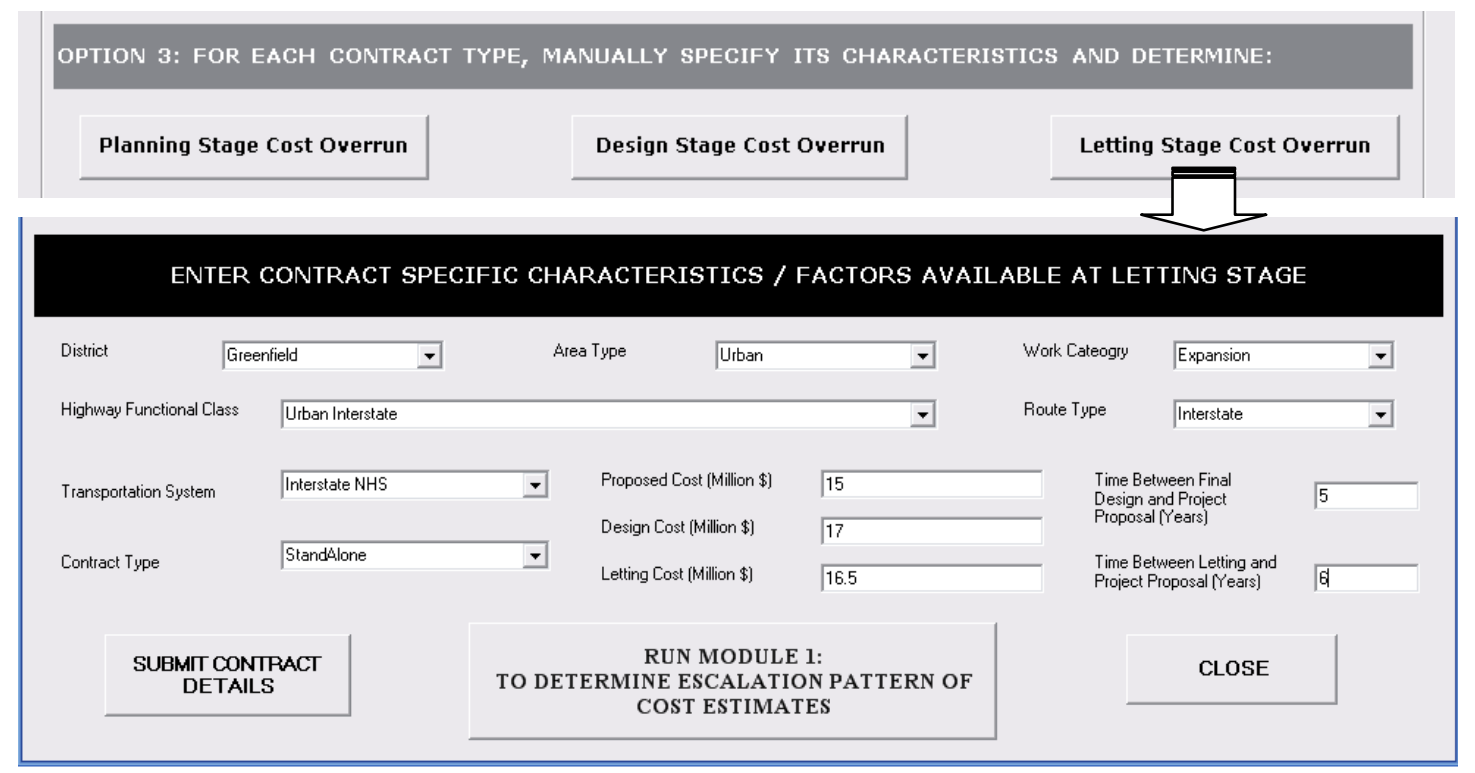

Figure 7.7: Entering Contract-Specific Factors to Determine Letting Stage Cost Overrun

\subsection{Example - Identifying Contracts Susceptible to Cost Overrun}

Irrespective of the option that is selected $(1,2$, or 3$)$, the three modules of the software are run to compute the probability of an escalation pattern, probability of cost overrun, and the magnitude of cost overrun, respectively. When options 1 or 2 are selected, the modules are run, one after the other, once for each contract type, in the list of contract types that are desired to be compared. For example, INDOT may plan to implement 15 expansion contracts during the next ten years (say 2010-2020) for which an estimate of the construction cost has been prepared for all the contracts at the planning stage (proposed cost). The agency is then looking to identify the contracts that are more relatively susceptible to cost overrun. Table 7.1 presents the information on contract-specific factors corresponding to the hypothetical contracts. 
Table 7.1: A List of 15 Hypothetical Expansion Contracts

\begin{tabular}{|c|c|c|c|c|c|c|}
\hline $\begin{array}{l}\text { Contract } \\
\text { ID }\end{array}$ & District & $\begin{array}{l}\text { Area } \\
\text { Type }\end{array}$ & Route Type & $\begin{array}{l}\text { Functional } \\
\text { Class }\end{array}$ & NHS Status & $\begin{array}{c}\text { Proposed } \\
\text { Cost } \\
(\$ \\
\text { Million) }\end{array}$ \\
\hline 1 & Greenfield & Rural & State Road & $\begin{array}{c}\text { Rural Minor } \\
\text { Arterial }\end{array}$ & Non-NHS & 6 \\
\hline 2 & Greenfield & Rural & Interstate & Rural Interstate & Interstate & 11 \\
\hline 3 & Greenfield & Urban & Interstate & $\begin{array}{c}\text { Urban } \\
\text { Interstate }\end{array}$ & Interstate & 15 \\
\hline 4 & Greenfield & Rural & U.S. Road & $\begin{array}{c}\text { Rural Principal } \\
\text { Arterial }\end{array}$ & $\begin{array}{c}\text { Non-Interstate } \\
\text { NHS }\end{array}$ & 7 \\
\hline 5 & Seymour & Rural & U.S. Road & $\begin{array}{c}\text { Rural Principal } \\
\text { Arterial }\end{array}$ & $\begin{array}{c}\text { Non-Interstate } \\
\text { NHS }\end{array}$ & 3 \\
\hline 6 & Seymour & Rural & Interstate & Rural Interstate & Interstate & 5.5 \\
\hline 7 & Seymour & Urban & State Road & $\begin{array}{l}\text { Rural Principal } \\
\text { Arterial }\end{array}$ & Non-NHS & 8 \\
\hline 8 & Seymour & Urban & Interstate & $\begin{array}{c}\text { Urban } \\
\text { Interstate }\end{array}$ & Interstate & 10 \\
\hline 9 & Laporte & Urban & State Road & $\begin{array}{c}\text { Urban Other } \\
\text { Principal } \\
\text { Arterial }\end{array}$ & Non-NHS & 6 \\
\hline 10 & Laporte & Rural & State Road & $\begin{array}{l}\text { Rural Minor } \\
\text { Arterial }\end{array}$ & Non-NHS & 4 \\
\hline 11 & Laporte & Urban & U.S. Road & $\begin{array}{l}\text { Urban Freeway } \\
\text { / Expressway }\end{array}$ & $\begin{array}{c}\text { Non-Interstate } \\
\text { NHS }\end{array}$ & 5 \\
\hline 12 & Crawfordsville & Urban & U.S. Road & $\begin{array}{l}\text { Urban Freeway } \\
\text { / Expressway }\end{array}$ & $\begin{array}{c}\text { Non-Interstate } \\
\text { NHS }\end{array}$ & 8 \\
\hline 13 & Crawfordsville & Rural & Interstate & $\begin{array}{c}\text { Urban } \\
\text { Interstate }\end{array}$ & Interstate & 9 \\
\hline 14 & Fort Wayne & Urban & U.S. Road & $\begin{array}{c}\text { Urban Other } \\
\text { Principal } \\
\text { Arterial }\end{array}$ & $\begin{array}{c}\text { Non-Interstate } \\
\text { NHS }\end{array}$ & 3.5 \\
\hline 15 & Vincennes & Rural & Interstate & Rural Interstate & Interstate & 2 \\
\hline
\end{tabular}

Module $I$ of the software is run to determine the probability of occurrence of escalation patterns 'A', 'B', 'C', and 'D'. Figure 6.8 presents a plot of the mean probability of the four escalation patterns. A detailed analysis of the propensity of each contract type to exhibit pattern ' $\mathrm{B}$ ' (increasing cost trend) is presented in Figure 6.9. It is found that contracts 1, 2, 3, and 7 are most likely to experience an increasing trend of cost from planning to final construction. 


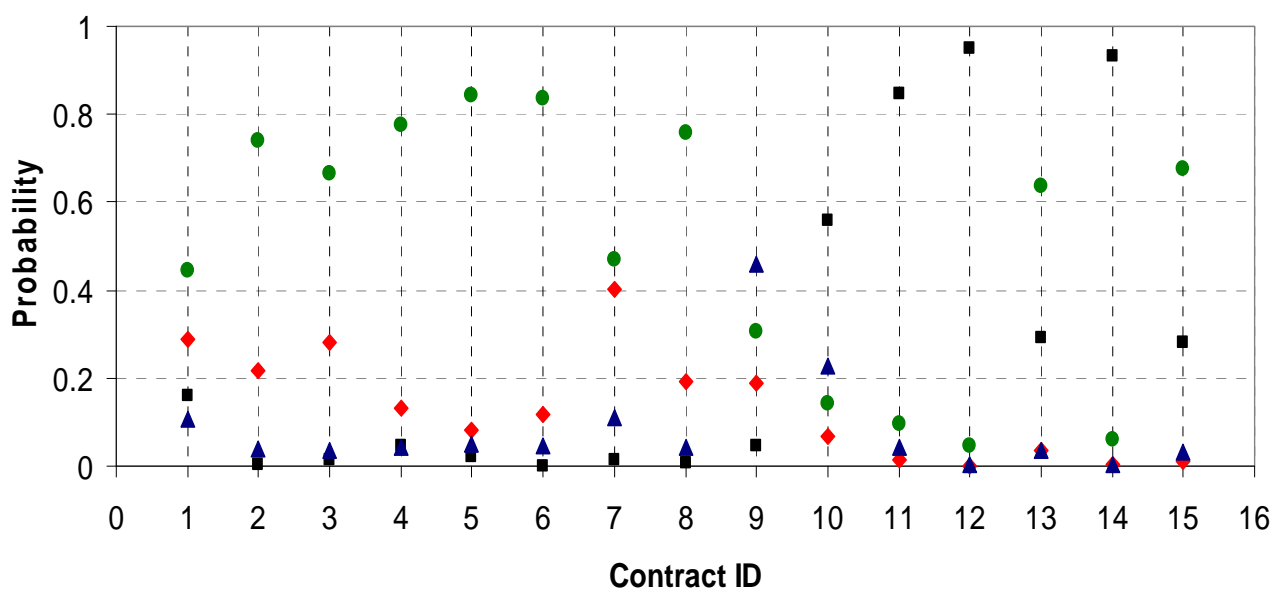

- Pattern 'A' - Pattern 'B' - Pattern 'C' $\triangle$ Pattern 'D'

Figure 7.8: Probability of Occurrence of Escalation Pattern for the Hypothetical Contracts

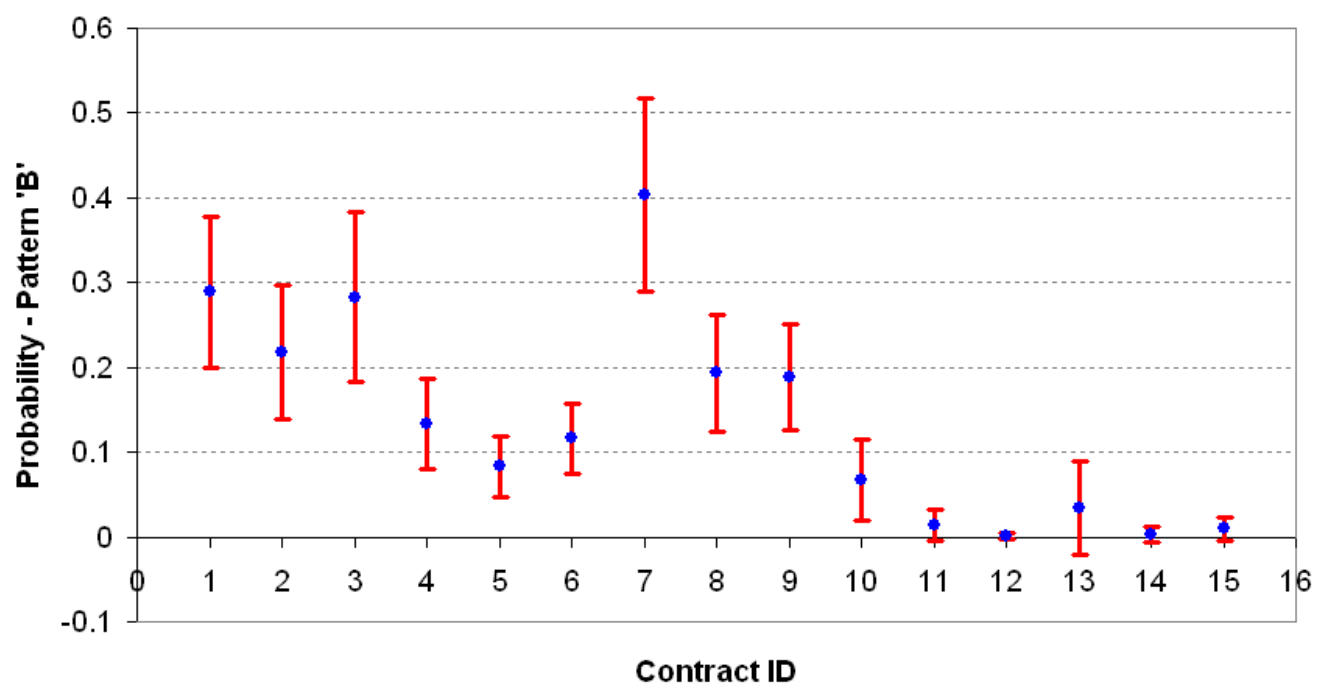

Figure 7.9: Probability of Occurrence of Escalation Pattern 'B' and its Variability

Module II of the software is run to determine the probability of planning stage cost overrun. The objective is to identify the contracts that are most likely to have an inaccurate estimate of proposed cost. Figure 7.10 presents a plot of the probability of occurrence of cost overrun in each of the four cost overrun categories. Contracts 1, 2, 3, and 7 were found more likely to experience a cost overrun of greater than $10 \%$ compared to other contracts. The variability in the probability of occurrence of the four cost overrun categories can be analyzed in the same way as the variability in the probability of escalation pattern (see Figure 7.9). Module III of the software is used to determine the expected magnitude of cost overrun (Figure 7.11). 


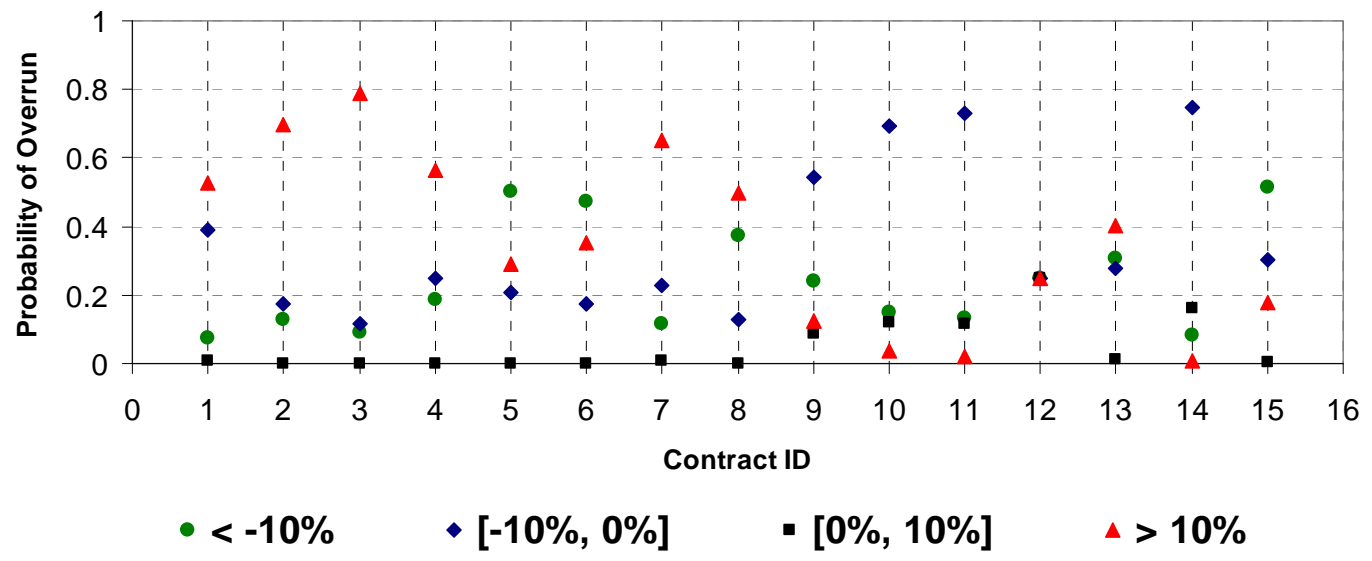

Figure 7.10: Probability of Planning Stage Cost Overrun Categories for Hypothetical Contracts

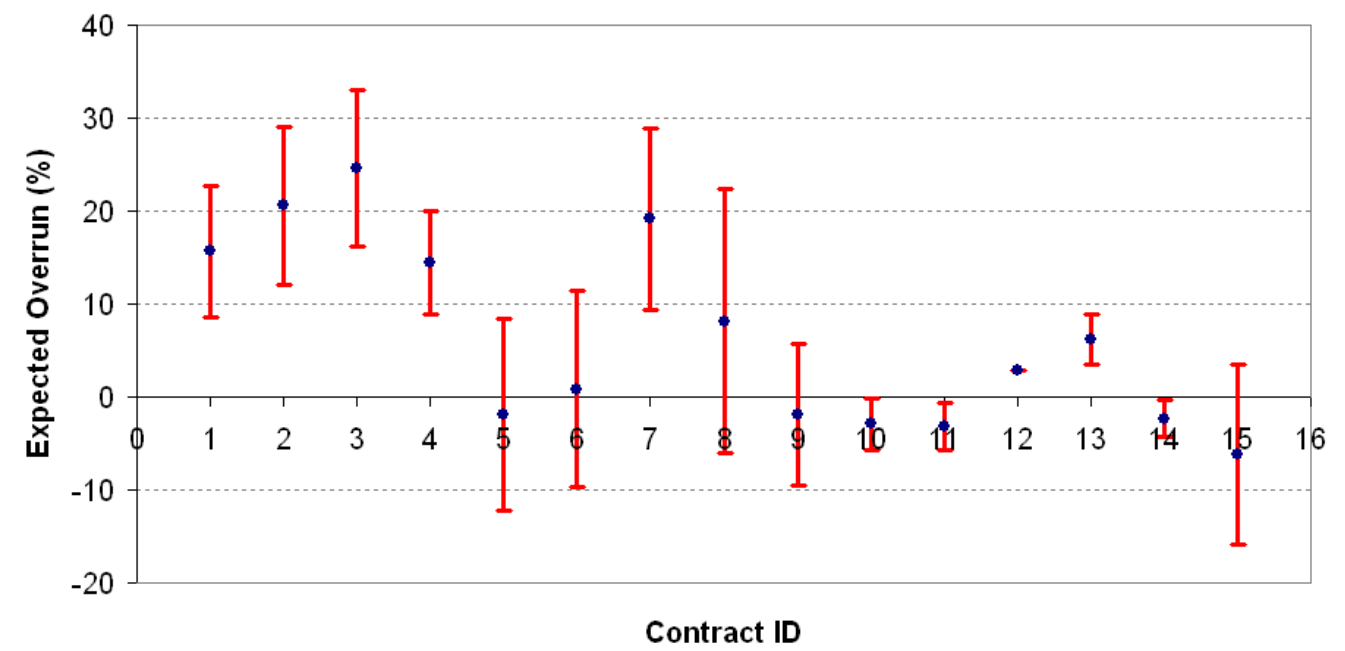

Figure 7.11: Expected Cost Overrun for Hypothetical Contracts

By selecting option 3, the user is allowed to run the three modules for each contract type individually, one at a time. This way the user is able to track the workings of the software and the flow of information from one module to another as described in Figure 7.1. For example, say option 3 is selected and the contract specific factors for contract 3 in Table 7.1 are specified as follows (see Figure 7.5):

District: Greenfield; Area type: Urban; Work Category: Expansion; Functional Class:

Urban Interstate; Route type: Interstate; NHS Status: Interstate; Proposed Cost: \$15 M.

The contract details are submitted by clicking on the "submit contract details" button (Figure 7.5), then, Module $I$ is run. Figure 7.12 shows the inputs to and output of Module I. The mean, standard deviation, coefficient of variation, and $95 \%$ confidence interval of the probability of each escalation pattern 
is computed using Module I. The probability of each escalation pattern was calculated in two ways: the first way is to use the calibrated multinomial logit models for determining the escalation pattern of expansion contracts (as presented in Chapter 6) to determine the mean U-function values and probabilities corresponding to each escalation pattern (these probabilities are shown under "Without Risk Analysis (Using Mean U-function Values)" tab) and the second way is to use Monte Carlo Simulation to determine the probability of each escalation pattern, so as to take into consideration the variability in the probability of each escalation pattern across all the contracts of the type that is being analyzed here. A total of 100 simulation runs were done. The mean probability of each escalation pattern that was computed, based on all the simulation runs, was found to converge to the mean probability of each escalation pattern that was determined without conducting a Monte Carlo simulation. The mean probability, its standard deviation, $95 \%$ confidence interval, and coefficient of variation were calculated for each pattern and are shown under the "With Risk Analysis (Based on Monte Carlo Simulation)" tab.

The results indicate that contracts of the specified type are likely to exhibit pattern ' $A$ ', $68 \%$ of the time. However, the risk of cost overrun increases with pattern ' $\mathrm{B}$ ' and the probability of pattern ' $\mathrm{B}$ ' was considerable (27\%). The upper limit of the $95 \%$ confidence interval of this probability was $48 \%$, which further indicated that there is a chance that some of the contracts of the specified type will experience an increasing trend in cost estimates due to unforeseen costs.

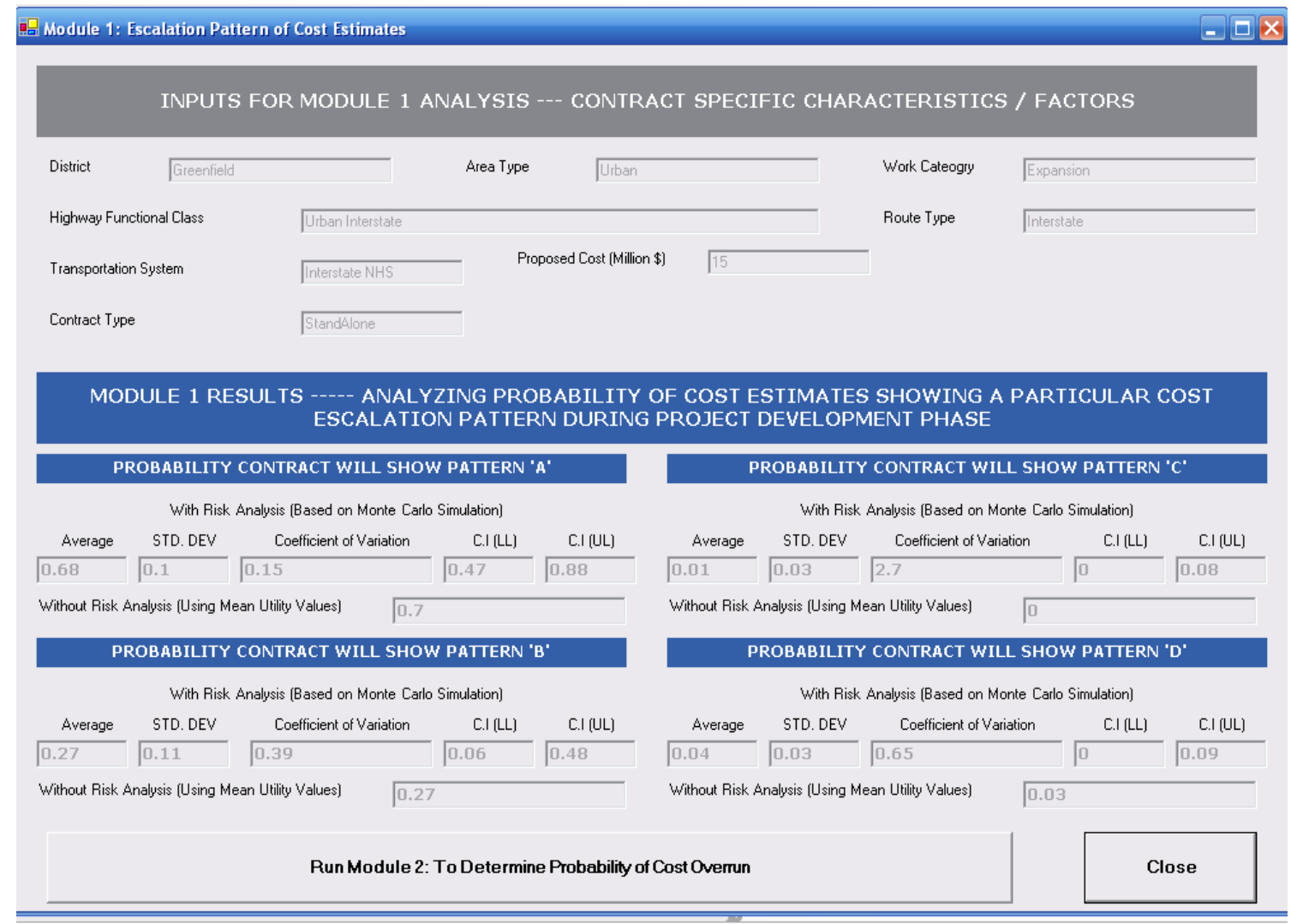

Figure 7.12: Interface Showing the Inputs and Results from Module 1 
Module II is run next by clicking on the "Run Module 2" button. Module II is used to calculate the probability of cost overrun. Figure 7.13 presents the interface showing the inputs to and output of Module II. The probability of cost overrun is computed using the planning stage cost overrun models for expansion contracts, which were presented in Chapter 6. Monte Carlo simulation is conducted, as in Module I, to determine the variability in the probability of cost overrun across all the contracts of the type that is being analyzed here. It was found that the contracts of the specified type were significantly more likely to experience cost overruns greater than $10 \%$. The probability of overruns greater than $10 \%$ was found to be $75 \%$ and was likely to be between $52 \%$ and $98 \%$ for $95 \%$ of the contracts that are of the type that is being analyzed here. However, it is important to note here that the multinomial logit models, that were presented in chapter 6 , were developed to identify contracts that were more likely to experience high cost overrun by conducting a comparative analyses of a set of contract types. The developed models were more suitable to study the impact of variations in the specified inputs on the probability of escalation pattern and on the probability and magnitude of cost overrun. The predictions made using the developed models for planning stage cost overrun are likely to be less reliable as the models McFadden R-squared values were low (0.15 0.25). However, the models developed for design stage and letting stage cost overrun had comparatively higher R-squared values $(0.20-0.40)$. Despite the low R-squared value, the results in Figure 7.9 do provide a reasonable estimate of the probability of cost overrun corresponding to the specified contract types.

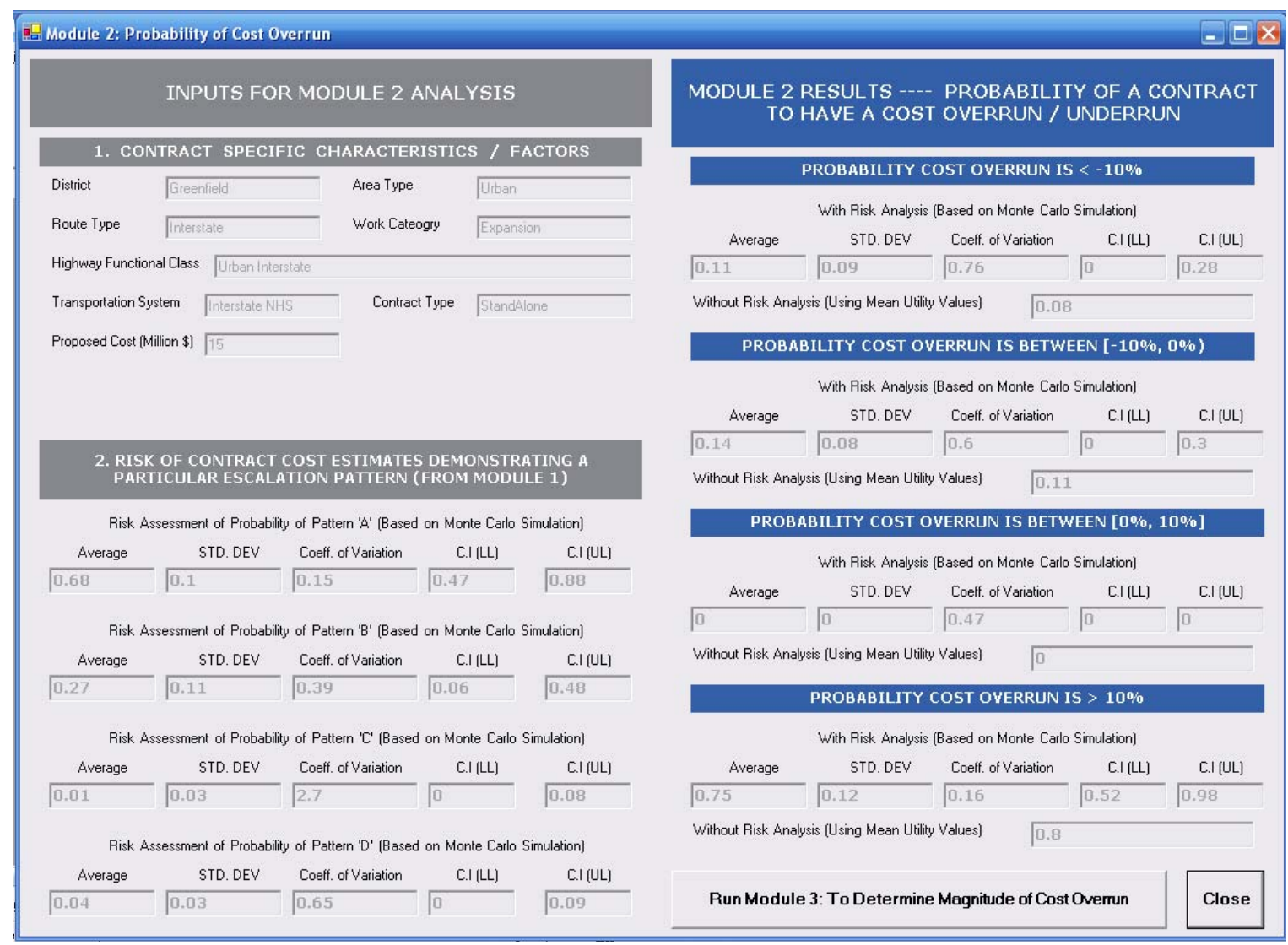

Figure 7.13: Interface Showing the Inputs and Results from Module 2 
Module III is run next to determine the magnitude of cost overrun using the probability of cost overrun computed in Module II. The magnitude of cost overrun is determined corresponding to each draw of the Monte Carlo simulation that was conducted in Module II. The average magnitude of planning stage cost overrun is calculated based on the magnitude of overrun in all the draws. The standard deviation, coefficient of variation, and $95 \%$ confidence interval of the average are also computed. Figure 7.14 presents the interface that presents the results of Module III.

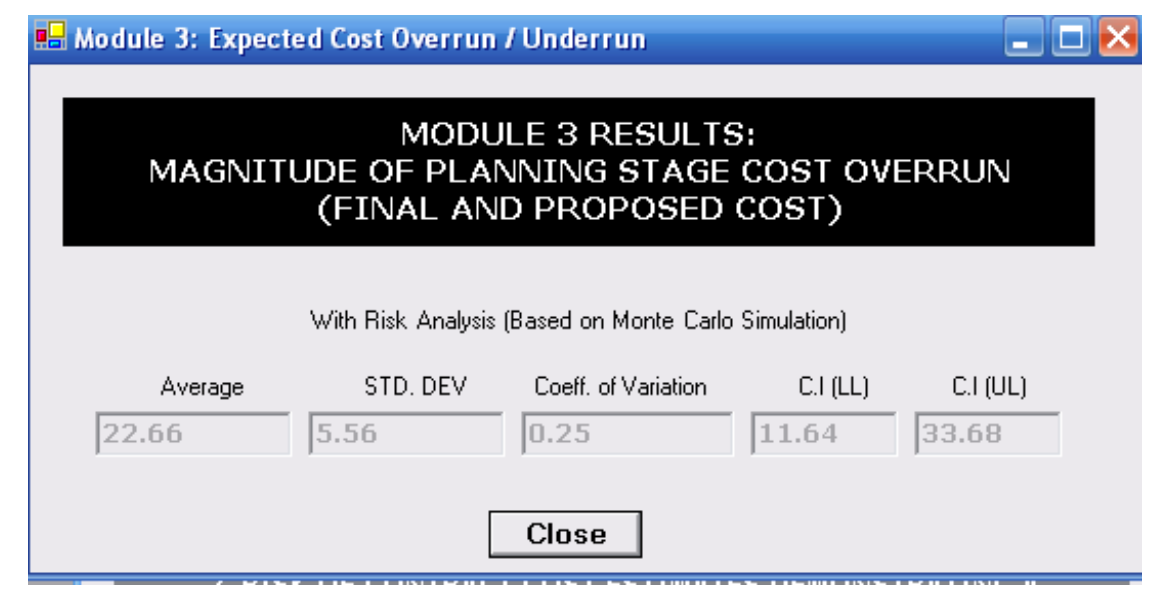

Figure 7.14: Interface Showing the Inputs and Results from Module 3

\subsection{Chapter Summary}

The Cost Overrun Analysis Software was presented in this chapter. The working of the three modules of the software was demonstrated with the help of an example. The framework of the software was also presented. The software can be used by highway agencies as a tool to identify the contract types that are likely to experience high cost overrun, based on the trends seen for historical contracts. The use of the software for predictive purposes is limited and is likely to give less reliable results. However, the estimated cost overrun using the software provide planners and decision-makers with an approximate idea about the expected cost overrun. Such information can be useful in establishing monetary amounts for contract contingencies. 


\title{
CHAPTER 8. SUMMARY CONCLUSIONS AND RECOMMENDATIONS
}

\begin{abstract}
8.1. Summary
8.1.1. Background

Highway construction costs are estimated at several stages during the project cycle. The first estimate is prepared at the planning stage, followed by the engineer's assessment, design estimates, engineer's estimate, and letting cost. A comprehensive literature review was conducted on highway construction cost overruns. It was found that most of the highway agencies focused on the comparison of final and letting costs. However, the overrun of the final cost relative to the design estimate, engineer's estimate, or proposed cost has been rarely studied. More importantly, the pattern of escalation of the cost estimate from one stage to another during the planning and development phase received little or no attention. Highway agencies resorted to calculating cost overruns using simple averages for contracts within their jurisdiction as means to measure the severity of final cost overrun with respect to the letting cost. This approach often results in serious underestimation of construction cost overruns. This is because large positive cost overruns $(>10 \%)$ are often compensated by large negative cost overruns $(<-10 \%)$, resulting in a simple average of zero. To resolve the issue, some highway agencies have started to look at the distribution of cost overruns, taking into account factors, such as change orders, unforeseen site conditions, and inflation that may be responsible for cost overruns. However, there is still a huge vacuum in research and practice as transportation planners and decision-makers need a tool that can help them identify contracts that are likely to experience cost overruns. Knowledge about the inaccuracy of the estimates prepared at various stages of planning and development phase allows planners to plan appropriately by readjusting contingency amounts and planning risk-prone contracts in efficient ways.
\end{abstract}

\subsubsection{Contribution}

\subsubsection{Methodology for the Analysis of Construction Costs}

Most agencies do not have a methodological framework to identify projects where final cost is likely to exceed the cost estimate, or where the cost estimate is likely to exceed the final cost. This study proposes a methodology consisting of a risk-based econometric analysis framework that can be used to analyze the escalation pattern of the cost estimates from planning stage to final construction and to determine the probability and magnitude of cost overruns. Cost overrun is determined on the basis of a comparison of the 
final cost with any one of the cost estimates prepared at a prior stage. Those contracts that are more likely to experience an increasing trend of cost estimates and are more likely to experience high cost overrun can be identified using the risk-based econometric analysis framework. The proposed framework comprises three modules.

Module I comprises models that can be used to determine the probability that for a given contract, the cost estimates across the entire project development cycle will exhibit a particular escalation pattern. Information on contract-specific factors that are available during the planning and development phase is required for determining the probability of escalation pattern. Such factors include: work category (expansion, bridge, pavement), geographic location (district and area type), highway functional class, NHS status (NHS, Non-NHS), route type (Interstate, U.S. highway, State Road), contract size (based on proposed cost), and contract classification as a stand-alone or kin contract. These contract-specific factors define a contract type. In practice, several contracts can have these characteristics. In order to take into account the variability in the probability of an escalation pattern across the contracts of a particular type, a Monte Carlo simulation approach is used in this study. The coefficients of the models, that are used to determine the required functions, are multivariate, normal-distributed, therefore, the functions are also multivariate, normal-distributed. In each draw of Monte Carlo simulation the functions of the escalation patterns are drawn from the multivariate normal distribution. The probabilities of the escalation patterns are determined using the randomly drawn functions. The risk that the given contract type will exhibit a particular escalation pattern is determined by calculating the mean, standard deviation, and $95 \%$ confidence interval of the probability of an escalation pattern. The escalation pattern of the construction cost estimates has not been analyzed in past studies and the proposed approach to determine the risk associated with occurrence of an escalation pattern has also been used rarely, if at all, in the field of transportation engineering.

Module II comprises models that use information on contract-specific factors and the risk that a contract type will exhibit a particular escalation pattern to determine the probability of cost overrun. Therefore, the models in this module use a combination of deterministic and random independent variables to identify the contract types that are most likely to experience high positive and negative cost overruns. In order to take into account the variability in the probability of overrun across the contracts of a particular type, the Monte Carlo simulation approach was used to determine the mean, standard deviation, and 95\% confidence interval of the probability of overrun. Since the models in Module II take into account the risk of an escalation pattern to determine the probability of overrun, they are referred to as risk-based econometric models, and consequently the developed framework has been referred to as the risk-based econometric analysis framework.

Module III is used to determine the magnitude of cost overrun based on the probability of cost overrun greater than $10 \%$, between $0 \%$ and $10 \%$, between $-10 \%$ and $0 \%$, and less than $-10 \%$ (as computed using Module II models). The use of the conditional probability principle has been proposed to calculate the 
magnitude of cost overruns. The conditional probability concept involves the use of the probability of overrun in each cost overrun category and the magnitude of overrun, corresponding to each category, so as to determine the expected magnitude of cost overrun. Statistical models or simple averages can be used to determine the magnitude of overrun corresponding to each category, depending upon the extent of variability in the data.

\subsubsection{Application of Proposed Methodology}

The proposed methodology was used to develop a risk-based econometric analysis framework for Indiana. Risk-based multinomial logit models were developed to compare the escalation pattern of the cost estimates across contract types (Module $I$ ) and to identify contracts that are likely to experience high cost overrun (Modules II and III). Separate models were developed for different work categories. Corresponding to each work category, models were developed to analyze planning stage cost overrun (final cost vs. proposed cost), design stage cost overrun (final cost vs. design cost), and letting stage cost overrun (final cost vs. letting cost). The proposed methodology was also used to compare letting cost with the proposed cost, to identify the contracts that are likely to have a high percentage difference between the two estimates.

A software tool was developed for Indiana based on the developed models. The tool was used to compare contract types in Indiana and to determine the ones with unfavorable escalation patterns and high planning, design, and letting stage cost overruns. The variability in the probability of escalation pattern and the probability and magnitude of cost overrun across contracts of the same type, were also determined by conducting a Monte Carlo simulation using the software tool.

\section{2. $\underline{\text { Conclusions }}$}

The study develops and applies a methodology for risk-based econometric analysis to identify contracts that are likely to experience unfavorable escalation patterns and high cost overruns. The framework was developed for expansion, bridge, and pavement contracts in Indiana. Specifically, the framework identifies contracts that were likely to experience planning, design, and letting stage cost overruns, based on the contract-specific factors and the probability that the contract exhibits a particular escalation pattern. Appendix A presents the contract types that were identified as those that are likely to experience high cost overrun on the basis of contract-specific factors.

Factors that were found to affect the probability and magnitude of cost overrun in Indiana included: contract work category, size, geographic location, highway functional class, route type, NHS status, contract classification, time duration between final design completion and project proposal, time duration between letting and project proposal, percentage difference between design estimate and proposed cost, percentage difference between letting and proposed cost, the probability of a contract type to exhibit a 
particular escalation pattern, and the variability in the probability to exhibit a particular escalation pattern. Information on these factors is available during the planning and development phase. Appropriate decisions can be taken and contingencies can be allocated before the start of construction, for the contract types that are found likely to experience high risk of cost overrun.

\subsection{Recommendations for Future Work}

\subsubsection{Data Quality}

In the present study, historical contract data were acquired from the INDOT Management Information Portal. The recorded construction cost estimates were those prepared at the planning, design, and letting stages of the historical contracts. Hence, the recorded estimates were costs in current dollars. However, when these costs were inflated to the year of construction for each contract type, it was found that the inflated costs were significantly higher than the final construction cost for $80 \%$ of the contracts. This implied that if inflation was to be taken into consideration, the prepared cost estimates would be overestimated. This seems contrary to the popular belief that costs are underestimated. It is likely that there is an implicit adjustment for inflation during the planning and development phase. For example, if the unit averages were used to prepare the estimates, it is likely that the unit averages were determined based on the final cost of historical contracts that had experienced inflation. On the other hand, it is also likely that the recorded cost estimates were prepared in the construction year dollars. This could particularly be true for design and letting costs. More information on the data such as the methods used for the preparation of the estimates can provide additional insights in cost overrun analysis studies.

The proposed cost (planning stage estimate) and the engineer's assessment cost (post programming stage estimate), that were recorded from the Management Information Portal, were not found to be significantly different from each other. The design estimate was also found to be very close to these estimates for most of the contracts. The similarity of these cost estimates raises the issue of data quality.

A larger database of historical contracts with appropriate cost information can provide more validity and credibility to the developed models. Also, information on additional variables such as population, number of bids at letting stage, and specific type of construction activities that were identified during the design stage can also help in improving the developed models. Additional information from the planning and development phase should be retained and maintained in the form of a database to provide further insights. 


\subsubsection{Development of Risk-based Econometric Framework}

The developed econometric analysis framework for expansion, pavement, and bridge contracts comprises of multinomial logit models for determining the escalation pattern and probability of cost overrun. As more data becomes available about the contract-specific factors that are available during the planning and development phase, better models with higher McFadden R-squared values could be developed. Also, as more observations about the contracts become available (the present study used 419 contracts), the models that are developed will cover a wide range of cost overrun behavior.

The models developed in the present study for determining the probability of cost overrun, were developed on the basis of deterministic contract-specific factors and random variables, such as the probability of escalation pattern and the variability in the escalation pattern probability. This approach can be used in the future to determine the probability of cost overrun as a function of other random variables that are not available during the planning and development phase but are estimated using statistical models. For example, the time duration from project proposal to design completion and the time duration from project proposal to letting can be estimated using duration models, and the predicted values can be used as independent variables in the cost overrun models. This methodology allows planners and decision-makers to model the probability of cost overrun as a function of the risk associated with experiencing a large time duration between project proposal and letting or between project proposal and design completion.

\subsubsection{Development of Cost Overrun Analysis Software}

The Cost Overrun Analysis Software that was developed in the present study can be further improved for increased user-friendliness and self-sufficiency. The current version of the software creates a Microsoft Access file and writes all the results in the file. The file needs to be imported in Excel or other data analysis software to analyze the computed probabilities of cost overruns across the set of contract types. That is, the current version of the software cannot be used to plot graphs and conduct statistical analysis of the probabilities of cost overrun. It calculates the probability and magnitude of cost overrun but graphical analysis has to be done in other software (such as Excel, Access or SAS). In addition to the capability to draw graphs, the current version of the software can be made more user-friendly by allowing the user to update the statistical models without having to go into the source. Further, the software can be developed to be able to calibrate models instead of requiring the user to calibrate the models and update those that are presently embedded into the software. Statistical models in the software need to be updated periodically (23 years), as the relationship between the contract-specific factors and the cost overrun may change due to changes in the way contracts are planned, managed, estimated, and constructed. 
LIST OF REFERENCES 


\section{LIST OF REFERENCES}

AACE (1997), Recommended Practice No.17R-97: Cost Estimate Classification System, AACE, Inc.

AASHTO (2006). A Guide for Estimating Cost Using Historic Bid Prices. AASHTO Technical Committee on Cost Estimating. Draft Report. November 6. 2006. Accessed Online: Jan 2008.

AASHTO (2009). AASHTOWARE - Transportation Software Solutions. www.aashtoware.org. Accessed Online: April 2009.

Aho, E., Cosnard, M., Henkel, H., Soete, L., Stame, N., and Telicka, P. (2008). Information Society Research and Innovation: Delivering Results with Sustained Impact - Evaluation of the Effectiveness of Information Society Research in the 6th Framework Programme 2003-2006. European Commission, DG Information Society and Media. Retrieved April 16, 2009 from http://ec.europa.eu/dgs/information_society/evaluation/data/pdf/fp6_ict_expost/istfp6_panel_report.pdf

Anderson S., Molenaar K. and Schexnayder, C. (2007). Guidance for Cost Estimation and Management for Highway Projects During Planning, Programming and Preconstruction. NCHRP Report 574, TRB.

Andreassen, D. (1992). Hortations on the Use of Accident Cost Data. Traffic Engineering and Control, Vol. 33, No. 5, Printerhall Limited, p. 318-321.

Andrews, W.H. , Madsen, G.E., and Legaz, G.J. (1974). Social Impacts of Water Resources Developments and Their Implications for Urban and Rural Development: A Post-Audit Analysis of the Weber Basin Project in Utah. Research Monograph 4, Inst. for Soc. Sci. Res. on Nat. Res., Utah State University.

Anguera, R. (2005). The Channel Tunnel - An Ex Post Economic Evaluation. Strategic Rail Authority, London, Elsevier Ltd.

APREC - International Research Program: The Ex-post Evaluation of the European $\mathrm{CO} 2$ Market. Association for the Promotion of Research into the Economics of Carbon. $<$ http://www.aprec.net/uk_evaluation.php $>$.

Asian Development Bank (1990). Technical Assistance to the Independent State of Papua New Guinea for Strengthening Ex-post Evaluation Capability of the Department of Finance and Planning. Retrieved April 16, 2009 from http://www.adb.org/Documents/TARs/PNG/23384-PNG-TAR.pdf. 
Bhargava, A., Anastasopoulos, P., Labi, S., Sinha, K.C., and Mannering, F. (2008). An Analysis of Cost and Time Overrun of Construction Contracts Using System Equation Methods. Procs., 10th International Conference on Applications of Advanced Technologies in Transportation, Athens, Greece, May 2008.

Bokhari, S.M.H. (1975). Ex-post Evaluation of River Basin Developments in Pakistan. Working paper no. 22, UNDP/UN Interregional Seminar on River Basin and Interbasin Development, Budapest, Hungary, September 1975.

Bordat, C., McCulouch, B. G., Labi, S., and Sinha, K. C. (2004). An Analysis of Cost Overrun and Time Delays of INDOT Projects. FHWA/IN/JTRP-2004/7, W. Lafayette, IN.

Boumemellassa, H. and Valin, H. (2008). Vietnam's Accession to the WTO: Ex-post Evaluation in a Dynamic Perspective. Retrieved April 16, 2009 from http://ideas.repec.org/p/cii/cepidt/2008-31.html.

Bremmer, D., Hamond, P., and MacDonald D.B. (2005). Highway Project Delivery. Government Management Accountability \& Performance Program. GMAP Report. Washington Department of Transportation. Accessed Online: July 2008. http://www.wsdot.wa.gov/NR/rdonlyres/4940679D-E92D-46EB-8D4720B9E2015C39/0/July_GMAP.pdf

Burgess, P. and Arup, U.K. (2003). Ex-post Evaluation of Urban Development Projects in the EU. European Transport Conference 2003.

Cairncross, S. (1992). Sanitation and Water Supply: Practical Lessons from the Decade. Water and sanitation discussion paper series, DP no. 9. Washington, D.C.: UNDP - World Bank Water and Sanitation Program. NRDC. Covelo: Island Press.

Caltrans (2008). Project Development Procedures Manual, California Department of Transportation, Caltrans. http://www.dot.ca.gov/hq/oppd/pdpm/pdpmn.htm\#pdpm

Chen, S. and Ravallion, M. (May 2003). Hidden Impact? Ex-post Evaluation of an Anti-poverty Program. World Bank Policy Research Working Paper No. 3049. Retrieved April 16, 2009 from http://papers.ssrn.com/sol3/papers.cfm?abstract_id=417160.

Ciliberti, V.A. Jr. (1980). Libby Dam Project: Ex-Post Facto Analysis of Selected Environmental Impacts, Mitigation Commitments, Recreation Usage and Hydroelectric Power Production. Ph.D. dissertation. Montana Water Resources Research Center, Montana State University, Bozeman, Montana.

Cohen, M. J. (1995). Technological Disasters and Natural Resource Damage Assessment: An Evaluation of the Exxon Valdez Oil Spill. Land Economics, 71(1): 65-82.

Commonwealth of Australia (2007). Ex-post Economic Evaluation of National Highway Projects Case Study 1: Wallaville Bridge Working Paper 70.1. Department of Transport and Regional Services, Canberra, Australia.

Retrieved April 17, 2009 from http://www.bitre.gov.au/publications/48/Files/WP70_1.pdf. 
Crossett, J. and Hines, L. (2007). Comparing State DOTs Construction Project Cost and Schedule Performance - 28 Best Practices from 9 States. American Association of State Highway and Transportation Officials (AASHTO).

CSES, (2009). Ex Post Evaluation. Centre for Strategy \& Evaluation Services, Accessed May 10, 2009, http://www.cses.co.uk/?p=27

Damnjanovic, I., Nejat, A., and Sushanth, R. (2008). Synthesis on Construction Unit Costs Development. The Texas Transportation Institute (TTI). ftp://ftp.dot.state.tx.us/pub/txdot-info/rti/psr/6023.pdf

Dantata, N.A., Touran, A., and Schneck, D.C. (2006). Trends in U.S. Rail Transit Project Cost Overrun. Northeastern University and Booz, Allen, \& Hamilton, Inc., Procs., 2006 TRB Annual Meeting.

Dayton, J. (1998). World Bank HIV/Aids Interventions: Ex ante and Ex-post Evaluation. World Bank Discussion Paper No. 389, The World Bank. Retrieved April 16, 2009 from http://www.worldbank.org/aidsecon/interven.pdf.

Duckstein, L. (1975). Decision Making and Planning for River Basin Development. Working paper no. 27, UNDP/UN Interregional seminar on river basin and interbasin development, Budapest, Hungary.

Eatwell, J. Milgate, M., and Newman, P., Eds. (1987). The New Palgrave: A Dictionary of Economics. London and New York: Macmillan and Stockton. ISBN 0-333-37235-2 and ISBN 0-935859-10-1

Edwards, D.B. and Salt, E. (1993). Impact Evaluation of the Water and Sanitation Sector Project: U.S.AID/NWSDB Institutional Development, 1985-1991. WASH Field Report, no. 431. Arlington, Virginia: Camp Dresser and McKee, Inc. Retrieved May 11, 2009 from http://pdf.usaid.gov/pdf_docs/PDABH227.pdf.

ENR, 2001. Bay Bridge Replacement Comes in Above Estimate. ENR, p. 5, Dec. 31, 2001.

ENR, 2002(a). Heat Rises Over Central Artery. ENR, p. 15, May 15, 2002.

ENR, 2002(b). "Virginia's Big 'Mixing Bowl' is 180\% Over Budget, Late. ENR, p. 7, Dec. 2, 2002.

Entwicklungsbank (2009). Ex-post Evaluation Reports. kFw Entwicklungsbank. Retrieved April 16, 2009 from http://www.kfw-entwicklungsbank.de/EN_Home/Ex-post_Evaluation_at_KfW/Ex-post_evaluati on_reports/index.jsp.

Eriksen, J. H. and Bhatti, M. A. (1993). Pakistan Command Water Management Project: Final Evaluation. Arlington, Virginia: Camp Dresser and McKee, Inc.

European Social Fund (2009). Ex post Evaluation of the ESF (2000-2006) Evaluation of EU Structural Funds: Reinforcing Quality and Utilisation Vilnius, 26-27 March 2009. Retrieved April 16, 2009 from http://www.esparama.lt/es_parama_pletra/failai/fm/failai/Vertinimas_ESSP_Neringos/Vertinimo_konf erencija_2009/1.2.3_Galazka_ESF_ex_post_260309.pdf.

Evans, R. (2007). Central London Congestion Charging Scheme: Ex post Evaluation of the Quantified Impacts of the Original Scheme. Transport for London. Retrieved April 16, 2009 from http://www.tfl.gov.uk/assets/downloads/Ex-post-evaluation-of-quantified-impacts-of-original-scheme07-June.pdf. 
Farrell, D., Harrington, W., and Krupnick, A.J. (1998). Learning from Experiments: An Evaluation Plan for CMAQ Projects. Resources for the Future.

FDOT (2002). Transportation Costs. March 2003. Florida Department of Transportation, Office of Policy Planning. http://www.dot.state.fl.us/planning/policy. Accessed Online: July 2006.

Feeney, D.M. (1995). Post-development Audit of the Pick-Sloan program. The 1995 International Conference on Hydropower, Volume 2 (of 3), July 25-28, 1995, San Francisco, CA, pp. 1774-1783.

Fischl, P. (1993). Ex ante and Ex post Evaluation of the Kissimmee River Basin Flood Control Project. M.S.Thesis, Florida State University.

Fletcher, A. (March 2005). Ex post Evaluation of Mergers. Office of Fair Trading, Department of Trade and Industry and the Competition Commission by PricewaterhouseCoopers LLP, London. Retrieved April 16, 2009 from http://www.competition-commission.org.uk/our_role/evaluation/ex_post_evaluation_of_mergers.pdf.

Flyvbjerg, B., Holm, M.K.S., and Buhl, S.L. (2002). Underestimating Costs in Public Works Projects Error or Lie. Journal of American Planning Association, Vol. 68, No. 3, 279-295.

Flyvbjerg, B., Holm, M. K. S., and Buhl, S. L. (2003). How Common and How Large are Cost Overruns in Transport Infrastructure Projects? Transport Reviews, Taylor \& Francis Ltd, UK, 23(1), 71-88.

Flyvbjerg, B., Holm, M.K.S. and Buhl, S.L. (2004) What Causes Cost Overrun in Transport Infrastructure Projects? Transport Reviews, 24, 1, 3-18.

FHWA (2007). Major Project Program Cost Estimating Guidance - January 2007. Accessed Online. Dec 2008. http://www.fhwa.dot.gov/programadmin/mega/cefinal.pdf

FHWA, 2009. Economic Development - Three Levels of Analysis, U.S. Department of Transportation, Washington DC., Accessed May 10, 2009, http://www.fhwa.dot.gov/planning/econdev/

Galloway, G. 1980. Ex post Evaluation of Regional Water Resources Development: the Case of the YazooMississippi Delta. Institute for Water Resources. Fort Belvoir, Va.: U.S. Army Engineer Water Resources Support Center.

Geurs, K.T. and van Wee, B. (2006). Ex-post Evaluation of Thirty Years of Compact Urban Development in the Netherlands. Netherlands Environmental Assessment Agency, Delft University of Technology, Netherlands. Urban Studies, Vol. 43, No. 1, 139-160

Gkritza, K. and Labi, S. (2008). Estimating Cost Discrepancies in Highway Contracts: A Multistep Econometric Approach. ASCE Journal of Construction Engineering and Management, 134(12).

Gleave, S.D. (2008). Ex post Evaluation of Cohesion Policy Programmes 2000-2006 - Work Package 5A: Transport. Prepared for the European Commission Directorate General for Regional Policy Unit Evaluation and Availability. Retrieved April 16, 2009 from http://ec.europa.eu/regional_policy/sources/docgener/evaluation/pdf/expost2006/wp5_incepreport.pdf. Greene, W. (2003). Econometric Analysis, 5th Ed., Prentice-Hall Press, New York. 
Grillenzoni, M., Ragazzoni, A. and Marini, P. (1994). Post-project multiple-criteria evaluation of the Ridracoli Dam. ICOLD Congress 18, Question 69, pp. 535-53. Durban, South Africa.

Gruntfest, E. (1997). Twenty Years Later: What We Have Learned Since the Big Thompson Flood. Special Publication No. 33. Boulder, Colorado: Natural Hazards Research and Applications.

Gunnerson, C. G., Eds. (1989). Post-Audits of Environmental Programs and Projects. Proceedings of a session sponsored by the Environmental Impact Analysis Research Council of the ASCE, October 11, 1989. New York: ASCE, pp. 17-26.

Haveman, R.H. (1972). The Economic Performance of Public Investments: An Ex Post Evaluation of Water Resources Investments. Johns Hopkins Press.

Heckman, J.J., Lalonde, R.J. and Smith, J.A. (1999): The Economics and Econometrics of Active Labor Market Programs, in Handbook of Labor Economics, Volume 3A, Eds. O. C. Ashenfelter, D. Card.

Hegazy, T. and Ayed, A. (1998) Neural Network Model for Parametric Cost Estimation of Highway Projects. Journal of Construction Engineering and Management, Vol. 124, No. 3, pp. 210-218.

Hendrickson, C. and Au, T. (1998). Project Management for Construction - Fundamental Concepts for Owners, Engineers, Architects and Builders. Prentice Hall, ISBN 0-13-731266-0.

http://www.ce.cmu.edu/pmbook/

Hinze, J., Selstead, G., and Mahoney, J., P. (1992). Cost Overrun on State of Washington Construction Contracts. Transportation Research Record 1351, 87-93.

Hsu, A. and Wilcox, R. T. (2000). Stochastic Prediction in Multinomial Logit Models. Management Science. Vol 46. No. 8. pp 1137-1144.

IBRC - Indiana Business Research Center (2008). STATS Indiana: Inflation Calculator. Maintained at Indiana University. www.stats.indiana.edu/tools/InflationCalculator.aspx. Accessed Online: August 2008.

INDOT (2004). Annual Program Development Process for INDOT State Projects (PDP-S). Indiana Department of Transportation Divisions of Program Development and Budget and Fiscal Management. Version 8.01. Accessed Online: http://www.fhwa.dot.gov/indiv/pdpproc.htmt

INDOT (2009). Personal Communication with Mr. Brad Steckler, INDOT, Indianapolis, Jan $23^{\text {rd }}, 2009$.

Institut National de Recherche sur le Transports et Leur Securite (1997). Anticipatory Research and Knowledge Development. Dev. and Eval. of Road Transport Research Programmes, p. 124-130.

Isik-Dikmelik, A. (November 1, 2006). Trade Reforms and Welfare: An Ex-post Decomposition of Income in Vietnam. Policy Research Working Paper no. WPS 4049. Retrieved April 16, 2009 from $\mathrm{http} / / /$ econ.worldbank.org/external/default/main?entityID=000016406_20061025142437\&menuPK=64 166093\&page $\mathrm{PK}=64165259$ \&piPK=64165421\&theSite $\mathrm{PK}=469372$.

Israel, A. (1972). Reappraisal Project in Thailand: An Application of the Harvard Transport Models, The World Bank. 
Jacoby, C. (2001). Report on Supplemental Agreement Reasons. AASHTO-FHWA Project Cost Overrun Study, Federal Highway Administration. U.S. Department of Transportation. Washington D.C.

Jahren, C. T. and Ashe, A. M. (1990). Predictors of Cost Overrun Rates. Journal of Construction Engineering and Management. Volume 116. Issue 3. pp 548-552.

Jeannesson-Mange, E. and Chapulut,J. Taroux, J. (2007). French Ex-post Evaluation Practice and Results. Transportation Research Board Annual Meeting 2007 Paper \#07-1480.

Jingxun, C., Fujia, T., and Weijun, Q. (1991). Post-evaluation of the Environmental Impacts of the Pi-ShiHang Reservoir Group. ICOLD Congress 17, pp. 765-80. Vienna, Austria.

JLARC. (2001). Review of Construction Costs and Time Schedules for Virginia Highway Projects: A Report in a Series on Transportation Issues in Virginia. Joint Legislative Audit and Review Commission. House Document No. 31. Richmond, Va. http://jlarc.virginia.gov/meetings/December002/vdotbrief.pdf

Khisty, C.J. (1981). Evaluation of Two Residential Models for Land Use Allocation. Transportation Research Record, No. 820, Transportation Research Board, p. 29-33.

Kim D. Y., Kim B., and Han, H. S. (2008). Two-Staged Early Cost Estimation for Highway Construction Projects. The 25th International Symposium on Automation and Robotics in Construction. ISBN-9789955-28-329-4, ISARC-2008, Vilnius Gediminas Tech. Univ. Publishing House “Technika”, 490-495

KLRC (2009). Highway Construction Contingency Account. Kentucky Legislative Research Commission http://www.lrc.ky.gov/krs/045-00/247.PDF

Korman, R. and Daniel, S. (1998) Audit Notes ‘Avoidable’ Changes. Engineering News-Record, 240, 13.

Kyte, C. A., Perfater, M. A., Haynes, S. and Lee, H. W. (2004). Developing and Validating Highway Construction Project Cost Estimation Tool. Virginia Transportation Research Council, Charlottesville, Virginia. VTRC 05-R1. Accessed Online: May 122009. http://www.virginiadot.org/vtrc/main/online_reports/pdf/05-r1.pdf

Leong, D., Lichtman, L., Marcos, F., and Michelson, K. (December 2002; revised July 2003). Economic and Land Use Impacts Study of State Trunk Highway 29 Phase I - Chippewa Falls to Abbotsford, Wisconsin. Prepared for the Federal Highway Administration. Retrieved April 14, 2009 from http://www.fhwa.dot.gov/planning/econdev/wis29.htm\#contents.

MacDonald D.B., Hamond, P., and Conrad, J. (2005) (a). Highway Project Delivery. Government Management Accountability \& Performance (GMAP) Program. October, 2005 GMAP Report. Washington Department of Transportation (WSDOT). Accessed Online: July 2008. wsdot.wa.gov/NR/rdonlyres/02EFEB50-8BB7-4765-892C-23E39809162A/0/October_GMAP.pdf

McNeil, S. and Mizusawa, D. (September 2008). Measuring the Benefits of Implementing Asset Management Systems and Tools. Project 06-06, Midwest Regional University Transportation Center. Retrieved April 14, 2009 from http://www.mrutc.org/research/0606/06-06_FR.pdf. 
Meyer M. D. and Miller E. J. (2001). Urban Transportation Planning. McGraw Hill International Edition. ISBN: 0-07-242332-3

Millock, K. and Nauges, C. (2006). Ex Post Evaluation of an Earmarked Tax on Air Pollution. Land Economics 82.1: 68-84.

Ministry of Foreign Affairs of Japan (2000). 2000 Annual Evaluation Report on Japan's Economic Cooperation. Retrieved April 16, 2009 , http://www.mofa.go.jp/policy/oda/evaluation/2000/index.html. Murphy, S. (2002). Big Dig Review to Target Cost Overruns. The Boston Globe, 23 November 2002.

Nakamura, F., Ohta, K., Niitani, Y. (1989). Ex-post Evaluation of a Bus Priority Method in a New Town. Transport Policy, Management \& Technology Towards 2001: Selected Proceedings of the Fifth World Conference on Transport Research, Western Periodicals Company, p. 263-276.

Niemeier, D.A. and Beard, M.K. (1993). GIS and Transportation Planning: A Case Study. Computers, Environment and Urban Systems, Vol. 17, No. 1, Pergamon Press, Incorporated, p. 31-43

NJDOT (2006). Construction Cost Estimation Guide. State of New Jersey Department of Transportation. Prepared by Transport Support Group.

Overseas Development Administration (1984). The Evaluation Activities of the Overseas Development Administration, 1964-1984. Overseas Development Administration.

Oxera Consulting Ltd. (2005). How Should the Ex Post Evaluation of Trunk Road Schemes be Enhanced. Oxera. Retrieved April 15, 2009 from http://www.dft.gov.uk/pgr/roads/network/research/hsebe/houldtheexpostevaluation3912.pdf.

PennDOT. (2007). Construction Cost Estimating. HEEP Area 1 Meeting, https://www.nysdot.gov/iheep-2007/repository/8c_PennDOT's_Project_Cost_Estimating.pdf

Pickrell, Don H (October 1990). Urban Rail Transit Projects: Forecast versus Actual Ridership and Cost. Publication DOT-T-91-04. U.S. Dept. of Transportation.

Rowland, H. (1981). The causes and effects of change orders on the construction process. Ph.D. Dissertation. Georgia Institute of Technology, Atlanta, GA.

Rummel, Klepper. and Kahl, LLP. (2002). Maryland State Highway Administration Cost Estimating Program, Richmond, VA.

Rychnowski, D., Miller, P., Weisbrod, G., Gupta, M., Siethof, B.T., Porter, C., Suhrbier, J. (2003). Preliminary Economic Impact of the Southern Tier Expressway: Western Portion, Southern Tier West Regional Planning and Development Board, Economic Development Research Group, Inc., and Cambridge Systematics, Inc. for FHWA. Retrieved April 14, 2009 from http://www.fhwa.dot.gov/planning/econdev/i86ny.htm.

Sanders, S., Maxwell, R., Glagola, C. (1992). Preliminary Estimating Models for Infrastructure Projects. Assoc. for the Advancement of Cost Eng. International, Morgantown, WV, 34(8), 7-13.

Schexnayder, C.J., Weber, S.L., and Fioiri, C. (2003). Project Cost Estimating: A Synthesis of Highway Practice. Report for NCHRP Project 20-07/Task 152. 
http://cms.transportation.org/sites/design/docs/Project\%20Cost\%20Estimating\%20Report.pdf.

Sinha, K.C. and Labi, S. (2007). Transportation Decision Making - Principles of Project Evaluation and Programming. John Wiley and Sons.

Smith A. E., Mason, A. K. (1997). Cost Estimation Predictive Modeling: Regression versus neural network. The Engineering Economist, http://citeseerx.ist.psu.edu/viewdoc/summary?doi=10.1.1.42.3314

Stern, A. (1994). "The Best Estimating Methodology for Project Owners," 1994 AACE Transactions. Association for the Advancement of Cost Engineering International, Morgantown, WV.

Thurgood, G., S., Walters, L., C., Williams, G., R., and Wright, N., D. (1990). "Changing environment for highway construction: The Utah experience with construction cost overrun." TRR 1262, 121-130.

Turcotte, J. (1996). "Review of the Florida Department of Transportation's Performance in Controlling Construction Cost Overrun and Establishing Accountability for These Problems". The Florida Legislature. Report No. 96-21, November 27th 1996. Report accessed November 2007 at: http://www.oppaga.state.fl.us/reports/pdf/9621rpt.pdf

Van der Loop, H. (2000). Ex-post Evaluation of Policy Measures on Traffic Congestion. European Transport Conference 2000.

Wachs, M. (1982). Ethical Dilemmas in Forecasting for Public Policy. Public Administration Review 42, No. 6 (November/December): 562-67.

Wagner, T. (1998) Highway Construction Program Report. Accessed December 2008. Accessed Online: http://www.state.de.us/auditor/highway.pdf

Washington, S. P., Karlaftis, M. G., and Mannering, F. L. (2003). Statistical and Econometric Methods for Transportation Data Analysis. Chapman \& Hall/CRC Press.

Weisbrod, G., Collins, M., Howard, J., Porter, C., Suhrbier, J., and Wornum, C. (April 2001). Using Empirical Information to Measure the Economic Impact of Highway Investments. Prepared by the Economic Development Research Group, Inc. and Cambridge Systematics, Inc. for the Federal Highway Administration. Retrieved April 14, 2009 from http://www.edrgroup.com/library/highwaysroads/using-empirical-information-to-measure-economic-impact-of-highway-investments.html.

Weiss, M.H. and Figura, R. (2004). Economic Development Highways Initiative: Lessons Learned, and a Framework in the Sky. 9th National Conference on Transportation Planning for Small and Mediumsized Communities, Transportation Research Board.

Wescoat Jr., J.L. and Halvorson S. (2000). Ex Post Evaluation of Dams and Related Water Projects: Patterns, Problems and Promise. Report to the World Commission on Dams, South Africa. May 2000. Findings and Recommendations Incorporated in Dams and Development: A New Framework for Decision-Making. London: Earthscan. Retrieved April 15, 2009 from http://www.dams.org/docs/kbase/contrib/opt183.pdf. 
Williams, T. (2002). Predicting Completed Project Cost using Bidding Data. Construction Management and Economics. Volume 20, Issue 3, pp. 225 - 235

http://pdfserve.informaworld.com/442153_731193604_713763831.pdf

WSDOT (2008). Construction Contracts Annual Update. Washington State Department of Transportation. http://www.wsdot.wa.gov/biz/construction/performancemeasures.cfm

Yannis, G., Gitelman, V., Papadimitrou, E., Hakkert, A.S., Winkelbauer, M. (May 2008). Testing a Framework for the Efficiency Assessment of Road Safety Measures. Transport Reviews. Vol. 28, no. 3, pp. 281-301.

Zoeterman, A. (2004). A Life Cycle Approach in Railway Design and Maintenance: Opportunities and Obstacles. 10th World Conference on Transport Research, World Conference on Transport Research Society. 
APPENDIX 
Contract Types Experiencing Cost Overrun / Underrun in Indiana

\begin{tabular}{|c|c|c|c|c|c|}
\hline & & $\begin{array}{l}\text { Planning stage cost overrun } \\
\text { (Final Cost vs. Proposed Cost) }\end{array}$ & $\begin{array}{l}\text { Design Stage cost Overrun } \\
\text { (Final Cost vs. Design Cost) }\end{array}$ & $\begin{array}{l}\text { Letting Stage Cost Overrun } \\
\text { (Final Cost vs. Letting Cost) }\end{array}$ & Letting Cost vs. Proposed Cost \\
\hline \multicolumn{6}{|c|}{ FACTORS AFFECTING COST OVERRUN } \\
\hline \multirow{3}{*}{ Contract Size } & Expansion & $\begin{array}{c}\text { Contracts less than } \$ 15 \mathrm{M} \text { more likely to have } \\
\text { overrun between }-10 \% \text { and } 0 \% \text {. Contracts } \\
\text { greater than } \$ 15 \mathrm{M} \text { more likely } \\
\text { to have overrun }>10 \% .\end{array}$ & $\begin{array}{c}\text { Contracts less than } \$ 20 \mathrm{M} \text { more likely to have } \\
\text { overrun between - } 10 \% \text { and } 0 \% \text {. Contracts greater } \\
\text { than } \$ 20 \mathrm{M} \text { more likely to have overrun }>10 \%\end{array}$ & $\begin{array}{l}\text { More likely to have overruns. Probability of } \\
\text { overrun between } 0 \% \text { and } 5 \% \text { marginally } \\
\text { higher than the probability of overrun greater } \\
\text { than } 10 \% \text {. Average overrun increases with } \\
\text { increase in contract size. }\end{array}$ & $\begin{array}{l}\text { Letting Cost tends to be lower than the } \\
\text { Proposed Cost by } 0-10 \% \text {. Large Contracts } \\
\text { (>\$10M) more likely to have a lower letting } \\
\text { cost compared to small contracts. }\end{array}$ \\
\hline & Bridge & $\begin{array}{c}\text { Contracts greater than } \$ 2 \mathrm{M} \text { more likely } \\
\text { to have overrun between } 0 \% \text { and } 10 \% \text {. } \\
\text { Contracts less than } \$ 2 \mathrm{M} \text { more likely to have } \\
\text { overrun between }-10 \% \text { and } 0 \%\end{array}$ & $\begin{array}{c}\text { Contracts greater than } \$ 3 \mathrm{M} \text { more likely to have } \\
\text { overrun between } 0 \% \text { and } 10 \% \text {. Contracts } \\
\text { less than } \$ 2 \mathrm{M} \text { more likely to have overrun } \\
\text { between - } 10 \% \text { and } 0 \%\end{array}$ & $\begin{array}{l}\text { More likely to have overruns between } \\
0 \% \text { and } 5 \% \text {. Magnitude of overrun } \\
\text { increases with increase in contract size }\end{array}$ & $\begin{array}{l}\text { Letting Cost tends to be lower than the } \\
\text { Proposed Cost by 0-10\%. As Contract size } \\
\text { increases, the probability of letting cost } \\
\text { being lower than proposed cost increases. }\end{array}$ \\
\hline & Pavement & $\begin{array}{c}\text { Contracts greater than } \$ 5 \mathrm{M} \text { More likely to } \\
\text { have overrun }<-10 \% \text {. Contracts less than } \\
\$ 5 \mathrm{M} \text { more likely to experience } \\
\text { overrun }>10 \%\end{array}$ & $\begin{array}{c}\text { Contracts greater than } \$ 5 \mathrm{M} \text { More likely to have } \\
\text { overrun }<-10 \% \text {. Contracts less than } \$ 5 \mathrm{M} \text { more } \\
\text { likely to experience overrun }>10 \% .\end{array}$ & $\begin{array}{c}\text { More likely to experience positive cost overruns } \\
\text { between } 0 \% \text { and } 10 \% \text {. Contracts greater } \\
\text { than } \$ 5 \mathrm{M} \text { have average overrun between } \\
5 \% \text { and } 10 \% \text {. Contracts less than } \$ 5 \mathrm{M} \text { have } \\
\text { average overrun between } 3-4 \% \text {. }\end{array}$ & $\begin{array}{c}\text { Letting cost likely to be higher than } \\
\text { proposed cost for less than } \$ 5 \mathrm{M} \text { contracts. } \\
\text { Greater than } \$ 5 \mathrm{M} \text { Contracts more likely to } \\
\text { have a lower letting cost. }\end{array}$ \\
\hline
\end{tabular}

Contract Types Experiencing Cost Overrun / Underrun in Indiana

\begin{tabular}{|c|c|c|c|c|c|}
\hline & & $\begin{array}{l}\text { Planning stage cost overrun } \\
\text { (Final Cost vs. Proposed Cost) }\end{array}$ & $\begin{array}{l}\text { Design Stage cost Overrn } \\
\text { (Final Cost vs. Design Cost) }\end{array}$ & $\begin{array}{l}\text { Letting Stage Cost Overrun } \\
\text { (Final Cost vs. Letting Cost) }\end{array}$ & Letting Cost vs. Proposed Cost \\
\hline \multicolumn{6}{|c|}{ FACTORS AFFECTING COST OVERRUN } \\
\hline District & Expansion & $\begin{array}{c}\text { Greenfield and Seymour districts more likely to } \\
\text { have overruns }>10 \% \text {. The average cost overrun } \\
\text { in these districts is expected to be higher than } \\
10 \% \text { for greater than } \$ 5 \mathrm{M} \text { contracts. The } \\
\text { average overrun can go as high as } 25 \% \text { for } \\
\text { contracts greater than } \$ 15 \mathrm{M} \text {. Crawfordsville }\end{array}$ & \begin{tabular}{|c|} 
Contracts less than $\$ 15 \mathrm{M}$ in Greenfield and \\
Seymour more likely to have cost overrun greater \\
tha $10 \%$ compared to other districts. However \\
most of the contracts $(<\$ 15 \mathrm{M})$ in these districts \\
are likely to have overruns in the range of $0 \%$ to \\
$10 \%$. Therefore, average overrun is expected to be
\end{tabular} & $\begin{array}{l}\text { Greenfield and Seymour districts more likely to } \\
\text { have overruns }>10 \% \text {. Average overrun in all } \\
\text { districts expected to be between } 0 \% \text { and } 10 \% \text {, } \\
\text { except FortWayne. Average overrun in Fort } \\
\text { Wayne is expected to be }<0 \% \text {. }\end{array}$ & $\begin{array}{l}\text { Laporte, Seymour and Greenfield Districts are } \\
\text { more likely to have lower letting costs (vs. } \\
\text { proposed cost) compared to other districts. }\end{array}$ \\
\hline
\end{tabular}




\begin{tabular}{|c|c|c|c|c|}
\hline & $\begin{array}{l}\text { district also likely to have cost overruns } \\
\text { although not as high as Greenfield and } \\
\text { Seymour. }\end{array}$ & \begin{tabular}{|c|} 
around $10 \%$. Greater than $\$ 15 \mathrm{M}$ contracts in \\
Crawfordsville and Vincennes districts likely to \\
have high cost overruns. Average cost overrun for \\
$>\$ 15 \mathrm{M}$ contracts can be as high as $15 \%$ in \\
Crawfordsville and Vincennes districts.
\end{tabular} & & \\
\hline Bridge & $\begin{array}{c}\text { Expected Average Overrun: Crawfordsville }> \\
\text { Vincennes } \sim \text { Fort Wayne } \sim \text { Seymour }>> \\
\text { Greenfield } \sim \text { Laporte Districts. Contracts }> \\
\$ 3 \mathrm{M} \text { in Crawfordsville District more likely to } \\
\text { have cost overrun }>10 \% \text { compared to similar } \\
\text { contracts in other districts. Seymour, } \\
\text { FortWayne and Vincennes more likely to have } \\
\text { overrun between } 0 \% \text { and } 10 \% \text { compared to } \\
\text { other districts. Laporte and Greenfield more } \\
\text { likely to have overrun }<-10 \% \text { compared to } \\
\text { other districts. }\end{array}$ & $\begin{array}{c}\text { Expected Average overrun: Seymour } \sim \text { Laporte }> \\
\text { Crawfordsville }>\text { Vincennes }>\text { Fortwayne }> \\
\text { Greenfield. Contracts }>\$ 5 \mathrm{M} \text { in Crawfordsville } \\
\text { District more likely to have cost overrun }>10 \% . \\
\text { Seymour and Vincennes more likely to have } \\
\text { overrun }>10 \% \text { for less than } \$ 5 \mathrm{M} \text { Contracts. }\end{array}$ & $\begin{array}{c}\text { Expected Average Overrun and the probability of } \\
\text { overun }>10 \% \text { follows the following order: } \\
\text { Crawfordsville }>\text { Greenfield }>\text { Vincennes } ~ \\
\text { Seymour }>\text { FortWayne }>\text { Laporte }\end{array}$ & $\begin{array}{c}\text { Laporte }>\text { Seymour } \sim \text { Vincennes }> \\
\text { Crawfordsville }>\text { FortWayne }>\text { Greenfield }\end{array}$ \\
\hline Pavement & $\begin{array}{c}\text { Seymour district marginally more likely to have } \\
\text { overrun }>10 \% \text { compared to other districts. } \\
\text { Other districts do not differ significantly from } \\
\text { each other. }\end{array}$ & $\begin{array}{l}\text { Seymour more likely to have overrun }>10 \% \text {, } \\
\text { followed by Greenfield and Laporte. }\end{array}$ & $\begin{array}{c}\text { Expected Average Cost Overrun and the } \\
\text { probability of overrrun }>10 \% \text { follows the } \\
\text { following order: Seymour }>\text { Vincennes } \sim \text { Fort } \\
\text { Wayne }>>\text { Greenfield }>\text { Laporte }\end{array}$ & No Significant Difference \\
\hline
\end{tabular}


CONTRACT TYPES EXPERIENCING COST OVERRUN / UNDERRUN IN INDIANA

\begin{tabular}{|c|c|c|c|c|}
\hline & & $\begin{array}{l}\text { Planning stage cost overrun } \\
\text { (Final Cost vs. Proposed Cost) }\end{array}$ & $\begin{array}{l}\text { Design Stage cost Overrn } \\
\text { (Final Cost vs. Design Cost) }\end{array}$ & $\begin{array}{l}\text { Letting Stage Cost Overrun } \\
\text { (Final Cost vs. Letting Cost) }\end{array}$ \\
\hline \multicolumn{5}{|c|}{ FACTORS AFFECTING COST OVERRUN } \\
\hline \multirow[t]{3}{*}{ Area Type } & Expansion & $\begin{array}{l}\text { Urban and rural areas do not differ significantly from } \\
\text { each other with respect to their tendency to have } \\
\text { positive cost overruns. However, urban areas were } \\
\text { found more likely to experience negative cost } \\
\text { overruns }<-10 \%\end{array}$ & $\begin{array}{c}\text { Urban and rural areas do not differ significantly from each } \\
\text { other with respect to their tendency to have positive cost } \\
\text { overruns. However, urban areas were found more likely to } \\
\text { experience negative cost overruns }<-10 \%\end{array}$ & \\
\hline & Bridge & & & \\
\hline & Pavement & $\begin{array}{l}\text { Urban area contracts more likely to have high cost } \\
\text { overruns compared to rural area contracts }\end{array}$ & & \\
\hline \multirow{3}{*}{ NHS Status } & Expansion & $\begin{array}{l}\text { Contracts on Non-NHS highways more likely to have } \\
\text { high cost overruns. Contracts on Interstate and Non- } \\
\text { Interstate NHS highways more likely to have negative } \\
\text { cost overruns }>-10 \% \text {. Average cost overruns } \\
\text { expected to be greater than } 10 \% \text { for large contracts (> } \\
\quad \$ 15 \mathrm{M}) \text { on Non-NHS highways. }\end{array}$ & $\begin{array}{c}\text { Contracts on Non-NHS highways more likely to have high } \\
\text { cost overruns }(>10 \%) \text {. Contracts on Interstate and Non- } \\
\text { Interstate NHS highways more likely to have negative cost } \\
\text { overruns }(<-10 \%)\end{array}$ & Non-NHS > Non-Interstate NHS $\sim$ Interstate \\
\hline & Bridge & Interstate $>$ Non-Interstate NHS $>$ Non-NHS & Non-Interstate NHS $>$ Interstate $>$ Non-NHS & Interstate $>$ Non-NHS $\sim$ Non-Interstate NHS \\
\hline & Pavement & $\begin{array}{c}\text { Contracts on Non-NHS highways more likely to have } \\
\text { high cost overruns. Contracts on Interstate and Non- } \\
\text { Interstate NHS highways more likely to have negative } \\
\text { cost overruns }<-10 \%\end{array}$ & $\begin{array}{c}\text { Contracts on Non-NHS highways more likely to have high } \\
\text { cost overruns. Contracts on Interstate and Non-Interstate } \\
\text { NHS highways more likely to have negative cost overruns }< \\
-10 \% \text {. }\end{array}$ & $\begin{array}{l}\text { Contracts on Non-NHS highways more likely to } \\
\text { have high cost overruns followed by contracts on } \\
\text { Non-Interstate NHS and Interstate highways }\end{array}$ \\
\hline
\end{tabular}


Contract Types Experiencing Cost Overrun / Underrun in Indiana

\begin{tabular}{|c|c|c|c|c|}
\hline & & $\begin{array}{l}\text { Planning stage cost overrun } \\
\text { (Final Cost vs. Proposed Cost) }\end{array}$ & $\begin{array}{l}\text { Design Stage cost Overrn } \\
\text { (Final Cost vs. Design Cost) }\end{array}$ & $\begin{array}{l}\text { Letting Stage Cost Overrun } \\
\text { (Final Cost vs. Letting Cost) }\end{array}$ \\
\hline \multicolumn{5}{|c|}{ FACTORS AFFECTING COST OVERRUN } \\
\hline \multirow{3}{*}{ Standalone vs. Kin } & Expansion & - & - & $\begin{array}{c}\text { Kin contracts were more likely } \\
\text { to experience a letting stage cost overrun } \\
\text { between } 5-10 \%\end{array}$ \\
\hline & Bridge & - & - & \\
\hline & Pavement & - & - & $\begin{array}{l}\text { Kin Contracts more likely to } \\
\text { experience cost overrun }>10 \%\end{array}$ \\
\hline \multirow{3}{*}{$\begin{array}{c}\text { Time Duration } \\
\text { Between Design } \\
\text { Completion and } \\
\text { Project Proposal }\end{array}$} & Expansion & - & $\begin{array}{l}\text { Large Time Spans result in higher probability of cost } \\
\text { overrun }\end{array}$ & $\begin{array}{l}\text { Large time spans result in higher probability of } \\
\text { cost overrun }\end{array}$ \\
\hline & Bridge & - & $\begin{array}{l}\text { Large Time Spans result in higher probability of cost } \\
\text { overrun between } 0-10 \%\end{array}$ & Not Significant \\
\hline & Pavement & - & $\begin{array}{c}\text { Large Time Spans result in lower probability of } \\
\text { negative cost overrun }<-10 \%\end{array}$ & $\begin{array}{l}\text { Large time spans result in higher probability of } \\
\text { cost overrun }\end{array}$ \\
\hline \multirow{3}{*}{$\begin{array}{c}\text { Time Duration } \\
\text { Between Letting } \\
\text { and Project } \\
\text { Proposal }\end{array}$} & Expansion & - & - & Not Significant \\
\hline & Bridge & - & - & Not Significant \\
\hline & Pavement & - & - & $\begin{array}{c}\text { Large time spans result in lower probability of } \\
\text { cost overrun between 0-5\%. Probability of } \\
\text { higher cost overruns increases }\end{array}$ \\
\hline
\end{tabular}


Contract Types Experiencing Cost Overrun / Underrun in Indiana

\begin{tabular}{|c|c|c|c|c|}
\hline & & $\begin{array}{l}\text { Planning stage cost overrun } \\
\text { (Final Cost vs. Proposed Cost) }\end{array}$ & $\begin{array}{l}\text { Design Stage cost Overrun } \\
\text { (Final Cost vs. Design Cost) }\end{array}$ & $\begin{array}{l}\text { Letting Stage Cost Overrun } \\
\text { (Final Cost vs. Letting Cost) }\end{array}$ \\
\hline \multicolumn{5}{|c|}{ FACTORS AFFECTING COST OVERRUN } \\
\hline \multirow{3}{*}{$\begin{array}{l}\text { Percentage difference } \\
\text { between Design and } \\
\text { Proposed Cost }\end{array}$} & Expansion & - & $\begin{array}{l}\text { As the design cost becomes higher than the proposed cost, the } \\
\text { probability of design stage cost overrun decreases }\end{array}$ & $\begin{array}{c}\text { As the design cost becomes higher than the proposed } \\
\text { cost, the probability of letting stage cost overrun }>10 \% \\
\text { increases }\end{array}$ \\
\hline & Bridge & - & $\begin{array}{l}\text { As the design cost becomes higher than the proposed cost, the } \\
\text { probability of design stage cost overrun decreases (probability of } \\
\text { negative design stage cost overrun }<-10 \% \text { increases) }\end{array}$ & $\begin{array}{c}\text { As the design cost becomes higher than the proposed } \\
\text { cost, the probability of letting stage cost overrun } \\
\text { between } 0-10 \% \text { increases }\end{array}$ \\
\hline & Pavement & - & $\begin{array}{l}\text { As the design cost becomes higher than the proposed cost, the } \\
\text { probability of design stage cost overrun decreases }\end{array}$ & $\begin{array}{c}\text { As the design cost becomes higher than the proposed } \\
\text { cost, the probability of letting stage cost overrun } \\
\text { between } 0-5 \% \text { increases }\end{array}$ \\
\hline \multirow{3}{*}{$\begin{array}{l}\text { Percentage difference } \\
\text { between Letting and } \\
\text { Proposed Cost }\end{array}$} & Expansion & - & - & $\begin{array}{l}\text { As the letting cost becomes higher than the proposed } \\
\text { cost, the probability of negative letting stage cost } \\
\text { overrun }<-10 \% \text { increases }\end{array}$ \\
\hline & Bridge & - & - & $\begin{array}{l}\text { As the letting cost becomes higher than the proposed } \\
\text { cost, the probability of negative letting stage cost } \\
\text { overrun }<-10 \% \text { increases }\end{array}$ \\
\hline & Pavement & - & - & Not Significant \\
\hline
\end{tabular}

\begin{tabular}{|c|c|c|}
\hline \multirow{4}{*}{ Escalation Pattern } & Expansion & $\begin{array}{r}\text { Contracts exhibiting Pattern 'B' more likely to experience cost overrun. Contracts exhibiting pattern 'A' more likely to experience cost underrun. } \\
\text { As Variability of Pattern 'B' increases, probability of cost overrun increases. }\end{array}$ \\
\cline { 2 - 3 } & Bridge & $\begin{array}{r}\text { Contracts exhibiting Pattern 'B' more likely to experience cost overrun. Contracts exhibiting pattern 'A' more likely to experience cost underrun. } \\
\text { As Variability of Pattern 'B' increases, probability of cost overrun increases. }\end{array}$ \\
\cline { 2 - 4 } & Pavement & $\begin{array}{r}\text { Contracts exhibiting Pattern 'B' more likely to experience cost overrun. Contracts exhibiting pattern 'A' more likely to experience cost underrun. } \\
\text { As Variability of Pattern 'B' increases, probability of cost overrun increases. }\end{array}$ \\
\hline
\end{tabular}

